Programa de Doctorado en Tecnologías Industriales y Materiales

Escuela de Doctorado de la Universidad Jaume I

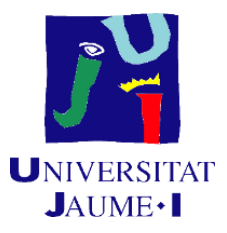

\title{
Diseño y análisis de un sistema de cavitación hidrodinámica mediante el uso de técnicas CFD para su utilización en sistemas de pretratamiento de fangos en las estaciones de aguas residuales
}

\author{
Tesis Doctoral
}

Junio 2021

Memoria presentada por Jose Vilarroig Herrera para optar al grado de doctor por la Universidad Jaume I

Autor

Jose Vilarroig Herrera
Director

Sergio Chiva Vicent 
Programa de Doctorado en Tecnologías Industriales y Materiales

Escuela de Doctorado de la Universidad Jaume I

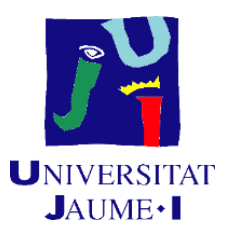

\title{
Diseño y análisis de un sistema de cavitación hidrodinámica mediante el uso de técnicas CFD para su utilización en sistemas de pretratamiento de fangos en las estaciones de aguas residuales
}

\author{
Tesis Doctoral
} Memoria presentada por Jose Vilarroig Herrera para optar al grado de
doctor por la Universidad Jaume I

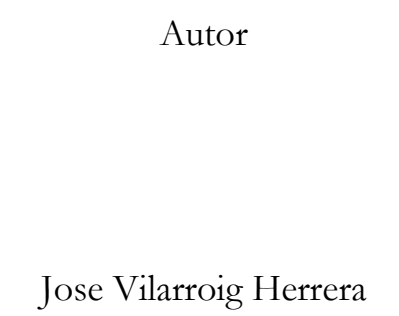

Autor

\begin{tabular}{|c|c|}
\hline LA & \\
\hline & \\
\hline & AA, JOSE \\
\hline (FIRMA) & $\begin{array}{l}\text { (FIRMA) } \\
\text { Fecha: 2021.07.09 }\end{array}$ \\
\hline ilaar & oig Herrera \\
\hline
\end{tabular}

Castellón de la Plana, junio de 2021

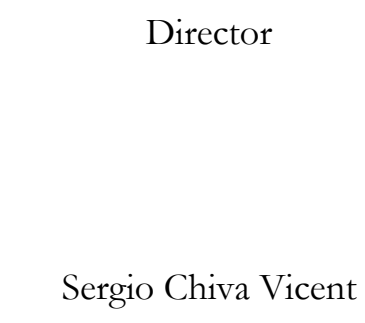

Director

CHIVA $\quad \begin{aligned} & \text { Firmado } \\ & \text { digitalmente por }\end{aligned}$

VICENT CHIVAVICENT

SERGIO - 527948990

$52794899 D_{10: 13: 16+020^{\prime} 00^{\prime}}^{\text {Fech: } 2021.12}$

Sergio Chiva Vicent 
Licencia CC Reconocimiento - Compartir igual (BY-SA).

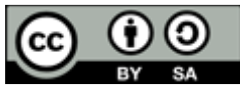

La presente tesis doctoral ha sido financiada con fondos de la Agencia Valenciana de Innovación (AVI) a través del programa INNODOCTO bajo el código de expediente INNTAL 31/19/008 

"Everybody seeks happiness. Not me, though.

That's the difference between me and the rest of the world. Happiness isn't good enough for me! I demand euphoria!"

[Bill Watterson (Calvin \& Hobbes)] 


\section{Agradecimientos}

No sería justo autoproclamarme como único autor de esta tesis cuando su realización ha sido posible gracias a un gran número de personas. Desde la gente de la universidad y del trabajo, pasando por amigos y por supuesto, la familia. Todos y cada uno de vosotros habéis hecho posible que este proyecto pudiera llevarse a cabo de forma exitosa.

En primer lugar, debo agradecer a Sergio Chiva y Raúl Martínez su labor como tutores y buenos consejeros, guiándome en todo momento y ayudándome con los obstáculos encontrados durante la realización de esta tesis. También quiero agradecer a mi amiga Eva la ayuda que me ha proporcionado para maquetar correctamente y no morir en el intento. Y por supuesto, no puedo olvidarme de todas las personas con las que he compartido incontables horas y grandes momentos en el altillo del taller TT2001, especialmente Salva, Sergio, Rosario, Aina, Rubén y los ya fugados Guillem, Lledó y Pablo.

Por otro lado, agradecer también a los que hoy día son mis compañeros de trabajo: Elena Zuriaga, por actuar como una tutora más, sin la cual, el proyecto Sto3re en el que se basa esta investigación no habría sido posible; Guillermo Berlanga, por facilitarme enormemente la complicada combinación entre el trabajo y el doctorado; y por supuesto Javier Climent, por involucrarse de forma desinteresada y ofrecer su ayuda desde el inicio hasta el fin de la tesis.

Finalmente, decir que no habría llegado hasta aquí sin el apoyo de mis padres Mari y Josan, mi novia y futura esposa Belén y mi abuela Carmen, a la cual tengo el enorme placer de ver sonreír mientras escribo estas palabras. Únicamente vosotros sabéis el esfuerzo y el sacrificio real que ha supuesto esta etapa de mi vida y me habéis dado vuestra ayuda, cariño y amor incondicional, sin importar el momento, ni la hora ni el lugar. No tengo palabras para expresar lo agradecido que estoy y lo mucho que os quiero. 


\section{Resumen}

Durante los últimos años, la necesidad de maximizar la producción energética a partir de la optimización del proceso de la digestión anaerobia de lodos ha centrado el interés tanto de la comunidad científica como de la industrial del ciclo del agua. Para ello, la cogestión y los pretratamientos de los lodos se presentan como una opción para incrementar la producción de biogás y la calidad del digestato obtenido.

La aplicación industrial de la codigestión anaerobia de los lodos de EDAR depende en una mayoría de los casos de la disponibilidad de cosustratos adecuados en las proximidades de la ubicación de la EDAR. Sin embargo, el objetivo de los pretratamientos es desintegrar las partículas sólidas mediante procesos físicos, químicos o biológicos. Como consecuencia, se acelera la etapa hidrolítica de la digestión anaerobia, permitiendo una mayor producción de biogás en un mismo proceso operado en las mismas condiciones. Existen numerosos estudios sobre el efecto de distintos pretratamientos en la producción de biogás, así como distintas experiencias a escala industrial. A pesar de ello, los pretratamientos no son de aplicación generalizada en la mayoría de las EDAR, debido principalmente a los elevados costes de inversión, operación y energéticos, que en muchas ocasiones no compensan económicamente el incremento en la producción de energía debido a su aplicación

En este sentido, en la presente tesis se pretende potenciar y optimizar el cambio de concepto del tratamiento de los lodos de depuradora, de un residuo que debe ser gestionado, a dos productos valorizables como son el biogás y el biofertilizante. Para ello, será necesario abordar conceptos tales como:

- Maximizar la cantidad de demanda química de oxígeno (DQO) soluble (materia orgánica), de este modo, se consigue incrementar la hidrólisis de la materia orgánica, lo que conllevará a un aumento de la producción de biogás.

- Generar productos de valor añadido, tales como el biogás (energía renovable) $y$ un digestato rico en nutrientes con calidad para ser usado como biofertilizante en enmienda de suelos y/o abono.

- Estudiar el comportamiento del perfil de ácidos grasos volátiles (AGVs) producidos (ácido acético, ácido propiónico, ácido butírico, etc.) y la influencia de la cavitación sobre ellos. Los AGVs son necesarios para que los microorganismos metanogénicos los conviertan en el digestor anaerobio en biogás.

- Maximizar el grado de higienización del digestato para su uso como fertilizante. En el proceso de pretratamiento del lodo mediante la cavitación hidrodinámica se libera calor, por lo que aumenta la temperatura del lodo, 
llegándose a valores cercanos a $60-70^{\circ} \mathrm{C}$. A estas temperaturas se consigue aumentar la higienización del lodo, y microorganismos patógenos como Escherichia Coli o Salmonella son eliminados.

- Desarrollar un modelo utilizando la dinámica computacional de fluidos (CFD) que permita determinar el comportamiento de los diferentes diseños propuestos y que facilite la toma de decisiones para obtener un cavitador optimizado minimizando el número de prototipos fabricados y, por ende, gasto económico asociado.

Todo lo anteriormente mencionado tendrá como finalidad última la de conseguir diseñar un sistema de cavitación hidrodinámica robusto mediante la utilización de técnicas CFD, que permita optimizar el proceso de pretratamiento para la digestión anaerobia de los lodos generados en una Estación Depuradora de Aguas Residuales (EDAR). 



\section{ÍNDICE}

1 Introducción 1

1.1 Antecedentes 1

1.2 Alcance y Objetivos 6

1.3 Esquema general de la Tesis 8

2 Estado del arte 9

2.1 El fenómeno de la cavitación 9

2.1.1 Ecuación de Rayleigh-Plesset 13

2.1.1.1 Condiciones de contorno y condiciones iniciales 14

$\begin{array}{ll}2.1 .2 & \text { Fase de generación y crecimiento } \\ & 18\end{array}$

2.1.2.1 Núcleos de cavitación o nucleación 20

2.1.2.2 Estabilidad de los núcleos. 21

2.1.2.3 Número de cavitación ( $\sigma) \quad 24$

$\begin{array}{lll}2.1 .3 & \text { Fase de colapso } & 27\end{array}$

2.1.3.1 Campo de presiones durante el colapso 30

2.1.3.2 Temperaturas durante la formación/colapso 32

2.1.3.3 Creación de radicales de hidroxilo e hidrógeno 35

2.2 Modelado del fenómeno de la cavitación 37

2.2.1 Modelo VOF 38

2.2.1.1 Ecuación de continuidad 39

2.2.1.2 Ecuación del momento 39

2.2.1.3 Ecuación de la energía 40

2.2.1.4 Limitaciones del modelo 41

2.2.2 Modelo Euleriano 41

2.2.2.1 Ecuación de continuidad 42

2.2.2.2 Ecuación del momento 43 
2.2.2.3 Ecuación de la energía 45

2.2.2.4 Limitaciones del modelo $\quad 45$

2.2.3 Modelo homogéneo 46

2.2.3.1 Ecuación de continuidad 46

2.2.3.2 Ecuación del momento 47

2.2.3.3 Ecuación de la energía 48

2.2.3.4 Limitaciones del modelo 49

2.2.4 Modelos de cavitación utilizados en CFD 50

2.2.4.1 Bubble Two-Phase Flow (BTF) 51

2.2.4.2 Merkle 52

2.2.4.3 Kunz 53

2.2.4.4 Schnerr-Sauer 54

2.2.4.5 Iben55

2.2.4.6 Full Cavitation 56

2.2.4.7 Zwart-Gerber-Belamri $\quad 57$

2.2.4.8 Modelos utilizados actualmente en software CFD 58

2.3 Sistemas generadores de cavitación $\quad 58$

2.3.1 La cavitación ultrasónica y la cavitación hidrodinámica 58

2.3.1.1 Cavitación ultrasónica (UC) 58

2.3.1.2 Cavitación hidrodinámica (HC) 59

2.3.2 Tipos de cavitadores hidrodinámicos 61

2.3.2.1 Dispositivos sin elementos móviles 61

2.3.2.2 Dispositivos con elementos móviles 66

2.3.2.3 Configuración del montaje experimental 69

2.4 Aplicaciones de la cavitación $\quad 71$

2.4.1 Procesos en la industria $\quad 71$

2.4.1.1 Producción de emulsiones 72

2.4.1.2 Tratamientos cosméticos o de belleza 73 
2.4.1.3 Sistemas de calentamiento de alta eficiencia 73

2.4.1.4 Síntesis de biocombustibles $\quad 75$

2.4.1.5 Otras aplicaciones $\quad 76$

2.4.2 Procesos biológicos y tratamiento de aguas residuales 77

2.4.2.1 Mecanismos para la desinfección y tratamiento de aguas $\quad 79$

2.4.2.2 Cavitación hidrodinámica en desinfección de aguas 81

2.4.2.3 Eficiencia energética del proceso de cavitación 84

2.4.2.4 Técnicas para incrementar la eficiencia del tratamiento 87

2.4.3 Mejora de los procesos de fangos activos y digestión anaerobia 93

2.4.3.1 La digestión anaerobia 94

2.4.3.2 Pretratamientos en la digestión anaerobia 95

2.5 Indicadores para determinar el impacto del proyecto 99

3 Diseño conceptual del sistema de cavitación 103

3.1 Introducción 103

$\begin{array}{ll}3.1 .1 \text { Objetivos } & 104\end{array}$

3.2 Proceso de selección del sistema de cavitación 104

3.2.1 Características requeridas en el cavitador $\quad 105$

3.2.2 Elección del sistema de cavitación 106

3.2.2.1 Cavitación ultrasónica o hidrocavitación 106

3.2.2.2 Dispositivos con y sin elementos móviles 107

3.2.2.3 Dispositivo elegido para su desarrollo 110

3.3 Proceso de diseño del sistema de cavitación 113

3.3.1 Análisis del sistema de cavitación de M. Petkovšek 113

$\begin{array}{ll}\text { 3.3.1.1 Ventajas del sistema } & 114\end{array}$

3.3.1.2 Inconvenientes del sistema 114

3.3.2 Parámetros de diseño del nuevo cavitador 115

3.3.2.1 Diseño del rotor 116

3.3.2.2 Diseño del estator 118 
3.3.2.3 Configuración del rotor y el estator

3.3.3 Conclusiones

4 Simulaciones CFD del sistema de cavitación

4.1 Introducción

4.1.1 Objetivos

4.1.2 Metodología del proceso de simulación

4.1.3 Parámetros de análisis

4.2 Simulación de un dispositivo Venturi

4.2.1 Montaje experimental

4.2.2 Ensayos experimentales con el Venturi

4.2.3 Geometría del submodelo

4.2.4 Set up del submodelo y condiciones de contorno 142

4.2.4.1 Modelos matemáticos utilizados

4.2.4.2 Condiciones y parámetros físicos del submodelo

4.2.4.3 Mallado del submodelo

4.2.5 Resultados

4.3 Análisis del comportamiento de los dientes del rotor

4.3.1 Geometría del submodelo

4.3.2 Set up del submodelo y condiciones de contorno

4.3.2.1 Modelos matemáticos utilizados

4.3.2.2 Condiciones y parámetros físicos del submodelo

4.3.3 Mallado del submodelo

\subsubsection{Resultados}

4.3.4.1 Resultados obtenidos con la configuración 1

4.3.4.2 Resultados obtenidos con la configuración 2

4.4 Simulaciones 2D del nuevo sistema de cavitación

4.4.1 Geometría del submodelo

4.4.2 Set up del submodelo y condiciones de contorno 
4.4.2.1 Modelos matemáticos utilizados 169

4.4.2.2 Condiciones y parámetros físicos del submodelo 169

4.4.3 Mallado del submodelo 172

$\begin{array}{ll}\text { 4.4.4 Resultados } & 174\end{array}$

4.4.4.1 Fase 1: Recuperación 176

4.4.4.2 Fase 2: Transición 177

4.4.4.3 Fase 3: Generación y colapso 180

4.4.4.4 Variación de la velocidad de rotación 185

4.4.4.5 Variación de la distancia entre rotor y estator 190

4.4.4.6 Variación de la geometría del diente del estator 194

$\begin{array}{ll}4.4 .5 \text { Conclusiones } & 199\end{array}$

4.4.5.1 Las simulaciones con el Venturi 199

4.4.5.2 Las simulaciones del diente del rotor 200

4.4.5.3 Las simulaciones del sistema de cavitación en 2 dimensiones 201

5 Experimentación a escala de laboratorio 203

5.1 Introducción 203

5.1 .1 Objetivos 203

5.1.2 Principales dificultades afrontadas 204

5.2 Métodos y materiales 206

5.2.1 Montaje experimental 206

5.2.1.1 Fase de llenado 207

5.2.1.2 Fase de vaciado y limpieza 208

5.2.2 Características del fango utilizado 208

5.2.3 Análisis de resultados 209

5.2.4 Ensayos realizados 210

5.2.4.1 Elección de los valores de velocidad de rotación 212

5.2.4.2 Elección de los valores de caudal de recirculación 213

5.2.4.3 Elección de los valores de temperatura 215 
5.3 Resultados y discusión 216

5.3.1 Efecto de la velocidad de rotación 216

5.3.1.1 Rendimiento energético de los ensayos LT1, LT2 y LT3 218

5.3.2 Efecto del caudal de recirculación y de la temperatura 219

5.3.2.1 Efecto de la temperatura 220

5.3.2.2 Efecto del caudal de recirculación 223

5.3.2.3 Rendimiento energético de los ensayos LT4-LT9 224

6 Experimentación a escala industrial 227

6.1 Introducción 227

6.1.1 Objetivos 229

6.1.2 Principales dificultades afrontadas 230

6.2 Métodos y materiales 231

6.2.1 Montaje experimental 231

6.2.1.1 Principales componentes de la planta piloto STO3RE 231

6.2.1.2 Sistema de cavitación en la planta piloto 237

6.2.2 Características del fango utilizado 238

6.2.3 Análisis de resultados 240

6.2.4 Ensayos realizados 242

6.2.4.1 Ensayo largo 243

6.2.4.2 Ensayos cortos 244

6.3 Resultados y discusión $\quad 244$

6.3.1 Resultados del ensayo de larga duración 244

6.3.1.1 Evolución de la temperatura 244

6.3.1.2 Evolución de la DQOS 246

6.3.1.3 Eliminación de patógenos 247

6.3.2 Resultados de los ensayos cortos 251

6.3.2.1 Efecto de la cavitación en el lodo utilizado 251

6.3.2.2 Valores del grado de desintegración (DD) 252 
6.3.2.3 Eliminación de patógenos según concentración inicial 254

6.3.2.4 Efecto en la producción de los AGVs 255

6.3.3 Efecto de escala 256

6.3.4 Análisis energético 257

$\begin{array}{ll}\text { 6.3.5 Conclusiones } & 264\end{array}$

7 Conclusiones $\quad 267$

$\begin{array}{ll}7.1 \text { En relación con el diseño } & 267\end{array}$

7.2 En relación con el modelo computacional 268

7.3 En relación con los ensayos experimentales 269

$\begin{array}{ll}7.4 \text { Desarrollos e investigaciones futuras } & 269\end{array}$

$\begin{array}{ll}\text { Bibliografía } & 271\end{array}$ 


\section{Capítulo 1}

\section{Introducción}

En este capítulo se proporciona una breve descripción sobre el trabajo de investigación desarrollado en la presente tesis. Se expondrán los motivos que han llevado a la necesidad de realizar esta investigación, así como los principales objetivos y alcance de esta.

\subsection{Antecedentes}

La presente tesis doctoral surge como respuesta a una necesidad generada en el marco de un proyecto LIFE europeo. Este proyecto ha recibido el nombre de LIFE Sto3re, más concretamente: Synergic TPAD and O3 process in WWTPs for Resource Efficient waste management (LIFE14 ENV/ES/000150), que fue concedido en la convocatoria del año 2014 y su duración se ha extendido desde septiembre del 2015 a diciembre del 2018 invirtiéndose para su fin, un presupuesto de $1.957 .874 €$.

El proyecto LIFE Sto3re tiene como finalidad última la reducción de la contaminación causada por microcontaminantes orgánicos, microorganismos patógenos y nitratos que se encuentran presentes en los fangos de las estaciones depuradoras de aguas residuales (EDARs) y en los purines procedentes de las industrias ganaderas. Para ello ha sido necesario no solo desarrollar un proceso industrial que incluya diferentes tecnologías y procesos sino también, desarrollar un modelo de gestión de los purines procedentes de la industria ganadera y de los lodos que se producen en las EDARs de pequeño y mediano tamaño.

Tal y como puede verse en el diagrama de la Figura 1, el proceso industrial planteado en el proyecto Sto3re está alimentado por dos tipos de sustratos: los fangos de EDAR, y los purines. La obtención de estas materias primas es la que se va a llevar a cabo mediante la implantación de un sistema de gestión que permite recolectar los fangos procedentes de pequeñas estaciones depuradoras y los purines generados en las industrias ganaderas locales. Tras procesar estas materias primas, se obtiene por un lado un biofertilizante de alto valor añadido (con bajo 
contenido en microcontaminantes y patógenos y con una alta asimilación de nitratos) y biogás que puede ser utilizado para autoabastecerse o mejorar notablemente el rendimiento energético del proceso.

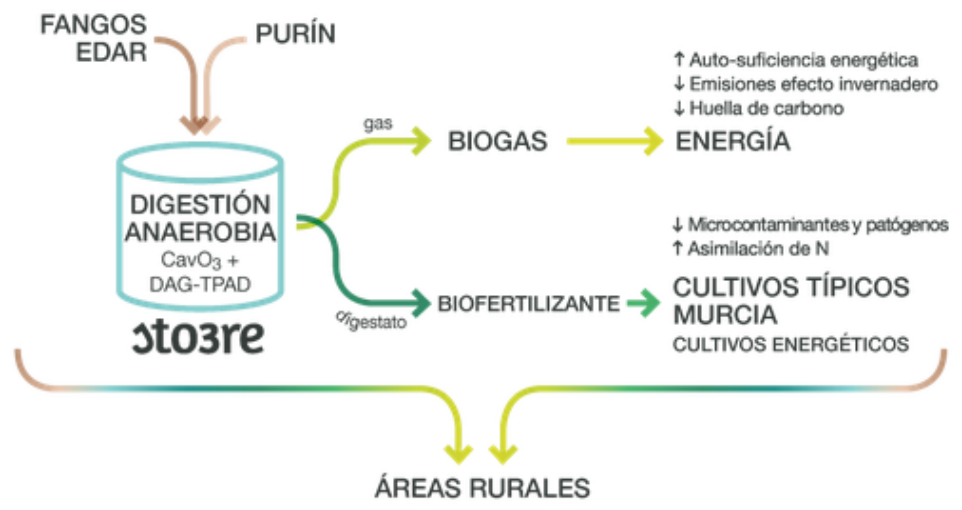

Figura 1: Diagrama del proceso industrial seguido en el proyecto LIFE Sto3re.

Considerando la finalidad y los requerimientos del proyecto, la región de Murcia ha resultado ser una muy buena candidata dado el gran número de industrias ganaderas porcinas que se encuentran cercanas a EDARs de pequeño y mediano tamaño y que garantizan un suministro constante de fangos y purines. Por tanto, es en esta comunidad donde se ha desarrollado todo el estudio e instalado la planta piloto. Concretamente, la planta piloto derivada del proyecto Sto3re se ha situado en la depuradora de Totana (Figura 2a), y es abastecida por fangos de otras 5 depuradoras (Figura 2b) además de la propia EDAR de Totana y por los purines de 5 industrias ganaderas cercanas.

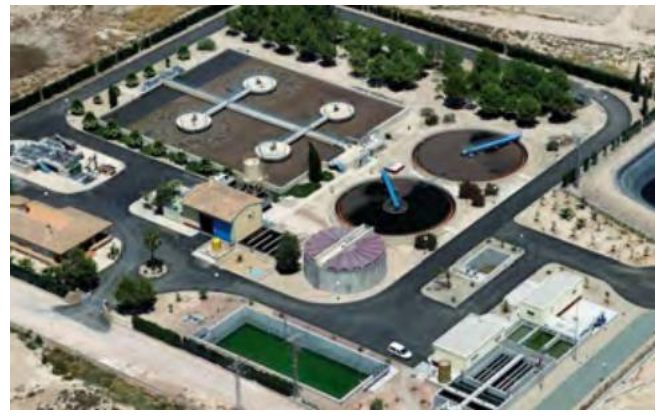

(a)

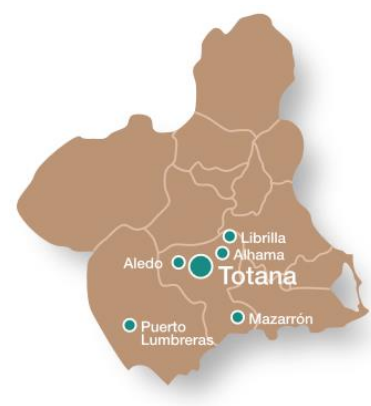

(b)

Figura 2: Depuradora de Totana donde se ha instalado la planta piloto (a) y depuradoras que han proporcionado el fango para el proyecto STO3RE (b). 
Los procesos desarrollados en el sistema del proyecto Sto3re, están claramente diferenciados y son esencialmente: la oxidación avanzada y la digestión anaerobia en doble fase de temperatura (ver Figura 3).

- Oxidación avanzada: Este primer proceso tiene como objetivo realizar un pretratamiento de los sustratos de entrada para conseguir un mayor rendimiento en la posterior etapa de digestión. Dentro de los procesos de oxidación avanzada se encuentran, a su vez, dos tecnologías diferentes: la ozonización y la hidrocavitación. Es esta última tecnología la que va a desarrollarse en profundidad en la presente tesis doctoral.

- Digestión anaerobia: La digestión anaerobia, se lleva a cabo en dos fases diferentes: una primera fase termófila $\left(a 5^{\circ} \mathrm{C}\right.$ de temperatura) donde se producen los procesos de hidrólisis y acidogénesis, y una segunda fase (a $35^{\circ} \mathrm{C}$ de temperatura) donde se producen los procesos de acetogénesis y metanogénesis siendo este último el que se traduce directamente en la producción de biogás (CH4).

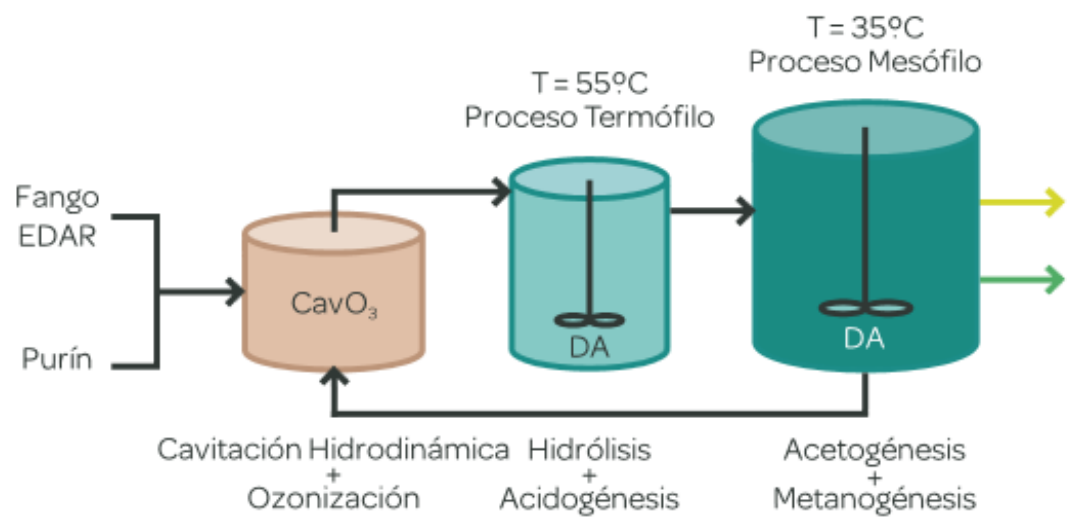

Figura 3: Detalle de los procesos utilizados en el proyecto LIFE STO3RE.

Como se ha comentado anteriormente, tras someter los fangos de EDAR y purines de granja a los procesos de hidrocavitación, ozonización y digestión en doble fase de temperatura, se consigue obtener dos productos de alto valor añadido: el biogás y los biofertilizantes. No obstante, existe una toda una serie de beneficios indirectos que se derivan de realizar este tratamiento de los fangos y de los purines utilizando el proceso propuesto en el proyecto Sto3re:

- Reducción el impacto de los purines y de los fangos de depuradora en las aguas superficiales y acuíferos. 
- Reducción de la huella de carbono y las emisiones de gases de efecto invernadero producidas por el almacenamiento de purines.

- Creación de un modelo de gestión conjunta de lodos y residuos con alto contenido en $\mathrm{N}$ para áreas rurales, con el fin de reducir costes.

- Maximización de producción de biogás por el efecto de la digestión en doble fase temperatura, la cavitación hidrodinámica y la ozonización.

- Obtención de un biofertilizante de calidad, que cumpla con las nuevas normativas legales destinadas a la aplicación de lodos en agricultura.

- Estudios del efecto de los biofertilizantes obtenidos, en cultivos del entorno.

Como puede observarse, se trata de un proyecto multidisciplinar y técnicamente complejo ya que se combinan varias tecnologías emergentes como la hidrocavitación aplicada al tratamiento fangos o la digestión anaerobia en una doble fase de temperatura. Además, aunque el efecto de otras tecnologías tradicionalmente utilizadas como la ozonización, es conocido, no lo es tanto la sinergia que se produce al ser combinadas con nuevos procesos como la hidrocavitación. Por tanto, dado el elevado grado de complejidad del proyecto, este ha sido desarrollado por un consorcio de 5 empresas españolas del entorno científico público y privado en la que cada una ha cumplido una determinada función:

FACSA (Sociedad de Fomento Agrícola Castellonense): La principal labor de FACSA es la gestión del agua, desde la captación hasta el tratamiento y distribución de agua. Las áreas en las que la compañía es activa incluyen el tratamiento de agua, tecnología de purificación, sistemas avanzados de gestión y automatización. Además, FACSA gestiona más de 240 plantas depuradoras y está a cargo de más de 315 sistemas de cloración. Actualmente abastece de agua a más de 1.000 .000 personas y ofrece servicios de alcantarillado y tratamiento de agua para 2.000.000 personas. FACSA es el coordinador del proyecto LIFE Sto3re. Dentro del proyecto, FACSA liderará el diseño y construcción de la planta demostrativa y su validación en la depuradora de Totana.

ESAMUR. Es la Entidad Regional de Saneamiento y Depuración de Aguas Residuales de la Región de Murcia. Es una empresa pública creada en 2002 y dependiente de la Consejería del Agua, Agricultura y Medio Ambiente de la Región de Murcia. ESAMUR es responsable de la recaudación y gestión del impuesto sobre tratamiento de aguas residuales. Este recurso económico se utiliza para la explotación, mantenimiento y control de las instalaciones de saneamiento y depuración de aguas residuales públicas. En el marco del proyecto LIFE Sto3re, 
ESAMUR ha colaborado en la construcción de la planta demostrativa debido a su conocimiento en la construcción de este tipo de instalaciones. ESAMUR es el responsable de las acciones de comunicación y difusión.

AINIA (Asociación de Investigación de la Industria Agroalimentaria): AINIA es un centro tecnológico español sin ánimo de lucro creado en 1987 y formado por empresas del sector de fabricación de alimentos e industrias relacionadas (más de 700 empresas de alimentos como miembros activos), cuyo objetivo es la promoción de la innovación y el desarrollo tecnológico en el sector agroalimentario. Es la encargada de la validación de nuevos sustratos, reducción de riesgos biológicos, control y modelado del proceso anaeróbico y caracterización microbiológica de la fermentación anaeróbica mediante herramientas de biología molecular (PCR / DGGE).

IPROMA (Investigación y proyectos Medio Ambiente): IPROMA ofrece una amplia gama de análisis de laboratorio, monitoreo y servicios de consultoría. Sus servicios comprenden el análisis de aguas, análisis de suelos contaminados, sedimentos, biota, indicadores biológicos en aguas, análisis de calidad del aire, higiene industrial, etc. Para llevar a cabo los análisis fisicoquímicos y microbiológicos, tienen implantados numerosos métodos analíticos la mayoría de ellos acreditados según la norma UNE-EN ISO 17025. En el marco del proyecto LIFE Sto3re, IPROMA proporciona ayuda en el análisis de las sustancias prioritarias y microcontaminantes emergentes, principalmente antibióticos humanos y animales, contaminantes orgánicos volátiles y contaminantes orgánicos no volátiles. IPROMA es la encargada de analizar tanto los sustratos como el digestato obtenido para estudiar la eficiencia del proceso.

CSIC (Agencia Estatal Consejo Superior de Investigaciones Científicas): La Agencia Estatal Consejo Superior de Investigaciones Científicas (CSIC) es la mayor institución pública dedicada a la investigación en España y la tercera de Europa. Su misión es el fomento, coordinación, desarrollo y difusión de la investigación científica y tecnológica, de carácter pluridisciplinar, con el fin de contribuir al avance del conocimiento y al desarrollo económico, social y cultural, así como a la formación de personal y al asesoramiento de entidades públicas y privadas en esta materia.

Finalmente, pero no menos importante, se encuentra el papel de la Universidad Jaume I de Castellón (UJI). Dentro de esta universidad, se encuentra el grupo de fluidos multifásicos (GFM) cuyos servicios han sido subcontratados por la empresa FACSA para que se lleve a cabo el diseño y estudio del hidrocavitador que va a instalarse en la planta piloto del proyecto LIFE Sto3re, dando ello lugar al desarrollo de esta tesis. El Grupo GFM desarrolla varias líneas de investigación relacionados con el comportamiento de fluidos, centrándose en 
aquellos en los que conviven más de una fase. Las principales líneas de investigación son:

- Experimentación y desarrollo de instrumentación para la caracterización de flujos multifásicos.

- Estudio del secado de gotas mediante técnicas de levitación ultrasónica, lo que permite analizar gotas individualizadas con gran detalle y precisión.

- Caracterización del atomizado de fluidos y estudio del secado por atomización en la industria cerámica

- Simulación mediante Códigos de Dinámica Computacional de Fluidos (CFD) de escenarios complejos en los que intervienen fluidos tanto monofásicos como multifásicos.

\subsection{Alcance y Objetivos}

Hasta este punto, ha quedado descrito en términos generales el proyecto LIFE Sto3re en el cual se enmarca el desarrollo de esta tesis. Ahora bien, de entre todas las tecnologías incorporadas y desarrolladas en el proyecto europeo, este trabajo de investigación está centrado única y exclusivamente en los procesos de oxidación avanzada, concretamente en el desarrollo de un sistema de hidrocavitación que permita realizar de forma satisfactoria y a escala industrial, el pretratamiento del fango para convertirlo en un buen cosustrato que será posteriormente utilizado en las etapas de digestión. Así pues, el estudio y desarrollo de la digestión en doble fase de temperatura, así como el estudio de otros procesos de oxidación avanzada que no estén directamente relacionados con la hidrocavitación (como puede ser el caso de la ozonización), quedan fuera del alcance de esta investigación. La aplicación del fenómeno de la cavitación para el tratamiento de aguas residuales es algo que ya se ha venido haciendo en los últimos años de manera más o menos exitosa. No obstante, es un proceso que hasta la fecha únicamente ha sido estudiado a escala de laboratorio, utilizándose cantidades de fango muy pequeñas si se comparan con las que se pretenden procesar con el sistema de hidrocavitación desarrollado en este estudio.

Por tanto, el primer objetivo de la investigación es el de poder desarrollar un sistema de hidrocavitación suficientemente robusto como para ser utilizado con mezclas de fangos y cosustratos con alto contenido en sólidos y que además pueda tratar volúmenes a escala semi industrial.

El segundo objetivo de la presente tesis consiste en la elaboración de un modelo computacional que permita describir el funcionamiento del sistema de 
hidrocavitación y pueda ser utilizado para realizar el rediseño y la optimización del mismo para conseguir los mejores resultados. Para alcanzar este objetivo, se requiere de la utilización de potentes herramientas de cálculo como es la simulación computacional de fluidos o CFD por sus siglas en inglés ("Computational Fluid Dynamics") las cuales exigen de un extenso trabajo de investigación y conocimiento en cuanto a modelos matemáticos de cavitación se refiere. La CFD, es una herramienta cada vez más extendida que permite calcular de forma muy precisa el comportamiento del flujo en cualquier sistema, es decir, se pueden conocer los campos de velocidad, presión, variables transportadas, reacciones producidas en el interior de fluido, interacción entre diferentes fases y, en definitiva, cualquier característica derivada del estado y naturaleza del fluido. Para ello es necesario no solo representar de forma fiel la geometría del sistema a simular, sino también conocer con exactitud las condiciones de contorno, cosa que en algunas ocasiones resulta de gran complejidad debido a la naturaleza de los efectos que quieren simularse.

En el caso concreto de la cavitación, la simulación utilizando CFD se torna muy dificultosa debido a la rapidez del fenómeno y a que las condiciones de contorno no siempre están claras. Además, aunque los actuales softwares de CFD llevan incorporados algunos modelos de cavitación, estos son genéricos y algunos casos no representan la realidad de la situación que se está simulando, ya que asumen que el fluido tiene unas determinadas características que no tienen por qué darse en el caso real de estudio. Por tanto, es necesario tener conocimientos muy detallados sobre las ecuaciones que rigen la cavitación y poder calibrar el modelo y que su simulación proporcione resultados representativos de lo que está ocurriendo en la realidad.

Así pues, dado que en la presente investigación se desea realizar el diseño de un sistema de cavitación a nivel industrial, también queda dentro del alcance de la presente tesis conocer, estudiar y desarrollar las herramientas necesarias (en este caso los modelos de cavitación utilizados en la CFD). Así se quiere conseguir que el diseño propuesto y desarrollado del sistema de hidrocavitación cuente con una serie de garantías a la hora de ser fabricado y que su diseño esté basado en una serie de cálculos matemáticos y simulaciones que deriven de una consecución de eventos lógicos y debidamente razonados. 


\subsection{Esquema general de la Tesis}

La presente tesis se encuentra estructurada en 7 capítulos diferentes, los cuales se describen brevemente a continuación:

- En el primer capítulo, se realiza una introducción donde se exponen los objetivos y el alcance de la investigación, así como los antecedentes del estudio que va a realizarse.

- El segundo capítulo es el más extenso de la tesis, y en él se describe el estado del arte actual referente al fenómeno de la cavitación: sus características físicas, modelos matemáticos que explican su comportamiento, principales dispositivos que permiten inducir el fenómeno, y aplicaciones en las que la cavitación es utilizada como base del proceso.

- En el tercer capítulo, se analizan detalladamente los criterios para realizar el diseño del sistema de cavitación para que no solo se adapte a las características del proceso y del fluido que va a tratarse, sino que también permita hacerlo de la manera más eficiente posible. El dispositivo diseñado se compara con los mejores sistemas que existen en la actualidad para detectar sus principales ventajas e inconvenientes.

- El cuarto capítulo está enteramente dedicado al estudio mediante simulación computacional de fluidos (CFD). En él se explican los diferentes submodelos (geometría, condiciones de contorno, mallado y modelos matemáticos) utilizados para conseguir describir el funcionamiento del dispositivo de cavitación, así como para poder realizar modificaciones en el diseño para conseguir optimizar el diseño planteado en el capítulo anterior.

- Los capítulos quinto y sexto comprenden todos los experimentos llevados a cabo por el dispositivo de cavitación, no solo en laboratorio (capítulo quinto) sino también en la planta piloto (capítulo sexto). Se analizan las principales variables para determinar el efecto real que el cavitador tiene sobre el proceso.

- Finalmente, en el séptimo capítulo, se resumen las principales conclusiones alcanzadas en cada uno de los apartados de la tesis junto con las reflexiones finales sobre la investigación realizada. 


\section{Capítulo 2}

\section{Estado del arte}

En este capítulo se presentan de forma muy resumida los principales fundamentos en los que se basa el fenómeno de la cavitación, las características que lo describen, sus principales aplicaciones, y los sistemas utilizados para producir cavitación de forma voluntaria y controlada. Asimismo, se han recopilado los principales modelos matemáticos utilizados para caracterizar el fenómeno, los cuales son utilizados en los actuales programas de CFD para conseguir cuantificar la cavitación generada y determinar las zonas sean susceptibles de producirla.

\subsection{El fenómeno de la cavitación}

La cavitación, al igual que la ebullición, son cambios de fase en los que una sustancia pasa de un estado líquido a un estado gaseoso. De manera muy ilustrativa, E. Brennen sugiere en su libro (Brennen, 1995) que una forma tosca de diferenciar entre ambos efectos, es asumir la ebullición como un proceso de nucleación producido por un aumento de temperatura a presión constante, mientras que la cavitación se produce por la una disminución de la presión a una temperatura constante. Obviamente, esta no es más que una explicación muy simplificada de toda la complejidad del fenómeno, pero permite hacerse una muy buena idea para poder diferenciar entre ambos fenómenos. Al hablar de cambio de estado, es inevitable presentar el diagrama de fases puesto que es dicho diagrama en el que establece cuáles son los límites de presión y temperatura entre las 3 fases de una sustancia.

En la Figura 4, se presenta el diagrama de fases para el agua. Los puntos A, B y $\mathrm{C}$ del diagrama son bien conocidos. El primero (A), se corresponde con el punto triple, en el cual las 3 fases coexisten, pudiendo estar una misma sustancia en estado sólido, líquido y gaseoso simultáneamente. El segundo (B), es el punto de congelación y el tercero (C) es el punto de ebullición. Finalmente, se tiene el punto E. Este punto, denominado punto crítico, representa la temperatura $\left(373.99^{\circ} \mathrm{C}\right)$ a partir de la cual las moléculas de agua se mueven de forma tan rápida que 
independientemente de la presión que se aplique, no se puede pasar de la fase gas a la fase líquida a no ser que se disminuya la temperatura.

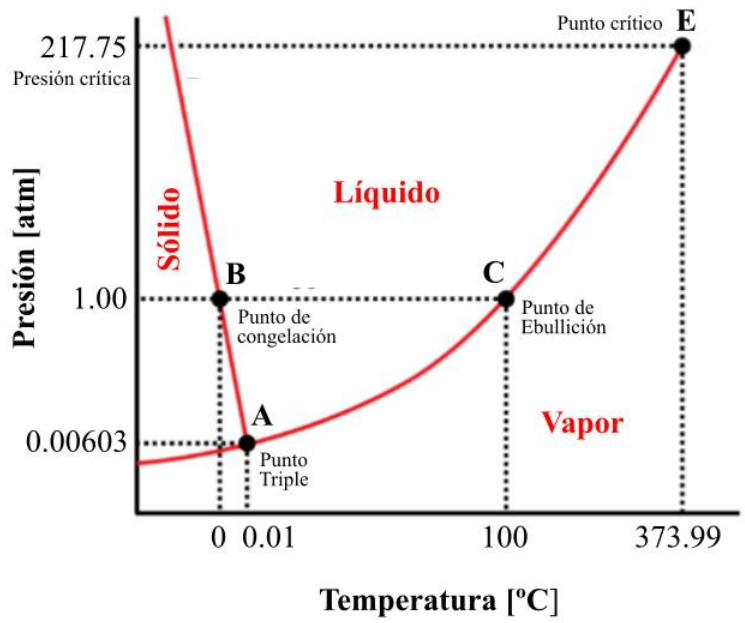

Figura 4: Diagrama de fases para el agua.

Como se puede ver en la Figura 4, la presión que sería necesario aplicar en el punto crítico para conseguir que el agua en estado gas pasara a estado líquido es de 217.75 atm. Centrando la atención de nuevo en los puntos $\mathrm{B}$ y C, nótese que, en condiciones de presión de 1 atm, el punto de congelación y de fusión para el agua se corresponde con $0^{\circ} \mathrm{C}$ y $100^{\circ} \mathrm{C}$ respectivamente. No obstante, a temperatura ambiente de por ejemplo $25^{\circ} \mathrm{C}$, también es posible obtener agua en estado gaseoso si se consigue disminuir la presión hasta alcanzar 0.3128 atm $(3170 \mathrm{~Pa})$, tal y como se muestra en la Figura 5. Esta presión, es la denominada presión de vapor $\left(\mathrm{p}_{\mathrm{v}}\right)$ y es principio fundamental para producir el efecto de la cavitación. Así pues, a efectos teóricos, si se consigue generar un campo de presiones en un fluido de forma que se alcancen valores inferiores a la presión de vapor en alguno de sus puntos, las moléculas de esa sustancia pasarán de fase líquida a fase gas.

Así pues, teóricamente, si se consigue generar un campo de presiones en un fluido de forma que se alcancen valores inferiores a la presión de vapor en alguno de sus puntos, las moléculas de esa sustancia pasarán de fase líquida a fase gas. No obstante, esto es sólo la condición necesaria para que se dé el fenómeno de la cavitación. A partir de este punto, la evolución y características que se producen en el cambio de fase dependen de un gran número de variables físicas, termodinámicas, reológicas y ambientales. Es importante mencionar, que tanto los diagramas de fases como las temperaturas de vaporización, presiones de vapor y otros puntos destacados, son referidos siempre a sustancias puras y se deben entender como información proporcionada en un marco teórico. En la práctica, 
estas sustancias se ven alteradas por distintos tipos de contaminantes (partículas o gases disueltos en el interior del fluido), lo que hace que su comportamiento diste del teórico en mayor o menor medida

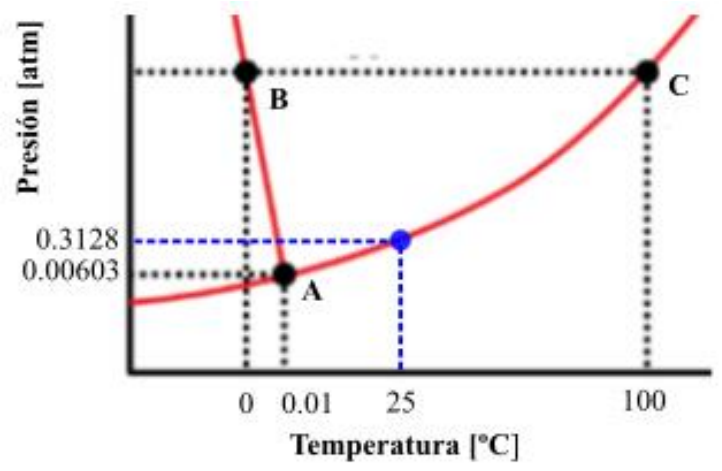

Figura 5: Detalle del diagrama de fases del agua.

Presión de vapor para una temperatura de $25^{\circ} \mathrm{C}$ (azul).

Una vez se han dado las condiciones adecuadas para que la cavitación se produzca, se puede considerar que el fenómeno siempre se desarrolla de la misma forma y consta de varias fases o etapas (Franc \& Michel, 2004):

Generación de las cavidades de vapor. Para que se produzca la cavitación, la presión local debe disminuir por debajo del valor de la $\mathrm{p}_{\mathrm{v}}$. No obstante, esta condición no garantiza necesariamente la existencia de un cambio de fase ya que, bien por diferencias entre la presión de vapor y la presión real de inicio de la cavitación (static delay), o bien por la inercia necesaria para que las cavidades de vapor crezcan y sean observables (dynamic delay), pueden existir demoras en la aparición del fenómeno de la cavitación. Estrictamente, en el proceso de generación se pueden distinguir 3 pasos secuenciales que son: creación del vacío, llenado del vacío con vapor y saturación del vapor. Esta secuencia es tan rápida que a efectos prácticos puede considerarse como una sola.

Crecimiento y desarrollo de las cavidades de vapor. Una vez presentes las cavidades de vapor o burbujas, estas pueden comportarse de 3 formas diferentes (Agostino \& Salvetti, 2007) dependiendo de las condiciones existentes:

- Cavitación adherida (attached cavities): aparece en las zonas de baja presión de formas geométricas como perfiles de ala o álabes de bombas hidráulicas y ocupa la totalidad de la zona en depresión (Figura 6)

- Burbujas transitorias aisladas (Transient isolated bubbles): son cavidades que se convierten en burbujas de vapor en las zonas de baja presión y colapsan al volver a tener condiciones de presión más elevada (Figura 7). Durante el 
proceso de transporte, las burbujas pueden viajar en solitario juntarse con otras, generando nubes de cavitación (cavitation clouds) (Figura 8).

- Vórtices cavitantes (cavitating vortices): aparecen en los núcleos de bajas presiones de las estelas turbulentas que se producen en las puntas de ala o en los extremos de las palas de las hélices (Figura 9).

Colapso de las burbujas. Generalmente, las burbujas se generan en una zona de baja presión, pero esa condición no es estable y la presión aumenta rápidamente fuera de esa zona localizada. En cuanto la burbuja se ve sometida a un nuevo gradiente de presión elevado, colapsa de forma rápida y violenta. Este colapso produce muy altas temperaturas y presiones de forma muy puntual, y es ahí donde reside todo el potencial (tanto negativo como positivo) del efecto de la cavitación.

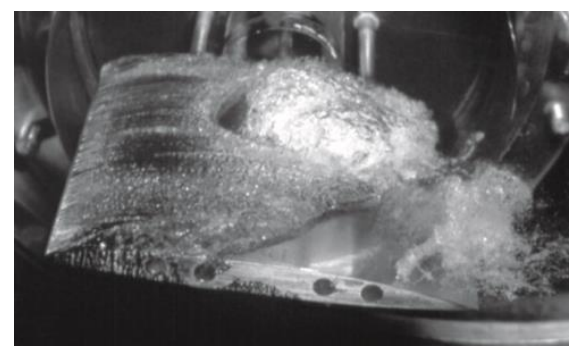

Figura 6: Cavitación adherida.

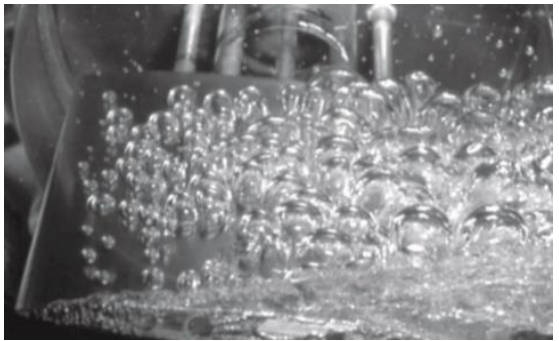

Figura 8: Nube de cavitación por la coalescencia de burbujas.

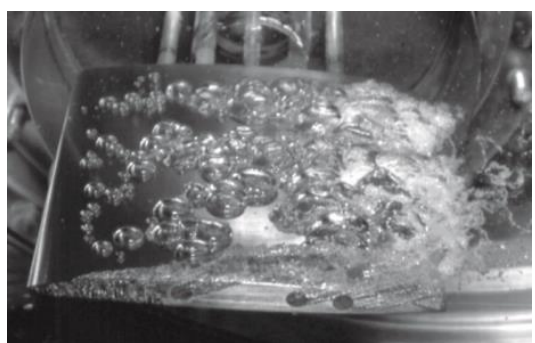

Figura 7: Burbujas transitorias aisladas sobe un perfil de ala.

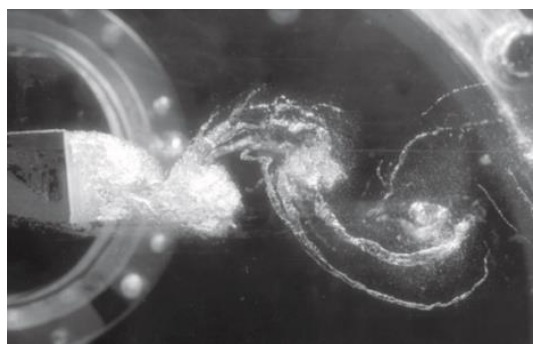

Figura 9: Vórtices cavitantes.

Por lo general, la cavitación es un proceso indeseable que en la mayoría de casos es sinónimo de graves problemas en las instalaciones. Esto se debe a que es un efecto altamente corrosivo y que en condiciones no controladas puede producir, en el caso de bombas hidráulicas, por ejemplo, la corrosión y desgaste prematuro del material. Paradójicamente, este efecto que resulta indeseable en algunas 
aplicaciones es realmente útil para otras cuyo principal objetivo es la desinfección, mezclado, emulsión o transferencia de calor entre otros.

El efecto destructivo de la cavitación sucede cuando el vapor generado debido a las condiciones de baja presión colapsa para volver de nuevo al estado líquido. Este cambio de fase se realiza de manera muy violenta, consiguiéndose valores muy altos de temperatura/presión de forma muy localizada y durante instantes de tiempo muy pequeños. Es decir, esto sería como tener "microrreactores" trabajando en condiciones extremas de presión y temperatura. Así pues, en condiciones controladas, el efecto corrosivo producido por la cavitación puede ser utilizado para un gran número de aplicaciones que van desde la emulsión de productos inmiscibles hasta la desinfección de aguas.

\subsubsection{Ecuación de Rayleigh-Plesset}

La ecuación de Rayleight-Plesset es la base para poder caracterizar de forma adecuada el fenómeno de cavitación. Desde el caso más simple, como es el comportamiento de una burbuja (crecimiento, equilibrio y colapso), hasta los efectos de cavitación más complejos que se dan en bombas y otras turbomáquinas (erosión, supercavitación, efectos termodinámicos o dinámica del flujo de cavitación entre otros), tienen como base esta expresión. No obstante, la cavitación es un fenómeno mucho más complejo, e incluso hoy en día, hay algunos aspectos que continúan siendo desconocidos. Por tanto, aunque la ecuación de RayleightPlesset resulta ser muy útil para comprender los aspectos fundamentales de la cavitación, en un análisis más profundo se requerirían modelos matemáticos mucho más complejos (consideración de las reacciones químicas, la difusión de los gases, la vaporización y condensación de agua a través de la interfase, etc.) que se escapan al alcance de esta investigación. Por tanto, en las explicaciones que se presentan a continuación, basadas en la ecuación de Rayleight-Plesset, se asumen las siguientes simplificaciones:

- El líquido en el cual se encuentran las burbujas se considera incompresible y newtoniano.

- Se considera que el proceso es adiabático. Por tanto, se desprecia cualquier intercambio de calor con el fluido, así como la inercia que pueda tener la burbuja. Esta asunción es válida incluso para burbujas grandes.

- La burbuja, se encuentra saturada de vapor cuya presión se corresponde con la presión de vapor del líquido a esa determinada temperatura

- La transferencia de masa a través de la interfase es despreciada.

- Los efectos de la gravedad son también despreciados. 
Considerando esta serie de condiciones, la ecuación de Rayleight-Plesset permite caracterizar el comportamiento de una burbuja de gas que se encuentra en el interior de un líquido finito. A grandes rasgos, se puede decir que la expresión considera que la fase líquida contiene una serie de incepciones y permite predecir de forma matemática todo el proceso de evolución, desde el crecimiento de las burbujas individuales hasta el equilibrio y posterior colapso de las mismas. Es un modelo que deriva de las ecuaciones de Navier-Stokes al asumir simetría esférica de una burbuja de radio $\mathrm{R}$ que puede variar a lo largo del tiempo.

Uno de los parámetros más importantes para describir la evolución de las burbujas en la ecuación de Rayleight-Plesset, es la presión. Se asume que la presión en el centro de la burbuja se corresponde con la presión que habría en ese punto del líquido si no existiera burbuja, es decir, la presión que existiría en la evolución normal del fluido sin existencia de gas ni formación de burbujas. La presión del medio en este punto se caracteriza por $\mathrm{p}_{\infty}$, y es uno de los principales parámetros para describir la dinámica de la burbuja. Los flujos inducidos por el crecimiento y el colapso de la burbuja son despreciados y por tanto se asume que toda la información del fluido original queda recogida única y exclusivamente por el parámetro po.

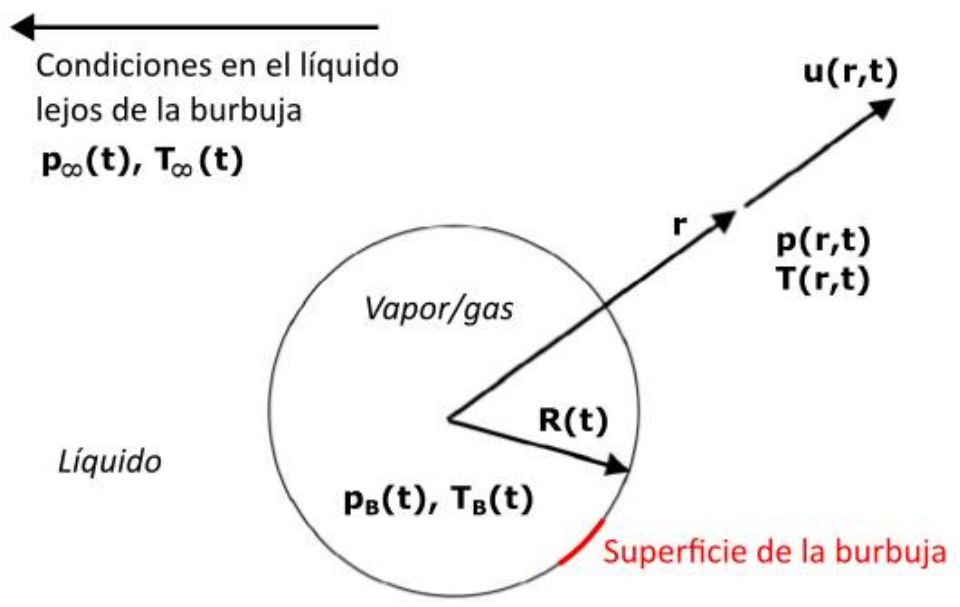

Figura 10: Esquema de una burbuja en el interior de un líquido infinito.

\subsubsection{Condiciones de contorno y condiciones iniciales}

Además de las simplificaciones anteriormente descritas, es necesario considerar las siguientes condiciones de contorno y condiciones iniciales para poder llegar a la expresión de Rayleight-Plesset (Franc \& Michel, 2004). 
En primer lugar, se desprecia la transferencia de masa desde la burbuja hacia el líquido, de manera que la velocidad del líquido en la interfase $u(R, t)$ es igual a la propia velocidad de la interfase (dR/dt). No obstante, sí se considera la tensión normal en la interfase, que para un fluido de viscosidad cinemática $\mu$ se describe como:

$$
t_{r r}(R, t)=-p(R, t)+\left.2 \mu \frac{\delta u}{\delta r}\right|_{r=R}
$$

Por otro lado, se tiene el balance de fuerzas en el cual la tensión superficial depende tanto de la presión parcial del gas en el interior de la burbuja $\left(\mathrm{p}_{\mathrm{g}}\right)$ cómo de la presión de vapor $\left(\mathrm{p}_{\mathrm{v}}\right)$ y la tensión superficial $(\mathrm{S})$ de la siguiente manera:

$$
-t_{r r}(R, t)=p_{v}+p_{g}(t)+\frac{2 S}{R}
$$

Y dado que se asume un comportamiento adiabático del gas, se puede relacionar la presión instantánea del gas $\mathrm{pg}_{\mathrm{g}}(\mathrm{t})$ en función de la presión del gas inicial $\mathrm{p}_{\mathrm{g} 0}$ con la siguiente ecuación:

$$
p_{g}(t)=p_{g 0}\left[\frac{R_{0}}{R(t)}\right]^{3 \gamma}
$$

Donde $\gamma$ es el coeficiente politrópico correspondiente a un comportamiento adiabático. Juntando las anteriores ecuaciones, se puede obtener el valor de la presión en la interfase que queda de la siguiente manera:

$$
p(R, t)=p_{v}+p_{g 0}\left[\frac{R_{0}}{R(t)}\right]^{3 \gamma}-\frac{2 S}{R}+\left.2 \mu \frac{\delta u}{\delta r}\right|_{r=R}
$$

En las zonas alejadas de la interfase, se considera que el fluido está en reposo, es decir $\mathrm{u}(\infty, \mathrm{t})=0$ y la presión se corresponde con $\mathrm{p}_{\infty}(\mathrm{t})$ tal y como puede verse en la 
Figura 10. Por tanto, para las condiciones de presión iniciales en las cuales se considera que la burbuja está en reposo, $\mathrm{dR} / \mathrm{dt}=0$, la Ec. 11 se convierte en:

$$
p_{\infty 0}=p_{v}+p_{g 0}-\frac{2 S}{R_{0}}
$$

Volviendo de nuevo a la expresión de la velocidad, se tiene un flujo irrotacional de tipo fuente o sumidero debido a la simetría esférica de la burbuja. Por tanto, se cumple:

$$
u(r, t)=\frac{d R}{d t}-\frac{R^{2}}{r^{2}}
$$

Ec. 6

En este caso en concreto, el término viscoso de la ecuación de Navier-Stokes es cero. Así pues, tanto para un flujo viscoso como no viscoso se cumple la ecuación del momento:

$$
\frac{\delta u}{\delta r}+u \frac{\delta u}{\delta r}=-\frac{1}{\rho} \frac{\delta p}{\delta r}
$$

y sustituyendo la Ec. $\mathbf{6}$ en la anterior ecuación, se obtiene:

$$
\frac{d^{2} R}{d t^{2}} \frac{R^{2}}{r^{2}}+2\left(\frac{d R}{d t}\right)^{2}\left[\frac{R}{r^{2}}-\frac{R^{4}}{r^{5}}\right]=-\frac{1}{\rho} \frac{\delta p}{\delta r}
$$

Ec. 8

y considerando las condiciones de presión en el infinito e integrando con respecto a r se llega a la ecuación:

$$
\frac{p(R, t)-p_{\infty}(t)}{\rho}=R \frac{d^{2} R}{d t^{2}}+\frac{3}{2}\left(\frac{d R}{d t}\right)^{2}
$$


Finalmente, utilizando la expresión de la presión en la interfase (Ec. 4) y sabiendo que $\left.\frac{\delta u}{\delta r}\right|_{r=R}=-\frac{2}{R} \frac{d R}{d t}$, y que $\mathrm{r}=\mathrm{R}$ (en la interfase), se llega a la ecuación de Rayleigh-Plesset que proporciona la evolución en el tiempo del radio de una burbuja de gas en el interior del fluido líquido principal.

$$
\rho\left[R \frac{d^{2} R}{d t^{2}}+\frac{3}{2}\left(\frac{d R}{d t}\right)^{2}\right]=\left[p_{v}-p_{\infty}(t)\right]+p_{g 0}\left(\frac{R_{0}}{R}\right)^{3 K}-\frac{2 S}{R}-\frac{4 \mu}{R} \frac{d R}{d t} \quad \text { Ec. } 10
$$

Donde $\rho$ y $\mu$ son la densidad y la viscosidad del fluido líquido respectivamente, $p_{v}$ es la presión de vapor, $R_{0}$ el tamaño inicial de las burbujas de gas, $\mathrm{S}$ la tensión superficial y $p_{g 0}$ la presión parcial del gas no condensable en las condiciones iniciales. Esta ecuación permite definir el comportamiento de la burbuja durante el crecimiento y colapso y, por tanto, se considera el punto de partida para la explicación del fenómeno de la cavitación en cualquiera de sus fases. Se puede observar como en la parte de la derecha de la igualdad, existen 4 términos diferentes:

Primer término: $\left[p_{V}-p_{\infty}(t)\right]$. Hace referencia a cuán cerca está la presión de trabajo a la presión de vapor. Es la parte fundamental de la ecuación ya que de ella depende directamente la evolución (crecimiento, colapso, oscilaciones...) de las burbujas de aire.

Segundo término: $p_{g 0}\left(\frac{R_{0}}{R}\right)^{3 K}$. Añade la contribución del gas no condensable a la ecuación. Se deben hacer dos suposiciones: la primera es que la masa de gas no condensable dentro de la burbuja permanece constante durante toda la evolución, y la segunda es considerar que la ecuación del gas no condensable se rige por un proceso politrópico caracterizado por el coeficiente politrópico $k$. Si se considera una evolución isotérmica, $\mathrm{k}=1$, si es adiabática $\mathrm{k}=\Upsilon$ y en caso de no poder asumir ninguna de las condiciones anteriores se debe resolver una ecuación de energía adicional. Si el tiempo de evolución de un núcleo en el flujo cavitante es más grande que el requerido para que se produzca la transferencia de calor y se consiga alcanzar la temperatura de equilibrio, se puede asumir que el proceso térmico es adiabático. Si se considerase que las burbujas de aire son resultado de una explosión violenta, el proceso tiende a ser adiabático. En cualquier caso, (Qin \& Alehossein, 2016) se estima necesario tener en cuenta todos los posibles efectos térmicos (conducción, convección y radiación) si se quiere describir con precisión 
el proceso completo de crecimiento y colapso de las burbujas, ya que de otro modo se estarían asumiendo una serie de suposiciones que no son necesariamente correctas.

Tercer término: $\frac{2 S}{R}$. Añade la contribución de la tensión superficial. Dado que $\mathrm{R}$ se encuentra en el denominador, es de esperar que este término solo tenga efecto significativo en burbujas cuyo radio es muy pequeño.

Cuarto término: $\frac{4 \mu}{R} \frac{d R}{d t}$ Tiene en cuenta la viscosidad dinámica del líquido. La disipación debida a la viscosidad es directamente proporcional a la tasa de deformación de la burbuja $\left(\frac{d R}{d t}\right)$ e inversamente proporcional a su radio. Por tanto, al igual que sucede con el término referente a la tensión superficial, el efecto de la viscosidad tendrá relevancia solo en burbujas de muy pequeño tamaño.

Como se ha comentado anteriormente, para el caso de cavitación con formación de burbujas suficientemente grandes, pueden despreciarse el tercer y cuarto término que hacen referencia a la tensión superficial y a la viscosidad respectivamente. Asimismo, también puede obviarse el efecto del gas no condensable lo que da lugar a la llamada ecuación simplificada de Rayleigh-Plesset que queda de la siguiente manera:

$$
\rho\left[R \frac{d^{2} R}{d t^{2}}+\frac{3}{2}\left(\frac{d R}{d t}\right)^{2}\right]=\left[p_{v}-p_{\infty}(t)\right] \quad \text { Ec. } 11
$$

Tal y como puede observarse, cuando si se obvian los efectos de la tensión superficial, viscosidad y gases condensables, el comportamiento dinámico de las burbujas únicamente se rige por las diferencias entre la presión a la que esté sometido el fluido y la presión de vapor.

\subsubsection{Fase de generación y crecimiento}

Para que pueda producirse un cambio de fase de líquido a gas y, por tanto, que el fenómeno de la cavitación tenga lugar, es imprescindible que se den unas determinadas condiciones de presión y temperatura. Estas condiciones de cambio de fase son bien conocidas (ver diagramas de fase de la Figura 4) y, por tanto, se sabe que a cada temperatura le corresponde una presión de vapor determinada a partir de la cual, comienza la fase de generación y crecimiento. Atendiendo a este criterio, la cavitación a una determinada temperatura debería producirse siempre cuando se alcanzase la presión de vapor para esa condición en concreto. No obstante, esto no es así. Algunos experimentos llevados a cabo con agua han demostrado que la cavitación no solo puede producirse por debajo de la presión de vapor teórica, sino que, en determinadas situaciones, se genera incluso a presiones 
negativas que pueden llegar a ser del orden de $27.7 \mathrm{MPa}$ (esto es, resistencia a la tracción del agua) (Briggs, 1950). Con esto se demuestra que la aparición de la fase gas no depende únicamente de las condiciones de presión y de temperatura, sino que está también ligada a otras características y condiciones independientes de estas variables.

Así pues, la explicación de estas variaciones en el comienzo de la fase de generación depende de los puntos de origen donde nacen las primeras burbujas de gas que hacen posible el desarrollo del fenómeno de la cavitación. Estos puntos de origen son los denominados núcleos de cavitación (cavitation nucler) y dependen en gran medida de propiedades como: la cantidad de gases no condensables que se encuentran en el interior del fluido, o las características que tengan las paredes del contenedor en el cual se encuentra. Por tanto, incluso para un mismo fluido la formación de las primeras burbujas de gas estará sujeta por un lado a los posibles pretratamientos que se le hayan realizado al fluido (como una desgasificación) pero también a la naturaleza de las paredes del sólido que se encuentre en contacto con el fluido (limpieza, acabado superficial, etc.).

Matemáticamente, se puede estimar el crecimiento de las burbujas de vapor con ayuda de la ecuación de Rayleight-Plesset. Si se considera que se tienen burbujas de cavitación suficientemente grandes $\left(\mathrm{R}>\mathrm{R}_{0}\right)$ se pueden despreciar los términos de la Ec. 10 que hacen referencia a la viscosidad dinámica del fluido, tensión superficial y contribución del gas no condensable y, por tanto, se puede utilizar la ecuación simplificada de Rayleigh-Plesset (Ec. 11). Integrando dicha ecuación una vez, se obtiene la velocidad de crecimiento de la burbuja:

$$
\frac{d R}{d t}=\sqrt{\frac{2}{3} \frac{p_{v}-p_{\infty}}{\rho}\left[1-\left(\frac{R_{0}}{R}\right)^{3}\right]}
$$

Se puede apreciar que esta ecuación está condicionada a la relación $\mathrm{R}_{0} / \mathrm{R}$. Atendiendo a esto, esta ecuación es válida desde prácticamente el inicio del crecimiento, ya que desde el momento en el que el radio $\mathrm{R}$ supera 3 veces el tamaño inicial del núcleo de cavitación $\mathrm{R}_{0}$, el error introducido al utilizar esta última con respecto a la Ec. 12, es inferior a un $2 \%$ (Franc, 2007).

$$
\frac{d R}{d t}=\sqrt{\frac{2}{3} \frac{p_{v}-p_{\infty}}{\rho}}
$$


Así pues, de forma simplificada y basándose en la ecuación de Rayleigh-Plesset, la velocidad de crecimiento de un núcleo que se encuentre en el interior de un fluido depende de la densidad de este fluido y de las diferencias entre la presión a la que estén sometidos él y la presión de vapor. Este crecimiento tiene como base los núcleos de cavitación que se encuentran en el interior del fluido y, por tanto, la cantidad y distribución de estas nucleaciones juega un papel fundamental en la evolución del proceso de cavitación.

\subsubsection{Núcleos de cavitación o nucleación}

Los núcleos de cavitación son considerados como "huecos" que se encuentran en la fase líquida y que actúan como puntos de inicio donde comienza la aparición de la fase gas que posteriormente y en las condiciones adecuadas, dará paso a la cavitación. Inicialmente estos núcleos son microburbujas (entre $1 \mu \mathrm{m}$ y menos de $1 \mathrm{~mm}$ ) formadas por gas no condensable o por partículas de tamaño inferior a 1 $\mu \mathrm{m}$ que se encuentran en el interior del líquido. Aunque estas burbujas se pueden encontrar libres en el fluido, también es posible que se encuentren confinadas en huecos y grietas microscópicas que se encuentran en la pared del contenedor (Harvey et al., 1944). Una última posibilidad en cuanto a los núcleos de cavitación, es que estos no sean consecuencia ni de la existencia de gas no condensable en el líquido o en las superficies del contenedor, ni de pequeñas micropartículas contaminantes, sino que sean producidas por la radiación cósmica (Sette \& Wanderlingh, 1962). En ese caso, las colisiones entre partículas de alta energía y las moléculas de del fluido, puede transmitir suficiente energía como para generar puntos de nucleación en el interior de la fase líquida. Sin embargo, este efecto, aunque es posible, es muy poco probable y por tanto no se considera salvo en estudios muy específicos.

Los tipos de núcleos de cavitación anteriormente mencionados se hallarían englobados dentro de lo que se denomina la nucleación heterogénea. No obstante, existe otro tipo de nucleación que es consecuencia de los movimientos térmicos producidos en el interior del líquido los cuales generan una serie de vacíos microscópicos. Es la llamada nucleación homogénea (Brennen, 1995). Este tipo de nucleación es muy difícil de distinguir con respecto a la heterogénea ya que, en este último tipo, incluso la más pequeña partícula a escala micrométrica puede actuar como un núcleo de cavitación. Por tanto, todos los estudios relacionados con la cavitación homogénea tienen en común la realización de tratamientos de limpieza al fluido de estudio (generalmente agua) que consisten mayormente en procesos de desgasificación y limpieza exhaustiva de los recipientes. Existen una gran cantidad de modelos y teorías que se han ido desarrollando a lo largo de los años para dar respuesta a cómo y por qué se forman estos núcleos de cavitación durante la nucleación homogénea. Un buen resumen de gran parte de ellas, se puede apreciar en el estudio de (MØRCH, 2009). En dicho estudio, se acaba proponiendo un 
modelo de nucleación que explica por qué los núcleos de cavitación pueden originar variaciones en la resistencia a tracción del agua que van desde prácticamente cero a cientos de bares, aunque no explica cómo se realiza la difusión del gas en los núcleos de cavitación. Además, hace hincapié en la dificultad para mantener los núcleos estables a la hora de realizar los experimentos y la gran importancia de realizar una limpieza exhaustiva del contenedor, así como del fluido para evitar la interferencia de partículas y gases no condensables en el interior del fluido y en las paredes del contenedor que pudieran actuar también como núcleos de cavitación y afectaran al resultado de los experimentos.

\subsubsection{Estabilidad de los núcleos.}

Dado que el fenómeno de la cavitación tiene su origen en los núcleos (ya sean consecuencia de la nucleación homogénea o heterogénea), la estabilidad y equilibrio dinámico de estas burbujas o núcleos juega un papel fundamental en la evolución del proceso de cavitación. Para conocer la expresión que rige el comportamiento de una burbuja o núcleo en equilibrio dentro de un líquido, es suficiente con anular todas las derivadas con respecto al tiempo de la ecuación de Rayleigh-Plesset (Ec. 10) y considerar constante la presión externa ( $\mathrm{p}_{\infty}$ ). Por otro lado, el análisis en equilibrio se considera como un proceso isotérmico en el que el coeficiente politrópico $\mathrm{k}$ es igual a 1 . Con estas consideraciones, la ecuación queda de la siguiente manera:

$$
0=\left[p_{v}-p_{\infty}\right]+p_{g 0}\left(\frac{R_{0}}{R}\right)^{3}-\frac{2 S}{R}-0
$$

Despejando la presión externa (la del fluido que envuelve la burbuja o núcleo), se llega a la siguiente ecuación:

$$
p_{\infty}=p_{v}+p_{g 0}\left(\frac{R_{0}}{R}\right)^{3}-\frac{2 S}{R}
$$

Se puede observar cómo la diferencia entre la presión interna de la burbuja y la externa se debe la tensión superficial, la cual permite obtener el radio que tendrá la burbuja sumergida en un fluido cuya presión es $\mathrm{p}_{\infty}$.

Al graficar la ecuación anterior, se puede observar que el radio de la burbuja aumenta gradualmente de tamaño conforme la presión va disminuyendo. Durante ese tramo de curva, el equilibrio es estable. No obstante, al alcanzar unos ciertos valores críticos de presión $\left(\mathrm{p}_{c}\right)$ y de tamaño de burbuja $\left(\mathrm{R}_{\mathrm{c}}\right)$, se pasa a una zona de equilibrio inestable donde el tamaño de la burbuja tiende a crecer de forma ilimitada. 

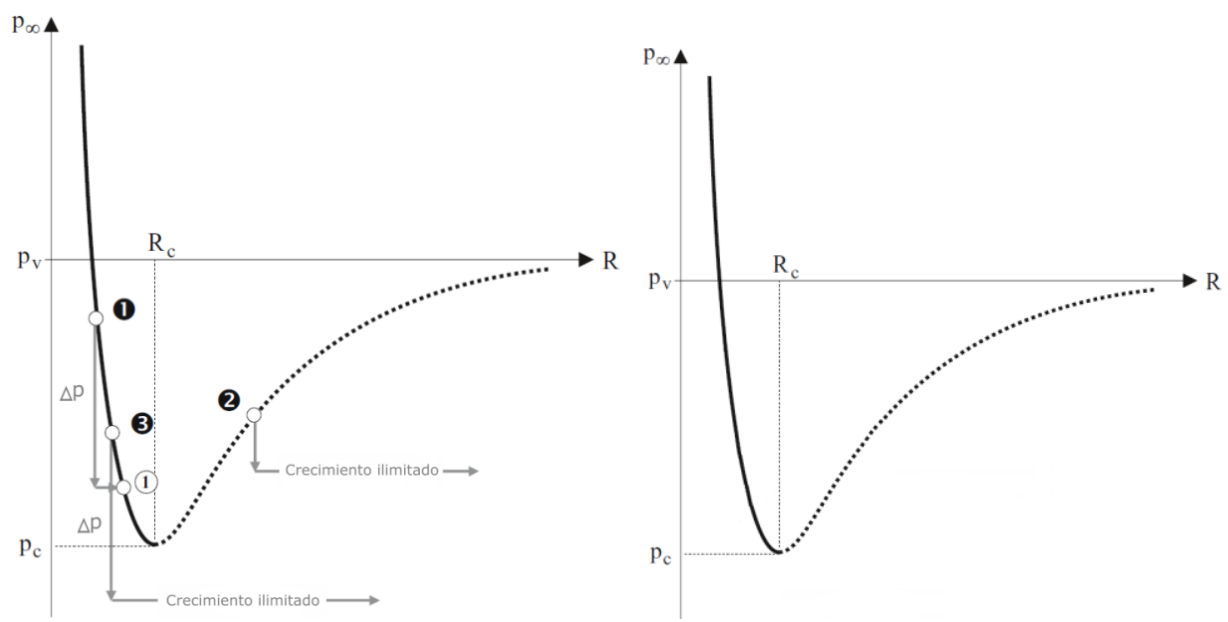

Figura 11: Radio de equilibrio para núcleos de cavitación en función de la presión externa (izq.) y su evolución al aplicarse un pequeño decremento de presión (der.).

Considerando 3 núcleos en equilibrio en diferentes condiciones, se puede observar qué ocurre al aplicarles a cada uno de ellos una pequeña disminución de la presión. En el caso 1, el núcleo de cavitación aumentará de tamaño a partir de su radio inicial $\mathrm{R}_{0}$ al aplicarle esa disminución de presión, pero continuará dentro de la zona de equilibrio estable y por tanto se establecerá permanentemente con un nuevo tamaño de radio $R$. En el caso 2, dado que inicialmente el núcleo se encuentra en un equilibrio inestable, la burbuja crecerá de forma ilimitada independientemente de la disminución de presión aplicada. Por último, en el caso 3, la disminución de presión dará lugar a que el núcleo con un radio inicial $\mathrm{R}_{0}$ entre en un nuevo estado de equilibrio inestable y aumente de tamaño de forma ilimitada, es decir, la presión crítica puede considerarse como el punto a partir del cual una microburbuja deja de ser un núcleo de cavitación y se convierte en una burbuja de cavitación de escala macroscópica.

Por tanto, la estabilidad del núcleo viene proporcionada por el mínimo de la Ec. 14. Al derivar la ecuación respecto a la presión externa del fluido y al radio de la burbuja e igualarla a 0 , se obtiene la presión crítica $\left(\mathrm{p}_{c}\right)$ y el radio crítico $\left(\mathrm{R}_{c}\right)$ a partir de los cuales los núcleos se vuelven inestables y se produce un crecimiento ilimitado de los mismos.

$$
R_{c}=\sqrt{\frac{3 p_{g 0} R^{3}}{2 S}}
$$




$$
p_{c}=p_{v}-\frac{4 S}{3 R_{c}}
$$

Ec. 16

En la Ec. 16se puede observar como la presión crítica es más pequeña que la de vapor y la diferencia entre ellas es debida al efecto de la tensión superficial. Esta diferencia se denomina retraso estático del núcleo (nucleus static delay) es despreciable para núcleos pequeños, pero cobra importancia para aquellos más grandes. De la Ec. 15 se deduce que cuanto mayor es el tamaño inicial del núcleo $\left(\mathrm{R}_{0}\right)$, mayor será el radio crítico de las burbujas de cavitación; y de la Ec. 16 se deduce que cuanto mayor sea el radio crítico, más grande será la presión crítica. Es decir, los núcleos más grandes cavitarán antes dado que su presión crítica es mayor y más cercana a la presión de vapor. Por tanto, a no ser que se realice un proceso especial para eliminar todos aquellos núcleos de cavitación grandes, se puede asumir que la presión de cavitación es igual a la presión de vapor puesto que son estos núcleos más grandes los que actuarán como puntos débiles iniciando el proceso de cavitación.

Cabe también decir, que las burbujas en el interior de un líquido pueden actuar como elementos oscilantes ya que están sometidos al comportamiento elástico del gas no condensable y a la inercia del líquido. Por tanto, considerando un núcleo o burbuja en equilibrio $\left(R=R_{\circ}\right)$, se puede obtener a partir de la Ec. 14:

$$
p_{\infty 0}=p_{v}+p_{g 0}-\frac{2 S}{R}
$$

Si se suponen unas oscilaciones de la presión $\mathrm{p}_{\infty}$ alrededor de la presión de equilibrio p $\infty_{\infty}$, con un pulso de $\omega$ y una pequeña amplitud $\delta p$ de la forma:

$$
p_{\infty}=p_{\infty 0}+\delta \mathrm{p} \sin (\omega \mathrm{t})
$$

Ec. 18

Entonces, se podría obtener la variación del radio de la burbuja mediante la ecuación de Rayleight-Plesset y obtener la frecuencia de resonancia, que vendría descrita por la siguiente ecuación (Franc, 2007): 


$$
f_{0}=\frac{1}{2 \pi R_{0}} \sqrt{\frac{1}{\rho}\left[3 k\left(p_{\infty 0}-p_{v}+\frac{2 S}{R_{0}}\right)-\frac{2 S}{R_{0}}\right]}
$$

La frecuencia de oscilación de la burbuja depende en gran medida de su radio, siendo inversamente proporcional a este. Se puede observar también, que el efecto de la tensión superficial solo será notable para burbujas de pequeño tamaño y tendrá poco efecto cuando las burbujas sean más grandes. En cualquier caso, estas solo se producirá una frecuencia de resonancia en la burbuja cuando su frecuencia natural sea de orden similar a las variaciones de presión en po. Además, estas oscilaciones pueden no ser lineales y en determinadas situaciones, aunque $\mathrm{p}_{\infty}$ tenga una variación de forma periódica, esto no se traduce en variaciones periódicas en el radio de la burbuja, sino en una respuesta con subharmónicos que distan mucho de la variación que presenta po. (Franc \& Michel, 2004).

\subsubsection{Número de cavitación $(\sigma)$}

El número de cavitación ( $\sigma$ ) (cavitation number) es un parámetro adimensional que proporciona la intensidad y/o el grado de desarrollo de la cavitación. Se expresa como la diferencia entre la presión del sistema y la presión de vapor dividido por la presión dinámica. Está definido por la siguiente ecuación:

$$
\sigma=\frac{P_{r e f}-P_{v}}{\frac{1}{2} \cdot \rho \cdot V^{2}}
$$

Donde $\mathrm{P}_{\text {ref }}$ es la presión de referencia en un determinado punto del fluido mientras que $\mathrm{V}$ es la velocidad característica de dicho fluido. Estos dos parámetros deben estar perfectamente definidos para cada caso práctico en concreto, ya que es el propio autor el que determina dónde situarlos. Como norma general, los valores de la velocidad y de la presión de referencia se eligen en zonas donde el flujo permanece inalterado, es decir, lejos de la zona donde se produce la cavitación. Los valores grandes de $\sigma$ se corresponden con flujos no cavitantes, dado que van asociados a valores grandes de presión de referencia $P_{\text {ref. }}$ Esto indica que la mayor parte del fluido se encuentra por encima de la presión de vapor $\mathrm{P}_{\mathrm{v}} \mathrm{y}$ por tanto lejos de las condiciones para que se produzca cavitación. Es importante destacar que este parámetro es altamente dependiente de la geometría y de valores de referencia considerados en cada sistema en particular, y únicamente es adecuado para ser 
considerado como un parámetro de escala que mide la extensión global de la cavitación en un determinado sistema.

Un valor interesante de $\sigma$, resulta ser aquel en el cual comienza a hacerse visible el fenómeno de la cavitación. Este valor es conocido como número de cavitación inicial $\left(\sigma_{\mathrm{i}}\right)$ (incipient cavitation number). Considerando como punto de partida un flujo estable y no cavitante, el valor $\sigma_{i}$ se alcanza disminuyendo la presión de referencia o incrementando la velocidad del fluido. El valor de $\sigma$ disminuirá hasta alcanzar el valor de $\sigma_{i}$ y una vez llegado a este punto, cualquier aumento en la velocidad o disminución de la presión de referencia, producirá la aparición de cavitación en el sistema de estudio.

Son muchos los autores que utilizan este parámetro para el estudiar y comparar sus sistemas de cavitación (I. Lee \& Han, 2013), (Rudolf, Hudec, Gríger, \& Štefan, 2014), (Tomov et al., 2016a) ya que puede utilizarse para cualquier dispositivo de cavitación, Venturi, placas con orificios, inductores rotativos, máquinas rotativas y en definitiva cualquier sistema cuyo flujo sea susceptible de ser monitorizado con sensores de presión y de velocidad. No obstante, son muchas las inconsistencias encontradas en los estudios que utilizan este parámetro. Principalmente interesante resulta el estudio realizado por Šarc, Stepišnik-Perdih, Petkovšek, \& Dular, 2017 en el cual se advierte de la mala utilización por parte de algunos investigadores de este parámetro. En dicho artículo, se hace también un profundo análisis para determinar cómo varía el fenómeno de la cavitación para un mismo valor de $\sigma$ con respecto a diferentes aspectos como la velocidad y calidad (cantidad de aire disuelto) del fluido, la temperatura, o diferentes definiciones de $\sigma$ encontradas en bibliografía. El estudio muestra como para un mismo valor de $\sigma$, se obtienen diferentes resultados en el efecto de cavitación. Estas variaciones pueden observarse, por ejemplo, en la longitud de la nube cavitante (L) tal y como se muestra en la Figura 12 pero también en otros aspectos como la frecuencia de desprendimiento de la nube de cavitación o las variaciones de presión registradas con un hidrófono.

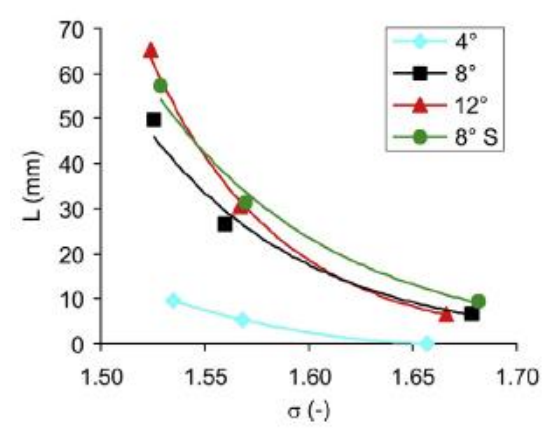

(a)

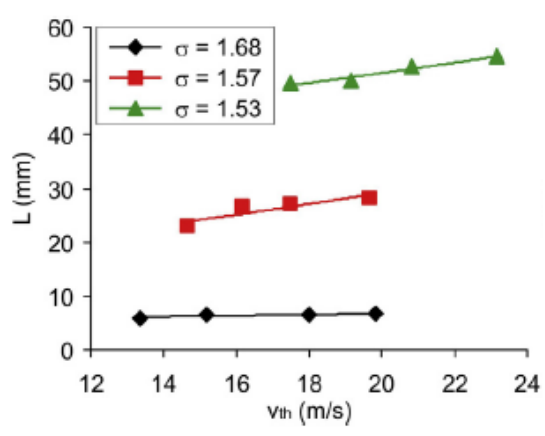

(b) 


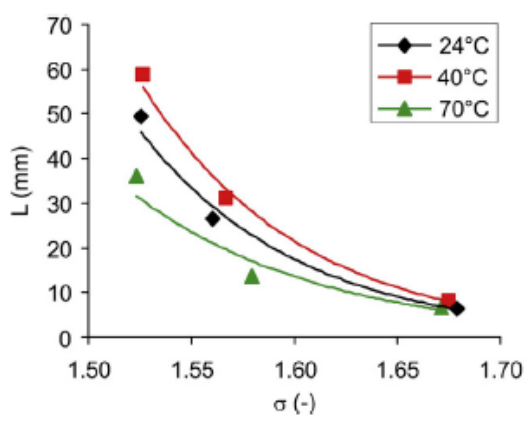

(c)

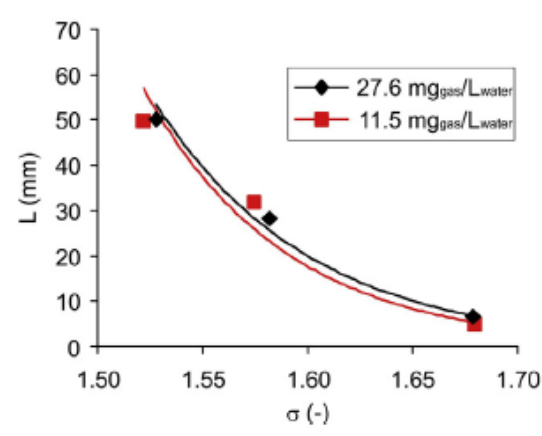

(d)

Figura 12: Variación de las longitudes de la nube cavitante en función de la geometría del ángulo de salida del Venturi (a), Velocidad en el estrechamiento (b), temperatura del fluido (c) y cantidad de gas disuelto (d) (Šarc et al., 2017).

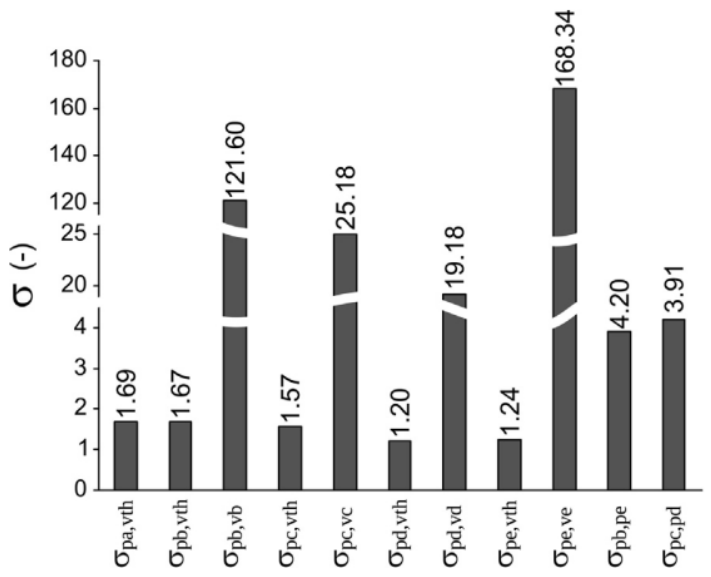

Figura 13. Variación del valor de $\sigma$ en función de los puntos donde definen la presión de referencia y la velocidad para un mismo caso (misma velocidad, temperatura, geometría del Venturi y calidad del fluido) (Šarc et al., 2017).

La principal conclusión del estudio es que el valor de $\sigma$, no debe utilizarse nunca como único parámetro indicador de las condiciones de cavitación. Por otro lado, deben caracterizarse con precisión los puntos donde se han realizado las mediciones para definir la presión de referencia y de la velocidad (Ec. 20), puesto que el número de cavitación es altamente dependiente de estos dos parámetros tal y como se muestra en la Figura 13.

Por tanto, la única forma de poder realizar comparaciones del fenómeno de la cavitación utilizando este parámetro es utilizando no solo los mismos puntos de 
referencia para la velocidad y la presión, sino también realizando la comparación entre dos sistemas de cavitación idénticos.

\subsubsection{Fase de colapso}

La fase de colapso de las burbujas es una de las partes más importantes dentro del proceso de cavitación. Cuando las burbujas de gas generadas durante el fenómeno de la cavitación entran en contacto con zonas donde la presión vuelve a estar por encima de la de vapor, éstas pasan de estado gas a estado líquido de forma muy violenta. Debido a esto, se consiguen alcanzar condiciones extraordinarias de presión, y temperatura de manera puntual. Bajo estas condiciones extremas, se libera gran cantidad de energía en forma de sonido y calor que, en determinadas situaciones, puede ser sinónimo de problemas indeseados (como el desgaste de los rodetes de las bombas hidráulicas). No obstante, estas condiciones extremas alcanzadas durante el colapso son, a la vez, la clave del funcionamiento en numerosas aplicaciones entre las cuales se encuentran los procesos de limpieza de materiales o la eliminación de microorganismos como se verá en secciones posteriores.

Una vez más, una primera aproximación para realizar la explicación matemática de esta fase es utilizando la ecuación de Rayleigh-Plesset. Cabe decir que la caracterización completa de esta fase es muy compleja, y la investigación del efecto de cada uno de los parámetros de la ecuación (gas no condensable, viscosidad y tensión superficial) ya están sujetos por sí solos a un extenso estudio. Como aproximación válida, se puede despreciar el efecto de la viscosidad, ya que su efecto, incluso cuando se aumenta moderadamente con respecto al valor del agua, no parecen tener un efecto significativo en el colapso de la burbuja. Lo mismo ocurre con el efecto de la tensión superficial que solo parece tener importancia para burbujas muy pequeñas y que se ve enmascarado por otros fenómenos de mayor importancia como la inercia del líquido o la presión (Ivany \& Hammitt, 1965). De esta forma, puede realizarse la explicación de la fase de colapso en base a la ecuación de Rayleigh-Plesset simplificada (Ec. 11). (Franc, 2007)

Considerando núcleos de cavitación que se encuentran en la zona de equilibrio estable (Figura 11), se puede observar cómo al aumentar la presión por encima de la del vapor, el radio de las burbujas disminuye. Esto se conoce como la fase de colapso. Al integrar la ecuación simplificada (Ec. 11):

$$
\frac{d R}{d t}=-\sqrt{\frac{2}{3} \frac{p_{\infty}-p_{v}}{\rho}\left[\left(\frac{R_{0}}{R}\right)^{3}-1\right]}
$$


La ecuación es prácticamente igual a la ecuación que proporciona la velocidad de crecimiento de la burbuja (Ec. 12) aunque en esta ecuación existe un signo menos debido a que la velocidad es de contracción y no de expansión.

Integrando la ecuación anterior en el rango 0-R, se obtiene el tiempo de vida de la burbuja (bubble lifetime) o tiempo de la fase de colapso. Esta expresión es también conocida como tiempo de Rayleigh-Plesset y proporciona el tiempo que tarda una burbuja en desaparecer completamente, es decir, en que su radio sea igual a 0.

$$
\tau \cong 0.915 R_{0} \sqrt{\frac{\rho}{p_{\infty}-p_{v}}}
$$

El tiempo de vida de la burbuja se adecúa correctamente a los resultados experimentales para un amplio rango de tamaños de burbuja iniciales que van desde 1 micrómetro a 1 metro de diámetro.

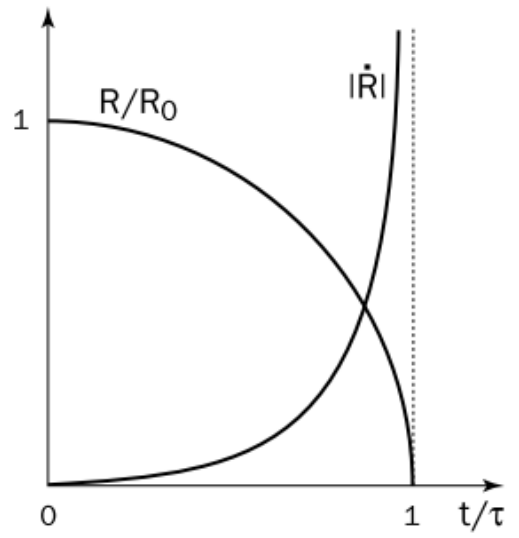

Figura 14: Evolución del radio (R) y de la velocidad (dR/dt) de la burbuja de gas (Franc \& Michel, 2004).

Se puede observar como la velocidad tiende a infinito para valores muy pequeños de $\mathrm{R}$ debido al cociente $\mathrm{R}_{0} / \mathrm{R}$, mientras que el tamaño de la burbuja disminuye hasta desaparecer (cociente $\mathrm{R} / \mathrm{R}_{0}=0$ ). Para valores muy pequeños de $\mathrm{R}$ (justo antes del colapso) podría considerarse la siguiente variante de la Ec. 21: 


$$
\frac{d R}{d t}=-\sqrt{\frac{2}{3} \frac{p_{\infty}-p_{v}}{\rho}} \cdot\left(\frac{R_{0}}{R}\right)^{3 / 2}
$$

Sustituyendo el valor de $\tau$ en la Ec. 23 se obtiene:

$$
\frac{d R}{d t} \cong 0.747 \frac{R_{0}}{\tau}\left[\frac{R_{0}}{R}\right]^{3 / 2}
$$

Es decir, en el momento justo antes del colapso la velocidad debería ser infinita. Obviamente, esto no es así y esta incongruencia física se debe a las simplificaciones realizadas. En los instantes inmediatamente anteriores al colapso, el radio evoluciona según la siguiente ecuación:

$$
\frac{R}{R_{0}} \cong 1.87\left[\frac{\tau-t}{\tau}\right]^{2 / 5}
$$

Considerando esta última expresión, para valores muy pequeños de $\mathrm{R}$, por ejemplo, $R / R_{0}=1 / 20$, la velocidad estimada sería cercana a los $720 \mathrm{~m} / \mathrm{s}$, es decir, aproximadamente la mitad de la velocidad del sonido en el agua. Con estos valores, se hace evidente la necesidad de considerar la condición de líquido compresible para el momento del colapso y aunque los efectos termales, viscosos y de la tensión superficial continúen despreciándose, la ecuación de Rayleight-Plesset se complica de manera sustancial al considerar la compresibilidad (Keller \& Kolodner, 1956). Lo mismo ocurre con la simplificación de no considerar el efecto del gas no condensable cuya presión aumenta de forma drástica en los últimos momentos justo antes del colapso. Este efecto, por ejemplo, generaría una disminución sustancial de la velocidad de la interfase de la burbuja justo antes del colapso que podría llegar incluso a generar una inversión del movimiento, originando así una especie de efecto rebote (Hickling \& Plesset, 1964a).

Por tanto, aunque la ecuación de Rayleight-Plesset permite entender el comportamiento de la fase de colapso de forma general, presenta una serie de limitaciones que son consecuencia de las simplificaciones adoptadas inicialmente en la ecuación (pág. 13) y las condiciones extraordinarias que se dan en el momento puntual del colapso. Por tanto, aunque la ecuación de Rayleight-Plesset 
es considerada siempre como el punto de partida para la explicación de cualquier fase de la cavitación, para el momento del colapso en particular, algunos de los efectos despreciados inicialmente (compresibilidad del líquido, efectos térmicos o efectos viscosos y reacciones térmicas) cobran una gran relevancia y se vuelven imprescindibles para una correcta caracterización y explicación del fenómeno de la cavitación en todas sus fases.

\subsubsection{Campo de presiones durante el colapso}

El campo de presiones puede definirse a partir de la Ec. 9 obteniendo la velocidad de la interfase de la Ec. 12. De esta manera se puede derivar para

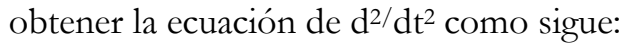

$$
\frac{d^{2} R}{d t^{2}}=-\frac{p_{\infty}-p_{v}}{\rho} \frac{R_{0}{ }^{3}}{R^{4}}
$$

Ec. 26

A partir de este punto, se puede calcular el comportamiento de la presión adimensional $\Pi$ (Franc \& Michel, 2004) obteniendo:

$$
\Pi(r, t)=\frac{p(R, t)-p_{\infty}}{p_{\infty}-p_{v}}=\frac{R}{3 r}\left[\frac{R_{0}^{3}}{R^{3}}-4\right]-\frac{R^{4}}{3 r^{4}}\left[\frac{R_{0}^{3}}{R^{3}}-1\right]
$$

Ec. 27

de donde puede sacarse el máximo de la expresión en el momento que el radio de la burbuja se vuelve más pequeño de $(1 / \sqrt[3]{4}) R_{0} \cong 0.63 R_{0}$, consiguiendo un valor máximo para la presión adimensional de:

$$
\Pi_{\max }=\frac{p_{\max }-p_{\infty}}{p_{\infty}-p_{v}}=\frac{\left[\frac{R_{0}{ }^{3}}{4 R^{3}}-1\right]^{4 / 3}}{\left[\frac{R_{0}^{3}}{R^{3}}-1\right]^{1 / 3}}
$$

Este valor se sucede cuando se alcanza la distancia $r_{\max }$ desde el centro de la burbuja, es decir:

$$
\frac{r_{\max }}{R}=\left[\frac{\frac{R_{0}^{3}}{R^{3}}-1}{\frac{R_{0}^{3}}{4 R^{3}}-1}\right]^{1 / 3}
$$


Con esto se deduce que cuando la relación entre $\mathrm{R} / \mathrm{R}_{0}$ se vuelve muy pequeña se obtienen sendos valores de $\Pi_{\max } \mathrm{y}$ de $\frac{r_{\max }}{R}$ de $0.157\left[\frac{R_{0}}{R}\right]^{3}$ y 1.59 respectivamente. Por tanto, considerando una diferencia entre $p_{\infty}-p_{v}$ es de 1 bar, el valor de la presión máxima durante el colapso alcanzaría los 1260 bares. Esto se da para una relación $\mathrm{R} / \mathrm{R}_{0}=20$. El comportamiento de la presión adimensional en función de la relación $r / R_{0}$ puede verse en la siguiente figura:

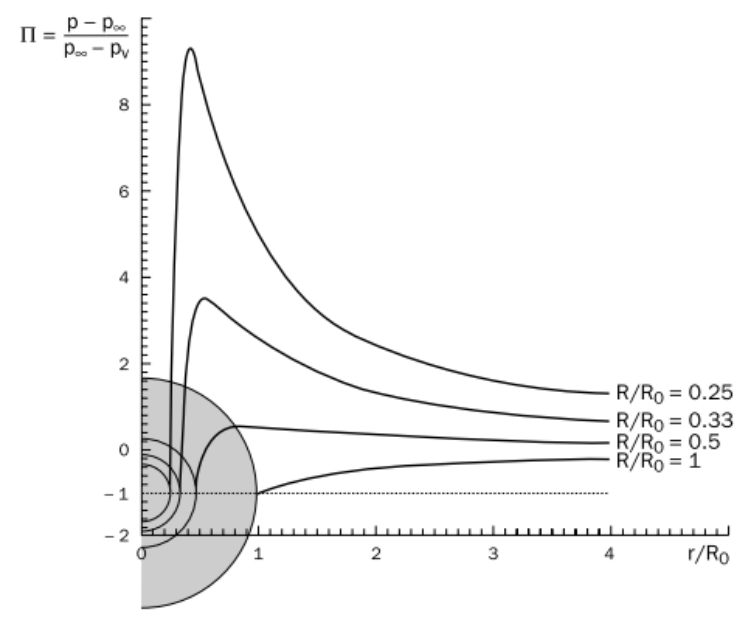

Figura 15: Evolución del campo de presión durante el colapso de la burbuja. Imagen de (Franc \& Michel, 2004).

Así pues, el pulso de presión transferido al líquido tiene una magnitud de presión máxima cuyo valor es más grande cuanto más pequeño es el radio de la burbuja en el momento del colapso. A medida que la onda de presión se aleja, esta se va atenuando. No obstante, dependiendo de las circunstancias en el momento del colapso, es posible que la onda de presión se atenúe casi por completo a unos pocos radios de distancia.

Según algunos estudios (Hickling \& Plesset, 1964b), existe una expresión que permite calcular de forma muy aproximada la atenuación de este pico de presión y cuál será su valor $\left(\mathrm{p}_{\mathrm{p}}\right)$ en función de los radios de distancia a la cual se encuentre y de la presión en el infinito del líquido:

$$
p_{p} \approx \frac{100 R p_{\infty}}{r}
$$


De acuerdo con la anterior ecuación, para una presión po=1 bar, a una distancia de un radio $(\mathrm{r}=\mathrm{R})$ la presión que cabría esperar es de aproximadamente 100 bar. Estos valores fueron confirmados años después (Fujikawa \& Akamatsu, 1980) cuando a partir de un experimento se pudo registrar la magnitud de la onda de presión impactando sobre la pared de un recipiente situado a 1 radio de distancia de la burbuja colapsada, y cuyo valor medido fue de 100 bar.

Estas expresiones permiten hacerse una idea de las extremas condiciones de presión que pueden alcanzarse cuando las burbujas producidas durante el fenómeno de la cavitación colapsan. Si bien es cierto que estos valores se producen en zonas muy puntuales, en una situación en la que existan unas condiciones de cavitación adecuadas se puede producir gran cantidad de burbujas colapsando de forma continuada. Esto genera zonas más o menos extensas en las que existen unas condiciones de presión muy elevadas que pueden ser muy provechosas para determinadas aplicaciones.

\subsubsection{Temperaturas durante la formación/colapso}

De manera habitual, el aporte térmico producido durante la formación y colapso de las burbujas es despreciado, ya que el efecto global que produce en el líquido principal de transporte de las burbujas es prácticamente imperceptible. No obstante, de manera similar a los pulsos de presión, durante el colapso se pueden alcanzar de forma puntual temperaturas extremas que pueden llegar a varios miles de grados centígrados. Así pues, analizando en detalle el fenómeno a nivel de una burbuja en particular, el efecto térmico tiene una gran relevancia.

Para comprender cómo se producen estas temperaturas, debe analizarse el comportamiento térmico durante un cambio de fase. Durante el comienzo de la cavitación, se produce el crecimiento de un núcleo o burbuja, es decir, existe una vaporización. Dado que la burbuja se encuentra completamente rodeada por el líquido, la única forma de obtener la energía necesaria para realizar el cambio de fase es extraerla del propio líquido. Así pues, durante el crecimiento de la burbuja, el líquido que se encuentra a su alrededor tiende a enfriarse porque cede energía para que se produzca el vapor en la burbuja. El efecto contrario se produce cuando la burbuja colapsa, ya que se produce una condensación donde se libera energía que es absorbida por el líquido y, por tanto, este se calienta (Dular \& CoutierDelgosha, 2013). Debe considerarse, que las variaciones de temperatura que se producen durante el crecimiento o colapso afectan a la presión de vapor. Así pues, en el caso de que se produzca una expansión y el líquido se enfríe reduciéndose su temperatura, también disminuirá la presión de vapor necesaria para realizar el cambio de fase. Esto retrasará el crecimiento de la burbuja en lo que se conoce como thermal delay o retardo térmico que puede llegar a tener un efecto significativo en el desarrollo del fenómeno de la cavitación (Brennen, 1995). 
Entre las dos etapas de la cavitación mencionadas (crecimiento y colapso) es en el colapso donde la energía térmica resulta interesante para muchos procesos dado que se traduce en una elevación de la temperatura del líquido. En cualquiera de los dos casos, en la interfase entre el líquido y gas aparece una capa límite térmica cuya magnitud puede calcularse de la siguiente manera (Franc, 2007):

$$
C_{\text {límite }}=\sqrt{\frac{\lambda_{l}}{\rho_{l} c_{p l}} t}
$$

donde: $\lambda_{l} / \rho_{l} c_{p l}$ es la difusión térmica del líquido $\left(\alpha_{l}\right), \lambda_{l}$ la conductividad, $\rho_{l}$ la densidad $c_{p l}$ la capacidad calorífica del líquido, y $t$ es el tiempo de crecimiento/colapso que se esté considerando.

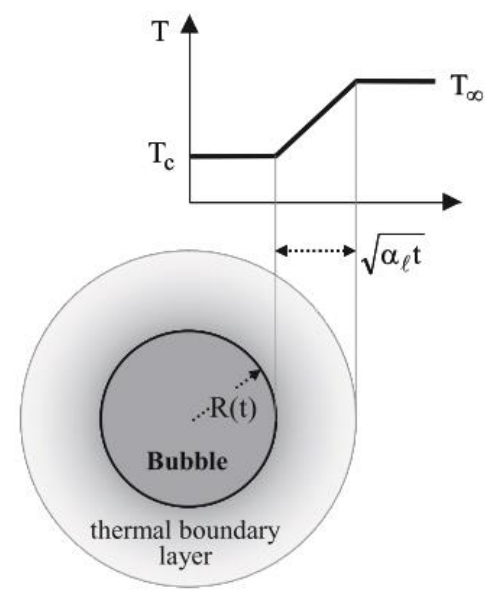

Figura 16: Capa límite térmica en la interfase entre el líquido y el gas. Imagen de Franc, 2007.

Esta capa límite térmica aparece tanto en la formación de la burbuja, donde existe una evaporación de líquido y expansión del gas, como durante el colapso, donde el líquido se condensa y se comprime. Para poder determinar cuál es el coeficiente politrópico en la ecuación de Rayleigh-Plesset (Ec. 10), es necesario saber si el proceso es adiabático $(\mathrm{k}=\gamma)$ o isotérmico $(\mathrm{k}=1)$, o lo que es lo mismo, si el proceso dominante es la expansión/compresión o la evaporización/ condensación. El conocimiento del proceso dominante también está asociado a la magnitud de las variaciones de temperatura obtenidas en la capa térmica (Franc \& Michel, 2004). 
Para determinar cuál es el mecanismo principal en la evolución del proceso, se debe realizar un balance energético del gas en el interior de la burbuja donde se asume que esta se forma debido a una caída de presión que se produce en un tiempo $\Delta t$ durante el cual el radio crece desde $\mathrm{R}$ hasta $\mathrm{R}+\Delta \mathrm{R}$ y se produce un cambio de temperatura de $\Delta \mathrm{T}$. El balance queda de la siguiente manera:

$$
\left(\frac{4}{3} \pi R^{3}\right) \rho_{g} C_{v g} \Delta T=\Delta Q-p\left(4 \pi R^{2} \Delta R\right)
$$

Ec. 32

Donde $\rho_{g}$ y $C_{v g}$ son la densidad y la constante calorífica del gas a volumen constante, $\Delta Q$ es la energía recibida del líquido y $\mathrm{p}$ es la presión en la interfase. Conociendo el valor de la capa límite (Ec. 31) y asumiendo que la variación de temperatura en el interior de la burbuja se debe exclusivamente al intercambio térmico, se llega a la siguiente expresión que permite obtener el tiempo característico de transferencia de energía $\left(\Delta T_{t r}\right)$ :

$$
\Delta T_{t r}=\frac{\left(\rho_{g} c_{v g} R\right)^{2}}{9 \lambda_{l} \rho_{l} c_{p l}}
$$

Si el tiempo de vida de la burbuja es mucho menor que $\Delta T_{t r}$, entonces el proceso predominante es la expansión/compresión de los gases. Si por el contrario, el tiempo de vida es mayor que $\Delta T_{t r}$, podrá producirse una trasferencia de calor hasta alcanzar el equilibrio, lo cual se asemeja a un proceso adiabático, es decir, regido por la evaporación/condensación.

Según estudios recientes (Dular \& Coutier-Delgosha, 2013), los mecanismos predominantes en la transferencia de energía térmica durante la cavitación son la evaporación y la condensación (es decir, la transferencia de masa), mientras que la expansión y el colapso únicamente tienen relevancia en las etapas inmediatamente anteriores al crecimiento o inmediatamente posteriores a la desaparición de la burbuja. Es durante esta última etapa del colapso cuando, según los cálculos analíticos de diversos autores, la temperatura que se alcanza en el centro de la burbuja va desde los $8800^{\circ} \mathrm{K}$ hasta los $3400^{\circ} \mathrm{K}$ aunque únicamente sea durante fracciones de microsegundos, ya que transcurridos $2 \mathrm{~ns}$, la temperatura vuelve a descender hasta los $300^{\circ} \mathrm{K}$ (Brennen, 1995). La magnitud de estas temperaturas también ha sido medida de forma experimental (Suslick, Hammerton, \& Cline, 1986) localizando las diferentes zonas donde se producen las reacciones químicas 
como consecuencia de las altas temperaturas y se han registrado valores de $5200^{\circ} \mathrm{K} \pm 650$.

\subsubsection{Creación de radicales de hidroxilo e hidrógeno}

La energía que se libera durante el colapso causa la disociación térmica de las moléculas de agua, lo que resulta en la formación de hidrógeno activo $(\mathrm{H})$ y radicales de hidroxilo $(\mathrm{OH})$ de la siguiente manera y según (Weissler, 1959):

$$
\mathrm{H}_{2} \mathrm{O} \rightarrow \mathrm{H}+\mathrm{OH}
$$

Tras la descomposición del agua, los radicales pueden volver a recombinarse para formar hidrógeno o peróxido de hidrógeno según:

$$
\begin{gathered}
\mathrm{H}+\mathrm{H} \rightarrow \mathrm{H}_{2} \\
\mathrm{OH}+\mathrm{OH} \rightarrow \mathrm{H}_{2} \mathrm{O}_{2}
\end{gathered}
$$

pero también pueden reaccionar entre ellos destruyéndose de manera que se vuelve a genera agua y un radical libre:

$$
\begin{gathered}
\mathrm{H}+\mathrm{H}_{2} \mathrm{O}_{2} \rightarrow \mathrm{H}_{2} \mathrm{O}+\mathrm{OH} \\
\mathrm{OH}+\mathrm{H}_{2} \rightarrow \mathrm{H}_{2} \mathrm{O}+\mathrm{H}
\end{gathered}
$$

Finalmente, también es posible que los radicales permanezcan libres el tiempo suficiente como para poder reaccionar con algunos de las sustancias que se encuentren solubilizadas en el agua (Rs) y que actúen como receptores (scavengers):

$$
\mathrm{Rs}+\mathrm{OH} \rightarrow \mathrm{RsOH}
$$

Esta última reacción resulta especialmente interesante dado que si la sustancia receptora se considera contaminante, esta puede transformarse en un contaminante inorgánico o en un contaminante orgánico, pero con unas características tóxicas notablemente inferiores a la sustancia original (Gagol, Przyjazny, \& Boczkaj, 2018). Las reacciones anteriormente presentadas únicamente tienen en consideración la existencia de los radicales y de la propia agua. No obstante, la realidad es que la cantidad de posibles reacciones que pueden producirse tras la formación de los radicales es muy extensa y depende mucho de 
las sustancias presentes en el momento de la aparición de estos radicales (J. M. Wu, Huang, \& Livengood, 1992).

La formación de los radicales $\mathrm{OH}$ y $\mathrm{H}$ pudo ser determinada por primera vez cuantificando la reacción resultante al interactuar con sustancias receptoras como benzoato, etanol, metanol, 1-propanol, acetona, o 2-metil-propanol (Maklno, Mossoba, \& Rlesr, 1983). Otra posible forma de determinar la formación de estos radicales es mediante la temperatura. Dado que la disociación de las moléculas de agua es un proceso endotérmico, la temperatura en el momento del colapso se ve reducida, y de la misma manera, durante la expansión, los radicales se recombinan mediante un proceso exotérmico que aumenta la temperatura. Algunos autores (Hauke, Fuster, \& Dopazo, 2007) han conseguido cuantificar la disminución de temperatura que se produce durante el colapso de una burbuja de Argón (Figura 17), así como la producción de radicales $\mathrm{OH}$ y $\mathrm{H}$ (Figura 18).

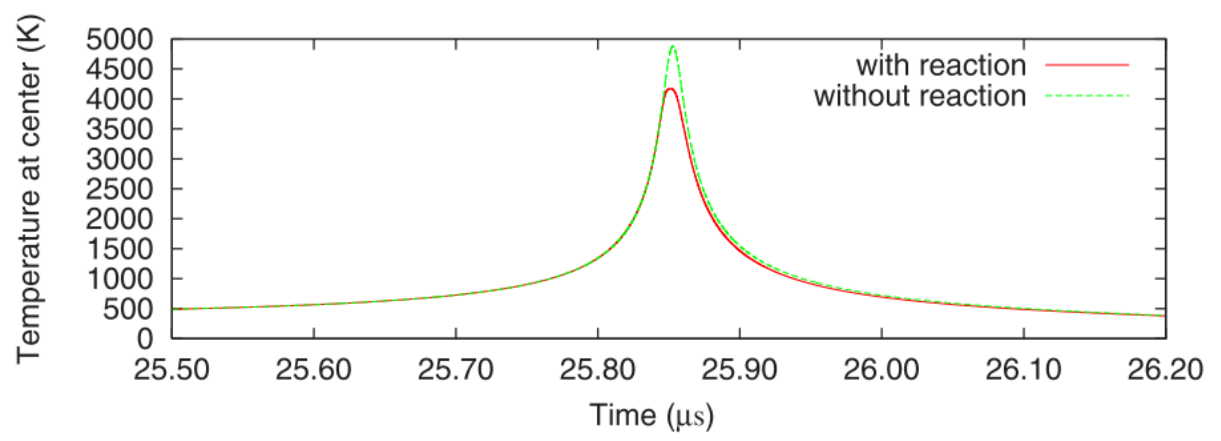

Figura 17: Influencia de la reacción de disociación durante el colapso de burbujas de Argón. Imagen de (Hauke et al., 2007).
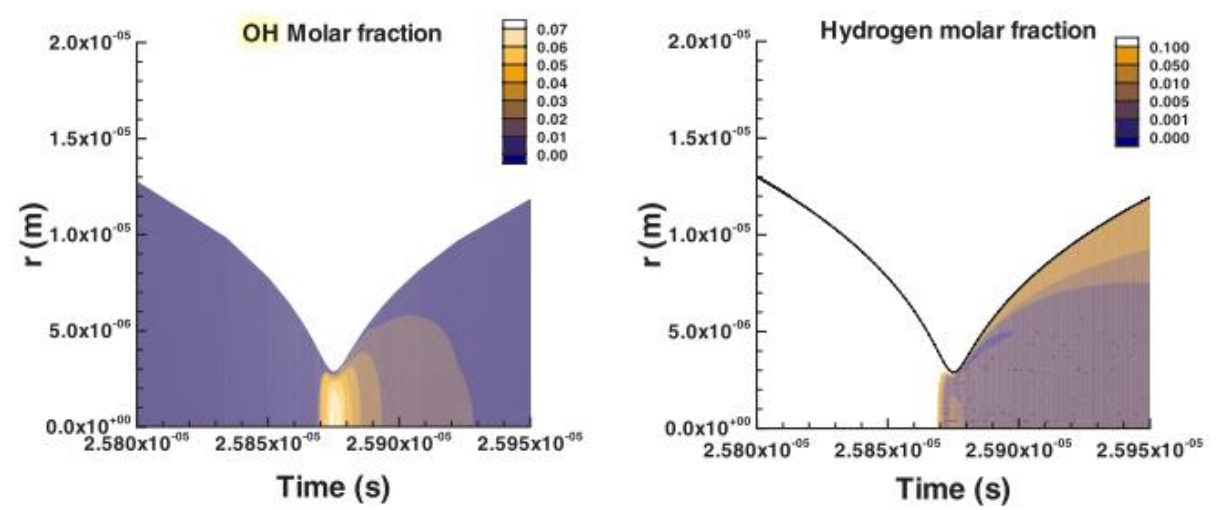

Figura 18: Formación de radicales $\mathrm{OH}$ y $\mathrm{H}$ durante el colapso de una burbuja de Argón. Gráficas de Imagen de (Hauke et al., 2007). 
La cantidad de radicales $\mathrm{OH}$ obtenidos puede ser utilizado como un indicador de la efectividad que se está teniendo durante la cavitación. La cantidad de radicales obtenidos está directamente relacionada con la concentración de agua. Por tanto, para conseguir un modelo que prediga correctamente la formación de los radicales (Hauke et al., 2007), es necesario utilizar modelos que tengan en cuenta la transferencia de masa, ya que de otro modo no se puede determinar la concentración existente de agua, y por tanto no se obtiene concentración de radicales alguna.

\subsection{Modelado del fenómeno de la cavitación}

Hasta el momento se ha descrito detalladamente el fenómeno de la cavitación desde el punto de vista del comportamiento de una burbuja individual (ecuaciones de Rayleigh-Plesset). Sin embargo, la comprensión de la cavitación desde esta perspectiva ha perdido interés durante las últimas décadas y ha sido sustituido por estudios que explican el comportamiento del fenómeno como un todo. La mayoría de los modelos numéricos conocidos y que se utilizan en la actualidad, han sido desarrollados en los últimos 50 años y algunos de ellos han sido implementados ya en programas de dinámica computacional de fluidos (CFD) tras una extensa etapa de validación experimental bajo diferentes condiciones y en múltiples sistemas (Venturi, perfiles NACA, cuerpos cilíndricos, etc.). Esto ha sido posible gracias a los avances en materia de CFD y al desarrollo de aproximaciones al modelado multifásico, concretamente al enfoque Euler-Euler.

La aproximación Euler-Euler, permite un tratamiento matemático de las diferentes fases como si fuesen continuas e interpenetrantes. Puesto que el volumen de una fase no puede ser ocupado por otras, aparece el concepto de fracción volumétrica. Estas fracciones volumétricas se consideran porciones continuas en el espacio-tiempo, y la suma de todas ellas debe ser siempre igual a la unidad. Los modelos multifásicos basados en la aproximación Euler-Euler más utilizados son:

- El modelo VOF (Volume of Fluid)

- El modelo homogéneo

- El modelo Euleriano

En el presente apartado se presentan estos 3 modelos y se explican las principales ventajas e inconvenientes de utilizar cada uno de ellos. Asimismo, se profundizará en aquellos modelos que son más comúnmente utilizados para realizar estudios mediante la CFD, exponiendo sus principales características para poder ser implementados en estos softwares de cálculo. 


\subsubsection{Modelo VOF}

Con el modelo VOF, se pueden estudiar dos o más fluidos inmiscibles resolviendo el mismo sistema de ecuaciones para todas las fases y determinando la fracción volumétrica de cada uno de los fluidos que componen el dominio. Está especialmente pensado para aquellas aplicaciones donde es importante conocer y determinar con precisión la posición de la interfase entre los diferentes fluidos que conforman el sistema, con la condición de que, si una de estas fases se encuentra dispersa, su fracción volumétrica no represente más de un $10 \%$ del total de dicha fase. Generalmente, este modelo se utiliza en las siguientes aplicaciones:

- Análisis de la ruptura de un chorro líquido (jet breakup).

- Movimiento de grandes burbujas de gas en un líquido.

- Comportamiento del gas en una tubería con líquido (slug flow).

- Análisis de llenado y de salpicaduras.

- Análisis en régimen estacionario o transitorio de cualquier interfaz líquido-gas. Flujos estratificados o superficie en lámina libre.

Las ecuaciones del modelo VOF se basan en el hecho de que los diferentes fluidos o fases que componen el sistema no son interpenetrantes. De esta manera, es necesario introducir por cada fase del sistema y en cada celda de cálculo, una variable denominada fracción volumétrica. En todo momento, la suma de las fracciones volumétricas de todas las fases que componen el sistema en cualquier volumen de control debe ser igual a la unidad. Los campos para todas las variables y propiedades se comparten por cada una de las fases que componen el sistema y sus valores vienen representados por la media volumétrica. Por tanto, las variables y propiedades en cualquier celda de cálculo solo son representativas de una de las fases o de una mezcla de estas. Esto dependerá de la fracción de volumen en celda de cálculo en concreto, es decir, si la fracción volumétrica del fluido q-ésimo se denota con $\alpha_{q}$, entonces pueden darse las siguientes 3 condiciones:

- $\alpha_{q}=1$ : La celda de cálculo está vacía del fluido $\mathrm{q}$

- $\alpha_{q}=0$ : La celda de cálculo está llena de la fluido $\mathrm{q}$

- $0<\alpha_{q}<1$ : La celda de cálculo contiene la interfase entre el fluido q y otro (u otros) fluidos

Una vez introducido el concepto de fracción volumétrica, es necesario determinar de qué manera afecta a las diferentes ecuaciones que gobiernan el comportamiento de los fluidos. 


\subsubsection{Ecuación de continuidad}

Para poder calcular la posición de las interfases entre cada uno de los fluidos, debe resolverse la ecuación de continuidad considerando la fracción volumétrica de uno o varios fluidos. Para el fluido q, la ecuación queda de la siguiente manera:

$$
\frac{1}{\rho_{q}}\left[\frac{\partial}{\partial t}\left(\alpha_{q} \rho_{q}\right)+\nabla \cdot\left(\alpha_{q} \rho_{q} \vec{v}_{q}\right)=S_{\alpha_{q}}+\sum_{p=1}^{n}\left(\dot{m}_{p q}-\dot{m}_{q p}\right)\right]
$$

donde, $\dot{m}_{p q}$ y $\dot{m}_{q p}$, son la transferencia de masa desde la fase $\mathrm{p}$ a la fase $\mathrm{q}$ y de la fase q a la fase p respectivamente. En caso de ser necesario, puede establecerse un término fuente de masa para cada una de las fases $\left(S_{\alpha_{q}}\right.$ que puede ser constante o comportarse según una función establecida. Esta ecuación se resuelve para todas las fases salvo para la que se haya establecido como primaria, la cual puede ser sustituida sabiendo que la suma de todas las fracciones volumétricas es igual a la unidad.

\subsubsection{Ecuación del momento}

A diferencia de la ecuación de continuidad, la ecuación de momento es única para todo el dominio y el campo de velocidades se comparte para todas y cada una de las fases que forman el sistema. Es una ecuación que guarda relación con la fracción volumétrica a través de las propiedades de densidad $\rho$ y viscosidad $\mu$ :

$$
\frac{\partial}{\partial t}(\rho \vec{v})+\nabla \cdot(\overrightarrow{\rho v} \vec{v})=-\nabla \mathrm{p}+\nabla \cdot\left[\mu\left(\nabla \vec{v}+\nabla \vec{v}^{T}\right]+\rho \vec{g}+\vec{F} \quad \text { Ec. } 35\right.
$$

La principal limitación se presenta en aquellos casos donde las diferencias de velocidad entre las fases del dominio son muy grandes. En esos casos, los resultados cerca de las interfases pueden verse muy alterados. Asimismo, pueden presentarse problemas de convergencia cuando la ratio entre viscosidades es de más de un orden 1000, haciéndose necesario en ese caso, la utilización de modelos adicionales que permitan resolver la ecuación con precisión. 


\subsubsection{Ecuación de la energía}

Al igual que la ecuación del momento, la ecuación de la energía también es única para todo el dominio y se expresa de la siguiente manera:

$$
\begin{aligned}
\frac{\partial}{\partial t}(\rho E)+\nabla \cdot( & (\rho E+p)) \\
& =\nabla \cdot\left(k_{e f f} \nabla T-\sum_{q} \sum_{j} h_{j, q} \vec{J}_{j, q}+\left(\overline{\bar{\tau}}_{e f f} \cdot \overrightarrow{v)}\right) \quad \text { Ec. } 36\right. \\
& +S_{h}
\end{aligned}
$$

Los términos a la derecha de la igualdad representan, por orden de aparición, la transferencia de energía debida a la conducción, la difusividad de las especies y la disipación viscosa. En la ecuación $k_{\text {eff }}$ se refiere a la conductividad efectiva, la cual es la suma de la conductividad turbulenta y la conductividad propia del fluido $\left(k+k_{t}\right), \vec{j}_{j, q}$, es el flujo difusivo de la especie $j$ en la fase $q$ y $h_{j, q}$, es la entalpia de la especie $j$ en la fase $q$. Como en la ecuación de continuidad, se incluye un término fuente $\left(S_{h}\right)$.

En este caso, la relación con la fracción volumétrica se presenta a través de la densidad $\rho$, la viscosidad efectiva $\mu_{e f f}$, y la conductividad térmica efectiva $k_{e f f}$. También se manifiesta a través de la energía E, la cual se calcula como la suma de la energía proporcionada por cada fracción másica de la fase que se encuentra en cada celda de cálculo:

$$
E=\frac{\sum_{q=1}^{n} \alpha_{q} \rho_{q} E_{q}}{\sum_{q=1}^{n} \alpha_{q} \rho_{q}}
$$

De igual manera que sucede con el campo de velocidades, la precisión en el cálculo de la temperatura cerca de la interfase se ve limitada por la diferencia de temperaturas que puedan existir entre los diferentes fluidos. Cuanto más grande es esta diferencia, mayores serán las dificultades para obtener un resultado preciso. A su vez, la convergencia del resultado, también se ve afectada cuanto mayores son las diferencias entre las propiedades de las distintas fases. 


\subsubsection{Limitaciones del modelo}

En el apartado 2.2.1, se han explicado las principales bondades, ecuaciones y aplicaciones del modelo VOF. Todos sus beneficios residen en la capacidad de este modelo para calcular de forma precisa la posición de las interfases de los diferentes fluidos que forman el sistema, y cuyas ecuaciones se basan en el principio de nointerpenetrabilidad de dichas fases. Por otra parte, el modelo solo es adecuado en aquellas situaciones en las que, la fracción volumétrica de la fase que se encuentra dispersa no supere el $10 \%$ del total de dicha fase.

Uno de los principales objetivos de la presente tesis es poder reproducir el fenómeno de la cavitación mediante la CFD para poder llevar a cabo el diseño y desarrollo de un cavitador. Sin embargo, los modelos de cavitación existentes se basan en una suposición de fluidos continuos e interpenetrantes. Esto es incompatible con las suposiciones y ecuaciones de cálculo del modelo VOF, y por tanto ninguno de los modelos de cavitación puede ser implementado utilizando el modelo VOF como base. Asimismo, mientras se produce la cavitación, prácticamente el $100 \%$ de la fase gas, se encuentra dispersa dentro de la fase continua (agua), lo que nuevamente vuelve a invalidar la utilización del modelo VOF a la hora de reproducir este efecto.

Es por ello por lo que, aunque el modelo VOF resulta muy útil para ciertas aplicaciones, no puede ser utilizado para realizar modelos en los que se produzca el fenómeno de la cavitación, y por ende ha sido descartado a la hora de realizar el estudio mediante CFD que se lleva a cabo en apartados posteriores.

\subsubsection{Modelo Euleriano}

El modelo Euleriano, es el más complejo dentro de las posibilidades existentes en la simulación del flujo multifásico. Este modelo resuelve un sistema de $\mathrm{n}$ ecuaciones (momento, continuidad y energía) para cada una de las fases existentes en el sistema. La conexión y acoplamiento entre las ecuaciones se realiza a través de la presión y coeficientes de intercambio en la interfase. En función de la tipología de las fases participantes, estos intercambios a través de la interfase varían y deben ser configurados apropiadamente.

Este modelo se aplica principalmente en las siguientes aplicaciones

- Lechos fluidizados donde existe una fase granular.

- Flujos con burbujas.

- Partículas en suspensión.

- Sedimentación.

- Flujos de lodos e hidrotransportados. 
- Transporte neumático.

Las ecuaciones del modelo Euleriano se basan en el hecho de que los diferentes fluidos o fases que componen el sistema son interpenetrantes. Al igual que con el modelo VOF, las fracciones volumétricas representan el espacio ocupado por cada fase, pero en este caso las leyes de conservación del momento masa y energía se deben cumplir independientemente para cada una de las fases. El volumen de una fase en concreto puede ser calculado como:

$$
V_{q}=\int_{V} \alpha_{q} d V
$$

Donde se cumple que:

$$
\sum_{q=1}^{n} \alpha_{q}=1
$$

y que la densidad efectiva de la fase q $\left(\widehat{\rho}_{q}\right)$ se calcula como:

$$
\hat{\rho}_{q}=\alpha_{q} \rho_{q}
$$

\subsubsection{Ecuación de continuidad}

Para la resolución de la ecuación de continuidad es necesario conocer la densidad en la fase de referencia $\left(\rho_{r q}\right)$. La solución de esta ecuación para cada fase secundaria, y junto con la condición de que la suma de todas las fracciones volumétricas debe ser igual a la unidad, permite calcular la fracción volumétrica de la fase primaria o de referencia. Esta metodología es común en los casos en los que se dispone un sistema fluido-fluido o granular.

La ecuación de continuidad se expresa de la siguiente manera: 


$$
\frac{1}{\rho_{r q}}\left[\frac{\partial}{\partial t}\left(\alpha_{q} \rho_{q}\right)+\nabla \cdot\left(\alpha_{q} \rho_{q} \vec{v}_{q}\right)=\sum_{p=1}^{n}\left(\dot{m}_{p q}-\dot{m}_{q p}\right)\right]
$$

donde $\vec{v}_{q}$ es la velocidad de la fase q mientras que $\dot{m}_{p q}$ y $\dot{m}_{q p}$, representan la transferencia de masa de la fase $\mathrm{p}$ a la fase $\mathrm{q}$ y de la fase $\mathrm{q}$ a la fase $\mathrm{p}$ respectivamente. En este caso, es posible especificar esta transferencia de masa independientemente para cada una de las variables.

\subsubsection{Ecuación del momento}

La ecuación del momento en el modelo Euleriano tiene una mayor complejidad dado que tiene en cuenta la interacción de cada una de las fases y por tanto deben considerarse una serie de fuerzas que no son tenidas en cuenta en los otros modelos: Para la fase q se expresa de la siguiente forma:

$$
\begin{gathered}
\frac{\partial}{\partial t}\left(\alpha_{q} \rho_{q} \vec{v}_{q}\right)+\nabla \cdot\left(\alpha_{q} \rho_{q} \vec{v}_{q} \vec{v}_{q}\right)=-\alpha_{q} \nabla \mathrm{p}+\nabla \cdot \overrightarrow{\bar{\tau}}_{q}+\alpha_{q} \rho_{q} \vec{g} \\
\left.+\sum_{p=1}^{n} \overrightarrow{(R}_{p q}+\dot{m}_{p q} \vec{v}_{p q}-\dot{m}_{q p} \vec{v}_{q p}\right)+\left(\vec{F}_{q}+\vec{F}_{l i f t, q}+\vec{F}_{w l, q}+\vec{F}_{v m, q}\right. \\
\left.+\vec{F}_{t d, q}\right)
\end{gathered}
$$

donde el tensor tensión-deformación en la fase q viene determinado por la siguiente expresión:

$$
\overline{\bar{\tau}}_{q}=\alpha_{q} \mu_{q}\left(\nabla \vec{v}_{q}+\nabla \vec{v}_{q}^{T}\right)+\alpha_{q}\left(\lambda_{q}-\frac{2}{3} \mu_{q}\right) \nabla \cdot \vec{v}_{q} \overline{\bar{I}}
$$

En este caso, $\mu_{q}$ es la viscosidad de la fase q y $\lambda_{q}$ es su viscosidad aparente. Tal y como se ha comentado anteriormente, en este modelo se consideran una serie de fuerzas como son:

- la fuerza debida a un objeto externo $\vec{F}_{q}$, 
- la fuerza de sustentación $\vec{F}_{\text {lift,q }}$ (lift force),

- la fuerza debida al efecto lubricante de la pared $\vec{F}_{w l, q}$ (wall lubrication),

- la fuerza debida al cambio de velocidad relativo al cuerpo sumergido $\vec{F}_{\text {vm,q }}$ (virtual mass force),

- la fuerza debida a la dispersión turbulenta $\vec{F}_{t d, q}$,

- y la fuerza de interacción entre las fases del sistema $\vec{R}_{p q}$.

Esta última fuerza depende de la fricción, presión, cohesión y otros efectos, por lo que debe ser expresada de forma apropiada.

Por otro lado, $\vec{v}_{p q}$ indica la velocidad de la interfase la cual cumple las siguientes condiciones:

- Si se está transfiriendo masa de la fase $\mathrm{p}$ a la fase $\mathrm{q}$, es decir $\dot{m}_{p q}>0$, entonces la velocidad en la interfase es igual a la velocidad de la fase p, $\vec{v}_{p q}=\vec{v}_{p}$

- Si se está transfiriendo masa de la fase q a la fase $\mathrm{p}$, es decir $\dot{m}_{p q}<0$, entonces la velocidad en la interfase es igual a la velocidad de la fase q, $\vec{v}_{p q}=\vec{v}_{q}$

El sumatorio de todas las fuerzas de interacción entre las fases que intervienen en el sistema se rigen por la siguiente ecuación:

$$
\sum_{p=1}^{n} \vec{R}_{p q}=\sum_{p=1}^{n} K_{p q}\left(\vec{v}_{p}-\vec{v}_{q}\right)
$$

Ec. 44

donde el término $K_{p q}$ (que es igual a $K_{q p}$ ), hace referencia al coeficiente de intercambio de momento. En el caso de la interacción fluido-fluido, este término depende de múltiples parámetros como el área interfacial, la densidad, el diámetro de las burbujas, la densidad de la fase o la función de arrastre (drag function) utilizada. Este coeficiente de intercambio de momento representa el momento medio intercambiado entre fases y no incluye ninguna contribución debida a la turbulencia ya que esto se considera con el término $\vec{F}_{t d, q}$. 


\subsubsection{Ecuación de la energía}

La ecuación de conservación de la energía en el modelo Euleriano requiere una ecuación de entalpia para cada una de las fases tal y como sucede con las ecuaciones de conservación del momento y de continuidad:

$$
\begin{aligned}
& \frac{\partial}{\partial t}\left(\alpha_{q} \rho_{q} h_{q}\right)+\nabla \cdot\left(\alpha_{q} \rho_{q} \vec{v}_{q} h_{q}\right) \\
& =\alpha_{q} \frac{\mathrm{d} p_{q}}{d t}+\overline{\bar{\tau}}_{q}:+\nabla \vec{v}_{q}-\nabla \vec{q}_{q}+S_{q} \\
& +\sum_{p=1}^{n}\left(Q_{p q}+\dot{m}_{p q} h_{p q}-\dot{m}_{q p} h_{q p}\right)-\sum_{j} h_{j, q} \vec{J}_{j, q}
\end{aligned}
$$

donde:

- $\quad h_{q}$ es la entalpía específica de la q-ésima fase.

- $\quad \vec{q}_{q}$ es el flujo de calor.

- $S_{q}$ es un término fuente para añadir otras fuentes de entalpia provenientes, por ejemplo, de una reacción química de la radiación.

- $\quad Q_{p q}$ es la intensidad de calor intercambiado ente la fase p y q.

- $\quad h_{p q}$ es la interfase de la entalpía, por ejemplo, la entalpia del vapor a la temperatura de las gotas en el caso de evaporización.

- $\quad h_{j, q}$ es la entalpía de las especies j en la fase q.

- $\quad \vec{J}_{j, q}$ es el término difusivo de las especies $j$ en la fase q.

El intercambio de calor entre las fases debe cumplir con la condición de equilibrio $Q_{p q}=-Q_{q p}$ y $Q_{q q}=0$.

\subsubsection{Limitaciones del modelo}

De los 3 modelos multifásicos, este es sin duda el más complejo, pero también el más preciso. La posibilidad de poder incorporar y controlar parámetros tan detallados como por ejemplo las diferentes fuerzas de interacción entre las fases, los intercambios de energía o los procesos de intercambio de masa hacen que este modelo sea extremadamente sensible y permita obtener resultados muy cercanos al comportamiento real del sistema.

Sin embargo, esta gran capacidad personalización del modelo, requiere un conocimiento muy profundo del proceso a simular, así como de una gran 
información derivada de ensayos experimentales que en muchos casos resultan difíciles de realizar y se deben utilizar modelos ya establecidos. Además, a la complejidad y extensión de las ecuaciones presentadas, debe sumarse que su resolución se debe realizar no solo para una fase, sino para todas y cada una de las fases que forman el sistema de estudio. Esto puede llegar a incrementar de forma sustancial el tiempo computacional hasta el punto de ser inasumible en ciertas situaciones.

\subsubsection{Modelo homogéneo}

Este modelo puede ser utilizado tanto con fases fluidas como particuladas, y al igual que el modelo Euleriano, en el modelo homogéneo las fases son tratadas como si fuesen continuas e interpenetrantes. Sin embargo, en esta aproximación el fluido es tratado como una mezcla de dos fases incompresibles y las ecuaciones que rigen el comportamiento del fluido (continuidad, momento y energía) no se calculan para cada una de las fases por separado (como ocurre en el modelo Euleriano) sino que únicamente se resuelven para el fluido mezcla (al igual que en modelo VOF). El modelo permite considerar, o no, la velocidad relativa existente ente las diferentes fases de estudio.

Generalmente, este modelo es utilizado en las siguientes aplicaciones:

- Flujos con baja carga de partículas

- Flujos con burbujas

- Sedimentación

- Separadores y ciclones

Se puede observar cómo algunas de las aplicaciones son comunes a las del modelo Euleriano. Sin embargo, en función de la calidad de los resultados, la complejidad del modelo y la capacidad de cálculo disponible, un mismo caso podrá ser resuelto de forma más adecuada utilizando un modelo u otro.

\subsubsection{Ecuación de continuidad}

Como se ha comentado anteriormente, en el modelo homogéneo las ecuaciones se resuelven únicamente para el fluido mezcla. En el caso de la ecuación de continuidad, esta se expresa de la siguiente manera:

$$
\frac{\partial}{\partial t}\left(\rho_{m}\right)+\nabla \cdot\left(\rho_{m} \cdot \vec{v}_{m}\right)=0
$$


donde $\rho_{m}$ y $\vec{v}_{m}$ son la densidad y la velocidad del fluido mezcla respectivamente, y se calculan como el promedio del volumen ponderado de las diferentes fases. En el caso de la $\vec{v}_{m}$, esta sería calculada como:

$$
\vec{v}_{m}=\frac{\sum_{k=1}^{n} \alpha_{k} \rho_{k} \vec{v}_{k}}{\rho_{m}}
$$

donde $\alpha_{k}$ y $\rho_{k}$ es la fracción volumétrica de la fase $\mathrm{k}$ y la densidad de la fase $\mathrm{k}$ respectivamente. Por otro lado, $\rho_{m}$ viene determinada por la siguiente expresión:

$$
\rho_{m}=\sum_{k=1}^{n} \alpha_{k} \rho_{k}
$$

A partir de la ecuación de continuidad para la fase secundaria p, podría obtenerse la fracción volumétrica de dicha fase de la siguiente forma:

$$
\frac{\partial}{\partial t}\left(\alpha_{p} \rho_{p}\right)+\nabla \cdot\left(\alpha_{p} \rho_{p} \vec{v}_{m}\right)=-\nabla \cdot\left(\alpha_{p} \rho_{p} \vec{v}_{d r, p}\right) \sum_{p=1}^{n}\left(\dot{m}_{p q}-\dot{m}_{q p}\right) \quad \text { Ec. } 49
$$

donde $\vec{v}_{d r, p}$ es la velocidad relativa entre las fases p y q, mientras que $\dot{m}_{p q} \mathrm{y}$ $\dot{m}_{q p}$ representan la transferencia de masa de la fase $\mathrm{p}$ a la fase $\mathrm{q}$ y de la fase $\mathrm{q}$ a la fase $\mathrm{p}$ respectivamente.

\subsubsection{Ecuación del momento}

La ecuación del momento para la mezcla se obtiene sumando las ecuaciones de los momentos individuales para cada una de las fases.

$$
\frac{\partial}{\partial t}\left(\rho_{m} \cdot \vec{v}_{m}\right)+\nabla \cdot\left(\rho_{m} \cdot \vec{v}_{m} \cdot \vec{v}_{m}\right)=-\nabla \mathrm{p}+\nabla \cdot\left[\mu_{m}\left(\nabla \vec{v}_{m}+\nabla \vec{v}_{m}^{r}\right]+\rho_{m} \vec{g}+\vec{F}-\nabla \cdot\left(\sum_{k=1}^{n} \alpha_{k} \rho_{k} \vec{v}_{d r k} \vec{v}_{d r k}\right)\right.
$$

Ec. 50 
donde n es el número de fases del sistema, $\vec{F}$ es la fuerza externa y $\mu_{m}$ es la viscosidad de la mezcla, la cual se calcula se forma similar a la $\rho_{m}$ :

$$
\rho_{m}=\sum_{k=1}^{n} \alpha_{k} \mu_{k}
$$

Ec. 51

Por otro lado, la velocidad relativa $\vec{v}_{d r, k}$ (también utilizada en la descripción de la ecuación de la continuidad), se define como la diferencia entre la velocidad de una fase y de la fase mezcla:

$$
\vec{v}_{d r, k}=\vec{v}_{k}-\vec{v}_{m}
$$

Ec. 52

Dado que generalmente el modelo homogéneo es utilizado cuando existe un acoplamiento muy fuerte entre las diferentes fases, las velocidades relativas entre fases suelen despreciarse, y se considera que la fase continua arrastra la fase discreta y por tanto comparten el mismo campo de velocidades. Esto permite asumir una velocidad relativa nula y simplificar, de este modo tanto la ecuación de momento como la ecuación de continuidad.

\subsubsection{Ecuación de la energía}

La ecuación de la energía para la mezcla se describe mediante la siguiente expresión:

$$
\frac{\partial}{\partial t} \sum_{k}\left(\alpha_{k} \rho_{k} E_{k}\right)+\nabla \cdot \sum_{k}\left(\alpha_{k} \vec{v}_{k}\left(\rho_{k} E_{k}+p\right)\right)=\nabla \cdot\left(k_{e f f} \nabla T-\sum_{k} \sum_{j} h_{j, k} \vec{J}_{j, k}+\left(\overline{\bar{\tau}}_{e f f} \cdot \vec{v}\right)\right)+S_{h}
$$

donde, $h_{j, k}$ es la entalpía de las especies j en la fase $\mathrm{k}, \vec{J}_{j, k}$ es el flujo difusivo de las especies $\mathrm{j}$ en la fase $\mathrm{k}, \mathrm{y} \boldsymbol{k}_{\text {eff }}$ es la conductividad efectiva calculada como

$$
k_{e f f}=\sum \alpha_{k}\left(k_{k}+k_{t}\right)
$$


donde $k_{t}$ es la conductividad térmica turbulenta definida en función del modelo de turbulencia utilizado y $\mathrm{k}$ es la conductividad propia del fluido. Al igual que en el modelo VOF, los términos a la derecha de la igualdad hacen referencia a la energía de transferencia debida a la conductividad, la difusión de las especies, y la disipación viscosa. Se incluye un término $S_{h}$, que es un término volumétrico de calor. Este término no incluye las fuentes de calor generadas por tasas volumétricas finitas o reacciones en superficie ya que la entalpia de formación de las especies ya está considerada en el cálculo de la entalpía total descrito en la Ec. $\mathbf{5 3 .}$

\subsubsection{Limitaciones del modelo}

El modelo homogéneo puede ser considerado como un modelo intermedio entre el modelo VOF y el modelo Euleriano, que permite aprovechar las principales ventajas de cada uno de estos modelos y de esta manera, conseguir un modelo estable con un buen equilibrio entre fidelidad de los resultados y complejidad de cálculo en determinados sistemas.

La principal similitud con el modelo VOF es que utiliza la misma aproximación de fluido único. De esta forma, las ecuaciones de continuidad momento y energía son resueltas únicamente para el fluido mezcla, y las fases secundarias se calculan con la aplicación de la ecuación de la fracción volumétrica. Esto facilita la convergencia y disminuye el tiempo computacional necesario para la resolución de los cálculos. Por otro lado, tiene tres importantes diferencias con respecto al modelo VOF:

- Permite que las fases sean interpenetrantes. Esta condición permite que las fracciones volumétricas $\alpha_{q} \mathrm{y} \alpha_{p}$ para un volumen de control, puedan presentar valores entre 0 y 1 dependiendo del espacio ocupado por la fase $\mathrm{q}$ y la fase $p$.

- Permite que exista una velocidad relativa entre las diferentes fases introduciendo el concepto de slip velocity. De esta manera se puede visualizar la separación de las diferentes fases debido a un efecto de sedimentación, por ejemplo.

- No es adecuado para flujos estratificados o en lámina libre.

Esta última diferencia es la que, generalmente, marca el límite para utilizar un modelo VOF frente a un homogéneo o Euleriano, ya que estos dos últimos son adecuados cuando la fracción volumétrica de la fase que se encuentra dispersa supera el $10 \%$. Por otro lado, cabe recordar que la condición de fase interpenetrante es condición necesaria para poder simular el fenómeno de la cavitación por lo que, ante un sistema que cavite, el modelo VOF quedaría descartado. Nótese que, ante un sistema que no presente cavitación y donde no 
exista velocidad relativa entre las fases, el modelo VOF y el modelo homogéneo son prácticamente idénticos y el único criterio para elegir entre uno u otro es la forma en la que una fase se encuentra dispersa en la otra.

Por tanto, en determinados sistemas únicamente puede utilizarse el modelo homogéneo o el Euleriano y la elección entre uno u otro dependerá de la complejidad del sistema, pero también de los resultados que se busquen en cada situación. Así pues, para sistemas donde es necesario conocer con precisión la localización de la interfase entre cada uno de los fluidos y caracterizar perfectamente el movimiento entre cada una de las fases, el modelo Euleriano será una mejor elección, dado que los resultados obtenidos serán mucho más precisos y cercanos a la realidad. Sin embargo, la calibración de los modelos Eulerianos requiere de una gran cantidad de datos experimentales y puesto que se resuelven las ecuaciones continuidad, momento y energía para cada una de las fases, el coste computacional es más elevado. En este sentido, el modelo homogéneo proporciona soluciones mucho más fáciles de converger, a la vez que presenta un buen equilibrio entre la calidad de los resultados obtenidos y el coste computacional empleado.

Para la presente investigación en particular, el principal objetivo es la caracterización de la cavitación bajo diferentes condiciones y sistemas. Esto, sumado a la limitación en la potencia computacional disponible, hacen que la mejor elección sea la utilización de un modelo homogéneo, elección compartida por la gran mayoría de investigadores que desarrollan estudios bajo estas mismas condiciones.

\subsubsection{Modelos de cavitación utilizados en CFD}

Tal y como se ha explicado al comienzo del apartado 2.1, las ecuaciones de Rayleigh-Plesset permiten analizar de forma numérica el comportamiento y la dinámica de las burbujas durante el fenómeno de la cavitación. Estas ecuaciones son la base de los actuales modelos utilizados en la dinámica computacional de fluidos y que ayudan a analizar y estudiar el fenómeno como un todo y no solo desde el punto de vista de una burbuja individual.

Anteriormente se han expuesto los principales modelos utilizados a la hora de analizar sistemas donde estén involucrados, al menos, dos fluidos o fases; VOF, homogéneo y Euleriano. Aunque en todos los modelos resulta indispensable la resolución de las ecuaciones de continuidad momento y energía que gobiernan el comportamiento de los fluidos, no todos lo hacen utilizando las mismas aproximaciones. Mientras que el VOF y el modelo de homogéneo utilizan un mismo sistema de ecuaciones para todo el dominio, en el modelo Euleriano cada sistema de ecuaciones es resuelto independientemente para todas y cada una de las 
fases del dominio. Además, tal y como se ha explicado en el apartado 2.2.3.4 no todos los modelos son válidos y en prácticamente la totalidad de los estudios desarrollados en los últimos años en simulación computacional es el modelo homogéneo el utilizado para lleva a cabo los análisis (Niedzwiedzka, Schnerr, \& Sobieski, 2016).

Sin embargo, para analizar numéricamente el fenómeno de la cavitación, además de las ecuaciones anteriormente descritas, es necesario también introducir una expresión que considere la fracción de líquido que se convierte en vapor y viceversa. Generalmente, esto se hace mediante una ecuación de transporte que en la mayoría de los casos tiene como base la ecuación de Rayleigh-Plesset. Esta transformación de fases puede expresarse de dos formas distintas: como una ecuación de transferencia de masa o como una pérdida o ganancia de fracción másica de vapor (Niedzwiedzka et al., 2016).

En el primer caso se produce una condensación, y por tanto un aumento en la masa del líquido cuando la presión se incrementa por encima de la presión de saturación de vapor, y una evaporación o disminución de la masa del líquido cuando dicha presión desciende por debajo de la de saturación de vapor:

$$
\begin{aligned}
& \dot{m}=\dot{m}^{+} \text {si } p>p_{\text {sat }} \\
& \dot{m}=\dot{m}^{-} \text {si } p<p_{\text {sat }}
\end{aligned}
$$

En el segundo caso, cuando la presión local de fluido se incrementa por encima de la de saturación de vapor, el volumen de vapor disminuye y aumenta cuando dicha presión se encuentra por debajo de la de saturación:

$$
\begin{array}{lll}
\alpha=\alpha^{+} & \text {si } & p>p_{\text {sat }} \\
\alpha=\alpha^{-} & \text {si } & p<p_{\text {sat }}
\end{array}
$$

A continuación, se presentan los modelos numéricos de cavitación más utilizados actualmente y que, por tanto, son los más recurrentes a la hora de realizar estudios donde se desea predecir el fenómeno en un entorno de CFD.

\subsubsection{Bubble Two-Phase Flow (BTF)}

Este primer modelo homogéneo basado en una ecuación de transporte fue desarrollado en el año 1992 por A. Kubota, H. Kato y H. Yamaguchi (Kubota, 
Kato, \& Yamaguchi, 1992). Es un modelo que puede ser utilizado en simulaciones estacionarias en 2 dimensiones y ha sido testado en perfiles NACA a diferentes ángulos. El modelo se basa en la siguiente ecuación:

$$
\begin{aligned}
\left(1+2 \pi r^{2} n_{o} R\right) & R \frac{D^{2} R}{D t}+\left(\frac{3}{2}+4 \pi r^{2} n_{o} R\right)\left(\frac{D R}{D t}\right)^{2} \\
+ & 2 \pi r^{2} \frac{D n_{o}}{D t} R^{2} \frac{D R}{D t}=\frac{p_{s a t}-p}{\rho_{l}}
\end{aligned}
$$

Ec. 57

Esta expresión está basada prácticamente en su totalidad, en la ecuación de Rayleigh-Plesset. Sin embargo, debido a la no linealidad de la expresión, el modelo es muy inestable y presenta grandes dificultades para converger en un modelo informático.

\subsubsection{Merkle}

En su trabajo presentado en el $3^{\text {er }}$ Simposio Internacional de Cavitación en Grenoble en 1998 (Merkle, Feng, \& Buelow, 1998), Merkle planteó una variante del modelo de Kubota cuyos términos fuente permitían cuantificar la transferencia de masa que se produce desde la fase líquida en función de la presión del sistema:

$$
\begin{gathered}
\dot{m}^{+}=\frac{C_{p} \rho_{v}\left(1-\alpha_{l}\right)\left(p_{s a t}-p\right)}{\left(0.5 \rho_{l} v_{\infty}^{2}\right) t_{\infty}}, \quad p>p_{\text {sat }} \\
\dot{m}^{-}=-\frac{C_{d} \rho_{l} \alpha_{l}\left(p_{s a t}-p\right)}{\left(0.5 \rho_{l} v_{\infty}^{2}\right) t_{\infty}}, \quad p<p_{s a t}
\end{gathered}
$$

Ec. 59

donde $\rho_{l}$ y $\rho_{v}$ son las densidades de la fase líquida y vapor respectivamente, $\alpha_{l}$ la fracción volumétrica de la fase líquida y $v_{\infty}$ la velocidad en freestream aguas arriba del punto de cavitación. Este modelo es el primero en introducir una serie de constantes para calibrar la condensación $\left(C_{p}\right)$ y la evaporación $\left(C_{d}\right)$, las cuales son obtenidas de manera experimental. Además, se incorpora el término donde se 
define la escala de tiempo característica para el fluido $t_{\infty}$ que se define como en cociente entre el diámetro de la burbuja y la velocidad en freestream.

Tal y como puede apreciarse, a diferencia del modelo propuesto por Kubota, estos términos fuentes no están basados en el radio de la burbuja sino en el cambio de la densidad del líquido, el cual es proporcional a la presión:

$$
\left|p_{s a t}-p\right|=\frac{\kappa \rho_{\infty} v_{\infty}^{2}}{2}
$$

donde aparece una nueva constante experimental $(\kappa)$ que puede adquirir valores desde 0.2 a 0.5. De esta manera, los cambios en el volumen de fluido causados por los cambios en su densidad permiten considerar el fluido como compresible.

El modelo fue validado en simulaciones estacionarias utilizando perfiles NACA al igual que hizo su predecesor Kubota. Este modelo también fue utilizado para realizar predicciones del comportamiento de la cavitación en estado estacionario alrededor de cuerpos cilíndricos en dos dimensiones y a través de geometrías convergentes/divergentes como los Venturis.

\subsubsection{Kunz}

En el año 2000, Robert F. Kunz planteó unos nuevos términos fuente muy similares a los de Merkel con la diferencia de que en el término fuente $\dot{m}^{+}$, existe una relación potencial con la fracción volumétrica de la fase líquida y en el término $\dot{m}^{-}$existe una variación proporcional con la densidad de la fase gas y no de la fase líquida:

$$
\begin{aligned}
& \dot{m}^{+}=\frac{C_{p} \rho_{v} \alpha_{l}^{2}\left(p_{s a t}-p\right)}{\left(0.5 \rho_{l} v_{\infty}^{2}\right) t_{\infty}}, \quad p>p_{\text {sat }} \\
& \dot{m}^{-}=-\frac{C_{d} \rho_{v} \alpha_{l}\left(p_{s a t}-p\right)}{\left(0.5 \rho_{l} v_{\infty}^{2}\right) t_{\infty}}, \quad p<p_{s a t}
\end{aligned}
$$

Ec. 61

Ec. 62 
Con ello se pretendía enfatizar la utilizad de la teoría potencial de GinzburgLandau para predecir la dinámica del fenómeno. Se implementó para el modelo de turbulencia $\mathrm{k}-\varepsilon$ en formas simétricas bidimensionales tanto para flujos estacionarios como no estacionarios.

\subsubsection{Schnerr-Sauer}

Este modelo de cavitación desarrollado por Günter H. Schnerr y Jürgen Sauer (Schnerr \& Sauer, 2001), resulta especialmente interesante por ser el primer modelo que plantea una ecuación de transporte que no depende de ninguna constante experimental:

$$
\begin{array}{cc}
\dot{m}^{+}=\frac{\rho_{v} \rho_{l}}{\rho_{m}} \alpha_{v}\left(1-\alpha_{v}\right) \frac{3}{R} \sqrt{\frac{2}{3} \frac{\left(p-p_{s a t}\right)}{\rho_{l}}}, & p>p_{\text {sat }} \\
\dot{m}^{-}=-\frac{\rho_{v} \rho_{l}}{\rho_{m}} \alpha_{v}\left(1-\alpha_{v}\right) \frac{3}{R} \sqrt{\frac{2}{3} \frac{\left(p_{s a t}-p\right)}{\rho_{l}}}, \quad p<p_{\text {sat }}
\end{array}
$$

Estas ecuaciones llevan incluidas la expresión que describe la dinámica de crecimiento del radio de la burbuja, la cual es una ecuación simplificada de la expresión original de Rayleigh-Plesset. Esta expresión se ha continuado utilizando en las ecuaciones de transporte de modelos de cavitación posteriores.

$$
\dot{R}=\frac{d R}{d t}=\sqrt{\frac{2}{3} \frac{\left(p-p_{s a t}\right)}{\rho_{l}}}
$$

De igual manera, las fracciones volumétricas de la fase líquida también aumentan o disminuyen en función de la presión y únicamente dependen de valores cuantitativos de parámetros físicos: 


$$
\begin{gathered}
\alpha^{+}=\frac{n_{0}}{1+\frac{4}{3} n_{0} \pi R^{3}} 4 \pi R^{2} \sqrt{\frac{2}{3} \frac{\left(p-p_{\text {sat }}\right)}{\rho_{l}}}, \quad p>p_{\text {sat }} \quad \text { Ec. } 66 \\
\alpha^{-}=-\frac{n_{0}}{1+\frac{4}{3} n_{0} \pi R^{3}} 4 \pi R^{2} \sqrt{\frac{2\left(p-p_{\text {sat }}\right)}{\rho_{l}}}, \quad p<p_{\text {sat }} \quad \text { Ec. } 67
\end{gathered}
$$

Los principales valores requeridos para el cálculo es el valor inicial del radio de las burbujas (R) que, por defecto es considerado con un valor de 30 micrómetros y la cantidad de nucleaciones por unidad de volumen $\left(n_{0}\right)$ con un valor de $10^{8}$ nucleaciones $/ \mathrm{m}^{3}$. El modelo fue validado mediante simulaciones bidimensionales tanto en flujos estacionarios como transitorios, y utilizando geometrías divergentes y convergentes tipo Venturi.

\subsubsection{Iben}

Uwe Iben (Iben, 2002) desarrolló una variante del modelo de Schnerr-Sauer cuya principal diferencia reside en que permite la posibilidad de utilizar una constante empírica para regular la tasa de condensación.

$$
\begin{array}{lll}
\dot{m}^{+}=C_{p} \rho_{v} \frac{6 \alpha_{v}}{2 R} \sqrt{\frac{2}{3} \frac{\left(p-p_{\text {sat }}\right)}{\rho_{l}}}, & p>p_{\text {sat }} & \text { Ec. } 68 \\
\dot{m}^{-}=-\rho_{l} \frac{6 \alpha_{v}}{2 R} \sqrt{\frac{2}{3} \frac{\left(p-p_{\text {sat }}\right)}{\rho_{l}}}, & p<p_{\text {sat }} & \text { Ec. } 69
\end{array}
$$

El principal objetivo de este modelo es conseguir una evolución más lenta del proceso de condensación para conseguir controlar el tamaño de la nube de cavitación generada. En este caso se utiliza un valor inicial en el radio de las burbujas de 5 micrómetros y el modelo ha sido probado en sistemas tipo Venturi en dos dimensiones. 


\subsubsection{Full Cavitation}

Este modelo fue desarrollado por Ashok K. Singhal (Singhal, Athavale, Li, \& Jiang, 2002) y fue el primero en ser implementado en softwares comerciales. Es un modelo muy similar tanto al de Schnerr-Sauer como al de Iben y al igual que estos, tanto el término de condensación como el de evaporación están multiplicados por la raíz cuadrada del cociente entre la diferencia de presión local y de saturación y la densidad del líquido.

$$
\begin{gathered}
\dot{m}^{+}=C_{p} \frac{\sqrt{k}}{\sigma} \rho_{l} \rho_{l} \sqrt{\frac{2}{3} \frac{\left(p-p_{\text {sat }}\right)}{\rho_{l}}} f_{v}, \quad p>p_{\text {sat }} \quad \text { Ec. } 70 \\
\dot{m}^{-}=-C_{d} \frac{\sqrt{k}}{\sigma} \rho_{l} \rho_{v} \sqrt{\frac{2}{3} \frac{\left(p-p_{\text {sat }}\right)}{\rho_{l}}}\left(1-f_{v}-f_{g}\right), \quad p<p_{\text {sat }} \quad \text { Ec. } 71
\end{gathered}
$$

La principal novedad introducida por este modelo es que los términos fuentes no solo expresan el cambio en función de la dimensión de las burbujas (basado en las ecuaciones de Rayleigh-Plesset), sino que también considera:

- La energía cinética turbulenta $(\sqrt{k})$

- La tensión superficial ( $\sigma$ con un valor de $0.0717 \mathrm{~N} / \mathrm{m}$ )

- El contenido de gases no condensables $\left(f_{g}\right)$

Para esta última consideración es necesario determinar la fracción másica del vapor $\left(f_{v}\right)$, la cual se calcula como el cociente entre la fracción volumétrica del vapor y la densidad de la mezcla (líquido vapor). En la fracción másica del gas no condensable se considera por defecto $10 \mathrm{ppm}$.

Este modelo fue validad en simulaciones estacionarias bidimensionales llevadas a cabo tanto en perfiles NACA como en cuerpos cilíndricos sumergidos y en orificios con perfiles angulares. 


\subsubsection{Zwart-Gerber-Belamri}

Este modelo desarrollado en 2004 (Zwart, Gerber, \& Belamri, 2004) también ha sido y es utilizado en softwares comerciales para predecir el fenómeno de la cavitación. Tiene una forma similar a las ecuaciones de Iben y de Scherr-Sauer, pero la fracción volumétrica de vapor en el término de condensación es sustituida por el producto de la nucleación y la fracción volumétrica restante.

$$
\begin{gathered}
\dot{m}^{+}=C_{p} \frac{3 \alpha_{v} \rho_{v}}{R} \sqrt{\frac{2}{3} \frac{\left(p-p_{\text {sat }}\right)}{\rho_{l}}, \quad p>p_{\text {sat }}} \quad \text { Ec. } 72 \\
\dot{m}^{-}=-C_{d} \frac{3 \rho_{v}\left(1-\alpha_{v}\right) \alpha_{n u c}}{R} \sqrt{\frac{2}{3} \frac{\left(p-p_{\text {sat }}\right)}{\rho_{l}}}, \quad p<p_{\text {sat }} \quad \text { Ec. } 73
\end{gathered}
$$

Existen dos pequeñas variaciones más:

- El uso del modelo k-E, es modificado por una expresión para la viscosidad de la siguiente manera:

$$
\mu_{t m}=f(\rho) C_{\mu} \frac{k^{2}}{\varepsilon}
$$

- La densidad de la mezcla utilizada en la expresión original fue reemplazada por la siguiente expresión:

$$
f(\rho)=\rho_{v}+\left(\frac{p_{v}-p_{m}}{p_{v}-p_{l}}\right)^{n}\left(p_{l}-p_{v}\right)
$$

El valor inicial del radio de la burbuja es el mismo que en el modelo Kubota y tiene un valor de 1 micrómetro, mientras que el valor de la fracción volumétrica de las nucleaciones se establece en $5 \cdot 10^{-4}$. 
Este modelo, a diferencia de los anteriores ha sido validado para ser utilizado en sistemas en 3 dimensiones. Alguno de los sistemas donde se ha comprobado su robustez son perfiles alares, Venturi, e inductores de cavitación rotativos.

\subsubsection{Modelos utilizados actualmente en software CFD}

En los apartados anteriores se han mostrado algunos de los modelos de cavitación más relevantes desarrollados durante los últimos 20 años. Sin embargo, de entre todos, actualmente solo hay 3 que han demostrado ser lo suficientemente robustos como para ser implementados en software de CFD comercial:

- Singhal (Full Cavitation)

- Schnerr-Sauer

- Zwart-Gerber-Belamri

Aunque desde el 2004 se han desarrollado otros modelos, estos no han sido implementados todavía en softwares comerciales y aún a día de hoy, los más utilizados para realizar estudios CFD relacionados con el fenómeno de la cavitación son los anteriormente descritos, especialmente el modelo de SchnerrSauer (Shi, Li, Nikrityuk, \& Liu, 2019a) y Singhal (Dastane et al., 2019a).

\subsection{Sistemas generadores de cavitación}

\subsubsection{La cavitación ultrasónica y la cavitación hidrodinámica}

El primer punto a tener en cuenta a la hora de estudiar un sistema de cavitación es el fenómeno físico a través de los cuales se induce. Basándose en el modo en el cual se genera, la cavitación se puede clasificar en 4 tipos diferentes: la cavitación ultrasónica o Ultrasonic Cavitation, (también conocida como cavitación acústica), la cavitación hidrodinámica o Hydrodynamic Cavitation y las llamadas Optic Cavitation y Particle Cavitation. De todas ellas, las dos últimas únicamente son útiles para conseguir la cavitación sobre una única burbuja y realizar estudios muy detallados sobre ella, y únicamente la cavitación ultrasónica (UC) y la cavitación hidrodinámica (HC) han resultado ser eficientes para producir los cambios fisicoquímicos deseados en determinadas aplicaciones. (Parag R Gogate, Tatake, Kanthale, \& Pandit, 2002).

\subsubsection{Cavitación ultrasónica (UC)}

Este tipo de cavitación ocurre cuando el fluido se somete a una serie de vibraciones en distintas frecuencias. Estas fluctuaciones consiguen hacer entrar en resonancia las pequeñas cavidades o núcleos de cavitación que se encuentran en el 
interior del fluido de manera que la interfase comienza a expandirse y contraerse de forma cada vez más violenta hasta que acaban colapsando.

La generación de cavitación mediante la inducción ultrasónica suele producir muy buenos resultados debido, principalmente, a la facilidad y simplicidad para controlar el proceso. Aunque el resultado final va a depender en gran medida de las propiedades del fluido tales como temperatura, viscosidad, presión de vapor o tensión superficial (Parag R Gogate, Marie, \& Pandit, 2003), los parámetros dependientes del propio inductor son mínimos y se reducen básicamente a la intensidad y la frecuencia de oscilación. Esta última se encuentra dentro de un rango muy extenso puede ir desde los $16 \mathrm{kHz}$ a $100 \mathrm{MHz}$ (P R Gogate et al., 2001), aunque en cualquier caso, los efectos producidos por las distintas configuraciones se encuentran muy bien recopilados bibliográficamente (Parag R Gogate et al., 2002) de manera que es relativamente sencillo predecir el fenómeno de la cavitación y por tanto conseguir el efecto deseado en cada aplicación.

Para aumentar la eficacia, se suelen utilizar configuraciones de varios inductores ultrasónicos que vibran a frecuencias iguales o diferentes para intentar maximizar la zona y la intensidad de la cavitación. (Parag R. Gogate \& Kabadi, 2009). La utilización de varios inductores es necesaria en la mayoría de las aplicaciones, ya que uno de los principales problemas de este tipo de cavitadores reside en que la cantidad de cavitación producida disminuye muy rápidamente a medida que el fluido se aleja del centro del inductor. Las distancias a las cuales el efecto de la cavitación desaparece o es prácticamente imperceptible son del orden de unos pocos centímetros (Parag R Gogate et al., 2002), lo que reduce significativamente el volumen a tratar que muy rara vez supera los 2-3 litros (P R Gogate et al., 2001). Por otra parte, este tipo de cavitadores suele funcionar en lotes (batches) y utiliza unas potencias que oscilan entre los 25-150 W/L lo cual limita esta forma de producir cavitación únicamente a escala de laboratorio. Así pues, para producir cavitación en un sistema a escala industrial (cientos de litros), la cavitación ultrasónica queda desaconsejada por los pequeños volúmenes de producción y por el elevado consumo energético que conllevaría.

\subsubsection{Cavitación hidrodinámica (HC)}

La cavitación hidrodinámica, al igual que la ultrasónica, también se debe al descenso repentino que se produce en el seno del fluido. No obstante, en este tipo de dispositivos la caída de presión se produce al hacer pasar el fluido a través de uno o múltiples orificios, válvulas o estrechamientos donde la velocidad del flujo aumenta y, por tanto, se consigue descender la presión hasta conseguir cavitar. Además de la caída de presión, tras el estrechamiento donde se produce la cavitación existe también una gran intensidad turbulenta. Tanto la turbulencia generada aguas abajo del dispositivo como la intensidad y magnitud de la cavitación dependen casi por completo de las características geométricas del 
cavitador. Al comparar la cavitación hidrodinámica con la cavitación ultrasónica, pueden observarse dos grandes diferencias.

La primera de ellas es la complejidad a la hora de realizar el control del dispositivo. Mientras que con los cavitadores ultrasónicos los pulsos de presión que producen la cavitación pueden ser fácilmente controlados variando la intensidad (amplitud de las ondas de presión) y la frecuencia, en los dispositivos basados en la cavitación hidrodinámica los pulsos de presión vienen determinados por la configuración geométrica del propio dispositivo, así como la magnitud del caudal que pasa a través de ellos. Además, en los dispositivos de cavitación hidrodinámica se produce una caída de presión que es función de la velocidad de paso, es decir, del caudal que circula, lo que dificulta todavía más cualquier intento de estudio parametrizado (Parag R. Gogate, 2007).

La segunda diferencia y quizás la más representativa reside en la escala temporal de cada proceso (Arrojo \& Benito, 2008). Como se ha comentado anteriormente, la cavitación ultrasónica suele utilizar frecuencias que oscilan entre los $16 \mathrm{kHz}$ y los $100 \mathrm{MHz}$. Las intensidades altas generan mayor cantidad de colapsos por unidad de tiempo, lo que acelera las reacciones químicas. Además, cuanto más rápido se producen los colapsos, existe una mayor difusión de los radicales OH. Por otra parte, al incrementar la rapidez con la que suceden los colapsos, también se reduce el tiempo que las burbujas tienen para crecer, lo que se traduce en un menor tamaño de estas burbujas. Dado que cuanto mayor es la relación entre el radio máximo de la burbuja con respecto al tamaño inicial de la burbuja $\left(\mathrm{R}_{\max } / \mathrm{R}_{0}\right)$, mayor es la violencia y la energía liberada durante el colapso (debido a las fuerzas inerciales), la cavitación ultrasónica producida a altas frecuencias produce burbujas más pequeñas que liberan menos energía al colapsar, lo que tiene que ser compensado por un incremento sustancial en los ciclos de crecimiento y colapso. Sin embargo, el comportamiento a bajas frecuencias (al cual se asemeja la hidrocavitación) es justo el contrario. Aunque se producen menos pulsos de presión, la cantidad de cavidades es mayor dado que el ciclo es más lento y las nucleaciones tienen más tiempo para crecer y colapsar. Además, las burbujas son más grandes en el momento del colapso y por tanto la energía liberada es mayor lo que incrementa sustancialmente la temperatura. Por otro lado, la liberación de radicales $\mathrm{OH}$ se ve mermada y su difusión no es tan grande como cuando se utiliza la cavitación ultrasónica. Las escalas temporales de los pulsos de los dispositivos de hidrocavitación pueden estimarse a partir del volumen de la cámara donde se produce la cavitación y el caudal de circulación a través del dispositivo. Algunos autores han concluido que las escalas temporales pueden llegar a ser hasta tres órdenes de magnitud inferiores a las conseguidas con los dispositivos de cavitación ultrasónica (Arrojo \& Benito, 2008). 
Las consecuencias de la particular forma de generar cavitación por medio de un dispositivo hidrodinámico hacen que se puedan tratar volúmenes de fluido mucho más elevados de manera mucho más eficiente. Esto se debe a que, con el mismo aporte energético, la cavitación generada de forma hidrodinámica permite un mejor aprovechamiento de la energía liberada durante el fenómeno, con lo que su eficiencia energética se incrementa sustancialmente. Existen numerosos dispositivos con principios de funcionamiento muy variados que serán explicados en mayor detalle en apartados posteriores. En cualquier caso, conocidas las características de ambos tipos de cavitación, y teniendo en cuenta que se desea construir un sistema de cavitación a escala industrial que pueda tratar grandes cantidades de fluido, queda claro que la mejor y más eficiente forma de producir el fenómeno de cavitación es mediante un dispositivo hidrodinámico.

\subsubsection{Tipos de cavitadores hidrodinámicos}

Desde que se tiene constancia del fenómeno de la cavitación, se han venido desarrollando una serie de dispositivos para lograr generar la cavitación en la cantidad y calidad deseada. En los casos más simples, la aparición del vapor depende únicamente de los parámetros geométricos del dispositivo. Así pues, el flujo pasa simplemente a través del dispositivo y dependiendo del diseño del mismo (curvatura, estrechamientos, orificios...) se consiguen generar zonas de baja presión que de forma localizada se encuentra por debajo de la presión de vapor. En otros dispositivos más complejos, la aparición de estas zonas de baja presión son consecuencia de la forma en la que se induce el movimiento al fluido, por ejemplo, generando cierto tipo de turbulencias o a través de mecanismos rotatorios como tambores, bombas o discos. Por tanto, la primera gran diferenciación entre los cavitadores hidrodinámicos, es la de aquellos que requieren de algún dispositivo móvil para generar la cavitación (dispositivos con elementos móviles), frente a los que únicamente se sirven del paso del flujo a través de su geometría para generarla (dispositivos sin elementos móviles).

\subsubsection{Dispositivos sin elementos móviles}

Se consideran de este tipo aquellos dispositivos que no requieren de ninguna parte móvil para inducir el fenómeno de la cavitación. Así pues, la cavitación aparece únicamente como consecuencia del paso del flujo a través de la geometría concreta del cavitador y de las características (velocidad, presión, temperatura, viscosidad...) del propio flujo de entrada. A continuación, se describen los más utilizados. 


\section{Venturi}

El Venturi es quizás uno de los sistemas de cavitación más utilizados. Este dispositivo consiste en un conducto generalmente circular que presenta un estrechamiento seguido posteriormente de una sección divergente denominada difusor. Debido a esta reducción de sección se produce un aumento de la velocidad y por tanto una caída de presión de acuerdo con la ecuación de Bernouilli:

$$
\frac{v_{1}{ }^{2}}{2}+g \cdot h_{1}+\frac{p_{1}}{\rho}=\frac{v_{2}{ }^{2}}{2}+g \cdot h_{2}+\frac{p_{2}}{\rho}+g \cdot \sum h_{p e r d}
$$

donde, $v_{1}, h_{1}$ y $p_{1}$ son la velocidad, altura y presión en la entrada respectivamente, $v_{2}, h_{2}$ y $p_{2}$ son la velocidad altura y presión en la salida respectivamente y $h_{\text {perd }}$ son las pérdidas debidas a la resistencia del fluido que se disipan en forma de calor.

Como puede observarse en la ecuación de Bernouilli, en función de la ratio entre la velocidad de entrada y la de salida, se puede producir una caída de presión suficientemente grande como para producir cavitación. Todos los parámetros geométricos del Venturi han sido ampliamente estudiados para optimizar al máximo la cantidad, así como la intensidad de cavitación producida.
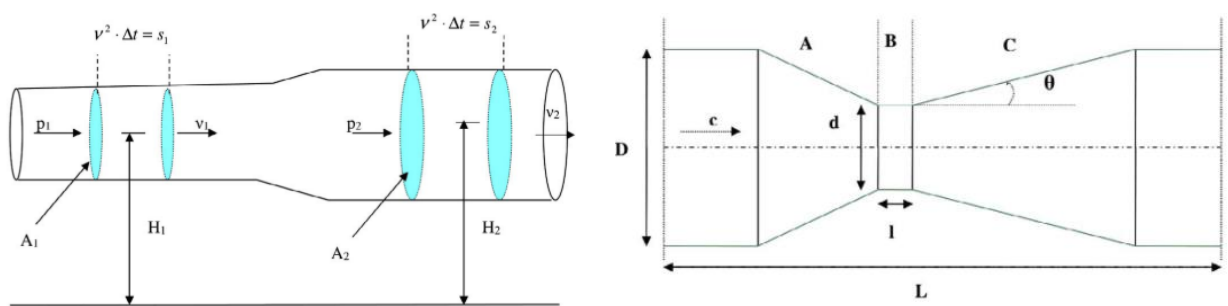

Figura 19: Velocidades y presiones producidas en un Venturi (izq.) y parámetros geométricos estudiados en los Venturi (der.) Imágenes de (Gaggol et al., 2018).

La principal ventaja de este dispositivo es su simplicidad. Es relativamente fácil de fabricar e implementar, y únicamente requiere de una bomba que haga circular el fluido a través del dispositivo. Además, es muy versátil dado que ha sido ampliamente estudiado y se conocen muy bien los parámetros geométricos óptimos para conseguir un buen grado de cavitación minimizando la caída de presión (Rudolf et al., 2014). Sin embargo, su utilización se ha limitado casi exclusivamente a ensayos de laboratorio dado que resulta complicado realizar un escalado de esta tecnología a nivel industrial. 
Los Venturi se han utilizado como sistema de cavitación hidrodinámica en numerosos procesos como por ejemplo tratamientos para la eliminación de fármacos (Širok et al., 2012), eliminación de bacterias como la E. coli (Arrojo, Benito, \& Martínez Tarifa, 2008) y tratamiento de fango para incrementar la cantidad de metano obtenido en la digestión (Machnicka, Grubel, \& Suschka, 2009).

\section{Platos con orificios}

Es un dispositivo con un comportamiento muy similar al Venturi. En este caso, el flujo también circula a lo largo de un conducto circular pero no se somete a un estrechamiento paulatino de la sección. En este caso, el flujo es forzado a pasar a través de una serie de orificios que representan entre el $8 \%$ y el $20 \%$ (Gagol et al., 2018) de la superficie total del plato, el cual ocupa la sección total de paso del fluido en la tubería. En función de la cantidad y tamaño de estos orificios se consiguen diferentes condiciones de cavitación.
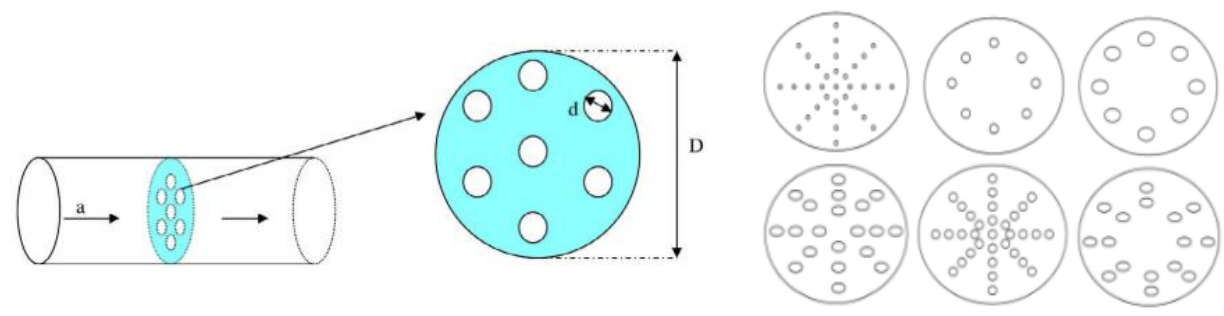

Figura 20: Algunas de las configuraciones utilizadas para degradación de contaminantes en aguas residuales. Imágenes de (Gągol et al., 2018).

$\mathrm{Al}$ igual que con el Venturi, la cavitación se produce cuando el fluido se ve forzado a pasar por el estrechamiento generado por los orificios, lo que produce a un aumento de velocidad con su consecuente disminución depresión. La principal ventaja frente al Venturi es que con este dispositivo no existe un único punto de cavitación, sino que hay tantos puntos generadores como orificios tiene el plato. Esto también los convierte en un sistema más personalizable, ya que, en función del número de agujeros, su tamaño y su disposición, se consigue variar el efecto obtenido en el proceso. En este sentido, algunos estudios en degradación de rodamina $\mathrm{B}$, concluyen que utilizar un mayor número de orificios con un menor diámetro aumenta la intensidad del colapso, y por tanto el poder de degradación (Sivakumar \& Pandit, 2002). Por otra parte, su principal desventaja reside en que la caída de presión que introducen los orificios es mucho mayor si se comparan con el estrechamiento suave del Venturi. Por tanto, se necesita generar una mayor diferencia de presión para hacer pasar el flujo a través de los orificios y como 
consecuencia, su demanda energética también es mayor. Además, al igual que sucede con el Venturi, esta técnica no resulta muy adecuada para escalarse a nivel industrial, por lo que su utilización se encuentra prácticamente limitada a un uso de laboratorio con pequeños volúmenes de tratamiento.

Al igual que con los Venturi, la utilización de platos con orificios como sistema de cavitación está ampliamente extendida y aplicada en numerosos procesos como pretratamiento del fango para obtener una mayor cantidad de metano (I. Lee \& Han, 2013), biocombustibles a partir de especies vegetales continentales (Kim, Lee, Jeon, Hwang, \& Han, 2015) y marinas (A. K. Lee, Lewis, \& Ashman, 2014), y por supuesto para desinfectar el agua (Joshi \& Gogate, 2012a)(Angaji \& Ghiaee, 2014).

\section{Liquid Whistle Reactor (LWR)}

Este tipo de reactores no está quizás, tan extendido como lo pueden estar los sistemas basados en Venturi o platos con orificios. Su traducción literal sería "reactor de silbato líquido" y recibe este nombre porque el dispositivo consiste en hacer pasar el agua a través de un orificio a gran velocidad y hacerlo impactar posteriormente sobre una superficie en forma cónica, lo cual se asemeja mucho al funcionamiento de un silbato. En este caso, la cavitación se produce cuando el fluido pasa a través del conducto generando un jet de alta velocidad que impacta sobre la superficie cónica. Esta superficie crea una fluctuación en la presión que produce el colapso de las burbujas generadas durante la cavitación y se genera una gran turbulencia en esa zona que favorece enormemente el mezclado del líquido (Tao, Cai, Huai, Liu, \& Guo, 2016). De hecho, este dispositivo ha sido utilizado como sistema para generar emulsiones debido al alto grado de mezclado que produce (Tang \& Sivakumar, 2012)

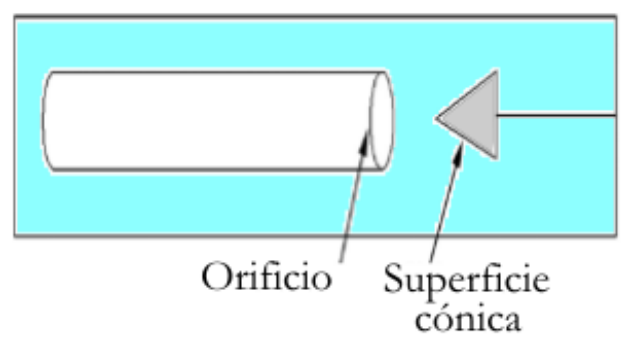

Figura 21: Ejemplo ilustrado de un Liquid Whistle Reactor (LWR).

La principal ventaja de este tipo de dispositivos reside precisamente en esta alta capacidad de mezclado que se produce tras la cavitación. Es por ello, que estos sistemas suelen combinarse con un proceso químico para aumentar el rendimiento con la sinergia entre cavitación y reacción química. Pueden encontrarse ejemplos 
de utilización de este sistema de cavitación en la desinfección de agua con adición de ozono (Chand, Bremner, Namkung, Collier, \& Gogate, 2007), o en la eliminación de contaminantes combinado con proceso Fenton (Chakinala, Gogate, Burgess, \& Bremner, 2008).

Al igual que sucede con los sistemas de platos con orificios y Venturi, este dispositivo suele utilizarse a escala de laboratorio con volúmenes muy reducidos. Es una tecnología que presenta buenas eficiencias y sinergias cuando se combina con otros procesos de oxidación química, pero su dificultad para realizar un escalado a nivel industrial la mantiene únicamente dentro del campo de la investigación.

\section{Swirling Jet Reactor (SJR)}

$\mathrm{Al}$ igual que los LWR, el uso de los SJR no está tan extendido como el de otros dispositivos como Venturis u orificios. Estos dispositivos basan su funcionamiento en la generación de un vórtice de baja presión donde se produce la cavitación. Son dispositivos con geometrías muy complejas en las que la forma de introducir el fluido es clave para un buen resultado. Generalmente, se introduce un flujo de forma tangencial a una cámara cónica o cilíndrica dónde el fluido comienza a rotar desplazándose hacia las paredes de la cámara y generando una zona de bajas presiones en el centro.

La principal dificultad de este tipo de dispositivos (además del complejo diseño geométrico) reside en la forma en la que se realiza el colapso del vórtice (Okamura \& Kubota, 2006). Aunque la zona de cavitación generada es grande, permanece estable en el centro del reactor y a no ser que se produzca un cambio drástico en la presión, no se consigue colapsar el vapor para obtener el efecto degradante de la cavitación. Por ello es necesario no solo un correcto diseño de la inyección y la generación del vórtice, sino también de una zona que, bien por un cambio abrupto en su geometría o bien por un cambio violento en las condiciones de presión, permita colapsar el vapor generado de forma drástica. 

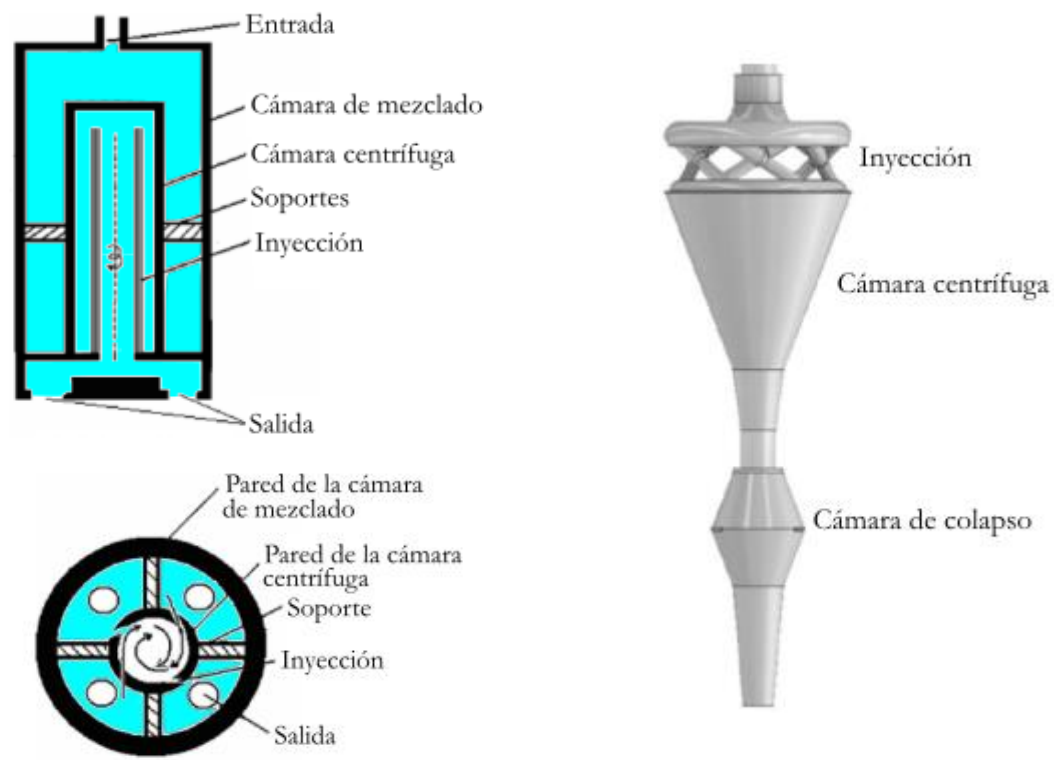

Figura 22: Modelos de Swirling Jet Reactor. A la izquierda (Wang \& Zhang, 2009) y a la derecha (Mancuso, Langone, \& Andreottola, 2017).

La eficacia de estos dispositivos ha sido comprobada en la degradación de la rodamina B (Wang, Wang, Guo, Guo, \& Wang, 2009)(Mancuso, Langone, Laezza, \& Andreottola, 2016), herbicidas como el alacloro (Wang \& Zhang, 2009). Especialmente interesante resulta su aplicación para tratar fangos y aumentar su solubilización, donde se han conseguido tratar cantidades de 50 litros con unas concentraciones de sólidas que alcanzan hasta los $50 \mathrm{~g} / 1$ (Mancuso et al., 2017). Así pues, aunque la mayor desventaja de estos dispositivos reside en su complejo diseño para conseguir generar y colapsar las burbujas de vapor en su interior, presentan una buena capacidad de escalabilidad para realizar el tratamiento a nivel industrial, lo que los convierte en unos buenos candidatos a tener en cuenta en un futuro.

\subsubsection{Dispositivos con elementos móviles}

Estos cavitadores se caracterizan por tener partes móviles que pueden rotar y, por tanto, están siempre compuestos por dos elementos principales: un rotor y un estator. En este tipo de dispositivos, la cavitación se genera gracias a las grandes 
revoluciones de giro del rotor, que pueden variar entre 2200 y 8000 rpm, y también al correcto diseño de los rotores y estátores que están formados por dientes y orificios (Gagol et al., 2018). Un buen diseño del rotor induce velocidades muy elevadas al fluido y después lo hace pasar a través de una serie de huecos y dientes produciendo regiones de bajas presiones donde se genera la cavitación. La principal desventaja frente a los dispositivos sin elementos móviles es que en estos últimos el control del fenómeno de la cavitación es mucho más sencillo y sus consumos energéticos son más reducidos. Sin embargo, en determinadas aplicaciones donde se requiere de una gran robustez debido a la complejidad del fluido a tratar, resultan mucho más convenientes dispositivos con elementos dinámicos que permitan facilitar el tránsito del flujo. Además, aunque si bien es cierto que su demanda energética es mayor, sigue siendo sustancialmente más pequeña que la requerida por los inductores ultrasónicos para producir cavitación por ultrasonidos. Por otro lado, se ha demostrado que algunos dispositivos rotorestator, pueden llegar a tratar volúmenes de casi 200 litros (Martin Petkovšek et al., 2015), mientras que la mayoría de pruebas realizadas con dispositivos tipo Venturi o platos con orificios, rara vez superan los 25 litros (Machnicka et al., 2009) (G. Lee, Lee, \& Han, 2019).

\section{Tambor rotativo con orificios}

Este tipo de cavitación comprende un conjunto de rotor y estator. El rotor, consistente en un tambor con una serie de orificios ciegos, gira a una velocidad muy elevada en un espacio confinado donde el líquido pasa a través del espacio entre el estator y el rotor. Debido a la elevada velocidad de rotación, se generan velocidades muy altas en la superficie del rotor el cual entra en los orificios ciegos por la acción giratoria. Cuando el líquido sale del orificio debido a la acción del flujo centrífugo, se crea una región de baja presión que resulta en cavitación. Generalmente, una mayor velocidad de rotación incrementa la intensidad turbulenta y con ello la intensidad de la cavitación. Sin embargo, superado cierto límite en la velocidad de rotación, puede generarse un exceso de cavitación que amortigua la fase del colapso y reduce la capacidad de degradación del proceso (M. Badve, Gogate, Pandit, \& Csoka, 2013).

Es un sistema en el que los huecos del tambor juegan un papel determinante. La cavitación se genera en función de la profundidad, diámetro, forma, y número de orificios además de la disposición de los mismos y también de los tamaños del rotor y el estator. Es un sistema que proporciona buenos resultados si el fluido tiene una reología similar a la del agua, pero que puede presentar problema si se utilizan fluidos con alto contenido en sólidos o con partículas que puedan obstruir los huecos del tambor donde se genera la cavitación. 


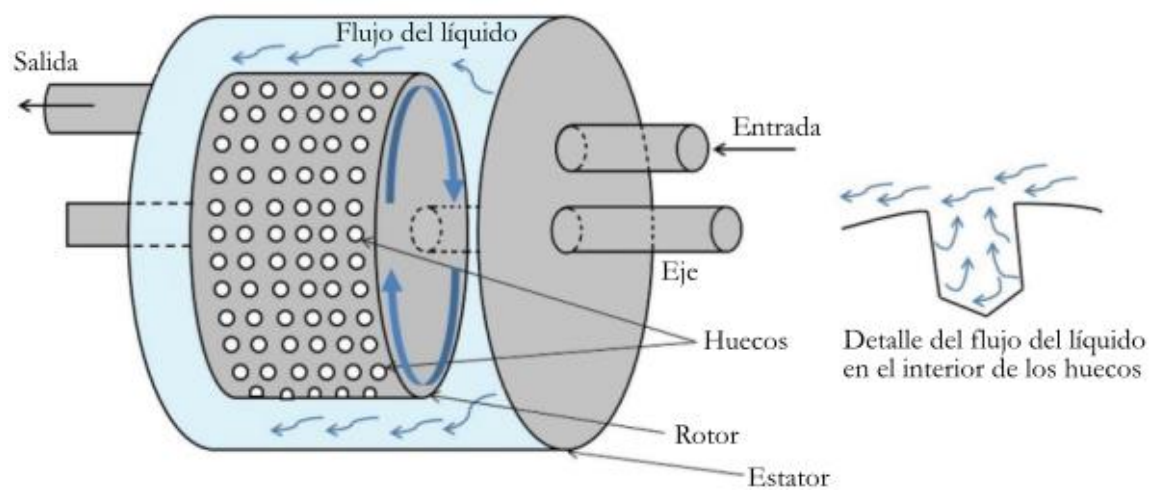

Figura 23: Dispositivo de cavitación del tipo tambor rotativo con orificios. Imagen de (Rajoriya, Carpenter, Saharan, \& Pandit, 2016).

La eficiencia del tambor rotativo con orificios ha sido probada en términos de descomposición de yoduro de potasio (M. P. Badve, Alpar, Pandit, Gogate, \& Csoka, 2015), en el tratamiento de las aguas residuales de industrias madereras (M. Badve et al., 2013), y en el tratamiento de restos vegetales para incrementar la producción de biogás (Patil, Gogate, Csoka, Dregelyi-Kiss, \& Horvath, 2016).

\section{Discos rotativos}

Este tipo de dispositivos engloba todos aquellos sistemas que inducen la cavitación gracias a las fuerzas tangenciales que los dientes del rotor ejercen sobre los dientes del estator (o de otro rotor). De esta manera se produce la denominada shear stress cavitation o cavitación por esfuerzos tangenciales que ocurre cuando las diferentes capas de fluido son sometidas a grandes esfuerzos de cortadura y se "rasgan".

Para inducir este tipo de cavitación existen varias configuraciones. Una de ellas es utilizar un estator dentado y hacer rodar un rotor (también dentado) en su interior (Cerecedo, Dopazo, \& Gomez-Lus, 2018). Otra posibilidad, es la de enfrentar dos discos ranurados que giran en direcciones opuestas, sometiendo al fluido a enormes esfuerzos tangenciales (Martin Petkovšek et al., 2013). En cualquiera de los casos, el correcto diseño de los dientes, así como los huecos del rotor y del estator, es la clave para conseguir que la cavitación produzca una degradación óptima. 

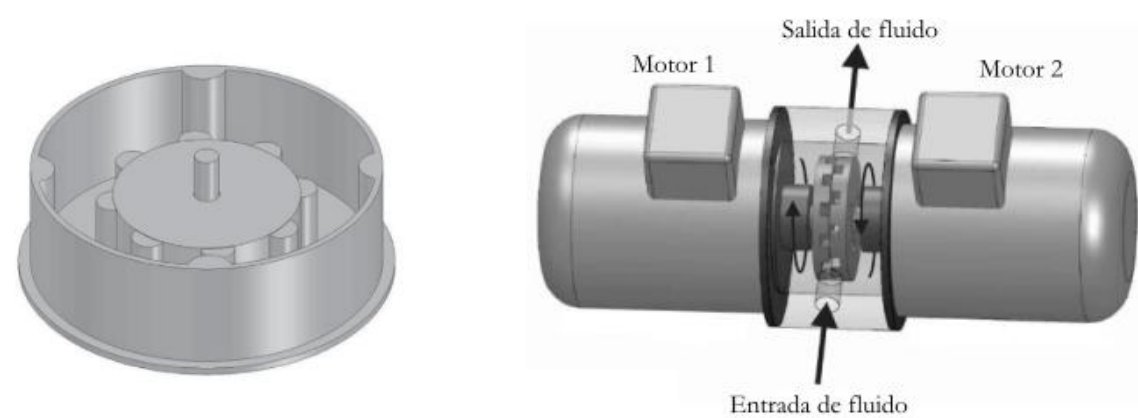

Figura 24: Dispositivos de cavitación de discos rotativos. Rotor-Estator (izquierda) y Rotor-Rotor (derecha). Imágenes de (Cerecedo et al., 2018) y (Martin Petkovšek et al., 2013).

Este tipo de cavitadores tiene la ventaja de ser muy robusto y poder tratar grandes cantidades de volumen de fluidos con una reología compleja. De hecho, existen casos de éxito en el tratamiento de volúmenes de casi 200 litros de fango activo (Martin Petkovšek et al., 2015). Además de su robustez, estos dispositivos presentan una rápida recuperación de la presión, introducen poca pérdidas de presión y su instalación es sencilla (Tao et al., 2016). Las principales desventajas que destacar son la complejidad en su diseño y el consumo energético. Para conseguir mejora el rendimiento energético cabe la posibilidad de realizar el diseño del rotor para que impulse a la vez que cavite, ahorrando así la energía necesaria para la incorporación de una bomba adicional que haga circular el fluido por la instalación.

Los dispositivos con discos rotativos se han utilizado con éxito en el tratamiento de aguas contaminadas por E. coli y E. feacalis (Cerecedo et al., 2018), en la eliminación de fármacos y otros contaminantes (Zupanc et al., 2014) (Dular et al., 2016) así como en el pretratamiento de fango para mejorar su biodegradabilidad (Martin Petkovšek et al., 2015).

\subsubsection{Configuración del montaje experimental}

Prácticamente todos los montajes realizados para llevar a prueba experimentos con dispositivos de cavitación hidrodinámica (ya sean a escala industrial o escala laboratorio) tienen una serie de elementos comunes:

- Válvulas de control: estas válvulas se encuentran aguas arriba y aguas debajo del dispositivo de cavitación y son utilizadas para controlar la presión existente en el interior del cavitador. También son utilizadas para realizar recirculaciones de flujo hacia depósitos de refrigeración o intercambiadores. 
- Bomba de impulsión: es el elemento que controla el flujo que circula por la instalación. Por lo general se suelen utilizar bombas centrífugas ya que son económicas y habituales, y sus rangos de caudales y presiones son muy amplios. Su situación dentro de la instalación no está totalmente definida. La mayoría de autores que utilizan dispositivos de cavitación sin elementos móviles (Venturi y platos con orificios mayormente) suelen situar las bombas aguas arriba del cavitador, tal y como se sugieren en diversos artículos recopilatorios recientes como el de S. Rajoriya (Rajoriya et al., 2016) o Y. Tao (Tao et al., 2016). No obstante, otros autores que utilizan cavitadores con elementos móviles, sitúan la bomba aguas abajo del dispositivo de cavitación, para conseguir disminuir la presión local en el interior de dicho dispositivo (Martin Petkovšek et al., 2013). En algunos montajes especiales es posible que no sea necesaria la bomba de impulsión ya que el movimiento del fluido se realiza variando las presiones en el interior de los depósitos que se encuentran a ambos lados del dispositivo de cavitación (Dular et al., 2016).

- Sistema de refrigeración: Generalmente, el sistema de refrigeración es necesario para disminuir la temperatura debida a la disipación de energía de las bombas de impulsión y del propio fenómeno de la cavitación. Este elemento es especialmente importante al realizar pruebas a escala de laboratorio con pocos volúmenes de fluido y durante tiempos prolongados, ya que la temperatura del fluido puede llegar a ser muy elevada en esos casos.(Dular et al., 2016)

- Elementos de monitorización: Son todos aquellos sensores o dispositivos que permiten extraer información del sistema. Generalmente se suelen utilizar sensores de presión, de temperatura y caudalímetros. Sin embargo, en ciertas investigaciones se han incluido sistemas más sofisticados como hidrófonos para visualizar los pulsos de presión debidos al colapso de las burbujas y determinar así la intensidad de la cavitación (Martin Petkovšek et al., 2013) o también cámaras rápidas (Martin Petkovšek et al., 2015). Estos dos últimos sistemas no suelen ser tan habituales debido a su complejidad de uso. 


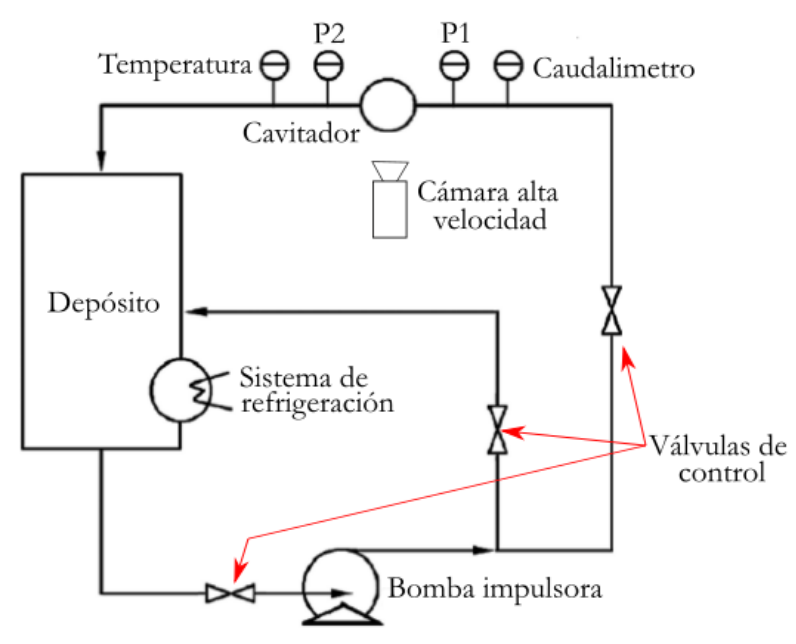

Figura 25: Configuración estándar en los sistemas de cavitación hidrodinámica.

\subsection{Aplicaciones de la cavitación}

Aunque históricamente la cavitación ha sido un fenómeno para evitar dado el efecto negativo que tiene al erosionar rodetes de bombas hidráulicas y hélices de grandes barcos, en las últimas décadas se ha estado generando de forma voluntaria en dispositivos muy diversos para ser aplicada en numerosos procesos. Además de la existencia de una gran diversidad de sistemas para producir la cavitación, también se pueden utilizar diferentes mecanismos para inducir el fenómeno en función del proceso, volumen y características requeridas por la aplicación. En el presente apartado se van a distinguir, por un lado, las principales aplicaciones en el ámbito del tratamiento y mejora de procesos en aguas residuales (temática principal de la presente tesis) y por otro, diversas aplicaciones en la industria en las que la cavitación juega un papel fundamental y que gozan de una gran popularidad por los buenos resultados proporcionados.

\subsubsection{Procesos en la industria}

Actualmente la cavitación es utilizada de forma común en un gran número de industrias con un extenso alcance en el mercado como por ejemplo la química, alimentaria, farmacéutica o médica. A continuación, se explican algunas de las aplicaciones más comunes donde el fenómeno de la cavitación es utilizado de forma activa como parte del proceso. 


\subsubsection{Producción de emulsiones}

Las emulsiones consisten en la homogeneización de dos líquidos inmiscibles. Para conseguir homogeneizarlos, lo uno de ellos debe actuar como fase continua y el otro debe ser dispersado en su interior en forma de pequeñas gotas o partículas finas. Las emulsiones son necesarias en un gran número de aplicaciones industriales de naturalezas muy diversas y han sido ampliamente estudiadas para llevarlas a cabo bajo unas condiciones lo más eficientes posibles.

A la hora de producir las emulsione, se puede diferenciar entre dos técnicas: una es el mezclado mediante un sistema rotor-estator y la otra, la inducción del fenómeno de la cavitación a través de elementos mecánicos o de ultrasonidos.

En el primer caso, se utilizan los denominados High-Shear Impellers, es decir, agitadores de alta cizalladura (Atiemo-obeng \& Calabrese, 2004). Estos agitadores funcionan a velocidades muy elevadas y generalmente, se utilizan cuando una de las sustancias a emulsionar posee una viscosidad muy elevada y se desea que la otra sustancia (ya sea, un gas, un líquido o un sólido en forma de polvo) se disperse en su interior de manera homogénea. Dado que la capacidad de bombeo de estos agitadores es muy limitada, dependen de una bomba auxiliar para producir el movimiento del fluido a través del circuito. Esto aumenta sustancialmente la cantidad de energía requerida por este tipo de dispositivos.

En el segundo caso, la emulsión se produce tras la inducción del fenómeno de la cavitación. La forma de producir la cavitación se puede conseguir mediante homogeneizadores de alta presión, High-Pressure Homogenizer, (cavitación hidrodinámica) o inductores ultrasónicos (cavitación ultrasónica). Los homogeneizadores de alta presión no son más que dispositivos que contienen un estrechamiento de tipo Venturi, aunque en algunos casos, pueden presentar diseños más elaborados para conseguir maximizar y controlar de forma más precisa la cavitación generada. Los resultados de las emulsiones generadas mediante la cavitación hidrodinámica, dependen, del número de pasadas por el dispositivo, presión de entrada y características del fluido (Tang \& Sivakumar, 2012). Suelen presentar buenas eficiencias energéticas dado que únicamente es necesario una bomba que produzca el movimiento del fluido a través del dispositivo para producir la cavitación. Por otra parte, están las emulsiones producidas mediante la cavitación ultrasónica. En este caso, la calidad de la emulsión depende del tiempo e intensidad con el que se produzca el fenómeno de la cavitación, y también de las propiedades de los fluidos a emulsionar (Gaikwad \& Pandit, 2007). Los resultados obtenidos suelen ser muy buenos dado que es más fácil controlar la cantidad y calidad de cavitación generada. El principal inconveniente es que el proceso de emulsión se lleva a cabo por lotes (batches) y no de manera continua, lo que reduce sustancialmente las cantidades a tratar y 
complica enormemente la operación a escala industrial por el incremento que supone en términos de consumo energético.

\subsubsection{Tratamientos cosméticos o de belleza}

Desde principio de los años 80 , los ultrasonidos han sido estudiados como una terapia para facilitar la eliminación de la grasa localizada del cuerpo. Inicialmente los ultrasonidos se utilizaban como una técnica auxiliar para aumentar la eficiencia y la efectividad de los procesos de liposucción mediante los cuales la grasa era eliminada a través de una cánula que la succionaba. En estos casos, el efecto térmico producidos por la energía liberada gracias a las ondas ultrasónicas facilitaba el ablandamiento de la grasa corporal para su posterior eliminación (Kuwahara et al., 2003).

No obstante, además de este efecto térmico, cobra gran importancia el efecto producido por el fenómeno de la cavitación. Los ultrasonidos, inducen la cavitación de aquellos núcleos presentes en los tejidos que presentan una cohesión molecular débil como es el caso del tejido adiposo. Por otro lado, los tejidos con una alta densidad (como los huesos) no son susceptibles de ser cavitados ya que no existen las nucleaciones necesarias para producir el fenómeno. Debe considerarse que el flujo sanguíneo, sobre todo el que se encuentra cerca de las turbulencias cercanas a válvulas artificiales, podría llegar a cavitar, aunque es menos probable que esto ocurra en otros flujos sanguíneos debido a la baja presencia de gases disueltos o nucleaciones. La energía liberada durante el colapso de las microburbujas y nucleaciones localizadas en el interior de las células grasas produce la fragmentación celular de los adipocitos y la difusión de los lípidos a través de los espacios intercelulares. (Lawrence \& Coleman, 1997).

Para esta aplicación en particular, únicamente puede inducirse la cavitación mediante ultrasónicos, ya que la cavitación hidrodinámica no es válida por razones obvias. Así pues, la cavitación ultrasónica es conocida actualmente por ser una técnica no invasiva en la cual simplemente se rompen las células que forma el tejido adiposo para que el propio cuerpo las elimine sin necesidad de una actuación tan agresiva como es el caso de la liposucción. La potencia de las ondas de ultrasonido así como su frecuencia deben ser adecuadas para conseguir la destrucción en las células de los tejidos adiposos y no generar efectos negativos en otros tejidos como la piel (Moretti, Londoño, Caballero, Galetto, \& Godoy, 2016).

\subsubsection{Sistemas de calentamiento de alta eficiencia}

El fenómeno de la cavitación ha sido y está siendo investigado como un sistema alternativo a los métodos de calentamiento actuales en los que se utiliza una resistencia eléctrica o la energía liberada tras la quema de un combustible. Como se ha comentado anteriormente, durante la cavitación se producen una serie de variaciones térmicas. Durante la generación y expansión de las burbujas de gas, el 
calor latente necesario es proporcionado por el líquido y, por tanto, este se enfría. No obstante, durante el colapso, se produce la condensación del gas y en las últimas etapas de da una violenta compresión de lo gases que producen un aumento puntual de la temperatura muy elevado (Hauke et al., 2007).

Casi la totalidad de los sistemas de calentamiento regidos por el fenómeno de la cavitación, se basan en la cavitación hidrodinámica. El principal motivo reside en la eficiencia energética que se obtiene al utilizar los cavitadores hidrodinámicos frente a los ultrasónicos. Aunque el efecto termodinámico conseguido al utilizar sendos tipos de cavitación es el mismo, en el caso de la cavitación generada mediante ultrasonidos, la energía necesaria es mucho mayor porque se necesita un aporte para la generación (en el inductor ultrasónico) y otro para producir el movimiento del fluido (bomba hidráulica). Sin embargo, los sistemas que aprovechan la cavitación hidrodinámica suelen estar formados por un estrechamiento tipo Venturi donde se produce la cavitación, o un sistema rotor-estator que induce la cavitación a la vez que bombea el fluido.

Las consecuencias termodinámicas producidas por la cavitación hidrodinámica han sido ampliamente estudiadas en Venturis. Los experimentos realizados, muestran cómo se produce un ligero enfriamiento que puede hacer disminuir la temperatura del líquido en $0,12-0,27 \mathrm{~K}$ en la zona del estrechamiento donde se produce el crecimiento y expansión del gas (M. Petkovšek \& Dular, 2015), seguido de un calentamiento en la zona de colapso que puede llegar a suponer incrementos de la temperatura en el líquido de hasta 1,4 K (Martin Petkovšek \& Dular, 2013). Los resultados obtenidos están en concordancia tanto con la explicación termodinámica a través de las ecuaciones de Rayleight-Plesset como de la teoría del termal delay (Brennen, 1995). El efecto térmico obtenido, guarda estrecha relación con el número de cavitación, es decir, con las diferencias de presión en la entrada y salida del dispositivo que es lo que indica la cantidad de cavitación que se está produciendo. Atendiendo a esto, se ha llegado a la conclusión que tan desfavorable es una cavitación insuficiente como una cavitación excesiva, ya que el pico de temperatura obtenido se ve mermado en ambos casos, existiendo un máximo en un numero de cavitación determinado que depende de la geometría del cavitador que se esté utilizando (Martin Petkovšek \& Dular, 2013). Estudios realizados con un sistema en bucle cerrado han determinado que el aumento de la temperatura se produce de forma lineal con el tiempo y que efectivamente la cavitación produce un aumento extra en la temperatura del líquido que no se alcanza cuando únicamente se bombea el líquido a través del sistema sin que exista cavitación (Katz, Bermejo, Escaler, Dular, \& Ruíz, 2019).

Los sistemas de calentamiento industriales funcionan en bucle cerrado. Disponen de un depósito de agua aislado térmicamente, un cavitador que puede ser de tipo Venturi o de configuración rotor-estator (Tahmid, Gill, Park, Ryu, \& 
Lee, 2013) y un sistema de tuberías repartido por las instalaciones que se desea aclimatar. En función del régimen de la bomba y los tiempos de funcionamiento, se consigue controlar la temperatura del agua y con ello, la de la zona habitada. (Nikolsky, Oliynyk, Lipeev, \& Ved, 2017). Estos sistemas se están utilizando también para aclimatar la temperatura de las piscinas. En este caso se consiguen dos efectos: aumentar la temperatura del agua para mejorar el confort de la instalación y realizar un proceso de desinfección aprovechando esta capacidad del propio fenómeno de la cavitación.

\subsubsection{Síntesis de biocombustibles}

Debido al encarecimiento progresivo del petróleo y a la disminución de las reservas disponibles en el planeta, la síntesis de los biocombustibles se está convirtiendo en una alternativa, cada vez más eficiente, a la utilización de los combustibles fósiles tradicionales. Los biocombustibles están químicamente formados por los ésteres metílicos de los ácidos grasos o FAMEs por sus siglas en inglés (fatty acid methyl esters). Éstos son producidos por la metanólisis de los triglicéridos naturales como, por ejemplo, las grasas animales y también los aceites vegetales que pueden provenir tanto de plantas, como también de algas. Las técnicas convencionales suelen utilizar temperaturas entre 70 y $200^{\circ} \mathrm{C}$ y presiones que se encuentran en un rango de entre 6 y 10 atmósferas. En función del material utilizado para la síntesis del biocombustible, se pueden llegar a conseguir conversiones del orden del 90-95\% empleando tiempos de tratamiento que suelen extenderse hasta las 70 horas (Parag R. Gogate \& Kabadi, 2009).

Tanto la cavitación hidrodinámica como ultrasónica han resultado ser unas alternativas muy eficientes a los procesos utilizados de forma convencional. Aunque la cavitación ultrasónica ha mostrado resultados ligeramente mejores a los obtenidos mediante la cavitación hidrodinámica producida con platos agujereados, en ambos casos se han obtenido conversiones superiores al $90 \%$ en tiempos que oscilan entre los 10 y 15 minutos para diferentes sustancias tratadas (Parag R. Gogate, 2007). No obstante, es la cavitación hidrodinámica la principal candidata para realizar un tratamiento a nivel industrial dado la baja ratio energética empleado para realizar la conversión del biocombustible. Dicho ratio, puede llegar a ser del orden de 1.4 veces inferior al utilizado por un cavitador ultrasónico y 2.7 veces inferior al necesario en procesos convencionales (Ji, Wang, Li, Yu, \& Xu, 2006) Asimismo, la cavitación ultrasónica quedaría renegada a ser utilizada únicamente a escala de laboratorio debido a los bajos volúmenes que puede tratar. La única opción para poder aumentar el volumen tratado mediante inductores ultrasónicos sería utilizar un diseño de múltiples transductores y múltiples frecuencias, pero esto también aumentaría de manera crítica la cantidad de energía necesaria para llevar a cabo el proceso. 
De entre los cavitadores hidrodinámicos utilizados para la síntesis del biodiesel, cabe destacar el plato con orificios y el tambor rotativo (configuración rotorestator). Ambos sistemas han demostrado tener buenas características para el escalado y muy buenas ratios energéticas que han llegado a ser del orden de $0.0125 \mathrm{kWh} / \mathrm{l}$. para los platos con orificios utilizando microalgas como materia prima (Ji et al., 2006) y del orden de $0.03 \mathrm{kWh} / \mathrm{l}$. para el caso de utilizar configuraciones rotor-estator con aceites vegetales como producto de partida (Crudo et al., 2016).

\subsubsection{Otras aplicaciones}

En la sección anterior, se han comentado algunas de las aplicaciones más comunes donde el fenómeno de la cavitación es el principal mecanismo del proceso que se quiere desarrollar. No obstante, existen un gran número de aplicaciones aisladas que se sirven del fenómeno de la cavitación para llevar a cabo algún tipo de proceso o reacción.

\section{Cristalización}

La cristalización es un proceso utilizado en muchas industrias como la petroquímica, o la farmacéutica. La cavitación por ultrasónicos es ampliamente utilizada no solo para controlar el proceso de cristalización y nucleación (ya sea homogénea o heterogénea) sino también para conseguir aumentar la reproducibilidad de los procesos.

Modificando parámetros como la frecuencia, la intensidad, el tamaño/profundidad del inductor ultrasónico, duración del proceso de cavitación y volumen de muestra cavitada se pueden conseguir modificar un gran número de propiedades, tales como la velocidad de cristalización, el tamaño de los cristales, su forma o incluso su ordenación y composición atómica (Luque de Castro \& PriegoCapote, 2007). Esto permite la generación de cristales "a medida" asegurando que sus principales cualidades se mantengan constantes durante la cristalización, evitando así, defectos y variaciones en el proceso productivo.

\section{Transferencia de genes}

Desde mediados de los años 90, ha sido creciente el interés por encontrar métodos que permitieran liberar de forma simple y eficiente el material genético del interior de las células para su posterior tratamiento y transformación. Uno de los principales campos donde la ingeniería genética ha experimentado un mayor crecimiento es en la agricultura. La alteración de la genética de las plantas permite desarrollar cepas que presenten características muy concretas como resistencia a herbicidas, resistencia a plagas, tolerancia a la sal o producción de ciertas proteínas (Parag R. Gogate \& Kabadi, 2009). 
La cavitación ultrasónica ha sido aplicada de forma satisfactoria con el fin de extraer el material genético de las células (Y. Liu, Yang, \& Sakanishi, 2006). Las condiciones de presión y temperatura que se producen en el momento del colapso de las burbujas permiten romper la plasmalema de las células y liberar el material genético para su posterior tratamiento. Aunque la cavitación ultrasónica es un método más simple comparado con los tradicionalmente utilizados (bombardeo de partículas, electroporación y microinyección), puede causar daño a las células si no se conocen y controlan bien los parámetros de funcionamiento. Por ello es vital establecer aquellas condiciones de operación que permitan liberar el material genético de las células sin causarles ningún daño.

\section{Tratamiento de vinos}

Uno de los principales procesos en la industria vinícola es el envejecimiento del vino, ya que, de esta etapa dependen características críticas del vino como su sabor y su aroma. (García Martín \& Sun, 2013). Tradicionalmente, el envejecimiento se lleva a cabo en barriles de madera, que lejos de ser un simple contenedor de almacenamiento durante esta etapa, confiere al vino ciertos sabores y aromas en función del tipo de madera que se esté utilizando. No obstante, estos barriles presentan un elevado coste económico de mantenimiento y sustitución y los procesos de envejecimientos se alargan durante meses incluso años.

Por ello, la cavitación ultrasónica se ha comenzado a utilizar en esta industria, ya que permite acelerar las reacciones que se llevan a cabo durante el proceso de envejecimiento del vino, y también permite incrementar la extracción de los compuestos fenólicos de la uva o el mosto durante el proceso previo al envejecimiento (Chang \& Chen, 2002). Su efecto ha sido estudiado en diferentes propiedades del vino como la cantidad de compuestos fenólicos, el $\mathrm{pH}$ la intensidad, el tinte o la acidez perceptible (Q.-A. Zhang, Shen, Fan, \& García Martín, 2016). La efectividad en determinados vinos ha sido comprobada, reduciendo la cantidad de taninos y aumentando la de antocianinas lo cual es considerado una característica necesaria en los vinos de alta calidad.

\subsubsection{Procesos biológicos y tratamiento de aguas residuales}

Para la presente tesis en particular, la aplicación del fenómeno de la cavitación se enmarca en el ámbito del tratamiento de las aguas residuales y concretamente en la mejora del proceso biológico de la digestión para conseguir mejorar el potencial de biometanización obtenido durante esta fase. En el presente apartado, se recogen de forma más detallada los fundamentos y aplicaciones de la cavitación en este tipo de procesos en concreto.

En primer lugar, es necesario destacar el creciente aumento del interés por la aplicación del fenómeno de la cavitación en este tipo de procesos. Tal y como 
puede verse en la Figura 26, el número de artículos de investigación en relación con el tema de la cavitación y más concretamente con la hidrocavitación aplicada a tratamientos de agua residuales ha ido en aumento desde el año $2000 \mathrm{y}$ ha experimentado un crecimiento muy acusado durante los últimos 4 años.

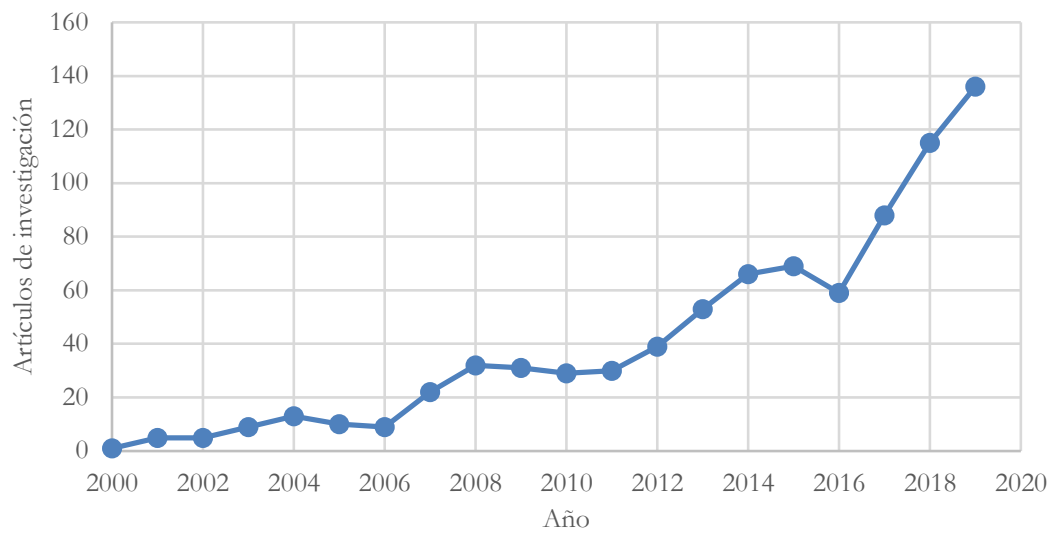

Figura 26: Artículos de investigación sobre hidrocavitación aplicada a tratamiento de aguas residuales. Basado en los archivos de ScienceDirect.com a fecha de 25/08/2019.

Este gran crecimiento de los últimos años se debe a diversos factores:

- Medioambientales. El agua potable en un bien cada vez más escaso y del cual debe hacerse un uso responsable. Su reutilización se ha convertido en un proceso clave para evitar sustraer de forma continua el agua necesaria de pozos, embalses y ríos, que dependen de las condiciones climáticas que, por otro lado, son cada vez más adversas, y a menudo se dan períodos de sequía más y más extensos. Así pues, es imperativo conseguir realizar tratamientos que eliminen no solo bacterias y virus, sino también otras formas contaminantes presentes en el agua, como por ejemplo fármacos o microalgas.

- Legislativos. La legislación en materia no solo de agua sino también en de los residuos derivados del tratamiento de aguas residuales (como por ejemplo los fangos activos) es cada vez más estricta. Así pues, las características de calidad que deben superar tanto el agua tratada como los residuos derivados de su tratamiento obligan a eliminar mayor cantidad y variedad de contaminantes. Estas restricciones, fuerzan el desarrollo de nuevas técnicas que permitan cumplir con los requisitos legales de vertido y/o reutilización.

- Económicos. Dentro de los factores económicos podrían diferenciarse dos tipologías diferentes. La primera correspondería con la realización de aquellos procesos que, siendo de obligado cumplimiento (como por ejemplo 
mantener los parámetros de calidad de agua por debajo de unos mínimos legales), se lleven a cabo de la manera más eficiente posible para reducir costes derivados de la energía y de productos químicos. El segundo consiste en la reutilización y revalorización de los residuos derivados de la actividad principal. En el caso del tratamiento de aguas residuales sería, por ejemplo, la reutilización de los fangos activos como fertilizantes para agricultura los cuales, a su vez, deben cumplir con unas características determinadas para poder ser utilizados en este ámbito.

Como puede observarse, los motivos que han llevado a este creciente interés por nuevas técnicas de desinfección, tratamiento de agua, y tratamiento y reutilización de residuos derivados, no pueden sino volverse cada vez más restrictivo. Por tanto, se prevé que estas nuevas técnicas emergentes continúen desarrollándose y evolucionando en un futuro, continuando la creciente tendencia iniciada hace unos años.

\subsubsection{Mecanismos para la desinfección y tratamiento de aguas}

La desinfección constituye una de las principales etapas en el proceso del tratamiento de aguas residuales. Aunque los métodos convencionales como la cloración son baratos y muy efectivos, su utilización produce una serie de subproductos en el agua tratada que pueden resultar peligrosos. Con el objeto de evitar estos subproductos han aparecido otras técnicas como la utilización de luz ultravioleta, que evita la dosificación de productos químicos y se sirve de la energía de este tipo de luz para producir la desinfección. No obstante, la desinfección UV también tiene sus limitaciones ya que, en aguas turbias, su eficiencia se ve muy reducida debido a que las partículas presentes en el agua bloquean y absorben la radiación inhibiendo o mermando el proceso de desinfección.

Las técnicas de desinfección emergentes tienen como objetivo mantener la eficiencia en la desinfección, pero subsanando los puntos débiles de los métodos convencionales. Las nuevas técnicas de desinfección empleadas como sustitución a las convencionales se basan, en gran medida, en las siguientes tecnologías:

- Cavitación ultrasónica

- Cavitación hidrodinámica

- Homogeneizadores de alta velocidad (High Speed Homogenizer)

- Homogeneizadores de alta presión (High Pressure Homogenizerer)

- Molinos de bolas (Bead Mills)

En todas las tecnologías mencionadas al principio del apartado (cavitación ultrasónica e hidrodinámica, homogeneizadores de alta presión y velocidad y molinos de bolas), la destrucción y degradación de los contaminantes se consigue mediante el estrés y la abrasión que sufren las paredes celulares durante la intensa 
agitación, y también por las grandes fuerzas de cizallamiento que estos sistemas son capaces de producir. No obstante, la condición necesaria para conseguir degradaciones significativas es la cavitación (como demuestran numerosos estudios realizados con fármacos, cianobacterias, microalgas bacterias y virus). La importancia de la cavitación en la degradación de los contaminantes se hizo patente hace décadas tras confirmar que los homogeneizadores de alta velocidad y homogeneizadores de alta presión (que no están expresamente diseñados para producir cavitación) pueden ser diseñados para conseguir que caviten dentro de unos rangos determinados (Kumar \& Pandit, 1999), y que cuando esto sucede, su efectividad en cuanto a poder de degradación y rotura de las paredes celulares de las bacterias aumenta sustancialmente (Balasundaram \& Pandit, 2001).

Por último, cabe también destacar que la desintegración o inactivación de los contaminantes sometidos al proceso de cavitación puede localizarse en 3 zonas: el interior de la cavidad de gas, la interfase gas-líquido, o en la fase líquida (Gagol et al., 2018). Tal y como puede verse en la Figura 27, las diferentes condiciones de presión y temperatura que se dan en las diferentes zonas donde se produce el fenómeno de la cavitación pueden propiciar la generación de determinadas reacciones químicas, algunas de las cuales (como la formación de radicales libres $\mathrm{OH}$ ) son las encargadas de producir la degradación de las diferentes sustancias contaminantes. Así pues, en función del tipo de contaminante a eliminar, puede resultar interesante realizar el diseño de los cavitadores de manera que se potencien la intensidad y frecuencia que se produce en estas zonas (como puede ser la zona del colapso), y así se intensifique la generación de aquellas reacciones que resulten más adecuadas para el proceso que quiera llevarse a cabo. 


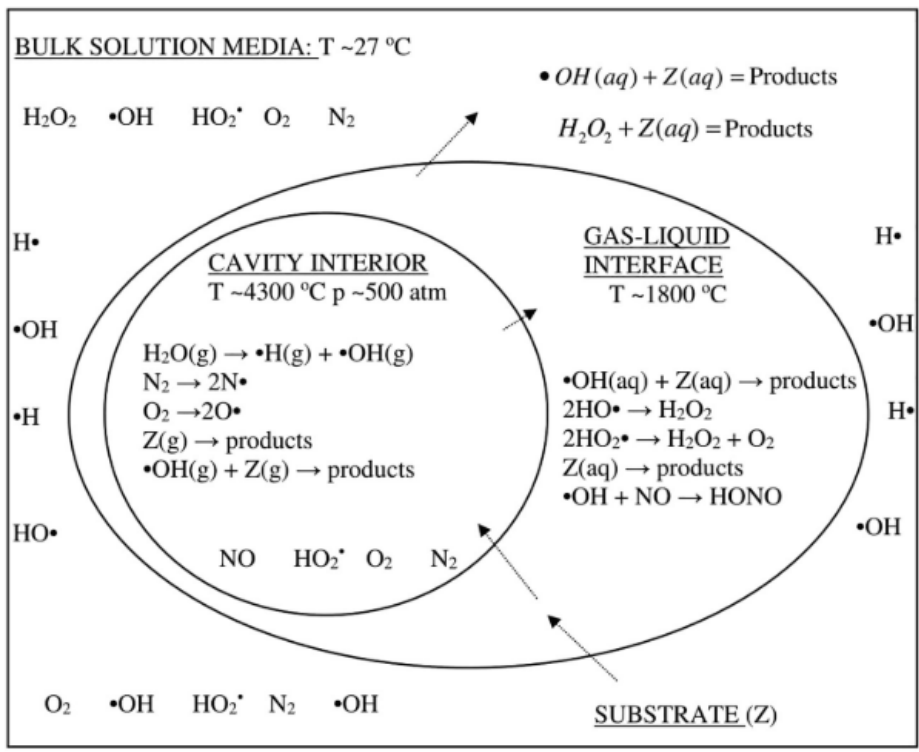

Figura 27: Diferentes zonas durante la cavitación donde pueden producirse las reacciones químicas en función de las condiciones de presión y temperatura alcanzadas (Gągol et al., 2018).

\subsubsection{Cavitación hidrodinámica en desinfección de aguas}

Tras realizar varios estudios con homogeneizadores de alta presión y comparar sus resultados con los obtenidos mediante cavitación ultrasónica y sistemas diseñados específicamente para cavitar, se ha podido comprobar que los mejores resultados desinfectantes se dan: o bien cuando los homogeneizadores trabajan en rangos donde la cavitación generada no es ni demasiado débil, ni demasiado extensa (Balasundaram \& Pandit, 2001), o bien cuando se utilizan dispositivos que han sido específicamente diseñados para cavitar como pueden ser Venturis o sistemas de válvulas estranguladas (Jyoti \& Pandit, 2001). Es a partir de estos estudios cuando el fenómeno de la cavitación empieza a estudiarse como principal alternativa a los sistemas de desinfección convencionales. Tal y como algunos autores sugieren, el efecto desinfectante de la cavitación se debe a dos motivos:

- Químicos: Durante la cavitación se producen radicales $\mathrm{OH}$ que son altamente oxidantes y actúan como biocidas (Riesz \& Kondo, 1992)(Hauke et al., 2007)

- Físicos: La cavitación conlleva condiciones de presión (Fujikawa \& Akamatsu, 1980) y temperatura muy elevadas (Suslick et al., 1986) que son críticas para los microorganismos y sus paredes celulares. 
El mecanismo de destrucción predominante depende del proceso a partir del cual se genera la cavitación (Arrojo et al., 2008). Si la cavitación es generada en bajas frecuencias, los colapsos son más violentos alcanzando temperaturas y presiones más elevadas, pero se producen en menor cantidad por unidad de tiempo, lo que reduce la difusión de los radicales OH. Si por el contrario la cavitación es generada en altas frecuencias, existirá una mayor difusión de los radicales $\mathrm{OH}$, pero la energía liberada durante el colapso será menor, lo que se traduce en menores temperaturas y presiones alcanzadas. Por otro lado, la efectividad de los procesos de desinfección, no solo depende del método utilizado, sino también del tipo de contaminante que se esté tratando de eliminar (Dular et al., 2016), por ejemplo:

\section{Cianobacterias y Microalgas}

Las cianobacterias y las microalgas pueden ser eliminadas mediante 3 métodos: biológicos, químicos y físicos. Los más baratos y fáciles de implementar son los químicos, pero su utilización puede afectar a especies benignas y además se pueden generar contaminantes secundarios o metales pesados. La cavitación ultrasónica ha sido el tipo de cavitación más utilizado para analizar la eliminación de estos contaminantes. Las temperaturas y los radicales $\mathrm{OH}$ generados durante el colapso afectan a las células de las algas causando daño en su sistema fotosintético. Los resultados obtenidos varían mucho en función de los valores de intensidad y frecuencia utilizados (en los transductores ultrasónicos) y de las características geométricas del sistema (en los dispositivos de cavitación hidrodinámica). Los resultados conseguidos mediante cavitación hidrodinámica han resultado ser eficientes contra ciertas cianobacterias ( $M$. Aeruginosa) y han dado resultados variados en microalgas, realizando una eliminación selectiva que no afecta a todas las especies por igual (Dular et al., 2016)

\section{Fármacos}

La eliminación de determinados fármacos como el ácido clofíbrico, la carbamazepina, el diclofenaco o el ibuprofeno no puede realizarse biológicamente en las depuradoras y deben buscarse alternativas para su degradación. Tratamientos como fotolisis, ozonización y diversos procesos de oxidación avanzada se han llevado a cabo en numerosos estudios. La cavitación hidrodinámica también ha sido estudiada como posible proceso de degradación de fármacos de tipologías variadas, y ha resultado ser eficaz en numerosos estudios (Braeutigam et al., 2012a) (Bagal \& Gogate, 2014a) (Dular et al., 2016). La eficacia de la cavitación hidráulica reside en que la descomposición de los compuestos orgánicos durante la cavitación puede ocurrir en varios lugares (fase gas, interfase gas-líquido y en la fase líquida), de manera que se maximiza su degradación. Además, se ha demostrado que la adición de agentes oxidantes externos durante el proceso de cavitación (como por 
ejemplo peróxido de hidrógeno), incrementa sustancialmente la degradación de estos.

\section{Bacterias}

Debido al tamaño relativamente grande que poseen las bacterias, los radicales oxidantes $(\mathrm{OH})$ que se forman durante la cavitación no son suficientes para conseguir su erradicación. No obstante, las altas temperaturas alcanzadas y, sobre todo, las ondas de presión que producen valores puntuales muy elevados permiten romper la pared celular y liberar los componentes internos de la bacteria. El efecto que la cavitación produce sobre las bacterias ha sido analizado desde hace tiempo y su efectividad confirmada en numerosos estudios (Geciova, Bury, \& Jelen, 2002).

\section{Virus}

El caso de los virus es muy similar al de las bacterias. Se conocen dos métodos que son efectivos en su eliminación: el calor (Duizer et al., 2004) y las altas presiones (Kovač, Diez-Valcarce, Raspor, Hernández, \& Rodríguez-Lázaro, 2012). En principio, los efectos producidos por la cavitación deberían ser efectivos contra los virus, pero las investigaciones con estos son escasas dada la dificultad y los peligros biológicos que conlleva su manipulación.

Sabiendo los beneficios que la cavitación proporciona a los tratamientos de desinfección del agua, debe establecerse cuál es la mejor forma de inducirla: de forma hidrodinámica o de forma acústica/ultrasónica. Diversos estudios apuntan a que la cavitación hidrodinámica es más adecuada para ser desarrollada como un sistema de desinfección eficiente. En primer lugar porque el volumen y las concentraciones de contaminantes que se pueden tratar son mucho más elevados que en cualquier otra técnica, por tanto sus posibilidades de ser escalado a nivel industrial para tratar grandes volúmenes es mucho más factible (Jyoti \& Pandit, 2001). Y en segundo lugar, porque la eficiencia energética en el caso de los sistemas que utilizan la cavitación hidrodinámica está muy por encima de los sistemas que utilizan la cavitación ultrasónica incluso de los homogeneizadores de alta presión y homogeneizadores de alta velocidad (Balasundaram \& Pandit, 2001) (Save, Pandit, \& Joshi, 1994) (Arrojo et al., 2008). Esta segunda condición, es consecuencia del volumen que los sistemas con cavitación hidrodinámica permiten tratar. Dado que con la misma o incluso menor energía empleada se pueden tratar mayores cantidades de agua contaminada, las eficiencias energéticas conseguidas son mucho más grandes que las obtenidas mediante cualquier otro tipo de sistema. En el siguiente apartado se detalla la forma en la que se determina la eficiencia de un proceso que utilice cavitación hidrodinámica para el tratamiento de aguas. 


\subsubsection{Eficiencia energética del proceso de cavitación}

Tras conocerse los múltiples beneficios que la desinfección mediante cavitación hidrodinámica puede ofrecer, se han comenzado a desarrollar multitud de tipologías diferentes de diseño de estos cavitadores. Muchos de estos cavitadores ya han sido comentados en el apartado 2.3 y, algunos de ellos, han mostrado buenos resultados en los procesos de desinfección. Para poder comparar entre los diferentes dispositivos utilizados, es necesario determinar su eficiencia en el proceso en el cual se esté utilizando. Aunque la forma de evaluar la eficiencia depende del tipo de proceso en el que se produce la cavitación, debe ser igual e invariable para cualquier tipología de cavitador hidrodinámico empleado para garantizar así una comparación válida y realista.

Para el caso concreto de los dispositivos de hidrocavitación aplicados al tratamiento de aguas, resulta complejo y biológicamente peligroso trabajar con bacterias y virus. Por ello, se suelen emplear colorantes como azul de metileno y sobre todo rodamina B en lugar de cepas reales de microorganismos. La efectividad de los dispositivos se obtiene mediante la determinación de la degradación que se consigue en el colorante. Es la denominada tasa de cavitación (cavitation yield) que se calcula a través de la siguiente fórmula.

\section{Tasa de cavitación $(m g \cdot L / J)$}

$$
=\frac{m g \text { de contaminante degradado }}{\left(P_{m} \cdot t\right) / V}
$$

Ec. 77

Donde $P_{m}$ es la potencia de la bomba que impulsa el fluido a través del cavitador, t es el tiempo durante el cual se está cavitando y $\mathrm{V}$ es el volumen tratado durante el proceso. Esta expresión es válida para realizar comparaciones entre distintas técnicas de cavitación (incluso entre procesos con cavitación ultrasónica y cavitación hidrodinámica) siempre que se utilice el mismo contaminante en los sistemas a comparar (Tao et al., 2016). Probablemente el método más popularizado para determinar la eficiencia, así como la calidad de la cavitación hidrodinámica producida en los diferentes dispositivos diseñados a lo largo de las investigaciones sea evaluando la degradación del colorante rodamina B. En la Tabla 1, se presentan las eficiencias conseguidas por múltiples cavitadores hidrodinámicos y ultrasónicos durante experimentos realizados con este colorante. 


\begin{tabular}{|c|c|c|c|c|c|c|}
\hline $\begin{array}{l}\text { Tipo de } \\
\text { cavitador }\end{array}$ & Tecnología & Autor & $\begin{array}{c}\text { Volumen } \\
\text { tratado } \\
{[\mathrm{L}]} \\
\end{array}$ & $\begin{array}{c}\text { Tiempo de } \\
\text { operación } \\
\text { [min] }\end{array}$ & $\begin{array}{c}\text { Potencia } \\
\text { empleada } \\
\text { [W] }\end{array}$ & $\begin{array}{c}\text { Tasa de } \\
\text { cavitación } \\
{[\mathrm{mg} \cdot \mathrm{L} / \mathrm{J}]} \\
\end{array}$ \\
\hline Swirling Jet & $\mathrm{HC}$ & $\begin{array}{c}\text { (G. Li, Guo, Wang, Guo, \& } \\
\text { Wang, 2007) }\end{array}$ & 20 & 180 & 3500 & $9.90 \cdot 10^{-5}$ \\
\hline Plato Orificios & $\mathrm{HC}$ & (Sivakumar \& Pandit, 2002) & 50 & 60 & 5500 & $1.10 \cdot 10^{-4}$ \\
\hline Plato Orificios & $\mathrm{HC}$ & (Mishra \& Gogate, 2010a) & 4 & 120 & 1100 & $4.64 \cdot 10^{-6}$ \\
\hline Venturi & $\mathrm{HC}$ & (Mishra \& Gogate, 2010b) & 4 & 120 & 1100 & $5.25 \cdot 10^{-6}$ \\
\hline $\begin{array}{c}\text { Generador } \\
\text { Ultrasónico } \\
(300 \mathrm{kHz})\end{array}$ & $\mathrm{UC}$ & $\begin{array}{l}\text { (Merouani, Hamdaoui, } \\
\text { Saoudi, \& Chiha, 2010a) }\end{array}$ & 0.3 & 140 & 60 & $8.93 \cdot 10^{-7}$ \\
\hline $\begin{array}{c}\text { Generador } \\
\text { multifrecuencia } \\
(20-30-50 \mathrm{kHz})\end{array}$ & $\mathrm{UC}$ & $\begin{array}{c}\text { (Parag R. Gogate, Sivakumar, } \\
\text { \& Pandit, 2004) }\end{array}$ & 7.5 & 30 & 900 & $1.04 \cdot 10^{-4}$ \\
\hline
\end{tabular}

Tabla 1: Comparación energética entre diferentes tipos de cavitadores hidrodinámicos y ultrasónicos durante experimentos con rodamina B. Datos obtenidos de (Tao et al., 2016)

Analizando la Tabla 1 se puede observar como la mejor tasa de cavitación se corresponde al generador multifrecuencia con un valor de $1.04 \mathrm{mg} \cdot \mathrm{l} / \mathrm{J}$. Este valor es prácticamente idéntico al conseguido por el plato con orificios $(1.10 \mathrm{mg} \cdot \mathrm{l} / \mathrm{J})$, aunque en este caso el volumen tratado es de 501 frente a los 7.51 del generador multifrecuencia. En este caso es donde se hace patente la escalabilidad de la cavitación generada de forma hidrodinámica frente a la ultrasónica. Además, cabe destacar que el generador multifrecuencia es quizás el sistema más eficiente dentro de los métodos de cavitación ultrasónica, ya que si se consideran los métodos convencionales (generador ultrasónico de una única frecuencia a $300 \mathrm{kHz}$ ) la tasa de cavitación cae hasta valores que se encuentran un orden de magnitud por debajo del peor caso realizado vía cavitación hidrodinámica.

En el caso de utilizar cepas de microorganismos reales (ya sean virus o bacterias) la eficiencia se obtiene determinando la evolución de las unidades formadoras de colonias (en adelante expresado como UFC, aunque también se conocen como CFU por sus siglas en inglés [Colony-forming unit]). En este caso, algunos autores (Cerecedo et al., 2018) han utilizado una variante de la Ec. 77 para considerar la reducción de UFC conseguida.

$$
\text { Tasa de cavitación }\left(U F C_{\text {muertas }} / J\right)=\frac{U F C_{\text {muertas }}}{\left(P_{m} \cdot t\right)}
$$

$\mathrm{Al}$ igual que en la Ec. 77, $P_{m}$ es la potencia de la bomba que impulsa el fluido a través del cavitador (W) y t es el tiempo (s) durante el cual se está cavitando. La principal diferencia se encuentra en el contaminante estudiado que en este caso son 
las UFC que se han eliminado (UFC muertas). En este caso, en la expresión no se relaciona la cantidad que se elimina en función del volumen. Para ello es necesario utilizar una segunda expresión:

$$
E(k W h / l)=\frac{\dot{W}(k W h)}{V} \cdot \frac{t}{\log \left(C F U_{i} / C F U_{f}\right)}
$$

Ec. 79

En este caso, el tiempo se expresa en horas, el volumen en litros y las UFC tanto iniciales como finales en $\mathrm{UFC} / \mathrm{ml}$. De esta forma se obtiene una relación entre la energía empleada por cada litro de agua tratado, donde la efectividad del proceso de desinfección se encuentra integrada como un coeficiente que incrementa el coeficiente $\mathrm{E}(\mathrm{kWh} / \mathrm{l})$ en función de la ratio de reducción en las UFC. En la Tabla 2 , se presentan las eficiencias conseguidas por múltiples cavitadores hidrodinámicos y ultrasónicos durante experimentos realizados bacterias y microorganismos de diferentes índoles.

\begin{tabular}{|c|c|c|c|c|c|c|}
\hline Tipo de cavitador & Tecnología & Autor & $\begin{array}{c}\text { Volumen } \\
\text { tratado } \\
{[\mathrm{L}]} \\
\end{array}$ & $\begin{array}{c}\text { Tiempo } \\
\text { operación } \\
\text { [min] } \\
\end{array}$ & $\begin{array}{c}\text { Tasa de } \\
\text { cavitación } \\
{\left[\mathrm{UFC}_{\text {muertas }} / \mathrm{J}\right]} \\
\end{array}$ & $\begin{array}{c}\mathrm{E} \\
{[\mathrm{kWh} / \mathrm{L}]}\end{array}$ \\
\hline Rotor-Estator \#1 & $\mathrm{HC}$ & (Cerecedo et al., 2018) & 0.5 & 15 & 0.43 & 0.12 \\
\hline Rotor-Estator \#2 & $\mathrm{HC}$ & (Cerecedo et al., 2018) & 0.25 & 6 & 34.19 & 0.06 \\
\hline Rotor-Estator \#3 & $\mathrm{HC}$ & (Cerecedo et al., 2018) & 0.25 & 8 & 480.77 & 0.06 \\
\hline Plato Orificios & $\mathrm{HC}$ & (Arrojo et al., 2008) & 50 & 120 & 12.5 & 1.49 \\
\hline Venturi & $\mathrm{HC}$ & (Arrojo et al., 2008) & 50 & 120 & 59.88 & 0.145 \\
\hline $\begin{array}{l}\text { Homogeneizador de } \\
\text { alta velocidad }\end{array}$ & $\mathrm{HC}$ & (Jyoti \& Pandit, 2001) & 1 & 15 & 23.92 & 0.02 \\
\hline $\begin{array}{l}\text { Cavitación en } \\
\text { válvulas }\end{array}$ & $\mathrm{HC}$ & (Jyoti \& Pandit, 2001) & 75 & 15 & 13.94 & 0.16 \\
\hline $\begin{array}{l}\text { Homogeneizador } \\
\text { Ultrasónico }\end{array}$ & UC & $\begin{array}{c}\text { (Gao, Lewis, } \\
\text { Ashokkumar, \& } \\
\text { Hemar, 2014) }\end{array}$ & 0.015 & 1 & 62496.79 & 0.124 \\
\hline $\begin{array}{c}\text { Generador } \\
\text { Ultrasónico }(22 \\
\text { kHz) } \\
\end{array}$ & UC & (Jyoti \& Pandit, 2001) & 0.050 & 15 & 1.33 & 1.61 \\
\hline
\end{tabular}

Tabla 2: Comparación energética entre diferentes tipos de cavitadores hidrodinámicos y ultrasónicos durante experimentos con bacterias y otros microorganismos. Estudio realizado por (Cerecedo et al., 2018).

Una vez más, se puede observar como la mejor tasa de cavitación (en este caso medida en $\mathrm{UFC}_{\text {muertas }} / \mathrm{J}$ ), se corresponde a un sistema de cavitación ultrasónica (homogeneizador ultrasónica) aunque el volumen tratado es muy pequeño 0.0151 . Los volúmenes más grandes se corresponden nuevamente a sistemas de cavitación 
hidrodinámica, en los cuales se consiguen tasas de cavitación similares con unas eficiencias que parecen ser mejores cuando se utiliza un único orificio, ya sea una válvula o un Venturi. Resulta también interesante observar como un mismo dispositivo funcionando bajo condiciones diferentes o cambiando ligeramente su configuración geométrica consigue mejorar sustancialmente, su tasa de cavitación, manteniendo la eficiencia energética (Cerecedo et al., 2018).

Como conclusión a este apartado, debe destacarse dos puntos. En primer lugar, la escalabilidad de los procesos llevados a cabo vía cavitación hidrodinámica. Como se ha podido ver en los resultados de las investigaciones que otros autores han realizado con rodamina $\mathrm{B}$ y desinfección de bacterias y microorganismos, los procesos que utilizan la cavitación hidrodinámica (ya sea mediante Venturi, platos con orificios o dispositivos rotativos) permiten tratar una mayor cantidad de volumen con un coste energético aceptable. En segundo lugar, las tasas de cavitación conseguidas tanto en relación con la degradación de rodamina $\mathrm{B}$ $(\mathrm{mg} \cdot \mathrm{l} / \mathrm{J})$, como en eliminación de bacterias $\left(\mathrm{UFC}_{\text {muertas }} / \mathrm{J}\right)$ son igual o mejores cuando se utilizan dispositivos de cavitación hidrodinámica. Por tanto, parece lógico pensar que el camino para desarrollar sistemas industriales de desinfección y tratamiento de agua sea a través de dispositivos de cavitación hidrodinámica.

\subsubsection{Técnicas para incrementar la eficiencia del tratamiento}

Hasta el momento, todos los estudios e investigaciones presentados consideraban única y exclusivamente los efectos producidos por la cavitación ya fuese generada de forma hidrodinámica o ultrasónica. No obstante, existen diversas maneras de incrementar la eficiencia conseguida durante los procesos de cavitación que, generalmente, consisten en la adición de sustancias químicas que actúan como oxidantes y aumentan la degradación ya de por sí conseguida con la cavitación. Algunas de las sustancias químicas y procesos más utilizados para incrementar la efectividad de los tratamientos de cavitación son:

- Adición de peróxido de hidrógeno $\left(\mathrm{H}_{2} \mathrm{O}_{2}\right)$

- Adición de tetracloruro de carbono $\left(\mathrm{CCl}_{4}\right)$

- Ozonización $\left(\mathrm{O}_{3}\right)$

- Combinación con proceso Fenton

Todos estos procesos (al igual que la propia cavitación) se denominan procesos de oxidación avanzada o AOP por sus siglas en inglés (Advanced Oxidation Process). Aunque pueden aplicarse de forma independiente, la idea es conseguir sinergias cuando estos procesos se combinan entre sí de manera adecuada. De esta forma se incrementa la cantidad de radicales oxidantes $\mathrm{OH}$ que se producen y que son los encargados de romper los enlaces entre moléculas y degradar todo tipo de compuestos ya sean orgánicos o inorgánicos. 


\section{Adición de peróxido de hidrogeno $\left(\mathrm{H}_{2} \mathrm{O}_{2}\right)$}

El peróxido de hidrógeno es uno de los compuestos más utilizados en procesos de oxidación avanzada dado que, al descomponerse, se convierte en una gran fuente de radicales hidroxilo:

$$
\mathrm{H}_{2} \mathrm{O}_{2} \rightarrow \mathrm{OH}+\mathrm{OH}
$$

La descomposición del peróxido de hidrógeno es facilitada por el proceso de cavitación y, por tanto, se pueden conseguir efectos sinérgicos muy potentes que no se alcanzan utilizando la cavitación o la adición del peróxido de forma separada. Estudios llevados a cabo con rodamina B (Mishra \& Gogate, 2010b) y con metil paratión (Patil \& Gogate, 2012a) han demostrado el efecto sinérgico entre la cavitación hidrodinámica y la adición del peróxido de hidrógeno. En estos estudios se ha analizado la adición de diferentes concentraciones de este oxidante (entre 10 y $200 \mathrm{mg} / \mathrm{l}$ ) durante el proceso de cavitación. Se ha comprobado que la tasa de degradación del contaminante en cuestión se ve incrementada al aumentar la concentración de peróxido de hidrógeno introducida. Incluso con la adición de pequeñas concentraciones $(10-20 \mathrm{mg} / \mathrm{l})$ se puede conseguir una mejora en la degradación entre un 50-60\% durante los primeros instantes del proceso. Sin embargo, se pueden conseguir tasas de eliminación de hasta el $99 \%$ si la concentración de peróxido de hidrógeno se aumenta hasta los 50-100 mg/l. Para conseguir incrementar la tasa de degradación de manera exitosa, es necesario encontrar las concentraciones de peróxido de hidrógeno óptimas para cada proceso. De otro modo, se pueden generar reacciones que recombinan o destruyen los radicales OH generados (Weissler, 1959), lo que se traduce en un decremento de la eficiencia conseguida con la sinergia entre el proceso de oxidación del peróxido y el de cavitación.

\section{Adición de tetracloruro de carbono ( $\left.\mathrm{CCl}_{4}\right)$}

El tetracloruro de carbono es un compuesto sintético que durante muchos años ha sido utilizado como plaguicida, fungicida, desengrasante y líquido refrigerante. Dado que es más volátil que el agua, esta sustancia se encuentra en forma de cavidades de vapor en el interior del líquido. Al ser sometidas a un proceso de cavitación, estas cavidades de vapor de $\mathrm{CCl}_{4}$, colapsan y liberan radicales $\mathrm{Cl}^{-}$que participan en la reacción de oxidación e incrementan la tasa de degradación de los contaminantes presentes en el agua. Las reacciones en las que el $\mathrm{CCl}_{4}$ se ve involucrado pueden llegar a producir múltiples agentes oxidantes como el cloro 
$\left(\mathrm{Cl}^{2}\right)$, ácido clorhídrico $(\mathrm{HCl})$ o ácido hipocloroso $(\mathrm{HOCl})$. Las posibles reacciones a las que puede dar lugar son las siguientes:

$$
\begin{gathered}
\mathrm{CCl}_{4} \rightarrow: \mathrm{CCl}_{3}+\mathrm{Cl} \\
\mathrm{CCl}_{4} \rightarrow: \mathrm{CCl}_{2}+\mathrm{Cl}_{2} \\
\cdot \mathrm{CCl}_{3} \rightarrow: \mathrm{CCl}_{2}+\mathrm{Cl} \\
\cdot \mathrm{CCl}_{3}+\cdot \mathrm{CCl}_{3} \rightarrow \mathrm{CCl}_{4}+: \mathrm{CCl}_{2} \\
\cdot \mathrm{CCl}_{3}+\cdot \mathrm{CCl}_{3} \rightarrow \mathrm{C}_{2} \mathrm{Cl}_{6} \\
: \mathrm{CCl}_{2}+: \mathrm{CCl}_{2} \rightarrow \mathrm{C}_{2} \mathrm{Cl}_{4} \\
\cdot \mathrm{Cl}+\cdot \mathrm{Cl} \rightarrow \mathrm{Cl}_{2} \\
\mathrm{Cl}_{2}+\mathrm{H}_{2} \mathrm{O} \rightarrow \mathrm{HClO}+\mathrm{HCl}
\end{gathered}
$$

En estudios realizados con diferentes plaguicidas y utilizando dispositivos para generar cavitación de forma hidrodinámica se han conseguido degradaciones más elevadas que si solo se utiliza únicamente un proceso de cavitación, pero menores que cuando se combina la cavitación con los procesos Fenton. Así pues, para el caso particular del diclorvos se han registrado tasas de degradación de hasta el $24 \%$ al utilizando concentraciones de $\mathrm{CCl}_{4}$ de $5 \mathrm{mg} / 1$ (Joshi \& Gogate, 2012b)y tasas de hasta el $82.8 \%$ en el metil paratión al utilizar concentraciones de $6 \mathrm{~g} / \mathrm{l}$ (Patil \& Gogate, 2012b). En los experimentos con rodamina B, se han conseguido degradaciones de hasta el $82 \%$ utilizando concentraciones de $\mathrm{CCl}_{4}$ de $1 \mathrm{~g} / 1 \mathrm{y}$ combinando el aditivo con un proceso de cavitación hidrodinámica de unos 120 minutos (Mishra \& Gogate, 2010b). Utilizando las mismas concentraciones de $\mathrm{CCl}_{4}$ pero combinadas con un proceso de cavitación ultrasónica, han conseguido degradaciones del $100 \%$ en 40 minutos (Merouani, Hamdaoui, Saoudi, \& Chiha,

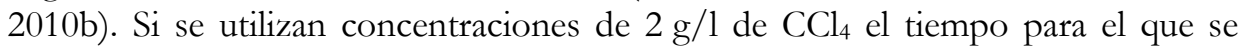
consigue la degradación del $100 \%$ del colorante se reduce a los 5 minutos.

La utilización del perclorato de carbono como aditivo para mejorar la degradación de los contaminantes durante los procesos de cavitación está cayendo en desuso debido, principalmente, a la toxicidad de este compuesto. El efecto que se consigue al añadir este aditivo es muy variable en función del contaminante que se desea eliminar. Sin embargo, las concentraciones que se introducen deben estar muy controladas para asegurarse que todo el $\mathrm{CCl}_{4}$ se degrada durante el proceso de cavitación. De otro modo, las concentraciones residuales de este compuesto podrían llevar a incrementar la toxicidad del agua que se está tratando de descontaminar. 


\section{Combinación con procesos Fenton}

El proceso Fenton es uno de los procesos de oxidación avanzada más utilizados en la industria de las aguas residuales. Para realizar el proceso Fenton, se utiliza el peróxido de hidrógeno catalizado posteriormente con un metal de transición que generalmente es $\mathrm{Fe}^{2+}$. De esta reacción de catálisis surgen los radicales oxidantes según la siguiente reacción:

$$
\mathrm{H}_{2} \mathrm{O}_{2}+\mathrm{Fe}^{2+} \rightarrow \cdot \mathrm{OH}+\mathrm{OH}^{-}+\mathrm{Fe}^{3+}
$$

Los $\mathrm{OH}$ pueden reaccionar con un compuesto orgánico, o pueden desaparecer al reaccionar nuevamente con el $\mathrm{Fe}^{2+} \mathrm{o}$ con el peróxido de hidrógeno:

$$
\begin{gathered}
\cdot \mathrm{OH}+\mathrm{Fe}^{2+} \rightarrow \mathrm{OH}^{-}+\mathrm{Fe}^{3+} \\
\cdot \mathrm{OH}+\text { Cotaminante } \rightarrow \text { Producto degradado } \\
\cdot \mathrm{OH}+\mathrm{H}_{2} \mathrm{O}_{2} \rightarrow \mathrm{H}_{2} \mathrm{O}+\cdot \mathrm{HO}_{2} \\
\cdot \mathrm{OH}+\cdot \mathrm{OH} \rightarrow \mathrm{H}_{2} \mathrm{O}_{2}
\end{gathered}
$$

El ion de hierro puede descomponer el peróxido de hidrogeno de forma catalítica, también gracias a la existencia de condiciones de cavitación, devolviendo el ion de hierro en el proceso, lo que puede desembocar en la generación de $\mathrm{OH}$ adicionales:

$$
\begin{aligned}
\mathrm{H}_{2} \mathrm{O}_{2}+\mathrm{Fe}^{3+} & \leftrightarrow \mathrm{H}^{+}+\mathrm{FeOOH}^{2+} \\
\mathrm{FeOOH} & \leftrightarrow \cdot \mathrm{HO}_{2}+\mathrm{Fe}^{2+}
\end{aligned}
$$

Mediante algunos estudios realizados con un plato con orificios como dispositivo de hidrocavitación, se ha intentado determinar la relación óptima entre la cantidad de $\mathrm{FeSO}_{4}$ y la de $\mathrm{H}_{2} \mathrm{O}_{2}$ para conseguir los máximos grados de degradación posibles. En estudios realizados con plaguicidas como diclorvos (Joshi \& Gogate, 2012b) y metil paratión (Patil \& Gogate, 2012b), se ha observado que al mantener constante la concentración de $\mathrm{H}_{2} \mathrm{O}_{2}$ e ir aumentando progresivamente la dosis de $\mathrm{FeSO}_{4}$, se incrementa significativamente la tasa de degradación del plaguicida. En los experimentos llevados a cabo con diclorvos se han conseguido 
degradaciones de entre el $12.5 \%$ utilizando únicamente el proceso de hidrocavitación. Al añadir peróxido de hidrógeno esta degradación ha aumentado hasta el $16 \%$, y al combinar la hidrocaviación con el proceso Fenton utilizando proporciones de $\mathrm{FeSO}_{4} / \mathrm{H}_{2} \mathrm{O}_{2}$ de 3:1, se han conseguido degradaciones de hasta el $91.5 \%$. Los resultados obtenidos son muy similares al utilizar el plaguicida metil paratión (Patil \& Gogate, 2012b) consiguiendo incrementar su degradación desde un $22.4 \%$ (utilizando únicamente hidrocavitación) hasta un $93.8 \%$ al combinar la hidrocavitación con el proceso Fenton utilizando proporciones de $\mathrm{FeSO}_{4} / \mathrm{H}_{2} \mathrm{O}_{2}$ de 1:4. Además de con plaguicidas, se han realizado investigaciones analizando la degradación de colorantes como la rodamina B. En este caso, la combinación de la cavitación hidrodinámica con el proceso Fenton en proporciones $\mathrm{FeSO}_{4} / \mathrm{H}_{2} \mathrm{O}_{2}$ de 1:5, ha producido degradaciones prácticamente del $100 \%$ (Mishra \& Gogate, 2010b).

Aunque tal y como puede observarse, la combinación entre la cavitación hidrodinámica y el proceso Fenton incrementa sustancialmente la degradación de algunas sustancias contaminantes como plaguicidas o colorantes, debe obtenerse la proporción óptima entre de $\mathrm{FeSO}_{4} / \mathrm{H}_{2} \mathrm{O}_{2}$ y no solo eso. El resultado final es dependiente del tipo de dispositivo que se utilice para producir la cavitación y la cantidad y calidad de cavitación obtenida, así como de otros parámetros como la temperatura del proceso, concentraciones iniciales de contaminante o $\mathrm{pH}$. Esto pone de manifiesto que, aunque efectivamente la cavitación combinada con el proceso Fenton, es muy efectiva, los resultados obtenidos dependen de multitud de parámetros que deben controlarse para conseguir mantener el proceso en condiciones óptimas.

\section{Ozonización $\left(\mathrm{O}_{3}\right)$}

El ozono es uno de los oxidantes más utilizados en la industria de tratamiento de aguas residuales. Debido a su alta potencia de oxidación $(2.08 \mathrm{~V})$ permite degradar un gran número de contaminantes orgánicos incluso si están formados por enlaces dobles. Su utilización como único sistema de desinfección de aguas está muy limitado debido, entre otros motivos, porque se ve muy afectado por el $\mathrm{pH}$ del medio, porque las reacciones redox que genera son muy selectivas y por su alto coste económico (Gagol et al., 2018).

Sin embargo, la ozonización combinada con procesos de cavitación (ya sean hidrodinámicos o ultrasónicos) incrementa sustancialmente la eficiencia en la degradación de contaminantes en comparación con la utilización del ozono de forma independiente. Esta combinación entre cavitación hidrodinámica y ozonización ha proporcionado buenos resultados en la eliminación de bacterias como la E. coli (Chand et al., 2007), microalgas como la Microcystis aeruginosa (Z. Wu et al., 2012) o insecticidas (Parag R Gogate \& Patil, 2015). En todos estos estudios 
se han utilizado dispositivos de cavitación hidrodinámica (mayormente, platos con orificios o sistemas con estrechamientos como Venturi o whistle reactors) que, en combinación con el ozono han demostrado aumentar sustancialmente la degradación desde valores de un 20-25\% al utilizar únicamente la cavitación hasta un $80-100 \%$ al realizar un tratamiento combinado.

En condiciones de pH básico, el ozono sufre descomposición produciendo varios tipos de radicales con un alto potencial de oxidación (radicales $\mathrm{OH}$ y $\mathrm{HO}_{2}$ ), lo que mejora la eficiencia de la degradación. Sin embargo, en pH ácidos, el ozono tiene un déficit de electrones, lo que limita su reacción únicamente con contaminantes con alta densidad de electrones como los alcanos. En condiciones de $\mathrm{pH}$ neutro, la cavitación permite la pirólisis en la fase gaseosa del oxígeno atómico (durante el colapso de las burbujas) que reacciona con las moléculas de agua produciendo $\mathrm{OH}$ reactivos (Gagol et al., 2018):

$$
\begin{gathered}
\mathrm{O}_{3} \rightarrow \mathrm{O}+\mathrm{O}_{2} \\
\mathrm{O}+\mathrm{H}_{2} \mathrm{O} \rightarrow \cdot 2 \mathrm{OH}
\end{gathered}
$$

El ozono también se descompone gracias a los $\mathrm{OH}$ y de esta manera, se producen más radicales $\mathrm{OH}$ así como $\mathrm{HO}_{2}$ los cuales son los encargados de degradar los contaminantes.

$$
\begin{gathered}
\mathrm{O}_{3}+\mathrm{OH}^{-} \rightarrow \mathrm{HO}_{2}^{-}+\mathrm{O}_{2} \\
\mathrm{O}_{3}+\mathrm{HO}_{2}^{-} \rightarrow \cdot \mathrm{OH}+\mathrm{O}_{2}+\mathrm{O}_{2}^{-} \\
\mathrm{O}_{2}^{-}+\mathrm{H}^{+} \rightarrow \cdot \mathrm{HO}_{2} \\
\mathrm{O}_{3}+\cdot \mathrm{OH} \rightarrow \cdot \mathrm{HO}_{2}+\mathrm{O}_{2} \\
\mathrm{O}_{3}+\mathrm{HO}_{2} \rightarrow \cdot \mathrm{OH}+\mathrm{OH}^{-}+\mathrm{O}_{2}
\end{gathered}
$$

Bajo condiciones de cavitación, se produce peróxido de hidrógeno que también reacciona con el ozono, descomponiéndolo en más $\mathrm{OH}$ e hidroperoxilo.

$$
\begin{gathered}
\mathrm{HO}_{2}{ }^{-}+\mathrm{H}^{+} \rightarrow \mathrm{H}_{2} \mathrm{O}_{2} \\
\mathrm{O}_{3}+\mathrm{H}_{2} \mathrm{O}_{2} \rightarrow \mathrm{O}_{2}+\cdot \mathrm{OH}+\cdot \mathrm{HO}_{2}
\end{gathered}
$$

En este apartado se han presentado las principales técnicas para incrementar los tratamientos basados en procesos de cavitación, las cuales consisten en la adición 
de sustancias químicas que, al degradarse debido al fenómeno de la cavitación, liberan radicales altamente oxidantes. Aunque algunos de estos tratamientos muestran aumentos en la eficiencia de hasta el $100 \%$, en muchas ocasiones esto supone la adición de concentraciones elevadas del químico. Esto supone un riesgo dado que es necesario asegurar que todo el aditivo incorporado se transforma en los radicales que posteriormente contribuyen al proceso de degradación. Si esto no sucede, el aditivo incorporado puede convertirse en un contaminante residual o combinarse con otras sustancias generando nuevos contaminantes. Por otro lado, la efectividad de estos tratamientos depende de muchos factores como el tipo de contaminante que se desee eliminar, la cantidad y calidad de la cavitación generada, la forma de generarla y propiedades fisicoquímicas como el $\mathrm{pH}$ o la temperatura del tratamiento. Debido a esto, no existen procedimientos claros de cuando utilizar cada aditivo ni en qué cantidad, sino que la utilización de cada uno de ellos, así como sus concentraciones, dependerán de cada situación concreta y deberán determinarse de forma experimental.

\subsubsection{Mejora de los procesos de fangos activos y digestión anaerobia}

Las estaciones de aguas residuales (EDAR), generan una gran cantidad de fangos como subproducto de los procesos físicos, químicos y biológicos. La cantidad de fangos generados (expresados en sólidos secos) asciende aproximadamente a unos 60-90 gramos por habitante, lo que en Estados Unidos, por ejemplo, se traduciría en una cantidad de unos 10 millones de toneladas de fango deshidratado al año (Appels, Baeyens, Degrève, \& Dewil, 2008). Para realizar el tratamiento de toda esta cantidad de fangos, es necesario realizar una serie de pasos:

1. Reducir la cantidad de agua presente en el fango (espesado).

2. Transformar la materia orgánica biodegradable en un residuo orgánico o inorgánico que sea inerte o suficientemente estabilizado.

3. Tratar el residuo para cumplir con la normativa vigente de eliminación. En función de la normativa de cada país, se puede utilizar el residuo resultante como abono o si la normativa es muy estricta, se realiza una incineración donde se recupera parte de la energía.

La digestión anaerobia entraría dentro del segundo paso y un proceso primordial para el tratamiento de los fangos sea cual sea el resultado final que se esté buscando (aplicación en agricultura, generación de biofuel, incineración o eliminación al vertedero). 


\subsubsection{La digestión anaerobia}

La digestión anaerobia es un proceso a partir del cual los microorganismos, en ausencia de oxígeno, descomponen el material biodegradable presente en el fango resultante de los procesos de decantación primaria y secundaria y su posterior deshidratación. Gracias a este proceso, la materia orgánica puede ser transformada en biogás (metano en su mayor parte), reducir la cantidad de sólidos del fango, y eliminar la mayor parte de los patógeno presentes en el mismo de manera que se reduce enormemente el impacto por olores asociado a la materia orgánica permanente en el lodo. El gas obtenido puede ser acumulado y posteriormente utilizado como combustible para producir energía eléctrica que alimente a la propia planta de aguas residuales o volcarla a la red. Debido a la gran cantidad de energía que puede obtenerse del biogás, la digestión anaerobia es la parte más importante en las EDAR modernas y resulta de gran interés cualquier proceso que permita aumentar la cantidad de biogás generado durante la digestión.

El proceso mediante el cual se puede obtener biogás a partir de la digestión anaerobia consta de 4 etapas, tal y como puede verse en la Figura 28.

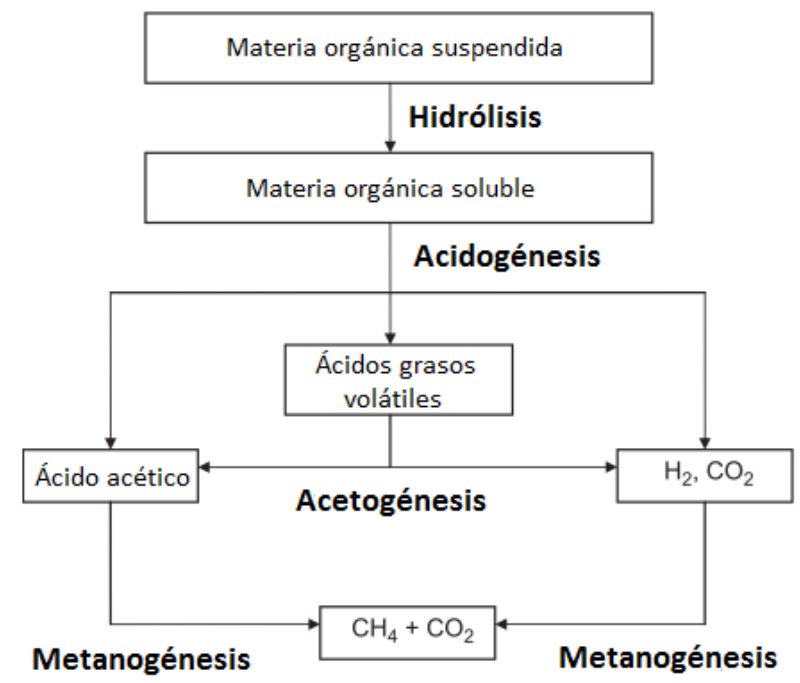

Figura 28: Etapas del proceso de digestión anaerobia. Ilustración modificada de L. Appels et al. 2008.

La primera etapa (hidrólisis) es la fase más lenta, donde la materia orgánica insoluble, así como los compuestos moleculares pesados, se convierten en materia orgánica soluble. Las proteínas se descomponen en aminoácidos, las grasas en ácidos grasos de cadena larga, y los azúcares en monosacáridos. La segunda etapa (acidogénesis) es la más rápida y es donde se producen ácidos grasos volátiles 
generados por bacterias fermentativas y/o acido génicas. En la tercera etapa (acetogénesis) los ácidos orgánicos más grandes, así como los alcoholes producidos durante la acidogénesis, son digeridos por acetógenos que producen ácido acético, así como dióxido de carbono e hidrógeno molecular. Finalmente, en la cuarta y último etapa (metanogénesis), se produce metano debido a la actuación de dos tipos de bacterias diferentes: un primer grupo que transforma el acetato en metano y dióxido de carbono y un segundo grupo que utiliza el hidrógeno como donante de electrones y el dióxido de carbono como receptor de los mismos para generar el metano (Appels et al., 2008).

\subsubsection{Pretratamientos en la digestión anaerobia}

Como se ha visto anteriormente, las técnicas de digestión biológica (digestión anaerobia) ha sido el procedimiento más popularizado en las últimas décadas para reducir el volumen de los lodos producidos en las EDAR, así como para intentar dotar este residuo de cierto valor energético al producir biogás. No obstante, el proceso está lejos de estar optimizado y muchos de las sustancias presentes en el fango activo, se encuentran encapsulados en el interior de las membranas celulares. Esta membrana que recubre los microorganismos, es una estructura semirrígida que proporciona a la célula la suficiente fuerza intrínseca como para protegerla de la lisis osmótica (rotura de la pared celular) (Weemaes Marjoleine \& Verstraete, 1998).

Debido a esto, los procesos convencionales de digestión anaeróbica requieren de largos tiempos de retención que pueden extenderse hasta los 20-30 días. Por tanto, los pretratamientos utilizados en el proceso de la digestión anaerobia tienen como objetivo conseguir la rotura de la pared celular para liberar los componentes internos y reducir los tiempos de retención, es decir, mejorar la etapa de la hidrólisis en el proceso de digestión anaerobia. Los pretratamientos utilizados para mejorar la hidrólisis se dividen en biológicos, químicos, térmicos y mecánicos.

\section{Pretratamientos Biológicos}

Consisten en la introducción de ciertas cepas de bacterias para que realicen el proceso de digestión anaerobia. La literatura que existe al respecto es escasa debido a que las compañías no quieren divulgar resultados (Appels et al., 2008), pero se han dado casos de aumentos de hasta el $210 \%$ en la producción de metano concretamente tras la introducción de la cepa AT1 de la bacteria Geobacillus sp. (Miah, Tada, \& Sawayama, 2004).

\section{Pretratamientos Químicos}

El objetivo de estos pretratamientos es introducir un químico que sea capaz de debilitar o degradar la pared celular para favorecer la hidrólisis y la liberación del material intracelular. Estos pretratamientos se dividen en 3 grupos: hidrólisis acida 
y alcalina, ozonización y métodos de oxidación avanzada (Appels et al., 2008). El primer caso resulta muy complicado de utilizar ya que el $\mathrm{pH}$ del lodo durante la digestión debe estar muy controlado para no eliminar las bacterias que realizan el proceso. En cuanto a la ozonización y la oxidación avanzada, ambos procesos son muy similares y la diferencia reside en que en la ozonización se utiliza ozono como sustancia oxidante mientras que en los métodos de oxidación avanzada se utiliza $\mathrm{H}_{2} \mathrm{O}_{2}$ o procesos Fenton para la liberación de $\mathrm{OHs}(\mathrm{OH})$ que tienen un poder altamente oxidante.

\section{Pretratamientos térmicos}

Debido a su relativa simplicidad, esta clase de pretratamientos es la que se lleva aplicando durante más tiempo en la digestión anaerobia. Consiste en someter el fango activo a un calentamiento que oscila en un rango de entre los $60 \mathrm{y}$ los $220^{\circ} \mathrm{C}$ y a presiones entre 6 y 25 bar. El calor altera los enlaces químicos de las paredes celulares, permitiendo la liberación del material interno de los microorganismos (Appels et al., 2008). Diferentes autores han estudiado cómo los pretratamientos térmicos afectan tanto a la fase mesófila como termófila del proceso de la digestión y han cuantificado tanto el incremento en la producción de metano como la reducción de sólidos volátiles y sólidos totales. En este sentido es evidente que los pretratamientos térmicos mejoran los rendimientos de la digestión anaerobia. No obstante, las condiciones bajo las cuales el pretratamiento proporciona resultados óptimos dependen mucho de los rangos de temperaturas, duración del pretratamiento y naturaleza del pretratamiento. Así pues, un fango difícil de hidrolizar, necesitará mayores temperaturas y tiempos de pretratamiento (Gavala, Yenal, Skiadas, Westermann, \& Ahring, 2003).

\section{Pretratamientos mecánicos}

Los tratamientos mecánicos tienen como objetivo destruir o deteriorar las paredes celulares mediante diferentes procesos físicos. La reducción de las partículas presentes en el fango tiene como consecuencia la exposición de la superficie disponible para que se produzca el proceso biológico. Esto produce dos efectos: una mejora en la producción de biogás y una reducción de los tiempos de retención durante la digestión anaerobia (Mata-Alvarez, Macé, \& Llabrés, 2000). Entre los sistemas de pretratamiento más utilizados pueden encontrarse los siguientes dispositivos (Muller, 2000):

- Molinos de bolas (Stirred Ball Mills). Consisten en cámaras cilíndricas con bolas de acero o de cerámica en su interior que machacan el fango reduciendo el tamaño de las partículas sólidas más grandes. 
- Homogeneizadores de alta presión (High Pressure Homogenizers). Están formados por una bomba hidráulica multietapa, que contiene una válvula homogeneizadora a través de la cual se hace pasar el lodo a alta presión.

- Sistema de impacto por Jet (Mechanical Jet Smash Technique). Consiste en presurizar el fango a presión elevada para después proyectarlo sobre una superficie sólida donde se genera una gran turbulencia y fuerzas de cizalladura que destruyen las paredes celulares

- Sistema de pulsos de alto rendimiento (High Performance Pulse Technique). Se trata de un método electrohidráulico que pace pasar pulsos eléctricos de alta tensión $(10 \mathrm{kV})$ a través del fango

- Técnica centrífuga de Lysat (Lysat Centrifugal Tecbnique). Utiliza un decante que está equipado con un dispositivo de desintegración en la zona de descarga de manera que se producen altas fuerzas de cizalladura.

Las investigaciones desarrolladas utilizando pretratamientos mecánicos, han puesto de manifiesto su baja eficiencia en cuanto a mejora del proceso de digestión anaerobia se refiere. Comparado con otros métodos, los pretratamientos mecánicos generan menos degradación y no permiten extraer tanto biogás del fango. No obstante, requieren menos potencia que otros tratamientos y no necesitan la adición de ningún químico ni aporte de calor.

\section{Pretratamientos con Cavitación}

La cavitación es sin duda el pretratamiento que proporciona un mayor rendimiento en cuanto a la distupción de la pared celular, consiguiendo degradaciones de hasta el $100 \%$ (Appels et al., 2008). Como se ha explicado más en detalle en apartados anteriores, durante el fenómeno de la cavitación, se produce un colapso en las burbujas de gas que permite alcanzar temperaturas y presiones muy elevadas de forma muy localizada. Esta energía liberada durante el colapso es suficiente para romper las paredes celulares de múltiples tipos de microorganismos.

Cuando la cavitación se genera de forma ultrasónica utilizando transductores ultrasónicos, se han conseguido muy buenos resultados en relación con la disrupción de las paredes celulares cuando se utilizan frecuencias bajas cercanas a los $40 \mathrm{kHz}$, donde se ha visto que la turbidez aumenta y el tamaño de las partículas disminuye. Esto pone de manifiesto que las partículas del fango activo sufren una desintegración considerable (Gewa, 2009) que posteriormente se traduce en un incremento de la producción de biogás durante la digestión secundaria. Por ello, muchos autores que utilizan los ultrasonidos como pretratamiento de cavitación utilizan frecuencias de $20 \mathrm{kHz}$, ya que son las que producen unas condiciones óptimas para maximizar la desintegración de los microorganismos y otros 
contaminantes (Dewil, Baeyens, \& Goutvrind, 2006) (Feng, Lei, Deng, Yu, \& Li, 2009) (Lee \& Han, 2013).

La principal limitación de este tipo de pretratamiento, cuando se genera de forma ultrasónica, es la gran cantidad de energía necesaria para lleva a cabo el proceso, la cual puede incluso llegar a ser superior al consumo energético necesario en los pretratamientos mecánicos. Es por ello que, desde hace más de dos décadas, se ha comenzado a estudiar la cavitación hidrodinámica como una alternativa más eficiente a la cavitación ultrasónica en lo que se refiere a la capacidad para producir una disrupción en las paredes celulares (Save et al., 1994).

\begin{tabular}{|c|c|c|c|c|}
\hline & Desintegración & $\begin{array}{l}\text { Coste } € / \\
\text { tonelada }\end{array}$ & Ventajas & Inconvenientes \\
\hline $\begin{array}{c}\text { Molino de bolas } \\
\text { (Seber) }\end{array}$ & $50 \%$ & ND & Simplicidad & Disipación de la energía \\
\hline $\begin{array}{l}\text { Molino con agitación } \\
\text { de bolas }\end{array}$ & $90 \%$ & $414-2500$ & Alta eficiencia, simplicidad & Coste energético \\
\hline $\begin{array}{l}\text { Homogeneización de } \\
\text { alta presión }\end{array}$ & $85 \%$ & $42-146$ & Alta eficiencia, bajo coste & Complejidad \\
\hline $\begin{array}{l}\text { Cavitación } \\
\text { hidrodinámica }\end{array}$ & $75 \%$ & 3 & $\begin{array}{l}\text { Excelente eficiencia } \\
\text { energética }\end{array}$ & $\begin{array}{c}\text { **Poca información y } \\
\text { experiencia }\end{array}$ \\
\hline Cavitación ultrasónica & $100 \%$ & 8330 & Desintegración total & Coste energético \\
\hline $\begin{array}{l}\text { * Krepro (hidrólisis } \\
\text { térmica) }\end{array}$ & $55 \%$ & 224 & Reciclaje de residuos & $\begin{array}{c}\text { Corrosión y problemas de } \\
\text { olores }\end{array}$ \\
\hline $\begin{array}{c}* \text { Cambi (hidrólisis } \\
\text { térmica) }\end{array}$ & $30 \%$ & 190 & Flexibilidad del proceso & $\begin{array}{l}\text { Baja eficiencia y dependencia } \\
\text { del tipo de fango }\end{array}$ \\
\hline $\begin{array}{l}\text { Tratamientos } \\
\text { termoquímicos }\end{array}$ & $15-60 \%$ & ND & Simplicidad & $\begin{array}{l}\text { Corrosión, problemas de olores } \\
\text { y necesidad de neutralización }\end{array}$ \\
\hline $\begin{array}{l}\text { Tratamientos } \\
\text { biológicos }\end{array}$ & $5-50 \%$ & ND & Simplicidad, bajo coste & $\begin{array}{c}\text { Muy baja eficiencia, problemas } \\
\text { de olores }\end{array}$ \\
\hline *Vertech (Fenton) & $95 \%$ & 450 & $\begin{array}{l}\text { Alta desintegración, no } \\
\text { necesita bombas }\end{array}$ & $\begin{array}{c}\text { Corrosión, bloqueo de los ejes } \\
\text { de las bombas }\end{array}$ \\
\hline $\begin{array}{l}\text { *Loprox (hidrólisis } \\
\text { térmica) }\end{array}$ & $90 \%$ & 800 & Alta desintegración & Corrosivo, coste energético \\
\hline & \multicolumn{4}{|c|}{$\begin{array}{l}\text { ND: información no disponible } \\
(*) \text { Métodos comerciales } \\
\text { Coste económico calculado con } 1 \mathrm{kWh}=0.075 € \\
\text { Costes totales }=\text { Inversión }+ \text { Coste de operación } \approx 2 \text { x costes de operación }\end{array}$} \\
\hline
\end{tabular}

Tabla 3: Resumen de los pretratamientos de fangos activos más utilizados y sus principales características. Table obtenida de (Weemaes Marjoleine \& Verstraete, 1998). 
En la Tabla 3, puede verse un resumen de todos los pretratamientos presentados en este apartado. Se puede observar que los procesos de cavitación ultrasónica son los que mayor capacidad de desintegración tienen, aunque su coste energético es también el más elevado, limitándolo únicamente a aplicaciones de laboratorio e imposibilitando su utilización a escala industrial. Algunos pretratamientos mecánicos como los molinos de bolas o homogeneizadores de alta presión, si que se utilizan de manera común en la industria, pero al igual que los transductores ultrasónicos, requieren un coste energético alto o, como en el caso de los homogeneizadores, son complejos de implementar. El resto de los pretratamientos (químicos, térmicos y comerciales), suelen tener eficiencias bajas. Como excepciones se pueden encontrar los pretratamientos comerciales de Vertech (Fenton) y Loprox (hidrólisis térmica) que tienen buenas eficiencias, pero acarrean costes energéticos medios-altos.

Finalmente se tienen los pretratamientos de cavitación generada de forma hidrodinámica. Este proceso presenta buenos rendimientos dado que se basan en el mismo principio que la cavitación ultrasónica $y$, sin embargo, sus costes energéticos son muy bajos. Debido a esto, los pretratamientos mediante cavitación hidrodinámica son los mejores candidatos a la hora de ser implementados en procesos a escala industrial, donde se deben tratar cantidades elevadas de fangos. El principal inconveniente es que son métodos cuya aplicación como pretratamiento de fangos ha sido poco explorada, y los dispositivos que pueden utilizarse para generar la cavitación hidrodinámica son muy extensos. Esto abre todo un abanico de posibilidades para conseguir obtener un sistema de cavitación que permita el tratamiento de cantidades de fango a escala industrial, manteniendo una buena eficiencia en el proceso y manteniendo los costes energéticos dentro de un rango asequible.

\subsection{Indicadores para determinar el impacto del proyecto}

La lista de indicadores para evaluar los beneficios ambientales de la tecnología STO3RE en comparación con una digestión anaeróbica de lodos convencionales se clasifica en tres grandes bloques:

Valorización agronómica: está compuesto por tres parámetros: contenido de nutrientes (nitrógeno, fósforo, potasio), indicadores higiénicos, y pruebas de germinación de fitotoxicidad con lepidm sativum (intoxicación por metales y compuestos orgánicos) y latuca sativa (intoxicación por sales).

Indicadores de contaminación: están compuesto por disminución de microcontaminantes, eliminación de materia orgánica (concentración de TS, VS y DQO) y balance de $\mathrm{CO}_{2}$ y emisiones de $\mathrm{NO}_{2}$ y $\mathrm{N}_{2} \mathrm{O}$. 
Parámetros de eficiencia energética: está compuesto por producción de biogás (producción de energía con un motor combinado de energía térmica) y consumo de energía de cada unidad del prototipo STO3RE.

La eficiencia obtenida durante los procesos de pretratamiento de los fangos activos se puede expresar utilizando múltiples parámetros. En función de las características del fango utilizado y de la finalidad del pretratamiento, puede ser interesante obtener la eficiencia de una forma u otra.

Por ejemplo, puesto que en muchos estudios el principal objetivo consiste en obtener la mayor cantidad de biogás posible, el parámetro que se utiliza como indicador de la eficiencia es precisamente el incremento de la producción de metano tras el tratamiento expresado directamente en $\mathrm{m}^{3}$ / día (Zieliński et al., 2019) o litros (Martin Petkovšek et al., 2015). En algunos casos se consideran expresiones más complejas para considerar de alguna forma las características del fango que se ha tratado como DQO de la forma $\mathrm{ml} / \mathrm{gDQO}_{\text {añadidos }}$ (I. Lee \& Han, 2013) o la cantidad de sólidos volátiles (SV) presentes en el fango $\mathrm{ml} / \mathrm{gSV}_{\text {añadidos }}$ (Kavitha et al., 2015). En otros estudios donde el pretratamiento está más enfocado a la eliminación de patógenos o eliminación de fármacos, la eficiencia del proceso se expresa en las unidades formadoras de colonias eliminadas por mililitro (UFC/ml) (Cerecedo et al., 2018) o en el porcentaje de eliminación del fármaco en cuestión respectivamente (Zupanc et al., 2014). Estas unidades formadoras de colonias pueden pertenecer a múltiples especies como la E. coli o E. feacalis.

En cualquier caso, en todos los estudios donde la investigación se centra en el pretratamiento de la cavitación llevada a cabo con fango activo se utiliza el llamado grado de desintegración o DD por sus siglas en ingés (disintegration degree), que complementa al resto de indicadores de eficiencia como puede ser la cantidad de metano generado o la energía utilizada en el proceso. Este indicador fue propuesto inicialmente por G. Lehne y A. Müller (Lehne, Müller, \& Schwedes, 2001) el cual propuso en primera instancia un indicador basado en el consumo específico de oxígeno (CO) del fango. Dado que el consumo específico de oxígeno está directamente relacionado con la actividad metabólica de los microorganismos aeróbicos, la diferencia en porcentaje entre el consumo específico antes del pretratamiento $\left(\mathrm{CO}_{\mathrm{i}}\right)$ y después $\left(\mathrm{CO}_{\mathrm{f}}\right)$, permite estimar el grado de desintegración de los microorganismos mediante la siguiente expresión:

$$
D D(\%)=\left[1-\left(C O_{f} / C O_{i}\right)\right] \cdot 100 \%
$$

donde obtener un valor del $100 \%$ significaría que la totalidad de los microorganismos presentes en el fango habrían sido completamente desintegrados. 
El mismo autor propuso un indicador alternativo muy similar basado en la demanda química de oxígeno. En este indicador se describe la liberación de material orgánico originado por la disrupción de la pared celular, el cual se hace patente en un incremento en la demanda química de oxígeno soluble (DQOS). Por tanto, se establece la relación entre la máxima cantidad de DQOS que se podría obtener, esto es la diferencia entre la demanda química de oxígeno total antes del pretratamiento (DQOT) menos la demanda química de oxígeno soluble antes del pretratamiento (DQOSi) y la cantidad de DQOS obtenida tras el pretratamiento $\left(\mathrm{DQOS}_{\mathrm{f}}-\mathrm{DQOS}_{\mathrm{i}}\right)$. La expresión queda de la siguiente manera:

$$
D D(\%)=\frac{D Q O S_{f}-D Q O S_{i}}{D Q O T-D Q O S_{i}} \cdot 100 \%
$$

En este caso, un valor de DD $=100 \%$ se da cuando toda la DQOT se ha convertido en soluble, es decir, que se ha liberado todo el material celular del interior de los microorganismos $y$, por ende, se ha conseguido desintegrar la totalidad de estos.

Este último indicador es sin duda el más utilizado cuando el pretratamiento de cavitación se emplea para fangos activos o aguas residuales. En la presente tesis, este será el parámetro clave que indicará la eficacia del proceso en función de las diferentes condiciones estipuladas en los experimentos en los cuales se utilice el mismo tipo de fango. La fiabilidad de las tendencias mostradas por este indicador cuando se está tratando el mismo tipo de fango son aceptables, pero pierde fiabilidad si se comparan resultados entre tipologías de fangos muy diferentes. Por ello, además de acompañar este indicador con los valores de producción de metano, eliminación de patógenos, o eliminación de fármacos u otros contaminantes (como se ha comentado anteriormente) es necesario también obtener indicadores en los cuales se encuentre presente de alguna forma las características del fango que se está tratando. La forma más simple de realizar esto es indicando la cantidad de sólidos totales presentes en el fango (ST), lo que da una idea de las características reológicas y de la dificultad que puede presentar este tipo de fango a ser cavitado, ya que, a mayor cantidad de sólidos totales, mayor es la dificultad para obtener buenos resultados en el pretratamiento.

Además de un indicador que proporcione información sobre la eficacia del proceso, es necesario conocer de alguna forma la eficiencia, es decir, emplear un indicador que nos relacione cuánta energía se está utilizando para lleva a cabo la degradación durante el proceso de pretratamiento. Si la finalidad del pretratamiento es la eliminación de bacterias, virus, o determinados contaminantes como fármacos, una primera alternativa sería la de utilizar la Ec. 77 que se ha 
presentado en el apartado 2.4.2.3. y que es de gran utilizad cuando se desea observar cómo diferentes procesos de degradación (en este caso de sistemas de cavitación hidrodinámica) afectan a la eliminación de un determinado contaminante (Tao et al., 2016). No obstante, para el caso concreto del pretratamiento de fango, G. Lehne y A. Müller (Lehne et al., 2001) sugirieron una expresión que relaciona la energía empleada en función de la cantidad de sólidos del fango y del volumen tratado:

$$
E E(k J / k g S T)=\frac{P \cdot t}{V \cdot S T}
$$

Donde $\mathrm{P}$ es la potencia consumida por el sistema, $\mathrm{t}$ el tiempo que dura el tratamiento, V, el volumen de fango tratado y ST la cantidad de sólidos totales presentes en el fango de. De la fórmula se obtiene la energía específica (EE) en $\mathrm{kJ} / \mathrm{kg} \cdot \mathrm{ST}$, que permite hacerse una primera idea de la cantidad de energía necesaria en función de un parámetro físico del fango como son los sólidos totales. No obstante, en la fórmula no se relaciona ni la cantidad de contaminante degradado (para ello necesitaríamos aplicar la Ec. 77) ni tampoco el grado de desintegración obtenido. Por ello, algunos autores (I. Lee \& Han, 2013) (Tomov et al., 2016a) acompañan esta ecuación con otros indicadores como el DD para comprender completamente el efecto del pretratamiento que se esté aplicando. Para ello, se utiliza una expresión propuesta por M. Kuglarz (Kuglarz, Karakashev, \& Angelidaki, 2013a) la cual proporciona la energía específica de solubilización de fango (EE $\left.E_{\mathrm{DQOS}}\right)$, que sí tiene en cuenta el grado de desintegración de la siguiente manera:

$$
\mathrm{EE}_{\mathrm{DQOS}}\left(k J / g D Q O S_{\text {liberada }}\right)=\frac{P \cdot t}{V \cdot\left(D_{Q O S S_{f}}-D_{Q O S}\right)}
$$

Como puede observarse, esta expresión sí que considera la cantidad de DQOS liberada, es decir, la solubilización del fango y, por tanto, la degradación obtenida. 


\section{Capítulo 3}

\section{Diseño conceptual del sistema de cavitación}

Aunque en la actualidad existen ya dispositivos cuyo objetivo no es otro que el de producir cavitación, estos han sido diseñados prácticamente en su totalidad para tratar agua libre de cualquier tipo de partícula o residuo sólido. Sin embargo, debido a la aplicación requerida en la presente tesis, es necesario diseñar un dispositivo de cavitación robusto que garantice un funcionamiento continuo, libre de atascos y fallos mecánicos derivados del tratamiento de un fluido tan complejo y exigente como son los purines y fangos procedentes de las EDAR.

En este capítulo se han analizado en detalle las principales características requeridas por el sistema de cavitación, con el objetivo de seleccionar el mejor sistema para llevar a cabo el desarrollo de la planta piloto bajo las condiciones exigidas. Así pues, ha sido necesario un primer triaje de entre todos los dispositivos actualmente conocidos y recogidos en el apartado 2.3, para elegir los mejores candidatos sobre los que desarrollar un nuevo diseño mejorado y optimizado según las necesidades de este estudio en concreto.

\subsection{Introducción}

Dado que la presente tesis doctoral se encuentra enmarcada dentro del proyecto LIFE Sto3re, es crítico obtener un sistema de cavitación que cumpla con una serie de requisitos que hagan posible el cumplimiento de los objetivos establecidos en dicho proyecto. Para ello, debe tenerse en cuenta que el sistema de cavitación será integrado dentro de una planta piloto a escala semi-industrial, y, por tanto, los resultados obtenidos durante la fase de estudios experimentales a escala de laboratorio deben ser extrapolables, en la medida de lo posible, a escala industrial. Este proceso de escalado presenta un importante reto ya que el diseño debe ser 
suficientemente robusto como para funcionar con una sustancia tan compleja como son los purines y fangos de EDAR, pero también presentar un consumo energético suficientemente reducido como para que el escalado sea viable garantizando unos resultados dentro de unos límites aceptables.

\subsubsection{Objetivos}

El objetivo principal del presente capítulo es establecer un diseño conceptual de un sistema de cavitación que pueda ser testado experimentalmente en laboratorio para, posteriormente, implementarse en la planta piloto donde se llevará a cabo el proceso de pretratamiento de fango enmarcado dentro del proyecto LIFE Sto3re. Es importante mencionar que, dado que este desarrollo es completamente innovador y sin precedentes, deberá explorarse el grado de cumplimiento de los requisitos una vez caracterizado el sistema y proponer, si fuese necesario, cambios en el diseño o en el proceso que no necesariamente lleguen a hacerse efectivos durante el desarrollo de esta tesis. De esta manera, se deja la puerta abierta a investigaciones futuras donde se mejore el diseño o se estudie su funcionamiento en otras aplicaciones y procesos.

Por tanto, el principal punto que se persigue durante el desarrollo de este capítulo es:

- Establecer cuál va a ser el mecanismo y dispositivo encargado de producir la cavitación analizando las ventajas e inconvenientes de cada sistema atendiendo a criterios de consumo energético, eficiencia, características del fluido a tratar y condiciones de funcionamiento.

El cumplimiento de este objetivo permitirá desarrollar un diseño basado en las necesidades específicas del sistema que podrá ser fabricado y ser validado en las posteriores simulaciones CFD y estudios experimentales, llevados a cabo tanto a escala de laboratorio como industrial (en la planta piloto).

\subsection{Proceso de selección del sistema de cavitación}

Tal y como se ha descrito en el apartado 2.4 , en los últimos años el fenómeno de la cavitación se ha utilizado en múltiples aplicaciones desde procesos industriales como producción de emulsiones, sistemas de calentamiento o síntesis de biocombustibles, hasta aplicaciones relacionadas a la limpieza, desinfección incluso tratamientos de belleza. Como se ha podido comprobar, para cada una de las aplicaciones es necesario utilizar un sistema de cavitación que se adapte a los requerimientos del proceso. Por tanto, habrá algunos procesos en los cuales será imposible utilizar cierto tipo de cavitadores, como por ejemplo los ultrasónicos, mientras que en otras aplicaciones esta será la única opción. 
Por tanto, antes de llevar a cabo el desarrollo del sistema de cavitación, es necesario determinar cuáles son los requerimientos principales y las condiciones de funcionamiento a las que va a estar sometido dicho sistema. A continuación, se presentan las principales características que se requieren en el sistema de cavitación.

\subsubsection{Características requeridas en el cavitador}

El primer paso en el proceso de diseño del sistema de cavitación es determinar la aplicación para la que va a ser empleado que, en este caso, se corresponde con un proceso de pretratamiento e higienización de fangos activos procedentes de las EDARs así como de purines procedentes de la actividad en granjas porcinas. Además de ello, es muy importante considerar el contexto dentro del cual se va a enmarcar su actividad, ya que este dispositivo deberá ser testeado no solo en la planta piloto sino también a escala de laboratorio en las instalaciones de un centro de investigación y, por tanto, serán necesarios ciertos requisitos que faciliten el funcionamiento y operatividad del cavitador no solo en la planta piloto sino también durante su proceso de desarrollo en el laboratorio.

Atendiendo a esto, se presentan a continuación las principales características que debe presentar el sistema de cavitación a diseñar:

Robustez: El sistema va a tener que procesar una sustancia muy compleja como es la mezcla de purines y fangos de EDAR. Especialmente problemáticos resultan los purines porcinos dado que en ellos se pueden encontrar, no solo las propias excreciones de los animales sino gran variedad de sólidos de diferentes tamaños que van desde los propios pelos de los animales hasta chapas metálicas o plásticas identificativas que se pierden en las zonas de cría. Debe considerarse especialmente la dureza de las cerdas de estos animales que pueden llegar a colapsar en cuestión de segundos tuberías u orificios de diámetros considerables.

Escalabilidad: Aunque la finalidad última del sistema de cavitación sea su instalación en la planta piloto a escala industrial, es necesario llevar a cabo toda una serie de experimentos a escala de laboratorio durante el proceso de diseño. Por ello, aunque el dispositivo de cavitación utilizado durante la fase de ensayos de laboratorio sea el mismo que finalmente acabe instalado en la planta piloto, requiere de una infraestructura (depósitos, tuberías, bombas...) que le permitan trabajar tanto a escala de laboratorio como industrial. Esto no solo facilitará el proceso de diseño durante esta investigación, sino que también permitirá realizar rediseños del sistema en estudios futuros, pudiendo realizar ensayos a pequeña o gran escala según convenga y de manera rápida y sencilla.

Versatilidad: Se refiere a la facilidad con la que puede ser modificado el dispositivo para adaptarse a las diferentes situaciones planteadas durante el desarrollo del estudio. Esta característica es extremadamente necesaria ya que, 
durante el proceso de diseño, será necesario plantear diferentes geometrías y/o condiciones de funcionamiento para las cuales se requerirá un dispositivo cuyas partes sean fácilmente sustituibles por otras nuevas diferentes y su infraestructura se adapte en consecuencia a estos cambios. Además, esta característica permitirá que el sistema pueda ser utilizado para diferentes aplicaciones y no solo para la de esta investigación en particular. Esto deja nuevamente la puerta abierta a estudios futuros donde el fenómeno de la cavitación sea requerido en otros procesos y que puedan ser abordados implementando variaciones en este mismo dispositivo.

Los criterios de diseño se llevarán a cabo con el objetivo de cumplir las características anteriormente mencionadas. Con ello se espera desarrollar un sistema de cavitación que no sea útil únicamente para la actividad de la presente investigación, sino que pueda ser estudiado a escala de laboratorio y escala industrial en posibles aplicaciones futuras, maximizando las posibilidades de éxito en este $\mathrm{u}$ otros procesos.

\subsubsection{Elección del sistema de cavitación}

Una vez conocido el proceso para el cuál va a ser utilizado el sistema de cavitación, así como las principales características en él requeridas, se debe realizar un proceso de selección en el que se puedan ir descartando dispositivos y formas de funcionamiento que no cumplan los requisitos necesarios. De esta manera, de entre la amplísima gama inicial de posibilidades, se conseguirá reducir drásticamente los sistemas susceptibles a ser estudiados y desarrollados en una siguiente etapa.

\subsubsection{Cavitación ultrasónica o hidrocavitación}

La primera decisión importante en el proceso de selección requiere determinar si la cavitación se producirá mediante un dispositivo de cavitación ultrasónica o de hidrocavitación. Diversos estudios con dispositivos de cavitación ultrasónica (Gewa, 2009) (Dewil et al., 2006) (Bandelin, Lippert, Drewes, \& Koch, 2018) у cavitación hidrodinámica (I. Lee \& Han, 2013) (Martin Petkovšek et al., 2015) (Lehne et al., 2001) demuestran que ambas aplicaciones son válidas para realizar procesos de tratamiento en fangos de EDAR proporcionando buenos resultados en cuanto a la degradación de fango y posterior incremento de la cantidad de biogás producido.

La cavitación ultrasónica ha demostrado ser especialmente efectiva en numerosas aplicaciones de limpieza, desinfección, y también en tratamiento de fangos. Su principal ventaja reside en que se utilizan dispositivos comerciales tecnológicamente muy desarrollados. Con estos sistemas se tiene un gran control sobre el fenómeno de la cavitación, ya que modificando únicamente dos parámetros como son la amplitud y la frecuencia de las oscilaciones, se consigue producir la cavitación en la cantidad e intensidad deseada. Además, a escala de 
laboratorio se han registrado rendimientos superiores al $90 \%$ en múltiples estudios y aplicaciones, lo que la convierte en un sistema robusto y versátil. Sin embargo, aquellas situaciones donde por ejemplo, se estudia la eliminación de ciertos contaminantes, si bien es cierto que proporciona mayores índices de degradación que la cavitación hidrodinámica, el ratio entre degradación y energía consumida es muy elevado (Jyoti \& Pandit, 2001) (Jyoti \& Pandit, 2003a) (Jyoti \& Pandit, 2003b). Por tanto, la cavitación ultrasónica presenta un grave inconveniente en cuanto a escalabilidad del proceso y aunque los resultados obtenidos a escala de laboratorio son satisfactorios, su aplicación en entornos industriales es inviable debido al reducido volumen de tratamiento y a la gran cantidad de energía requerida. Esto entra en grave conflicto con los requisitos buscados para el dispositivo de esta investigación (ver Tabla 4) y, por tanto, los ultrasonidos quedan totalmente descartados como fuente de producción de cavitación

\begin{tabular}{c|c|c|c|} 
& Robustez & Escalabilidad & Versatilidad \\
\hline Cavitación Ultrasónica & 0 & 0 & 0 \\
$\begin{array}{c}\text { Cavitación } \\
\text { Hidrodinámica }\end{array}$ & 0 & 0 & 0
\end{tabular}

Tabla 4: Cumplimiento de requisitos para la cavitación hidrodinámica y la cavitación ultrasónica. Verde: cumple el requisito, rojo: no cumple el requisito.

Descartada la cavitación ultrasónica, únicamente cabe la posibilidad de desarrollar un sistema de hidrocavitación. Aunque estos dispositivos tienen una mayor complejidad geométrica y son mucho más difíciles de configurar para que produzcan la cavitación en la "cantidad y calidad" deseadas, requieren mucha menos energía manteniendo unos rendimientos adecuados. Esto hace posible realizar un proceso de escalado para tratar grandes volúmenes tal y como se muestra en la comparativa de la Tabla 1 (Tao et al., 2016) que es una de las principales características necesarias en el dispositivo.

\subsubsection{Dispositivos con y sin elementos móviles}

Una vez descartados los ultrasonidos como fuente de generación de cavitación, es necesario determinar qué sistema de hidrocavitación cumple con los requisitos exigidos en el estudio. Para ello, tal y como se ha descrito más detalladamente en el apartado 2.3.2 existen dos grandes familias de cavitadores hidrodinámicos, los que presentan elementos móviles y los que son dispositivos de una única pieza donde la cavitación se produce debido a paso del flujo a través de ciertas constricciones en la geometría y no por el movimiento relativo entre diferentes cuerpos (también llamados dispositivos estructurales). 


\section{Dispositivos cavitadores sin elementos móviles}

Generalmente, son los más simples y fáciles de implementar y por ello, han sido testados en numerosas aplicaciones para aguas residuales. Así pues, se tiene constancia de la utilización de los Venturi y platos con orificios en el tratamiento de fango para incrementar la cantidad de metano obtenido en la digestión (Machnicka et al., 2009) (I. Lee \& Han, 2013), los Swirling Jet Reactors (SJR) en procesos para aumentar la biodegradabilidad del lodo (Mancuso et al., 2017) y los Liquid Whistle Reactors (LWR) que aunque no han sido directamente utilizados en procesos de aguas residuales, si han dado buenos resultados en procesos de desinfección de agua con ozono (Chand et al., 2007) o eliminación de contaminantes en combinación con proceso Fenton (Chakinala et al., 2008) con lo que a priori, podrían también ser candidatos en procesos llevados a cabo con fangos de EDAR.

Sin embargo, aunque estos sistemas han sido utilizados en aplicaciones donde se ha visto envuelto fango procedente de la EDAR, casi en la totalidad de las veces se ha utilizado licor mezcla cuyo contenido en sólidos es relativamente pequeño (por debajo del $1 \%$ y que ha sido previamente pretratado para dejar pasar partículas muy pequeñas que, en el peor de los casos, forman flóculos que pueden ser fácilmente desintegrables. Quizás la única excepción se encuentre en el dispositivo SJR donde se han conseguido pretratar fangos con una concentración de sólidos de hasta el $5 \%$ (Mancuso et al., 2017). El hecho de que no se utilicen grandes concentraciones de sólidos en estos dispositivos, se debe a que la cavitación se produce cuando el fluido pasa por unos estrechamientos que, en algunos casos, como los platos con orificios o el Venturi, pueden llegar a ser de tan solo unos pocos milímetros. La existencia de una gran cantidad de sólidos en suspensión o de partículas de escala igual o superior a milimétrica (como ocurre en el caso de utilizar purines de procedencia porcina), podrían producirse atascos y grandes caídas de presión en los dispositivos que llevarían a su destrucción total o parcial. En el caso del SJR esto no ocurre dado que la cavitación se produce en el interior de un torbellino producido artificialmente. No obstante, el principal inconveniente de este dispositivo es que posee un diseño muy complejo y costoso de construir. Además, una vez realizado un primer diseño resulta muy dificultoso realizar cambios sobre el mismo lo cual no lo convierte en una buena opción para realizar pruebas y cambios en su geometría.

\section{Dispositivos cavitadores con elementos móviles}

Son dispositivos que consisten en un estator y un rotor que da vueltas de manera que en puntos concretos de su geometría se producen caídas de presión suficientemente grandes como para cavitar. La totalidad de estos dispositivos están formados por un sistema rotativo donde un motor eléctrico mueve una de las 
partes con respecto a la otra. Los elementos rotativos pueden ser básicamente de dos tipos, tambores o discos. Actualmente, no hay constancia de estudios en los que los tambores hayan sido directamente utilizados en procesos de tratamiento de fango para aumentar el biogás, pero sí han sido utilizados por un en aguas residuales industriales (M. Badve et al., 2013) y también en el tratamiento de materia vegetal para incrementar la producción de biogás (Patil et al., 2016). Por otro los dispositivos que utilizan discos, pueden estar formados por un rotor y un estator (Cerecedo et al., 2018)(Kavitha et al., 2015) o por dos rotores (Zupanc et al., 2014). En este caso, sí que existe constancia de un mayor número de estudios llevados a cabo en aguas residuales, en condiciones en las que el fango contenido de sólidos de entre el $1 \%$ (Martin Petkovšek et al., 2015) y el $1.5 \%$ (Kavitha et al., 2015).

Por tanto, en cuanto a los dispositivos con elementos móviles rotativos de discos y de tambor, estos últimos presentan un gran inconveniente mientras que los segundos tienen una gran cualidad. El inconveniente de los tambores rotativos es que están formados por centenares de orificios de pequeño diámetro (entorno a $2 \mathrm{~mm}$ ) que, como se ha comentado anteriormente, pueden colapsar y obstruirse debido a la gran cantidad de sólidos en suspensión presentes en el fango a tratar. Sin embargo, la gran cualidad de los discos es que en ellos se producen grandes esfuerzos tangenciales que pueden ayudar, precisamente, a destruir y disolver los sólidos más voluminosos evitando atascos y favoreciendo la cavitación.

\begin{tabular}{c|c|c|c|} 
& Robustez & Escalabilidad & Versatilidad \\
\hline $\begin{array}{c}\text { Dispositivos } \\
\text { estructurales }\end{array}$ & $\bigcirc$ & $\bigcirc$ & $\bigcirc$ \\
$\begin{array}{c}\text { Dispositivos con } \\
\text { elementos móviles }\end{array}$ & $\bigcirc$ & $\bigcirc$ & $\bigcirc$
\end{tabular}

Tabla 5: Cumplimiento de requisitos para los dispositivos de cavitación estructurales y con elementos móviles Verde: cumple el requisito. Amarillo: en algúnos casos se puede conseguir cumplir el requisito.

En resumen, de entre las dos grandes familias de partidas (con y sin elementos móviles) se hace evidente que, para garantizar la robustez y el correcto funcionamiento del sistema, es necesario evitar los estrechamientos y pequeños orificios que están presentes en prácticamente la totalidad de dispositivos sin elementos móviles. La única excepción dentro de esta familia sería el reactor SJR pero debido a su compleja geometría y dificultad para realizar cambios de manera rápida, también debe ser descartado por su evidente problema de versatilidad. Así pues, únicamente queda la posibilidad de desarrollar un dispositivo de cavitación con elementos móviles tal y como se muestra en la Tabla $\mathbf{5}$. 
Sin embargo, se ha podido observar cómo dentro de este grupo, los tambores rotativos quedarían descartados por presentar pequeños orificios que, al igual que los dispositivos estructurales, pueden ser obstruidos debido al fango utilizado. Por tanto, dentro de la familia de los dispositivos con elementos móviles únicamente pueden ser utilizados los sistemas de discos rotativos donde se generen grandes fuerzas de cizalladura que permitan eliminar los sólidos presentes en el lodo, y cumplir así con las 3 condiciones requeridas en el estudio (Tabla 5). Además, los elementos móviles de estos dispositivos (discos) son relativamente fáciles de intercambiar y rediseñar, lo que los dota de una gran versatilidad por su facilidad para realizar cambios en sus elementos.

\subsubsection{Dispositivo elegido para su desarrollo}

En el anterior apartado, se ha concluido que los únicos sistemas de cavitación que pueden ser utilizados para el fin del proyecto son los dispositivos móviles que están formados por discos rotativos, los cuales pueden tener una configuración tanto de rotor-estator como de rotor-rotor. Dentro de esta tipología de cavitadores, los más destacados por su minucioso proceso de desarrollo y por los buenos resultados obtenidos en diferentes aplicaciones, son el sistema de cavitación de configuración rotor-estator de Luis M. Cerecedo et al. (Cerecedo et al., 2018) y el de configuración rotor-rotor de Martin Petkovšek (Martin Petkovšek et al., 2013).

El primero de ellos se muestra en la imagen de la Figura 29, y consiste en un estator con dientes redondos en cuyo interior gira un rotor con unas dimensiones que oscilan entre los 55 y los $77.5 \mathrm{~mm}$. Tal y como puede verse en la imagen central de la Figura 29, el tamaño, número y forma de los dientes del rotor y del estator, así como sus diámetros, han sido estudiados con tal de optimizar los resultados obtenidos en el proceso. Además, también se han explorado diferentes regímenes de rotación que van desde los 0 hasta las 3000 rpm. La cavitación se genera cuando el fluido arrastrado por el rotor es inducido a través del pequeño hueco que queda entre los dientes, generando un efecto similar al Venturi donde se produce un aumento de la velocidad y una disminución drástica de la presión. 

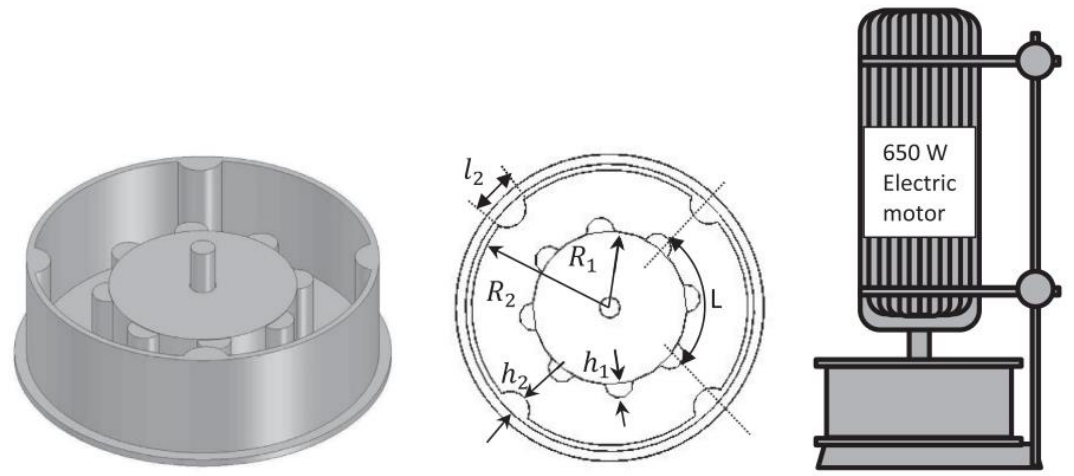

Figura 29: Sistema de hidrocaviación de configuración rotor-estator utilizado por Luis M. Cerecedo et al.

El segundo dispositivo, de M. Petkovšek et al., tiene una configuración rotorrotor (Figura 30). En este caso, se dispone de dos discos con dientes enfrentados uno al otro y acoplados a dos motores eléctricos independientes pudiendo girar cada uno de ellos a velocidades de hasta $2800 \mathrm{rpm}$ en direcciones opuestas. Los discos tienen 11 y 12 dientes cada uno para evitar entrar en resonancia y sus diámetros son de aproximadamente $90 \mathrm{~mm}$.

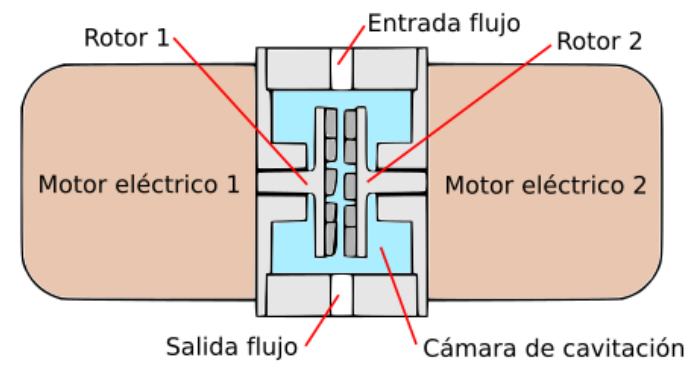

Figura 30: Sistema de hidrocaviación de configuración rotor-rotor utilizado por M. Petkovšek et al.

El diseño ha sido optimizado utilizando diferentes tipos de dientes, llegando a la conclusión de que la mejor geometría consiste en utilizar un rotor con 11 dientes planos de $7 \mathrm{~mm}$ de profundidad y $10 \mathrm{~mm}$ de longitud y el otro rotor con 12 dientes que cuya superficie no sea plana, sino que forme un pequeño ángulo de $8^{\circ}$. En este dispositivo, la cavitación se produce debido a tres efectos diferentes tal y como se muestra en la Figura 31. 

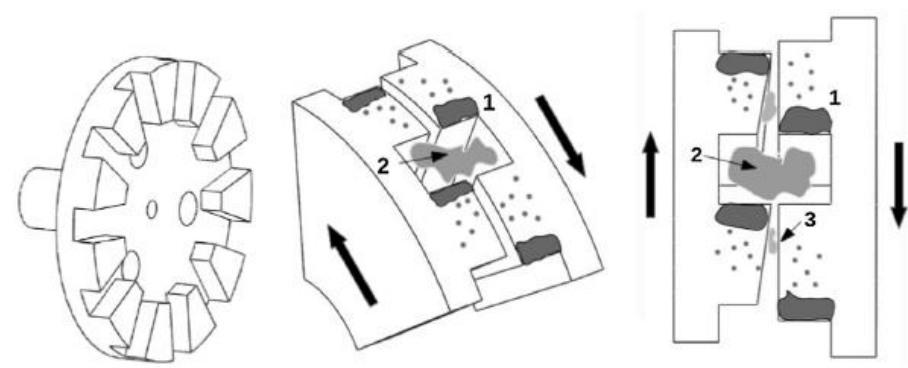

Figura 31: Discos utilizado en el dispositivo de M. Petkovšek et al. y las diferentes zonas de cavitación observadas.

La visualización del fenómeno de la cavitación fue posible gracias a la utilización de una carcasa transparente y una cámara rápida que permitió observar la formación de la cavitación en 3 zonas diferenciadas:

1. En el borde exterior de los dientes. En este punto se forma una nube de cavitación adherida en la arista de la cual se van desprendiendo microburbujas de aire. Se produce debido a la gran velocidad a la que se desplaza el borde del diente, la cual alcanza los $26 \mathrm{~m} / \mathrm{s}$.

2. En la zona donde se alinean las ranuras o huecos. En esta zona se da un efecto de descompresión muy rápido debido a que el fluido es comprimido entre los dientes y posteriormente expandido en los huecos. Esto produce un descenso repentino de la presión que permite cavitar.

3. En la zona donde se alinean los dientes. Este efecto únicamente es visible en el caso de utilizar dientes inclinados. Cuando el diente inclinado pasa cerca de la superficie plana del otro diente, se produce un efecto similar al que se origina en los Venturi, lo cual permite una bajada de presión muy puntual donde el fluido cavita.

Ambos dispositivos de cavitación han sido probados y han dado muy buenos resultados en la eliminación de bacterias y otros patógenos presentes en el agua residual. Además, el caso del cavitador de M. Petkovšek et al. ha sido también testado exitosamente en la eliminación de fármacos (Zupanc et al., 2014) y, más importante si cabe, en el tratamiento de fangos de EDAR para incrementar la producción de metano en etapas posteriores (Martin Petkovšek et al., 2015). En este último caso, aunque se mantuvo la geometría de los discos utilizados, se cambió la configuración rotor-rotor a una configuración rotor-estator.

Llegados a este punto, y tras estudiar todas las opciones disponibles, se ha llegado a la conclusión que, actualmente, el proceso de tratamiento de fango de EDAR con purines de cerdo para maximizar la cantidad de biogás generado en etapas posteriores, únicamente podría llevarse a cabo con garantías mediante los 
dispositivos desarrollados por M. Petkovšek y Luis M. Cerecedo. Sin embargo, en el momento en el que se llevó a cabo esta fase de diseño (2016) no se disponía todavía de la información proporcionada por Luis M. Cerezedo en su artículo de 2018 y, por tanto, el diseño del presente sistema de cavitación está basado en el dispositivo de M. Petkovšek prácticamente en su totalidad. No obstante, debido a la gran relevancia del trabajo de Luis $\mathrm{M}$. Cerezedo y la gran similitud con las actividades desarrolladas en la presente tesis, se ha considerado importante incluir este dispositivo ya que, como se verá en los siguientes apartados, guarda muchas similitudes con el cavitador hidrodinámico que finalmente acaba siendo desarrollado en este estudio.

\subsection{Proceso de diseño del sistema de cavitación}

En el apartado anterior, se ha descrito de forma muy detallada el razonamiento seguido para descartar todos los sistemas de cavitación que hay disponibles actualmente, pero no cumplen con los requisitos necesarios en el proceso que se desea desarrollar en el presente proyecto. De esta manera, las opciones disponibles para llevar a cabo el desarrollo del nuevo sistema de cavitación se reducen al máximo, y se puede establecer de forma clara un punto de partida para comenzar a realizar el diseño del nuevo cavitador. Por otro lado, se ha concluido que el único dispositivo que actualmente presentaría garantías de éxito en el proceso que quiere llevarse a cabo en esta investigación, sería el de Martin Petkovšek (Martin Petkovšek et al., 2013). Por tanto, el éxito en el diseño del nuevo sistema de cavitación pasa por analizar los diseños y mecanismos presentes en el de M. Petkovšek y de esta manera, detectar sus principales ventajas e inconvenientes con el objetivo de obtener un nuevo sistema de cavitación mejorado que permita obtener mejores resultados y que, en definitiva, sea un avance en el desarrollo de este tipo de cavitadores.

\subsubsection{Análisis del sistema de cavitación de M. Petkovšek}

El sistema de M. Petkovšek surge en 2013 gracias a las investigaciones de un grupo presente en la facultad de ingeniería mecánica de la universidad de Ljubljana (Eslovenia), de mano de autores con amplia experiencia en el campo de la cavitación como Matevz Dular. Anteriormente al sistema rotor-rotor que implementaron en 2013, ya habían conseguido desarrollar y testar con éxito el efecto de la hidrocavitación en otros sistemas como el "reactor de hidrocavitación continua" (Širok et al., 2012) y habían estudiado en detalle los efectos termodinámicos del crecimiento y colapso de la cavitación (Dular \& CoutierDelgosha, 2013) analizándolos y visualizándolos gracias a la tecnología de visualización infrarroja de alta velocidad (Martin Petkovšek \& Dular, 2013). A día de hoy, el grupo continua activo publicando investigaciones en el campo de la cavitación, incluso han presentado recientemente un nuevo sistema de cavitación 
basado también en una configuración rotor-estator (Kosel, Šinkovec, \& Dular, 2019).

A continuación, se describen de forma detallada las principales ventajas e inconvenientes del sistema de cavitación desarrollado por M. Petkovšek en 2013.

\subsubsection{Ventajas del sistema}

El sistema de M. Petkovšek presenta una serie de ventajas que no han sido encontradas, en su conjunto, en ningún otro sistema de cavitación del momento. Estos puntos fuertes son:

- La cavitación se produce en múltiples puntos. A diferencia de otros sistemas, la cavitación se genera de forma simultánea en varios puntos del cavitador tal y como se ha explicado anteriormente en la Figura 31. Esto permite maximizar el número de burbujas producidas y, por ende, el efecto destructor que producen al colapsar.

- Su efectividad ha sido probada en aplicaciones con fangos. Actualmente es el único dispositivo de esta índole (rotativo) que ha mostrado buenos resultados en una aplicación idéntica a la requerida en esta investigación: desintegración de fangos para aumentar la producción de metano en etapas posteriores (Martin Petkovšek et al., 2015). Si bien es cierto que no se ha probado en fangos con una cantidad tan elevada de sólidos como los requeridos en el sistema de esta investigación (5\%), es de lejos el que ha tratado con éxito concentraciones iguales o superiores al $1 \%$ de concentración.

- La robustez del sistema es muy grande. El sistema se basa en la llamada shear cavitation la cual se genera cuando se producen grandes esfuerzos tangenciales debidos al paso muy cercano de unos dientes con otros. Este efecto es muy beneficios para destruir cualquier partícula sólida presente en el fango y evitar de esta forma atascos que puedan llevar al mal funcionamiento del sistema o incluso a su destrucción.

- Es un sistema muy versátil utilizado en otras aplicaciones: El sistema ha sido probado con éxito en la desinfección de agua residual donde ha sido capaz de reducir el contenido de diferentes fármacos como ibuprofeno, naproxeno, ketoprofeno, diclofenaco, carbamazepina y ácido clofíbrico entre otros, añadiendo pequeñas dosis de peróxido de hidrógeno.

\subsubsection{Inconvenientes del sistema}

Aunque el sistema cumple con características de robustez, escalabilidad y versatilidad, establecidas como requisitos indispensables a cumplir en el nuevo sistema de cavitación, es posible desarrollar algunas características presentes en el 
cavitador de M. Petkovšek, de manera que puedan mejorarse algunas de las debilidades encontradas en el diseño como son:

- Formación de caminos preferenciales: Debido a la configuración del dispositivo, es posible que se formen caminos preferenciales en los que no todo el flujo que entra en el interior de la cámara pueda llegar a cavitar (Figura 32). El flujo puede desplazarse hacia la parte trasera de los rotores sin necesidad de pasar a través de los dientes lo que puede disminuir el rendimiento del cavitador.

- Necesidad de utilizar dos motores: La configuración rotor-rotor requiere de la utilización de dos motores eléctricos que giren a la misma velocidad, pero en direcciones opuestas. De cara a obtener un mejor rendimiento, es recomendable utilizar un único motor, aunque esto suponga que gire al doble de revoluciones para compensar las velocidades relativas que se suceden entre los dientes de los rotores. Para el caso de la aplicación en fangos de EDAR, se estudió el cambio de configuración rotor-estator manteniendo velocidades relativamente bajas $(2850 \mathrm{rpm})$ con resultados satisfactorios (Martin Petkovšek et al., 2015)

- La fabricación de los discos es laboriosa: El diseño de los discos es complejo y requiere de operaciones de mecanizado que van más allá de un simple corte o ranurado. Por tanto, aunque resulte fácil realizar el cambio de los discos, probar con múltiples diseños puede acarrear gastos económicos importantes.

- Desaprovechamiento de parte de los discos: La cavitación se produce en la zona donde la velocidad de los dientes es más elevada, es decir, en los extremos del disco. En el resto del disco las velocidades lineales no son suficientemente elevadas y por tanto no se produce cavitación con lo que se está malgastando una gran superficie de trabajo.

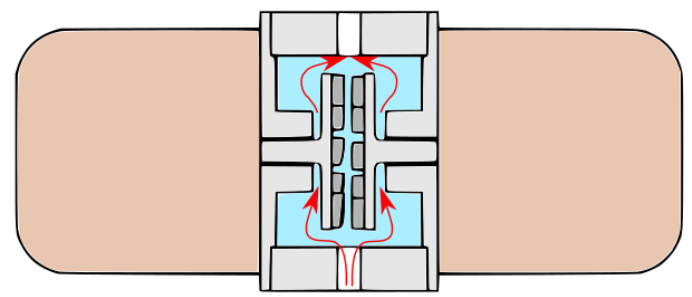

Figura 32: Posible formación de caminos preferenciales en el cavitador de M. Petkovšek.

\subsubsection{Parámetros de diseño del nuevo cavitador}

Una vez conocidas las principales ventajas e inconvenientes del dispositivo de M. Petkovšek, se ha podido plantear un nuevo diseño en el que se realcen los 
puntos fuertes y se minimicen o eliminen completamente los puntos débiles. A continuación, se describe punto por punto todos los parámetros de diseño del nuevo sistema de cavitación y el efecto que tienen sobre las diferentes características que quieren mejorarse y que han sido numeradas en los apartados 3.3.1.1 y 3.3.1.2.

\subsubsection{Diseño del rotor}

Uno de los cambios más significativos en el diseño del nuevo cavitador es que se va a utilizar un único motor para hacerlo funcionar $\mathrm{y}$, de esta forma, resolver los inconvenientes derivados de utilizar dos motores tal y como se ha comentado en el apartado 3.3.1.2.

Al utilizar un único motor, se pasa de la configuración rotor-rotor de $\mathrm{M}$. Petkovšek, a una configuración rotor-estator. El mayor efecto de este cambio se produce en la velocidad relativa que existe entre los dientes de los rotores, o en este caso, entre los dientes del rotor y del estator. Es decir, en la configuración rotor-rotor los motores giran a velocidades opuestas y de valor $2800 \mathrm{rpm}$ y dado que el diámetro de los discos es de $90 \mathrm{~mm}$ y cada uno de los discos gira en direcciones opuestas (Martin Petkovšek et al., 2013), la velocidad tangencial (entre los dientes) resulta de:

$$
v=\omega \cdot R \cdot 2=\frac{2800 \cdot 2 \pi}{60} \cdot \frac{0.09}{2} \cdot 2=26.4 \mathrm{~m} / \mathrm{s}
$$

Mantener exactamente la misma velocidad tangencial entre los dientes resulta muy importante para conseguir un efecto de cavitación semejante. Este parámetro ha sido estudiado en otros dispositivos de cavitación rotativos donde se ha puesto de manifiesto su importancia para conseguir los efectos deseados (Cerecedo et al., 2018) Para conseguir dicha velocidad en los dientes de un solo rotor, existen dos posibilidades:

- Aumentar el radio del disco al doble, es decir $180 \mathrm{~mm}$.

- Aumentar la velocidad del rotor al doble, es decir a 5600 rpm.

La primera de las opciones se ha descartado dado que al aumentar el diámetro de los discos se incrementa el riesgo de que aparezcan vibraciones en el rotor y dado que el rotor y el estator giran muy próximo entre sí, estas vibraciones podrían ser peligrosas para la integridad del dispositivo. 


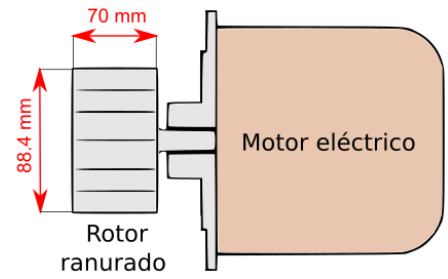

(a)

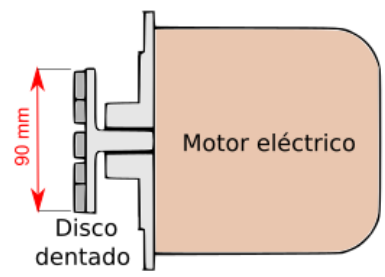

(b)

Figura 33: Diferencias entre el rotor del sistema actual (a) y el de M. Petkovšek (b).

Por tanto, se ha optado por utilizar un diámetro del rotor prácticamente idéntico $(88.4 \mathrm{~mm})$ y aumentar el número de revoluciones al doble. Esto es mecánicamente posible dado que existen motores y rodamientos preparados para soportar velocidades angulares de estas magnitudes. En la Figura 33 se muestra un croquis con las principales diferencias entre el dispositivo actual (Figura 33a) y el de M. Petkovšek (Figura 33b). El motivo de utilizar un diámetro ligeramente inferior a $90 \mathrm{~mm}$, es el de habilitar el hueco entre los dientes del rotor y el del estator. De este parámetro se hablará más en detalle en apartados posteriores.

Tal y como puede verse en la Figura 34 , el rotor planteado para el nuevo diseño no es un disco, sino que es un cilindro de acero inoxidable ranurado unido a un eje muy rígido para soportar las vibraciones sin problemas. Se puede observar que los dientes son totalmente planos y siguen la curvatura del rotor.
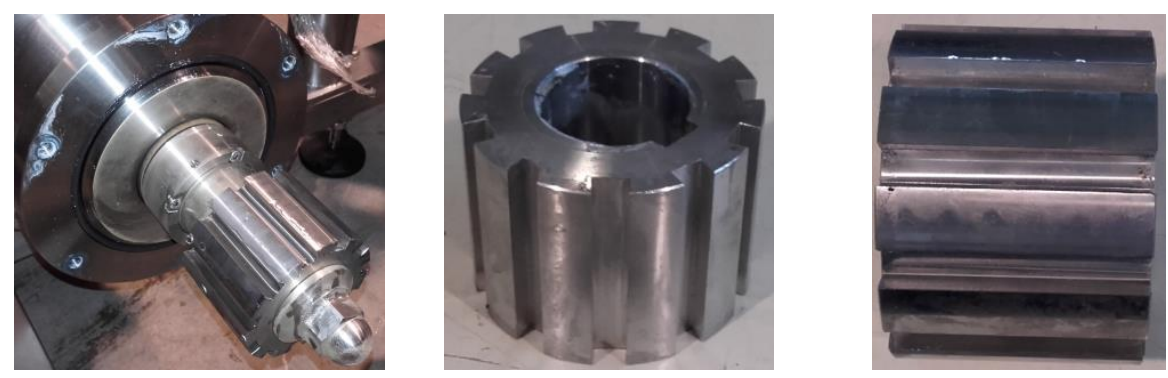

Figura 34: Detalle del rotor real en el dispositivo de cavitación.

En el diseño original de M. Petkovšek (Martin Petkovšek et al., 2013), se ha utilizado un disco de diámetro $90 \mathrm{~mm}$ con ranuras de $7 \mathrm{~mm}$ de profundidad y una longitud de $10 \mathrm{~mm}$. Para el diseño del rotor del nuevo cavitador, se ha mantenido prácticamente el mismo diámetro de $88.4 \mathrm{~mm}$ y la profundidad de las ranuras de $7 \mathrm{~mm}$. Por otro lado, la longitud total del rotor es de $70 \mathrm{~mm}$ donde se han 
mecanizado 11 dientes, cada uno de los cuales ocupa un barrido de $20^{\circ}$. De esta forma, se consigue que el arco de circunferencia de las ranuras por su cara externa sea de $9.8 \mathrm{~mm}$ y, por tanto, esté muy próxima a los $10 \mathrm{~mm}$ utilizados en el diseño de M. Petkovšek (Figura 35).

Se puede observar que, aunque la forma del rotor es completamente diferente a la del diseño de M. Petkovšek, se han mantenido prácticamente invariables los principales parámetros relacionados con las dimensiones de los dientes para intentar reproducir los efectos visualizados en dicho cavitador. Además, con el objeto de reducir el número de variables a estudiar durante el proceso de diseño del cavitador, se ha decidido mantener fijos los parámetros establecidos para la geometría del rotor durante el resto del proceso de diseño. Dado que está fabricado a partir de un cilindro macizo de acero inoxidable y sus características geométricas están basadas en las de otros dispositivos que han resultado exitosos, este rotor presenta una gran robustez en todos los sentidos. Por tanto, se establece como base para el desarrollo del resto del cavitador utilizando la configuración rotor-estator y simplificando, de este modo, la utilización de dos motores eléctricos.
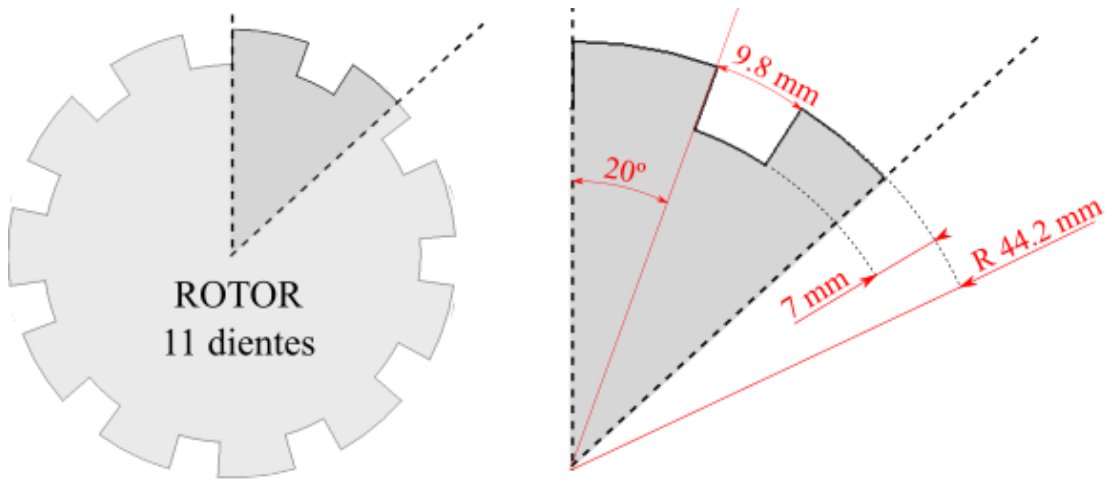

Figura 35: Dimensiones utilizadas en el rotor del nuevo cavitador.

\subsubsection{Diseño del estator}

Tras determinar la forma y las dimensiones del rotor, es necesario llevar a cabo el desarrollo del estator. Tal y como se ha comentado en el apartado anterior, con objeto de simplificar el número de variables establecidas en el proceso de diseño, se han fijado los parámetros geométricos del rotor. Por tanto, en el diseño del estator, se encuentra la clave para conseguir un sistema de cavitación que cumpla con los requisitos y expectativas esperadas para esta investigación. Dada la importante necesidad de tener un sistema versátil, el diseño del estator no solo debe contemplar el éxito en cuanto la generación de cavitación, sino también en cuanto a capacidad para realizar cambios rápidos y de bajo coste en el cavitador, 
que permitan mejorar su funcionamiento en el proceso actual o incluso en futuras investigaciones.

Es importante mencionar que el ritmo de la investigación siempre ha estado fijado por las necesidades del proyecto europeo Sto3re al que iba asociado. En este punto del proyecto, era de vital importancia proporcionar de forma inmediata un prototipo de cavitador con un mínimo de garantías de éxito. Por tanto, el primer diseño del estator será construido en base a las investigaciones llevadas a cabo por el grupo en la facultad de ingeniería mecánica de la universidad de Ljubljana sobre el sistema desarrollado por M. Petkovšek (Martin Petkovšek et al., 2013) y será optimizado más adelante gracias al modelado CFD descrito en detalle en el siguiente apartado.

Atendiendo a las características utilizadas en el dispositivo de M. Petkovšek, los principales parámetros a tener en cuenta a la hora de realizar el diseño del estator son:

- Inclinación de la superficie de los dientes

- Distancia entre rotor-rotor o rotor-estator

- Tamaño de los huecos

\section{Inclinación de la superficie de los dientes}

Respecto a este parámetro, únicamente se han realizado estudios con dientes totalmente rectos y con una inclinación de $8^{\circ}$. En el estudio del diseño inicial (Martin Petkovšek et al., 2013) se estableció como preferencia la utilización de dientes con inclinación de $8^{\circ}$ ya que estos producían unas variaciones de presión más elevadas y por tanto, una cavitación más agresiva. Esta comparación se hizo utilizando agua limpia y captando las variaciones de presión producidas por cada una de las configuraciones (dientes planos y dientes inclinados). Sin embargo, ambos diseños han dado buenos resultados durante su utilización en diferentes aplicaciones. Por ejemplo, la configuración con los dientes inclinados $8^{\circ}$ fue probada con éxito en la eliminación de fármacos (Zupanc et al., 2014) mientras que los dientes planos han dado buenos resultados en el procesos de tratamiento de fangos incluso con una configuración rotor-estator (Martin Petkovšek et al., 2015). Sin embargo, no existen comparativas directas de estos dos tipos de dientes utilizados en los mismos procesos de eliminación de fármacos o de desintegración de fango y, por tanto, resulta difícil determinar la verdadera eficacia de cada uno de ellos.

Considerando que en el estudio inicial (Martin Petkovšek et al., 2013) se utilizan los dientes inclinados con el objetivo de reproducir el efecto del Venturi, el valor de la inclinación utilizado es adecuado, ya que, según investigaciones centradas en 
el comportamiento del Venturi, el mejor ángulo de expansión a utilizar es $7^{\circ}$ porque se reduce significativamente la perdida de presión, y por tanto, la energía necesaria para producir la cavitación (Ashrafizadeh \& Ghassemi, 2015). De hecho, resulta habitual la utilización de este ángulo de expansión en aplicaciones donde se utiliza un Venturi para producir cavitación (Dular et al., 2016) (Tomov et al., 2016)(Bagal \& Gogate, 2014b).

Sin embargo, el objetivo del diseño del cavitador es producir una cavitación agresiva gracias a compresiones y expansiones fuertes y repentinas que la generen. Es decir, se desea que la cavitación se produzca y desaparezca de forma rápida ya que, de esta forma, la energía acumulada en el interior de las burbujas se libera en un intervalo de tiempo más pequeño y por tanto resulta más agresiva (Martin Petkovšek et al., 2015). En este sentido, este concepto sería opuesto al de utilizar ángulos de inclinación de $7^{\circ}$ donde se reduce la caída de presión atenuando sus gradientes, y deberían utilizarse ángulos mayores de $15^{\circ}$ o $20^{\circ}$ (o incluso dientes rectos) que permitieran una generación y colapso de las burbujas más repentinos con gradientes de presión mucho más bruscos (Ashrafizadeh \& Ghassemi, 2015). No obstante, esta explicación se encontraría en conflicto con lo observado en la investigación de M. Petkovšek (Martin Petkovšek et al., 2013) donde los dientes inclinados (con un supuesto gradiente de presiones más atenuado) producen una cavitación más agresiva que al utilizar los dientes rectos.

Se concluye pues, que con las evidencias bibliográficas actuales no puede determinarse con seguridad cual es la forma e inclinación óptima de los dientes. Por tanto, para este caso en particular, se ha decidido, utilizar la inclinación de $8^{\circ}$ puesto que, de esta forma, la esquina de ataque del diente es más afilada y puede favorecer el efecto de desintegración en caso de encontrarse con partículas gruesas. En cualquier caso, deberá estudiarse de forma más detallada el valor de este parámetro durante el desarrollo del modelo CFD.

\section{Distancia entre rotor-rotor o rotor-estator}

Con respecto al valor óptimo de la distancia entre rotor y estator, todas las investigaciones apuntan a que, cuanto menor es la distancia entre estos dos elementos, mayores son los beneficios obtenidos por el fenómeno de la cavitación. Luis M. Cerecedo et al. (Cerecedo et al., 2018), llegó a la conclusión de que una reducción del gap de un $40 \%$ (desde los $7.5 \mathrm{~mm}$ a los $4.5 \mathrm{~mm}$ ) proporciona unos mejores resultados, ya que se incrementan los esfuerzos tangenciales generados y la eficiencia en la desagregación de colonias bacterianas aumenta significativamente.

Por otro lado, M. Petkovšek et al. (Martin Petkovšek et al., 2013) llega a conclusiones similares en su sistema de cavitación. Tras analizar las oscilaciones de presión producidas por el sistema de cavitación con unas distancias entre rotor y estator de 3.5, 1.5 y $0.8 \mathrm{~mm}$, ha llegado a la conclusión de que es esta última 
distancia la que proporciona unas oscilaciones de presión más grandes. Sin embargo, también puntualiza que, aunque las diferencias entre utilizar 3.5 y $0.8 \mathrm{~mm}$ son muy significativas las diferencias entre 1.5 y $0.8 \mathrm{~mm}$, son mucho más modestas.

Para el diseño del nuevo sistema de cavitación, se ha decido utilizar la menor distancia entre rotor y estator que permita garantizar un funcionamiento seguro, considerando que las velocidades de rotación pueden llegar a alcanzar las $5600 \mathrm{rpm}$. Por tanto, se ha establecido que, según las características mecánicas de los diferentes elementos a utilizar en su fabricación, una distancia de $0.8 \mathrm{~mm}$ entre rotor y estator sería la mínima necesaria dentro de unos márgenes de seguridad aceptables.

\section{Tamaño de los huecos y número de dientes}

En el momento en el que se planteó el diseño de los dientes no existían estudios que proporcionaran información sobre cuantos dientes utilizar ni la profundidad o altura de los mismos. Por ello, tal y como se sugiere en el estudio de M. Petkovšek et al. (Martin Petkovšek et al., 2013), se decidió utilizar un diente más que el utilizado en el diseño del rotor (12 dientes en total), para evitar que el sistema entrara en resonancia. Una vez determinado el número de dientes en el estator, su longitud (o arco de circunferencia utilizado) está directamente relacionada con la longitud de los huecos. Al igual que en el sistema de M. Petkovšek, se estableció que, aunque se utilizara un numero de dientes diferente en el rotor y en el estator, la longitud de los huecos en ambos elementos debía ser la misma. Por tanto, al establecer la distancia de los huecos del estator, la de los dientes queda fijada en función del número utilizado (en este caso 12 dientes). En cuanto a la profundidad, uno de los lados del hueco está determinado por la inclinación del diente, mientras que el otro, presenta una altura de $8 \mathrm{~mm}$, ligeramente superior a la altura de los huecos del estator.

Aunque podría haberse aumentado el número de dientes tanto del rotor como del estator (manteniendo el requisito de que el tamaño de los huecos en ambos elementos fuera el mismo), esto no se hizo por temor a producir un fenómeno similar al de la supercavitación. De nada sirve aumentar el número de "encuentros" entre los dientes y los huecos para aumentar el número de eventos o puntos de cavitación, si no hay tiempo para que las burbujas producidas colapsen. En ese caso, surge la posibilidad de que, en lugar de incrementarse el efecto positivo de la cavitación, este se vea reducido debido a que las burbujas se junten entre ellas reduciendo sustancialmente la energía liberada durante su colapso.

Más tarde, Luis M. Cerecedo et al. (Cerecedo et al., 2018) confirmó, mediante el estudio de su sistema de cavitación, que al incrementar el número de constricciones/dilataciones (mediante el incremento del número de dientes), se producía una mayor disipación de energía cinética que se traducía en un 
incremento en la temperatura del fluido. Independientemente del beneficio que este aumento de temperatura pudiera producir al proceso en sí, al aumentar el número de dientes y huecos se incrementa el número de puntos de cavitación. A priori, esto también produciría un beneficio en el proceso, sin embargo, en el estudio se hace hincapié en la necesidad de limitar el número de eventos de cavitación que se producen (limitando el número de dientes) para evitar la coalescencia entre las burbujas generadas, ya que la intensidad en los colapsos puede verse mermada y comprometer el éxito del tratamiento. Esto confirma que la decisión adquirida durante el proceso de diseño del estator fue la adecuada, y que no excederse en el número de dientes para mantener un numero adecuado de puntos de cavitación, es consistente.

Tras haber analizado detalladamente los principales parámetros de diseño del estator (forma, tamaño, número de dientes y distancia entre rotor y estator) se ha establecido que el diseño del estator que mejor se acopla a la forma del rotor y cuyas dimensiones están respaldadas por otros estudios exitosos, es el que se presenta a continuación:
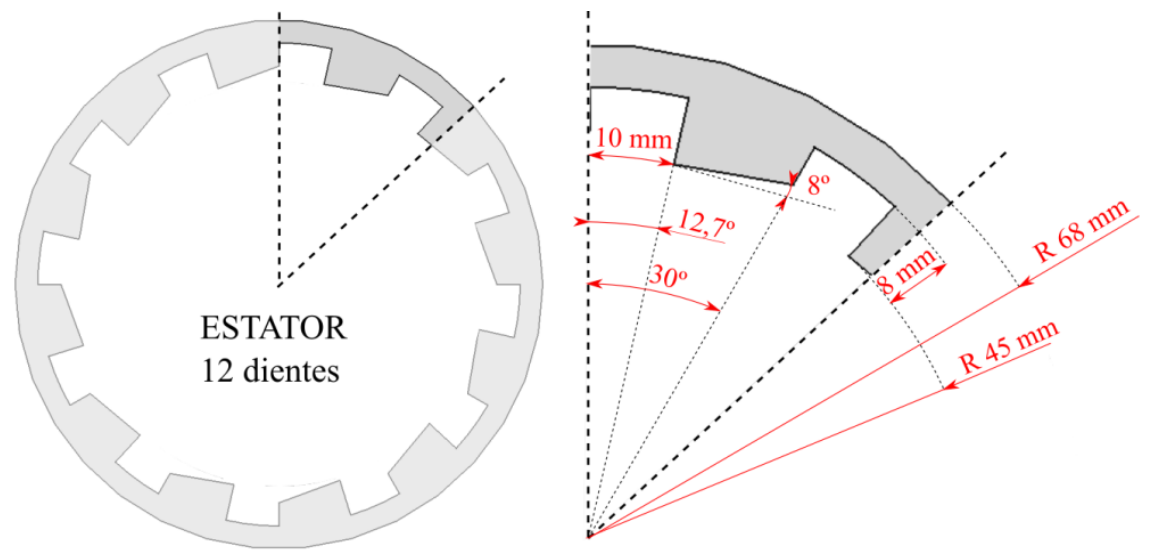

Figura 36: Dimensiones utilizadas en el rotor del nuevo cavitador.

A diferencia del rotor, el estator no está formado por una sola pieza maciza, y es aquí donde reside toda la versatilidad de este diseño. En este caso, el estator está formado por 7 discos de $5 \mathrm{~mm}$ de espesor cada uno. Además, entre cada uno de los discos dentados se encuentran unas piezas denominadas "separadores" que consisten en unos discos sin dientes (también de $5 \mathrm{~mm}$ de espesor) cuya única función es dejar un pequeño espacio entre los discos dentados. Al separar los diferentes discos que componen el estator, se rompe su continuidad y se consigue una zona más ancha donde el fluido puede expandirse favoreciendo el colapso y evitando fenómenos no deseados como la supercavitación. 

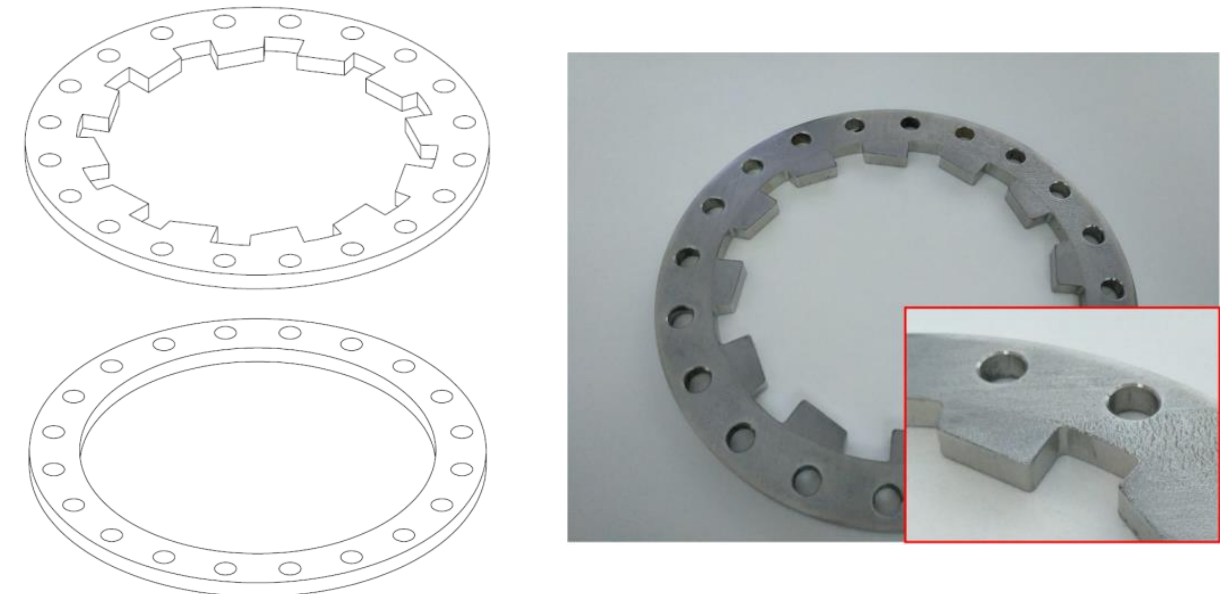

Figura 37: Esquema de un disco del estator y de un separador (izquierda) y detalle de uno de los discos reales del estator (derecha).

En la Figura 37, se muestra la geometría exacta del disco del estator y del separador. Se observa como ambos pueden unirse gracias a múltiples orificios que se encuentran en su periferia y que permiten alinear los diferentes discos utilizando pernos de M6. Para poder incorporar dichos orificios, el diámetro total (exterior) del disco del estator es de $136 \mathrm{~mm}$ De esta manera las posibilidades de montaje son enormes, pudiéndose crear diferentes combinaciones entre separadores y discos dentados para favorecer la coalescencia o incluso desfasar los diferentes discos para intentar optimizar el proceso de cavitación.
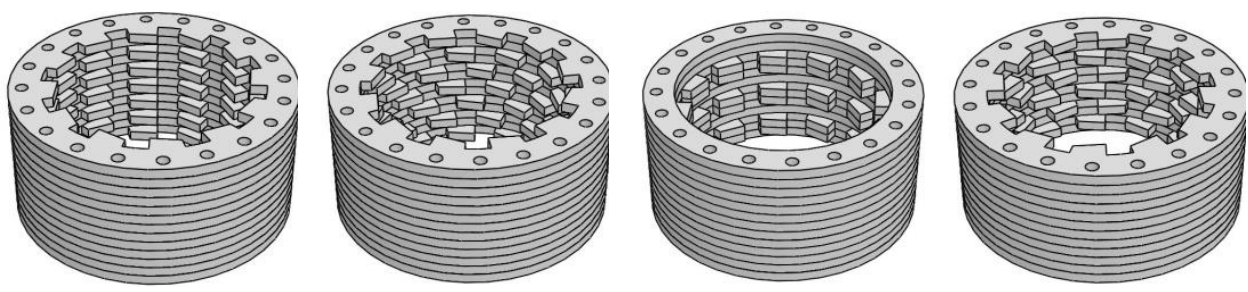

Figura 38: Posibles combinaciones entre discos dentados y separadores para formar el bloque del estator.

Por último, es importante mencionar que, debido al poco grosor de los discos del estator, estos pueden ser fabricados de forma ágil mediante el corte por chorro de agua. De esta manera, se obtiene un cavitador muy versátil donde resulta fácil, 
rápido y económico plantear e implementar nuevos diseños, permitiendo la configuración de múltiples combinaciones con una misma geometría del disco.

\subsubsection{Configuración del rotor y el estator}

Una vez establecidas la forma y especificaciones del rotor, es necesario determinar cómo se dispondrá el estator y qué forma tendrá el cavitador en su conjunto. Para ello, es necesario tener en consideración el diseño que se ha establecido para el rotor y realizar una cámara de cavitación que albergue el estator en consecuencia.

Tal y como se ha descrito en el apartado 3.3.2.1, el rotor está formado por un cilindro ranurado de $70 \mathrm{~mm}$ de altura y $88.4 \mathrm{~mm}$ de diámetro. Para facilitar el paso del flujo a través de las ranuras diseñadas en el rotor, se ha establecido una carcasa cilíndrica denominada cámara de cavitación, que permite albergar el estator en su interior, y el estator a su vez, alberga el rotor en su interior (Figura 39a). Gracias a esta novedosa configuración, el flujo es forzado a circular de un lado a otro pasando a través de todos los huecos y espacios que quedan entre el rotor y el estator sin posibilidad de un camino alternativo.

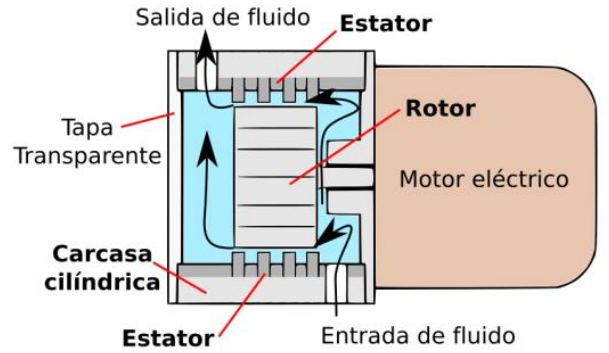

(a)

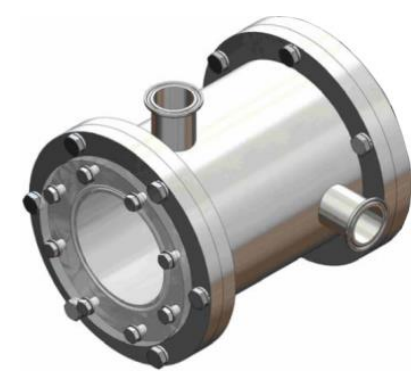

(b)

Figura 39: Esquema con la disposición del rotor, estator y cámara de cavitación (a) e imagen de la cámara de cavitación (b).

La entrada y la salida a la cámara de cavitación se realiza por dos orificios de $38 \mathrm{~mm}$ desfasados 90 grados entre sí (Figura 39b). Uno de los orificios se sitúa justo antes del rotor y el otro justo después, tal y como puede verse en el esquema. (Figura 39a). La carcasa tiene una longitud de $210 \mathrm{~mm}$ de largo, $168 \mathrm{~mm}$ de diámetro exterior, y un espesor de $16 \mathrm{~mm}$. Ha sido fabricada totalmente de acero inoxidable salvo la tapa delantera que está compuesta por un disco de metacrilato de $175 \mathrm{~mm}$ de diámetro y $10 \mathrm{~mm}$ de grosor. 


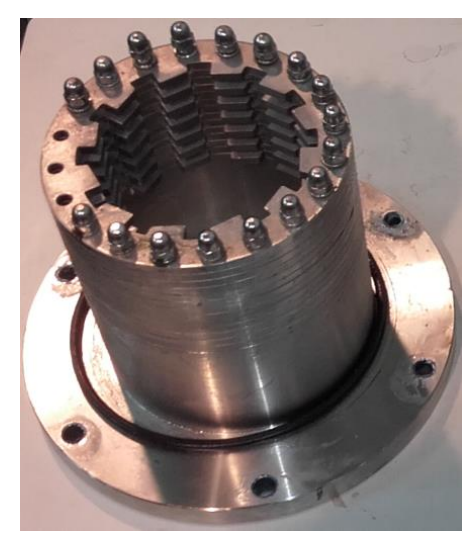

(a)

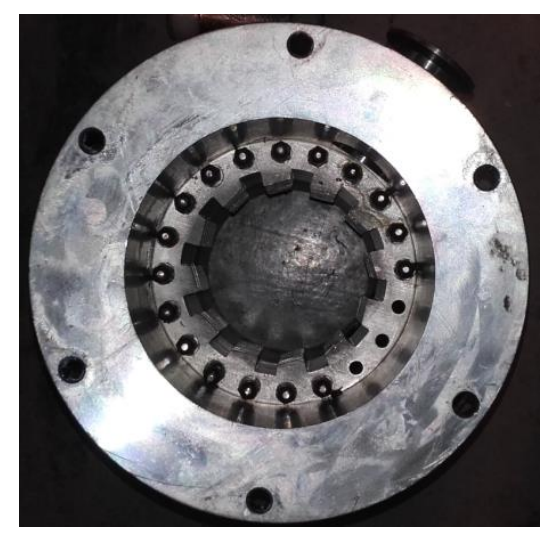

(c)

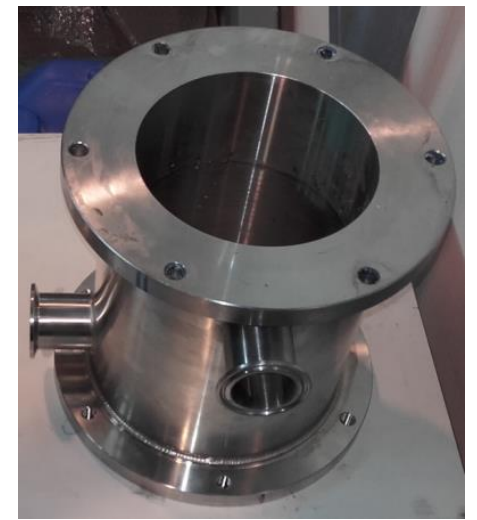

(b)

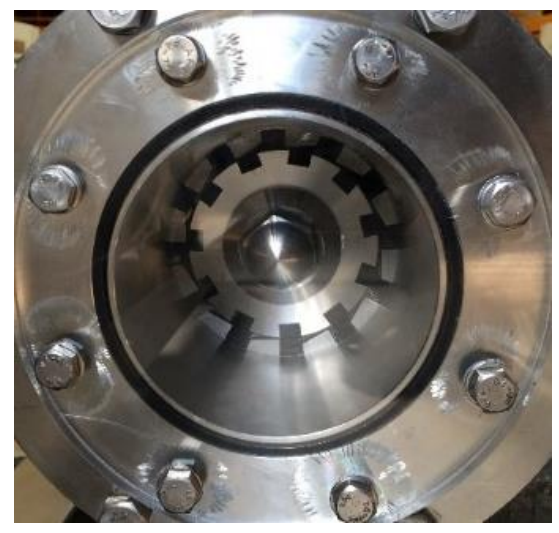

(d)

Figura 40: Esquema desarrollado durante la fase de diseño (a) e imagen real del rotor y el estator en el interior de la cámara de cavitación a través de la tapa transparente de metacrilato (b).

Por otro lado, tal y como puede verse en la Figura 40a, el bloque del estator completo consiste en una pieza cilíndrica con 20 pernos de M6 donde van insertados 7 discos dentados y 6 separadores intercalados. Dado que tanto los separadores como los discos tienen un espesor de $5 \mathrm{~mm}$ la longitud total del estator es de $65 \mathrm{~mm}$. Tanto la parte exterior de los discos y separadores como la parte interior de la carcasa tienen el mismo diámetro donde existe una pequeña tolerancia. De esta forma, el bloque del estator se puede insertar de forma muy ajustada en el interior de la carcasa (Figura 40b) y una vez dentro, se fija a esta gracias a 6 tornillos M8. En la Figura 40c, se puede ver el acoplamiento del bloque 
del estator con la carcasa desde la parte de atrás, es decir, desde la parte que se une con la carcasa del motor eléctrico. Finalmente, todo el conjunto del bloque del estator y carcasa se unen con el motor eléctrico en cuyo eje se encuentra el rotor que queda totalmente centrado con el estator tal y como puede verse en la Figura 40d.

Esta configuración del rotor y el estator en el interior de la cámara permite maximizar el número de puntos de cavitación. Debe recordarse, que los sistemas de M. Petkovšek y Luis M. Cerecedo, la cavitación se produce cuando los dientes o los huecos se encuentran y, por tanto, el número de puntos de cavitación puede establecerse como $\mathrm{N}_{\mathrm{r}} \times \mathrm{N}_{\mathrm{s}}$, dónde $\mathrm{N}_{\mathrm{r}}$ es el número de dientes/huecos del rotor $\mathrm{y}$ $\mathrm{N}_{\mathrm{s}}$, es el número de dientes/huecos del estator. Sin embargo, una de las principales fortalezas del nuevo diseño del cavitador reside en que el mismo rotor se mueve en el interior de 7 discos estáticos diferentes con lo que la fórmula $N_{r} \times N_{s}$ debe multiplicarse por el número de discos del estator. De esta manera, en el diseño del nuevo cavitador con 11 dientes en el rotor y 12 en el estator se tendrían 132 puntos de cavitación por cada vuelta, pero al tener 7 discos en el estator interrumpidos por los separadores, se tiene un total de $132 \cdot 7=924$ puntos de cavitación por vuelta. Esto significa que al funcionar a $5600 \mathrm{rpm}$ se están generando 1437 puntos de cavitación cada segundo. Además, estos puntos se generan de manera secuencial y para que exista una nueva expansión que produzca la cavitación debe existir antes una compresión que la haga colapsar. Esto garantiza que no se produzca supercavitación en ningún momento y que los puntos de cavitación estén en continua generación y colapso produciendo un tipo de cavitación agresiva que tal y como se indica en el estudio de M. Petkovšek et al. (Martin Petkovšek et al., 2013) es la más adecuada para eliminación de residuos y fármacos así como para garantizar una buena desintegración del fango de EDAR.
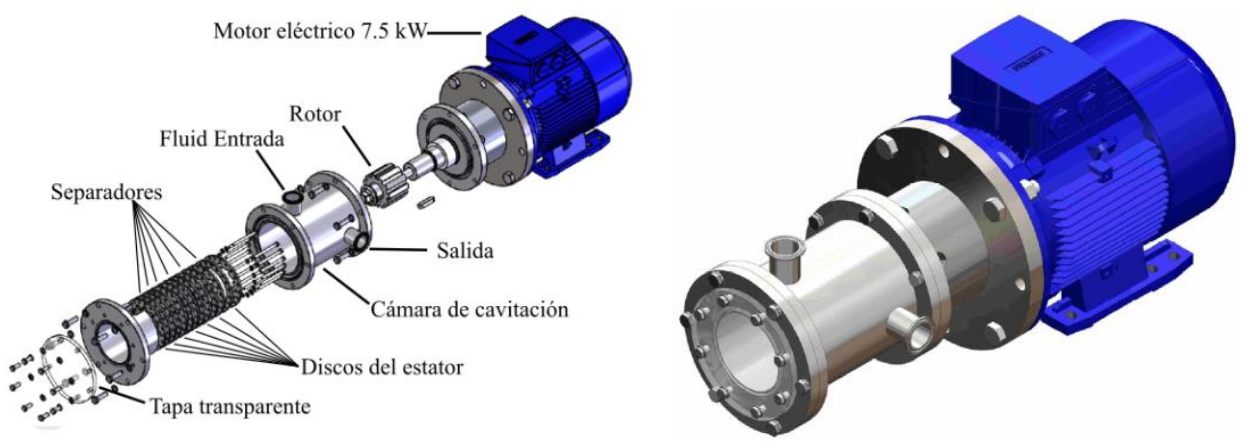

Figura 41: Ensamblaje final del prototipo del cavitador. 
En la Figura 41, se muestra la apariencia final del sistema de cavitación, así como la distribución de las diferentes partes (cámara de cavitación, separadores, discos, rotor...) diseñadas en el presente apartado. Tal y como puede verse, se trata de un dispositivo muy compacto y robusto, pero a la vez versátil, permitiendo un fácil acceso a los discos del estator, así como del rotor para poder agilizar las labores de mantenimiento o el intercambio por nuevas piezas evolucionadas.

\subsubsection{Conclusiones}

En este capítulo se han analizado y estudiado en detalle un amplio rango de posibles cavitadores con el objetivo de obtener un diseño que permita operar en las condiciones exigidas en la planta piloto. Finalmente, de entre todos los posibles diseños, se ha decidido utilizar una configuración de rotor-estator. El rotor consiste en un cilindro de $70 \mathrm{~mm}$ de largo y $88.4 \mathrm{~mm}$ de diámetro, donde se han ranurado 11 dientes mientras que el estator, está formado por 7 discos separados $5 \mathrm{~mm}$, cada uno de los cuales tiene 12 dientes con una inclinación específica de $8^{\circ}$. Esta configuración ha permitido:

- Obtener un diseño robusto adecuado para el tratamiento de sustancias muy complejas como los lodos de depuración y purines agrícolas, minimizando la posibilidad de un mal funcionamiento como consecuencia del atascamiento de pelos, partículas sólidas u otros elementos presentes en estas sustancias.

- Maximizar el número de puntos de cavitación, produciendo una cavitación poco extensiva pero muy intensa. Esto ha sido posible gracias a la creación de zonas de baja presión muy puntuales que se generan y colapsan de forma muy rápida, gracias al movimiento relativo entre los dientes del rotor y del estator. Esta característica es la clave para conseguir optimizar la eficiencia del proceso de cavitación.

- Funcionamiento versátil y económico. La forma en la que se ha realizado el ensamblaje permite la fácil extracción del estator para cambiar la disposición de los discos y los separadores de manera que con un mismo tipo de discos dentados se pueden obtener múltiples configuraciones. Si a esto se le añade que la creación de nuevos discos dentados es muy económica debido a la simplicidad de su mecanizado, las posibilidades para este estudio y otros futuros son prácticamente infinitas.

Por tanto, el diseño realizado para el dispositivo de cavitación no solo permite cumplir con los requisitos de funcionamiento que van a exigirse durante su funcionamiento en la planta piloto, sino que también puede ser fácilmente modificado para cumplir nuevos requisitos u optimizar su funcionamiento a través de estudios futuros. 
Capitulo 3. Diseño de un hidrocavitador 


\section{Capítulo 4}

\section{Simulaciones CFD del sistema de cavitación}

En el presente capítulo se ha desarrollado un modelo de cavitación que pueda ser implementado y calibrado utilizando técnicas CFD para, posteriormente, obtener un diseño optimizado y eficiente del cavitador. Para llevar a cabo los objetivos de este capítulo, ha sido necesario realizar un primer estudio sobre un dispositivo de cavitación conocido, donde se pudiera controlar y monitorizar con facilidad su comportamiento en diferentes regímenes de funcionamiento. Con esta información, ha sido posible seleccionar, ajustar y validar los modelos de cavitación ya conocidos y presentados en el apartado 2.2, para su posterior utilización en el análisis CFD del nuevo dispositivo que va a ser desarrollado

\subsection{Introducción}

Tras haber establecido un primer diseño conceptual en el capítulo anterior, ahora se debe desarrollar un modelo CFD que permita llevar a cabo la optimización del rotor y de los discos del estator, de manera que se pueda analizar y determinar tanto la cantidad como la "calidad" de la cavitación generada por el cavitador. Sin embargo, la utilización de las herramientas de simulación computacional no es un proceso sencillo, y para poder sacar el máximo provecho de las simulaciones CFD realizadas, es importante establecer claramente y desde el principio, dos puntos fundamentales:

- Metodología a seguir en el proceso de simulación

- Parámetros de análisis

A continuación, se desarrollan de forma más extensa la explicación de estos dos puntos fundamentales para el desarrollo de las simulaciones CFD. Los resultados derivados de este capítulo marcarán el rumbo de las etapas posteriores en la 
investigación. Por ello, es muy importante tener claros cuales van a ser los requisitos necesarios en la planta piloto y realizar un diseño ad hoc validado mediante CFD, que garantice el correcto funcionamiento del sistema.

\subsubsection{Objetivos}

El principal objetivo perseguido durante el desarrollo de este capítulo es el de conseguir obtener un modelo de cavitación robusto que permita desarrollar modelos basados en el diseño conceptual desarrollado durante el capítulo anterior. De esta manera se espera, por un lado, mejorar la comprensión sobre el diseño propuesto del cavitador que posteriormente funcionará en los ensayos a nivel de laboratorio y en planta piloto y, por otro lado, obtener un modelo CFD que permita la optimización y desarrollo del propio cavitador o de otros diseños que puedan ser utilizados en estudios futuros. sino:

Por tanto, el principal punto perseguido durante el presente capitulo no es otro

- Desarrollar, calibrar y validar un modelo mediante la utilización de técnicas CFD que permita determinar detalladamente, el diseño geométrico del sistema de cavitación que haya decidido desarrollarse en base a las necesidades requeridas establecidas en el diseño conceptual.

\subsubsection{Metodología del proceso de simulación}

El proceso de elaboración de un modelo CFD requiere de una serie de pasos secuenciales que deben repetirse sea cual sea el tipo de modelo que va a desarrollarse. Cada paso requiere de una serie de información necesaria para su correcto desarrollo y debe hacerse utilizando un software específico. En el presente estudio se ha utilizado el software ANSYS 19.2, el cual está dotado de todos los módulos necesarios para desarrollar cada tarea específica dentro del proceso de elaboración del modelo CFD. Por tanto, con un único software se puede desarrollar el modelo completo sin necesidad de utilizar ningún programa auxiliar. En el diagrama de la Figura 42 se muestra de forma esquematizada los pasos necesarios para realizar un análisis mediante CFD así como los módulos de ANSYS utilizados en cada uno de ellos.

Se puede observar cómo la realización de un modelo computacional de cualquier tipo implica, no sólo la realización de una geometría en CAD y su posterior mallado, sino también la introducción de todas las condiciones de contorno necesarias para el funcionamiento del modelo. Esto requiere el establecimiento de los correctos valores de presión, caudales y demás condiciones físicas de funcionamiento, además de la elección de un modelo de turbulencia y de cavitación adecuados, que se ajusten a la realidad observada y/o mesurada. 


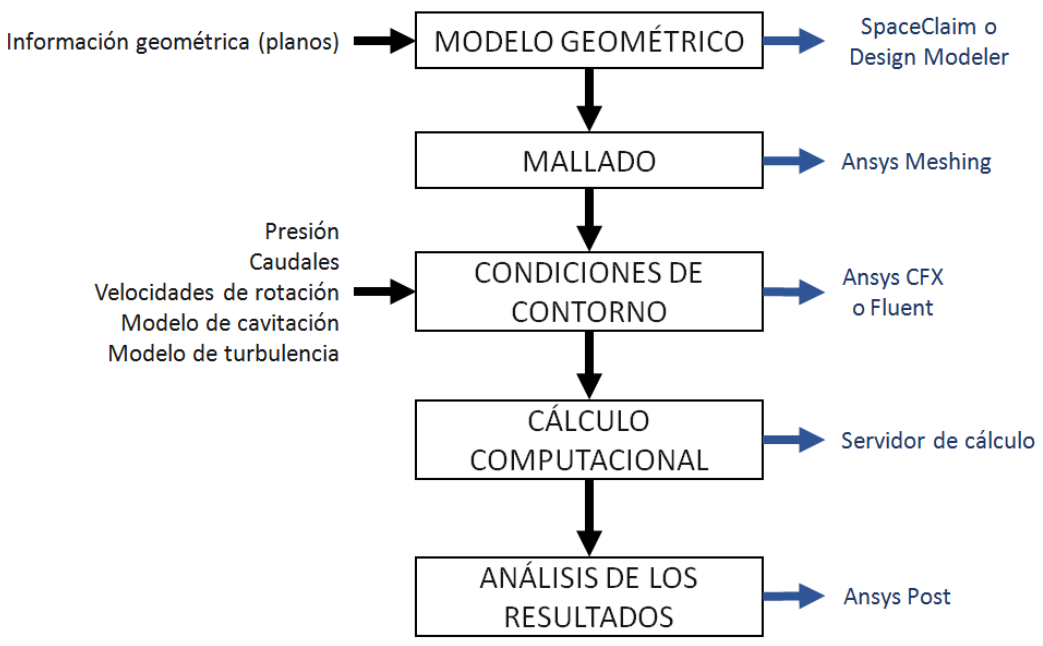

Figura 42: Flujo de trabajo para la elaboración de un modelo CFD.

Aunque el flujo de trabajo anteriormente descrito es exactamente igual para cualquier tipo de simulación independientemente de su índole, la metodología seguida en el proceso de resolución del sistema puede tener múltiples variantes.

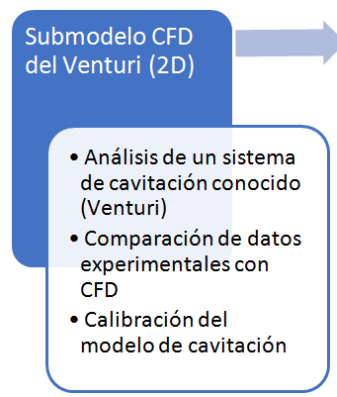

\section{Submodelo \\ detallado de un diente (2D)}

- Análisis de un diente del rotor a escala real en 2D

- Determinación detallada del gradiente de presiones en diferentes supuestos
Submodelo

completo rotorestator (2D)

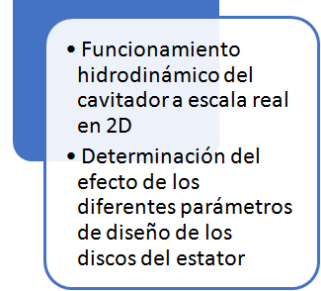

Figura 43: Submodelos utilizados para realizar el análisis completo mediante CFD del sistema de cavitación.

Generalmente, se suele utilizar un único modelo que representa íntegramente el sistema a estudiar. Sin embargo, el fenómeno que quiere analizarse en este estudio es muy complejo, al igual que la geometría del sistema. Esto resulta en una importante limitación en la capacidad computacional, que obliga a desglosar el sistema en un conjunto de submodelos que permiten dar respuesta a todas las incógnitas que acarrea el sistema. Tal y como puede observarse en la Figura 43, 
para poder realizar el análisis completo mediante CFD del nuevo sistema de cavitación, ha sido necesario realizar 3 submodelos diferentes que serán explicados más detalladamente en los siguientes apartados. La resolución y análisis de cada uno de estos submodelos se realiza de forma secuencial, de manera que la solución de un subsistema es utilizada como condición en el siguiente para, de este modo, garantizar el buen funcionamiento y fiabilidad de todos los submodelos. Así, en lugar de intentar resolver un único modelo de gran complejidad se subdivide el sistema en pequeñas partes más simples y fáciles de resolver y así, en conjunto, se reduce el tiempo y la dificultad del proceso de simulación.

\subsubsection{Parámetros de análisis}

Los parámetros de análisis hacen referencia a aquellos datos obtenidos tras las simulaciones CFD, que permiten describir el sistema, y su elección depende mucho de la finalidad y el objetivo de cada uno de los submodelos. Por ejemplo, en los modelos CFD donde se estudia la cavitación sobre un Venturi o un orificio, es habitual analizar la distribución de presiones y velocidades, así como la fracción volumétrica de gas formada (Charrière, Decaix, \& Goncalvès, 2015)(Simpson \& Ranade, 2018b) (Shi, Li, Nikrityuk, \& Liu, 2019b) (Jangir, Diwedi, \& Ghosh, 2017). Generalmente, en estos estudios, las simulaciones CFD se comparan con datos del sistema real y, por tanto, se seleccionan parámetros de análisis que pueden ser relativamente fáciles de observar mediante sensores o cámaras.

Para sistemas más complejos como pueden ser inductores axiales y otro tipo de máquinas rotativas, obtener los valores de presión y velocidad en las zonas de interés puede llegar a ser físicamente imposible. En estos casos, es habitual realizar comparaciones utilizando imágenes del sistema real, donde se puede apreciar con claridad las zonas donde aparece la cavitación, y de las simulaciones CFD (Bakir, Rey, Gerber, Belamri, \& Hutchinson, 2004)(Campos, Bakir, Campos, Palaciosgallegos, \& Rey, 2015). En estos casos, es muy importante que el sistema real esté dotado de algún elemento transparente que permita visualizar de forma directa el fenómeno y, además, en función del fenómeno que quiera registrarse, es posible que una cámara normal no sea suficiente y sea necesario registrar las imágenes mediante una cámara de alta velocidad.

También existen estudios en los que además de utilizar una cámara de alta velocidad para captar y analizar visualmente el fenómeno de la cavitación, se registran las variaciones de presión mediante un hidrófono (Zupanc et al., 2014) (Martin Petkovšek et al., 2015). Aunque este dispositivo no es capaz de determinar la presión en un punto concreto del sistema, permite registrar las ondas de presión que se producen con el colapso de las burbujas al cavitar. De este modo, se puede medir la amplitud de las oscilaciones en la presión y determinar la agresividad de la cavitación y la extensión que se produce tras generarse la zona de vapor. 
Para el estudio de la presente investigación, se han tenido a disposición elementos de medición básicos como sensores de presión, caudalímetros y cámaras (tanto normales como de alta velocidad), pero no se ha dispuesto de un hidrófono que permita analizar las variaciones de presión en el interior del dispositivo. Por tanto, los parámetros de análisis en los diferentes submodelos deben limitarse a aquellos que puedan medirse experimentalmente o que puedan comparase con resultados de otros estudios similares. A continuación, se describen los parámetros considerados en cada uno de los submodelos estudiados:

- Submodelo 2D del Venturi: para el estudio de este submodelo se ha realizado un pequeño montaje experimental y se han utilizado sensores de presión, caudalímetros y una cámara fotográfica réflex para registrar el fenómeno. Por tanto, los parámetros analizados en las simulaciones han sido los valores de presión en determinados puntos y su variación en función del caudal de entrada. Además, también se han analizado las fracciones volumétricas de gas para compararlas con las capturadas por la cámara fotográfica para hacer más fiable la validación del modelo.

- Submodelo detallado de un diente 2D: en este modelo el principal parámetro de análisis ha sido la distribución de presiones que se produce en el interior de los huecos del rotor como consecuencia de la rotación. Conociendo dicha distribución, se puede determinar con mucho detalle el comportamiento hidrodinámico de los dientes únicamente como consecuencia de la velocidad angular del rotor. La comparación entre estas simulaciones y las proporcionadas por el submodelo completo, permitirán discernir los efectos que se producen como consecuencia de la incorporación de los discos del estator.

- Submodelo completo 2D rotor-estator: debido a las características de este submodelo, se ha decidido realizar el análisis como si se tratara de un modelo experimental real donde se utilizan hidrófonos. Así pues, se han analizado las variaciones de presión en función del movimiento del rotor, dando como resultado una gráfica característica para cada uno de los diseños propuestos que pueden ser comparadas entre sí para elegir la opción más conveniente.

En resumen, los parámetros de análisis utilizados durante el estudio de los diferentes submodelos son:

- Valores de presión en puntos conocidos.

- Variaciones de presión en una determinada zona o dominio.

- Área o volumen ocupado por la fracción de gas.

- Velocidades y caudales.

De esta manera, se pueden evaluar y comparar de forma ágil los diferentes submodelos sin necesidad de utilizar variables complejas que puedan ser de difícil 
interpretación. Estos simples parámetros permiten realizar comparaciones rápidas y fiables tanto entre modelos CFD, como entre el modelo CFD y el montaje experimental real (en el caso de que se disponga).

\subsection{Simulación de un dispositivo Venturi}

El desarrollo de un modelo CFD que permita analizar y predecir de forma detallada el comportamiento del cavitador exige la selección, calibración y validación, un modelo de cavitación que reproduzca de forma adecuada dicho fenómeno. Aunque la bibliografía relacionada con los modelos de cavitación es extensa (ver apartado 2.2.4), siempre se suelen utilizar los mismos modelos y parámetros ya testados, como por ejemplo la cantidad de núcleos de cavitación (cavitation nuclei), la presión de vapor, o los coeficientes de condensación y vaporización entre otros.

Para desarrollar y analizar el primer submodelo del estudio CFD, se ha construido un pequeño montaje experimental cuyo objetivo no es otro que el de permitir la observación del fenómeno de la cavitación bajo diferentes condiciones, para poder compararla posteriormente con los resultados obtenidos en la simulación computacional. De esta manera se determinarán los parámetros y condiciones de contorno necesarias para ajustar de forma óptima el modelo CFD. Este primer submodelo CFD del Venturi es quizás el más importante por ser el único al que se le ha dedicado un montaje experimental para su validación. Es por ello por lo que gran parte de la configuración de este primer modelo con el Venturi será traspasada a los submodelos posteriores donde se utilizarán los mismos ajustes en los modelos turbulentos y de cavitación.

\subsubsection{Montaje experimental}

El montaje experimental que se ha realizado para la validación del submodelo es relativamente simple y consta de los siguientes elementos:

- Venturi plano de metacrilato.

- Bomba axial de $2.2 \mathrm{~kW}$ con caudal máximo de $120 \mathrm{l} / \mathrm{min}$.

- Sensores de presión situados aguas arriba y aguas abajo del Venturi.

- Caudalímetro electromagnético.

- Depósito de aproximadamente 100 litros.

- Tubería de 1".

- Válvulas de regulación de caudal de 1".

- Cámara Réflex.

- Ordenador de registro de datos. 

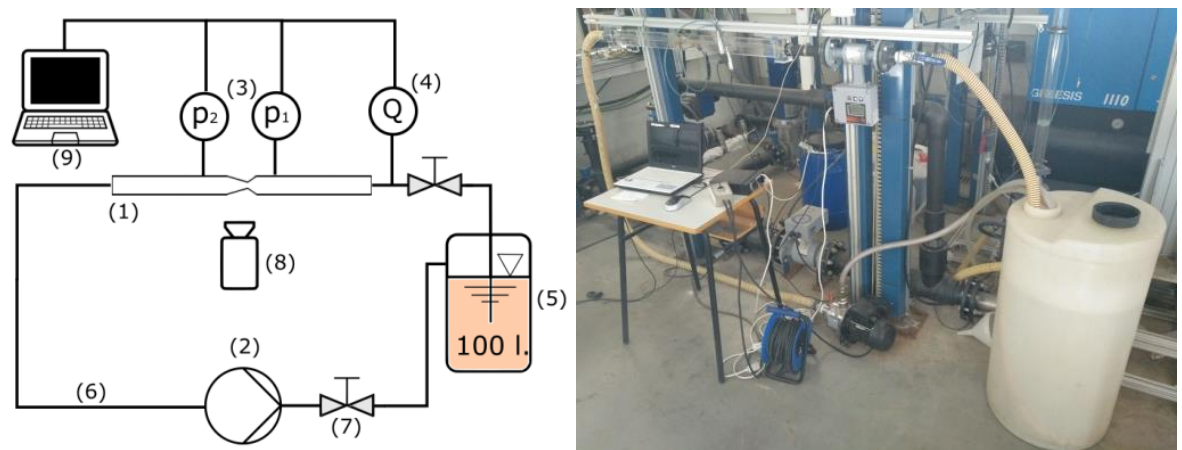

Figura 44: Esquema de montaje para validar el submodelo CFD del Venturi (izquierda) y foto del montaje real (derecha).

En la Figura 44 se muestra el esquema del montaje. La instalación está construida y cuenta con un depósito de agua de aproximadamente 100 litros (5). El agua es impulsada por la instalación realizada con tuberías de 1 pulgada (6) gracias a una bomba axial (2) que puede proporcionar hasta $120 \mathrm{l} / \mathrm{min}$. La bomba funciona en régimen continuo y su caudal se regula mediante la válvula situada en la propia bomba de impulsión (7) (ver Figura 45). Existen 2 sensores de presión (3) situados aguas arriba $\left(\mathrm{p}_{1}\right)$ y aguas abajo $\left(\mathrm{p}_{2}\right)$ del estrechamiento del Venturi con un rango de medición de -1 a 24 bar, un error de $\pm 0.5 \%$ y una repetitividad de $\pm 0.1 \%$. Se dispone también de un caudalímetro (4) situado aguas arriba del Venturi, el cual tiene un rango de medición de 0.9 a $353 \mathrm{l} / \mathrm{min}$, un error de $\pm 0.3 \%$ y una repetitividad de $\pm 0.1 \%$. Tanto los sensores de presión como el caudalímetro envían los datos registrados a un ordenador portátil (9) para su posterior análisis. Finalmente se tiene una cámara réflex (8) enfocada justo en la zona del estrechamiento del Venturi para captar la evolución del fenómeno de la cavitación.

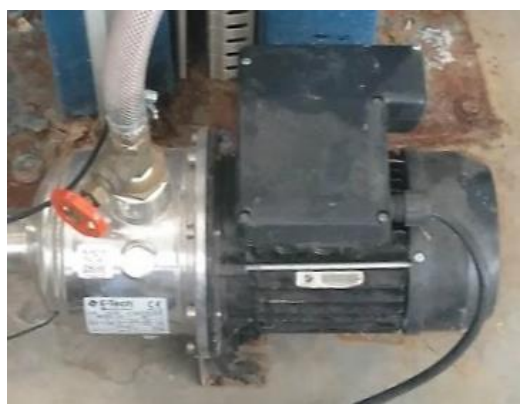

Figura 45: Foto en detalle de la bomba (2) donde se encuentra la válvula que regula el caudal (7). 
De todos los elementos, el de mayor importancia y que ha requerido de un estudio previo más profundo para determinar sus principales características, ha sido el Venturi (Figura 46). Tal y como puede observarse, está orientado en posición horizontal, es rectangular y tiene unas dimensiones totales de $30 \mathrm{~mm}$ de ancho, $50 \mathrm{~mm}$ de alto y $1000 \mathrm{~mm}$ de largo. Está formado por 3 láminas de metacrilato de $10 \mathrm{~mm}$ de grosor, dos de las cuales son completamente planas mientras que la tercera contiene la forma del Venturi a estudiar. De esta manera, el flujo bombeado en la instalación pasa a través de una sección rectangular del Venturi de 10 x $30 \mathrm{~mm}$ la cual se reduce hasta unas dimensiones de 10 x $10 \mathrm{~mm}$ en la zona del estrechamiento donde se induce la cavitación. El motivo por el cual la sección de paso del agua a través del Venturi es rectangular es para permitir una correcta captura de las imágenes para evitar la distorsión que se produciría al utilizar una sección circular en el metacrilato.
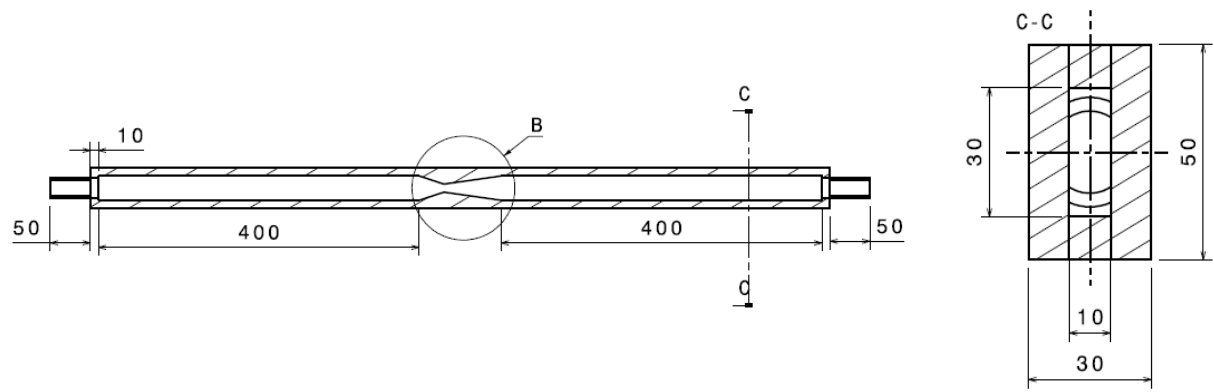

Figura 46: Dimensiones exteriores del Venturi.

Tanto el montaje experimental, como las dimensiones del Venturi, son muy similares a las utilizadas en otros estudios como (Tomov et al., 2016b) (Shi et al., 2019b) (Dastane et al., 2019a). En la Figura 47, se encuentran las dimensiones internas del Venturi, las cuales son prácticamente idénticas a las utilizadas por Tomov et al. (Tomov et al., 2016b) en su estudio sobre el efecto de la cavitación en Venturis con aireación.

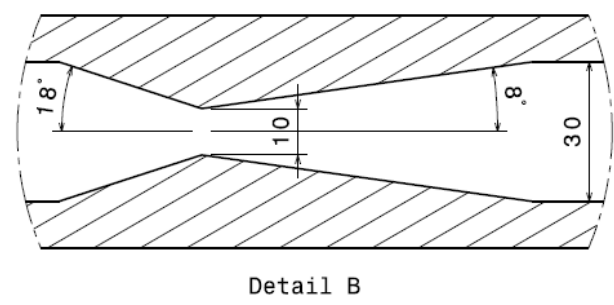

Figura 47: Detalle de las dimensiones internas del Venturi. 
Tanto el ángulo de entrada como el de salida del estrechamiento son idénticos a los utilizados por Tomov et al., ya que los valores adoptados en estos parámetros geométricos, resultan ser los más recurridos a la hora de realizar estudios sobre el comportamiento hidrodinámico de los Venturi (Ashrafizadeh \& Ghassemi, 2015) (Dular et al., 2016) (Dastane et al., 2019a) y han sido ampliamente estudiados por diversos autores (Bashir, Soni, Mahulkar, \& Pandit, 2011) (Simpson \& Ranade, 2018a)
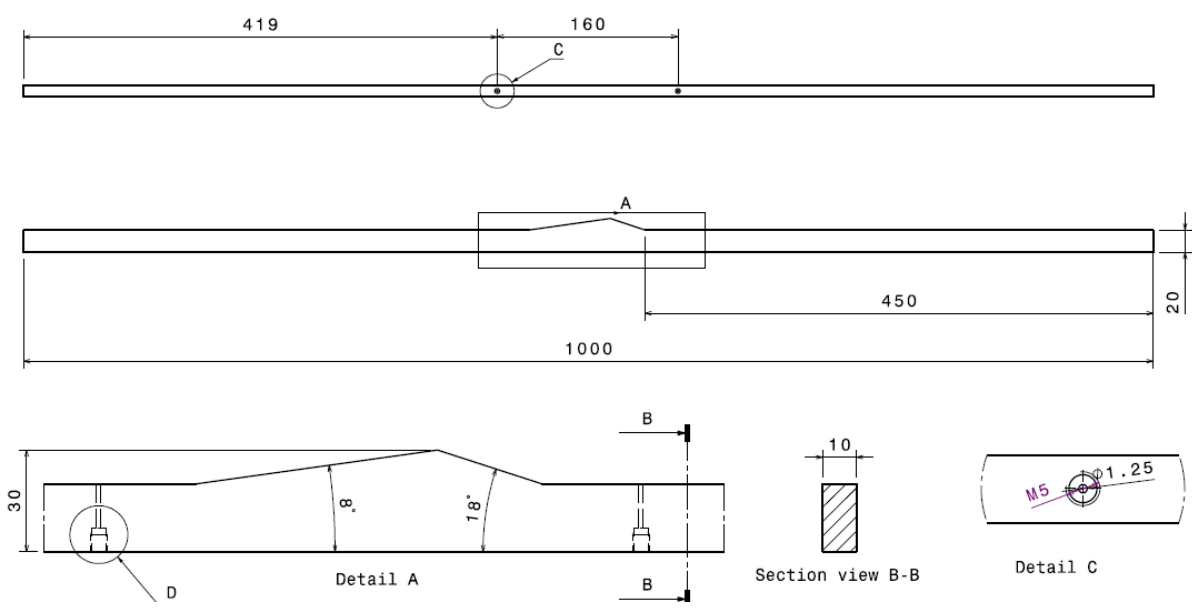

Figura 48: Detalle de la ubicación de los sensores de presión en el Venturi.

En cualquier caso, para esta situación en particular, la geometría del Venturi no es crítica, ya que únicamente se quiere inducir el fenómeno de la cavitación con la finalidad de poder reproducirlo y analizarlo sin intención de conseguir un comportamiento determinado. Sí que resulta especialmente importante la correcta situación y hermetización (Figura 48) de los sensores, así como de la cámara fotográfica, para poder caracterizar detalladamente el comportamiento y poder replicar, y posteriormente validad, las mismas condiciones en las simulaciones CFD.

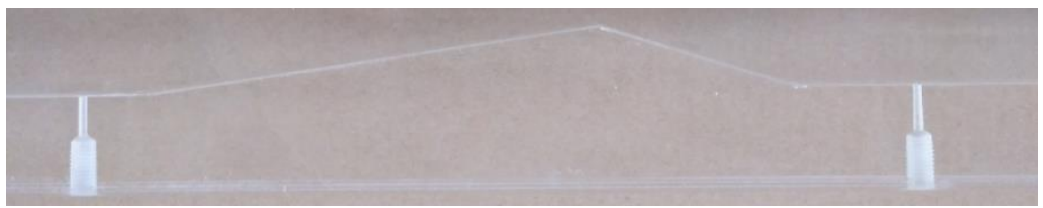

Figura 49: Detalle de la ubicación de los sensores de presión en el Venturi real.

Tras fabricar, seleccionar, y montar todas las piezas, se realizaron pruebas de funcionamiento para garantizar la estanqueidad de la instalación, prestando especial atención a posibles fugas o entradas de aire no deseadas y garantizando la correcta 
medición de los sensores de presión y del caudalímetro. La situación de los sensores de presión aguas arriba y aguas abajo del estrechamiento se ha establecido según el criterio de Tomov et al., debido a que le Venturi utilizado en sus estudios es muy similar al de montaje, y la situación que utilizó dicho autor, no presentó ningún problema en cuanto a interpretación o análisis de resultados se refiere. De este modo ha podido procederse a la realización de los ensayos para la obtención de datos requeridos en la validación de la simulación CFD.

\subsubsection{Ensayos experimentales con el Venturi}

Durante los ensayos experimentales, se han utilizado las mediciones de las presiones aguas arriba y aguas abajo del estrechamiento para obtener la caída de presión $\left(=\mathrm{p}_{1}-\mathrm{p}_{2}\right)$ producida en dicho tramo, y también los valores proporcionados por el caudalímetro para estimar la velocidad en el estrechamiento. Con estos valores, es posible no solo determinar la evolución de la presión en función del caudal sino también el número de cavitación en cada momento.

La metodología para desarrollar los ensayos experimentales es sencilla. Mediante la variación de la presión aguas arriba del Venturi (producido gracias a la válvula situada en la bomba), se fija un caudal mínimo a partir del cual comenzar a realizar las mediciones. Es importante que este caudal proporcione unas condiciones de velocidad y presión que se encuentren lejos de producir el fenómeno de la cavitación, y una vez fijado dicho caudal, este se va aumentando en intervalos regulares mediante la apertura de la válvula de la bomba. Con cada aumento en el caudal, se espera 30 segundos antes de registrar los valores de presión, con el objetivo de permitir que todo el sistema se estabilice tras el cambio. Una vez pasado este tiempo de estabilización, se vuelve a aumentar nuevamente el caudal y el proceso se repite hasta alcanzar el caudal máximo de la instalación. El caudal máximo viene determinado por el denominado Choked flow o caudal crítico (Critical Flow), que se da cuando el caudal másico a través del dispositivo queda limitado a un valor máximo, tras alcanzar un valor crítico en la presión aguas abajo (X. Zhang, Wang, Liao, Zhao, \& Shi, 2019). En esta instalación y con la geometría del Venturi utilizado, se ha determinado experimentalmente que el caudal critico se alcanza a los $60 \mathrm{l} / \mathrm{min}$ aproximadamente y llegados a ese punto, cualquier reducción de la presión aguas abajo del Venturi no conlleva ningún aumento del caudal, sino a una disminución drástica de la presión aguas abajo y un aumento en la fracción volumétrica de vapor observada.

En las gráficas de la Figura 50 y la Figura 51, se puede observar la evolución del valor de $\Delta \mathrm{p}$ y del número de cavitación respectivamente, en función del caudal que circula a través del Venturi. El ensayo se ha realizado 3 veces utilizando diferentes puntos de muestreo para comprobar su repetitividad. Concretamente se han analizado 25, 36 y 40 puntos de funcionamiento para los ensayos 1, 2 y 3 respectivamente. El rango de caudales ha sido siempre el mismo, utilizando como 
valor más bajo $30 \mathrm{l} / \mathrm{min}$ (salvo en el ensayo 1 que se ha partido de $40 \mathrm{l} / \mathrm{min}$ ) y como valor más elevado el caudal crítico (que se encuentra en unos $60 \mathrm{l} / \mathrm{min}$ tal y como se ha indicado anteriormente). Para la obtención del número de cavitación la presión de referencia ( $\mathrm{p}_{\text {ref }}$ ) se corresponde con $\mathrm{p}_{2}$ y la velocidad de referencia ( $\mathrm{v}_{\mathrm{ref}}$ ) se ha calculado como la velocidad existente en el estrechamiento del Venturi la cual es función del caudal proporcionado en cada momento por la bomba y el área del estrechamiento $\left(100 \mathrm{~mm}^{2}\right)$.

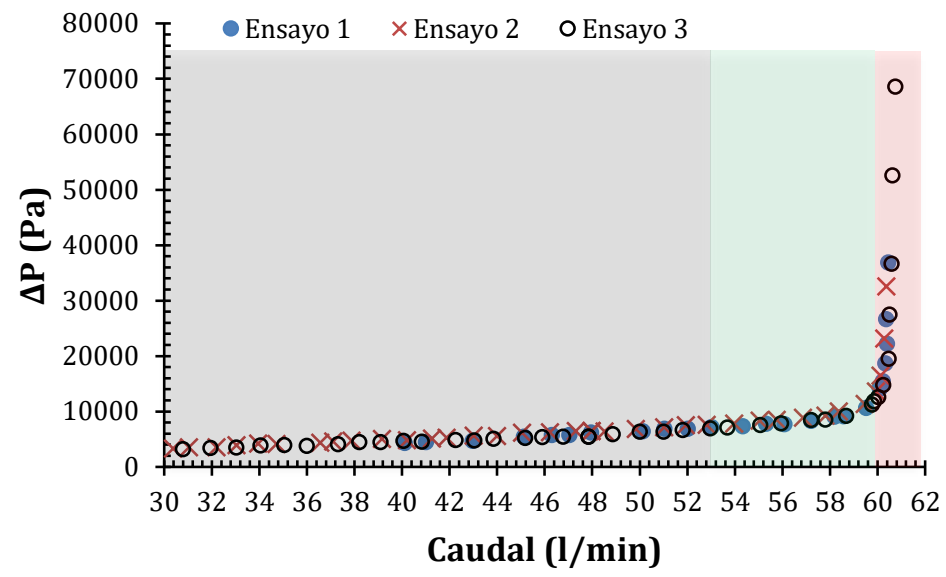

Figura 50: Evolución del incremento de presión en el estrechamiento del Venturi en función del caudal para los 3 ensayos realizados. Zona gris: sin cavitación, zona verde: cavitación estable, zona roja: cavitación inestable.

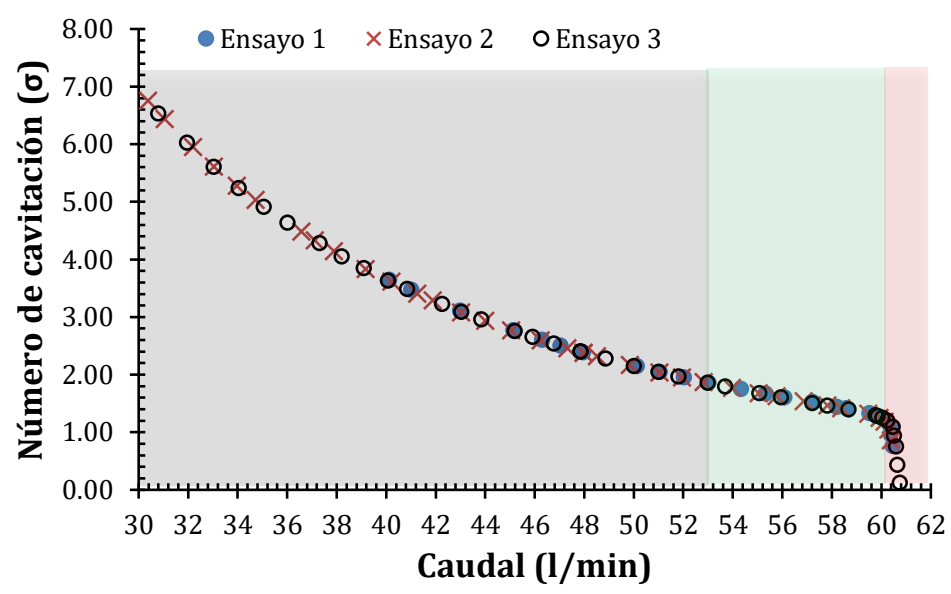

Figura 51: Evolución del número de cavitación en función del caudal. Zona gris: sin cavitación, zona verde: cavitación estable, zona roja: cavitación inestable. 
En los 3 ensayos realizados se puede observar cómo se ha reproducido exactamente el mismo comportamiento, y se han registrado los mismos valores en cuanto a caída de presión (Figura 50) y evolución del número de cavitación (Figura 51) se refiere. En el caso de la caída de presión, esta aumenta de forma proporcional al caudal hasta que se alcanza el valor crítico de $60 \mathrm{l} / \mathrm{min}$. A partir de ese momento, aunque se continúe disminuyendo la presión (abriendo la válvula de la bomba) para incrementar el caudal, este permanece constante y la presión aguas abajo disminuye de forma drástica. Un efecto similar puede observarse en el número de cavitación, el cual disminuye también de forma acusada cuando se alcanzan los $60 \mathrm{l} / \mathrm{min}$.

Así pues, tras la realización de los ensayos, se pueden diferenciar 3 modos de funcionamiento.

- Sin cavitación (zona gris): en esta situación, circula agua a través del Venturi con un caudal suficientemente bajo como para que no se produzca una caída de presión suficiente como para producir cavitación. El rango de funcionamiento en esta situación se extiende desde el caudal mínimo ensayado hasta los $52.9 \mathrm{l} / \mathrm{min}$, lo que se corresponde con valores de $\sigma>1.85$. En este punto comienza a producirse el fenómeno de la cavitación en las esquinas del estrechamiento del Venturi (Figura 53 izquierda). En este modo de funcionamiento no se produce vapor en el interior del Venturi y la caída de presión en la garganta es directamente proporcional al caudal.

- Cavitación estable (zona verde): Se produce cuando el caudal es superior a $\operatorname{los} 52.9 \mathrm{l} / \mathrm{min}$ o a partir de un valor de $\sigma<1.85$ (Figura 53 derecha). En esta situación se mantiene la evolución directamente proporcional entre el caudal y la caída de presión, pero se observa la generación de vapor debido a la cavitación. El número de cavitación también mantiene su tendencia, pero dado que esta es una exponencial decreciente, el número de cavitación comienza a descender más lentamente con el aumento del caudal. Este rango de funcionamiento se extiende hasta los $601 / \mathrm{min}$ o mientras que $\sigma>1.25$, momento a partir del cual se alcanza el caudal crítico y no se puede aumentar, aunque se descienda la presión de entrada.

- Cavitación inestable (zona roja): Se produce a partir de los $60 \mathrm{l} / \mathrm{min}$ o para valores de $\sigma<1 ., 25$. A partir de este punto, la caída de presión ya no es directamente proporcional al caudal porque este no puede aumentar (ya que se ha alcanzado el valor de caudal crítico). Por tanto, las pequeñas disminuciones de presión en la entrada (producidas al abrir ligeramente la válvula de la bomba) se traducen en grandes disminuciones de la presión aguas abajo (Figura 52) y, por tanto, en la caída de presión que se produce en el estrechamiento del Venturi. El límite de esta zona se alcanza cuando se 
produce el fenómeno de supercavitación (Figura 54) y toda la zona aguas abajo del Venturi se convierte en gas dado que la presión en toda esa área está por debajo de la presión de vapor.

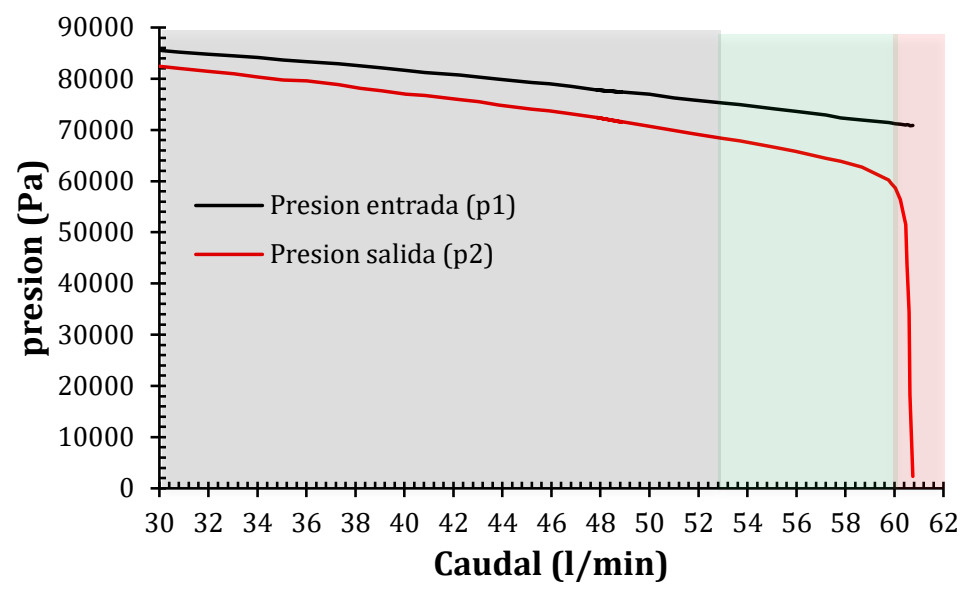

Figura 52: Evolución de las presiones aguas arriba (p1) y aguas abajo (p2), en función del caudal. Zona gris: sin cavitación, zona verde: cavitación estable, zona roja: cavitación inestable.
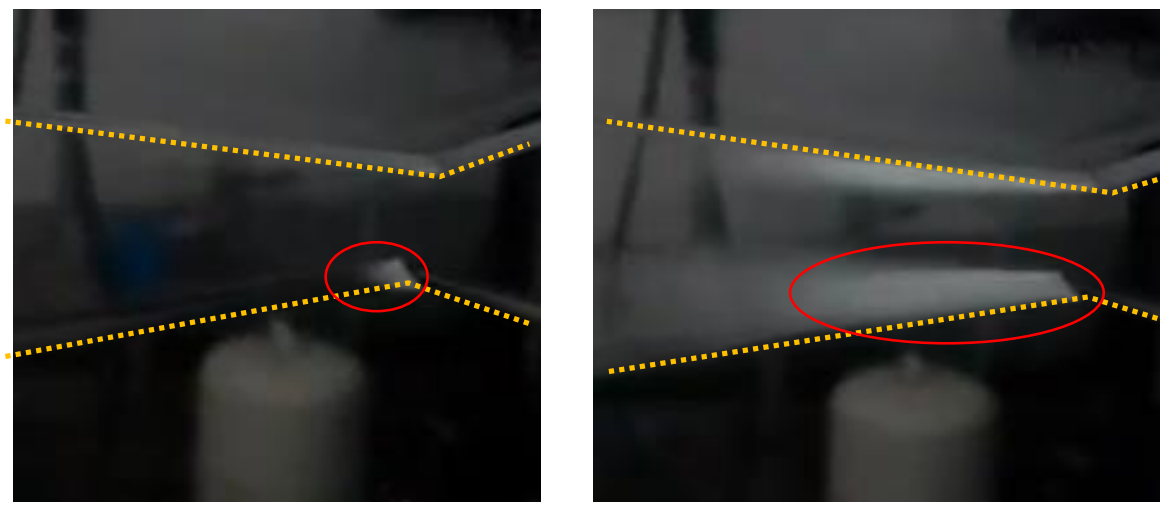

Figura 53: Situación observable durante la cavitación incipiente a caudal 52.91/min (izquierda) y en un punto dentro de la zona de cavitación estable (derecha).

De esta manera, el comportamiento del Venturi ha quedado completamente descrito y registrado para poder ser comparado con los resultados obtenidos utilizando la simulación CFD. Resulta interesante observar como en el momento en el que se produce la cavitación incipiente, esta se produce justo aguas abajo del vértice donde se encuentra el estrechamiento. Aunque la nube de cavitación se extiende conforme disminuye la presión, la zona donde se producen las bajas 
presiones es reducida y muy localizada. Una evidencia de esto es que el sensor de presión aguas abajo únicamente muestra valores cercanos a la presión de vapor en los últimos puntos donde existe supercavitación, y prácticamente la totalidad del Venturi aguas abajo del estrechamiento se encuentra ocupada por agua en fase gas.

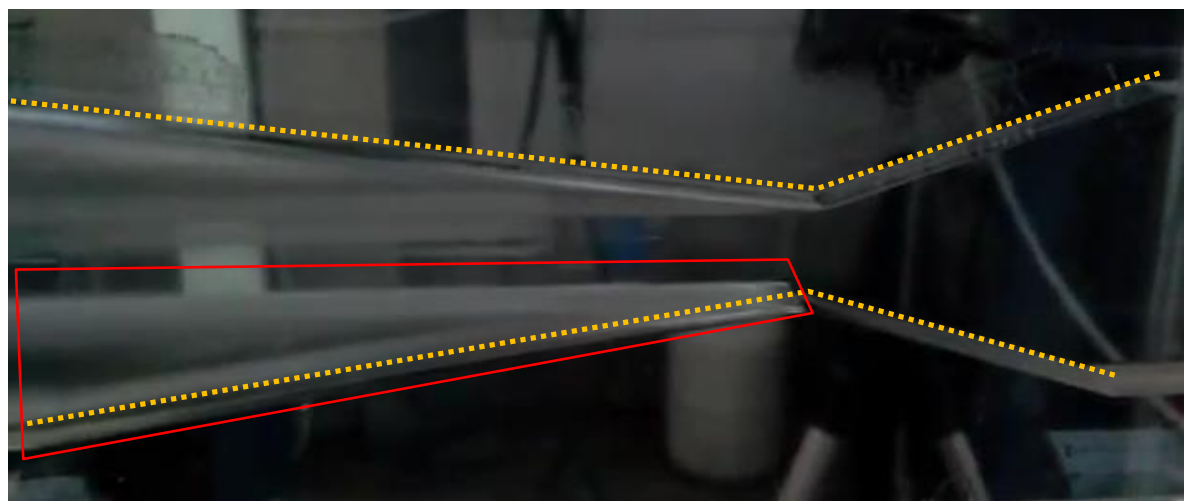

Figura 54: Supercavitación producida tras disminuir la presión de entrada una vez alcanzado al caudal crítico.

Finalmente, cabe destacar que tanto el comportamiento y distribución de la fracción volumétrica de gas, como los valores de los números de cavitación y los diferentes puntos de funcionamiento son muy similares al estudio de Tomov et al. (Tomov et al., 2016b), donde la geometría del Venturi es idéntica a la utilizada en este experimento. Se observa el mismo comportamiento dinámico en la fracción de gas, donde la nube de cavitación no permanece constante, sino que se produce una división intermitente en la nube de cavitación generada por el complejo comportamiento hidrodinámico que aparece tras el vértice donde se produce la cavitación.

\subsubsection{Geometría del submodelo}

La geometría del modelo en CFD se ha realizado acorde a la geometría presentada en el apartado 4.2.1, en la Figura 46 y Figura 47. Como se ha dicho anteriormente, la geometría se corresponde con la utilizada por Tomov et al. (Tomov et al., 2016b) y se ha realizado un modelo con simetría axial y en 2D para agilizar el cálculo (Figura 55) y reducir así los tiempos de computación (Shi et al., 2019a) (Bashir et al., 2011).

\subsubsection{Set up del submodelo y condiciones de contorno}

\subsubsection{Modelos matemáticos utilizados}

Las simulaciones se han llevado a cabo utilizando el modelo homogéneo donde las fases son tratadas como si fuesen continuas e interpenetrantes. Por tanto, 
únicamente se resuelve la ecuación del momento de la mezcla líquido-gas y se introduce la velocidad relativa que existe entre ambas fases, tal y como se ha explicado anteriormente en el apartado 2.2.3.

El desarrollo del modelo se ha llevado a cabo mediante Fluent 19.2, puesto que en este software la transferencia de masa en los modelos de cavitación se calcula utilizando modificaciones de la ecuación de Rayleigh-Plesset, y a la vez existen 3 modelos diferentes para determinar la fracción másica de líquido-gas producida. Estos 3 modelos utilizados en Fluent son Schnerr-Sauer (Schnerr \& Sauer, 2001), Singhal o Full Cavitation Mode (Singhal et al., 2002) y Zwart-Gerber-Belamri (Zwart et al., 2004) los cuales han sido explicados en detalle en el apartado 2.2.4. Además, este software permite el desarrollo de mallas $2 \mathrm{D}$, lo que reduce sustancialmente los tiempos de cálculo en sistemas que pueden ser simplificados a un comportamiento hidrodinámico en el plano (como es el caso particular del Venturi).

Las simulaciones se han realizado en régimen estacionario utilizando un intervalo de tiempo entre iteraciones (timestep) de $10 \mu \mathrm{s}$. Se ha utilizado el modelo de cavitación Schnerr-Sauer, el cual asume que la velocidad relativa entre ambas fases es nula y también que la mezcla se comporta de manera isoterma e incompresible. Debe recordarse que este modelo no considera el efecto del gas no condensable, pero dada la dificultad para determinar este parámetro de forma experimental y dado que la presencia del gas disuelto afecta muy poco la producción de vapor (Shi et al., 2019a), se ha decidido despreciar este término. El modelo se ha configurado para una densidad de líquido de $998.2 \mathrm{~kg} / \mathrm{m}^{3}$ y una viscosidad de $1.003 \mathrm{cP}$; mientras que para la fase gas, se ha establecido una densidad de $0.5542 \mathrm{~kg} / \mathrm{m}^{3}$ y una viscosidad de $0.0134 \mathrm{cP}$. Estos valores se corresponden a las propiedades físicas del agua y del vapor a 20 y $100^{\circ} \mathrm{C}$ respectivamente y para una presión de 1 atm. Estos son los valores típicos empleados por los autores que utilizan este y otros modelos como el de Singhal (Dastane et al., 2019b). Por otra parte, en el modelo de Schnerr-Sauer es necesario indicar también el número de núcleos por unidad de volumen de líquido disponibles. Dado que su determinación mediante métodos experimentales resulta inviable en este caso, se ha asumido un valor de $10^{13}$, considerado por muchos autores como el valor óptimo (H. Li, Kelecy, Egelja-maruszewski, \& Vasquez, 2008)(H. L. Liu, Liu, Wang, Wu, \& Wang, 2013) y utilizado en recientes estudios CFD con el mismo modelo de cavitación y el mismo tipo de cavitador (Shi et al., 2019b).

La cavitación suele ir acompañada de un alto nivel turbulencia y también de la formación de bolsas de vapor que crecen, se fusionan y colapsan. Las escalas temporales en las que esto sucede varían para cada evento individual de cavitación, y a su vez, dependen también de las condiciones del flujo principal y sus oscilaciones de presión. Debido a esto, la modelización de la cavitación utilizando 
simulaciones numéricas directas es una tarea inabordable y es necesario utilizar las ecuaciones promediadas de Navier-Stokes (RANS) (Dastane et al., 2019b). Esto hace que la elección del correcto modelo de turbulencia sea importante para conseguir un modelo que calcule de forma adecuada el fenómeno. Existen numerosas comparativas entre diferentes modelos de turbulencia realizados por diversos autores (Simpson \& Ranade, 2018b) (Dastane et al., 2019b) donde se concluye que el mejor modelo de turbulencia para este caso es el k- $\omega$ SST ya que permite introducir funciones que combinan los beneficios de un modelo $\mathrm{k}-\varepsilon$ utilizado en el fluido de transporte (líquido) y un modelo $k-\omega$ que permite obtener de forma adecuada el comportamiento de las regiones cercanas a las paredes.

En cuanto al resto de algoritmos y modelos utilizados para realizar la simulación, se han seguido las indicaciones de otras simulaciones CFD donde se ha utilizado Fluent (Dastane et al., 2019b) (Shi et al., 2019b). En la Tabla 6, se observan los diferentes modelos y algoritmos utilizados de forma habitual en el modelado de Venturi. Se observa cómo, en esencia, son muy similares y se basan en el modelo homogéneo de mezcla (denominado mixture en Fluent) donde existen pequeñas variaciones en las funciones utilizadas para la resolución de las diferentes ecuaciones. Para el presente caso en particular, cabe destacar la utilización de un modelo de turbulencia k- $\omega$ SST y un modelo de cavitación Schnerr-Sauer, que son los que pueden marcar una diferencia más significativa con respecto a la utilización de otros modelos.

\begin{tabular}{|c|c|c|c|}
\hline & Hongbo Shi et al. & G. Dastane et al. & J. Vilarroig et al. \\
\hline Multiphase flow & Mixture & Mixture & Mixture \\
\hline Volume fraction parameters & Implicit scheme & & Implicit scheme \\
\hline Viscous model & RANS-k- $\omega$ & RANS-k- $\omega$ SST & RANS-k- $\omega$ SST \\
\hline Cavitation model & Schnerr-Sauer & Singhal & Schnerr-Sauer \\
\hline Pressure-velocity coupling & Coupled scheme & SIMPLE & Coupled scheme \\
\hline Spatial discretization-gradient & Least square cell based & & Least square cell based \\
\hline Spatial discretization-pressure & PRESTO! & PRESTO! & PRESTO! \\
\hline Spatial discretization-momentum & 2nd-order upwind & 2nd-order upwind & 2nd-order upwind \\
\hline Spatial discretization-volume fraction & QUICK & 1st-order upwind & QUICK \\
\hline Spatial discretization-turbulence & 2nd-Order Upwind & 2nd-Order Upwind & 2nd-Order Upwind \\
\hline
\end{tabular}

Tabla 6: Modelos y algoritmos utilizados para realizar modelados CFD de un Venturi.

\subsubsection{Condiciones y parámetros físicos del submodelo}

La configuración de las variables físicas del modelo es sencilla. Atendiendo a las tablas estandarizadas se ha establecido una presión de vapor de $4210 \mathrm{~Pa}$ para una temperatura de $30^{\circ} \mathrm{C}$ (según las tablas de propiedades físicas estandarizadas para el agua) y una presión de operación que oscila entre los 85000-70000 pascales, coincidiendo con la presión experimental medida en la entrada (Figura 52). El 
valor de esta presión es menor a la atmosférica debido a 3 motivos: existe una válvula aguas arriba del estrechamiento que introduce una caída de presión, la succión de la bomba se encuentra aguas abajo del estrechamiento, y por último y más importante, el Venturi se encuentra por encima de la cota del depósito. Debido a esto, durante su operación el Venturi está sometido a una presión negativa, que por otro lado facilita la aparición del fenómeno de la cavitación sin necesidad de introducir caudales excesivamente elevados. Asimismo, se ha establecido una condición de simetría axial a lo largo del eje central del Venturi y otra condición de presión en la salida (Figura 55). La presión de salida varía en un rango que va desde los 82000 pascales y los 4210 pascales (presión de vapor) consiguiéndose de este modo, caudales de entre 33 y 61 l/min.

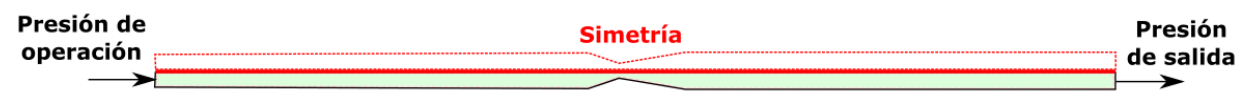

Figura 55: Condiciones de contorno establecidas en el modelo del Venturi.

\subsubsection{Mallado del submodelo}

El mallado se considera la parte más crítica en el proceso de simulación CFD. La correcta selección de los parámetros que forman la malla (tamaños y tipología de nodos, estructura, refinamientos, etc.), determina de manera esencial la coherencia de los resultados obtenidos.

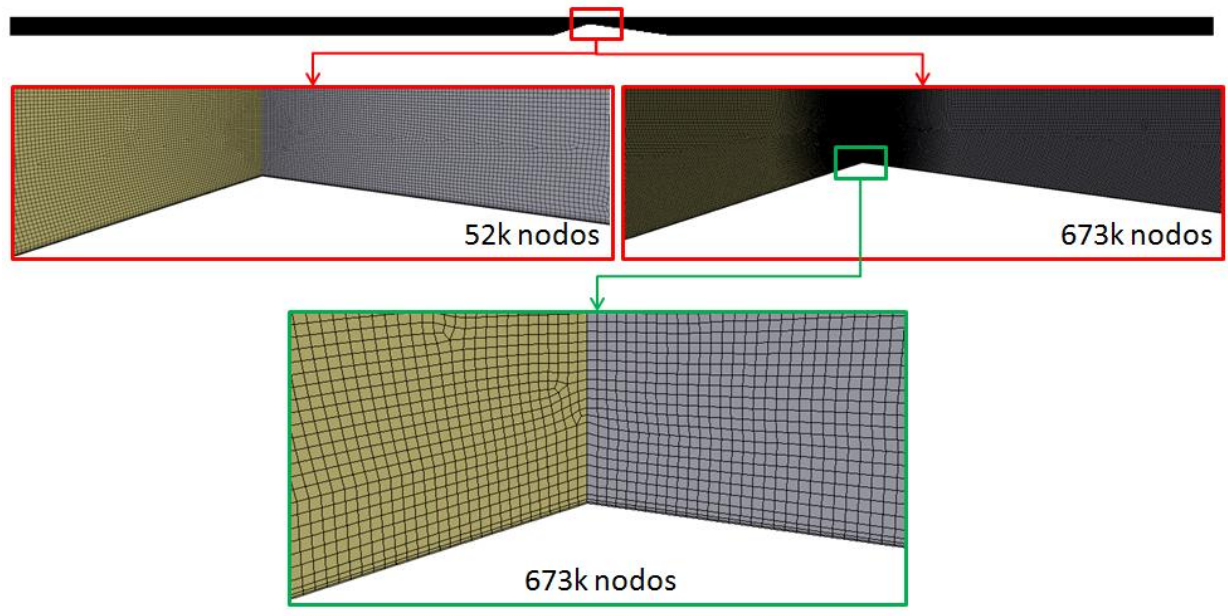

Figura 56: Diferentes mallados utilizados para la simulación CFD del Venturi. 
Por tanto, antes de proceder con las simulaciones CFD que determinan el efecto de la cavitación producido en el Venturi, se ha realizado un estudio de independencia de malla donde se ha analizado el perfil de velocidades obtenido en el centro del estrechamiento. Se han utilizado 6 mallados diferentes de $52 \mathrm{k}, 103 \mathrm{k}$, 280 k, 460 k y 673 k nodos. En todos los casos se ha utilizado una malla hexaédrica estructurada en 2 dimensiones y se han obtenido valores de $y+$ inferiores a 1 para garantizar un correcto cálculo de la subcapa viscosa utilizando el modelo turbulento k- $\omega$ SST. En la Figura 56 se puede observar las diferencias entre la malla de $52 \mathrm{k}$ y la de $673 \mathrm{k}$. El refinamiento cerca del vértice es mucho más acusado en la malla de $52 \mathrm{k}$ nodos que en la de $673 \mathrm{k}$ nodos, sin embargo, la distancia del primer nodo es la misma para ambos casos y tiene un valor de $1 \mu \mathrm{m}$. Con esto se obtienen valores de y+ que oscilan entre 0.71 y 0.62 .

En la gráfica de la Figura 57 se puede observar los perfiles de velocidad obtenidos a lo largo del estrechamiento (línea vertical que pasa justo por el vértice). Se observa cómo, cuando el tamaño de malla no es suficientemente grande, se produce una sobreestimación de la velocidad cerca del vértice. A medida que se aumenta el número de nodos, dicha velocidad se va reduciendo hasta que al llegar a un tamaño de malla de $460 \mathrm{k}$ nodos, la diferencia es prácticamente imperceptible y se confirma la independencia del tamaño de la malla con el resultado.

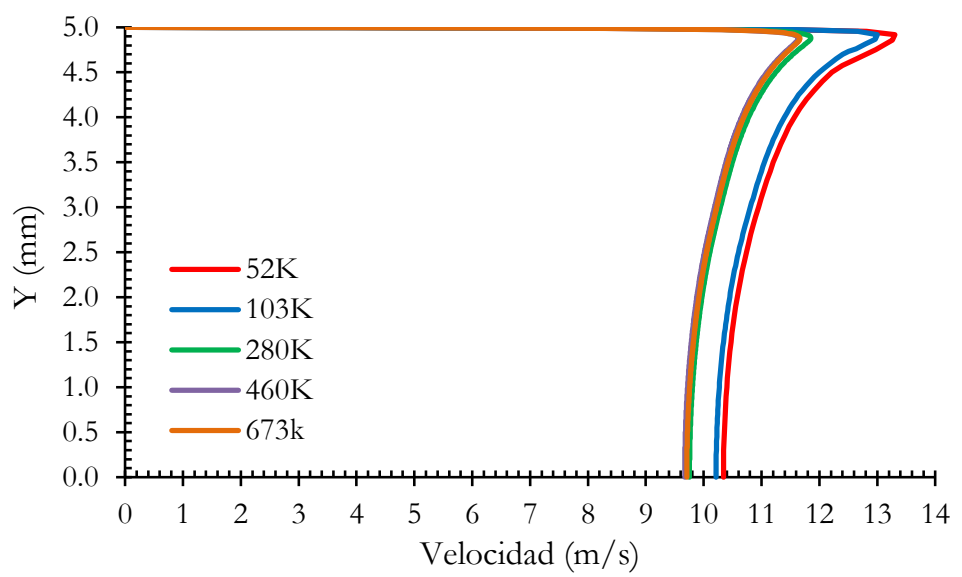

Figura 57: Perfiles de velocidad en el estrechamiento del Venturi para los diferentes mallados del modelo.

Por otro lado, se ha determinado la variación de dos parámetros en función del tamaño de malla: la velocidad a la salida del Venturi y la diferencia de presión en el estrechamiento. En las gráficas de la Figura 58 se observa como a partir de la malla de tamaño $280 \mathrm{k}$ nodos, las variaciones tanto en la velocidad de salida como en la caída de presión en el estrechamiento son muy pequeñas. Así pues, al pasar 
de 280 k a 460 k nodos hay una variación del 1.91 y 1.08 \% para la caída de presión y la velocidad de salida respectivamente, mientras que, al aumentar el número de nodos de $480 \mathrm{k}$ hasta $673 \mathrm{k}$, estos porcentajes únicamente se reducen hasta el 0.81 y $0.36 \%$ respectivamente.

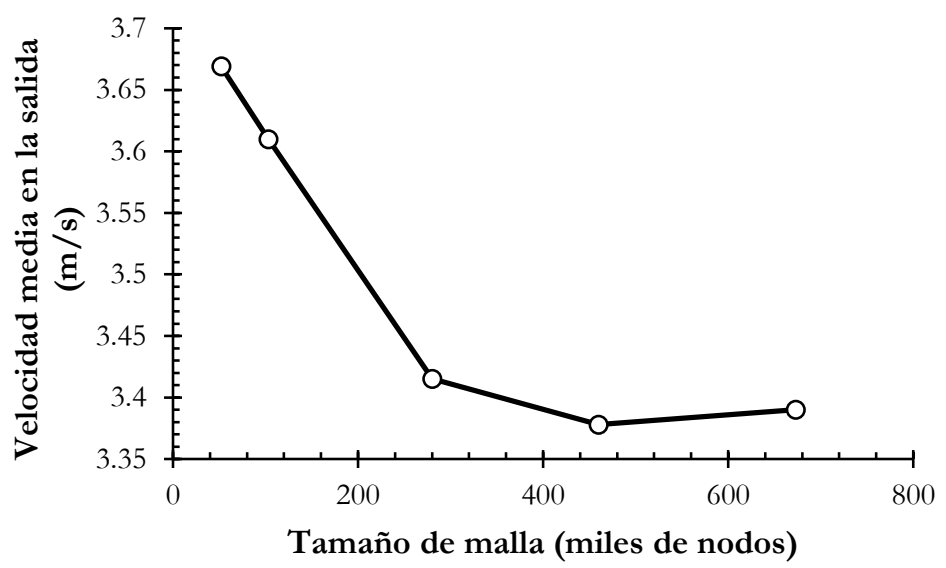

(a)

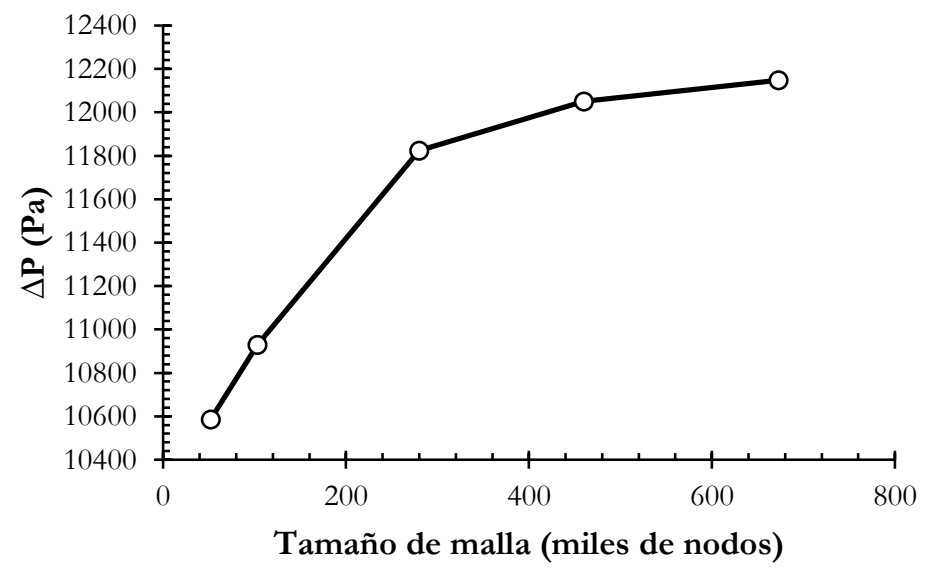

(b)

Figura 58: Variación de la velocidad en la salida del Venturi (a) y de la diferencia de presión en el estrechamiento (b) en función del mallado.

Así pues, tras el análisis de sensibilidad de malla, se concluye que la malla óptima para realizar las simulaciones en CFD es la de $460 \mathrm{k}$ nodos, ya que a partir de este punto un mayor refinamiento no afecta ni al perfil de velocidades del 
estrechamiento ni tampoco a parámetros críticos como la velocidad de salida en el Venturi ni la caída de presión en el estrechamiento.

\subsubsection{Resultados}

En el presente apartado, se muestran los resultados obtenidos tras las simulaciones con la malla del Venturi de $460 \mathrm{k}$ nodos. En la Figura 59, se representa la caída de presión que se produce en el estrechamiento del Venturi en función del caudal que por él circula. Se puede observar cómo los diferentes puntos de funcionamiento simulados mediante el modelo CFD se ajustan de manera adecuada a la curva obtenida en los ensayos experimentales.

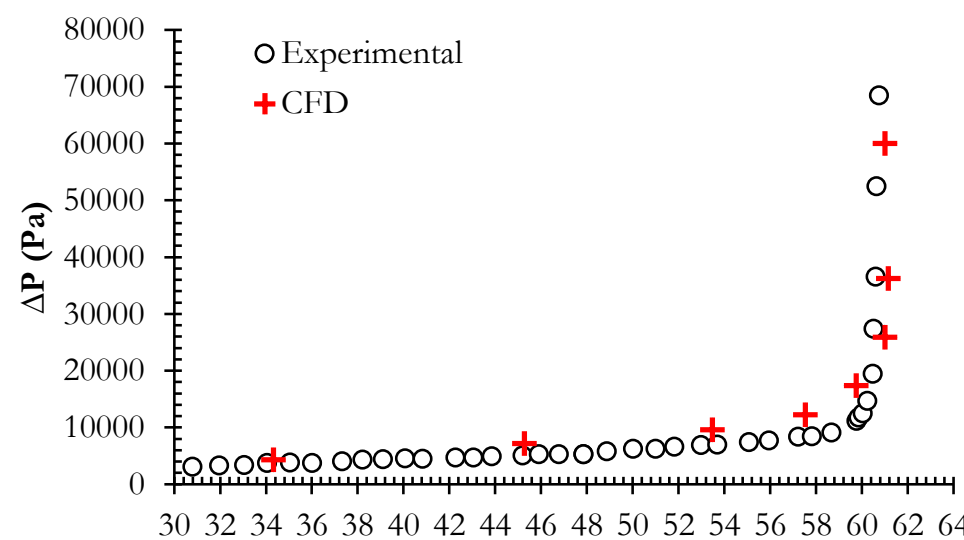

Caudal (1/min)

Figura 59: Comparación entre el ensayo experimental y las simulaciones realizadas con CFD.

Durante el primer tramo de la función (inexistencia de cavitación), los valores se corresponden adecuadamente con la curva de experimentación. La zona más conflictiva se encuentra cerca del caudal crítico de $60 \mathrm{l} / \mathrm{min}$, donde se encuentra la transición entre la zona de cavitación estable) y la zona de cavitación inestable. En este punto, variaciones muy reducidas en la caída de presión en el estrechamiento del Venturi se traducen en grandes variaciones en el caudal, por lo que el error de medida de los instrumentos (a pesar de ser muy reducidos) pueden acarrear variaciones significativas, lo que dificulta una comparación exitosa entre el caso experimental y el CFD. Sin embargo, en este caso, se puede observar como la tendencia entre la medición y el modelo CFD, se ajusta de manera muy satisfactoria. Durante el segundo tramo (cavitación estable) y el tercero (cavitación inestable), los errores tanto en la caída de presión como en el caudal se van 
reduciendo hasta valores por debajo del $1 \%$ y vuelve a aumentar cuando se alcanza el régimen de supercavitación (último punto).

Por otro lado, se tienen dos puntos de funcionamiento especialmente interesantes. Uno es el momento en el que se produce la cavitación incipiente y el otro cuando se alcanza el caudal crítico. En el primer caso, experimentalmente se ha determinado que la cavitación aparece por primera vez cuando se alcanza un caudal de $52.98 \mathrm{l} / \mathrm{min}$, aunque en las simulaciones este punto no se ha podido determinar de forma exacta, se puede afirmar que se encuentra entre los $45.27 \mathrm{y}$ los 57.23 1/min. En el segundo caso, tras el ensayo con el Venturi se ha podido obtener el caudal crítico en $60.2 \mathrm{l} / \mathrm{min}$ aproximadamente, mientas que para el caso de las simulaciones en CFD, dicho valor ronda los $61.0 \mathrm{l} / \mathrm{min}$, lo que supone un error del $1.3 \%$. En ambos casos se concluye que los resultados obtenidos mediante las simulaciones CFD son muy parecidos a los experimentales.

\begin{tabular}{cc|cc|cc}
\multicolumn{2}{c|}{ Simulación CFD } & \multicolumn{2}{|c}{ Datos experimentales } & \multicolumn{2}{c}{ Errores } \\
$\Delta \mathbf{P}(\mathbf{P a})$ & Caudal (1/min) & $\Delta \mathbf{P}(\mathbf{P a})$ & Caudal (1/min) & $\Delta \mathbf{P ~ ( P a )}$ & Caudal (1/min) \\
\hline 4322 & 34.33 & $4993 \pm 50$ & $43.63 \pm 0.14$ & $13.4 \%$ & $21.3 \%$ \\
7225 & 45.27 & $9178 \pm 92$ & $58.38 \pm 0.18$ & $21.3 \%$ & $22.5 \%$ \\
9609 & 53.48 & $11766 \pm 118$ & $59.86 \pm 0.18$ & $18.3 \%$ & $10.7 \%$ \\
12254 & 57.53 & $14710 \pm 147$ & $59.94 \pm 0.18$ & $16.7 \%$ & $4.0 \%$ \\
17385 & 59.76 & $19477 \pm 195$ & $60.16 \pm 0.18$ & $10.7 \%$ & $0.7 \%$ \\
25938 & 61.01 & $27413 \pm 274$ & $60.21 \pm 0.18$ & $5.4 \%$ & $1.3 \%$ \\
36277 & 61.15 & $36578 \pm 366$ & $60.29 \pm 0.18$ & $0.8 \%$ & $1.4 \%$ \\
60027 & 61.00 & $52516 \pm 525$ & $60.34 \pm 0.18$ & $14.3 \%$ & $1.1 \%$
\end{tabular}

Tabla 7: Comparativa y errores entre datos experimentales y CFD.

Por último, se han comparado las zonas de cavitación producidas durante los ensayos en laboratorio con las calculadas por el modelo CFD. Para ello, se han seleccionado las imágenes captadas durante los ensayos experimentales de aquellos puntos de funcionamiento más cercanos a los simulados mediante CFD. En cada punto de funcionamiento del ensayo experimental, se han captado 50 fotografías y dado que las zonas de cavitación presentan ligeras oscilaciones debido a los desprendimientos del flujo de vapor que se producen como consecuencia del flujo de reentrada producido tras el vértice (Tomov et al., 2016b). Mediante un pequeño script de Matlab, se han solapado las 50 fotografías en una sola para tener un área de cavitación clara y poder compararla con el punto simulado.

En la Figura 60, se muestra el solapamiento entre las imágenes obtenidas mediante la cámara durante los ensayos experimentales del Venturi, y las simulaciones realizadas mediante CFD. Los contornos coloreados se corresponden 
con la simulación en CFD mientras que el sombreado blanco indica la zona de cavitación registrada con las imágenes de la cámara fotográfica.

\section{Vapor.Volume Fraction}
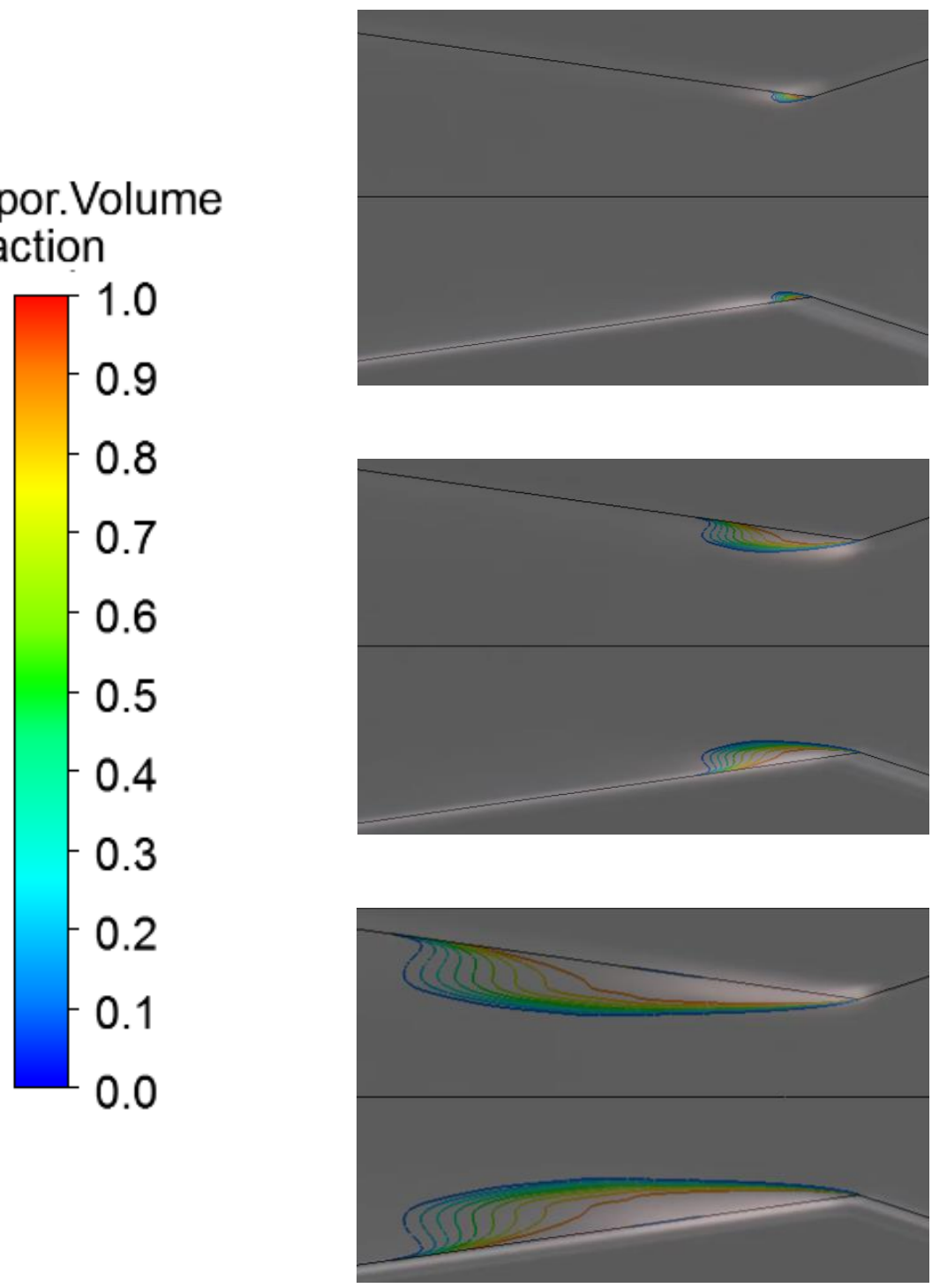

Figura 60: Comparativa de la fracción volumétrica de gas obtenida en los experimentos del Venturi y en las simulaciones CFD. De arriba a abajo se presentan los puntos de funcionamiento a caudales de 57.53, 59.76 y $61.011 / \mathrm{min}$. 
Los momentos mostrados coinciden con los 3 puntos simulados justo durante el codo de la curva de la Figura 59 (caudales de 57.53, 59.76 y 61.01 1/min), lo que corresponde al momento en el que se pasa de la zona de cavitación estable a la inestable. Se puede observar como la nube de cavitación producida coincide adecuadamente con lo observado en cada punto de funcionamiento en los ensayos experimentales. Tanto la forma de la nube de cavitación como la cantidad de vapor generado que se ha estimado mediante la simulación CFD, se ajustan y ocupan un área muy similar a la obtenida con la superposición de las fotografías realizadas durante el ensayo en cada punto de funcionamiento.

En la evolución del fenómeno de la cavitación mostrado en la Figura 60, se pone en evidencia la rapidez con la que se incrementa el área de formación de vapor, ya que desde los $57.53 \mathrm{l} / \mathrm{min}$ a los $61.01 \mathrm{l} / \mathrm{min}$ se pasa de una cavitación prácticamente incipiente a un área significativamente grande ocupada por vapor. Una vez alcanzado este caudal crítico, al continuar disminuyendo ligeramente la presión de entrada al Venturi (últimos 2 puntos de la gráfica de la Figura 59), se produce el fenómeno de supercavitación observado en la Figura 54, y prácticamente la totalidad del volumen que se encuentra aguas abajo del estrechamiento, queda ocupado por vapor (Figura 61: Estado de supercavitación producido al disminuir excesivamente la presión en la entrada del Venturi.).

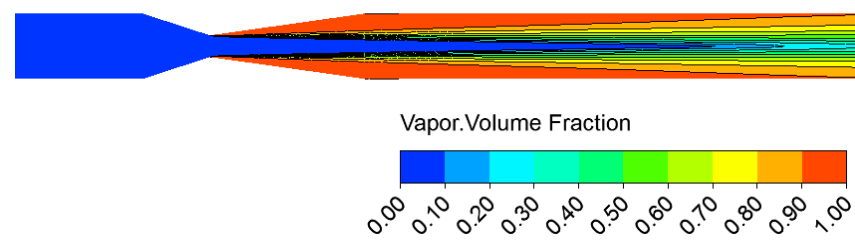

Figura 61: Estado de supercavitación producido al disminuir excesivamente la presión en la entrada del Venturi.

Se puede observar cómo al incrementar el caudal, las velocidades en todo el dominio del Venturi aumentan. Es interesante hacer hincapié en que las bajas presiones se producen en puntos muy localizados. Concretamente, la presión más baja de todo el dominio del Venturi se encuentra justo detrás del vértice del estrechamiento, donde debido a la alta velocidad que se sucede en ese punto, se produce una caída brusca de la presión. Este aumento localizado de la velocidad justo en el estrechamiento puede verse detalladamente en el perfil de velocidades presentado en la gráfica de la Figura 57. Es en ese punto donde se produce el fenómeno de la cavitación, el cual se inicia cuando la presión alcanza el valor de la presión de vapor. Una vez alcanzada la presión de vapor, el valor de la presión absoluta se mantiene constante en ese valor, y al continuar incrementando el caudal a través del Venturi (o disminuir la presión en la entrada), el área ocupada por la 
presión de vapor se vuelve cada vez más grande, lo que produce un incremento en la producción de vapor y en la nube de gas que se produce (Figura 60).

En las siguientes imágenes (Figura 62), se muestra la distribución tanto de presiones como de velocidades en el estrechamiento del Venturi para caudales de funcionamiento de 57.53, 59.76 y $61.01 \mathrm{l} / \mathrm{min}$.

$\underline{\text { Presión }}$

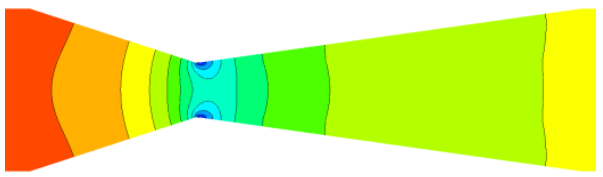

Funcionamiento a caudal de $57.53 \mathrm{l} / \mathrm{min}$
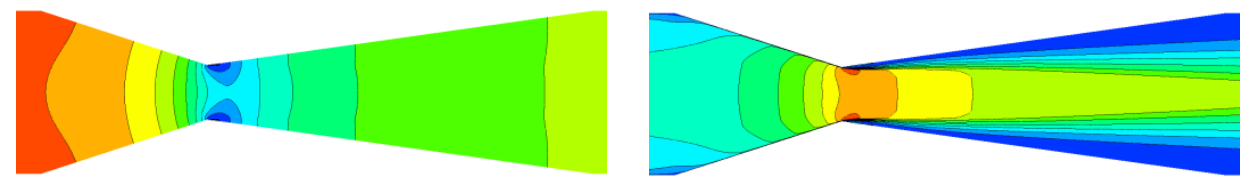

Funcionamiento a caudal de $59.76 \mathrm{l} / \mathrm{min}$
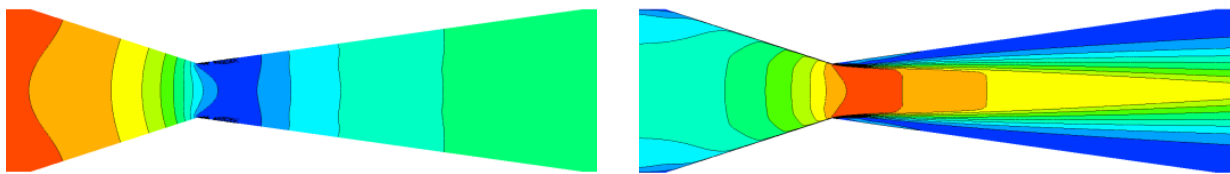

Funcionamiento a caudal de $61.01 \mathrm{l} / \mathrm{min}$
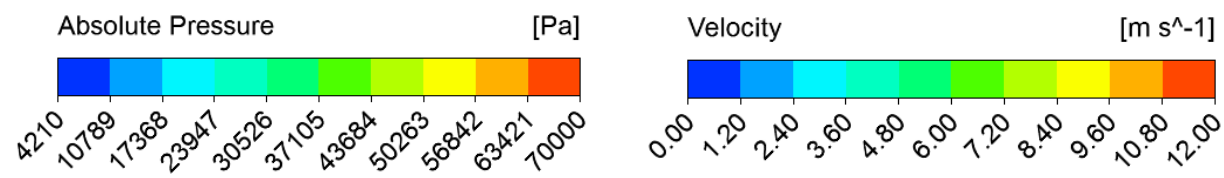

Figura 62: Distribución de velocidades y presiones en el estrechamiento del Venturi para caudales de funcionamiento de $57.53,59.76$ y $61.011 / \mathrm{min}$.

Para concluir este apartado de ensayos con el dispositivo Venturi, cabe decir que el modelo de cavitación configurado para las simulaciones CFD ha mostrado una muy buena concordancia con los resultados experimentales. Se ha observado una pequeña sobreestimación del caudal incipiente (a partir del cual surge el fenómeno 
de la cavitación) y del caudal crítico admitido por el Venturi. Esta sobreestimación se debe, muy posiblemente, a que la temperatura real del ensayo se encuentre ligeramente por encima de $\operatorname{los} 30^{\circ} \mathrm{C}$ a los que se ha configurado el modelo. Al realizarse los experimentos a una mayor temperatura, se aumenta el valor de la presión de vapor y el fenómeno de la cavitación se produce más fácilmente (a caudales más bajos). En cualquier caso, se considera que la configuración del modelo de cavitación es suficientemente robusta y precisa como para ser utilizada en las simulaciones del sistema de cavitación completo que permitirán determinar el diseño más adecuado para el sistema.

\subsection{Análisis del comportamiento de los dientes del rotor}

En este apartado se presenta un submodelo reducido cuyo objetivo es analizar en detalle el comportamiento del diente del rotor a altas revoluciones. Las principales diferencias con el modelo del Venturi desarrollado en el anterior apartado y el modelo del cavitador completo desarrollado en el apartado siguiente, es que en este caso se considera un dominio rotativo y que, por tanto, se encuentra sometido a las fuerzas y a las velocidades inducidas por el fluido como consecuencia del giro a altas revoluciones.

La razón por la cual se ha decidido analizar en detalle este punto se debe a que, en el modelo 2D utilizado para estudiar el funcionamiento del cavitador completo, resulta complicado discernir entre los fenómenos motivados por el giro del rotor y los que son consecuencia de las características geométricas de los discos del estator. Por tanto, el objetivo de este submodelo no es otro que el de obtener los gradientes de presión y de velocidad que se producen como consecuencia de la rotación para poder determinar los efectos que se producen al incorporar en el modelo los diferentes diseños propuestos del estator. En este sentido, el estudio es muy similar al planteado por otros autores como Badve et al., donde se ha estudiado en detalle el efecto hidrodinámico producido en el interior de los huecos de un tambor rotativo diseñado para un proceso de cavitación (M. P. Badve et al., 2015).

\subsubsection{Geometría del submodelo}

Tal y como se ha comentado, la geometría a simular consiste en una sección detallada del diente del rotor, que permitirá analizar en detalle el comportamiento hidrodinámico cuando los valores de la velocidad de rotación sean muy elevados. Concretamente, se ha seleccionado como dominio el interior de uno de los huecos, puesto que es en esa zona donde se concentra toda la actividad hidrodinámica del rotor. 
En la Figura 63, se puede observar como el modelo geométrico sobre el que se realizará la simulación engloba únicamente el área correspondiente al hueco del rotor, la cual se obtiene a partir de la geometría $2 \mathrm{D}$ del volumen fluido del rotor proyectado sobre un plano de corte.
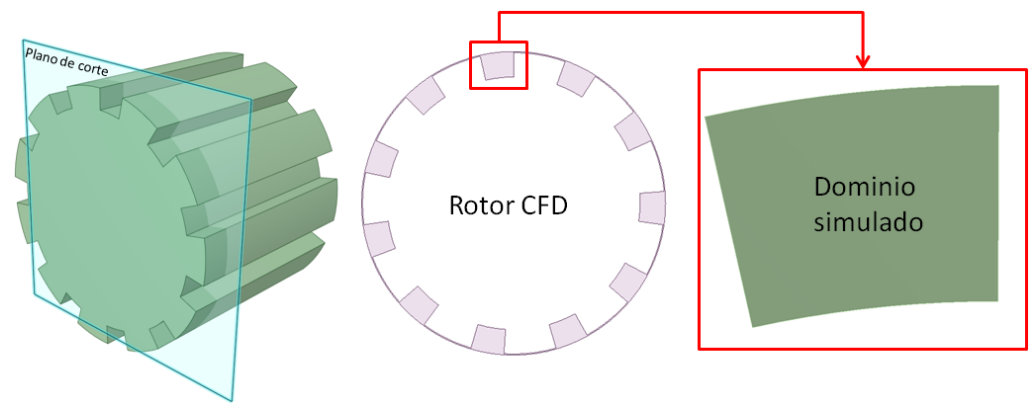

Figura 63: Dominio utilizado en las simulaciones del diente del rotor.

El dominio de simulación es muy pequeño y tiene un área aproximada de $65.11 \mathrm{~mm}^{2}$. Además, es un dominio con una geometría muy simple donde las condiciones de contorno serán la clave para obtener resultados coherentes y extraer información útil del modelo.

\subsubsection{Set up del submodelo y condiciones de contorno}

Tal y como se ha comentado anteriormente, en este modelo en particular, la correcta selección de las condiciones de contorno es crítica para conseguir que el sistema se comporte de la forma adecuada y proporcione los resultados esperados. Así pues, es importante contemplar la velocidad de rotación a la que está sometido el rotor $y$, por ende, los dientes, y configurar todo el dominio como un sistema rotativo que permita obtener una fotografía de lo que sucede a elevadas velocidades.

\subsubsection{Modelos matemáticos utilizados}

En la simulación del submodelo de este apartado se ha implementado el modelo de cavitación Schnerr-Sauer utilizando los parámetros obtenidos, gracias a las simulaciones validadas del Venturi descritas en el anterior apartado (apartado 4.2.4.1). En estas simulaciones no solo se ha mantenido el modelo homogéneo de mezcla (mixture model en Fluent) y las características de densidad y viscosidad de ambas fases, sino también las ecuaciones promediadas de Navier-Stokes (RANS), el modelo de turbulencia k- $\omega$ SST, y todos los algoritmos de cálculo utilizados y validados en las simulaciones del Venturi (ver Tabla 6).

Por tanto, a nivel matemático, todas las ecuaciones y modelos involucrados en la resolución de las simulaciones son homólogos a los anteriormente utilizados y 
validados en las simulaciones del Venturi. Así pues, las diferencias entre el modelo del Venturi y los submodelos simulados en este apartado residen en las características geométricas, y en las condiciones y parámetros físicos configurados para este modelo, los cuales se explican detalladamente en el siguiente apartado.

\subsubsection{Condiciones y parámetros físicos del submodelo}

Resulta importante mencionar que en este submodelo se han analizado dos supuestos diferentes cambiando ligeramente las condiciones de contorno. A continuación, se describen las diferentes condiciones de contorno para cada uno de los supuestos, así como el objetivo perseguido con cada uno de ellos:

- Configuración 1: se ha establecido el dominio como estacionario y, a excepción de la arista superior, se han configurado todas las aristas con la condición de pared lisa estática sin deslizamiento (smooth wall). La arista superior, se ha establecido como pared móvil con una condición de rotación con respecto al centro de giro natural del rotor, para diferentes velocidades de giro $(3600,4100,4600,5100$ y $5600 \mathrm{rpm})$. La presión de referencia en el dominio es de 101325 pascales y tanto la superficie frontal como trasera del modelo, se han considerado como simetrías transversales al eje del rotor. El establecimiento de esta condición es posible gracias a la peculiar geometría del rotor, que provoca que el comportamiento esperado a lo largo de todo el eje longitudinal sea idéntico (Figura 64).

La finalidad de esta primera configuración es determinar el efecto hidrodinámico que se produce en el interior del hueco como consecuencia de la velocidad inducida por el giro del rotor. Dado que el dominio es estático, no se considera el efecto de la fuerza centrífuga, y por tanto los gradientes de presión obtenidos mediante este modelo únicamente serán consecuencia de la velocidad y distribución del flujo en el interior del hueco.

- Configuración 2: el modelo se ha establecido con la condición de dominio rotativo y se han considerado las mismas velocidades de giro utilizadas en la configuración 1 (3600, 4100, 4600, 5100 y 5600 rpm). En este caso, todas las aristas se comportan de acuerdo con la condición de pared lisa estática sin deslizamiento (smooth wall) y se han mantenido las condiciones de simetría en la cara frontal y trasera, así como la presión de referencia en 101325 pascales (Figura 65).

La finalidad de esta segunda configuración es la de obtener el gradiente de presiones que se produce en el interior del hueco del rotor única y exclusivamente como consecuencia de la fuerza centrífuga producida por la rotación del volumen fluido. En este caso, no se producirán gradientes de velocidad puesto que todo el dominio actúa como un sólido rígido en rotación con respecto a un eje, pero se podrá determinar cómo la velocidad 
de rotación afecta a la caída de presión en el fondo del hueco, efecto registrado en diferentes estudios de Badve et. al. (M. P. Badve et al., 2015) (M. Badve et al., 2013).

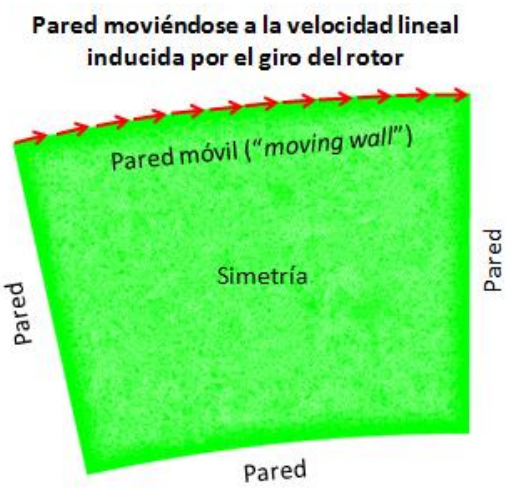

Figura 64: Condiciones de contorno establecidas para la configuración 1.

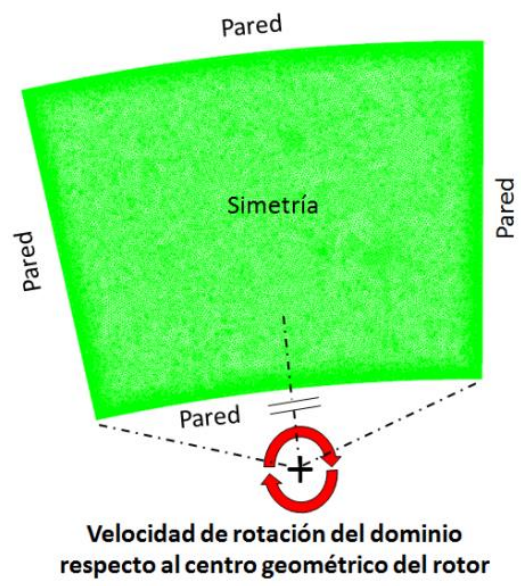

Figura 65: Condiciones de contorno establecidas para la configuración 2 .

Con las condiciones de contorno anteriormente mencionadas, se ha llevado a cabo la simulación del sistema utilizando un intervalo de tiempo entre iteraciones ("time step") de $1 \mu \mathrm{s}$ y garantizando que los residuales se encuentren siempre por debajo de $10^{-5}$, para de esta forma, considerar que se ha producido la convergencia del cálculo. 


\subsubsection{Mallado del submodelo}

Con el fin de obtener el mallado óptimo para realizar las simulaciones, tanto el mallado de la configuración 1 como de la configuración 2 son idénticos y utilizan los mismos criterios y parámetros utilizados en la simulación del Venturi a partir del cual se han calibrado el modelo de cavitación (apartado 4.2.4.3).

Por tanto, se ha generado una malla hexaédrica estructurada en 2 dimensiones con un mallado de capas (inflation) que permita obtener valores de $\mathrm{y}+$ inferiores a 1 con el fin de conseguir un que el cálculo realizado mediante el modelo turbulento k- $\omega$ SST sea adecuado (Figura 66). Para ello, ha sido necesario que la distancia del primer nodo a las paredes del dominio sea de $1 \mu \mathrm{m}$ y se han generado un total de 10 capas en cada una de las paredes. Asimismo, se ha utilizado un tamaño máximo en el dominio central (caras de simetría) de $50 \mu \mathrm{m}$ con el objetivo de conseguir que el número de Courant se encuentre siempre en valores cercanos a la unidad (o inferior a esta) y poder visualizar de forma adecuada los gradientes de velocidad y presión producidos dentro del intervalo de tiempo estipulado para el cálculo iterativo.

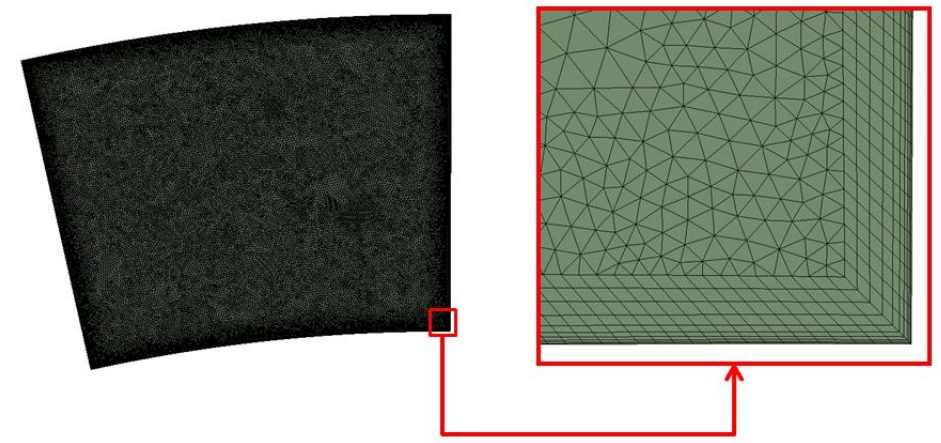

Figura 66: Mallado utilizado para las simulaciones del submodelo 2 en la configuración 1 y 2.

\subsubsection{Resultados}

\subsubsection{Resultados obtenidos con la configuración 1}

A continuación, se muestran los resultados obtenidos tras las simulaciones CFD del submodelo 2 en sus dos configuraciones. En primer lugar, se presentan los resultados obtenidos para la configuración 1.

Se puede observar cómo cuando la pared superior se mueve a diferentes velocidades dentro del rango de 3600 a $5600 \mathrm{rpm}$, se induce un movimiento de rotación en el interior del hueco que es mayor cuanto más elevada es la velocidad angular simulada (Figura 67). El comportamiento radial de la velocidad puede 
analizarse detalladamente gracias a la gráfica de la Figura 68. En ella se puede ver cómo las velocidades en el lateral derecho de la cavidad son negativas (dirección hacia el centro del rotor), mientras que en el lateral izquierdo son positivas (dirección hacia el exterior del rotor). Justo en el centro de la cavidad, la velocidad obtenida en todos los casos es 0 , poniendo en evidencia la generación de un movimiento circular semejante al de un remolino.
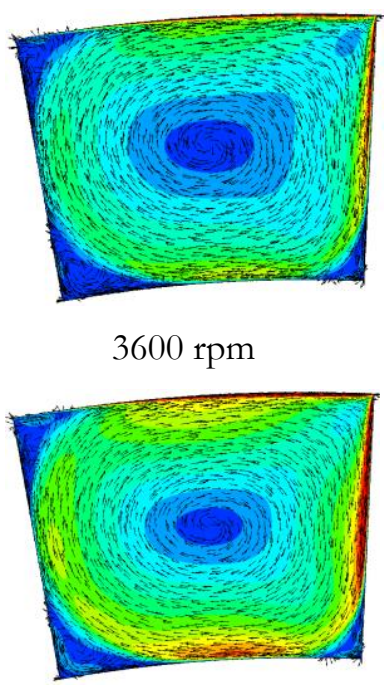

$5100 \mathrm{rpm}$
$3600 \mathrm{rpm}$

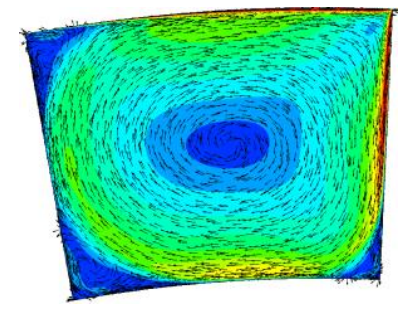

$4100 \mathrm{rpm}$

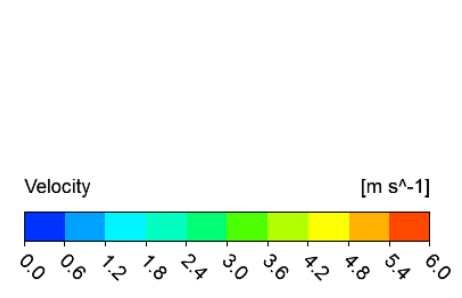

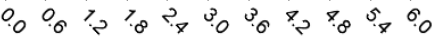

Figura 67: Distribución de velocidades radiales para diferentes velocidades de rotación en la configuración 1 del submodelo 2 .

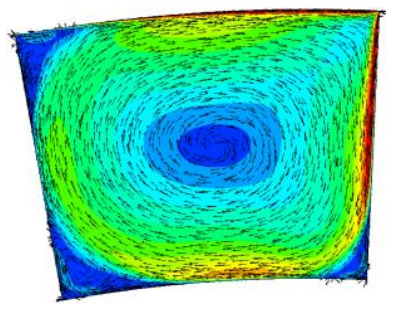

$4600 \mathrm{rpm}$

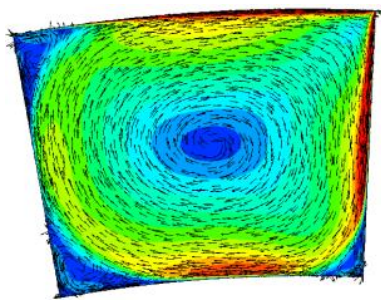

$5600 \mathrm{rpm}$ 


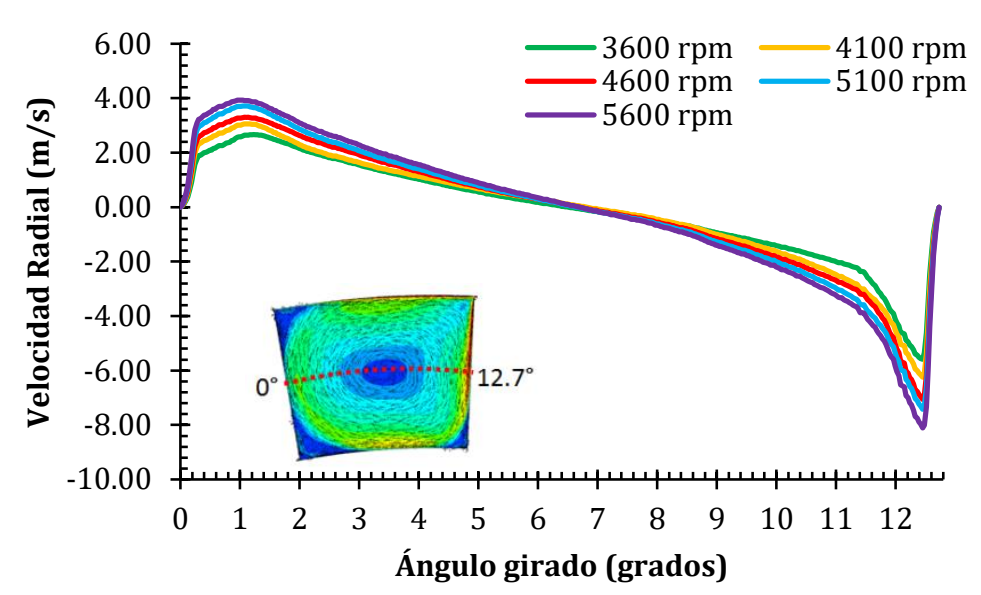

Figura 68: Variación de la velocidad a lo largo de la línea circunferencial que pasa por el centro de la cavidad.

Se observa también como las velocidades en la mitad derecha de la cavidad presentan valores máximos absolutos que varían desde los 5.59 a los $8.11 \mathrm{~m} / \mathrm{s}$ para velocidades angulares de 3600 a $5600 \mathrm{rpm}$ respectivamente. Sin embargo, en la mitad izquierda de la cavidad, los valores absolutos máximos son ligeramente inferiores, variando entre un rango que va desde los 2.67 y los $3.93 \mathrm{~m} / \mathrm{s}$ para velocidades angulares de 3600 a $5600 \mathrm{rpm}$ respectivamente. Estas diferencias de velocidad entre una cara y la otra de la cavidad se deben a que la superficie de la derecha es la que se enfrenta directamente con la dirección de movimiento, y además recibe el impacto frontal del flujo del remolino generado en el interior de la cavidad. Tras impactar en las 2 esquinas del fondo, el flujo pierde energía y por tanto se reduce su velocidad. En la gráfica de la Figura 69, se representan las velocidades correspondientes a los dos picos (máximos y mínimos) obtenidos en la gráfica de la Figura 68. 


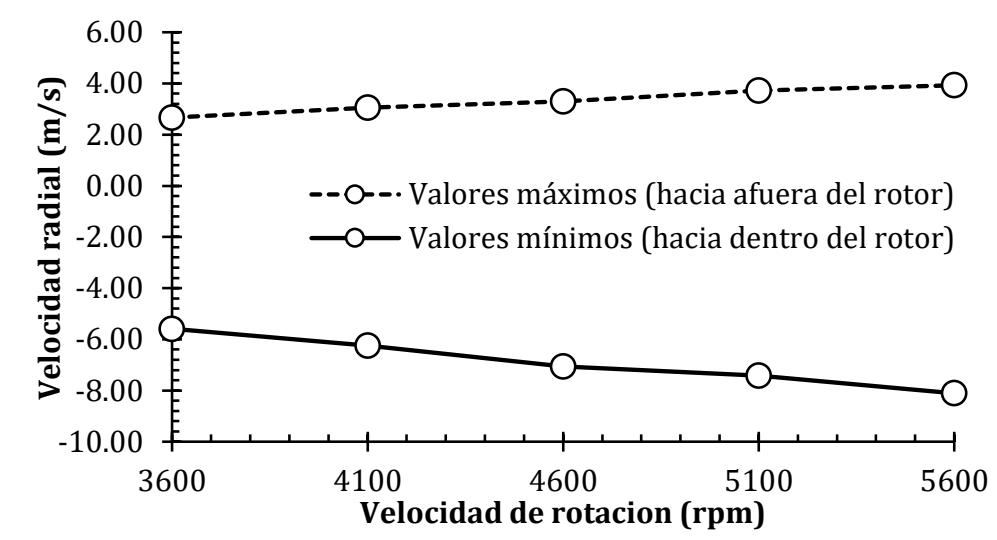

Figura 69: Velocidades radiales máximas y mínimas en función de la velocidad de rotación.

Resulta también interesante observar cómo en las esquinas inferiores, al igual que en el centro de la cavidad, las velocidades son muy reducidas y prácticamente 0 . Esto se debe a que el fluido impacta contra las esquinas, lo que reduce su velocidad y aumenta la presión (ver Figura 70). Este aumento de presión en las esquinas es más evidente en la cara de la cavidad donde el fluido impacta de forma directa, y para aquellos casos en los que la velocidad de rotación es elevada. Es aquí donde parece lógico pensar en una estrategia de redondeo de las ranuras del rotor para evitar la pérdida de energía como consecuencia del choque del flujo con las esquinas, y de esta forma conservar la velocidad que se induce al fluido. Debido al vórtice que se produce en la zona interna de la cavidad, aparece una fuerza centrífuga que es compensada mediante un gradiente de presión cuyo valor mínimo se da en el centro del vórtice (Katopodes, 2019). Por tanto, a mayor velocidad de rotación del vórtice, mayores fuerzas centrífugas y menores presiones en el centro de la cavidad (Figura 70).

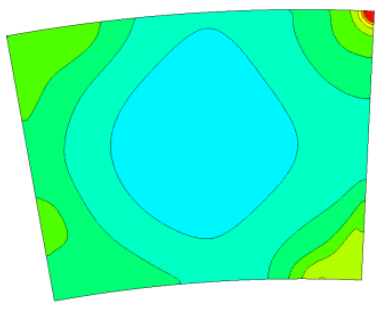

$3600 \mathrm{rpm}$

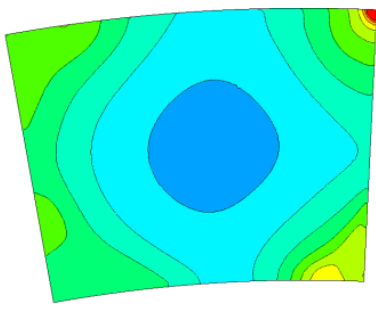

$4100 \mathrm{rpm}$

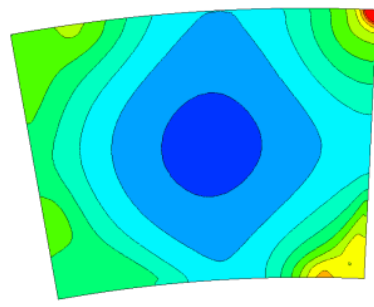

$4600 \mathrm{rpm}$ 


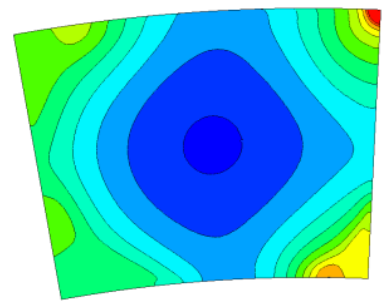

$5100 \mathrm{rpm}$

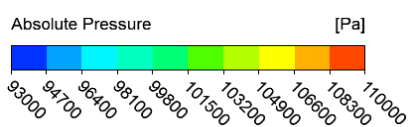

Figura 70: Distribución de presiones para diferentes velocidades de rotación en la configuración 1 del submodelo 2 .

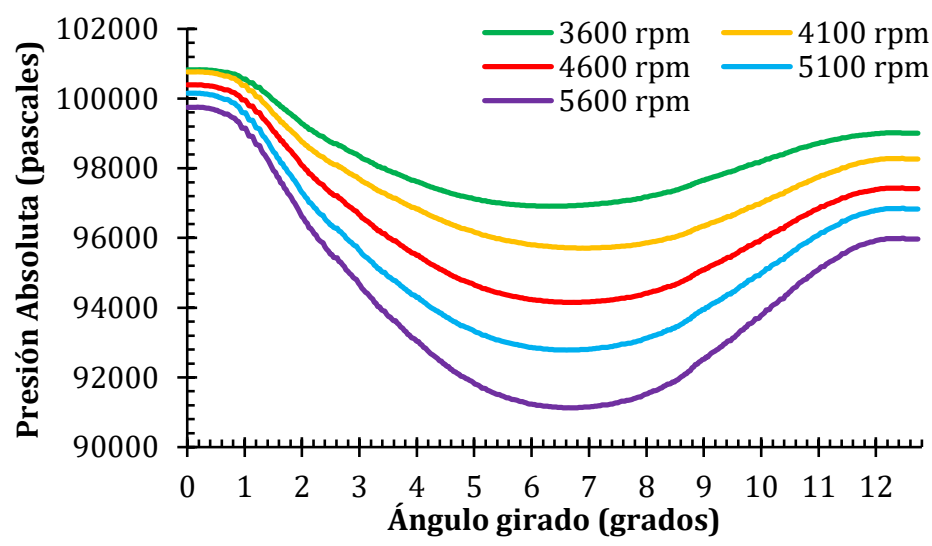

Figura 71: Variación de la presión a lo largo de la línea circunferencial que pasa por el centro de la cavidad.

Tal y como se ha mostrado en la gráfica de la Figura 68, al aumentar la velocidad de rotación aumenta el gradiente de velocidades radiales (la pendiente de las gráficas que pasa por $0 \mathrm{~m} / \mathrm{s}$ es cada vez más inclinada) lo que se traduce en mayores fuerzas centrífugas y una reducción de la presión cada vez más grande. Esto puede verse en la gráfica de la Figura 71, donde se ha representado la variación de la presión a lo largo de la misma línea circunferencial que pasa por el centro de la cavidad, y se observa que el valor mínimo disminuye a medida que la velocidad de rotación aumenta. 


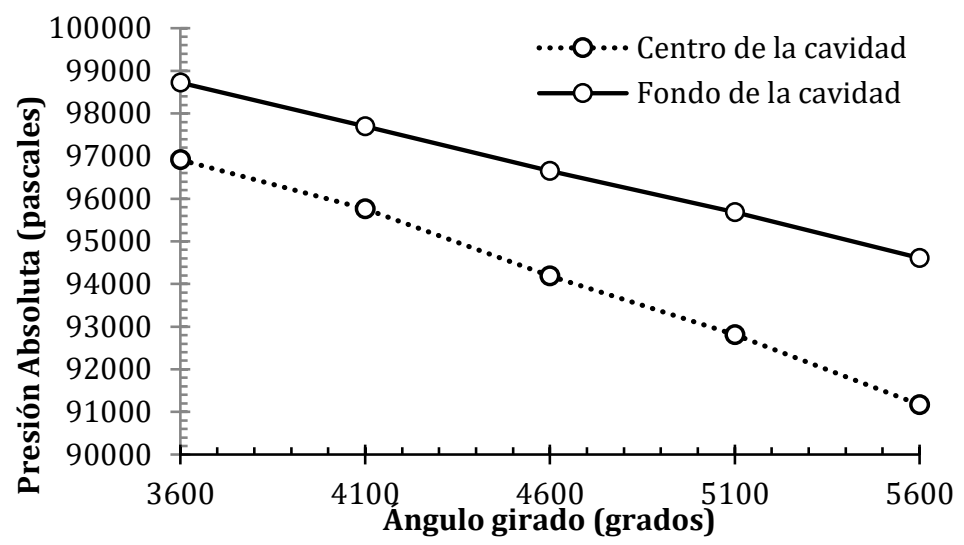

Figura 72: Variación de la presión en el centro de la cavidad en función de la velocidad de rotación.

Considerando la presión atmosférica como valor de referencia (101325 pascales), la presión en el centro de la cavidad disminuye desde los 96912 pascales, hasta los 91170 pascales para velocidades de rotación entre los 3600 y $5600 \mathrm{rpm}$ respectivamente, tal y como puede verse en la gráfica de la Figura 72. Por otro lado, justo en la parte central del fondo de la cavidad (donde la presión también disminuye como consecuencia del aumento de la velocidad en la pared debida al remolino), se produce también una disminución de la presión con la misma tendencia, pero valores ligeramente superiores.

Por tanto, analizando los resultados obtenidos tras la simulación de la configuración 1 del submodelo 2, se puede concluir que debido a la rotación se induce un flujo en el interior de la cavidad que, a su vez, produce un vórtice en cuyo centro la presión disminuye como consecuencia de gradientes de velocidades que en él se originan. Dada la presión de referencia de 101325 pascales, las presiones obtenidas se corresponden a caídas de presión que, a máxima velocidad de rotación (5600 rpm), oscilan entre los 10115 y los 6715 pascales (para el centro y el fondo de la cavidad respectivamente). Aunque en algunos sistemas se basan en la producción de la cavitación como consecuencia de la generación de un vórtice (Okamura \& Kubota, 2006) (Tsujimoto, 2007), en este caso, las características geométricas del cavitador no están pensadas para tal fin y por tanto, la caída de presión que se obtiene mediante este efecto no es suficiente por si sola para producir el fenómeno de la cavitación.

\subsubsection{Resultados obtenidos con la configuración 2}

A continuación, se muestran los resultados obtenidos para la configuración 2 del submodelo 2. Dadas las condiciones establecidas para esta configuración en particular, solo podrán analizarse las distribuciones de presiones ya que a diferencia 
de la configuración 1, ahora la cavidad se comporta como un sistema cerrado donde el fluido de su interior no se ve afectado por la inducción de ningún flujo procedente del exterior como consecuencia de velocidad de rotación del rotor.

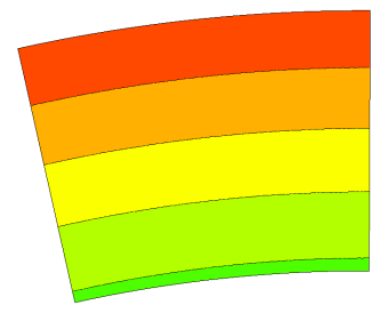

$3600 \mathrm{rpm}$

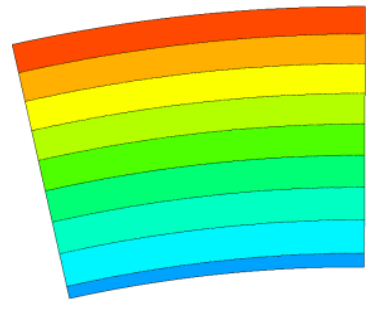

$5100 \mathrm{rpm}$

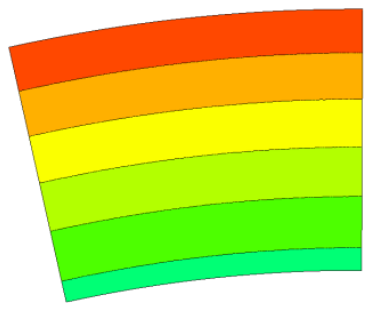

$4100 \mathrm{rpm}$

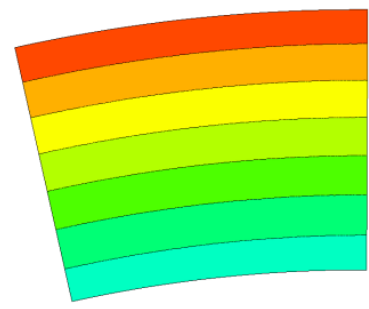

$4600 \mathrm{rpm}$

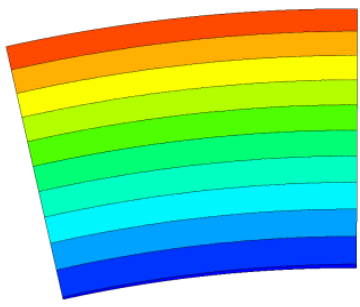

$5600 \mathrm{rpm}$

Figura 73: Distribución de presiones para diferentes velocidades de rotación en la configuración 2 del submodelo 2 .

Para analizar la distribución de presiones en el interior de la cavidad, se ha representado una variable que indica la caída de presión considerando como referencia: la superficie superior de la cavidad (por donde entra el fluido en el modelo real). De este modo, se puede observar como a medida que los puntos se alejan de la superficie superior de la cavidad, se reduce la presión a la que se encuentran (Figura 73). En este sentido, se hace patente la existencia de una fuerza repulsiva (fuerza centrífuga) como consecuencia de la rotación, fenómeno que ha sido reportado por Badve et. al, cuando analizaba su dispositivo de tambor rotativo con indentaciones (M. P. Badve et al., 2015) y muy similar al que ocurre durante la formación de un vórtice.

Tal y como se muestra en la gráfica de la Figura 74, conforme la velocidad de rotación aumenta, también lo hace la fuerza centrípeta, y por tanto la fuerza de repulsión sobre la cara más profunda de la cavidad. De esta manera, la presión en el fondo de la cavidad desciende de forma prácticamente lineal en función de la velocidad de rotación hasta que, al alcanzar las $5600 \mathrm{rpm}$, se produce la máxima caída de presión que se estima en unos 100000 pascales. Esto indica que, si la parte 
superior de la cavidad se encontrase sujeta a una presión similar a la atmosférica, someter al sistema a una velocidad de rotación de $5600 \mathrm{rpm}$ sería suficiente para que se produjera el fenómeno de la cavitación en el fondo de la cavidad. En la práctica esto no es así, puesto que el sistema real no presenta una cavidad completamente cerrada, con lo que se encuentra sometida al movimiento del flujo inducido por la rotación y que se introduce en el interior de la cavidad (configuración 1) y, además, la presión de referencia a la que se encuentra sometida el sistema de cavitación, es superior a la atmosférica.

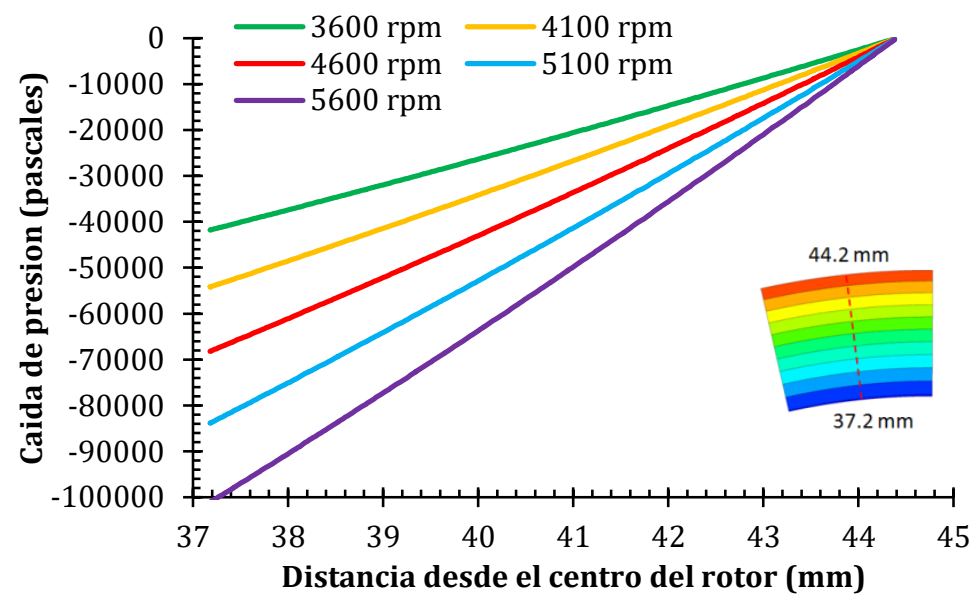

Figura 74: Variación de la presión a lo largo de la línea radial que pasa por el centro de la cavidad. 


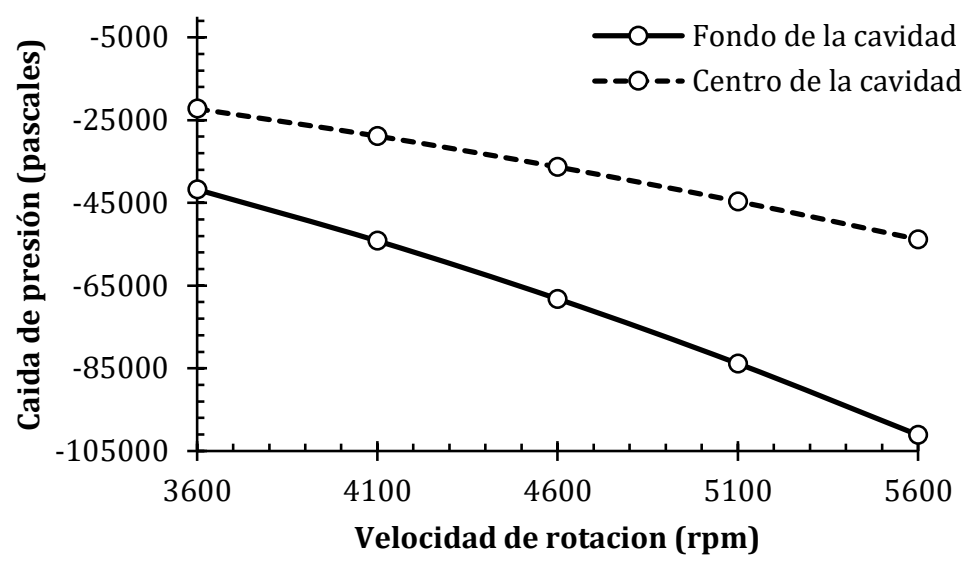

Figura 75: Variación de presiones en el centro y en el fondo de la cavidad en función de la velocidad de rotación.

$\mathrm{Al}$ analizar la variación de presión en el centro y en el fondo de la cavidad en función de la velocidad de rotación (Figura 75), se puede observar como en el fondo las presiones obtenidas en todos los casos son siempre más bajas que las obtenidas en el centro, ya que la fuerza de repulsión que actúa sobre el fluido es más elevada en puntos alejados al centro de rotación. En el caso más extremo de funcionar con una velocidad de rotación de $5600 \mathrm{rpm}$, la máxima reducción de presión conseguida en el centro de la cavidad es de 53837 pascales, mientras que en el fondo este valor asciende a casi el doble con 101099 pascales, siendo estos valores mucho más elevados que las caídas de presión obtenidas en la configuración 1 como consecuencia de las velocidades inducidas en el interior de la cavidad.

Como conclusión de este apartado, se ha conseguido obtener un submodelo que permite estimar las distribuciones de velocidad y de presión en el interior de las cavidades del rotor como consecuencia del vórtice inducido en el interior de la cavidad (configuración 1) y de las fuerzas de repulsión como consecuencia de la fuerza centrífuga (configuración 2). Se ha podido observar que las caídas de presión generadas como consecuencia de la fuerza centrífuga en esta última configuración son superiores a las que se producen como consecuencia del flujo inducido en el interior de la cavidad, siendo las primeras un orden de magnitud superiores (100000 pascales frente a 10000 pascales). 


\subsection{Simulaciones 2D del nuevo sistema de cavitación}

Las simulaciones llevadas a cabo en el siguiente apartado tienen como objetivo analizar el comportamiento completo del cavitador considerando el movimiento giratorio del rotor con respecto al del estator, y así comprender su funcionamiento y poder plantear cambios en consecuencia. Debido a las dimensiones del dispositivo a escala real y a la necesidad de utilizar tamaños de malla muy reducidos para apreciar los gradientes de presión y de velocidad cerca de los dientes, el tiempo necesario para realizar las simulaciones en 3D resulta inabordable. Es por ello que todas las simulaciones realizadas en el presente apartado se han llevado a cabo utilizando modelos $2 \mathrm{D}$ que permiten una resolución ágil para poder analizar múltiples soluciones derivadas de la modificación de diferentes parámetros geométricos y de funcionamiento.

En este caso en concreto, realizar la simplificación hacia un modelo 2D es posible dado que el flujo que circula de forma axial al cavitador, es mucho menor comparado con el flujo inducido por la rotación del dispositivo. Considerando las condiciones de funcionamiento más exigentes, se espera conseguir una velocidad de rotación de $5600 \mathrm{rpm}$ y un flujo de recirculación a través del cavitador de $100 \mathrm{l} / \mathrm{min}$. Atendiendo a estos datos, se puede obtener la velocidad aproximada inducida por el rotor multiplicando el radio de rotación con respecto al centro natural del rotor del cavitador por la velocidad angular del diente en $\mathrm{rad} / \mathrm{s}$. El radio existente desde el centro de rotación hasta la parte externa del diente del rotor es de $44.2 \mathrm{~mm}$ (ver Figura 35) y las $5600 \mathrm{rpm}$ equivalen a $586.43 \mathrm{rad} / \mathrm{s}$. Por tanto:

$$
v_{i}=\mathrm{r} \cdot \omega=0.0442 \cdot 586.43=\mathbf{2 5 . 9 2} \mathbf{m} / \mathbf{s}
$$

Por otro lado, se puede conocer la velocidad de paso (en la dirección axial) al sistema de cavitación, dividiendo el caudal de recirculación por el área de paso entre los dientes y huecos del rotor y del estator. Si el caudal de paso es de $1.67 \cdot 10^{-3} \mathrm{~m}^{3} / \mathrm{s}$ y el área de paso se ha estimado en $2193 \mathrm{~mm}^{2}$, la velocidad de paso se puede calcular como:

$$
v_{p}=\frac{\mathrm{q}}{\mathrm{A}}=\frac{1.67 \cdot 10^{-3}}{2.193 \cdot 10^{-3}}=\mathbf{0 . 7 6} \mathrm{m} / \mathrm{s}
$$


Tal y como puede observarse, la velocidad de paso $\left(\boldsymbol{v}_{p}\right)$ representa aproximadamente el $3 \%$ de la velocidad que puede llegar a inducir el rotor $\left(v_{i}\right)$. Esto sin contar que, debido a los gradientes de presión producidos al cavitar, se generan zonas locales con velocidades particularmente altas que pueden superar de forma significativa el valor obtenido de $25.92 \mathrm{~m} / \mathrm{s}$.

Por tanto, la simplificación del modelo a 2D resulta coherente desde el punto de vista del comportamiento esperado del flujo, y se considera como una alternativa válida para realizar las simulaciones del sistema de cavitación completo.

\subsubsection{Geometría del submodelo}

La geometría utilizada en el submodelo consiste en una "rebanada infinitesimal" del conjunto rotor-estator presentado en el apartado 3.3.2. En la Figura 76 se muestra el modelo 2D utilizado para realizar las simulaciones de este apartado. Tal y como puede verse, se ha utilizado la geometría que se obtiene al realizar un corte justo por mitad de uno de los discos del estator. Al realizar dicho corte, se obtendría una geometría similar a la que se presenta en la imagen central de la Figura 76. Sin embargo, cabe recordar que la geometría utilizada en las simulaciones CFD, se corresponden con la parte fluida y no la parte sólida. Por tanto, el dominio final utilizado en el modelo sería el de la imagen de la derecha de la Figura 76, correspondiente al área roja señalada en la imagen central.
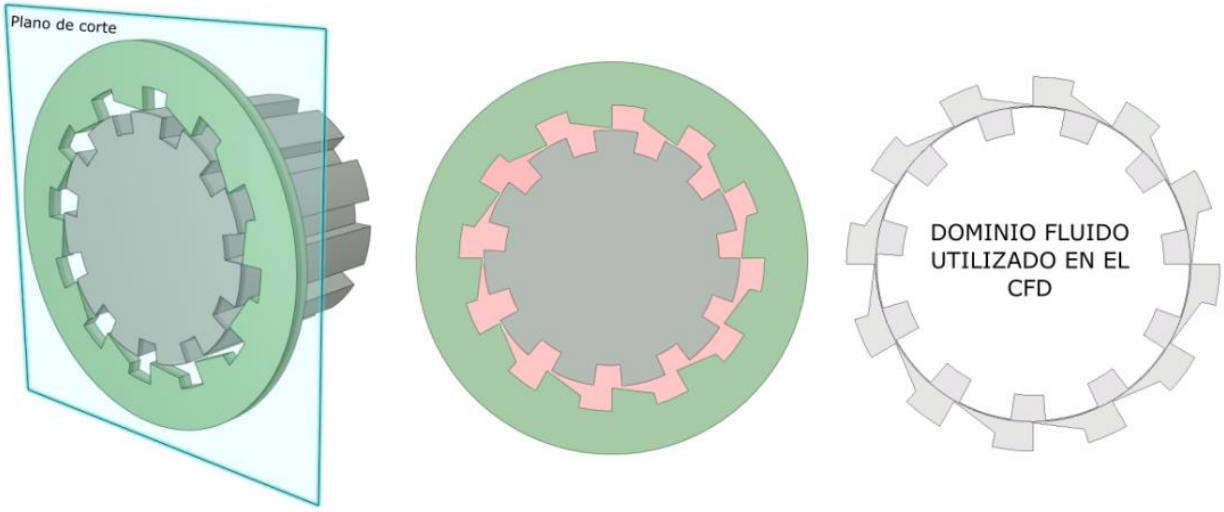

Figura 76: Geometría utilizada en el modelo CFD correspondiente al diseño construido.

En este caso, a diferencia del modelo del Venturi utilizado en el análisis del apartado 4.2, es necesario utilizar dos dominios: uno rotativo y otro estático. Esta es la única manera de poder determinar el comportamiento del sistema considerando que una de las partes se encuentra sometida a una velocidad de rotación. Tal y como puede verse en la Figura 77, el dominio rotativo gira por el 
interior del estacionario, y la interfase entre ambos dominios es una línea circular (línea roja), dado que el sistema está representado en 2D.
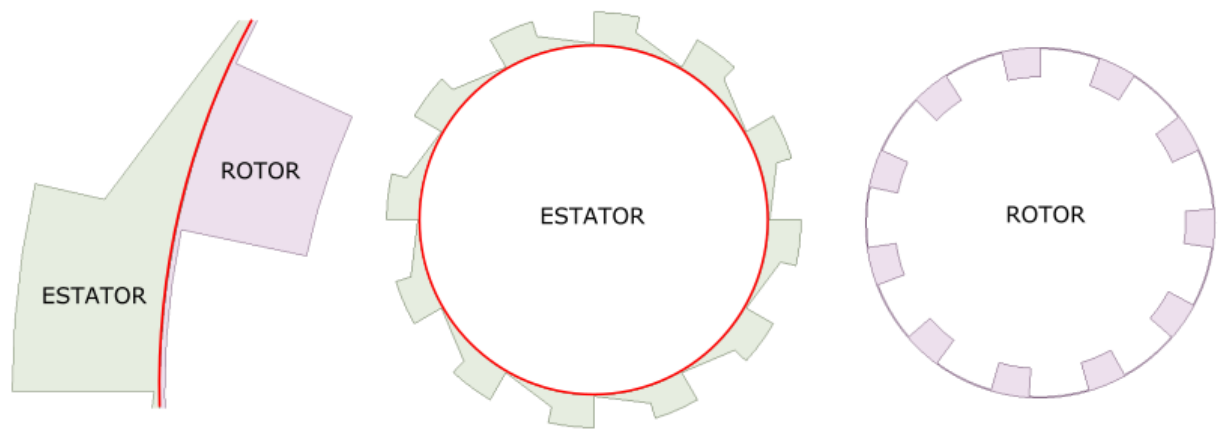

Figura 77: Detalle de los dos dominios del sistema (rotativo y estático) y de la interfase entre ambos (rojo).

La geometría presentada en las figuras anteriores se corresponde con la geometría del rotor y del estator, que ha sido utilizada para los ensayos experimentales. Esta geometría será estudiada en detalle para comprender el funcionamiento del sistema y posteriormente será modificada con el objetivo de conseguir optimizar el proceso y conseguir las mejores condiciones de cavitación. Las modificaciones del sistema que van a requerir un cambio en su geometría son:

- Variación de la distancia entre el rotor y el estator.

- Variación de la geometría del diente del rotor.

A pesar de que se estudiará el efecto de otros parámetros de funcionamiento como la velocidad de rotación o el tamaño de la malla, estos no requerirán de una nueva geometría. Por otro lado, tal y como se ha comentado en el apartado anterior, se espera que los cambios en la geometría se lleven a cabo sobre el estator por ser este mucho más fácil y económico de fabricar. Sin embargo, puede resultar interesante plantear hipotéticos cambios de geometría sobre el diente del rotor para comprender mejor el funcionamiento y poder plantear posibles modificaciones en el sistema a más largo plazo.

En cualquier caso, los cambios en la geometría no están encaminados a obtener una geometría específica, detallada y $100 \%$ optimizada, sino a conocer las tendencias de funcionamiento que se producen con el cambio de los diferentes parámetros geométricos. Esto permitirá obtener nuevos diseños cuyas formas y dimensiones principales se encuentren correctamente direccionadas hacia una optimización más precisa que podría desarrollarse en futuros estudios. 


\subsubsection{Set up del submodelo y condiciones de contorno}

De la misma manera que se ha realizado con el submodelo del diente del rotor, los esquemas numéricos para la resolución del acoplamiento presión-velocidad, así como discretización del gradiente, presión, momento, fracción volumétrica y turbulencia han sido los mismos que los utilizados en las simulaciones CFD del dispositivo Venturi y que están descritos en la Tabla 6. Dado que estos modelos han sido validados y han presentado una correlación adecuada con los resultados experimentales, únicamente ha sido necesario determinar las condiciones de contorno adecuadas para este submodelo en particular.

\subsubsection{Modelos matemáticos utilizados}

Tal y como se ha comentado anteriormente, la validación experimental de los modelos matemáticos utilizados durante las simulaciones CFD con el dispositivo Venturi descritos en el apartado 4.2, ha permitido utilizar la misma configuración en el submodelo de este apartado. Por tanto, las simulaciones se han llevado a cabo considerando un fluido bifásico (líquido-gas), es decir, considerando el modelo homogéneo (mixture model en Fluent) y se ha introducido el modelo de turbulencia k- $\omega$ SST, combinado con el modelo de cavitación Schnerr-Sauer, asumiendo que la velocidad relativa entre ambas fases es nula y que la mezcla líquido-gas se comporta de manera isoterma e incompresible. El número de núcleos por unidad de volumen establecidos para el modelo de cavitación se ha mantenido en de $10^{13}$, valor de referencia para otros autores (H. Li et al., 2008) (H. L. Liu et al., 2013) y que también ha mostrado coherencia en los resultados obtenidos en las simulaciones del Venturi.

Las simulaciones se han realizado en régimen estacionario utilizando la metodología conocida como Frozen Rotor. En esta forma de cálculo, las características del flujo se determinan acorde a su marco de referencia (estático o rotativo) pero la posición relativa de los componentes se mantiene constante. Este método debe utilizarse con sistemas que no tengan simetría rotacional (como es el caso) y es importante mencionar que no considera los efectos inerciales ni tiene tanta precisión para predecir los valores de flujo local y los efectos de las posiciones relativas entre el rotor el estator como el método Transient Rotor-Stator. Sin embargo, este último método es mucho más inestable y requiere de tiempos computacionales muy superiores y, por tanto, en esta situación la metodología Frozen Rotor se considera una opción válida. Esto se debe a que su robustez y ahorro de recursos informáticos compensan la posible falta de precisión en los resultados obtenidos.

\subsubsection{Condiciones y parámetros físicos del submodelo}

Además de utilizar los modelos y esquemas matemáticos de las simulaciones del Venturi, también se han conservado las propiedades físicas de las fases líquido y 
gas. Así pues, se ha establecido una densidad para la fase líquida de $998.2 \mathrm{~kg} / \mathrm{m}^{3}$ y una viscosidad de $0.001003 \mathrm{~kg} / \mathrm{m} \mathrm{S}$; mientras que para la fase gas, se ha establecido una densidad de $0.5542 \mathrm{~kg} / \mathrm{m}^{3}$ y una viscosidad de $1.34 \cdot 10^{-5} \mathrm{~kg} / \mathrm{m} \mathrm{S}$ (vapor de agua). Asimismo, se ha establecido una presión de vapor de $4210 \mathrm{~Pa}$ para una temperatura de $30^{\circ} \mathrm{C}$.

Para la realización del cálculo en las simulaciones se ha empleado un intervalo de tiempo de $10 \mu$ s y se ha establecido una velocidad angular del rotor, cuyo valor se encuentra entre las $3600 \mathrm{rpm}$ y las $5600 \mathrm{rpm}$ (en sentido antihorario según Figura 78), para reproducir el comportamiento del cavitador real en la planta piloto y en las pruebas de laboratorio. Al utilizar la metodología de cálculo del Frozen Rotor, las simulaciones únicamente proporcionan la solución del sistema para un instante de tiempo determinado, sin considerar ningún cambio en la posición relativa del rotor y el estator. Sin embargo, dada la particular geometría del cavitador, donde el rotor tiene 11 dientes y el estator 12, se produce un desfase entre los dientes de dichos elementos que permite analizar la secuencia completa que se produce cuando el rotor se encuentra en movimiento (Figura 78). Esta particularidad geométrica del sistema de cavitación es muy importante, ya que de otro modo, para cada condición a simular (diferentes geometrías o velocidad de rotación), sería necesario analizar distintas posiciones relativas entre el rotor y el estator para poder comprender el funcionamiento completo del sistema, con lo que sería imperativo cambiar el método de resolución al Transient Rotor-Stator con sus consecuentes inconvenientes.

Aunque esta particularidad geométrica del modelo se ha presentado como una gran ventaja, existe también un inconveniente importante. Al realizar la simulación en 2 dimensiones, se ha establecido una condición de simetría en la cara frontal y trasera del modelo (simetría a lo largo de la dirección axial de rotación). Sin embargo, esto convierte el modelo en un sistema hermético donde tanto el rotor como el estator son una extrusión infinita de sus caras a lo largo del eje de rotación. La simulación bajo estas condiciones, en las que se asume que todas las aristas del estator actúan como una pared, produce grandes presiones, ya que el flujo inducido por el rotor es proyectado hacia las cavidades del estator sin posibilidad de salir. Además, la carencia de entradas o salidas al sistema lo vuelve inestable, haciendo que el cálculo de presión y de la velocidad presente grandes dificultades para converger y provocando el eventual fallo del modelo. 

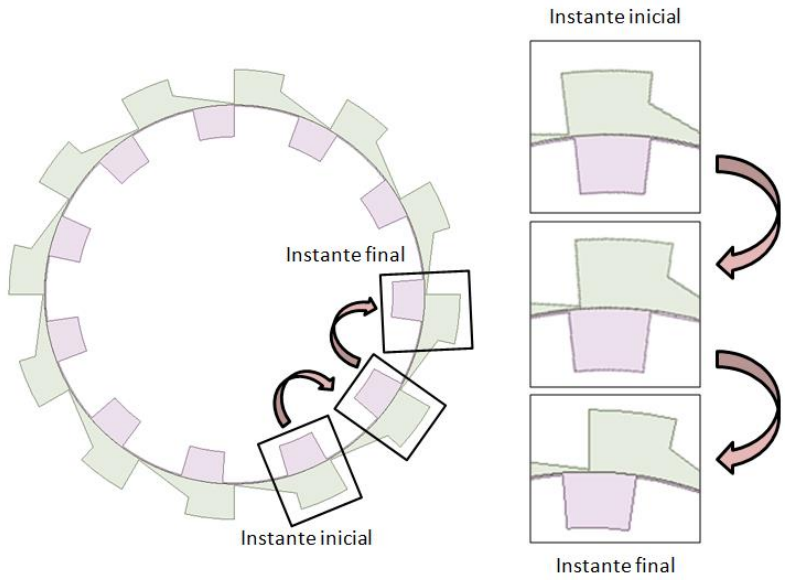

Figura 78: Desfase entre rotor y estator que permite analizar las diferentes posiciones relativas como instantes de tiempo independientes

La realidad del sistema físico es que, debido al pequeño espesor de los discos del estator $(5 \mathrm{~mm})$ y a la velocidad axial del flujo a través de los dientes (calculada en el apartado 4.4 y de valor $0.76 \mathrm{~m} / \mathrm{s}$ ), el fluido solo tarda unos $6.5 \mathrm{~ms}$ en recorrer la distancia correspondiente al espesor del diente del estator. Por tanto, puede asumirse que la superficie (arista) del estator que se encuentra más alejada del centro de rotación, actúa como una superficie de salida donde la presión es la de referencia del sistema (Figura 79). De esta forma, el cálculo del sistema se vuelve mucho más estable y permite converger a una solución coherente y representativa del sistema real.

Dado que la salida se ha establecido con una condición de pressure-outlet, es necesario establecer la presión a la que se encuentra la cámara de cavitación. Esta condición de pressure-outlet puede establecerse en aquellas zonas donde se tiene un gradiente de presión nulo. A efectos prácticos, en la zona del fondo del hueco del estator, se puede considerar un gradiente muy tenue y cercano a cero y, por tanto, es adecuado considerar dicha condición. Por otra parte, en el montaje real esta presión es función de la columna de agua que se encuentra por encima del cavitador, así como del gradiente de presión producido por la bomba que succiona aguas abajo del cavitador. Esta presión es importante porque establecerá el momento en el que se producirá la cavitación, así como la cantidad de vapor que generará. Tras realizar una batería de simulaciones a diferentes presiones, se ha concluido que el sistema debe trabajar a una presión absoluta de 190000 pascales (1.9 bar). Bajo estas condiciones la aparición de la cavitación coincide con lo observado experimentalmente, es decir, el fenómeno de la cavitación comienza a percibirse a partir de las $4100 \mathrm{rpm}$. 


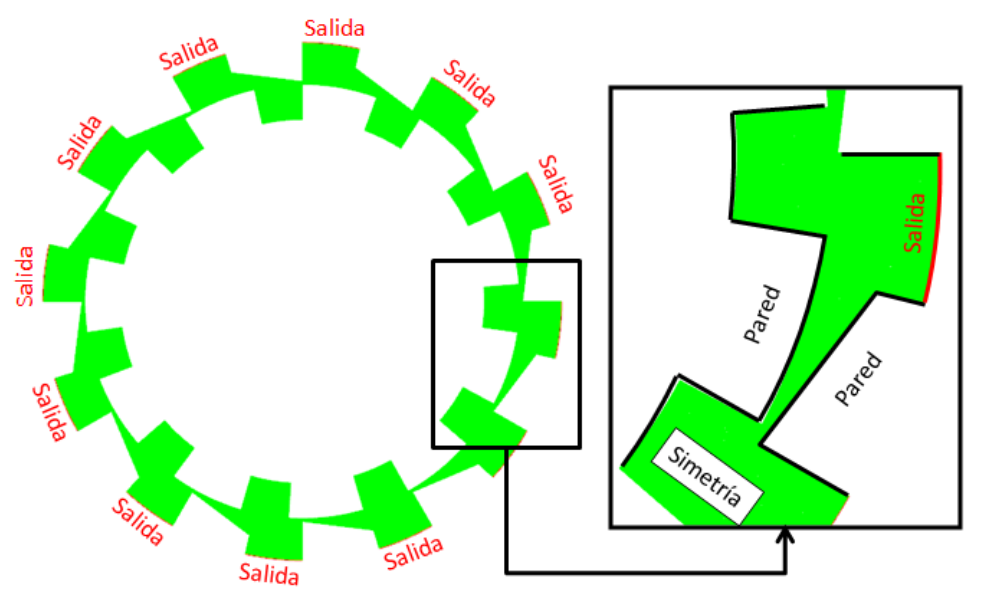

Figura 79: Condiciones de contorno para el modelo 2D completo del cavitador

Todas las simulaciones desarrolladas con este modelo se llevaron a cabo con el intervalo de tiempo anteriormente indicado $(10 \mu \mathrm{s})$ y se realizaron un total de 20000 iteraciones para conseguir que los residuales de todos los parámetros de la simulación (velocidades, presiones, turbulencia, continuidad y fracción volumétrica) alcanzaran valores inferiores a $10^{-4}$ para garantizar su correcta convergencia.

\subsubsection{Mallado del submodelo}

Al igual que en los anteriores submodelos, se han mantenido los criterios de calidad de malla regidos básicamente por el valor del y+, así como del número de Courant obtenido durante las simulaciones. Dado que, durante el análisis de sensibilidad de malla realizado durante las simulaciones del Venturi, se analizó la influencia de este y otros parámetros de la malla sobre los resultados, no se ha considerado necesario volver a realizar análisis de malla para este nuevo submodelo (lo que conllevaría un gran gasto de tiempo) pero sí que se cumplan los mismos criterios que condujeron a un buen funcionamiento del modelo del Venturi.

Así pues, ya que el modelo de turbulencia que se utiliza continúa siendo el mismo que en los otros submodelos ( $k-\omega \mathrm{SST}$ ), los valores de $\mathrm{y}^{+}$para garantizar un buen comportamiento del flujo cerca de las paredes se han mantenido en valores de 1 o similares. Para ello ha sido necesario realizar un mallado muy refinado en todas las paredes del modelo (dientes) y aumentar el tamaño del nodo en aquellas zonas más extensas como las cavidades del rotor o del estator. 


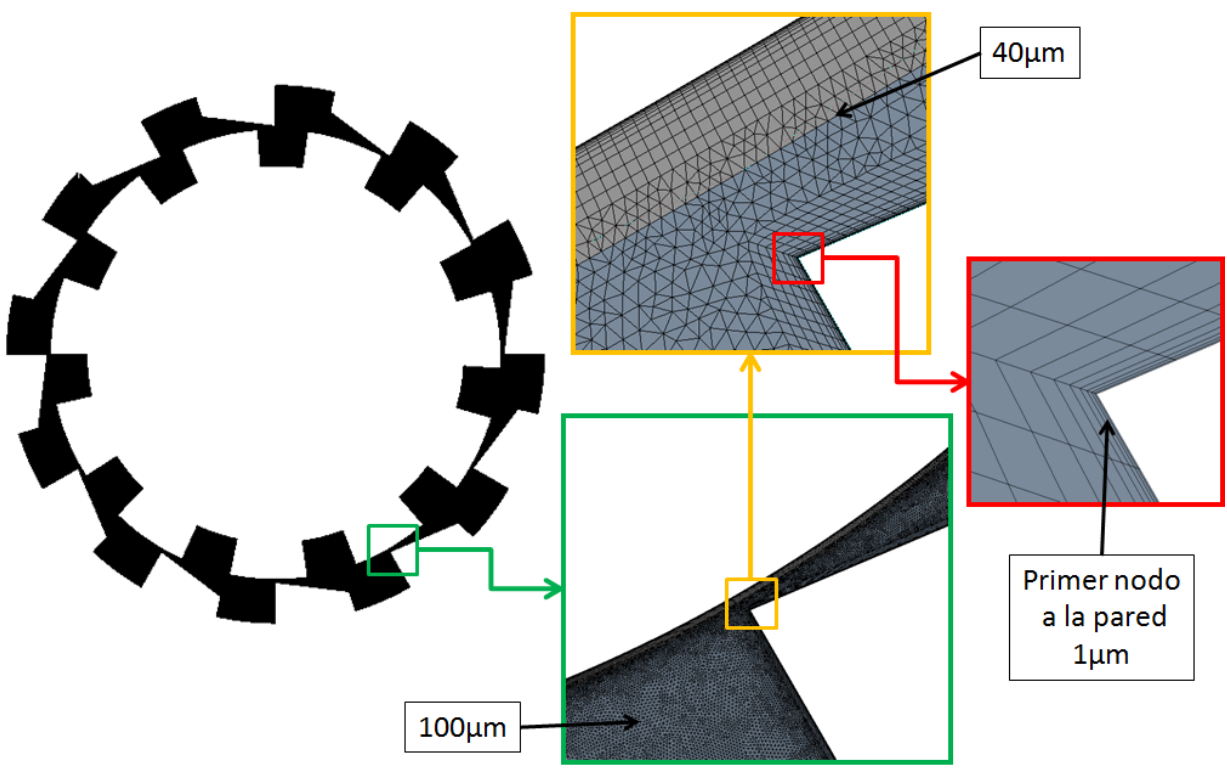

Figura 80: Detalle del mallado de las distintas zonas del submodelo completo del cavitador en $2 \mathrm{D}$.

Atendiendo al número de Courant, si consideramos como caso de referencia una velocidad de rotación de $5600 \mathrm{rpm}$, esto supone que para cada incremento de tiempo entre iteraciones $(10 \mu \mathrm{s})$, el rotor gire un total de 0.336 grados, o lo que es lo mismo, 0.0058 radianes. Dado que el radio del rotor del cavitador es de $44.2 \mathrm{~mm}$, el arco que describe la parte exterior de los dientes es de aproximadamente $260 \mu \mathrm{m}$. En el mallado se ha utilizado un tamaño de nodo de $40 \mu \mathrm{m}$ entre la interfase del rotor y el estator, ya que de esta forma la zona en la que los dientes del rotor y del estator se encuentran más próximas, se dispone de suficientes nodos entre las paredes para calcular de forma adecuada la distribución de velocidades y presiones (recuadro amarillo de la Figura 80). En esa zona en particular, se disponen de 30 nodos para cubrir una distancia de $0.6 \mathrm{~mm}$ (distancia entre dientes de rotor y estator), siendo los nodos más pequeños los que se encuentran cerca de las paredes, con un tamaño de $1 \mu \mathrm{m}$ para garantizar un $\mathrm{y}^{+}$por debajo de 1 (recuadro rojo de la Figura 80). El resto del modelo se ha cubierto con un tamaño máximo de malla de $0.1 \mathrm{~mm}$ (recuadro verde de la Figura 80), suficiente para garantizar números de Courant cercanos a 1 , dado el valor del campo de velocidades esperado.

En definitiva, se ha utilizado una combinación de elementos de 4 y 3 lados con refinamientos y mallados de capa (inflation) en las zonas de la pared que han originado un modelo con un número total de aproximadamente $600 \mathrm{k}$ nodos. El 
mallado del modelo es adecuado en cuanto a que permite la convergencia del cálculo en tiempos computacionales razonables (24-36 horas) y permite visualizar con precisión los efectos hidrodinámicos a la más pequeña escala que se producen.

\subsubsection{Resultados}

A continuación, se describe de manera detallada el comportamiento del cavitador con la geometría rotor-estator actual, es decir, la que se ha utilizado en los ensayos de laboratorio y en la planta piloto. La velocidad de rotación se corresponde con $5600 \mathrm{rpm}$ para simular exactamente la situación del sistema real y determinar las principales áreas de cavitación y la cantidad de vapor generado. Para explicar el funcionamiento se van a analizar por separado las diferentes posiciones relativas entre el rotor y el estator, tal y como se ha explicado en la Figura $\mathbf{7 8}$ del apartado 4.4.2. Dado que el rotor tiene 11 dientes, existen 11 posiciones a estudiar, denominadas a partir de ahora como etapas. En cada una de las etapas se presentan 2 imágenes diferentes cuyo contenido se describe a continuación.

La primera imagen, muestra la distribución de presiones absolutas y la fracción de gas observable (morado). Además, se ha superpuesto el campo de velocidades mediante vectores pequeños y también mediante la representación de las principales líneas de flujo correspondientes al rotor y al estator. En este caso, la velocidad en cada dominio se representa con respecto a un observador situado sobre dichos dominios, es decir un sistema de referencia fijo en el caso del estator y un sistema de referencia móvil (en rotación) con respecto al rotor.

La segunda imagen muestra el campo de velocidades producido y representado con respecto a un sistema de referencia fijo para ambos dominios (tanto estator como rotor). También se han superpuesto los vectores velocidad con respecto a dicho sistema de referencia para poder evaluar de forma más detallada el comportamiento y la intensidad real de las velocidades.

El proceso es cíclico y las 11 etapas se pueden clasificar en una serie de fases y subfases tal y como se puede observar en la siguiente figura: 


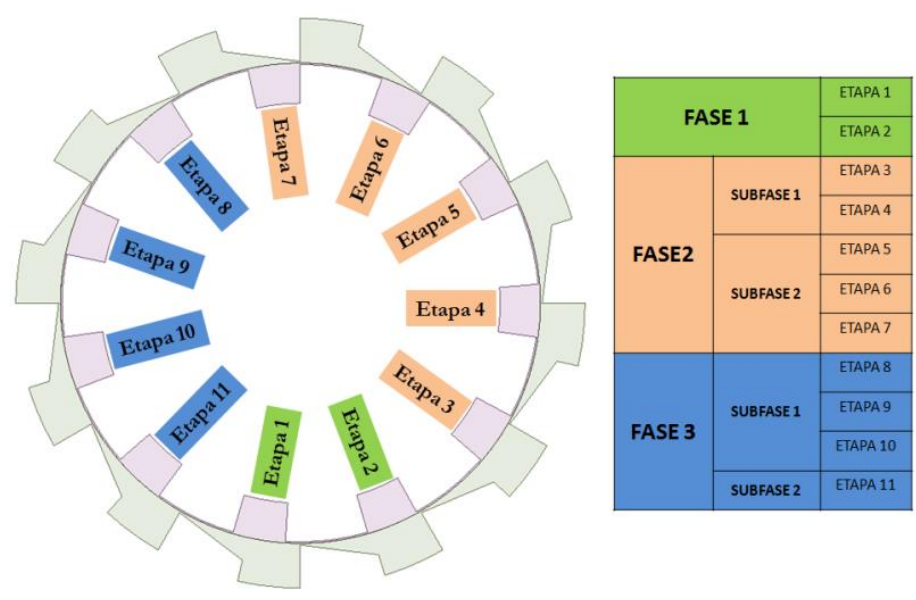

Figura 81: Fases, subfases y etapas que se suceden durante un ciclo de rotación del cavitador.

Así pues, todo el ciclo que se produce durante una vuelta de rotor puede desglosarse en 3 fases diferentes. La primera fase consta de 2 etapas, la segunda fase de 2 subfases y 5 etapas y la tercera fase de 2 subfases y 4 etapas. Las fases principales pueden describirse de la siguiente forma:

- $\quad$ Fase 1: Recuperación. Se produce durante el acercamiento de la cavidad del rotor al diente del estator, donde las velocidades y las zonas de bajas presiones son de mediana intensidad. En la etapa que le precede, se ha producido una gran cantidad de vapor como consecuencia de la cavitación, y es en esta fase donde se vuelve a recuperar la normalidad para iniciar el ciclo, es decir, las velocidades disminuyen y las presiones aumentan. Se considera como la fase de recuperación tras la cavitación intensa.

- Fase 2: Transición. Coincide con el paso de la cavidad del rotor sobre el diente del estator. Esta fase puede dividirse en dos subfases: el paso de la primera mitad de la cavidad del rotor (desde cara izquierda al centro de la cavidad), y el paso de la segunda mitad (desde el centro hasta la cara derecha de la cavidad). En la primera subfase las velocidades son bajas y las presiones muy homogéneas (momento más estable del todo el ciclo), mientras que en la segunda mitad la velocidad comienza a aumentar y las presiones disminuyen. Es la etapa de transición desde la recuperación, a la generación de cavitación intensa.

- Fase 3: Generación y colapso. Surge durante el acercamiento de la cavidad del rotor a la cavidad del estator. Esta fase, al igual que la anterior, se puede dividir en dos subfases: en la primera se aumenta drásticamente la velocidad en el interior de la cavidad y se disminuye la presión generando gran cantidad de vapor, y en la segunda, donde las cavidades se enfrentan, las 
presiones se igualan y el vapor colapsa dejando entrar el líquido en su interior. En esta fase, la intensidad de las velocidades, así como las zonas de bajas presiones, son de máxima intensidad y se considera la fase de generación y colapso.

A continuación, se describen de forma detallada, todas las etapas correspondientes a las diferentes fases y subfases.

\subsubsection{Fase 1: Recuperación}

Esta fase comprende las etapas 1 (Figura 82) y 2 (Figura 83), cuyo comportamiento hidrodinámico es muy similar. En el interior de la cavidad existe un flujo rotativo en sentido horario inducido por la rotación antihoraria del rotor, y se puede observar cómo durante la rotación parte del flujo es lanzado hacia el estator (fuera de la cavidad del rotor) por la mitad izquierda de la cavidad del rotor, mientras que por la mitad derecha existe un flujo que entra desde el estator hacia la cavidad del rotor (Figura 82). Este movimiento del flujo favorece la formación del remolino, ya que contribuye al giro horario del fluido en el interior de la cavidad del rotor. Asimismo, se puede observar la formación de un pequeño remolino en la esquina del diente del rotor como consecuencia de su impacto contra el fluido durante la rotación.
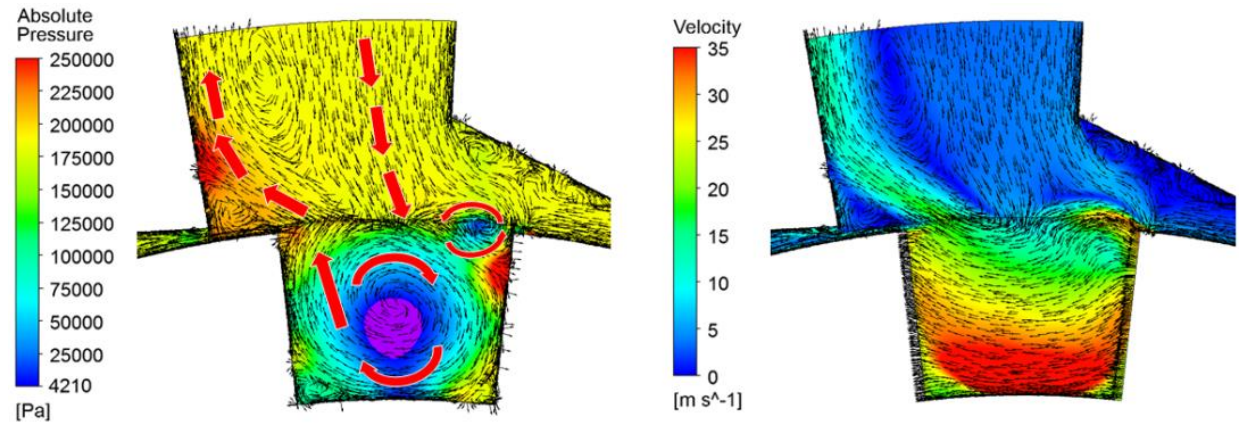

Figura 82: Etapa 1, correspondiente a la fase de acercamiento de la cavidad del rotor al diente del estator (fase 1 de recuperación). 

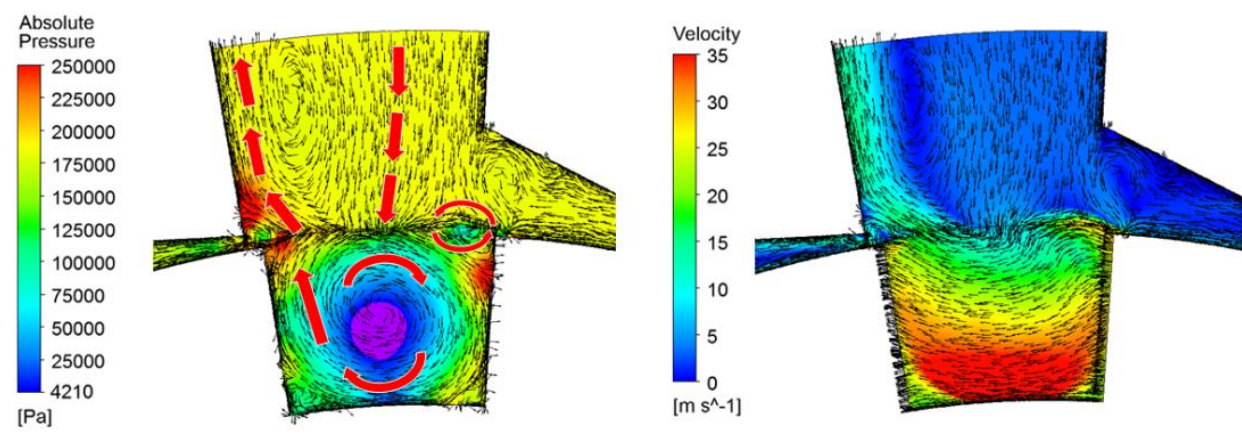

Figura 83: Etapa 2, correspondiente a la fase de acercamiento de la cavidad del rotor al diente del estator (fase 1 de recuperación).

A medida que la cavidad del rotor se aproxima al diente del estator (Figura 83), el flujo de salida impacta de forma más suave sobre el estator, mientras que el flujo que entra desde el estator a la cavidad del rotor lo hace perpendicular al centro de rotación del remolino, lo que disminuye ligeramente su velocidad. Se observa también que durante esta fase 1 (etapa 1 y 2 ) existe una zona de cavitación como consecuencia de la baja presión generada en el centro del remolino que se expande ligeramente hacia el fondo de la cavidad.

\subsubsection{Fase 2: Transición}

Tal y como se ha comentado anteriormente, esta fase consta de dos subfases: la primera, que abarca las etapas 3 (Figura 84) y 4 (Figura 85); y la segunda, que abarca las etapas 5 (Figura 86), 6 (Figura 87) y 7 (Figura 88). A continuación, se describen en detalle cada una de las subfases y de las etapas por separado.

\section{Fase 2, subfase 1}

Durante este periodo, el diente del estator comienza a aparecer sobre la mitad izquierda de la cavidad del rotor. Cuando esto sucede, el flujo que durante la fase 1 salía lanzado hacia la cavidad del estator, impacta ahora sobre la cara inclinada del diente del rotor y es lanzado hacia adelante (sentido antihorario). Al mismo tiempo, el flujo del estator que intenta entrar a la cavidad, lo hace de manera tangencial y oponiéndose al sentido de rotación del remolino generado en el interior de la cavidad. Esto hace disminuir la velocidad y aumentar la presión, lo que favorece el colapso de las zonas de cavitación que habían quedado aisladas en la anterior fase.

A medida que el diente penetra más sobre la cavidad del rotor (Figura 85 y Figura 85), se favorece el escape de fluido por la mitad izquierda de la cavidad y comienza a entrar un mayor flujo de líquido por la mitad derecha como consecuencia del flujo que, en la etapa 3, es lanzado como un jet sobre la superficie inclinada del diente del estator. Es en esta etapa donde las velocidades se reducen 
al máximo provocando que el campo de presiones sea el más homogéneo de todo el ciclo de funcionamiento.
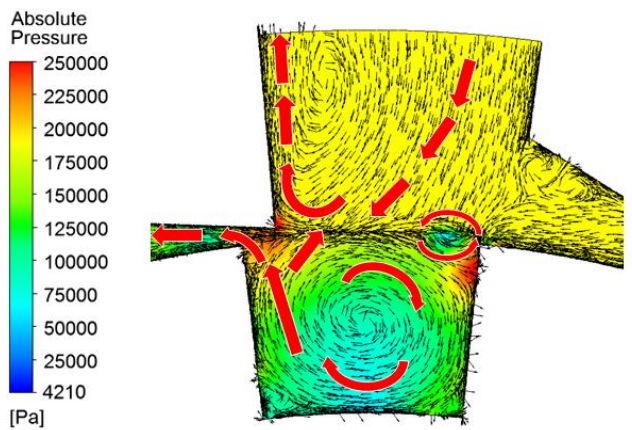
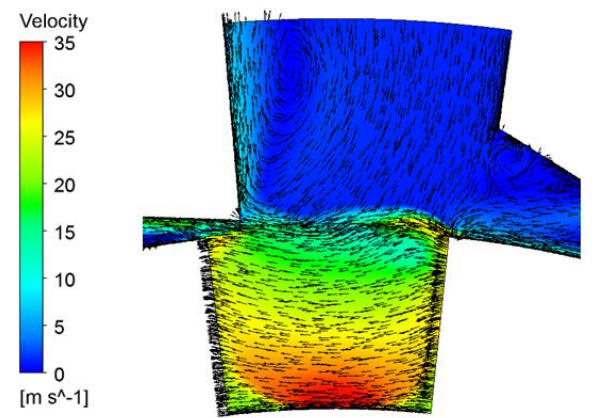

Figura 84: Etapa 3, correspondiente a la fase de paso de la cavidad del rotor sobre el diente del estator (fase 2 de transición, subfase 1).

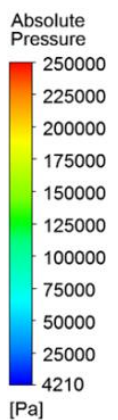

[Pa]
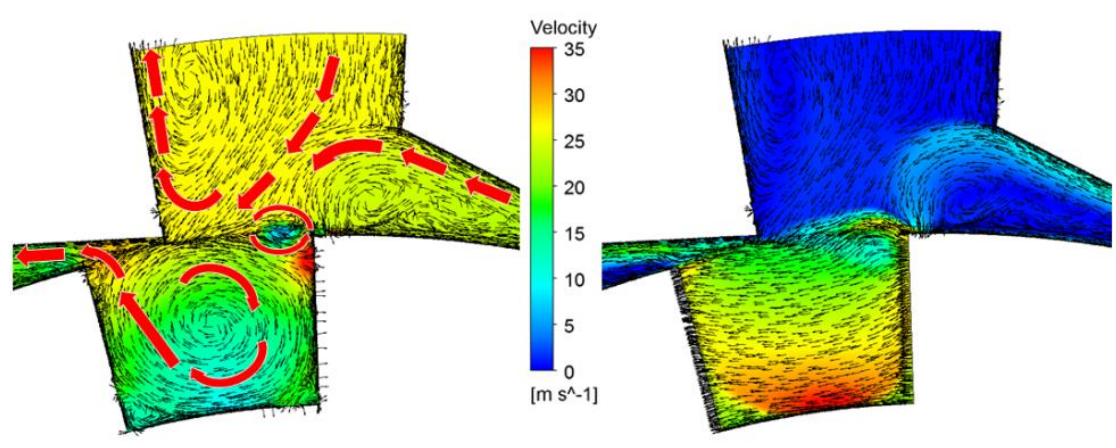

Figura 85: Etapa 4, correspondiente a la fase de paso de la cavidad del rotor sobre el diente del estator (fase 2 de transición, subfase 1 ).

\section{Fase 2, subfase 2}

El comienzo de esta subfase se produce cuando el diente del estator ya ha cubierto la mitad de la cavidad del rotor. A partir de ese momento, el flujo que entra desde la cavidad del estator, así como el flujo procedente del jet que se desplaza sobre la superficie inclinada del diente del estator, entran por la mitad derecha de la cavidad del rotor (Figura 86 y Figura 87), lo que acelera la rotación del flujo de su interior. Además, se incrementa la intensidad con la que el flujo golpea la parte inclinada del diente del estator para escapar hacia la parte delantera en sentido antihorario, lo genera una caída de presión suficientemente elevada como para cavitar en el centro. 
Es importante mencionar que durante esta subfase comienza a generarse un flujo de reentrada hacia la cavidad que se desplaza justo por debajo del jet. Este se produce en la superficie inclinada del estator e intenta introducirse en la cavidad del rotor, pero el flujo que intenta salir lo impide (Figura 87).

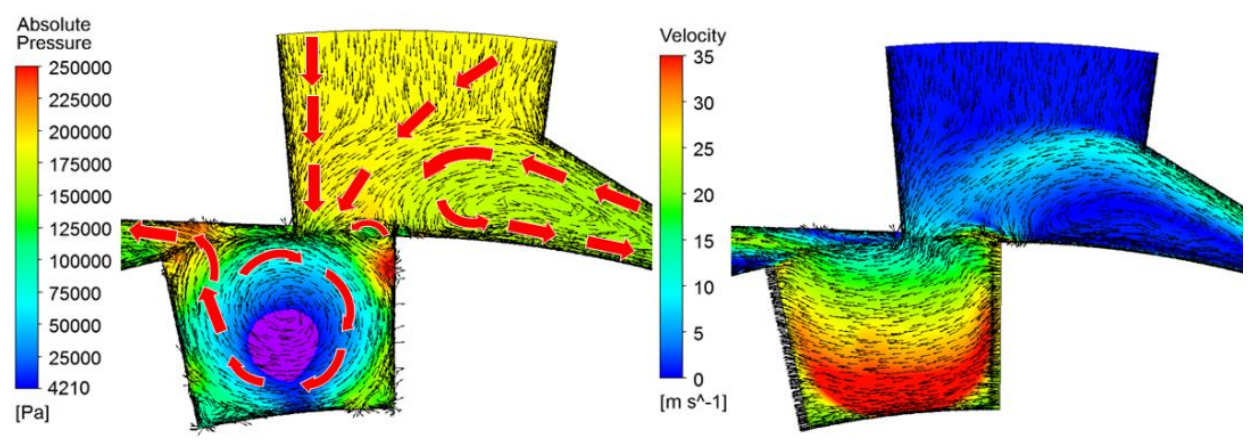

Figura 86: Etapa 5, correspondiente a la fase de paso de la cavidad del rotor sobre el diente del estator (fase 2 de transición, subfase 2).
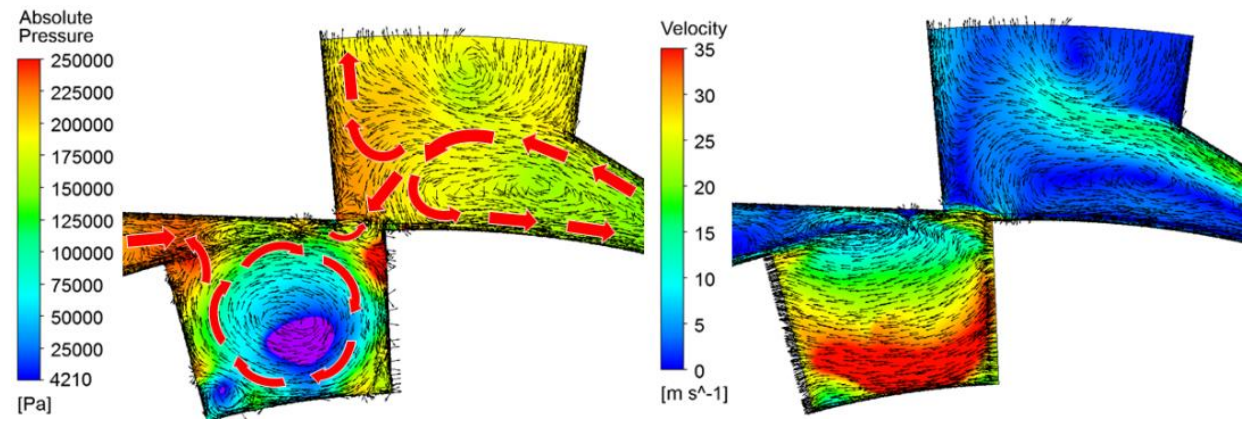

Figura 87: Etapa 6, correspondiente a la fase de paso de la cavidad del rotor sobre el diente del estator (fase 2 de transición, subfase 2).

En la última etapa de esta fase (etapa 7) (Figura 88), la cavidad del rotor queda completamente cubierta por el diente del estator. En ese punto, el flujo solo puede entrar hacia la cavidad por la parte de la izquierda, y el remolino del interior de la cavidad del rotor se desintegra formando varios remolinos más pequeños donde se produce la cavitación. 


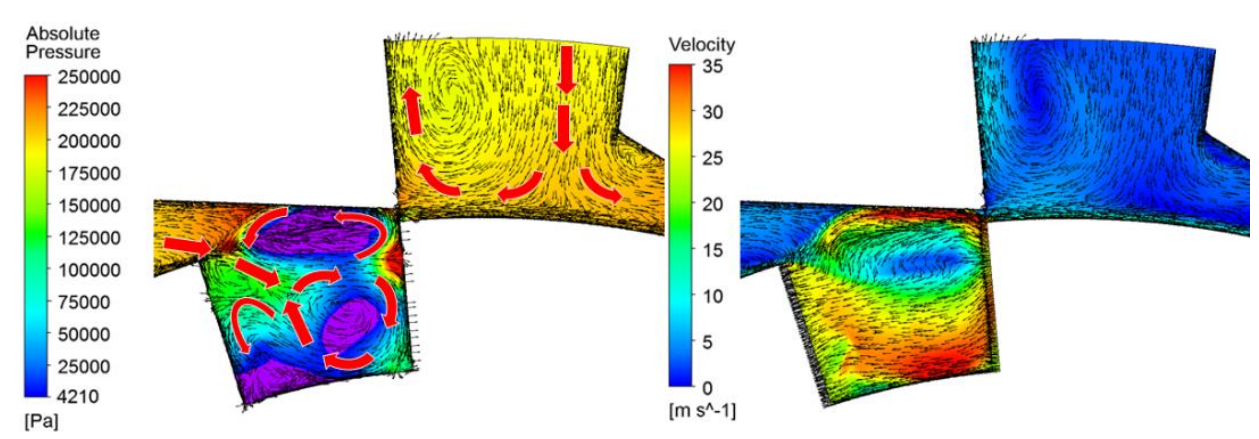

Figura 88: Etapa 7, correspondiente a la fase de paso de la cavidad del rotor sobre el diente del estator (fase 2 de transición, subfase 2).

\subsubsection{Fase 3: Generación y colapso}

$\mathrm{Al}$ igual que la fase anterior, esta fase 3 se encuentra dividida en 2 subfases. La primera de ella comprende las etapas 8 (Figura 89), 9 (Figura 90) y 10 (Figura 91), mientras que la segunda subfase se corresponde con la etapa 11 (Figura 92). En esta última fase es donde se produce la generación y colapso de la mayor cantidad de vapor en todo el ciclo. Es por ello que tanto los campos de velocidad como los campos de presión generados durante estas etapas son muy rápidos y violentos dificultando la explicación en alguna de las etapas.

\section{Fase 3, subfase 1}

En esta subfase es donde se produce la generación de la zona de cavitación. A medida que la cavidad del rotor se acerca a la del estator, la apertura que permite la entrada del fluido hacia el rotor se hace más grande como consecuencia de la inclinación del diente del estator (Figura 89).

Llegado un momento crítico, una gran cantidad de fluido procedente de la cavidad del estator entra violentamente hacia la cavidad del rotor, lo que produce dos grandes remolinos donde la presión baja por debajo de la presión de vapor, pero también dos zonas de alta presión (una sobre la superficie superior del diente del rotor y otra sobre la cara derecha de la cavidad del rotor) como consecuencia del fuerte flujo de entrada (Figura 90). De forma prácticamente instantánea el flujo dentro de la cavidad es acelerado y la presión baja drásticamente haciendo que prácticamente la totalidad de la cavidad cavite y origine una gran zona de vapor (Figura 91). 


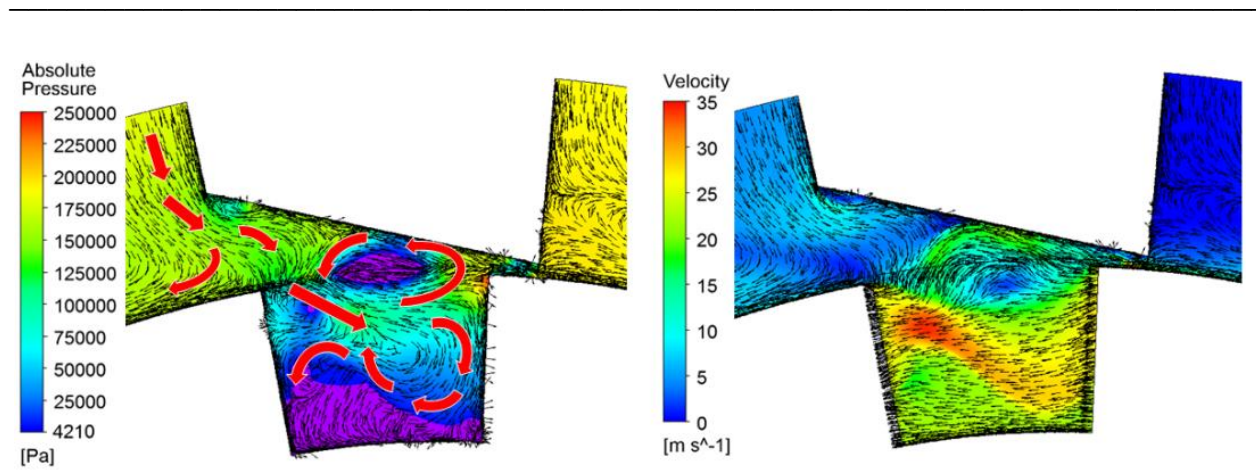

Figura 89: Etapa 8, correspondiente a la fase de acercamiento de la cavidad del rotor a la cavidad del estator (fase 3 de generación y colapso, subfase 1).

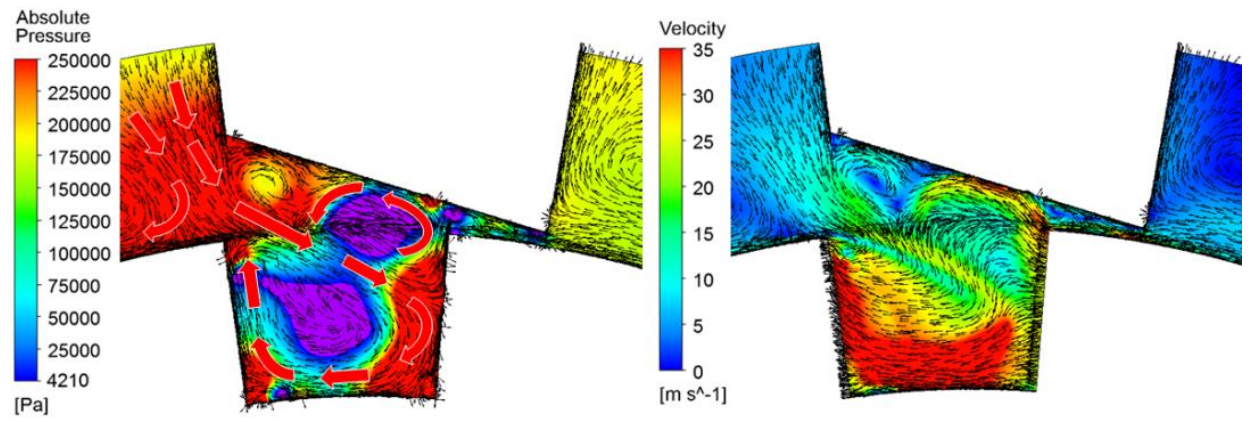

Figura 90: Etapa 9, correspondiente a la fase de acercamiento de la cavidad del rotor a la cavidad del estator (fase 3 de generación y colapso, subfase 1).
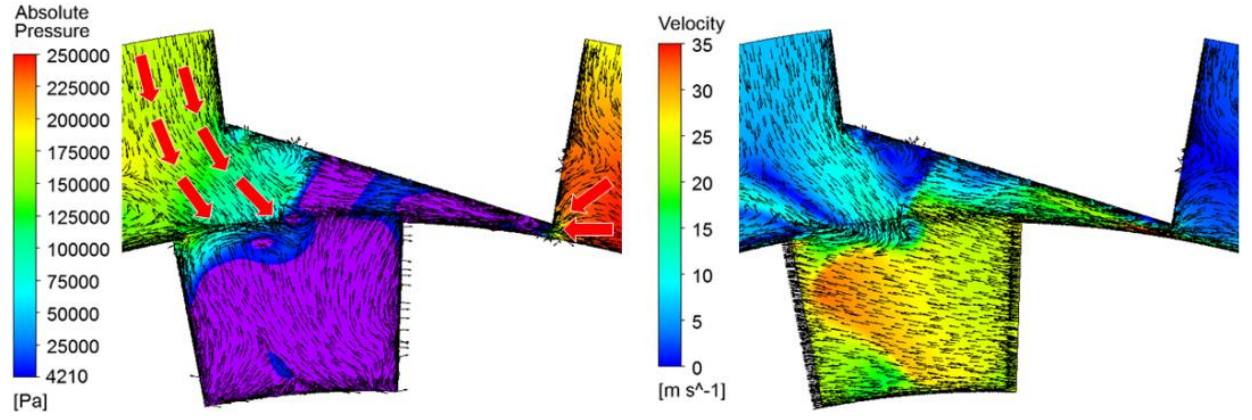

Figura 91: Etapa 10, correspondiente a la fase de acercamiento de la cavidad del rotor a la cavidad del estator (fase 3 de generación y colapso, subfase 1).

La consecución de las etapas 8, 9 y 10, debe comprenderse como un proceso muy rápido donde se produce el incremento de la velocidad y la bajada de la presión de forma muy rápida. Debido a la gran zona de vapor originada, es difícil 
determinar las velocidades exactas en la etapa 10, pero en cualquier caso esto sucede en un instante muy corto de tiempo del orden de $100 \mu \mathrm{s}$.

\section{Fase 3, subfase 2}

Esta subfase se corresponde con la etapa 11 (Figura 92), que es la última de todo el ciclo de funcionamiento del cavitador y es el momento en el que se produce el colapso del vapor. En esta situación, las cavidades tanto del estator como del rotor se encuentran alineadas y el flujo procedente del estator pasa a llenar toda la cavidad que se encontraba llena de vapor por la generación que se había sucedido justo en la etapa posterior (etapa 10).

Una vez llenada la cavidad, las presiones comienzan de nuevo a equilibrarse y se empieza a formar el remolino en el interior de la cavidad que dará paso a la etapa 1 que se ha descrito al comienzo de la explicación.

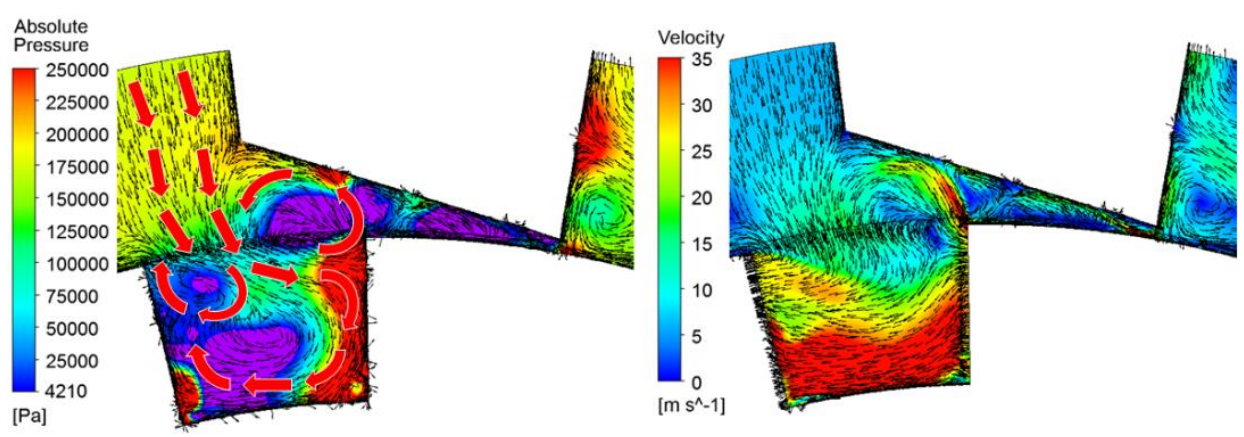

Figura 92: Etapa 11, correspondiente a la fase de acercamiento de la cavidad del rotor a la cavidad del estator (fase 3 de generación y colapso, subfase 2).

Para completar el proceso descriptivo de todo el ciclo, a continuación, se presentan las gráficas de presión y velocidad obtenidas a lo largo de una línea circunferencial que pasa por el centro de las 11 cavidades del rotor.

En la Figura 93, se muestra la distribución de presiones absolutas sobre el dominio completo y se grafican los valores de dicho parámetro sobre la línea circunferencial que pasa por el centro de las cavidades del rotor. Se puede observar cómo efectivamente las etapas 2 y 3 son las que muestran presiones más elevadas impidiendo que en ellas se produzca cavitación. Por contra, en las etapas 8, 9 y 10 las presiones son muy bajas, dando como resultado áreas de cavitación extensas dentro de la cavidad. Tanto en la etapa 9 como en la 11 se observan picos de presión muy elevados, como consecuencia del flujo que entra desde el estator hacia la cavidad y que golpea uno de los laterales de la cavidad del rotor. En cuanto al resto de las etapas, la presión se mantiene con valores bajos en el centro (que llegan 
a alcanzar la presión y producir cavitación) debido al flujo rotativo que se induce en el interior de la cavidad.
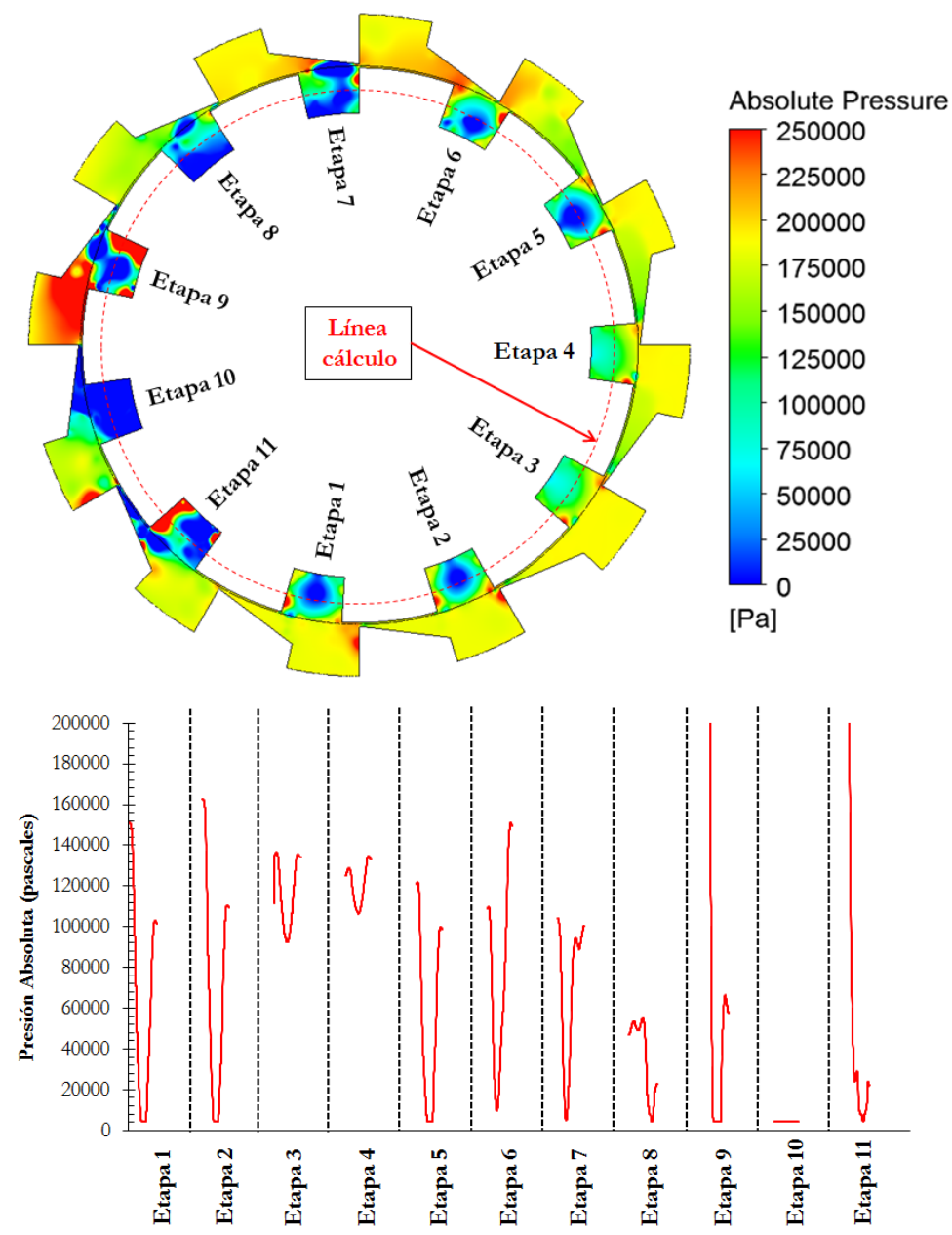

Figura 93: Distribución de presiones absolutas a lo largo de una línea circunferencial que pasa por el centro de las cavidades del rotor para una velocidad de rotación de $5600 \mathrm{rpm}$.

De la misma manera, en la Figura 93 se muestra la distribución de velocidades radiales en el dominio completo del cavitador y su evolución a lo largo de la misma línea circunferencial. Se puede ver como en todas las etapas el comportamiento del flujo se rige por el mismo patrón: un flujo hacia el centro del cavitador por un lado de la cavidad, y un flujo hacia afuera del cavitador en el lado opuesto. Esto evidencia la formación del remolino en el interior de la cavidad que únicamente se ve modificado en las etapas 7, 8 y 10, que son aquellas en las que o bien se produce 
un cambio brusco en el comportamiento (bloqueo del flujo de salida en la etapa 7 y 8), o bien se produce una gran cantidad de gas como consecuencia de la cavitación (etapa 10). Se puede observar también, como las etapas 9 y 11 son las que presentan diferencias más grandes entre las velocidades radiales máximas y mínimas. Esto es consecuencia del flujo de entrada desde el estator, que es la que a su vez produce el pico de elevadas presiones en las mismas etapas, observado en la gráfica de la Figura 94.
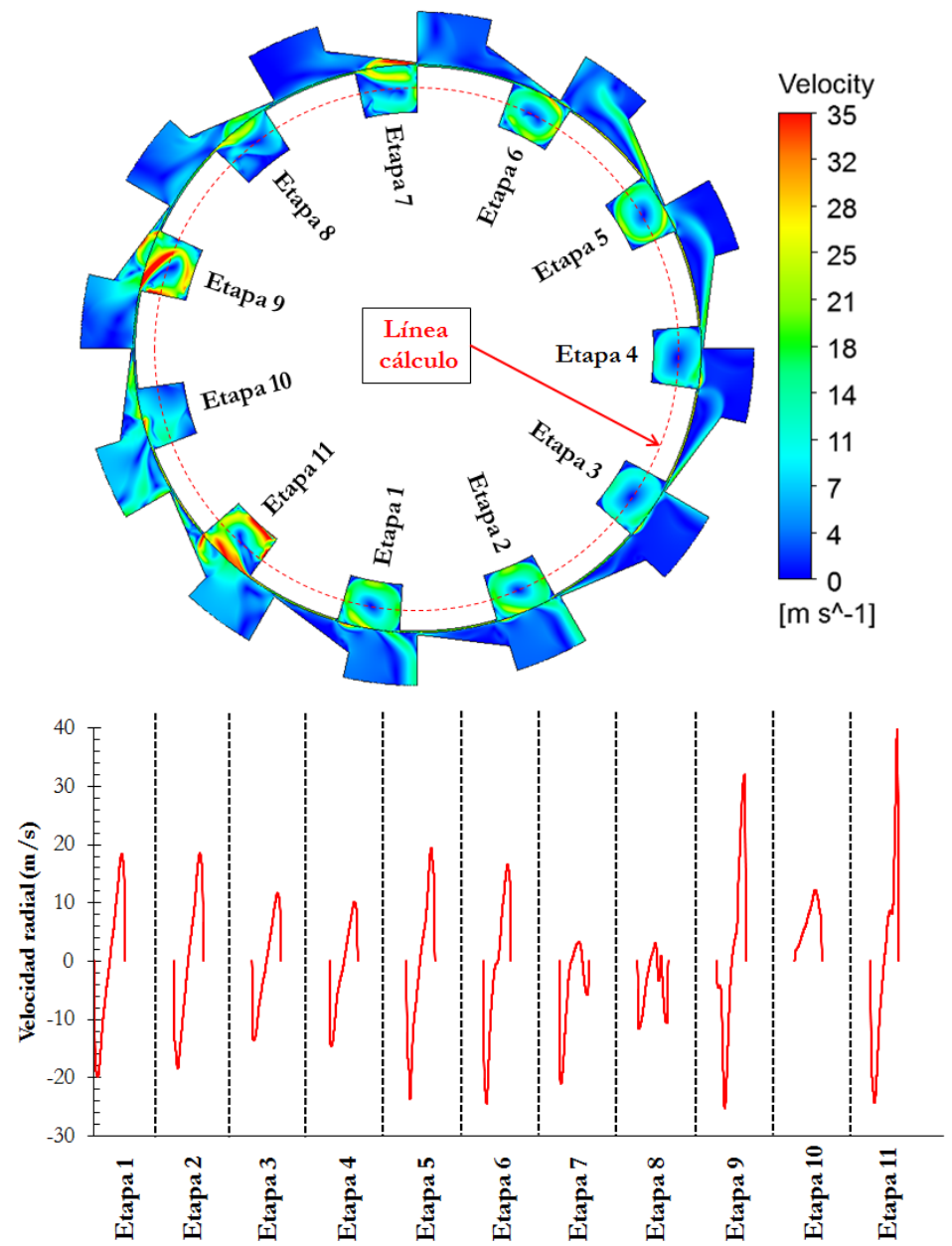

Figura 94: Distribución de velocidades radiales a lo largo de una línea circunferencial que pasa por el centro de las cavidades del rotor para una velocidad de rotación de $5600 \mathrm{rpm}$.

Finalmente, en la Figura 95 se muestra la fracción volumétrica de gas que se encuentra en cada punto del dominio simulado. Las zonas donde se produce 
cavitación en mayor extensión e intensidad se encuentran en las etapas 7, 8, 9, 10 y 11, siendo la etapa 10, aquella en la que se produce una mayor cantidad de gas con diferencia. En el resto de las etapas puede existir una pequeña fracción de gas (salvo las etapas 3 y 4 donde la totalidad del volumen es líquido).

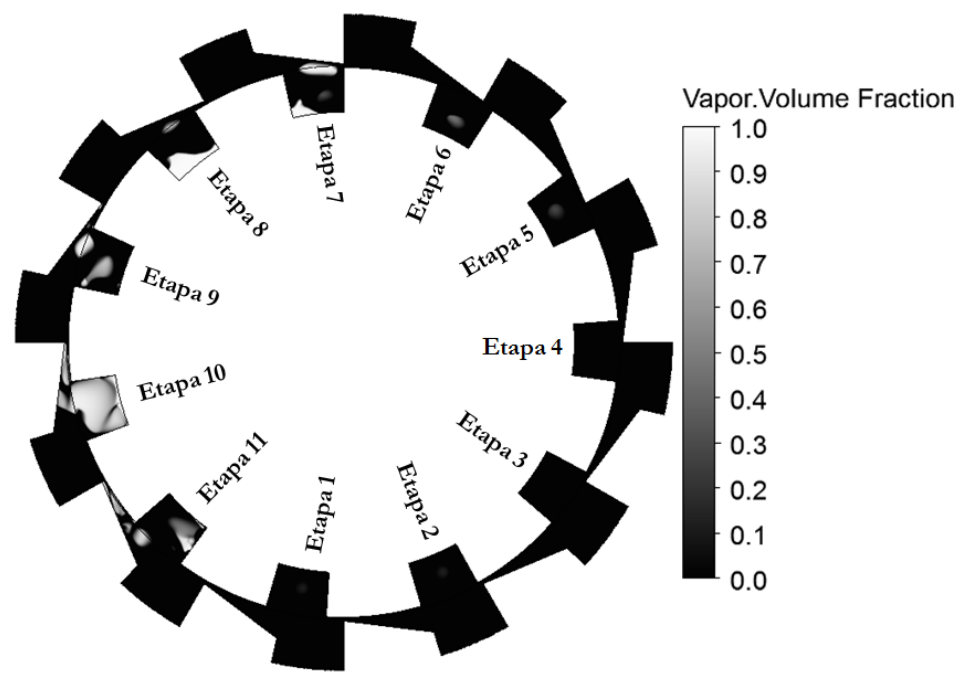

Figura 95: Distribución de la fracción de gas en el interior del dominio del cavitador.

El análisis en profundidad de los campos de velocidades y de presiones ha permitido describir el comportamiento detallado del sistema de cavitación durante su funcionamiento. El comportamiento en un régimen de giro de $5600 \mathrm{rpm}$, muestra la existencia de zonas de cavitación y zonas de no cavitación y, por tanto, se puede determinar que existirá una generación y colapso de las burbujas en cada ciclo de giro. Esto es importante, dado que la capacidad degradante de la cavitación se da durante el colapso de la fase gaseosa, y por tanto el hecho de que este efecto pueda producirse en cada rotación augura un buen funcionamiento del sistema real. Se puede concluir que este primer diseño propuesto, cumple con las condiciones que se espera de este tipo de dispositivos para el fin que le ha sido asignado.

\subsubsection{Variación de la velocidad de rotación}

Una vez analizado y conocido el comportamiento en detalle del sistema de cavitación, se han realizado simulaciones variando la velocidad de rotación con el objetivo de analizar cómo se comporta el sistema bajo diferentes regímenes de giro. Experimentalmente (y tal como se describirá durante el apartado 4 de la presente tesis), se ha podido determinar que existen evidencias de la aparición del fenómeno de la cavitación cuando se superan las 4100 rpm. Por tanto, se espera 
que en las simulaciones realizadas en este apartado la cavitación se produzca a partir de este régimen de giro y sea muy pequeña o imperceptible para regímenes de giro inferiores a este valor.

$\mathrm{Al}$ analizar la distribución de presiones absolutas en los diferentes regímenes de giro (Figura 96), se observa cómo las caídas de presión que se producen en las diferentes partes del cavitador. Analizando en detalle el comportamiento en cada régimen de giro, se puede ver como para las simulaciones llevadas a cabo a $3600 \mathrm{rpm}$ todo el dominio presenta presiones por encima de la presión de vapor y por tanto no se produce cavitación en ningún punto. Sin embargo, al aumentar la velocidad de giro hasta los $4100 \mathrm{rpm}$, se puede observar la generación de pequeñas zonas de cavitación cerca del borde del diente del rotor, lo que es coherente con las observaciones llevadas a cabo durante los ensayos experimentales.

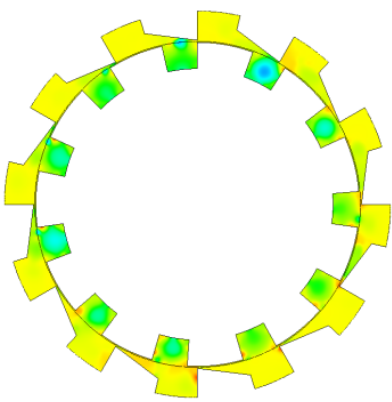

$3600 \mathrm{rpm}$

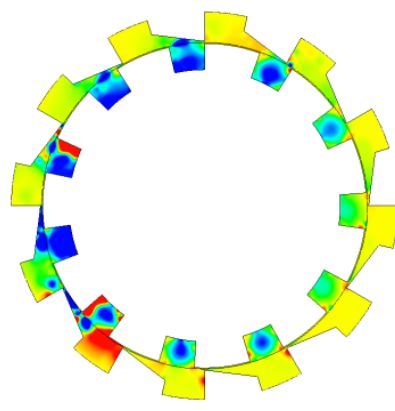

$5100 \mathrm{rpm}$

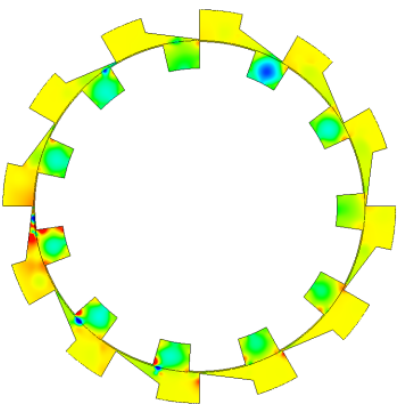

$4100 \mathrm{rpm}$

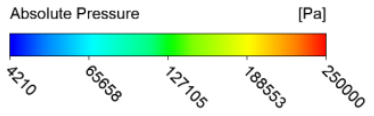

Figura 96: Distribución de presiones absolutas en el sistema de cavitación completo, a diferentes velocidades de giro.

En la gráfica de presiones a lo largo de la línea circunferencial que pasa por el centro de las cavidades del rotor (Figura 97), se puede observar cómo, 
efectivamente, la presión en el centro de la cavidad disminuye a medida que la velocidad de rotación aumenta. Aunque a partir de las $4100 \mathrm{rpm}$ se producen zonas de cavitación en partes concretas del dominio (p.ej. área cercana a la arista del diente del rotor), no es a partir de las $4600 \mathrm{rpm}$ cuando las velocidades inducidas son suficientemente altas como para producir caídas de presión en el interior de las cavidades del rotor que permitan la cavitación en ese punto.

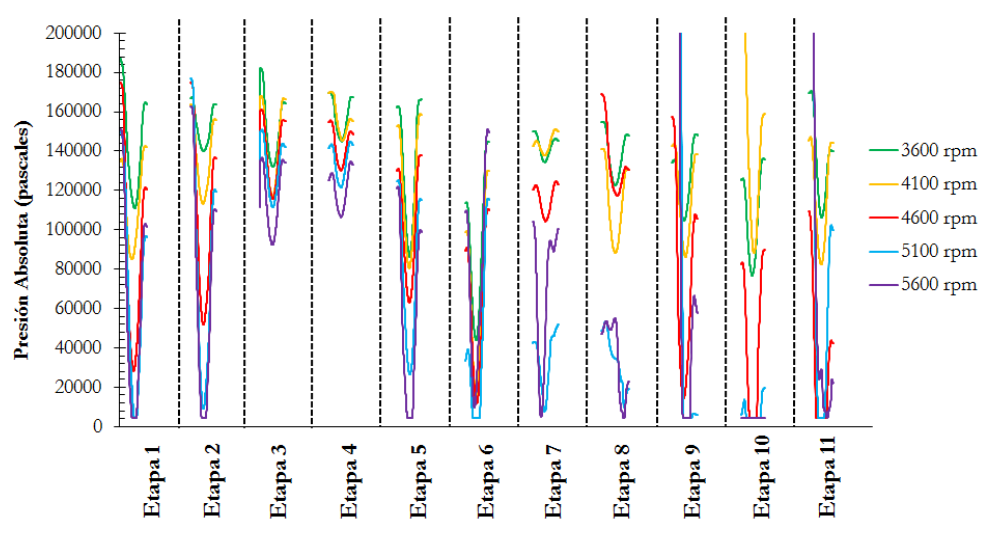

Figura 97: Distribución de presiones absolutas a lo largo de una línea circunferencial que pasa por el centro de las cavidades del rotor.

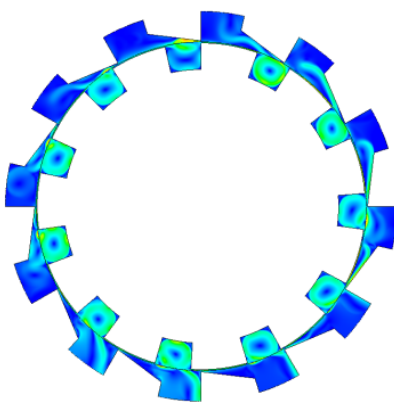

$3600 \mathrm{rpm}$

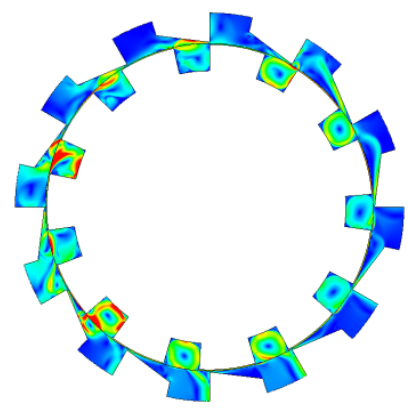

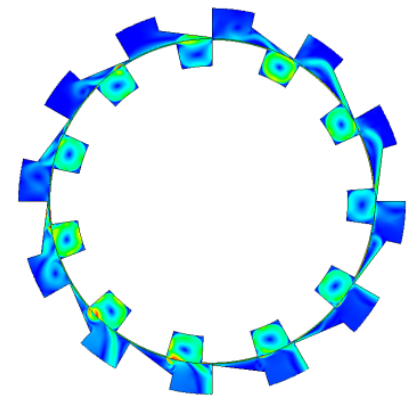

$4100 \mathrm{rpm}$

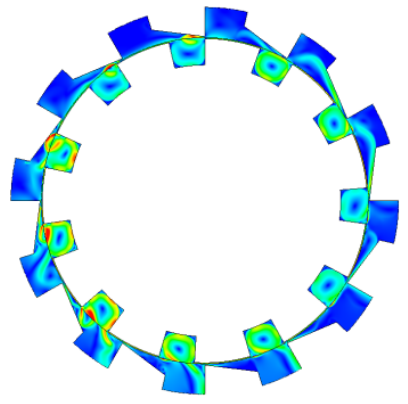

4600 rpm

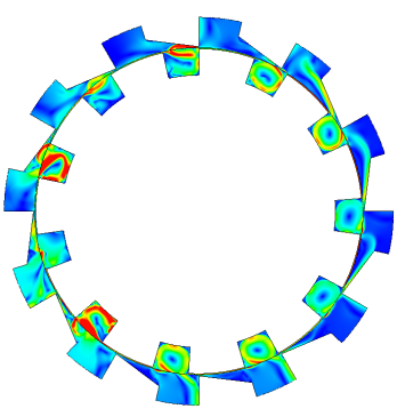


$5100 \mathrm{rpm}$

$5600 \mathrm{rpm}$

Figura 98: Distribución de velocidades en el sistema de cavitación completo, a diferentes velocidades de giro.

Al analizar la distribución de velocidades en los diferentes regímenes de giro (Figura 98), se observa cómo las velocidades que se inducen tanto en la cavidad del rotor como en el estator se incrementan a medida que se incrementa la velocidad de rotación hasta alcanzar valores que superan los $30 \mathrm{~m} / \mathrm{s}$. El comportamiento del flujo en cada etapa es prácticamente idéntico en todos los casos, siendo el módulo de la velocidad, la única diferencia entre los diferentes casos simulados.

Esto se evidencia también al analizar la evolución de las velocidades en el interior de las cavidades del rotor tal y como puede verse en la gráfica de la Figura 99. Se puede observar cómo, conforme la velocidad de rotación va aumentando, la velocidad lineal de los dientes del rotor es más elevada, y los dientes del estator permiten inducir una velocidad en el interior de las cavidades cada vez mayor. También puede verse cómo las diferencias entre las velocidades máximas y mínimas en el interior del rotor son mucho más elevadas cuando la velocidad de rotación aumenta. En el caso más extremo se tiene la etapa 11, donde las velocidades radiales en la cavidad obtenidos para $3600 \mathrm{rpm}$ oscilan entre los 11.7 y $\operatorname{los}-11.6 \mathrm{~m} / \mathrm{s}$, mientras que para $5600 \mathrm{rpm}$ esta oscilación aumenta hasta rangos entre los 40.4 y los $-25.3 \mathrm{~m} / \mathrm{s}$.

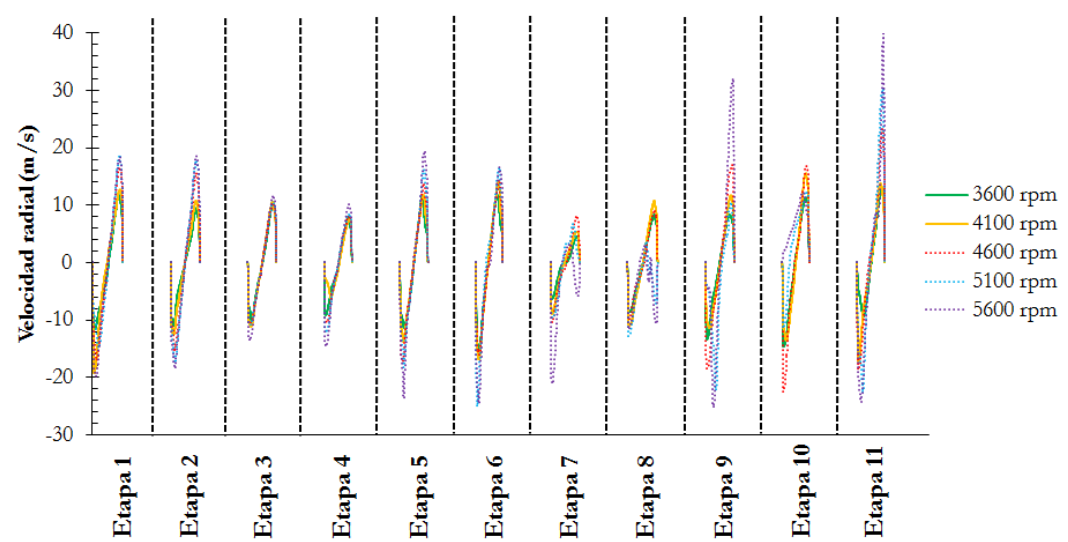

Figura 99: Distribución de velocidades radiales a lo largo de una línea circunferencial que pasa por el centro de las cavidades del rotor.

El aumento de estas velocidades en el interior de la cavidad tiene como consecuencia un aumento en la velocidad de rotación del remolino inducido en el interior de la cavidad del rotor y, por ende, una disminución de la presión más 
aguda en su centro, tal y como se ha visto en el gráfico de la distribución de presiones absolutas (Figura 97).

Finalmente, en la Figura 100, se muestra la fracción de gas que aparece como consecuencia de las caídas de presión que se generan en el sistema de cavitación. Analizando las imágenes, se podría decir que la cavitación incipiente sucede a partir una velocidad de rotación de $4100 \mathrm{rpm}$. Es a partir de esta velocidad cuando comienza a producirse gas en pequeñas zonas como las que se encuentran cerca de los dientes del rotor. A partir de las $4600 \mathrm{rpm}$, la aparición de la cavitación se consolida en el interior de los huecos de rotor en las etapas 9, 10 y 11, y a partir de ese régimen de velocidades la fracción de gas comienza a aparecer en mayor cantidad y en un mayor número de etapas $(5,67$ y 8 e incluso en menor medida en las etapas 1 y 2 ).

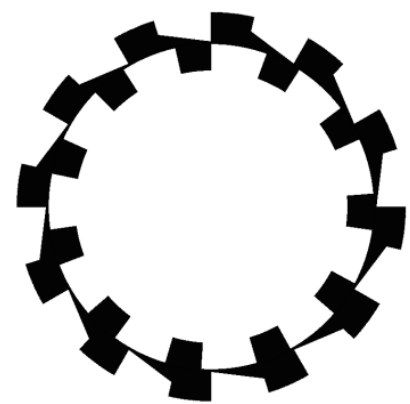

$3600 \mathrm{rpm}$

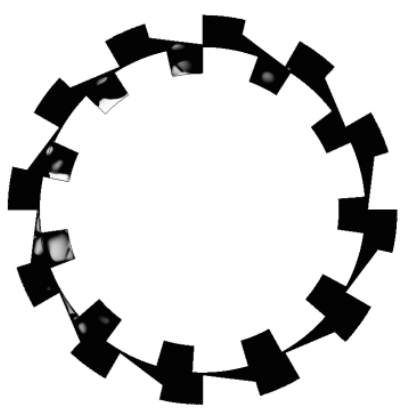

$5100 \mathrm{rpm}$

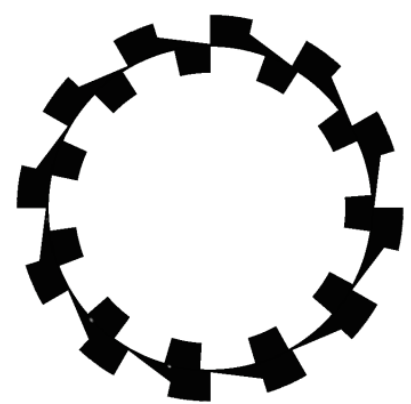

$4100 \mathrm{rpm}$

Vapor.Volume Fraction

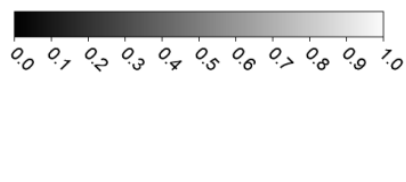

Figura 100: Distribución de la fracción de gas en el sistema de cavitación completo, a
diferentes velocidades de giro.

La adecuación de las simulaciones a las observaciones experimentales proporciona robustez al modelo CFD. Si hubiese existido coherencia en los resultados simulados, esto podría haber indicado la introducción unas condiciones 
de contorno incorrectas $\mathrm{y}$, por tanto, se tendrían que haber recalculado las simulaciones hasta conseguir unos resultados acordes a las observaciones experimentales. Sin embargo, y en vista de los resultados, se puede afirmar que el modelo se comporta conforme a lo esperado y parece reproducir de forma adecuada el funcionamiento real del sistema de cavitación.

\subsubsection{Variación de la distancia entre rotor y estator}

A continuación, se muestran los resultados obtenidos tras las simulaciones realizadas sobre el sistema de cavitación, variando la distancia entre el rotor y el estator. Para ello ha sido necesario realizar 2 geometrías adicionales en las cuales los dientes del estator se han acortado para conseguir aumentar la distancia con el rotor desde los $0.6 \mathrm{~mm}$ adicionales hasta $1 \mathrm{~mm}$ y $2.6 \mathrm{~mm}$. La geometría del rotor se ha mantenido invariable, mientras que el estator ha sido modificado manteniendo el ángulo de $8^{\circ}$ en sus dientes, así como el espaciado entre ellos. Únicamente se ha visto reducida la profundidad de sus huecos tal y como se muestra en la (Figura 101).

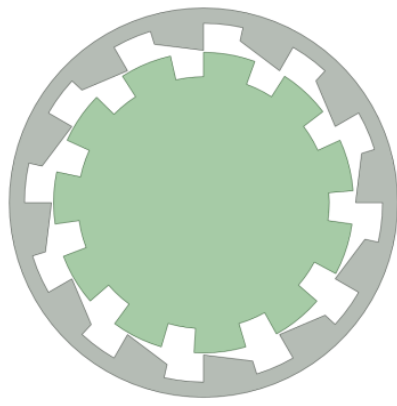

$0.6 \mathrm{~mm}$ de separación

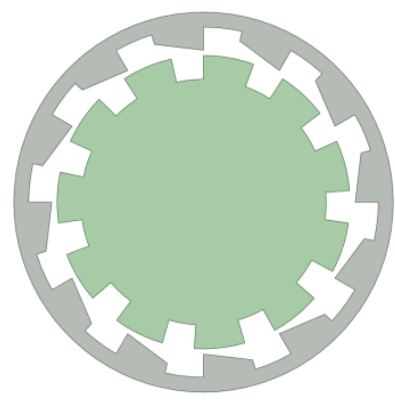

$1 \mathrm{~mm}$ de separación

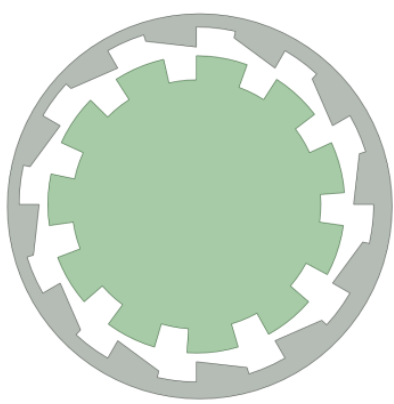

$2.6 \mathrm{~mm}$ de separación

Figura 101: Geometrías utilizadas para las simulaciones variando la distancia entre el rotor y el estator.

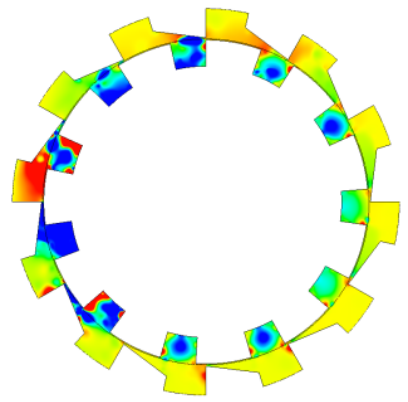

$0.6 \mathrm{~mm}$ de separación

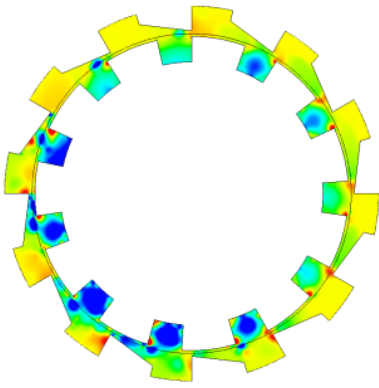

$1 \mathrm{~mm}$ de separación

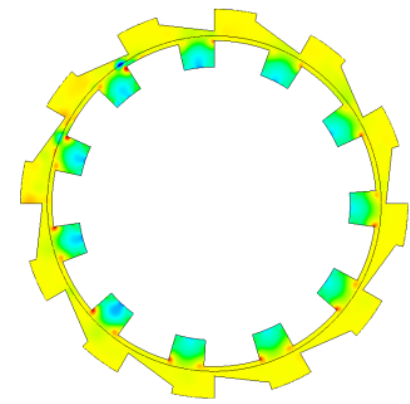

$2.6 \mathrm{~mm}$ de separación 


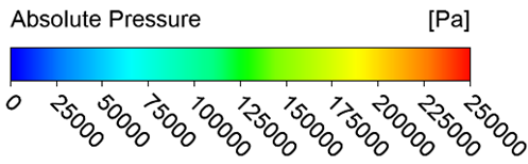

Figura 102: Distribución de presiones en el interior del cavitador para diferentes distancias de separación entre el rotor y el estator.

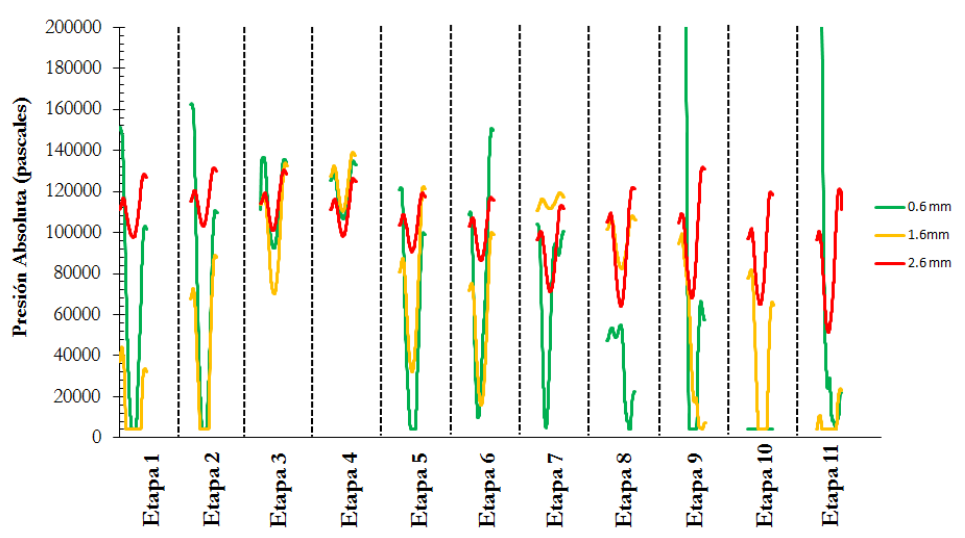

Figura 103: Distribución de presiones absolutas a lo largo de una línea circunferencial que pasa por el centro de las cavidades del rotor.

En las imágenes de la Figura 102, se puede observar la distribución de presiones obtenida para diferentes distancias de separación entre el rotor y el estator. Los resultados muestran cómo, a medida que la distancia entre el rotor y el estator se incrementa, aumenta la presión en el interior de las cavidades hasta el punto de no poder conseguir caídas de presión suficientemente elevadas como para conseguir cavitar en caso de $2.6 \mathrm{~mm}$ de separación (Figura 103).

En este último caso de $2.6 \mathrm{~mm}$ de separación, el comportamiento observado es muy similar al que cabría esperar para un sistema en el que no existiera una corona externa dentada (estator) y el rotor girara libremente en el interior de un cilindro liso. De hecho, la distribución de presiones obtenida describe perfectamente los resultados obtenidos en el apartado 4.3, donde se ha analizado detalladamente el comportamiento de las cavidades del rotor considerando únicamente el movimiento de rotación. En dicho apartado se ha podido concluir que la distribución de presiones en el interior de la cavidad del rotor es consecuencia de la fuerza centrípeta que tiende a expulsar el fluido hacia la parte exterior y del flujo entrante a la cavidad que induce un movimiento de rotación en el interior la misma. Debido a estos dos efectos, las mayores caídas de presión se producen en la parte central del fondo de la cavidad, lo cual se observa perfectamente en la 
distribución de presión de los dientes del rotor para el caso de una separación de $2.6 \mathrm{~mm}$ (Figura 104).

La depresión en el fondo no es homogénea, ya que el flujo rotativo impacta sobre las paredes en las esquinas de la cavidad. Es por ello que la presión en estas zonas es ligeramente superior y la mayor depresión se produce justo en el centro. Asimismo, esta depresión del fondo se extiende hacia el centro de la cavidad ya que en ella se encuentra la depresión generada por el remolino que, si bien no es tan aguda como la que se produce en el fondo, contrasta con las elevadas presiones que se encuentran cerca de las paredes y en la zona superior cercana a los dientes del estator.

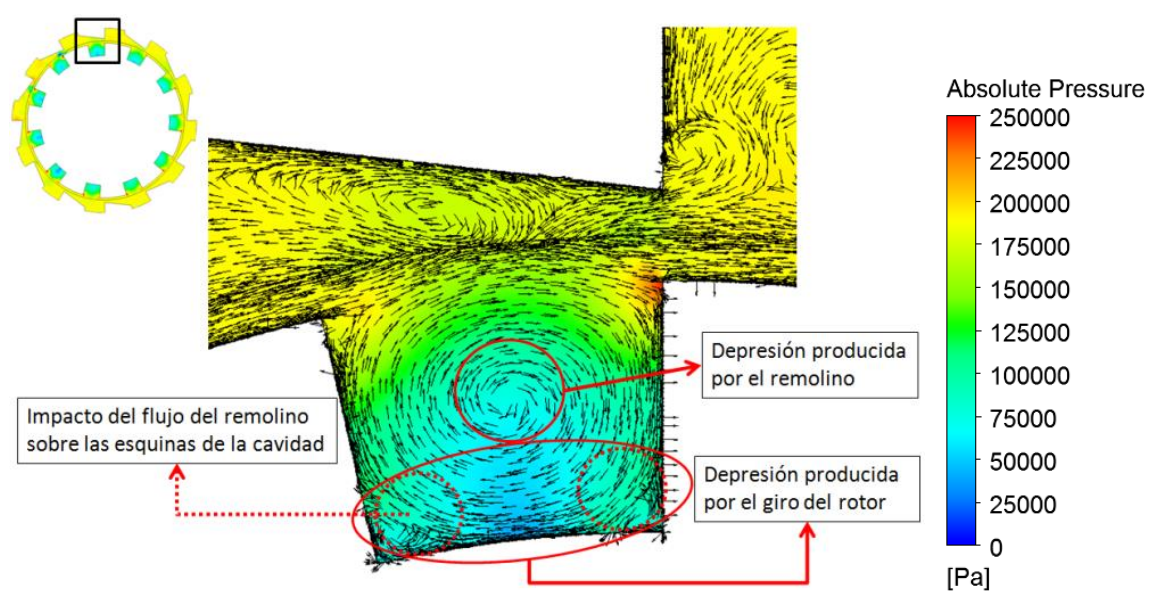

Figura 104: Detalle del comportamiento del flujo en el interior de las cavidades del rotor para el caso de una separación de $2.6 \mathrm{~mm}$ con el estator.

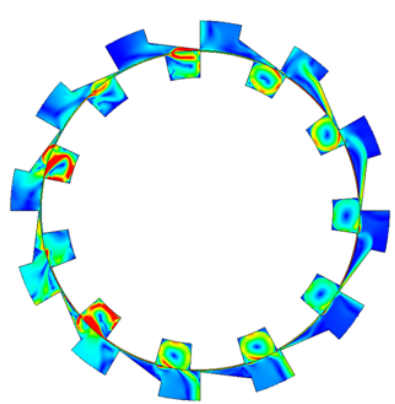

$0.6 \mathrm{~mm}$ de separación

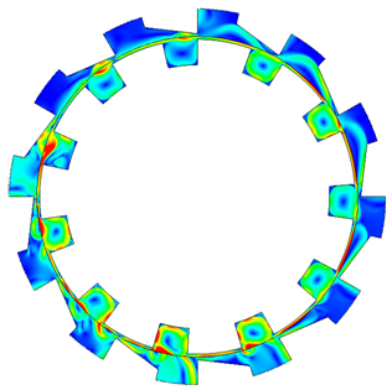

$1 \mathrm{~mm}$ de separación

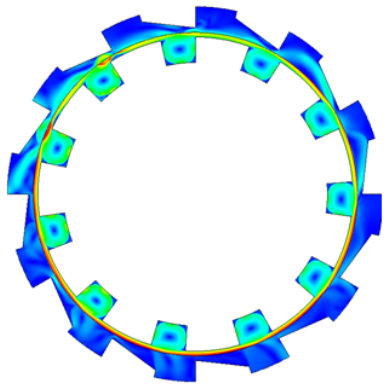

$2.6 \mathrm{~mm}$ de separación 


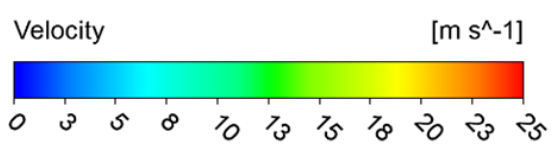

Figura 105: Distribución de velocidades en el interior del cavitador para diferentes distancias de separación entre el rotor y el estator.

Las distribuciones de velocidad (Figura 105), en el caso de una separación de $2.6 \mathrm{~mm}$, muestran como el flujo dentro de las cavidades se encuentra en una rotación constante, donde este patrón de flujo no se rompe en ninguna de las etapas. Esto reafirma que, para distancias de separación grandes, el efecto que induce el rotor sobre el estator es tan débil que, a efectos prácticos, el sistema de cavitación se comporta como si no existiera un estator dentado y únicamente se tuviese el efecto de un rotor ranurado girando a una velocidad angular constante.

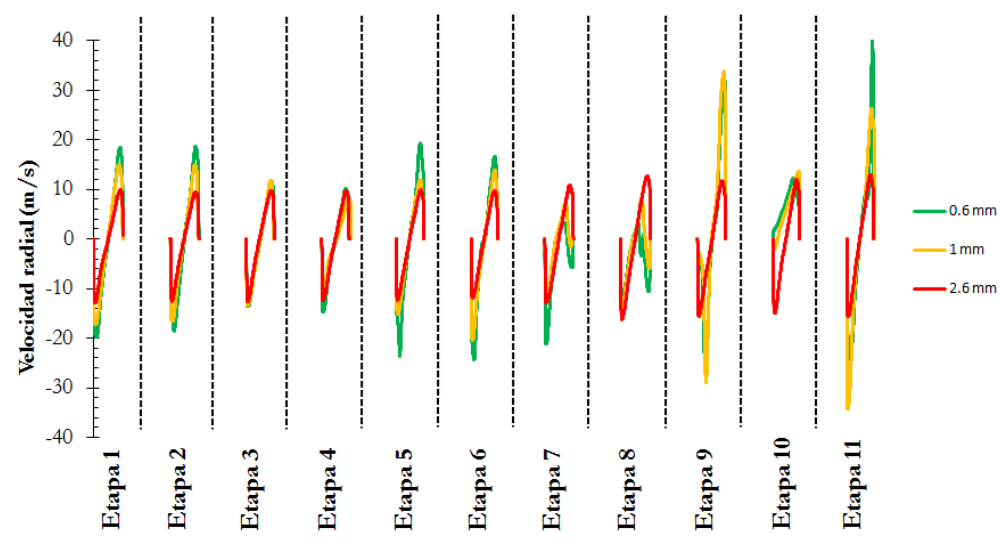

Figura 106: Distribución de velocidades radiales a lo largo de una línea circunferencial que pasa por el centro de las cavidades del rotor.

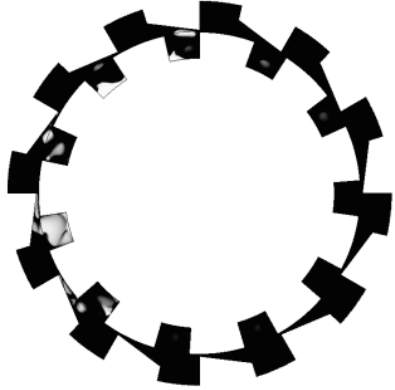

$0.6 \mathrm{~mm}$ de separación

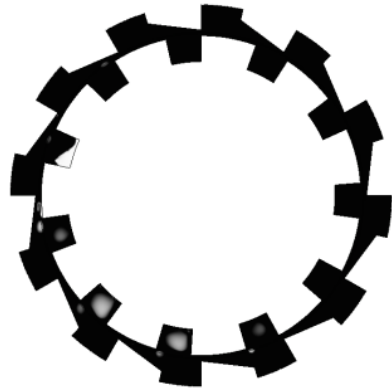

$1 \mathrm{~mm}$ de separación

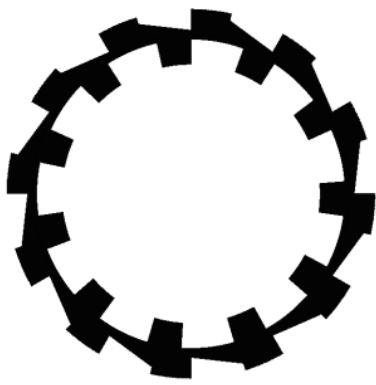

$2.6 \mathrm{~mm}$ de separación 


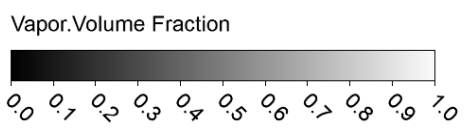

Figura 107: Distribución de la fracción de gas en el sistema de cavitación completo, con diferentes distancias de separación entre el rotor y el estator.

En la distancia de separación de $1 \mathrm{~mm}$ se puede observar un estado de transición entre la separación de $0.6 \mathrm{~mm}$ y de $2.6 \mathrm{~mm}$. En este caso, se pueden apreciar los mismos patrones de flujo, caídas de presión, y distribuciones de presión que aparecen en el caso de $0.6 \mathrm{~mm}$, y que han sido explicados detalladamente y etapa por etapa en el apartado 4.4.4. La única diferencia reside en la intensidad con la que suceden los eventos, lo cual se hace patente en las gráficas de presión (Figura 103) y velocidad (Figura 106), donde la tendencia de los valores en las distribuciones de 0.6 y $1 \mathrm{~mm}$ es muy similar pero los valores máximos alcanzados varían ligeramente.

Se puede apreciar cómo en el sistema con separación de $0.6 \mathrm{~mm}$ se consigue alcanzar la presión de vapor en todas las etapas salvo en la 3 y la 4 , mientras que, al aumentar la separación a $1 \mathrm{~mm}$, deja de producirse cavitación en las etapas 5, 6, 7 y 8. En el caso de una separación de $2.6 \mathrm{~mm}$, la presión en las etapas 8, 9, 10 y 11, presentan un descenso más acusado que el resto, pero se encuentra lejos del valor de la presión de vapor (la presión mínima se alcanza en la etapa 11 con un valor de 51429 pascales). Esto se traduce en una disminución de la capacidad de cavitación del dispositivo, tal y como puede observarse en la imagen de la Figura 107. En ella se aprecia que el gas que se produce al aumentar la distancia de separación a $1 \mathrm{~mm}$ se ve reducido, y es prácticamente inexistente al incrementar la separación hasta los $2.6 \mathrm{~mm}$

\subsubsection{Variación de la geometría del diente del estator}

Con objeto de determinar el efecto de la geometría de los dientes del estator, se ha realizado una geometría en la que en lugar de utilizar dientes con una inclinación de $8^{\circ}$ se han modelado dientes completamente rectos, tal y como puede verse en la imagen de la Figura 108. La distancia entre los dientes del rotor y las del estator se ha mantenido a $0.6 \mathrm{~mm}$ y se ha simulado el funcionamiento a un régimen de $5600 \mathrm{rpm}$. 

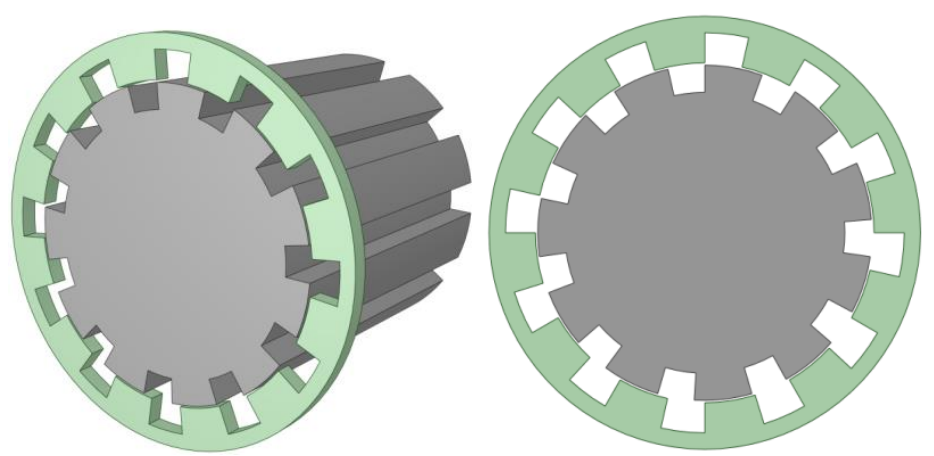

Figura 108: Modelo del sistema de cavitación con la geometría de dientes rectos.

$\mathrm{Al}$ analizar la distribución de presiones, se puede observar cómo los valores que se alcanzan son muy superiores a los obtenidos en la misma situación con una geometría de dientes inclinados (Figura 93). Es decir, existen una menor cantidad de zonas donde la presión presenta valores suficientemente bajos para alcanzar la presión de vapor y cavitar. Concretamente, únicamente existen dos momentos donde se produce cavitación y se corresponden con la etapa 1 y la etapa 2 . Aunque en el modelo de dientes inclinados estas dos etapas se correspondían a una fase de recuperación donde la cavitación producida en las etapas posteriores colapsaba, en esta nueva geometría dichas etapas se corresponden con el momento de máxima cavitación. Este fenómeno es consecuencia de la distribución del flujo y de las velocidades que se producen como se explicará más adelante.

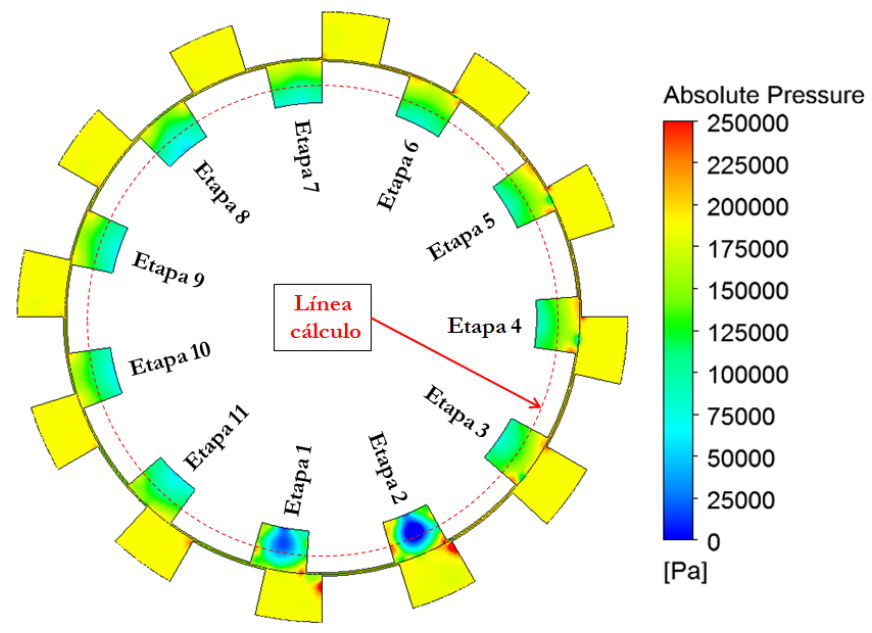




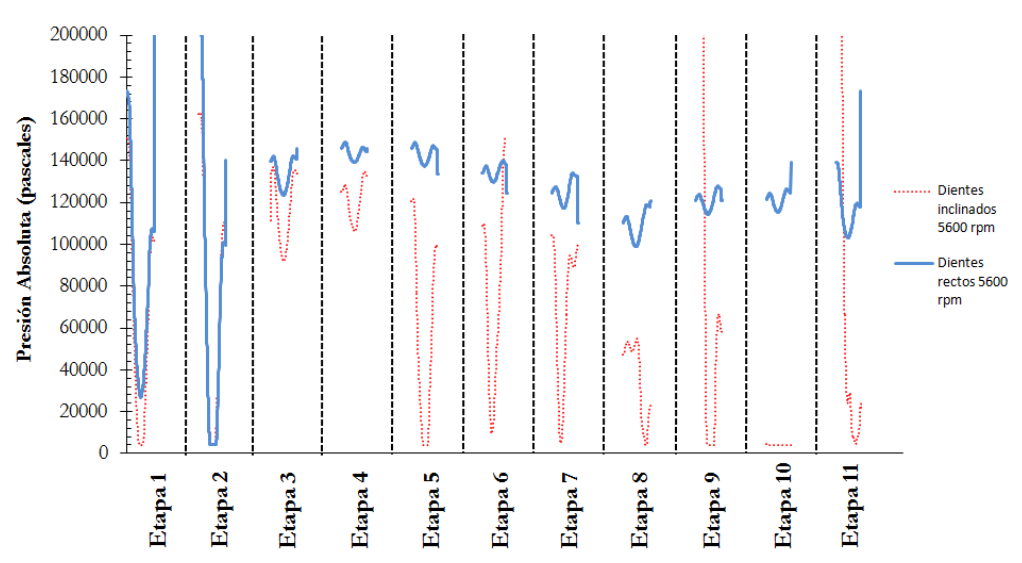

Figura 109: Distribución de presiones absolutas a lo largo de una línea circunferencial que pasa por el centro de las cavidades del rotor para una velocidad de rotación de $5600 \mathrm{rpm}$.

Al comparar la gráfica de presión obtenida en este caso (Figura 109) con la obtenida en el caso de dientes inclinados (Figura 93) se observa como la presión en todos los puntos analizados es mucho mayor (del orden de la presión atmosférica) salvo en las etapas 1 y 2 , que es cuando se produce una bajada suficientemente grande como para aproximarse (etapa 1) y alcanzar (etapa 2) la presión de vapor para finalmente cavitar. La distribución de presión en el interior de la cavidad del rotor es muy similar en prácticamente todas las etapas salvo en las etapas 1 y 2 . Se induce un remolino en el interior de la cavidad del rotor que permanece inalterado hasta que se produce el enfrentamiento de ambas cavidades (del rotor y del estator) que rompe la dinámica del flujo y permite la entrada en la cavidad, acelerando la velocidad de rotación del remolino y permitiendo la cavitación. En el interior de la cavidad del rotor se puede observar que existe una distribución de presiones muy similar a la obtenida en la Figura 73, donde se estudiaba el comportamiento de la cavidad como consecuencia de la rotación del rotor y se producía un gradiente radial, donde la menor presión se alcanzaba en el fondo de la cavidad. 

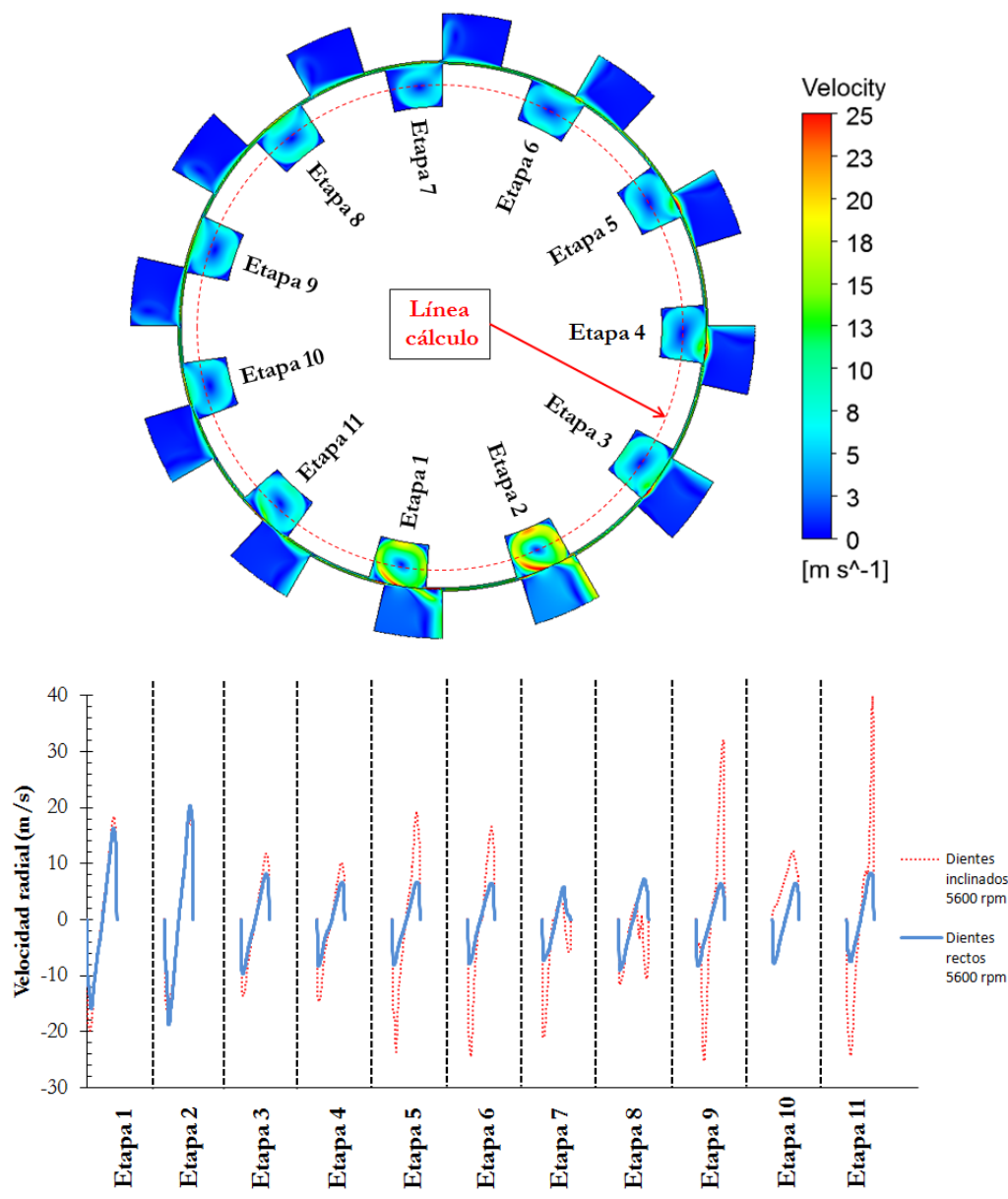

Figura 110: Distribución de velocidades radiales a lo largo de una línea circunferencial que pasa por el centro de las cavidades del rotor para una velocidad de rotación de $5600 \mathrm{rpm}$.

La explicación de por qué se produce esta reducción drástica en el rendimiento del cavitador al utilizar los dientes rectos se encuentra en la distribución de velocidades que se produce con esta nueva configuración. Mientras que en la configuración con dientes inclinados se facilita la entrada del flujo desde el estator a la cavidad del rotor en la etapa 9, cuando se tienen dientes rectos, no es hasta la etapa 11 o 1 cuando comienza a existir un hueco suficiente como para facilitar la entrada y producir esa aceleración del flujo en el interior de la cavidad del rotor que permite la producción de cavitación.

Tal y como se puede observar en la gráfica y en la distribución de velocidades de la Figura 110, durante las etapas 1 y 2 en el modelo de dientes rectos se producen 
unas velocidades radiales en el interior del estator entre los 20.4 y $-18.7 \mathrm{~m} / \mathrm{s}$, que son los que permiten producir un remolino en cuyo centro descienda la presión de manera suficientemente brusca como para alcanzar la presión de vapor en la etapa 2. Por otra parte, en el modelo de dientes inclinados esta fase se adelanta, ya que la inclinación del diente permite que el fluido del rotor comience a entrar en etapas posteriores (etapa 910 y 11), consiguiendo inducir velocidades en la cavidad del rotor ligeramente más elevadas del orden de los 40.4 y los $-25.3 \mathrm{~m} / \mathrm{s}$.
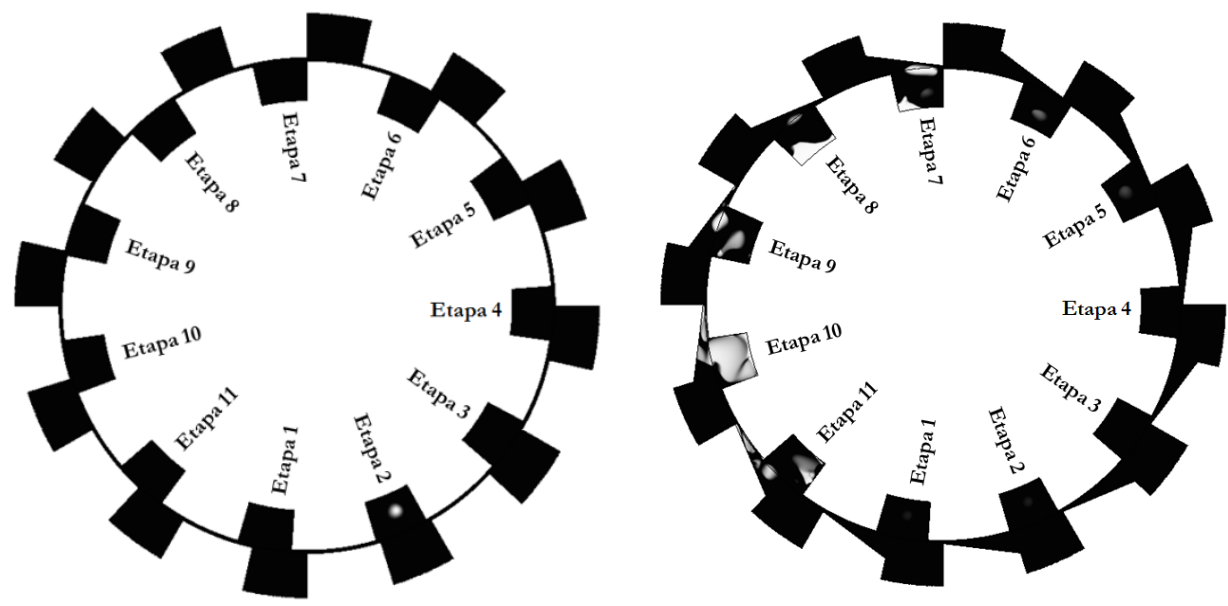

Vapor.Volume Fraction

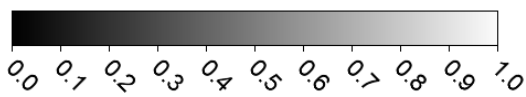

Figura 111: Comparación entre la fracción de gas obtenida con la geometría de dientes rectos, y la obtenida con la geometría de dientes inclinados.

Tal y como puede verse en la distribución de la fracción másica de gas que se produce en ambos sistemas de cavitación (Figura 111), la modificación de la geometría reduce de forma sustancial las zonas donde se produce la cavitación, así como la cantidad de gas que se produce al cavitar:

Con esta simulación se ha podido comprobar la existencia de una diferencia significativa en el comportamiento cuando se utilizan dientes rectos en lugar de dientes inclinados. De esta manera se demuestra que, aunque la cavitación se produce en el interior de las cavidades del rotor, la geometría de los discos del estator juega un papel crítico para conseguir que el sistema de cavitación sea capaz de producir las alteraciones necesarias en la presión y en la velocidad del flujo para generar cavitación de manera adecuada. El análisis y estudio detallado de la geometría exacta que debería poseer el estator del cavitador para optimizar su 
funcionamiento, se considera demasiado extenso y complejo para ser abordado en la presente tesis, y queda pendiente de ser debidamente estudiado en futuras líneas de investigación.

\subsubsection{Conclusiones}

Gracias a las simulaciones CFD realizadas mediante el software Fluent 19.2, ha sido posible realizar un modelo matemático que no solo describa el comportamiento hidrodinámico del sistema de cavitación, sino también el cambio de fase líquida a gas que se produce como consecuencia del efecto de la cavitación en las zonas de baja presión. Cada uno de los submodelos desarrollados ha permitido analizar aspectos concretos sobre el funcionamiento del dispositivo, y el conjunto de todos ellos ha permitido obtener una idea más precisa y fiable de cuál es el comportamiento del dispositivo de cavitación diseñado. Las principales conclusiones obtenidas en cada uno de los submodelos desarrollados se describen a continuación.

\subsubsection{Las simulaciones con el Venturi}

Gracias a la simplicidad de este submodelo, se han podido realizar y validar las simulaciones CFD utilizando un montaje experimental. La comparación entre los resultados experimentales y los obtenidos mediante las simulaciones $\mathrm{CFD}$, ha puesto de manifiesto que las características de los modelos matemáticos utilizados para simular el fenómeno, así como de los diferentes parámetros físicos que los rigen, son los siguientes:

- Las simulaciones se han llevado a cabo en régimen estacionario utilizando intervalos de tiempo (timestep) de $10 \mu \mathrm{s}$ y se ha utilizado el modelo homogéneo de mezcla (denominado mixture en Fluent), donde el sistema es bifásico y se encuentra formado por una fase líquida (agua) y otra fase gas (vapor).

- Para determinar la transferencia de masa entre ambas fases (líquido-gas) se ha utilizado el modelo de cavitación Schnerr-Sauer, el cual asume que la velocidad relativa entre ambas fases es nula y también que la mezcla se comporta de manera isoterma e incompresible. El modelo se ha configurado para una presión de vapor de $4210 \mathrm{~Pa}\left(30^{\circ} \mathrm{C}\right)$ y un número de núcleos por unidad de volumen de líquido disponibles de $10^{13}$ según la literatura disponible actualmente.

- El mejor modelo de turbulencia para este caso es el k- $\omega$ SST ya que permite introducir funciones que combinan los beneficios de un modelo $\mathrm{k}-\varepsilon$ utilizado en el fluido de transporte (líquido) y un modelo $\mathrm{k}-\omega$ que permite obtener de forma adecuada el comportamiento de las regiones cercanas a las paredes. 
Bajo estas condiciones se ha conseguido obtener un sistema calibrado y validado capaz de predecir de forma satisfactoria la transferencia de masa de líquido a vapor y viceversa, que se produce como consecuencia de la cavitación en el dispositivo Venturi. Estos modelos y condiciones de contorno han sido utilizadas como base en los sucesivos submodelos utilizados para analizar otros aspectos del sistema de cavitación estudiado.

\subsubsection{Las simulaciones del diente del rotor}

Gracias a este submodelo, se ha podido determinar el comportamiento que se produce en el interior de un hueco del rotor, únicamente como consecuencia de su velocidad de rotación y sin considerar otras variables como el efecto producido por los dientes del estator. El modelo se ha construido en base a los modelos matemáticos y demás variables físicas validadas en el submodelo del Venturi y ha permitido obtener las siguientes conclusiones:

- Las zonas de baja presión en el interior del hueco del rotor están producidas por dos efectos: un vórtice inducido como consecuencia de la velocidad del fluido que se encuentra en la cara superior abierta del hueco, y la fuerza centrífuga que expulsa el fluido hacia el exterior del rotor. El primer efecto produce una caída de presión en el centro de la cavidad mientras que el segundo, lo hace en el fondo de la esta.

- La presión que se alcanza en el centro del vórtice inducido se encuentra en un orden de magnitud que oscila entre 96912 pascales, hasta los 91170 pascales cuando se produce un aumento de la velocidad de los 3600 rpm a los 5600 rpm, es decir, a mayor velocidad de rotación, mayor caída de presión en el centro de la cavidad.

- Debido a la geometría rectangular del hueco del rotor, el flujo impacta sobre las esquinas produciéndose un aumento de la presión en esas zonas, con la consecuente pérdida de velocidad y energía cinética que podrían ser empleadas en disminuir la presión en el centro de la cavidad. Por tanto, resulta lógico pensar que podría producirse una mejora sustancial realizando un redondeo de las esquinas que forman el hueco del estator que podrían traducirse en una mejora del rendimiento.

- La caída de presión que se produce como consecuencia del efecto centrífugo produce una disminución de la presión en el fondo de la cavidad en un orden de magnitud que oscila entre 53837 a los 101099 pascales para velocidades de 3600 y $5600 \mathrm{rpm}$ respectivamente. Por tanto, si la presión global del sistema se encuentra en valores cercanos a la atmosférica, este efecto es suficiente como para producir el efecto de la cavitación en el fondo de la cavidad. 
En consecuencia, se concluye que, en caso de producirse cavitación, esta es más susceptible de generarse en el centro y en el fondo de la cavidad. De hecho, asumiendo que el sistema se encuentra a presión atmosférica rotando a una velocidad de $5600 \mathrm{rpm}$, la suma de las caídas de presión como consecuencia de ambos efectos (vórtice en la cavidad y fuerza centrífuga en el rotor), permite alcanzar las condiciones necesarias para la producción de la cavitación. Asimismo, cabe enfatizar que la configuración del estator juega un papel crítico para conseguir maximizar las caídas de presión en la cavidad del rotor y evitar que la cavitación se mantenga de forma permanente en las mismas zonas, es decir, debe favorecerse una situación de formación de gas, pero también de colapso.

\subsubsection{Las simulaciones del sistema de cavitación en 2 dimensiones}

Las simulaciones del sistema de cavitación en 2 dimensiones han permitido analizar el comportamiento del sistema completo considerando el movimiento del rotor sobre el estator. Se ha conseguido un modelo CFD simple y de rápida convergencia que ha permitido no solo analizar el comportamiento detallado del flujo durante el giro del rotor, sino también estudiar el funcionamiento del sistema en múltiples situaciones (diferentes velocidades de rotación, cambios en las distancias entre rotor y estator y cambios en la geometría del rotor). Las principales conclusiones extraídas de este modelo son:

- Durante una rotación completa del rotor sobre el estator se pueden diferenciar 3 fases de funcionamiento diferentes. Cada una de las 3 fases (recuperación, generación y colapso) se caracteriza por tener unos campos de velocidad y de presión determinados. De esta manera, durante todo el ciclo se producen momentos de generación, colapso y recuperación, lo que favorece una situación donde la cavitación no se genera de forma permanente en una zona localizada, sino que es forzada a generarse en diferentes lugares y colapsar múltiples veces en cada rotación.

- En la situación de diseño actual, es necesario una velocidad de giro del rotor de $4100 \mathrm{rpm}$ (coincidiendo con el valor registrado experimentalmente) para conseguir cavitar. A partir de este valor la cantidad de gas producido aumenta significativamente con la velocidad de giro. Se ha observado cómo incluso a la velocidad máxima posible del sistema (5600 rpm), continúan diferenciándose las fases de colapso, generación y recuperación por lo que se concluye que la velocidad de $5600 \mathrm{rpm}$ es la más adecuada para la operación en continuo del sistema de cavitación.

- $\mathrm{Al}$ aumentar la distancia entre el rotor y el estator, se atenúan los gradientes de velocidad y presión, y desciende la intensidad y cantidad de cavitación generada. Si el rotor y el estator se encuentran separados más de $2.6 \mathrm{~mm}$, no existe interacción entre ambos elementos y el sistema se comporta como si no existiera un estator y la cavitación es prácticamente inexistente. Por 
tanto, se concluye que la distancia entre el rotor y el estator ha de ser la mínima posible que garantice un correcto funcionamiento del sistema, la cual, en este caso, se corresponde con $0.6 \mathrm{~mm}$.

- La geometría del estator es crítica para el buen funcionamiento del sistema. Si en lugar de utilizar la geometría del estator seleccionada (con inclinación de los dientes de $8^{\circ}$ ), se utiliza una geometría diferente con los dientes totalmente rectos, se observa una atenuación en la intensidad y cantidad de cavitación, incluso manteniendo una velocidad de rotación de $5600 \mathrm{rpm}$ y una distancia entre el rotor y el estator de $0.6 \mathrm{~mm}$. Esto pone en evidencia la importancia de un buen diseño del estator y pone en evidencia el buen funcionamiento de la geometría seleccionada para este dispositivo.

Por tanto, tras analizar las simulaciones de este último submodelo, puede concluirse que, tanto la velocidad de rotación de $5600 \mathrm{rpm}$, como la separación entre el rotor y el estator de $0.6 \mathrm{~mm}$, y la inclinación y tamaño de los dientes considerada, se encuentran dentro de un rango adecuado para obtener gradientes de velocidad y de presión que permitan la generación y el colapso del gas en múltiples puntos durante el ciclo de giro del rotor. A pesar de ello, la investigación deja la puerta abierta a futuras investigaciones que analicen con mayor detalle parámetros geométricos del rotor y del estator que permitan optimizar todavía más el funcionamiento de este dispositivo (redondeo de esquinas, altura de dientes, inclinaciones...). 


\section{Capítulo 5}

\section{Experimentación a escala de laboratorio}

En este capítulo se presentan los ensayos realizados a pequeña escala (de laboratorio) con el fin de determinar las condiciones operacionales que proporcionan el mejor rendimiento en el proceso. Los ensayos se han llevado a cabo con el sistema de cavitación desarrollado y construido durante la etapa previa (ver capítulo 3), y los resultados obtenidos en esta fase serán los que permitirán establecer los parámetros de funcionamiento en el sistema de cavitación final que funcione a escala industrial en la planta piloto.

\subsection{Introducción}

En el capítulo anterior se han establecido una serie de criterios para el diseño del sistema de hidrocavitación que se han basado tanto en la bibliografía de otros sistemas ya utilizados, como en cálculos mecánicos, eléctricos e hidrodinámicos que han sido analizados y validados mediante simulaciones CFD. Este proceso previo de diseño ha permitido proporcionar un primer sistema que no parte de cero, sino que se ha construido a partir de una base que garantiza el cumplimiento de una serie de prerrequisitos necesarios para conseguir el efecto de cavitación deseado en el pretratamiento. En cualquier caso, dichos efectos pronosticados en la etapa de diseño previa son meramente orientativos y deben ser confirmados o desmentidos mediante la experimentación a escala de laboratorio que va a desarrollarse durante este capítulo.

\subsubsection{Objetivos}

Como se ha comentado anteriormente, la necesidad de realizar los ensayos a escala de laboratorio no es otra sino la de validar las conclusiones obtenidas en el 
capítulo anterior donde se ha desarrollado el sistema a un nivel meramente teórico mediante bibliografía y análisis CFD. Por tanto, los principales objetivos perseguidos en este capítulo de ensayos experimentales a escala de laboratorio son:

- Establecimiento de los parámetros óptimos de funcionamiento. Aunque los análisis realizados utilizando la CFD han permitido determinar las tendencias que relacionan las presiones y cantidad de vapor producido durante la cavitación en función de algunos parámetros como la velocidad de rotación, es necesario validar dichas tendencias y analizar otras que no han sido modelizadas por el CFD como son el efecto de la temperatura o la duración del tratamiento. Así pues, los parámetros operacionales analizados en los ensayos experimentales han sido:

- La velocidad de rotación del dispositivo de cavitación.

- El flujo de recirculación utilizado en el sistema.

- El efecto de la temperatura en el tratamiento.

- El efecto de la duración del tratamiento.

- Determinación de la efectividad del tratamiento. El análisis de los parámetros óptimos de funcionamiento lleva asociado una serie de resultados derivados de los análisis llevados a cabo. Tras los ensayos, es necesario determinar la efectividad alcanzada, para lo cual se ha analizado el grado de desintegración obtenido al tratar el fango activo. Además, en algunos casos se ha determinado también la cantidad de metano generado, así como el efecto de eliminación de ciertos contaminantes o microorganismos.

- Detección de fallos de funcionamiento del sistema. El sistema diseñado no cuenta únicamente con el dispositivo de cavitación. Consiste en un montaje en el cual intervienen depósitos, válvulas, sensores y otros elementos que deben ser testados en condiciones reales para garantizar su buen funcionamiento durante la puesta en marcha en la planta real y en condiciones reales.

\subsubsection{Principales dificultades afrontadas}

El principal inconveniente encontrado durante el desarrollo de los experimentos ha sido el de conseguir muestras de fangos activos adecuadamente mezclados con purines de cerdo, para obtener un cosustrato de características similares al que iba a ser utilizado en la planta real. La planta piloto a escala industrial estará situada en la región de Murcia, donde resulta fácil obtener los purines de cerdo procedentes de las industrias ganaderas vecinas. No obstante, los experimentos de la actual fase se 
han desarrollado en Castellón de la Plana, donde la obtención de este tipo de cosustrato resulta mucho más dificultosa.

Por este motivo, inicialmente se decidió sustituir los purines de cerdo por el fango deshidratado procedente tanto de la decantación primaria como de la secundaria y que ha sido previamente espesado por las centrifugas que se encuentran en la propia EDAR (Figura 112). De esta forma, resulta viable obtener ambos sustratos (licor mezcla y fango deshidratado) el mismo día a la misma hora y realizar una mezcla en laboratorio con las proporciones adecuadas para conseguir un cosustrato de características similares al que se debe utilizar en la planta piloto en Murcia. Por tanto, combinando el licor mezcla con un contenido de sólidos de aproximadamente un $0.5 \%$ y con el fango activo deshidratado con un contenido de sólidos de un $25 \%$, se puede conseguir un cosustrato con concentraciones de sólidos de entre el $5 \%$ y el $8 \%$ que es el que se espera tratara en la planta piloto de Murcia.

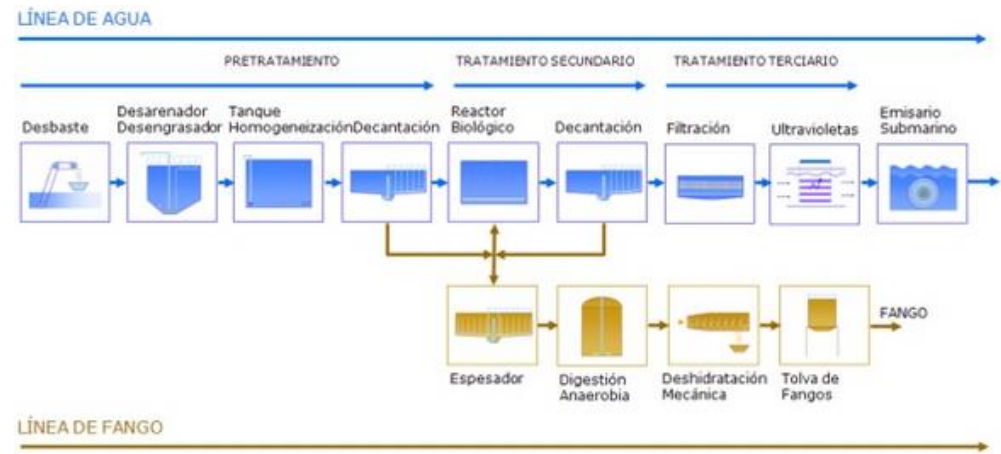

Figura 112: Diagrama de bloques de proceso de la EDAR de Castellón de la Plana.

No obstante, la utilización del fango deshidratado ha planteado una serie de problemas que se enumeran a continuación:

- Problemas asociados al olor. Como se ha comentado anteriormente, los experimentos a escala de laboratorio se llevaron a cabo en el laboratorio de hidráulica del edificio de talleres de la Universidad Jaume I de Castellón. Aunque los volúmenes de fango tratados en cada ensayo no eran excesivamente elevados (unos 40 litros), el fango deshidratado, incluso en pequeñas cantidades, produce un desagradable olor de una intensidad muy elevada. Las instalaciones de estos laboratorios no están preparadas para garantizar una correcta desodorización y por tanto no se podía mantener unas condiciones de higiene ambiental adecuadas. 
- Dificultad para manipular los fangos deshidratados. Los fangos deshidratados son una sustancia que resulta muy difícil de manipular debido a su reología. Esta sustancia tiene una consistencia similar a la miel, pero es mucho más pegajosa, con lo que obtener muestras para realizar un mezclado preciso resulta prácticamente imposible.

- Complejidad de las labores de limpieza. Debido a las características reológicas comentadas anteriormente, las labores de limpieza para garantizar unas condiciones de higiene adecuadas tras cada experimento resultan de una gran complejidad. Además, con cada ensayo se producen una gran cantidad de residuos (guantes de látex, monos, instrumentos, contenedores...) que deben ser tratados de manera especial por ser considerados como residuos con riesgo biológico.

Debido a los motivos expuestos anteriormente, se descartó la utilización del fango deshidratado. Así pues, los experimentos a escala de laboratorio se han realizado con licor mezcla procedente del reactor biológico. aunque este tiene características diferentes al cosustrato que debe tratarse a escala industrial, resulta válido para determinar las condiciones operacionales y ha sido utilizado con éxito por otros investigadores en cavitadores tanto de tipo Venturi o plato con orificios (I. Lee \& Han, 2013), así como dispositivos con elementos móviles (Martin Petkovšek et al., 2015) (Kavitha et al., 2015).

\subsection{Métodos y materiales}

A continuación, se presenta toda la información relativa al montaje experimental en esta fase del estudio, el sustrato utilizado durante los ensayos experimentales y la metodología seguida para realizar los análisis tras cada experimento. En la medida de lo posible, se han seguido las mismas pautas utilizadas por otros investigadores en estudios similares con fangos activos y dispositivos de cavitación. De esta forma, la comparativa entre estudios, resulta más fiable y la convierte en una herramienta más para el análisis y mejora del sistema.

\subsubsection{Montaje experimental}

El montaje experimental es muy similar al utilizado en otros estudios de la misma naturaleza, y está constituido por: un sistema de cavitación con el que realizar la degradación de los contaminantes o sustancias presentes en un fluido, un sistema de impulsión (bomba centrífuga), y una serie de depósitos y válvulas. El montaje típico para estos sistemas se ha presentado en detalle en el apartado 2.3.2.3. La principal diferencia del montaje de la presente tesis reside en que puede ser utilizado tanto a escala industrial (volúmenes de hasta 600 litros) como a escala laboratorio (volúmenes de 40 litros) con un simple cambio de posición de una de 
las válvulas. A continuación, se presenta el diagrama esquemático del montaje experimental para realizar los ensayos a escala de laboratorio.

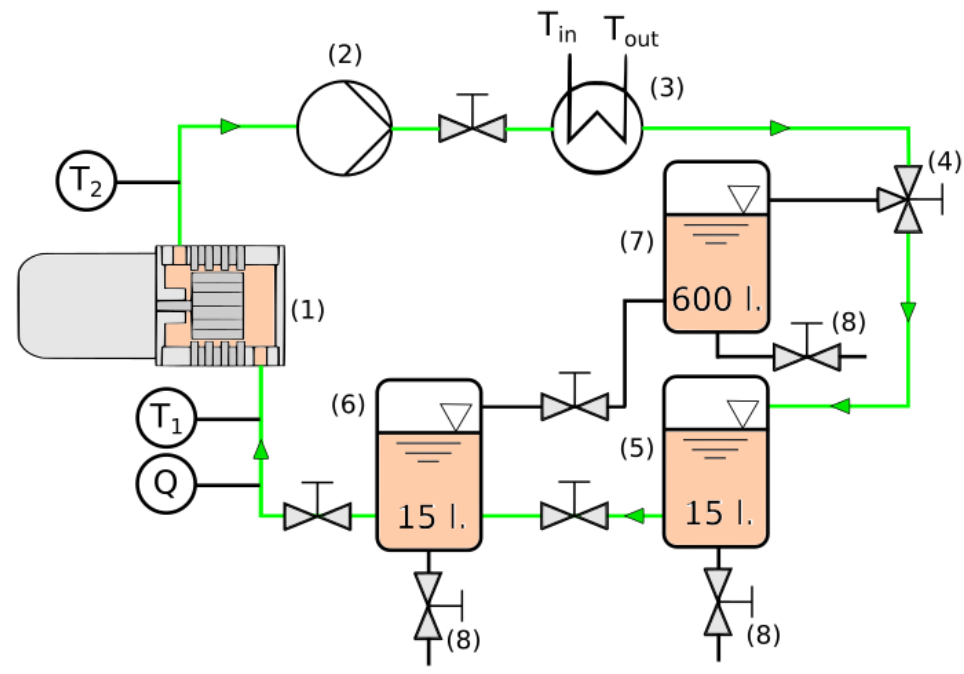

Figura 113: Esquema del montaje experimental para la realización de los experimentos a escala laboratorio.

Se puede observar cómo la válvula de 3 vías (4) es la encargada de dar paso bien al depósito de 15 litros o bien al depósito de 600 litros para que el sistema funcione a una escala u otra. El recorrido del fluido se encuentra marcado en color verde en la Figura 113. El fluido pasa por los mismos elementos que en el caso del montaje a escala industrial (salvo el depósito de 600 litros) tanto la bomba centrífuga de $2.2 \mathrm{~kW}$ (2) como el dispositivo de cavitación hidrodinámica (1) movido por un motor de $7.5 \mathrm{~kW}$ son los mismos que los utilizados en la experimentación a escala industrial. Para mantener la temperatura del sistema bajo control, se dispone de un intercambiador de calor (3) situado aguas debajo de la bomba. En este caso, el sistema tendría una capacidad aproximada de unos 40 litros (contando los dos depósitos de 15 litros más el fluido que se puede almacenar en el cavitador hidrodinámico y en las conducciones). El sistema está pensado para funcionar en lotes de manera que en cada ensayo debe realizarse un llenado y un vaciado del sistema para poder realizar el siguiente experimento.

\subsubsection{Fase de llenado}

Para cada ensayo, el llenado del sistema se ha realizado mediante el vaciado de 2 bidones de 20 litros de licor mezcla procedente del reactor biológico de Castellón. Los bidones se vacían en uno de los depósitos de 15 litros y su 
contenido se distribuye rápidamente a lo largo de las canalizaciones y del sistema de hidrocavitación.

\subsubsection{Fase de vaciado y limpieza}

Tras cada ensayo es necesario desinfectar, vaciar y limpiar el sistema para asegurar que no quedan restos en el interior del dispositivo que puedan producir problemas de olores en el interior del laboratorio. Para ello se ha seguido el siguiente procedimiento tras la finalización de cada ensayo:

- Vaciado directo a la red de aguas residuales. El sistema de purga se encuentra conectado directamente con la red de aguas residuales. Así después de cada ensayo se realiza el vaciado del sistema de manera que su contenido vuelve nuevamente a la EDAR de Castellón.

- Desinfección con hipoclorito de sodio. Una vez vaciado el sistema, se vuelve a llenar con una mezcla de agua e hipoclorito de sodio que se hace circular durante 5-10 minutos para garantizar varios pases por el sistema de cavitación, así como del propio circuito. Tras este proceso de desinfección se purga el contenido.

- Aclarado. Se vuelve a realizar la operación anterior pero únicamente con agua. De este modo se diluye y elimina por completo el hipoclorito de sodio para garantizar que no quedan residuos que puedan afectar al ensayo posterior.

Tras este procedimiento, el sistema de cavitación queda desinfectado y preparado para ser utilizado en la siguiente tanda de ensayos.

\subsubsection{Características del fango utilizado}

El fango utilizado para los ensayos a escala de laboratorio fue obtenido de la EDAR de Castellón de la Plana. Tal y como se ha comentado en el apartado 5.1.2, la dificultad para conseguir un cosustrato de las características reológicas deseadas (mezclado con purines de cerdo o fangos deshidratados), así como los problemas de higiene ambiental en el laboratorio de hidráulica asociados mayormente a la intensidad de olor emitida por este tipo de cosustratos, ha llevado a la utilización del licor mezcla procedente del reactor biológico (Figura 113). El licor mezcla se ha transportado en bidones de 20 litros de capacidad a través de furgonetas de la empresa de FACSA. El fango se transporta el mismo día del ensayo y se utiliza inmediatamente en el ensayo. Asimismo, las muestras obtenidas tras los resultados son enviadas al laboratorio de análisis de manera inmediata para realizar los análisis lo más rápidamente posible.

Las principales características del licor mezcla utilizadas durante los ensayos a escala experimental pueden verse en la siguiente tabla: 
Propiedades

Licor mezcla de la EDAR de

Castellón de la Plana

\begin{tabular}{rlc}
\hline DQO Total & $(\mathrm{mg} / \mathrm{L})$ & $4505 \pm 1744$ \\
DQO soluble & $(\mathrm{mg} / \mathrm{L})$ & $76 \pm 35$ \\
$\mathrm{pH}$ & $(-)$ & $7.3 \pm 0,1$ \\
Conductividad a $25^{\circ} \mathrm{C}$ & $(\mu \mathrm{S} / \mathrm{cm})$ & $(-)$ \\
Ácidos Volátiles & $(\mathrm{mg} / \mathrm{L})$ & $(-)$ \\
Alcalinidad Total & $(\mathrm{mg} / \mathrm{L})$ & $(-)$ \\
Nitrógeno & $(\mathrm{mg} / \mathrm{L})$ & $(-)$ \\
Nitrógeno Amoniacal & $(\mathrm{mg} / \mathrm{L})$ & $(-)$ \\
Fósforo Total & $(\mathrm{mg} / \mathrm{L})$ & $(-)$ \\
Sólidos Totales & $(\mathrm{mg} / \mathrm{L})$ & $5460 \pm 2820$ \\
Sólidos Volátiles & $(\mathrm{mg} / \mathrm{L})$ & $2640 \pm 1154$ \\
Humedad & $(\%)$ & $(-)$ \\
\hline
\end{tabular}

Tabla 8: Características del licor mezcla utilizado para los ensayos a escala de laboratorio.

Tal y como se explicará en el siguiente apartado, para esta parte del estudio únicamente resulta necesario conocer la DQO soluble y total, así como los sólidos totales del licor mezcla testado.

\subsubsection{Análisis de resultados}

De entre todos los posibles indicadores para determinar la eficacia del pretratamiento (apartado 2.5), se ha decidido utilizar el indicador del grado de desintegración (DD) implementado por G. Lehne y A. Müller (Lehne et al., 2001) y posteriormente adaptado a los valores obtenidos de DQO soluble y total mediante la ecuación:

$$
D D(\%)=\frac{D Q O S_{f}-D Q O S_{i}}{D Q O T-D Q O S_{i}} \cdot 100 \%
$$


El grado de desintegración es un parámetro ampliamente utilizado en los estudios cuya temática principal gira entorno a la biodegradabilidad de algún tipo de sustrato (generalmente fango activo). Esto se debe a que este parámetro permite evaluar la hidrolización conseguida del sustrato. La hidrólisis resulta indispensable para que durante la digestión, aumente el rendimiento de las etapas de acidogénesis, acetogénesis y metanogénesis, con el correspondiente aumento de biogás que ello conlleva (Appels et al., 2008).

Existen varios estudios que relacionan un incremento del grado de desintegración del fango con un aumento en la generación de metano conseguida. En algunos de estos estudios se han utilizado Venturis como dispositivo de cavitación, como es el caso de A. Machnicka et. al. (Machnicka et al., 2009) o de I. Lee \& J. Han (I. Lee \& Han, 2013), aunque también se ha comprobado esta relación entre el DD y el biogás producido en otro tipo de cavitadores como por ejemplo, los rotativos (Martin Petkovšek et al., 2015). Por tanto, el grado de desintegración puede considerarse como un indicador indirecto pero fiable de la cantidad de biogás que podrá extraerse del sustrato pretratado, y por ello ha sido el indicador elegido para cuantificar el rendimiento de cada ensayo.

La alternativa a la determinación del DD, pasaría por realizar ensayos de biometanización para determinar la cantidad de biogás generado por cada una de las muestras pretratadas. Aunque este sí sería un indicador directo y preciso, los ensayos para determinar la cantidad de metano generado pueden extenderse entre 15 días y 60 días, lo cual habría extendido la fase de análisis en exceso y dificultaría las etapas de rediseño y toma de decisiones.

Tras cada ensayo, las muestras de fango se han trasladado inmediatamente a los laboratorios de la empresa encargada de realizar el análisis (IPROMA) y de esta forma evitar cualquier reacción que pudiera alterar los resultados. En este caso, tanto la DQO soluble como la total se analizaron mediante espectrofotómetro utilizando la prueba estándar de Hach. Por otra parte, los sólidos totales y volátiles se determinaron según los métodos estandarizados APHA, AWWA y WEF 2005.

\subsubsection{Ensayos realizados}

Todos los ensayos llevados a cabo durante la realización de esta tesis se pueden dividir en 2 grupos: ensayos a escala de laboratorio y ensayos a escala industrial. El primer tipo de ensayos tiene como objetivo determinar las condiciones operacionales óptimas del cavitador, mientras que el segundo tipo de ensayos pretende establecer la efectividad de la configuración determinada en escala laboratorio cuando esta se aplica a escala industrial.

Los ensayos a escala de laboratorio, explicados en el presente apartado, se dividen a su vez en 3 grupos. Todos los experimentos persiguen el mismo objetivo: determinar los parámetros operacionales del sistema de cavitación (velocidad de 
rotación, caudal de recirculación, temperatura y duración del tratamiento) que maximizan el grado de desintegración conseguido en el fango tratado. El primer grupo de experimentos engloba los ensayos LT1, LT2 y LT3 (ver Tabla 9), y se estudia el efecto de la velocidad de rotación del dispositivo de cavitación. El segundo grupo de experimentos corresponde a los ensayos LT4, LT6 y LT8, donde se estudia el efecto del caudal de recirculación cuando se encuentra activo el sistema de refrigeración que mantiene la temperatura del sistema por debajo de los $35^{\circ} \mathrm{C}$. Finalmente, el tercer grupo de experimentos abarca los ensayos LT5, LT7 y LT9 y, al igual que en los ensayos del segundo grupo, se estudia el efecto del caudal de recirculación, pero esta vez cuando no hay activo un sistema de refrigeración y la temperatura puede aumentar más allá de los $40^{\circ} \mathrm{C}$.

\begin{tabular}{cccccc}
\hline Test & $\begin{array}{c}\text { Velocidad de } \\
\text { rotación } \\
(\mathrm{rpm})\end{array}$ & $\begin{array}{c}\text { Caudal de } \\
\text { Recirculación } \\
(1 / \mathrm{min})\end{array}$ & $\begin{array}{c}\text { Refrigeración } \\
(\mathrm{s} / \mathrm{n})\end{array}$ & $\begin{array}{c}\text { Volumen } \\
(\text { litros })\end{array}$ & $\begin{array}{c}\text { Duración del } \\
\text { tratamiento } \\
(\mathrm{min})\end{array}$ \\
\hline LT1 & 3455 & 30 & No & 40 & 60 \\
LT2 & 4100 & 30 & No & 40 & 60 \\
LT3 & 5600 & 30 & No & 40 & 30 \\
LT4 & 5600 & 50 & $\mathrm{Si}$ & 40 & 30 \\
LT5 & 5600 & 50 & No & 40 & 30 \\
LT6 & 5600 & 100 & $\mathrm{Si}$ & 40 & 30 \\
LT7 & 5600 & 100 & No & 40 & 30 \\
LT8 & 5600 & 150 & Si & 40 & 30 \\
LT9 & 5600 & 150 & No & 40 & 30 \\
\hline
\end{tabular}

Tabla 9: Resumen de las condiciones operacionales testadas en cada uno de los ensayos de laboratorio.

Durante la ejecución de los ensayos, se han obtenido muestras cada 10 minutos para poder analizar la evolución del proceso de pretratamiento durante el ensayo. En los primeros ensayos (LT1 y LT2), las condiciones operacionales del tratamiento han sido poco agresivas y se ha conseguido un grado de degradación muy pequeño en el fango (tal y como se comentará en detalle en el siguiente apartado). Por ello, estos ensayos han tenido el doble de duración que el resto (60 minutos frente a 30 minutos) ya que de otro modo no ha podido apreciarse evolución ninguna en el tratamiento. Con el resto de los ensayos 30 minutos de duración han sido suficientes para visualizar la progresión completa del pretratamiento. 
La elección del resto de parámetros operacionales (velocidad de rotación, caudal de recirculación y temperatura) se han realizado atendiendo a criterios que en algunos casos han sido relativos al particular diseño de este sistema de cavitación (como es el caso de la velocidad de rotación o caudal de rotación), mientras que otros casos han sido consecuencia de las conclusiones y resultados alcanzados por otros investigadores en sus propios sistemas de cavitación (como es el caso de la temperatura del tratamiento). A continuación, se explica de manera detallada el porqué de la elección de los parámetros operacionales de la Tabla 9.

\subsubsection{Elección de los valores de velocidad de rotación}

Tal y como puede verse en la Tabla 9, los valores de velocidad de rotación seleccionados para realizar los ensayos LT1, LT2 y LT3, han sido de 3450, 4100 y $5600 \mathrm{rpm}$. Los motivos por los cuales se han seleccionado estos valores para analizar el efecto de la velocidad de rotación son los siguientes:

- Tras realizar varios experimentos con agua limpia, se ha observado que mantener la velocidad por debajo de las $3600 \mathrm{rpm}$ no se produce ningún tipo cavitación. Esto queda patente tanto en el ruido emitido por el cavitador, como en la inspección visual a través de la ventana de metacrilato, donde puede observarse que no existe formación de burbujas en el agua ni se ha detectado la presencia del efecto de cavitación. Por ello, el valor de $3450 \mathrm{rpm}$ se ha fijado como un valor en el cual, aunque el dispositivo se encuentra en funcionamiento, no se induce ningún tipo de cavitación al fluido.

- A partir de las 3700-3800 rpm, aparecen los primeros indicios del efecto de la cavitación. Dicho efecto comienza a hacerse visible en el interior del cavitador a través de la ventana de metacrilato, y se manifiesta en forma de pequeñas burbujas de aire que produce un efecto niebla que enturbia el agua. Además, a estas velocidades se comienza a percibir el ruido característico de cavitación (ruido de arena) debido a las implosiones de las burbujas cavitando. Así pues, el valor de $4100 \mathrm{rpm}$ se ha fijado como el parámetro a partir del cual comienza a existir cavitación de forma atenuada, pero evidente.

- El valor de $5600 \mathrm{rpm}$ es el máximo que el dispositivo de cavitación puede alcanzar con seguridad. Alcanzado este valor, el efecto de la cavitación es muy evidente y agresivo. El cavitador emite un fuerte sonido característico, mientras que la inspección visual en el interior del cavitador confirma la existencia de una gran cantidad de microburbujas de aire atrapadas en su interior, y que se generan de manera continuada por el dispositivo. Este valor de $5600 \mathrm{rpm}$ es considerado como el punto donde se consigue una producción máxima de cavitación. 

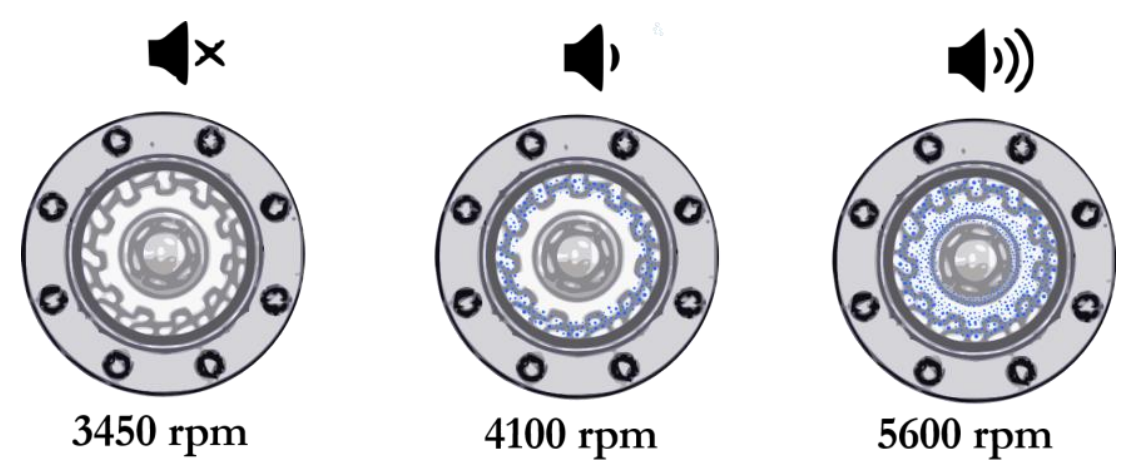

Figura 114: Apariencia y sonido de la cavitación registrada en el dispositivo a diferentes regímenes de funcionamiento.

De esta manera se han seleccionado los diferentes regímenes de velocidad a estudiar los cuales han permitido establecer cuál es el efecto durante un estado de poca o nula cavitación $(<3450 \mathrm{rpm}$ ), cavitación ligera/moderada (de 3450 a $4100 \mathrm{rpm}$ ) y cavitación evidente y agresiva. (de 4100 a $5600 \mathrm{rpm}$ ).

\subsubsection{Elección de los valores de caudal de recirculación}

Debido al diseño del cavitador este no es capaz de impulsar el fluido a través de la instalación. Dicha acción está a cargo de la bomba de recirculación que, como se ha comentado en el apartado 5.2.1 consiste en una bomba centrífuga de $2.2 \mathrm{~kW}$. Esta bomba es capaz de impulsar fluidos de hasta un $8 \%$ de sólidos, con temperaturas de hasta $80^{\circ} \mathrm{C}$ y a caudales que pueden alcanzar los $300 \mathrm{l} / \mathrm{min}$. Sin embargo, esto no ha sido así siempre. Inicialmente la instalación contaba con una bomba volumétrica de mucha menos potencia $(750 \mathrm{~W})$ que, aunque era de una gran robustez, únicamente podía proporcionar caudales de $81 / \mathrm{min}$, insuficientes para conseguir realizar un pretratamiento adecuado en un tiempo asumible. Tras la anulación de esta bomba volumétrica y hasta la instalación de la nueva bomba centrífuga, se utilizó una bomba axial portátil de $100 \mathrm{~W}$ aproximadamente que proporcionaba $30 \mathrm{l} / \mathrm{min}$ de caudal. Esta bomba fue utilizada durante los experimentos para determinar la velocidad de rotación óptima del cavitador (LT1, LT2 y LT3) y es por este motivo que en la Tabla 9 aparecen estos valores de caudal asociados a estos ensayos.

Debido a las pérdidas de presión de todos los elementos de la instalación, como por ejemplo codos, paso a través del cavitador, o la fricción de las propias tuberías, el máximo caudal medido a plena capacidad de la bomba ha sido de unos 168 l/min. El caudalímetro disponible en la instalación, no indica el caudal en valor numérico, sino que lo hace a través de una serie de leds. Existen 10 leds que se iluminan de forma progresiva y proporcional al caudal de paso por la tubería. Es necesario calibrar el caudalímetro en función del caudal máximo de recirculación 
de la red de manera que el último led se encienda cuando se dé la condición de caudal máximo de recirculación en la instalación. De esta manera el valor del caudal podía ser conocido en función del valor del led encendido de la siguiente manera:

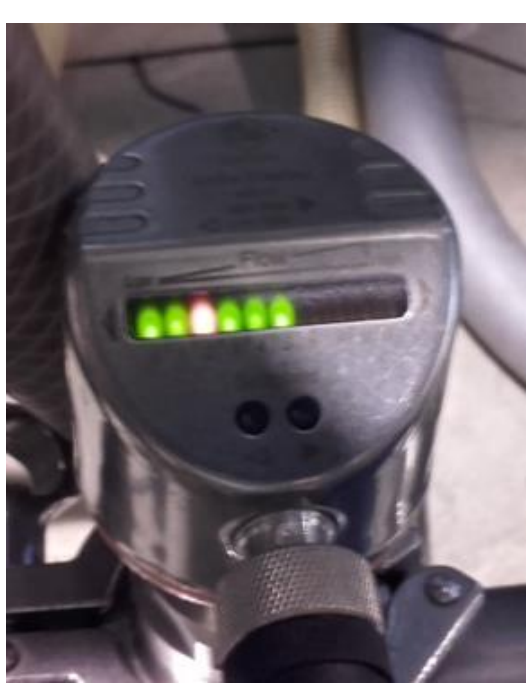

Figura 115: Caudalímetro de leds indicando un caudal de $1001 / \mathrm{min}$.

\begin{tabular}{|c|c|c|}
\multicolumn{1}{c}{ led } & \multicolumn{1}{c}{$1 /$ min } & Pasadas/minuto \\
\cline { 1 - 1 } 1 & 17 & 0,4 \\
\cline { 1 - 1 } 2 & 34 & 0,8 \\
\cline { 1 - 1 } 3 & 50 & 1,3 \\
\cline { 1 - 1 } 4 & 67 & 1,7 \\
\cline { 1 - 1 } 5 & 84 & 2,1 \\
\cline { 1 - 1 } 6 & 101 & 2,5 \\
\cline { 1 - 1 } 7 & 118 & 2,9 \\
\cline { 1 - 1 } 8 & 135 & 3,4 \\
\cline { 1 - 1 } 9 & 151 & 3,8 \\
\cline { 1 - 1 } 10 & 168 & 4,2 \\
\hline
\end{tabular}

Tabla 10: Valor del caudal y del número de pasadas por minuto en función del caudal $\left(\mathrm{n}^{\circ}\right.$ de pasadas para un volumen de 30 litros).

Atendiendo a los caudales proporcionados por la bomba, se decidió utilizar caudales de recirculación que se encontraran repartidos de forma homogénea en todo el rango de funcionamiento. Así pues, se decidieron utilizar valores de caudal de 50, 100 y $150 \mathrm{l} / \mathrm{min}$, correspondientes a los leds 3, 6 y 9 respectivamente. Dado que el volumen utilizado en los ensayos de laboratorio ha sido de 40 litros, estos caudales de recirculación proporcionan 1, 2 y 4 pasadas por minuto a través del dispositivo de cavitación aproximadamente, lo que en un ensayo de una duración de 30 minutos se traduce en 38, 75 y 113 pasadas por el cavitador.

Aunque el valor óptimo del caudal de recirculación (y por ende del número de pasadas) depende del dispositivo de cavitación y de las condiciones del pretratamiento, estos valores son coherentes con los utilizados por otros autores en investigaciones donde se ven involucrados sistemas de cavitación similares, como por ejemplo en el dispositivo de M. Badve et. al. (M. Badve et al., 2013), M. Petkovšek (Martin Petkovšek et al., 2015) o M. Sivakumar (Sivakumar \& Pandit, 2002). En los cuales se concluye que el tiempo de residencia, es decir, aumentar el número de pasadas, mejora el grado de degradación obtenido. 


\subsubsection{Elección de los valores de temperatura}

El efecto de la temperatura es mucho más complejo que el producido por la velocidad de rotación o el caudal de recirculación. Aunque es sabido que los efectos térmicos llevados a cabo entre los $100 \mathrm{y}$ los $150^{\circ} \mathrm{C}$ producen una mejora casi imperceptible en el grado de desintegración obtenido (I. Lee \& Han, 2013), esta se ve incrementada sustancialmente cuando el efecto de la temperatura se combina con la cavitación. El efecto de la temperatura es muy dependiente del tipo de contaminante o sustancia que se desea degradar, y aunque el impacto sobre fangos activos (solos o mezclados con otros cosustratos) no ha sido muy estudiado, sí que existen numerosos estudios sobre como la temperatura combinada con la hidrocavitación puede afectar a degradación de ciertas sustancias contaminantes. Por ejemplo, algunos autores han detectado que las temperaturas entre 25 y $35^{\circ} \mathrm{C}$ son óptimas para la degradación de carbamazepina (medicamento) (Braeutigam et al., 2012b), mientras que otros sugieren que para el caso del alacloro (pesticida) las temperaturas óptimas se encuentran entre 40 y $60^{\circ} \mathrm{C}$ (Wang \& Zhang, 2009). Resultados muy similares se han obtenido con la degradación de microcontaminantes en agua: las temperaturas entre $20-40^{\circ} \mathrm{C}$ tienen un ligero efecto en su degradación, pero se consigue duplicar la tasa de eliminación cuando la temperatura se aumenta entre los $40-60^{\circ} \mathrm{C}$ (Martin Petkovšek et al., 2013). Este último rango de temperaturas $\left(40-60^{\circ} \mathrm{C}\right)$ se ha testado también en la eliminación de fármacos, mostrando una degradación muy elevada a temperaturas de $50^{\circ} \mathrm{C}$ que en algunos casos (como en el ácido clofíbrico, ibuprofeno y diclofenaco) puede incluso mejorar más allá de los $60^{\circ} \mathrm{C}$ (Zupanc et al., 2014).

Atendiendo a la bibliografía, parece lógico pensar que existe un punto de inflexión sobre los $40^{\circ} \mathrm{C}$, a partir del cual la degradación de un gran rango de sustancias se ve incrementada al combinarlo con la cavitación. Es por ello por lo que, para el análisis del efecto de la temperatura, se realizaron ensayos utilizando dos rangos de temperatura diferentes: por debajo de $\operatorname{los} 35^{\circ} \mathrm{C}$, y por encima de los $35^{\circ} \mathrm{C}$. Para conseguir controlar la temperatura en estos rangos se ha utilizado un intercambiador de carcasa de tubos funcionando a contracorriente con un caudal de agua proveniente de una enfriadora.

Previamente a los experimentos con el fango activo, se realizaron una serie de ensayos de 30 minutos de duración utilizando agua. El objetivo principal era replicar los ensayos que se iban a realizar con fango, para determinar el comportamiento térmico del montaje experimental al utilizar el sistema de refrigeración. Los resultados pueden observarse en la siguiente gráfica: 


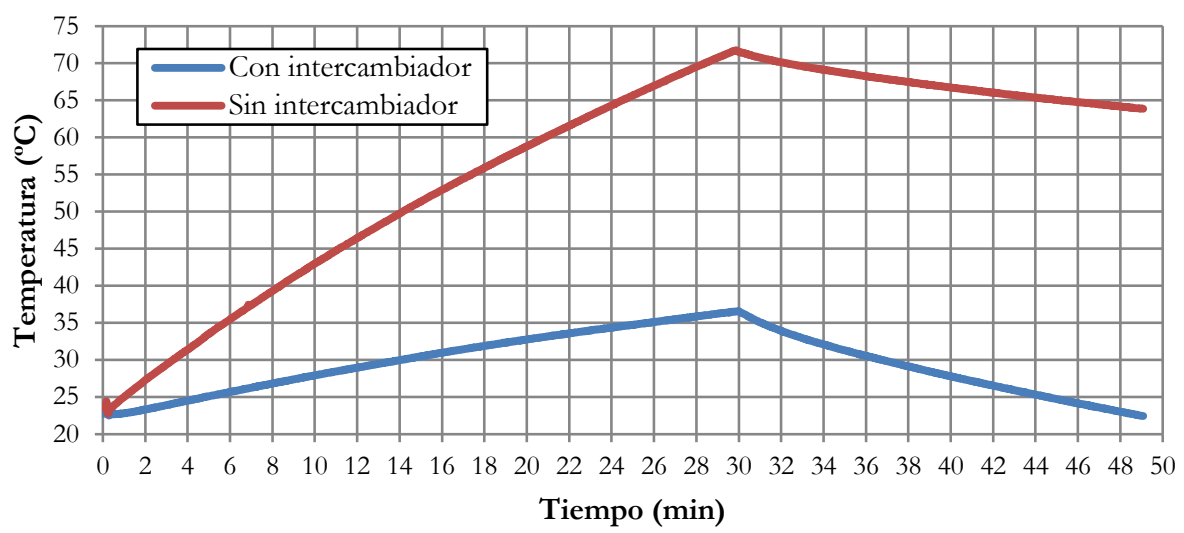

Figura 116: Evolución de las temperaturas en un test con agua de 30 minutos con y sin intercambiador.

Como se puede observar, si no se utiliza intercambiador $\operatorname{los} 35^{\circ} \mathrm{C}$ se superan a los 5 minutos del comienzo del experimento y la temperatura del sistema aumenta progresivamente hasta alcanzar los $71,8^{\circ} \mathrm{C}$ en los 30 minutos de duración del ensayo. Sin embargo, al utilizar el intercambiador, se consigue refrigerar la instalación y mantener la temperatura por debajo de los $40^{\circ} \mathrm{C}$. Concretamente, transcurridos los 30 minutos la temperatura alcanzada en el agua es de $36,6^{\circ} \mathrm{C}$. Modificando ligeramente la temperatura de salida del fluido de la enfriadora, se puede reducir aún más la temperatura para que no se superen $\operatorname{los} 35^{\circ} \mathrm{C}$ en ningún momento del ensayo.

Así pues, en los ensayos para analizar el efecto de la temperatura, se han considerado dos condiciones diferentes: una manteniendo la temperatura por debajo de los $35^{\circ} \mathrm{C}$, y otra manteniendo la temperatura por encima de $\operatorname{los} 35^{\circ} \mathrm{C}$ durante toda la duración del ensayo.

\subsection{Resultados y discusión}

A continuación, se presentan los resultados obtenidos en los diferentes ensayos a escala de laboratorio planteados en la Tabla 9.

\subsubsection{Efecto de la velocidad de rotación}

Para determinar la relación entre la velocidad de rotación y el DD obtenido, se analizaron 3 velocidades distintas de funcionamiento (ver Figura 114) correspondientes a los ensayos LT1, LT2 y LT3 de la Tabla 9. Investigaciones desarrolladas con sistemas de cavitación rotatorios concluyen que las velocidades de rotación elevadas producen mayores velocidades lineales en los bordes del rotor, y como consecuencia, se producen mayores oscilaciones en la presión 
(Martin Petkovšek et al., 2013) (Cerecedo et al., 2018). Esto produce una cavitación más agresiva, lo que se traduce en un mayor DD. Sin embargo, un incremento indefinido de la velocidad de rotación no necesariamente desemboca en mejores resultados. Estudios llevados a cabo con cavitadores de configuración rotor-estator muestran límites de velocidad a partir de la cual, la degradación de ciertos compuesto como el KI (M. P. Badve et al., 2015) (Tao et al., 2016), o la obtención de biogás a partir del fango (Patil et al., 2016) se ve mermada.

En los tres ensayos realizados, el caudal de recirculación y el volumen tratado se mantuvieron constantes a $30 \mathrm{l} / \mathrm{min}$ y $40 \mathrm{l} / \mathrm{min}$ respectivamente. El tiempo de cavitación empleado para cada ensayo ha sido de 60 minutos con excepción del LT3. Al no utilizar ningún sistema de refrigeración en esta ronda de ensayos, la temperatura en el ensayo LT3 se ha elevado hasta alcanzar temperaturas por encima de $70^{\circ} \mathrm{C}$ en los primeros 30 minutos, y por ello no ha sido posible prolongar el experimento más allá de ese tiempo en ese ensayo en concreto.

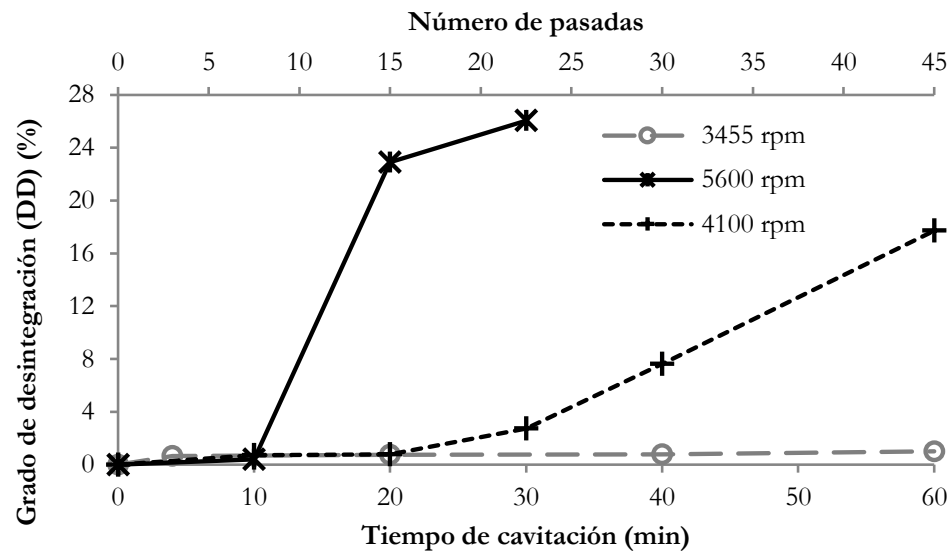

Figura 117: Relación entre la velocidad del rotor y el grado de desintegración obtenido en los experimentos a escala de laboratorio (40 1).

La evolución de la degradación en función del tiempo de cavitación, así como de la velocidad de rotación empleada, pueden verse en la Figura 117. Como cabía esperar, el DD se ha incrementado al aumentar la velocidad de rotación del cavitador. Analizando los primeros 30 minutos de tratamiento, se consigue mejorar el DD del $3 \%$ al $26 \%$ al aumentar la velocidad de rotación de 4100 a 5600 rpm respectivamente. Para la velocidad de rotación correspondiente a $3455 \mathrm{rpm}$, no se ha conseguido degradar prácticamente nada, lo que evidencia que la velocidad alcanzada en este caso es insuficiente para alcanzar condiciones que permitan generar cavitación. La tendencia observada concuerda con los resultados obtenidos con otras configuraciones rotor-estator donde un incremento en la velocidad de rotación, se ve traducida en una mayor eliminación de bacterias Jyoti \& Pandit, 
2001) y también en un incremento del DD (Martin Petkovšek et al., 2015). En este sistema en particular, no se ha llegado a obtener ningún límite de velocidad a partir del cual el rendimiento se vea afectado (descenso del DD al aumentar la velocidad de rotación). Dado que la velocidad máxima del sistema es de $5600 \mathrm{rpm}$, se ha considerado esta velocidad como aquella que maximiza el DD y por tanto la que consigue una mayor solubilización de la DQO.

\subsubsection{Rendimiento energético de los ensayos LT1, LT2 y LT3}

Llegados a este punto, se ha conseguido determinar la velocidad de rotación del sistema que maximiza el DD obtenido. No obstante, esto no significa necesariamente que esta velocidad de rotación proporcione el mejor rendimiento energético. En la Figura 118, se analiza la energía empleada en el experimento (energía de bombeo más la energía del cavitador en kW) y la energía específica para solubilizar el fango (EEDQOS).

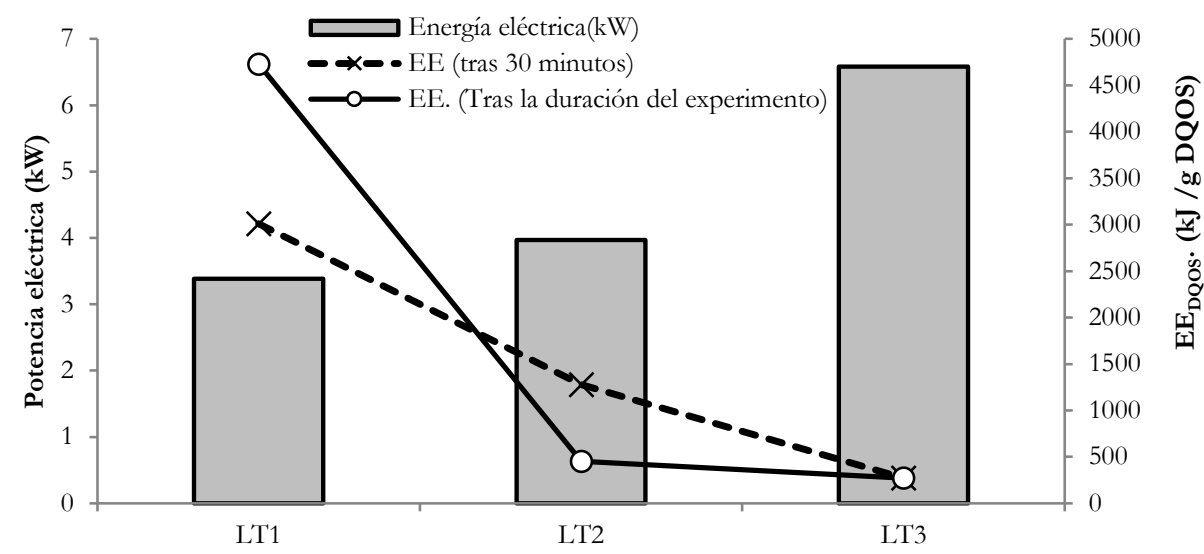

Figura 118: Energía total consumida $(\mathrm{kW})$ y energía específica de solubilización del fango (KJ/g DQOS) tras 30 minutos de cavitación y tras la duración del ensayo completo.

Se puede observar cómo, aunque el paso de $3455 \mathrm{rpm}$ a $4100 \mathrm{rpm}$ supone un pequeño aumento en la energía eléctrica consumida (de 3,4 a $4 \mathrm{~kW}$ ), cuando se pasa de $4100 \mathrm{rpm}$ a $5600 \mathrm{rpm}$ el salto energético es mucho mayor, incrementando de 4 a $6.6 \mathrm{~kW}$ de consumo eléctrico. Esto evidencia cómo el consumo energético se ve significativamente afectado por velocidades de rotación elevadas. Sin embargo, al analizar la EE $E_{D Q O S}$ para los 30 primeros minutos de tratamiento, se puede observar cómo al incrementar la velocidad de 3455 a $4100 \mathrm{rpm}$, se produce una disminución de 2364 a $1280 \mathrm{~kJ} / \mathrm{g}$ DQOS y tras volver a aumentar la velocidad de 4100 a $5600 \mathrm{rpm}$, se produce nuevamente una disminución de la EEDQos la cual pasa de 1280 a $272 \mathrm{~kJ} / \mathrm{g}$ DQOS. Esto representa una mejora en el rendimiento de 
un $45 \%$ y un $79 \%$ al aumentar las velocidades de rotación de 3455 a $4100 \mathrm{rpm}$, y de 4100 a $5600 \mathrm{rpm}$ respectivamente.

Al analizar la eficiencia energética obtenida tras la duración completa del experimento (60 minutos para los ensayos LT1 y LT2 y 30 minutos para el LT3), se puede observar cómo existe una mejora sustancial en el ensayo LT2 que pasa de 1280 a 452 kJ/g DQOS. Esta mejora significativa en la segunda mitad del ensayo se atribuye al aumento de la temperatura del fango, la cual, combinada con la cavitación, puede ser la causante del aumento en la eficiencia del proceso. Sin embargo, aun considerando esta mejora tras realizar el proceso a $4100 \mathrm{rpm}$ durante 60 minutos, no es suficiente como para superar la EE tratamiento durante 30 minutos a $5600 \mathrm{rpm}$, la cual continúa siendo un $60 \%$ inferior.

Por tanto, puede concluirse que el ahorro en energía eléctrica obtenido con bajas velocidades de rotación no compensa el incremento en los tiempos de duración del proceso para obtener valores de DD similares a los obtenidos cuando se opera a altas velocidades de rotación. Como consecuencia, el valor de $5600 \mathrm{rpm}$ se ha establecido como la velocidad de rotación óptima que permite maximizar el grado de degradación del fango con el mínimo consumo de energía eléctrica, es decir, es la velocidad de rotación que minimiza la EE

\subsubsection{Efecto del caudal de recirculación y de la temperatura}

Una vez determinada la velocidad de rotación óptima en $5600 \mathrm{rpm}$, ha sido necesario determinar el caudal de recirculación y la temperatura de operación. Así pues, se han repetido los experimentos para una velocidad de rotación de $5600 \mathrm{rpm}$, pero utilizando 3 flujos de recirculación diferentes (experimentos LT4 a LT9) y bajo dos condiciones de temperatura diferentes: con refrigeración $\left(\mathrm{T}<35^{\circ} \mathrm{C}\right)$ y sin refrigeración $\left(\mathrm{T}>35^{\circ} \mathrm{C}\right)$.

El caudal de recirculación está directamente relacionado con el número de pasadas a través del cavitador. Dado que el volumen tratado en los experimentos a escala de laboratorio ha sido de 40 litros, los caudales de recirculación de 50, 100 y 150 l/min estudiados, se corresponden con 38, 75 y 113 pasadas a través del cavitador para 30 minutos de tratamiento. Diversos estudios utilizando platos con orificios (Sivakumar \& Pandit, 2002) (I. Lee \& Han, 2013) y configuraciones rotorestator (Martin Petkovšek et al., 2015) han concluido que los efectos de la cavitación se incrementan cuando se incrementa el tiempo de residencia, es decir, cuando se incrementa el número de pasadas través del sistema de cavitación.

El efecto de la temperatura es mucho más complejo. Aunque los tratamientos térmicos entre $100 \mathrm{y} 150^{\circ} \mathrm{C}$ pueden aumentar ligeramente el grado de desintegración (I. Lee \& Han, 2013), cuando los efectos de la temperatura son combinados con la hidrocavitación, la eficiencia en términos de aumento del DD 
así como en la degradación de cierto tipos de contaminantes mejora significativamente. Sin embargo, el efecto de la temperatura está estrechamente relacionado con la sustancia que se está degradando. Mientas que algunos estudios apuntan a que las temperaturas entre 25 y $35^{\circ} \mathrm{C}$ pueden ser óptimas, por ejemplo, para la degradación de ciertos medicamentos como la carbamanzepina (Braeutigam et al., 2012b) otros afirman que el mejor rango para la degradación herbicidas como el alacloro se encuentra entre los 40 y los $60^{\circ} \mathrm{C}$ (Wang \& Zhang, 2009). En cuanto a la eliminación de microcontaminantes en el agua, se han observado resultados similares a estos últimos. En este caso, la temperatura parece tener muy poco efecto cuando se encuentra entre los 20 y los $40^{\circ} \mathrm{C}$, y sin embargo su degradación se duplica cuando se operan en rangos de temperatura que van entre los 40 y los $60^{\circ} \mathrm{C}$ (Martin Petkovšek et al., 2013). Este último rango de temperatura ha sido testado en la eliminación de farmacéuticos y se ha demostrado que la mejor tasa de degradación se da a los $50^{\circ} \mathrm{C}$ en algunos medicamentos como el ácido clofíbrico, ibuprofeno y diclofenaco; y que, en algunos casos, su degradación puede aumentar incluso a temperaturas superiores a los $60^{\circ} \mathrm{C}$. Sin embargo, según algunos investigadores como X. Wang et al. (Wang \& Zhang, 2009), aumentar la temperatura más allá de los $60^{\circ} \mathrm{C}$ puede resultar contraproducente. Esto se debe a que, al aumentar la temperatura por encima de este valor, se incrementa el vapor de agua presente y se produce un efecto de amortiguamiento durante la etapa de colapso de las burbujas. Otra explicación proporcionada por M. Dular et al. (Dular et al., 2016) es que la presión de vapor aumenta con la temperatura, lo que genera una disminución del número de cavitación. Al disminuir el número de cavitación, se incrementa de forma sustancial la generación de vapor, pero el efecto de degradación debido al colapso se ve mermado debido a la gran zona de cavitación producida que induce un efecto similar al de la supercavitación.

\subsubsection{Efecto de la temperatura}

En el actual estudio, todos los experimentos llevados a cabo con el sistema de refrigeración activo (Figura 119) no tienen prácticamente ningún efecto sobre el DD y los valores no superan en ningún caso el $5 \%$, independientemente del caudal de recirculación utilizado. Sin embargo, cuando los experimentos se dejan evolucionar sin un sistema de refrigeración que mantenga una temperatura por debajo de los $35^{\circ} \mathrm{C}$ (Figura 120), el DD aumenta hasta valores de 10, 18 y $11 \%$ para 38, 75 y 113 pasadas por el cavitador respectivamente (o lo que es lo mismo, para caudales de recirculación de 50,100 y $150 \mathrm{l} / \mathrm{min}$ respectivamente). Para este último caso sin refrigeración también se puede observar que para los primeros 20 minutos de experimento, la pendiente de la curva del grado de desintegración aumenta, pero luego su inclinación se ve reducida cuando los experimentos tienen una duración de 30 minutos. 


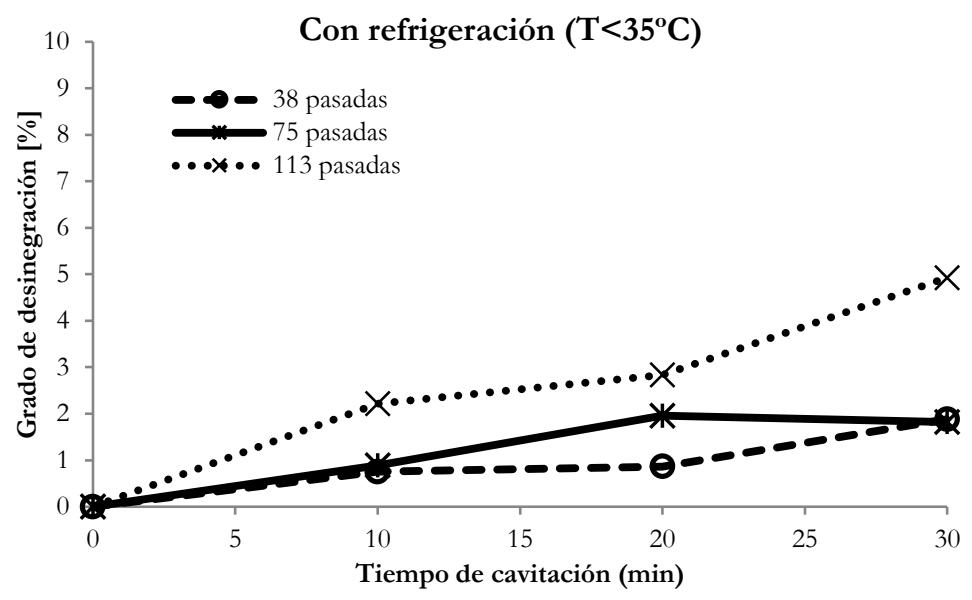

Figura 119: Grado de desintegración en función del caudal de recirculación con refrigeración (LT4, LT6, LT8). El número de pasadas se corresponden con 30 minutos de tratamiento.

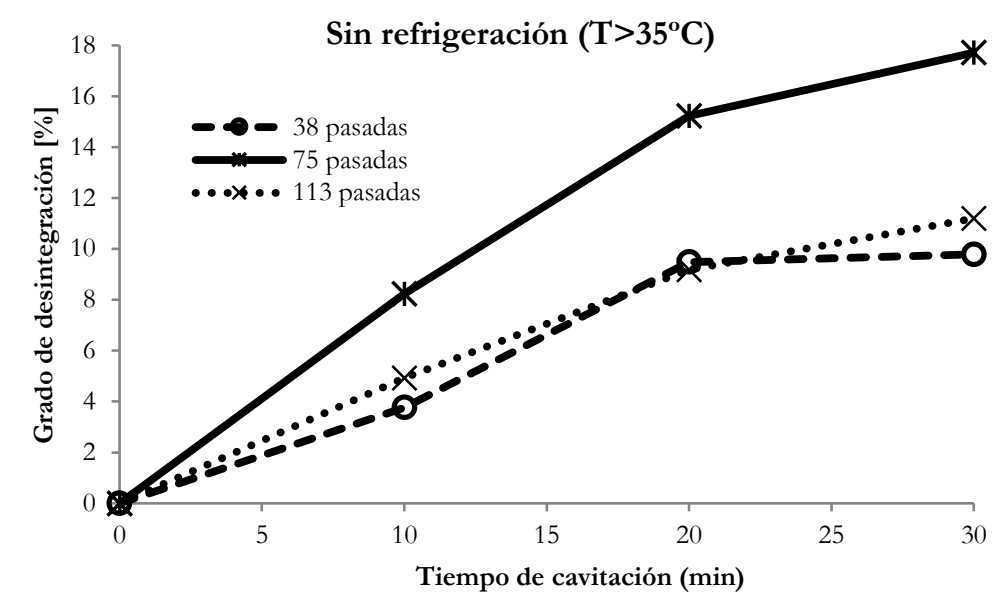

Figura 120: Grado de desintegración en función del caudal de recirculación sin refrigeración (LT5, LT7, LT9). El número de pasadas se corresponden con 30 minutos de tratamiento.

La explicación de por qué la pendiente de la curva del DD se vuelve menos acusada transcurridos 20 minutos se encuentra en la temperatura. Al analizar la evolución de la temperatura durante los experimentos (Figura 121), se puede observar que, durante los ensayos sin refrigeración, la temperatura excedía de los $60^{\circ} \mathrm{C}$ transcurridos aproximadamente 20 minutos de experimentos. Esto indica que aunque el DD aumenta de forma rápida en el rango de temperaturas de $40 \mathrm{a} 60^{\circ} \mathrm{C}$, su tendencia de crecimiento se ve mermada cuando se alcanzan temperaturas por 
encima de los $60^{\circ} \mathrm{C}$, lo que concuerda con otros estudios llevados a cabo en condiciones similares (Martin Petkovšek et al., 2013) (Zupanc et al., 2014).

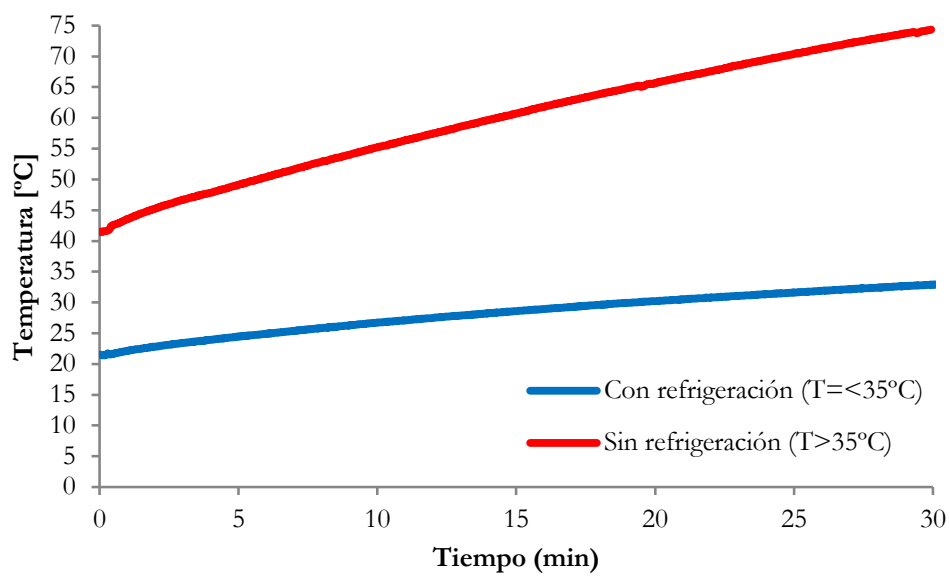

Figura 121: Evolución de la temperatura para los experimentos con refrigeración $\left(<35^{\circ} \mathrm{C}\right)$ y sin refrigeración $\left(>35^{\circ} \mathrm{C}\right)$.

Los anteriores resultados conducen a la conclusión de que las mejores condiciones operacionales pasan por no utilizar sistemas de refrigeración o, en su caso, mantener una refrigeración que permita conseguir temperaturas en el proceso de $60^{\circ} \mathrm{C}$ aproximadamente. El hecho de que el sistema muestre mejores rendimientos a temperaturas elevadas tiene importantes repercusiones energéticas. Durante los experimentos se registró el salto térmico producido en el cavitador, midiendo la temperatura de entrada y de salida de este. Este salto térmico está directamente relacionado con el caudal de recirculación de manera que, a mayor caudal de recirculación, menor diferencia de temperaturas obtenida entre la entrada y la salida del cavitador. Para el caso de $50 \mathrm{l} / \mathrm{min}$, se llegaron a registrar saltos térmicos de hasta $0.67^{\circ} \mathrm{C}$. Dado que la concentración de sólidos de los experimentos ha sido pequeña, se puede considerar que el licor mezcla tiene el mismo calor específico y densidad del agua. Para valores elevados de sólidos totales deberían considerarse el calor específico de los propios sólidos (Kuglarz, Karakashev, \& Angelidaki, 2013b). Dado que el volumen en el interior de cavitador (la carcasa donde se encuentra el rotor y el estator) es de 1,6 litros, la cantidad de energía que el cavitador transfiere al flujo en forma de calor se estima en $4.6 \mathrm{~kW}$, lo que representa un $80 \%$ de la energía de entrada al sistema. El hecho de que el proceso presente mejores resultados a temperaturas elevadas significa que gran parte de esa energía térmica producida durante la cavitación puede ser aprovechada. Esto no solo favorece al propio proceso de degradación, sino que es 
necesario para etapas posteriores de digestión donde el fango debe entrar precalentado para llevar a cabo el proceso de digestión.

\subsubsection{Efecto del caudal de recirculación}

Al igual que sucede con la temperatura o el número de pasadas a través del cavitador, el caudal de recirculación también presenta un valor óptimo que permite maximizar el DD. Considerando los experimentos llevados a cabo con él sin el sistema de refrigeración (que son los que han mostrado mejores resultados), cuando el número de pasadas se incrementa de 38 a 75 , el DD prácticamente duplica su valor y aumenta desde 9.8 hasta $17.7 \%$ tras 30 minutos de cavitación (Figura 120). Dado que la evolución de la temperatura de ambos experimentos se puede considerar idéntica, puede decirse que el número de pasadas a través del cavitador es proporcional al grado de desintegración obtenido, lo que concuerda con las observaciones realizadas tras las experimentaciones de otros investigadores (Sivakumar \& Pandit, 2002) (Martin Petkovšek et al., 2015) (I. Lee \& Han, 2013).

Sin embargo, para este sistema de cavitación en particular, cuando el número de pasadas se incrementa desde 75 a 113, el DD disminuye desde el $17.7 \%$ hasta el $11.2 \%$. Este fenómeno ha sido reportado también por otros autores como M. Badve (M. Badve et al., 2013) utilizando un cavitador de configuración rotorestator. La explicación proporcionada por este autor es que existe una reducción de la cantidad de implosiones producidas por las burbujas debido a que se genera una amplia zona de cavitación, que origina unas condiciones similares a las de supercavitación que reduce sustancialmente la energía liberada durante la etapa de colapso. En el cavitador utilizado en la presente tesis, esta reducción al aumentar el número de pasadas puede ser explicada debido a la particular configuración que utiliza 7 etapas diferentes ( 7 discos en el estator separados por 7 separadores). Dado que para aumentar el número de pasadas se debe aumentar el caudal de recirculación, el caudal pasa a través del cavitador a una mayor velocidad. Si esta velocidad es excesiva, las burbujas no pueden no tener tiempo suficiente colapsar de forma eficaz entre una etapa y la otra, lo que conlleva una reducción el grado de degradación obtenido.

Tras el análisis del número de pasadas y el caudal de recirculación, todo parece apuntar a que el número de pasadas óptimos para maximizar el DD es de 75 y que por tanto es necesario operar con un flujo de recirculación de $100 \mathrm{l} / \mathrm{min}$. Utilizar un mayor o un menor caudal de recirculación desembocará irremediablemente a menores grados de desintegración. No obstante, es imperativo analizar el rendimiento energético obtenido con este caudal de recirculación para poder confirmar si es o no un parámetro de funcionamiento adecuado. 


\subsubsection{Rendimiento energético de los ensayos LT4-LT9}

A diferencia de los ensayos LT1-LT4 para analizar la velocidad de rotación óptima, que fueron realizados utilizando exactamente el mismo licor mezcla obtenido el mismo día y a la misma hora, para los ensayos LT4 a LT9, fue necesario obtener la muestra durante varios días ya que, debido al número de ensayos a realizar, no pudieron llevarse a cabo todos el mismo día. Debido a esto, aunque la cantidad de sólidos totales de las diferentes muestras era muy similar, existían variaciones en la DQOT y la DQOS de las diferentes muestras. Si se comparan los valores de la $\mathrm{EE}_{\mathrm{DQOS}}$ únicamente se tiene en cuenta la cantidad de DQOS inicial y final sin considerar la cantidad de DQOT susceptible de ser solubilizada. Al tener diferentes muestras y variar la cantidad de DQOT, se pueden generar errores al comparar los resultados de los ensayos realizados con muestras diferentes, ya que en algunos casos puede resultar más fácil aumentar la DQOS debido a las características biológicas del licor mezcla en ese día en particular. Por estos motivos, se ha considerado que para poder realizar comparaciones entre los ensayos LT4 a LT9, resulta más adecuado comparar directamente valores de energía empleada y acompañarlos del grado de desintegración, tal y como puede verse en la Figura 122.

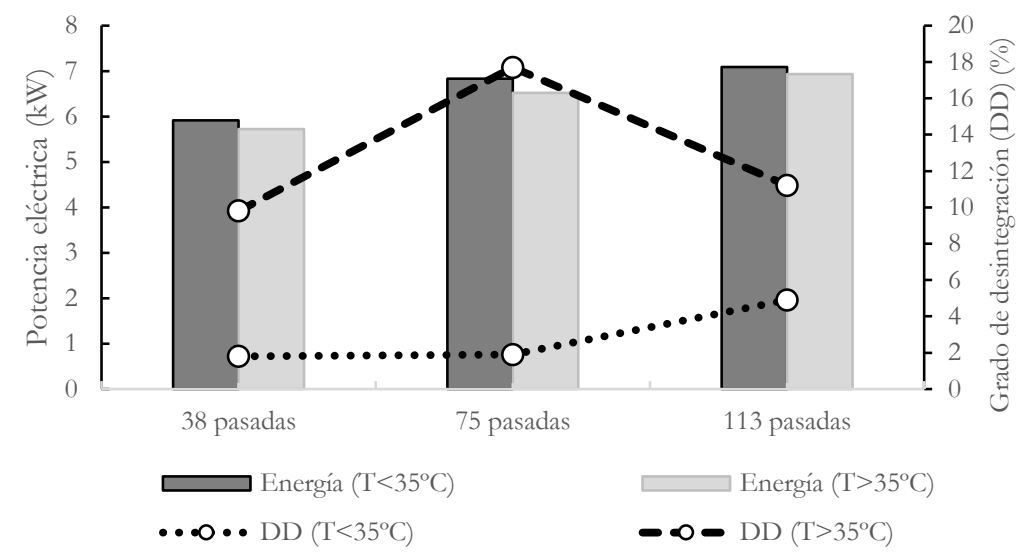

Figura 122: Máximos valores de DD obtenidos y energía eléctrica utilizada en función del número de pasadas.

En la gráfica anterior, se muestran los valores del DD obtenidos tras 30 minutos de tratamiento con el cavitador y la potencia eléctrica empleada durante ese tiempo. Se puede observar como la potencia eléctrica empleada para los ensayos sin refrigeración han sido de 5.72, 6.52 y $6.94 \mathrm{~kW}$ para 38, 75 y 113 pasadas 
respectivamente. Estos valores son ligeramente inferiores a los obtenidos cuando el sistema de refrigeración está activo y les corresponde unos valores de 5.91, 6.84 y $7.09 \mathrm{~kW}$. Este efecto se atribuye a que las temperaturas elevadas pueden cambiar ligeramente las características reológicas del licor mezcla, reduciendo su viscosidad y facilitando su bombeo. Sin embargo, esta potencia eléctrica se ha obtenido estrictamente para el bombeo y cavitación del licor mezcla, y para estos últimos casos en los que se encuentra activo el sistema de refrigeración debería considerarse la potencia empleada en el enfriamiento y bombeo del fluido refrigerante para el cómputo energético global. Considerando esto, la potencia requerida para los ensayos del sistema de refrigeración podría llegar a duplicarse.

Por otro lado, puede verse cómo aumentar el número de pasadas requiere bombear un mayor caudal, y por tanto aumenta la potencia eléctrica necesaria. Para los ensayos sin refrigeración concretamente, puede observarse como existe un incremento en la potencia energética del $12 \%$ al pasar de 38 a 75 pasadas y un incremento del $6 \%$ al pasar de 75 a 113 pasadas. Sin embargo, el mayor DD se obtiene con 75 pasadas, lo que pone en evidencia que un mayor aporte energético en forma de bombeo, no se ve traducido en una mejora en la degradación obtenida.

Llegados a este punto, el valor del grado de desintegración se considera como el parámetro más importante, dado que es el que está directamente relacionado con la cantidad de metano producido. Por tanto, aunque el consumo energético para realizar 38 pasadas (caudal de recirculación de $50 \mathrm{l} / \mathrm{min}$ ) es el más pequeño, proporciona el peor DD $(9.8 \%)$ y aumentando ligeramente la potencia, concretamente un $12 \%$, para conseguir realizar 75 pasadas $(100 \mathrm{l} / \mathrm{min})$, se consigue mejorar el DD hasta un valor de $17.7 \%$, lo que supone una mejora en el grado de desintegración del $44.6 \%$. Por ello, tras la realización de estos ensayos se ha establecido el caudal de recirculación de $100 \mathrm{l} / \mathrm{min}$ sin utilización de sistema de refrigeración, como la condición operativa óptima para maximizar el grado de desintegración obtenido. 
Capitulo 5. Experimentación a escala de laboratorio 


\section{Capítulo 6}

\section{Experimentación a escala industrial}

En este capítulo se presentan los ensayos realizados a escala industrial llevados a cabo en la planta piloto STO3RE situada en la EDAR de Totana (Murcia). Utilizando los parámetros de funcionamiento óptimos obtenidos durante los ensayos a escala de laboratorio (ver capítulo 4), se ha analizado el efecto que la cavitación produce cuando se tratan grandes volúmenes fango formado por purines de cerdo y lodos procedentes de la depuración. Estos ensayos han permitido determinar el efecto que la cavitación produce sobre la mezcla de lodos, y cómo se ven afectadas ciertas características biológicas que permitirán mejorar la cantidad de biogás en la etapa de digestión y utilizar el digestato como biofertilizante.

\subsection{Introducción}

Como ya se ha comentado en el capítulo 1, el desarrollo del sistema de hidrocavitación llevado a cabo en la presente tesis se enmarca en el proyecto Life STO3RE, el cual pretende desarrollar una innovadora tecnología basada en una digestión anaerobia en doble fase ácido-gas, junto con la oxidación del ozono y la cavitación hidrodinámica (CavO3 + DAG-TPAD). Por tanto, la finalidad última de los análisis y ensayos a escala de laboratorio expuestos durante el capítulo 4 no es otra que la de conseguir un sistema de cavitación que permita obtener el mejor rendimiento y aumentar la sinergia del resto de procesos (digestión anaerobia en doble fase de temperatura y ozonización) inmersos en la planta piloto STO3RE situada en la EDAR de Totana (Murcia) (Figura 123)

El objetivo de tratar diferentes lodos y purines es unificar las metodologías de gestión y compartir las instalaciones, por lo que se hará más eficiente el uso de los equipos y se reducirán los costes de inversión y operación en las áreas rurales.

Ambos residuos tienen un impacto nocivo en el medio ambiente, tanto para las masas de agua continental como para la atmósfera. Sin embargo, ambos pueden ser 
valorizados ya que son ricos en nutrientes (fósforo, $\mathrm{P}, \mathrm{y}$ nitrógeno, $\mathrm{N}$ ). Al tratarlos con el proceso de digestión anaerobia propuesto en el proyecto, es posible reutilizarlos aplicando el biofertilizante obtenido en la agricultura. Uno de los objetivos perseguidos en STO3RE es lograr un biofertilizante que cumpla con los futuros requisitos reglamentarios y normativos del cuarto borrador de la Directiva de la UE para la aplicación de lodos en la agricultura. Con el fin de evaluar la calidad del biofertilizante, se evaluarán los microcontaminantes seleccionados después del screening realizado a ambas matrices.
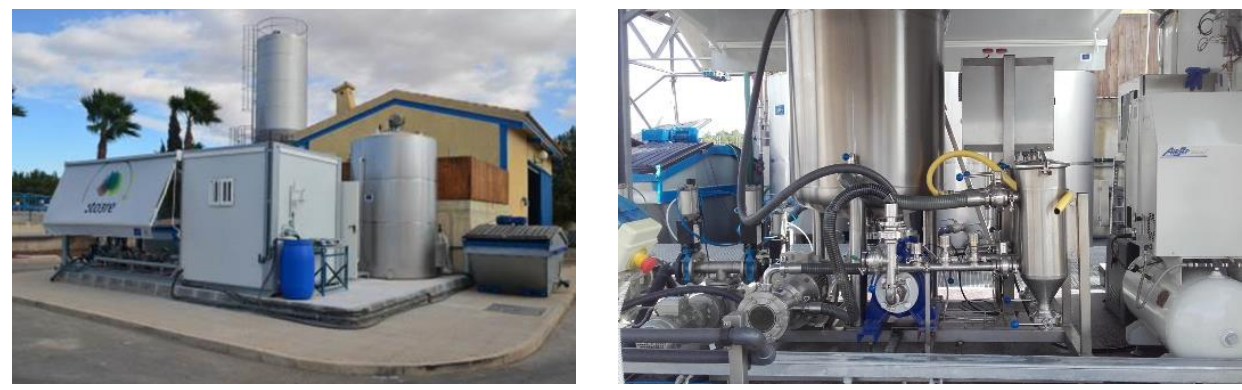

Figura 123: Planta piloto STO3RE situada en la EDAR de Totana (Murcia).

Para ello, han analizado y tratado el exceso de lodo de seis plantas de tratamiento de aguas residuales (Aledo, Alhama de Murcia, Librilla, Puerto Lumbreras, Mazarrón y Totana), situadas en una determinada zona de Murcia. Además, se han utilizado como cosustratos cinco purines de cerdo de diferentes explotaciones ganaderas.

La Región de Murcia tiene una gran tradición en el sector ganadero. En concreto, la zona donde se desarrolla el proyecto STO3RE, se muestra en la Figura 1 donde se observan las explotaciones ganaderas que se encuentran en los alrededores de Librilla, Totana y Alhama de Murcia. Estos datos han sido facilitados por la Consejería de Agua, Agricultura y Medio Ambiente de la Región de Murcia.

Las explotaciones porcinas se clasifican según su capacidad de producción. En la Tabla 11 se muestran los datos publicados en el RD 324/2000, que establece normas básicas para la planificación de explotaciones porcinas. Se pueden observar las equivalencias en unidades de cerdo (LSU) entre los diferentes tipos de ganado porcino y el contenido de nitrógeno de su purín al comienzo del período de almacenamiento.

La unidad ganadera (LSU) es una unidad de referencia que facilita la agregación de ganado de varias especies y edad, según convenga, a través del uso de 
coeficientes específicos establecidos inicialmente sobre la base de la necesidad de alimentación nutricional de cada tipo de animal.

\begin{tabular}{lccc}
\hline Type of livestock (stall) & $\begin{array}{c}\text { Manure liquid } \\
\text { and semi liquid } \\
\text { (m³ } / \text { year) }\end{array}$ & $\begin{array}{c}\text { Nitrogen } \\
\text { content } \\
\text { Kg/stall/ } \\
\text { year }\end{array}$ & $\begin{array}{c}\text { LSU } \\
\text { equivalence }\end{array}$ \\
Sow in closed sycle & 17,75 & 57,60 & 0,96 \\
Sow with piglets until & 5,10 & 15,00 & 0,25 \\
weaning (from 0 to $6 \mathrm{~kg}$ ) & 6,12 & 1 cer8,00 & 0,30 \\
Sow with piglets until $20 \mathrm{~kg}$ & 2,50 & 8,50 & 0,14 \\
Breeding sows & 0,41 & 1,19 & 0,02 \\
Piglets from 6 to $20 \mathrm{~kg}$ & 1,80 & 6,00 & 0,10 \\
Pigs from 20 to $50 \mathrm{~kg}$ & 2,50 & 8,50 & 0,14 \\
\hline Pigs from 50 to $100 \mathrm{~kg}$ & 2,15 & 7,25 & 0,12 \\
\hline Fattening pig from 20 to 100 & 6,12 & 18,00 & 0,30 \\
kg & & & \\
Boar & & & \\
\hline
\end{tabular}

Tabla 11: Producción de purín y contenido de $\mathbf{N}$ dependiendo del tipo de ganado y equivalencia de LSU.

\subsubsection{Objetivos}

De manera análoga a los objetivos de los ensayos a escala de laboratorio, los objetivos de los ensayos a escala industrial no son sino los de confirmar que los parámetros de diseño y funcionamiento determinados durante la etapa previa son correctos y proporcionan los efectos deseados. Así pues, los principales objetivos perseguidos en este capítulo de ensayos experimentales a escala industrial son:

- Determinación de los efectos de escala del proceso. Tras determinar que el sistema de hidrocavitación presenta unos buenos resultados a escala de laboratorio, es necesario determinar si dichos resultados se mantienen al aumentar la cantidad de volumen de lodo tratado y cambiar su tipología. Para ello, además de analizar el grado de desintegración obtenido al tratar los lodos, también se ha analizado la cantidad de ácidos grasos volátiles (AGVs) liberados tras el tratamiento, ya que de ellos depende la cantidad de biogás producido en la etapa de digestión. Además, dado que se desea que los lodos tratados puedan ser utilizados como biofertilizante, se ha determinado el efecto higienizante del tratamiento, es decir, si es capaz de bacterias como la Escherichia coli, Salmonella sp y Clostridium perfringens.

- Determinación de la eficiencia del proceso. Se debe cuantificar el coste energético del tratamiento de hidrocavitación para determinar si la mejora en la cantidad de metano producida compensa la energía empleada en dicho 
proceso. El sistema de hidrocavitación no es el único proceso empleado en la planta piloto STO3RE, sino que existen otros procesos como la ozonización o la digestión en doble fase de temperatura. Por tanto, se analizará también la sinergia que la cavitación produce con estos procesos de oxidación y de digestión para determinar que combinación desemboca en una mayor producción de biogás a un menor coste energético.

- Detección de fallos de funcionamiento del sistema. Durante los ensayos en la fase de laboratorio, se subsanaron diferentes fallos en el dimensionamiento, y operación de los diferentes elementos (depósitos, válvulas, bombas, tuberías y sensores) que intervenían en el sistema de cavitación hidrodinámica. Ahora, es necesario determinar si al integrar el sistema de cavitación en la planta piloto STO3RE se producen fallos en el funcionamiento del conjunto para, en su caso, subsanarlos de manera que pueda garantizarse su correcto funcionamiento.

\subsubsection{Principales dificultades afrontadas}

En esta fase del estudio, las principales dificultades no han residido en el propio sistema de cavitación sino más bien en la instalación de la planta piloto STO3RE donde se ha integrado. Estas dificultades han sido: conseguir una buena armonía en el funcionamiento de todos los procesos que se ven involucrados en la planta (cavitación, ozonización y digestión anaerobia) así como cuantificar la sinergia producida por la cavitación hidrodinámica sobre el resto de los procesos.

Durante los ensayos de laboratorio presentados en el capítulo 4, se ha hecho hincapié en la dificultad del tratamiento de este tipo de sustancia. Durante estos ensayos, las dificultades residían en el control y confinamiento de los olores generados, la manipulación y mezcla de estos lodos, y la complejidad de las labores de limpieza para realizar los experimentos de manera segura y fiable. Durante el desarrollo de los experimentos en la planta piloto. Nada de lo anteriormente enumerado ha supuesto un problema real en estos ensayos, ya que al trabajar en el interior de la EDAR, los olores no suponían un problema, las labores de manipulación y mezcla de lodos se realizaban por los propios granjeros que recogían y descargaban los fangos en un depósito de homogenización, y dado que el sistema de cavitación funcionaba en lotes (batches) de forma continua con volúmenes muy grandes, no era necesario realizar limpiezas a fondo entre experimentos.

En este caso, el principal problema ha sido la tipología del lodo. Los purines de cerdo recolectados en las granjas arrastraban muchos residuos que no eran propiamente lodos. Se acumulaba una gran cantidad de pelo de cerdo, el cual es muy duro y difícilmente degradable, así como partículas sólidas presentes en las heces e incluso placas identificativas que se desprendían de los animales. Debido al 
diseño robusto del cavitador, esto no suponía un problema para este dispositivo. Sin embargo, para la gran mayoría de elementos situados tanto aguas arriba como aguas abajo del sistema de cavitación (válvulas, bombas de impulsión y sensores), estos residuos podían llegar a producir atascos y fallos críticos que obligaban a para el funcionamiento de la planta piloto. Para reducir en la medida de lo posible este problema, se instaló al principio de la planta una trituradora para ayudar a degradar los pelos y partículas sólidas presentes y que no afectaran al funcionamiento de los elementos de la planta. En este sentido, el diseño del cavitador, también facilitó el tratamiento de los lodos ya que lejos de obstruirse y atascarse, actuaba como una segunda trituradora.

\subsection{Métodos y materiales}

Tanto la metodología como los materiales utilizados para realizar los ensayos en la planta piloto han sido muy similares a los empleados durante los ensayos en laboratorio. Si bien es cierto que la planta piloto STO3RE dispone de muchos más elementos como sistema de ozonización o digestores para realizar la digestión en doble fase de temperatura, los análisis realizados se centran en detalle sobre el dispositivo de cavitación (objeto de la presente tesis) y que efecto tiene al ser combinado con el resto de los procesos de la planta. Por tanto, los parámetros analizados durante estos experimentos son básicamente los mismos, con la adición de medidas de AGVs o determinación de unidades formadoras colonias y por supuesto de la cantidad de volumen tratado (que ahora pasa de los 40 a los 600 litros), así como la tipología del lodo tratado.

\subsubsection{Montaje experimental}

Como ya se ha dicho, el montaje experimental de esta fase del estudio se encuentra integrado dentro de la planta piloto STO3RE (Figura 123). A continuación, se describen de forma breve los principales elementos de la planta.

\subsubsection{Principales componentes de la planta piloto STO3RE}

Los principales componentes de la planta STO3RE, son los siguientes:

- Tanque de homogenización agitado.

- Depósito del pretratamiento de 600 litros.

- Sistema de cavitación.

- Sistema de ozonización.

- Digestor anaerobio mesófilo.

- Digestor anaerobio termófilo.

- Digestor anaerobio control.

- Bombas de impulsión de lodos. 
En la Figura 124, se muestra el esquema de funcionamiento de la planta piloto de forma simplificada. Al principio de la planta se encuentra un tanque de homogenización agitado. Este depósito es el que recibe la mezcla de los lodos procedentes de las diferentes EDAR y de los purines de las granjas. Para facilitar la mezcla y evitar la sedimentación, este tanque es agitado de forma continua. Tras la homogenización de los lodos de entrada se encuentran los pretratamientos de ozonización y de hidrocavitación. Ambos funcionan en lotes (batches) y utilizan el depósito de 600 litros para operar. Un sistema de válvulas permite actuar sólo con cavitación, sólo con ozonización o utilizando los dos sistemas. A la entrada del pretratamiento también existe una válvula que permite baipasear ambos (cavitación y ozonización) para operar sin realizar ningún tipo de pretratamiento. Aguas debajo de la ozonización y cavitación se encuentran los digestores. Por un lado, se encuentra la digestión en doble fase de temperatura que consta de dos digestores: uno termófilo (funcionamiento a $55^{\circ} \mathrm{C}$ ) y otro mesófilo (funcionamiento a $35^{\circ} \mathrm{C}$ ). Por otro lado, se encuentra un digestor control utilizado para cuantificar la mejora obtenida al operar con la planta piloto.

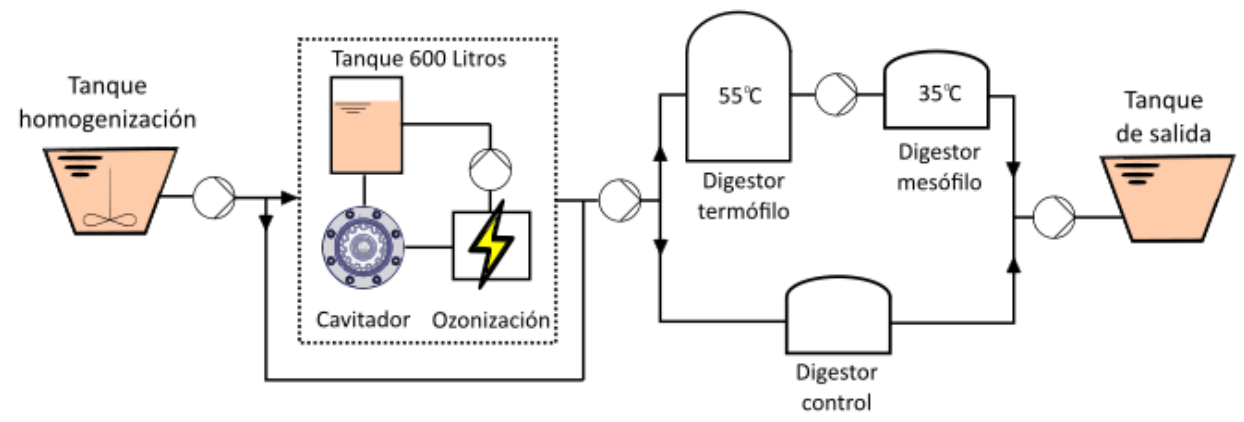

Figura 124: Diagrama de funcionamiento de la planta piloto STO3RE.

Para conseguir que el lodo circule a lo largo de la planta, ha sido necesaria la utilización de varias bombas especiales que permitieran trabajar a diferentes condiciones de sólidos, temperatura y caudal.

Por supuesto, además de todos los componentes anteriormente mencionados, se encuentran instalados una serie de dispositivos tales como válvulas, sensores de nivel, sondas de sólidos y de temperatura y analizadores de gases que permiten automatizar y controlar el funcionamiento de la planta en todo momento.

\section{Contenedores de homogeneización y almacenamiento del digestato}

Con el fin de mezclar el lodo en exceso de la EDAR,y la suspensión de cerdo en las condiciones requeridas, y almacenar el digestato obtenido después del tratamiento, la planta cuenta con 2 contenedores de acero galvanizado. Tienen una 
capacidad de $9 \mathrm{~m}^{3}$ con una longitud de $3578 \mathrm{~mm}$, una anchura de $1893 \mathrm{~mm}$, una altura de $1500 \mathrm{~mm}$ y un peso de $620 \mathrm{~kg}$. Los contenedores están cubiertos con una cubierta de plástico fácil de quitar para proteger el contenido del exterior.

En los depósitos se incluyen dos bridas de DN65 para bombear la mezcla de lodos y purín de cerdo y para posibilitar su recirculación si fuera necesario. También existe un orificio de $1 / 2$ " donde se encuentra instalado el sensor de control de nivel, complementado con una tira vertical de material transparente con una regla en el exterior que permite determinar en todo momento el nivel de volumen en los tanques.
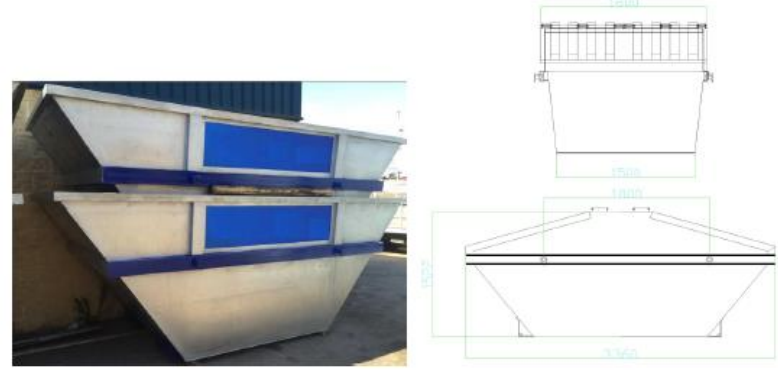

Figura 125: Tanques de homogenización.

\section{Caseta portátil para ubicación de cuadros eléctricos y pretratamiento}

La caseta tiene una superficie de $15 \mathrm{~m}^{2}(6.21 \times 2.44$ metros $)$, separada en dos zonas. La primera zona está completamente cerrada con una puerta y una ventana, y tiene $2 \mathrm{~m}$ de largo.

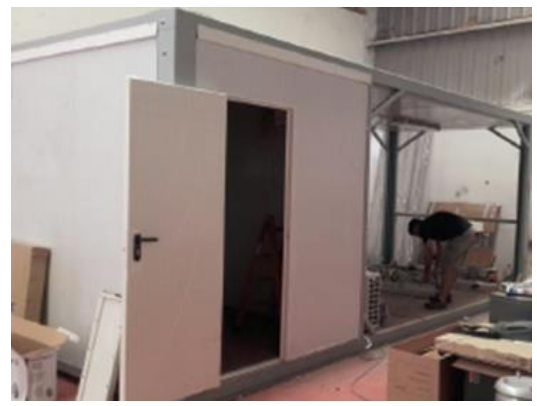

Figura 126: Cabina portátil donde se encuentra la instalación de la planta piloto STO3RE.

En esta sala se encuentran los cuadros eléctricos de los elementos de la planta, así como el ordenador de control y registro de datos. También tiene un sistema de aire acondicionado para refrigeración de los equipos. La segunda zona se encuentra abierta por los lados, y es donde se encuentran los sistemas de iluminación 
exteriores, conexiones de agua, compresor de aire, distribuidores de acero, bombas del sistema, módulo de cavitación y equipo de ozonización. La caseta está especialmente reforzada para el transporte y para soportar todo el peso de la cabina. El suelo es de hormigón, fácil de limpiar y anticorrosivo.

\section{Digestores anaerobios}

Existen 3 digestores en la planta piloto STO3RE (Figura 127): uno mesófilo, uno termófilo y un tercero también mesófilo que actúa como digestor de control. A continuación, se muestran las especificaciones de cada uno.
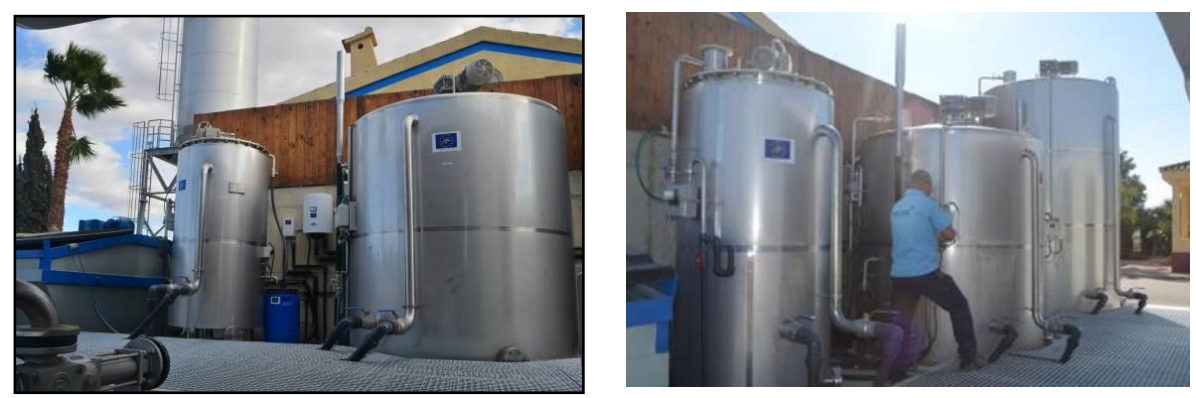

Figura 127: Digestores anaerobios utilizados en la planta piloto STO3RE.

- Digestor anaerobio 1: este digestor anaerobio funciona como digestor mesófilo. El tanque está hecho de acero inoxidable INOX 316. Tiene un diámetro de $2.00 \mathrm{~mm}$ y una altura de $3.30 \mathrm{~m}$, lo que supone un volumen total de $10.37 \mathrm{~m}^{3}$. El tanque tiene una tapa oval en la parte superior para facilitar su inspección y las labores de mantenimiento. Este digestor tiene un aislamiento de poliuretano de $50 \mathrm{~mm}$, agitación y sensores para monitorizar el nivel y la temperatura. También está dotado de un caudalímetro de gas, válvulas de drenaje y un sistema de salida de emergencia en caso de exceso de sobrepresión de la biomasa.

- Digestor anaerobio 2: este digestor anaerobio funciona como digestor termófilo. El tanque está hecho de acero inoxidable INOX 316. Tiene diámetro de $1,80 \mathrm{~mm}$ y una altura de $2.00 \mathrm{~m}$, lo que supone un volumen total de $5.09 \mathrm{~m}^{3}$. Dispone de los mismos componentes que el digestor anaerobio 1, salvo que este cuenta, además, con un sistema de calefacción formado por una bomba de circulación, un calentador de agua eléctrico y un tanque de expansión. 
- Digestor anaerobio 3: este digestor anaerobio funciona como digestor mesófilo y se usa como digestor control. El depósito es de acero inoxidable y tiene un volumen total de $1 \mathrm{~m}^{3}$. El tanque está hecho de acero inoxidable INOX 316. En esencia, lleva prácticamente la misma sensorización y elementos que el digestor anaerobio 1 el cuál, también es mesófilo.

\section{Cavitador hidrodinámico}

Se trata del mismo sistema utilizado durante las pruebas a escala de laboratorio al cual se le ha cambiado la configuración de las válvulas para que en lugar de utilizar los dos depósitos pequeños de 15 litros, utilice el depósito grande de 600 litros. Su funcionamiento se explica más en detalle en el siguiente apartado.
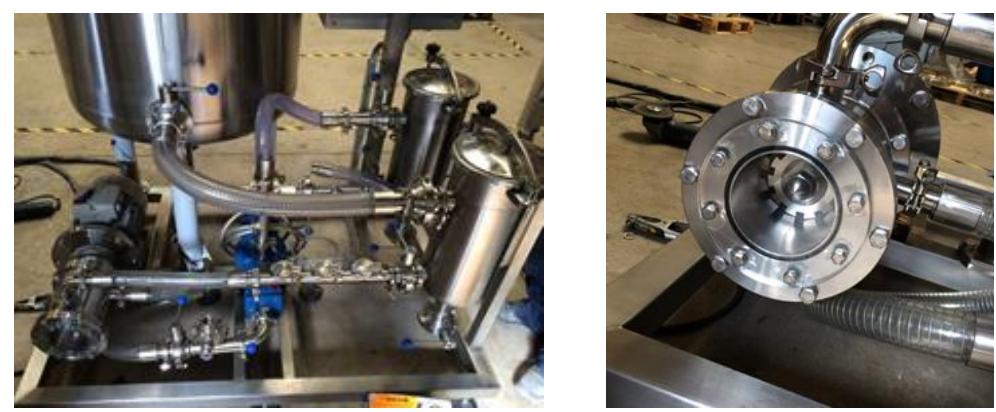

Figura 128: Sistema de cavitación utilizado en la planta piloto (el mismo que en la experimentación de laboratorio).

\section{Generador de ozono}

El ozono es una molécula altamente inestable que se descompone rápidamente tras su producción (en su mayoría para formar radicales libres $\mathrm{OH}$ ). Es por esto, que esta sustancia debe ser generada y utilizada in situ para aprovechar la máxima cantidad producida antes de su descomposición.
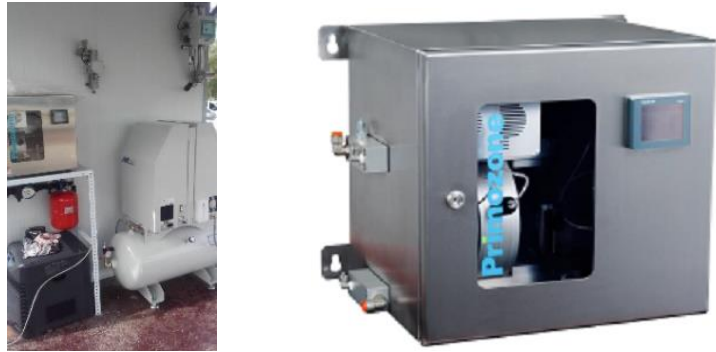

Figura 129: Sistema de ozonización utilizado en la planta piloto. 
En el generador se produce una alta tensión eléctrica que rompe el enlace de las moléculas de oxígeno y estas se recombinan para generar el ozono.

\section{Bombas de lodos}

Para conseguir la circulación de los lodos a través de la planta, ha sido necesaria la instalación de varias bombas especiales que permitieran impulsar un fluido con unas características tan complejas como las que presentan los lodos. Para ello, se han instalado 4 bombas (BEILLIN) de cavidad progresiva con bridas de $65 \mathrm{~mm}$ y una potencia eléctrica de $1.5 \mathrm{~kW}$. Estas bombas son las encargadas de traspasar el lodo entre las diferentes etapas, es decir, del tanque de homogenización al pretratamiento, del pretratamiento a la digestión, entre digestor termófilo y mesófilo y de la etapa de digestión al tanque de salida. Las bombas llevan incorporadas un sensor de temperatura para proteger el estator.

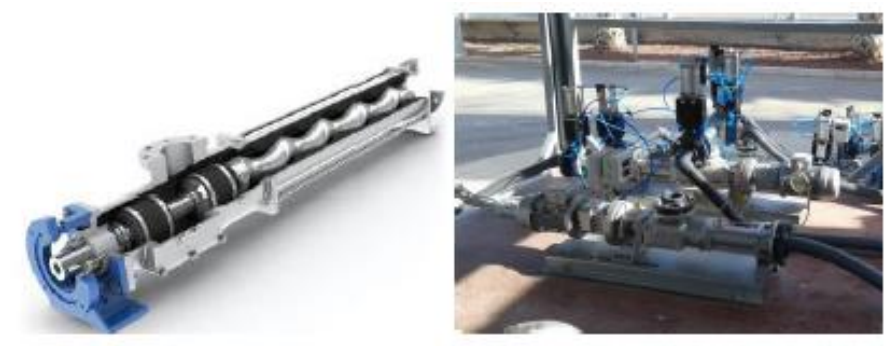

Figura 130: Bombas de lodos utilizadas para trasegar el lodo entre las diferentes etapas de la planta piloto.

Además de estas bombas, también debe considerase una quinta bomba, la cual se encarga de hacer circular el lodo en la etapa de pretratamiento, es decir, en el tratamiento de cavitación y ozonización. Esta bomba es la misma que se ha utilizado durante los ensayos a escala de laboratorio y que se encontraba incorporada en el sistema de cavitación. Está bomba de $2.2 \mathrm{~kW}$ está preparada para trabajar a altas temperaturas y a concentraciones de sólidos de hasta el $8 \%$.
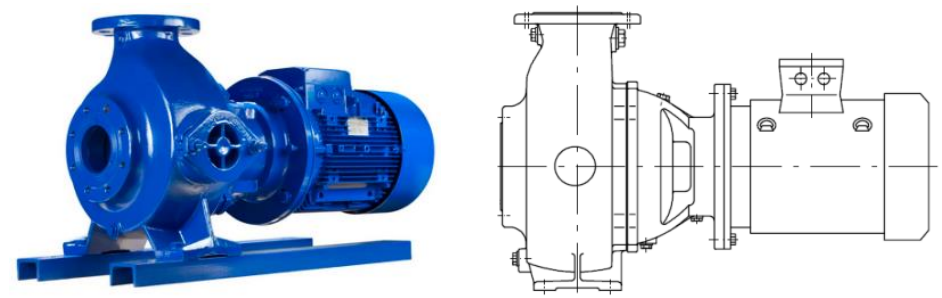

Figura 131: Bomba utilizada en la etapa de cavitación y ozonización. 


\subsubsection{Sistema de cavitación en la planta piloto}

Como se ha comentado en el apartado anterior, el sistema de cavitación utilizado en la planta piloto STO3RE, es el mismo que el que se ha utilizado para la realización de los ensayos experimentales con dos principales diferencias (Figura 132):

1. Se ha cambiado la posición de la válvula de 3 vías (4) para producir un baipás en uno de los depósitos pequeños de 15 litros (5) y hacer pasar los lodos a través del depósito grande de 600 litros (7) y por uno de los pequeños de 15 litros (6). Durante el funcionamiento del sistema de cavitación en las pruebas industriales, se utiliza la válvula de pura (8) del depósito pequeño habilitado (6), para realizar la extracción de las muestras que son posteriormente analizadas.

2. Se ha desinstalado el intercambiador de calor. Tal y como se puede observar en el esquema del sistema de cavitación ( Figura 132) se ha prescindido del sistema de intercambio de calor (3) utilizado en el montaje para los experimentos a escala de laboratorio (Figura 113). La eliminación del intercambiador de calor se debe principalmente a 2 motivos. El primero es que los ensayos a escala de laboratorio han determinado que trabajar a temperaturas elevadas resulta más beneficioso que hacerlo a temperaturas bajas (en cuanto a valores de DD obtenidos). El segundo es que tal y como se expondrá en los apartados posteriores, la temperatura alcanzada tras el ensayo experimental, se encuentra alrededor de $\operatorname{los} 55-60^{\circ} \mathrm{C}$ que es la temperatura ideal para alimentar al digestor termófilo.

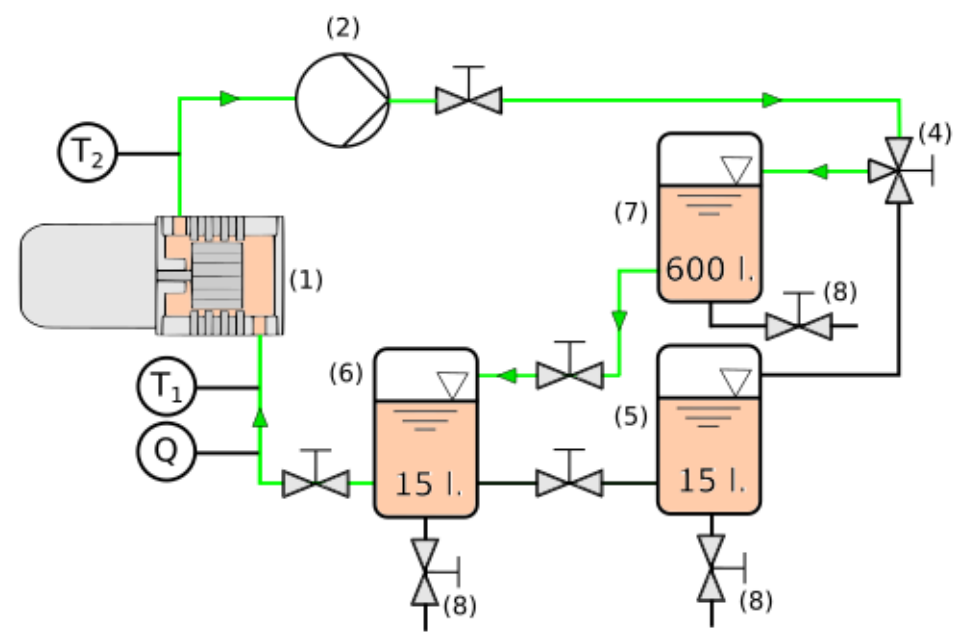

Figura 132: Esquema del sistema de cavitación en la planta STO3RE para la realización de los experimentos a escala industrial. 
En la planta STO3RE, el tratamiento de hidrocavitación se realiza por lotes (batches). Así pues, al igual que en los ensayos de laboratorio, habrá una fase de llenado y, tras la aplicación del tratamiento de cavitación, una fase de vaciado.

\section{Fase de llenado}

Al inicio de la planta piloto (Figura 124), se encuentra un tanque de homogenización donde los lodos de la EDAR y los purines de cerdo se encuentran en una agitación continua para evitar su sedimentación. Cuando se desea comenzar el tratamiento de cavitación, se activa el grupo de bombas de tornillo, las cuales se encargan de succionar el lodo desde el depósito de homogenización hasta el depósito de 600 litros perteneciente al sistema de cavitación. Una vez lleno, las bombas paran y la válvula situada aguas arriba del depósito 600 litros, se cierra. De esta manera el circuito del sistema de cavitación queda aislado y se activa la bomba encargada de hacer circular el lodo a través del cavitador por el circuito cerrado.

\section{Fase de vaciado}

Una vez finalizado el tratamiento, la bomba del sistema de cavitación para y se abre la válvula inferior del depósito de 600 litros. Las bombas de tornillo se activan para vaciar el depósito e introducir el lodo cavitado en el digestor termófilo. Una vez vaciado el sistema de cavitación, se cierra la válvula inferior del depósito, se activan las bombas de tornillo que succionan lodo fresco desde el depósito de homogenización, y la válvula situada aguas arriba del depósito de 600 litros del sistema de cavitación se abre para permitir su llenado y realizar el tratamiento al siguiente lote.

\subsubsection{Características del fango utilizado}

Tal y como se explica en el capítulo 1, la planta piloto STO3RE, además de por los lodos de la propia EDAR donde se encuentra la planta (Totana), es abastecida por lodos procedentes de otras 5 EDAR (Aledo, Alhama, Librilla, Mazarrón y Puerto Lumbreras) y por 5 granjas ganaderas diferentes (dos ubicadas en Totana y 3 en Librilla). El purín de cerdo es transportado con un camión cisterna que recoge el purín de las balsas de almacenamiento y luego lo descarga en la EDAR de Totana en unos depósitos GRG o directamente en el tanque de homogenización. Los tanques GRG permiten agregar la cantidad de purín necesario para generar la mezcla de purín y lodos en el tanque de homogenización previamente definida (mezcla $50 \%$ lodo de EDAR, $50 \%$ purín). 


\section{Propiedades}

Mezcla de lodo de EDAR y purín de cerdo de las granjas locales

\begin{tabular}{rcc}
\hline DQO Total & $(\mathrm{mg} / \mathrm{l})$ & $51655 \pm 13037$ \\
DQO soluble & $(\mathrm{mg} / \mathrm{l})$ & $6320 \pm 1950$ \\
$\mathrm{pH}$ & $(-)$ & $7,2 \pm 0,3$ \\
Conductividad a $25^{\circ} \mathrm{C}$ & $(\mu \mathrm{S} / \mathrm{cm})$ & $10959 \pm 2214$ \\
Ácidos Volátiles & $(\mathrm{mg} / \mathrm{l})$ & $3262 \pm 1053$ \\
Alcalinidad Total & $(\mathrm{mg} / \mathrm{l})$ & $4880 \pm 1074$ \\
Nitrógeno & $(\mathrm{mg} / \mathrm{l})$ & $7,4 \pm 0,9$ \\
Nitrógeno Amoniacal & $(\mathrm{mg} / \mathrm{l})$ & $2,7 \pm 0,8$ \\
Fósforo Total & $(\mathrm{mg} / \mathrm{l})$ & $1,5 \pm 0,2$ \\
Sólidos Totales & $(\mathrm{mg} / \mathrm{l})$ & $54737 \pm 10202$ \\
Sólidos Volátiles & $(\mathrm{mg} / \mathrm{l})$ & $35899 \pm 2739$ \\
Humedad & $(\%)$ & $94,5 \pm 1,0$ \\
\hline
\end{tabular}

Tabla 12: Características del licor mezcla utilizado para los ensayos a escala industrial.

En la tabla anterior se puede observar cómo la cantidad de DQO soluble y total está uno y dos órdenes de magnitud por encima respectivamente si se comparan con el licor mezcla utilizado en los ensayos de laboratorio (Tabla 8). Asimismo, los sólidos totales han pasado de valores del $0.5 \%$ aproximadamente, hasta valores del $5.4 \%$ con casos que han llegado a alcanzar incluso el $10.2 \%$.

\begin{tabular}{cc|cc}
\hline EDAR & $\begin{array}{c}\text { Volumen } \\
\text { Litros/semana }\end{array}$ & Granja & $\begin{array}{c}\text { Volumen } \\
\text { Litros/semana }\end{array}$ \\
\hline Aledo & 369 & Granja n ${ }^{\circ}$ 1 (Totana) & 553 \\
Alhama & 479 & Granja n ${ }^{\circ}$ (Totana) & 425 \\
Librilla & 91 & Granja n ${ }^{\circ}$ (Librilla) & 1036 \\
Mazarrón & 675 & Granja n ${ }^{\circ}$ (Librilla) & 1225 \\
Puerto Lumbreras & 338 & Granja nº (Librilla) & 744 \\
Totana & 1064 & & \\
\hline
\end{tabular}

Tabla 13: Cantidad de lodos y purines consumidos por semana en la planta STO3RE.

Estas características del lodo se obtenían gracias a las mezclas realizadas de los purines y fangos de EDAR de diferentes procedencias. En la Tabla $\mathbf{1 3}$ se muestra de forma aproximativa los volúmenes de lodos y purines consumidos cada semana 
en la planta piloto. Se puede observar como el total de volumen tratado en una semana es de 7000 litros. Esto es así puesto que se fijó un objetivo de tratar 1000 litros de lodos al día.

La mayor cantidad de los lodos ha sido suministrada por un lado por la propia EDAR de Totana, y por otro, por dos granjas situadas en la localidad de Librilla (Granja $\left.\mathrm{n}^{\circ} 3 \mathrm{y} \mathrm{n}^{\circ} 4\right)$ tal y como se indica en la imagen siguiente:

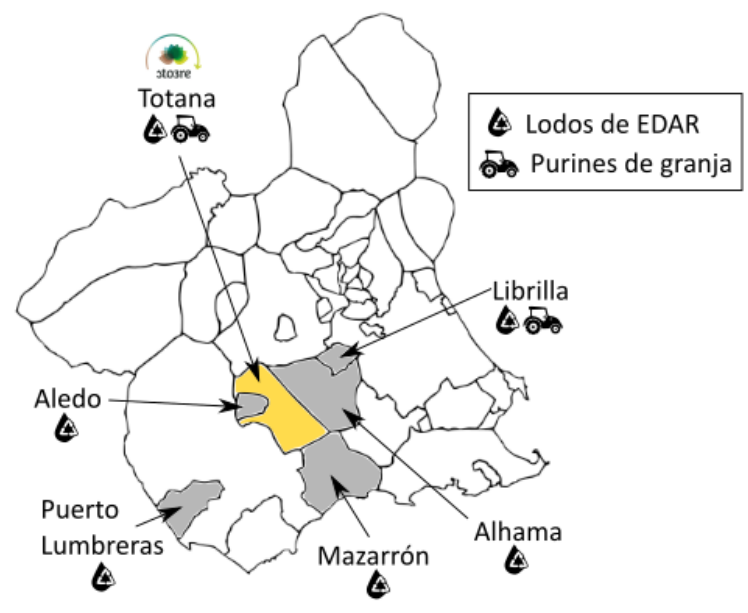

Figura 133: Procedencia de los lodos de EDAR y de los purines de cerdo de las diferentes granjas.

\subsubsection{Análisis de resultados}

Al igual que sucedía con los ensayos a escala de laboratorio del capítulo anterior, el principal parámetro analizado ha sido el grado de degradación del lodo (DD). Esto facilita la comparación con los ensayos realizados en el anterior capítulo para determinar cómo afecta el efecto escala al sistema de cavitación. El DD se ha determinado de la misma manera que en los experimentos precedentes, es decir, utilizando la Ec. 83 que cuantifica la cantidad de DQO total que es hidrolizada y convertida a DQO soluble.

Otro importante parámetro estudiado en estos ensayos ha sido la producción de ácidos grasos volátiles (AGVs) que son ácidos grasos con menos de seis átomos de carbono. Los AGVs son elementos importantes para controlar el proceso de digestión anaerobia, ya que permiten la generación de sustancias como el ácido acético, que son posteriormente utilizadas por las bacterias metanogénicas para producir biogás. Diferentes estudios llevados a cabo con procesos de cavitación ultrasónica (N. Liu et al., 2018) (Quarmby, Scott, Mason, Davies, \& Parsons, 1999) 
muestran un aumento en la cantidad de $\mathrm{AGVs}$, sobre todo del ácido acético, se traduce en una mayor cantidad de biogás generado.

En los procesos de digestión anaerobia convencionales es importante mantener un correcto equilibrio entre la cantidad de AGVs generados y los consumidos por las bacterias metanogénicas. Si este equilibrio no es adecuado, las bacterias metanogénicas no son capaces de eliminar los AGVs lo suficientemente rápido, por tanto, se acumulan y producen la acidificación del medio lo que produce una inhibición de las fases de hidrólisis y acetogénesis (Appels et al., 2008). En este caso, dado que la digestión se lleva a cabo en doble fase, las etapas de hidrólisis y acetogénesis se llevan a cabo en un digestor (termófilo) y las etapas de acidogénesis y metanogénesis en otro digestor diferente (mesófilo). De esta forma, se puede trabajar de forma más eficiente, ya que se puede mantener un mejor equilibrio entre los AGVs producidos y consumidos, y al estar las etapas separadas, la acumulación de los AGVs no supone un problema.

Los AGVs se han analizado mediante cromatografía de gases y concretamente se han mesurado el ácido acético, propiónico, isobutírico, butírico, isovalérico, $\mathrm{N}$-valeriánico, isocaproico, caproico y N-heptanoico. De esta manera, se ha podido determinar su producción en $\mathrm{mg} / \mathrm{l}$ antes y después del proceso de cavitación.

Por otro lado, se han analizado el efecto de la cavitación sobre ciertos patógenos. Concretamente, se ha estudiado la presencia y eliminación de Escherichia coli, Salmonella sp y Clostridium perfringens. En los casos de la Escherichia coli y de la Clostridium perfringens se han determinado las unidades formadoras de colonias por gramo de muestra UFC/g, mientras que en el caso de la Salmonella sp, únicamente se ha determinado su ausencia o presencia.

Finalmente, para estos ensayos a escala industrial se ha analizado la energía específica (EE) empleada durante el tratamiento de cavitación utilizando la Ec. 81. Esta ecuación, permite comparar los resultados que diferentes tratamientos de cavitación tienen sobre un mismo contaminante, en este caso sobre los lodos. Para poder realizar una comparativa más efectiva, el valor de la EE se ha acompañado del DD, para determinar de algún modo la eficiencia de cada tratamiento. Es necesario resaltar que para el cálculo de la EE se ha considerado únicamente el volumen y la energía empleados únicamente en el proceso de cavitación y no en la planta piloto STO3RE completa. Es decir, se ha considerado la energía absorbida por la bomba de recirculación del sistema de cavitación y por el propio cavitador y, por ende, únicamente se han analizado los efectos que la cavitación produce sobre el lodo tratado, sin considerar ningún otro tratamiento (ozonización o digestión en doble fase). 


\subsubsection{Ensayos realizados}

Los ensayos industriales se llevaron a cabo bajo las condiciones operacionales óptimas, determinadas en los ensayos a escala de laboratorio desarrollados en el capítulo anterior. Atendiendo a estos últimos ensayos, la configuración que ha proporcionado unos mejores resultados en términos de DD alcanzados ha sido:

- Velocidad de rotación del rotor de $5600 \mathrm{rpm}$.

- Caudal de recirculación de la bomba de 100 l/min.

- Duración del ensayo de 30 minutos.

- Volumen del ensayo de 40 litros.

- 75 pasadas a través del dispositivo de cavitación.

- Funcionamiento sin utilizar sistema de refrigeración $\left(\mathrm{T}>35^{\circ} \mathrm{C}\right)$.

Estas condiciones se han tenido que adaptar para un funcionamiento a escala industrial donde se ha pasado de trabajar con 40 litros de licor mezcla a 500600 litros de lodo. Este aumento en el volumen de trabajo no ha afectado de ningún modo a la velocidad de rotación utilizada, la cual ha continuado siendo de $5600 \mathrm{rpm}$.

Por otro lado, los ensayos de laboratorio han confirmado que aumentar el caudal de recirculación de la bomba por encima de los $100 \mathrm{l} / \mathrm{min}$ tiene efectos negativos sobre el DD y, por tanto, el valor de este caudal también se ha mantenido igual para los ensayos a escala industrial. Bajo estas condiciones de volumen (500 litros) y caudal de recirculación $(100 \mathrm{l} / \mathrm{min})$, es necesario determinar el tiempo del tratamiento para conseguir el mismo número de pasadas a través del cavitador que se estaban realizando en los ensayos de laboratorio, que con un caudal de $100 \mathrm{l} / \mathrm{min}$, un volumen de 40 litros y una duración del tratamiento de 30 minutos, han supuesto 75 pasadas.

Para la escala industrial con el volumen y el caudal de recirculación anteriormente estipulados, es necesario extender la duración del tratamiento a 6 horas y 15 minutos (375 minutos) para conseguir realizar las 75 pasadas a través del dispositivo de cavitación. Sin embargo, esta duración del tratamiento resultaba excesiva dado que se deseaba que el sistema de cavitación únicamente estuviese en funcionamiento durante 8 horas diarias. Esto significaba tener que realizar dos tratamientos de 500 litros cada 4 horas para alcanzar el objetivo de tratar 1000 litros diarios. Disminuir el tiempo del proceso a 4 horas, significa disminuir también el número de pasadas a través del cavitador a aproximadamente 48.

En cuanto a la temperatura de realización de los ensayos, no se ha utilizado ningún sistema de cavitación ya que como bien se observó durante los ensayos a nivel de laboratorio, mantener la temperatura por encima de $\operatorname{los} 35^{\circ} \mathrm{C}$ producía un 
efecto positivo en el DD alcanzado. En este caso, debido al gran volumen tratado, el aumento de la temperatura es mucho menos acusado que en el caso de los ensayos de laboratorio. Sin embargo, debido a que la duración de los ensayos industriales es mucho más extensa, los valores de temperatura alcanzados al finalizar el tratamiento son muy similares a los alcanzados en los ensayos de laboratorio.

Considerado las anteriores premisas, los ensayos a escala industrial se realizaron bajo las siguientes condiciones:

- Velocidad de rotación del rotor de $5600 \mathrm{rpm}$.

- Caudal de recirculación de la bomba de 100 1/min.

- Duración del ensayo de 240 minutos.

- Volumen del ensayo de 500 litros.

- 48 pasadas a través del dispositivo de cavitación.

- Funcionamiento sin utilizar sistema de refrigeración $\left(\mathrm{T}>35^{\circ} \mathrm{C}\right)$.

Como única excepción se realizó un ensayo más largo, de 420 minutos, con un volumen de 500 litros para poder obtener el mismo número de pasadas a través del dispositivo de cavitación que el conseguido en los ensayos de laboratorio y así alcanzar las mismas temperaturas en el lodo tratado. Por tanto, se pueden distinguir dos tipos de ensayos que se detallan a continuación.

\subsubsection{Ensayo largo}

Como se ha comentado anteriormente, en el funcionamiento normal de la planta piloto se deseaba que el tratamiento de cavitación funcionase durante tan solo 8 horas al día, lo que limitaba el tratamiento a dos lotes de 500 litros durante 4 horas cada uno. Sin embargo, se realizó un ensayo a plena capacidad del depósito (500 litros) en el que se realizó el tratamiento durante 420 minutos para conseguir hasta 84 pasadas a través del dispositivo del cavitador. A excepción de estos dos parámetros (tiempo y volumen) el resto de los parámetros de funcionamiento son los mismos que se han descrito en el apartado anterior.

A lo largo del ensayo se analizaron las variables de temperatura, DQO soluble, humedad, sólidos totales, sólidos volátiles, Escherichia coli, Salmonella sp y Clostridium perfringens. Los valores iniciales del lodo utilizado para este ensayo se muestran en la Tabla 12.

El objetivo de este ensayo ha sido el de monitorizar detalladamente las variables anteriormente mencionadas a lo largo del tiempo y realizar una comparación con los resultados obtenidos en los ensayos de laboratorio. Además, debido al tiempo de cavitación (420 minutos) y el volumen tratado (500 litros) no solo se está operando bajo las condiciones óptimas de funcionamiento (según los resultados de laboratorio) sino que se está empleando la capacidad total del sistema. 


\subsubsection{Ensayos cortos}

Los ensayos cortos se han realizado una vez a la semana durante 4 meses, dando como resultado un total de 12 ensayos. En estos ensayos se han monitorizado una mayor cantidad de variables, pero únicamente al inicio y al final del tratamiento. Las variables analizadas han sido los AGVs, conductividad, alcalinidad, nitrógeno, nitrógeno amoniacal, fósforo total, sólidos totales, sólidos volátiles DQO soluble, DQO total, Escherichia coli, Salmonella sp y Clostridium perfringens. Los valores iniciales del lodo utilizado para estos ensayos se muestran en la Tabla 12.

El principal objetivo de estos ensayos es el de determinar la repetitividad y efectividad del tratamiento bajo las condiciones reales de operación. Al prolongar los ensayos durante 4 meses, se pueden analizar los efectos que se producen con la variabilidad de los diferentes parámetros del fango y determinar qué parámetros tienen una mayor influencia en la eficiencia del proceso.

\subsection{Resultados y discusión}

En este apartado se van a presentar los resultados obtenidos por los ensayos cortos y por el ensayo largo. La explicación de cada uno de estos se ha realizado de forma separada, ya que la finalidad y, por tanto, las conclusiones que se derivan de cada uno son diferentes.

\subsubsection{Resultados del ensayo de larga duración}

La realización de este ensayo largo ha permitido obtener resultados que no habrían podido ser observados si se hubieran realizado experimentos de únicamente 240 minutos. Debe recordarse que, dadas las condiciones de recirculación de $100 \mathrm{l} / \mathrm{min}$ y un volumen de ensayo de 500 litros, es necesario extender el tratamiento hasta los 375 minutos (6 horas y 15 minutos) para obtener 75 pasadas a través del dispositivo cavitador (número de pasadas realizado en los ensayos en laboratorio). Dado que en estos ensayos se ha prolongado la duración hasta los 420 minutos ( 7 horas), se han podido realizar hasta 84 pasadas a través del dispositivo y observar lo que ocurre más allá del período de tratamiento estipulado. A continuación, se describen de forma detallada los resultados observados en los diferentes parámetros de control.

\subsubsection{Evolución de la temperatura}

Tal y como puede observarse en la Figura 134, la temperatura del lodo evoluciona desde los $21^{\circ} \mathrm{C}$ en el momento de inicio del ensayo, hasta los $71,2^{\circ} \mathrm{C}$ tras finalizar el ensayo transcurridos 420 minutos. De la evolución obtenida pueden extraerse algunas conclusiones interesantes. En primer lugar, se puede observar como el incremento de la temperatura no es constante como ocurría durante los ensayos de laboratorio (ver Figura 121), sino que inicialmente presenta una 
evolución más rápida y posteriormente existe un descenso para continuar ascendiendo hasta el final del experimento. La explicación a esta variación en la tendencia se debe a la falta de homogenización dentro del depósito grande de 600 litros. Durante el experimento, se observó como efectivamente la temperatura del lodo aumentaba de manera muy rápida por lo que, transcurridos aproximadamente 60 minutos de experimento, se procedió a la agitación manual del depósito. Tras esta acción, se consiguió mejorar la homogeneidad en el interior del depósito y la evolución de la temperatura se mantuvo constante durante prácticamente la totalidad del ensayo.

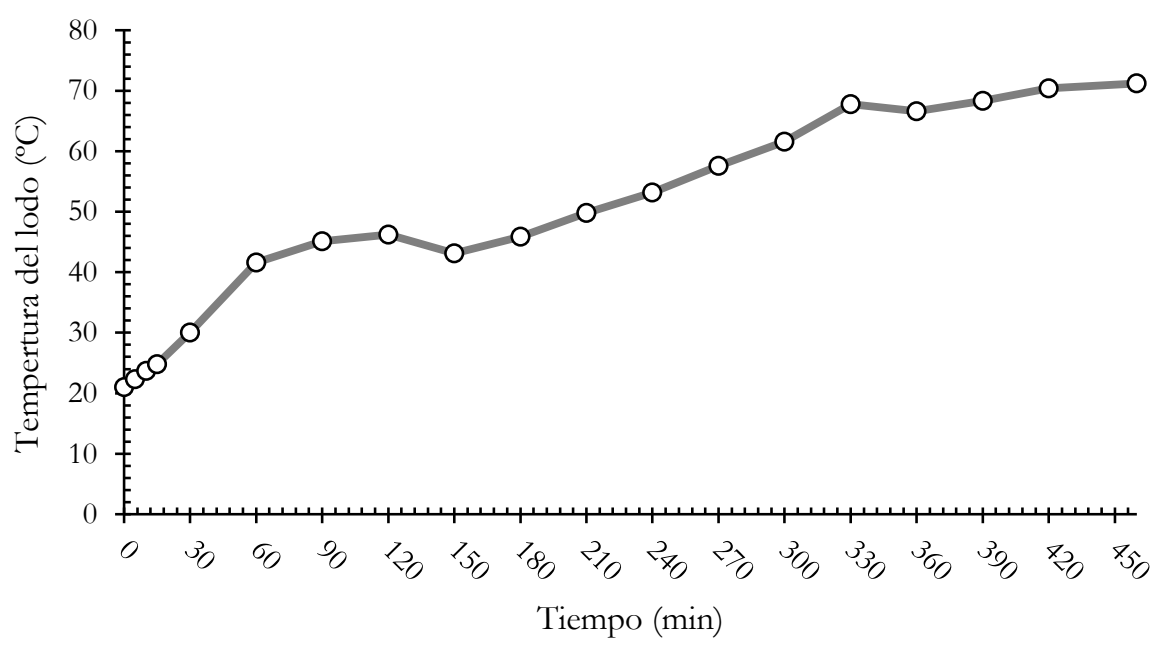

Figura 134: Evolución de la temperatura durante el ensayo de larga duración.

Este efecto no fue observado durante los ensayos en laboratorio debido a que el pequeño tamaño de los depósitos y su disposición garantizaban una homogenización prácticamente perfecta. Sin embargo, tras la monitorización de la temperatura, se ha puesto de manifiesto la importancia de mantener una buena agitación en el interior del depósito de 600 litros para conseguir una buena mezcla, que no solo garantice una temperatura homogénea en el fluido, sino que permita que todo el lodo pueda ser tratado bajo las mismas condiciones (número de pasadas a través del cavitador).

En segundo lugar, tal y como varios investigadores han observado en sus ensayos (Wang \& Zhang, 2009) (Martin Petkovšek et al., 2013) y como se observó en los ensayos de laboratorio de este dispositivo de cavitación en concreto, el rango óptimo de temperatura que maximiza la cantidad de DQO soluble obtenida se encuentra entre los 40 y los $60^{\circ} \mathrm{C}$. Esto significa que, en caso de no precalentar el lodo, es necesario un tiempo de 60 minutos para alcanzar los $40^{\circ} \mathrm{C}$ y entrar así 
dentro del rango óptimo de degradación. Transcurridos los 300 minutos de tratamiento se alcanzan $61,6^{\circ} \mathrm{C}$, temperatura a partir de la cual la capacidad de degradación se ve mermada (Dular et al., 2016) (Wang \& Zhang, 2009) (Zupanc et al., 2014). En cualquier caso, y tal y como se explicará en apartados posteriores, el tratamiento por encima de $\operatorname{los} 60^{\circ} \mathrm{C}$ presenta beneficios que pueden resultar interesantes aun cuando se produce una disminución en el valor del DD obtenido.

Por tanto, se podrían considerar dos fases diferenciadas en este ensayo de cavitación de larga duración:

- Desde el inicio hasta los 300 minutos el tratamiento permitiría incrementar el DD para conseguir transformar la mayor cantidad de DQO en soluble.

- Desde los 300 minutos hasta el final del tratamiento, se superan los $60^{\circ} \mathrm{C}$ con lo que el efecto de degradación de la cavitación podría comenzar a verse mermado pero las temperaturas permiten eliminar ciertos patógenos presentes en el lodo.

\subsubsection{Evolución de la DQOS}

Al igual que con la temperatura, la DQOS se ha controlado durante todo el proceso obteniendo y analizando muestras cada 20 minutos de tratamiento. En la Figura 135

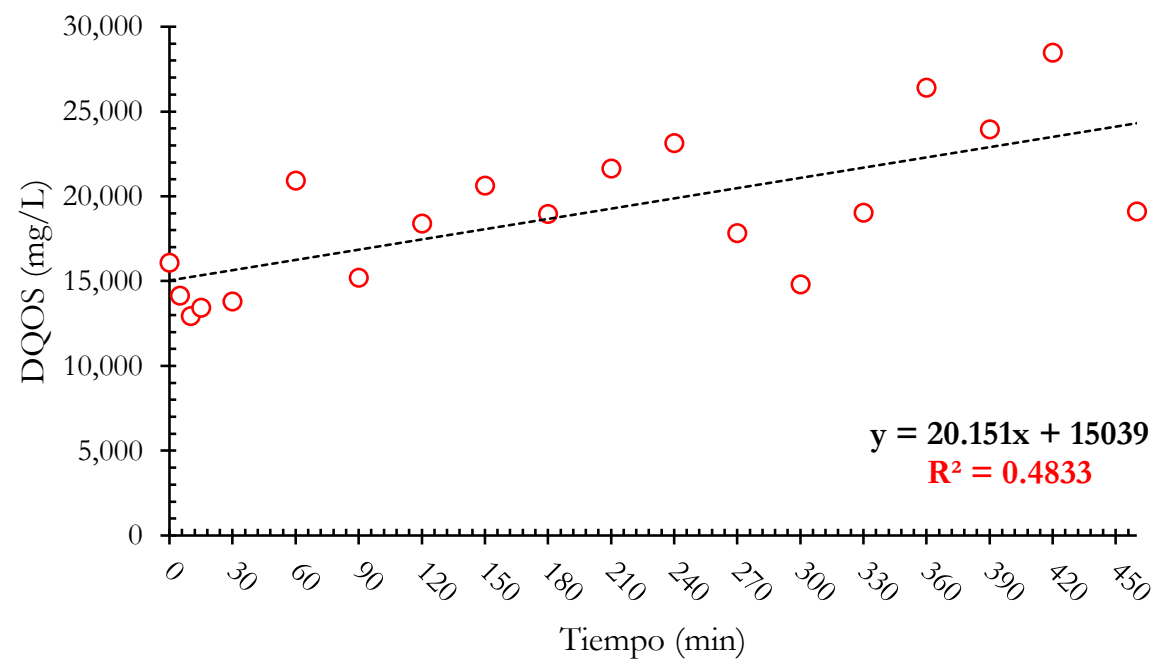

Figura 135: Evolución de la DQOS durante el ensayo de larga duración.

Tal y como puede observarse, la DQOS muestra una evolución ascendente a lo largo del tiempo. Al realizar y analizar el modelo de regresión entre ambas 
variables, se obtiene un coeficiente de regresión de 0,483 que, aunque no presenta una relación muy fuerte, se puede afirmar que es correcta ya que el valor de $p$ (p-value) obtenido ha sido de 0,00095 y es inferior al valor de significación de 0.01. Por tanto, puede afirmarse que existe una correlación creciente entre la DQOS y del tiempo de cavitación aplicado. Dado que el lodo tratado durante todo el ensayo ha sido el mismo (ya que el tratamiento se realiza por lotes), la variabilidad en la DQOS puede ser debida a la deficiente homogenización producida en el interior del depósito de 600 litros. Si en el interior del depósito existen caminos hidráulicos preferenciales, no todo el lodo tratado habrá sufrido el mismo número de pasadas a través del cavitador y, por ende, la cantidad de DQO transformada soluble no será la misma en todo el lodo. Una vez más, se pone de manifiesto la importancia de una buena agitación que deberá hacer replantear el diseño del depósito de 600 litros para permitir la instalación de un agitador que produzca un mezclado lento pero continuado durante el tratamiento.

En cualquier caso, atendiendo a la tendencia lineal obtenida con los resultados, tras el ensayo de larga duración se estima un aumento en la DQOS desde los $15039 \mathrm{mg} / \mathrm{l}$ hasta los $24308 \mathrm{mg} / \mathrm{l}$. Considerando que la DQO total en el inicio del ensayo fue de $66600 \mathrm{mg} / 1$ se estima que se ha obtenido un DD del $18 \%$. Este grado de desintegración obtenido se correspondería con 92 pasadas a través del dispositivo de cavitación. Para poder comparar con los ensayos de laboratorio es necesario considerar el mismo número de pasadas en ese caso, es decir, 75. Por tanto, se debe obtener el valor del DD tras 375 minutos de tratamiento en las condiciones de escala industrial. Transcurrido este tiempo, se estima un aumento de la DQOS hasta los $22595 \mathrm{mg} / \mathrm{l}$, lo que supone un DD del 14.6\%. Para este ensayo en concreto, esto supondría una diferencia de 3.4 puntos porcentuales si se compara con el ensayo de laboratorio LT7, llevado a cabo bajos las mismas condiciones de temperatura y número de pasadas a través del dispositivo de cavitación.

Así pues, aunque la reología del lodo utilizado en los ensayos de laboratorio y en la planta piloto han sido sustancialmente diferentes, los grados de desintegración obtenidos resultan muy similares, por lo que no parece apreciarse un efecto de escala significativo en cuanto a valores de DQOS obtenidos se refiere.

\subsubsection{Eliminación de patógenos}

De manera análoga al apartado anterior, se ha analizado la presencia de 3 patógenos presentes en el lodo (Escherichia coli, Salmonella sp y Clostridium perfringens), analizando muestras obtenidas cada 60 minutos a lo largo del ensayo. En los casos de la Escherichia coli y la Clostridium perfringens, se han obtenido las unidades formadoras de colonias por gramo [UFC/g] así como su base logarítmica [log (UFC/g)], mientas que para el caso de la Salmonella sp, únicamente se ha determinado su ausencia o presencia en el lodo. 
En la Tabla 14, se muestran los resultados obtenidos para cada uno de los patógenos. Tal y como puede observarse en la tabla, los únicos patógenos que consiguen ser eliminados tras el tratamiento de larga duración son la Escherichia coli y la Salmonella sp. En el caso de la Clostridium perfringens, aunque se consigue una reducción del $85 \%$ con respecto al valor de inicio en UFC/g, esto sólo significa un descenso de 0.82 unidades logarítmicas con respecto al valor inicial y deja el valor final en una cifra de 5.18 unidades logarítmicas, muy lejos de conseguir un efecto de desinfección de este patógeno.

\begin{tabular}{|c|c|c|c|c|c|c|c|c|c|}
\cline { 2 - 10 } \multicolumn{1}{c|}{} & $\begin{array}{c}\text { Tiempo } \\
(\mathrm{min})\end{array}$ & $\mathbf{0}$ & $\mathbf{6 0}$ & $\mathbf{1 2 0}$ & $\mathbf{1 8 0}$ & $\mathbf{2 4 0}$ & $\mathbf{3 0 0}$ & $\mathbf{3 6 0}$ & $\mathbf{4 2 0}$ \\
\hline \multirow{2}{*}{$\begin{array}{c}\text { Escherichia } \\
\text { coli }\end{array}$} & $\begin{array}{c}U F C / g \\
\\
(U F C / g)\end{array}$ & 27.000 & 51.000 & 220.000 & 130.000 & 460.00 & 0 & 0 & 0 \\
\hline \multirow{2}{*}{$\begin{array}{c}\text { Clostridium } \\
\text { perfrigens }\end{array}$} & \begin{tabular}{c}
$U F C / g$ \\
\cline { 2 - 10 }
\end{tabular} & 1.000 .000 & 400.000 & 450.000 & 24.00 .000 & 7.200 .000 & 240.000 & 160.000 & 150.000 \\
\hline Salmonella & 6,00 & 5,60 & 5,65 & 6,38 & 6,86 & 5,38 & 5,20 & 5,18 \\
\hline
\end{tabular}

Tabla 14: Evolución de diferentes patógenos durante el ensayo de larga duración.

Dado que todos los patógenos analizados durante los ensayos son organismos mesófilos, su temperatura de crecimiento óptima se encuentra entre los 20 y los $45^{\circ} \mathrm{C}$. En el caso de la Escherichia coli, y de la Salmonella sp, su temperatura de crecimiento óptima se encuentra sobre los $37^{\circ} \mathrm{C}$, mientras que en el caso de la Clostridium perfringens, esta temperatura está en un rango ligeramente más elevado, alcanzando valores de hasta $45^{\circ} \mathrm{C}$. Esto muestra coherencia con lo observado en la Figura 136 y la Figura 137., donde se muestran las gráficas de la evolución de población de los diferentes patógenos presentes en el lodo presentados en la Tabla 14. 


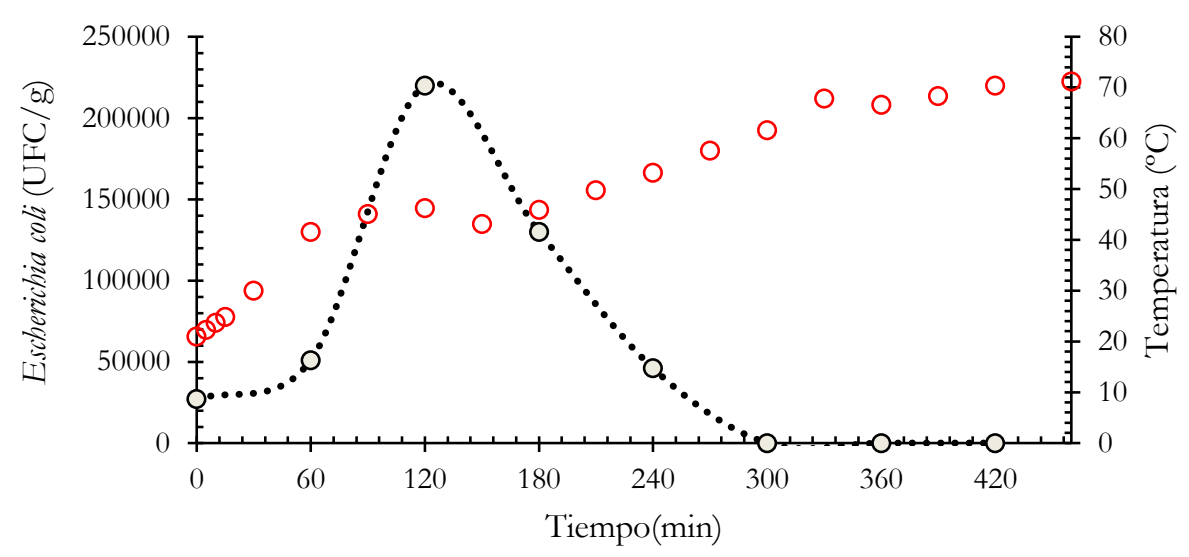

Figura 136: Evolución de la Escherichia coli y la temperatura durante el ensayo de larga duración.

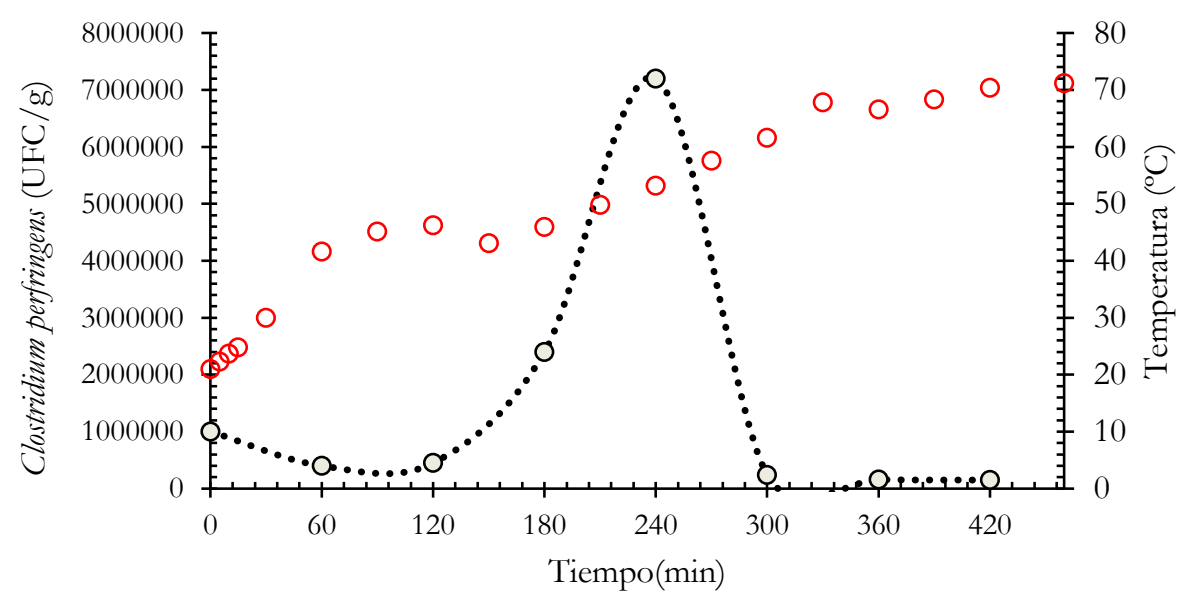

Figura 137: Evolución de la Clostridium perfringens y la temperatura durante el ensayo de larga duración.

Se puede observar como en el caso de la Escherichia coli (Figura 136), existe un crecimiento significativo transcurridos 60 minutos de experimento, momento en el que la temperatura del lodo se encuentra sobre los $41,6^{\circ} \mathrm{C}$. La Clostridium perfringens (Figura 137), experimenta este mismo crecimiento, pero transcurrido un intervalo más largo de tiempo. Es aproximadamente a los 120 minutos del tratamiento 
cuando comienza a existir un crecimiento de esta bacteria, momento en el que el lodo se encuentra a una temperatura de aproximadamente $46,2^{\circ} \mathrm{C}$.

Por otra parte, puede observarse cómo transcurridos 300 minutos de tratamiento, todas las bacterias son eliminadas totalmente (como es el caso de la Escherichia coli, y de la Salmonella sp), o como en el caso de la Clostridium perfringens, sus niveles de presencia disminuyen por debajo del valor inicial. Esto se debe a que la temperatura alcanzada a los 300 minutos es de $61,6^{\circ} \mathrm{C}$, lo que impide la proliferación de estos microorganismos. Estas mismas temperaturas de desinfección se han visto en el caso de la Escherichia coli, y de la Salmonella sp tras realizar tratamientos térmicos en lodos de cerdos (Turner, 2002) y desechos de aves de corral (Biswas, Nazmi, Pitesky, Gallardo, \& Pandey, 2018). Aunque la bacteria Clostridium perfringens también puede inactivarse alcanzados los $60^{\circ} \mathrm{C}$, como en este caso, también existen casos reportados donde la temperatura de inactivación alcanza un valor de $100^{\circ} \mathrm{C}$ (Byrne, Dunne, \& Bolton, 2006) (Silva, 2015).

Atendiendo a los resultados obtenidos, podrían barajarse dos posibles hipótesis para su explicación:

- La primera es que la degradación y eliminación de los patógenos se realiza única y exclusivamente por la vía térmica, siendo ineficaz el tratamiento de la cavitación para este fin.

- La segunda, es que sí que existe degradación debido al efecto de la cavitación, pero debido a las condiciones favorables para la proliferación de estos microorganismos, se produce un crecimiento de estos. Por tanto, la reducción final de cada patógeno es resultado del balance entre su tasa de degradación y su tasa de crecimiento.

Existe una evidencia que da mayor validez a esta segunda hipótesis. Analizando la evolución en la eliminación de la bacteria Clostridium perfringens (Figura 137), puede observarse que, cuando la temperatura es baja y se encuentra lejos de la óptima para que se produzca el crecimiento de esta bacteria, se observa una eliminación de esta en el intervalo de tiempo que va desde los 0 a los 60 minutos, pasando de 1.000.000 UFC/g a 400.000 UFC/g, es decir, una reducción de 0,4 unidades logarítmicas. Esto no se observa en el caso de la Escherichia coli puesto que, a los pocos minutos de iniciar el tratamiento, se entra dentro de un rango de temperaturas adecuado para la proliferación de esta bacteria. Por tanto, su tasa de crecimiento comienza a ser significativa en los primeros minutos del ensayo y no se consigue degradar tan rápido como se reproduce el microorganismo. Debido a que las altas temperaturas dificultan o directamente inhiben el crecimiento de estos microorganismos, su degradación aumenta significativamente al superar $\operatorname{los} 60^{\circ} \mathrm{C}$. 


\subsubsection{Resultados de los ensayos cortos}

Tras el ensayo de larga duración, se procedió a la realización de los ensayos cortos explicados en detalle en el apartado 6.2.4.2. Estos ensayos, llevados a cabo bajo las condiciones de operación óptimas obtenidas en los ensayos de laboratorio del capítulo 5, son los que han permitido determinar el efecto del tratamiento de cavitación sobre la mezcla de lodos y purines a escala industrial y en circunstancias reales.

Se ha estudiado en detalle el efecto producido por el tratamiento de cavitación analizando los cambios en determinados parámetros del lodo, los valores del DD obtenidos y también su efecto sobre la producción de AGVs. La energía empleada en cada uno de los ensayos también ha sido analizada con tal de determinar la eficiencia del proceso y su efecto de escala. De esta forma, se ha podido realizar una comparativa con otros dispositivos de cavitación utilizados en procesos similares.

\subsubsection{Efecto de la cavitación en el lodo utilizado}

En estos ensayos cortos, se han realizado análisis del lodo antes y después de pasar por el tratamiento de cavitación, con el objetivo de determinar qué parámetros fisicoquímicos del lodo se ven afectados tras la cavitación. Estos parámetros estudiados han sido el $\mathrm{pH}$, la conductividad, alcalinidad, nitrógeno total, nitrógeno amoniacal, fósforo total, sólidos totales, sólidos volátiles, humedad, DQO, DQOS, ácidos grasos volátiles, Clostridium perfringens y Escherichia coli. Estos 3 últimos parámetros son estudiados en más detalle en apartados posteriores.

En cuanto al resto de propiedades del lodo, se realizó un estudio estadístico para determinar la existencia o no de variaciones entre las medias de las 12 muestras de cada parámetro, antes y después de realizar el proceso de cavitación. Para ello se ha realizado el Shapiro test y el test F para determinar las hipótesis de normalidad de muestras y de igualdad entre las varianzas respectivamente. Tras obtener confirmación de dichos supuestos, se ha procedido a realizar una hipótesis de contraste de diferencia de medias para muestras relacionadas y varianzas conocidas e iguales con un intervalo de confianza de $99 \%$.

Con ello, se ha confirmado que existen diferencias significativas entre las medias antes y después de la cavitación para el nitrógeno amoniacal y la DQOS. Concretamente se ha establecido un aumento de las medias de $0.475 \%$ para nitrógeno amoniacal y de $4492 \mathrm{mg} / \mathrm{l}$ para la DQOS. 


\subsubsection{Valores del grado de desintegración (DD)}

Tal y como se observa en la Figura 138, los valores del DD varían de $4.8 \%$ a $17.4 \%$, lo que indica que los resultados dependen en gran medida de la prueba y el sustrato utilizado (fango + purín de cerdo). El purín de cerdo tratado en cada prueba se obtuvo de diferentes explotaciones ganaderas, por lo que sus características son diferentes según su origen.

Los estudios e investigaciones existentes han centrado los esfuerzos en determinar cuál es el mejor dispositivo y procedimiento que permita alcanzar los mayores valores de DD y, por ende, la mayor producción de biogás en etapas posteriores. Sin embargo, la gran mayoría de estos estudios se han llevado a cabo utilizando lodos procedentes de la misma EDAR (I. Lee \& Han, 2013) (Martin Petkovšek et al., 2015) o en el mejor de los casos, de dos instalaciones diferentes (Lehne et al., 2001). Sin embargo, aunque en este caso el fango activo sí que procede siempre de la misma EDAR, los purines proceden de 5 industrias ganaderas diferentes y, por tanto, la composición, así como la mezcla en el tanque de homogenización, es variable de un ensayo a otro.

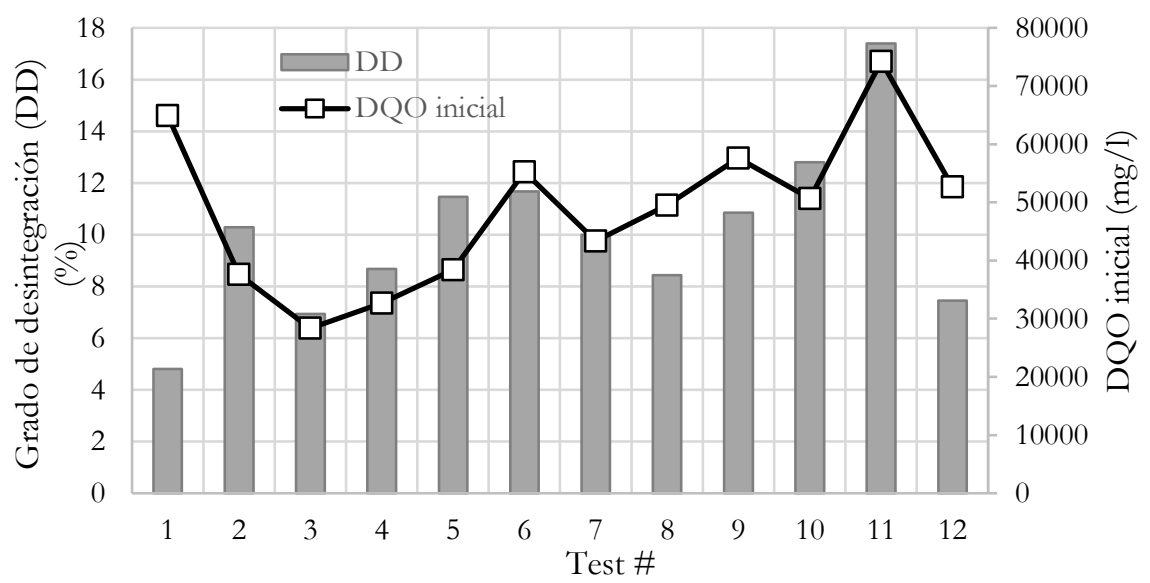

Figura 138: Grado de desintegración y valores de la DQO total inicial obtenidos en cada uno de los ensayos realizados.

Dada esta heterogeneidad en la composición del lodo tratado en los ensayos, resulta razonable pensar que la variabilidad en el DD alcanzado tras el tratamiento, (Figura 138) pueda ser consecuencia directa de la cantidad y/o condiciones de mezcla de las diferentes sustancias y parámetros que componen el lodo. Sin embargo, la bibliografía existente relativa a cómo la tipología del lodo puede afectar al DD alcanzado por un mismo sistema de cavitación, es muy escasa. Por ello, resulta interesante determinar si efectivamente existe un parámetro o 
parámetros de los analizados en el lodo que produzca alguna influencia en el DD conseguido en los ensayos.

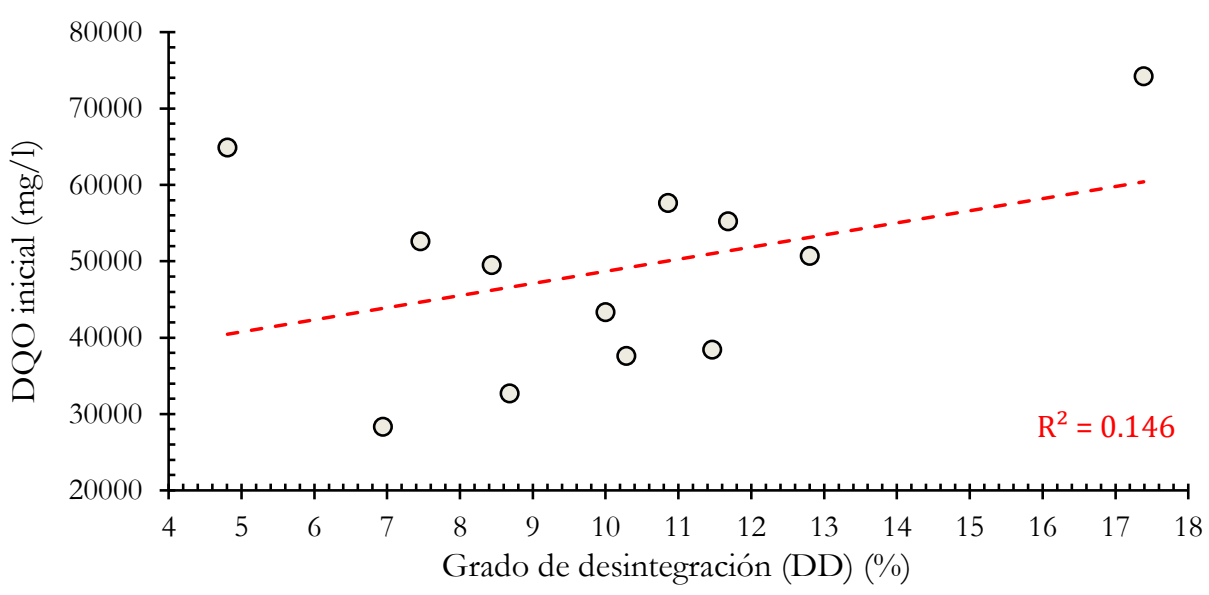

Figura 139: Relación entre la DQO inicial y el grado de desintegración (DD) alcanzado.

Uno de los parámetros que presenta una mayor variabilidad en el lodo de entrada es la DQO total inicial. Al analizar la relación de este parámetro con el DD obtenido, se puede observar la existencia de una correlación muy débil entre ambas variables (Figura 139). Sin embargo, aunque existe una ligera tendencia a obtenerse mayores grados de desintegración cuando la cantidad de DQO inicial disponible es mayor, el valor de $p$ obtenido para la correlación ha sido de 0.2203. Por tanto, asumiendo un nivel de significación de 0.01 , no puede asumirse que el nivel de correlación sea estadísticamente significativo.

Sí parece existir una relación más fuerte entre la cantidad o porcentaje de sólidos totales presentes en la muestra inicial y su concentración de DQO. En este caso se ha obtenido un coeficiente de regresión entre ambas variables de 0.6225 , lo cual es una relación moderada que, además, puede afirmarse que es correcta, ya que el valor de $p$ obtenido ha sido de 0,0023 y es inferior al valor de significación considerado de 0,01 (Figura 140). Obviamente, disponer de una mayor cantidad de sólidos en un mismo volumen de fluido aumenta la DQO, ya que se incrementa la cantidad de sustancias susceptibles de ser oxidadas. Sin embargo, cuanto mayor es el porcentaje de sólidos totales en el lodo, mayor es la cantidad de proteínas y polisacáridos, que son los que confieren las propiedades al fluido, y por tanto incrementan su viscosidad (Forster, 1982), haciendo que el efecto de cavitación resulte más dificultoso de conseguir (Nouri, Mackenzie, Gaskell, \& Dhunput, 2012). 


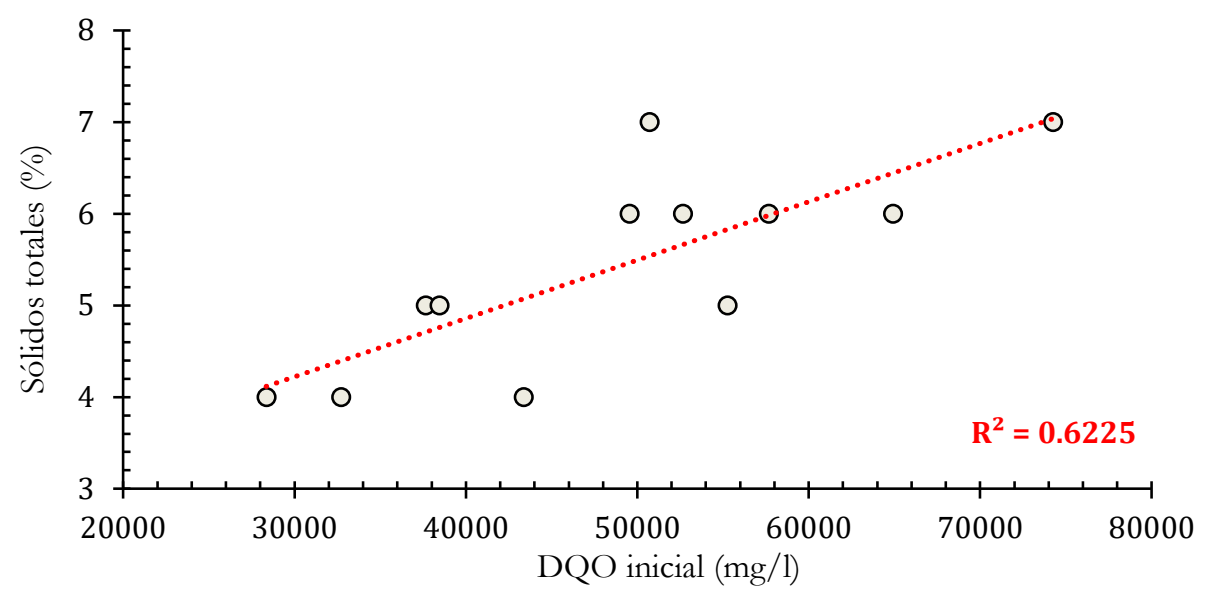

Figura 140: Relación entre los sólidos totales y la DQO inicial.

Por tanto, en caso de existir una relación creciente entre la DQO inicial presente en el lodo y el DD obtenido, este último parámetro podría verse reducido como consecuencia de una mayor dificultad para producir la cavitación debido al aumento de la viscosidad del fluido. Sin embargo, al analizar la correlación existente entre la DQO inicial y el grado de desintegración, o incluso entre la diferencia entre la DQO inicial y la DQOS inicial (DQO inicial - DQOS inicial) y el grado de desintegración, en ambos casos se obtiene una correlación ascendente muy débil. Además, no puede afirmarse que esta es correcta, ya que los valores de $p$ obtenidos han sido de 0.2192 y 0.2203 respectivamente y ambos son inferiores al valor de significación considerado de 0.01 .

\subsubsection{Eliminación de patógenos según concentración inicial}

Se ha analizado el efecto de cómo concentraciones iniciales de ciertas sustancias afectan al tratamiento. Por ejemplo, Michał Gagol (Gagol et al., 2018) hizo una comparación entre diferentes autores que estudiaron cómo la concentración inicial de contaminante podría afectar a su eliminación. Concluyeron que la mejor eficiencia en la degradación de contaminantes al realizar un tratamiento con cavitación hidrodinámica se logra a sus bajas concentraciones iniciales, ya que, si las concentraciones son elevadas, los $\mathrm{OH}$ generados en la cavitación no son suficientes para degradar toda la cantidad de patógenos presentes. Sin embargo, este efecto no se ha evidenciado en los actuales ensayos realizados donde ni la concentración inicial de Clostridium Perfingens ni la de Escherichia Coli, han mostrado ningún tipo de correlación con su porcentaje de reducción obtenido tras la cavitación. 


\subsubsection{Efecto en la producción de los AGVs}

Además de la evaluación del índice de desintegración (DD), existe un gran interés en el análisis de los AGVs y el efecto de la cavitación sobre su producción.

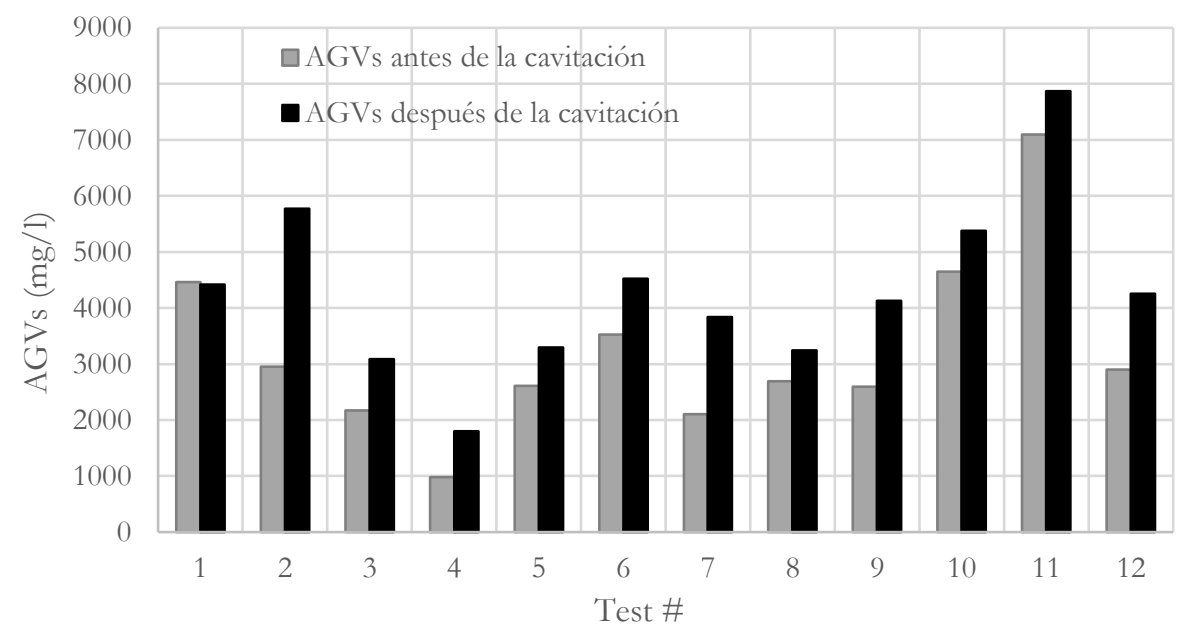

Figura 141: Evolución de los AGVs totales antes y después del proceso de cavitación.

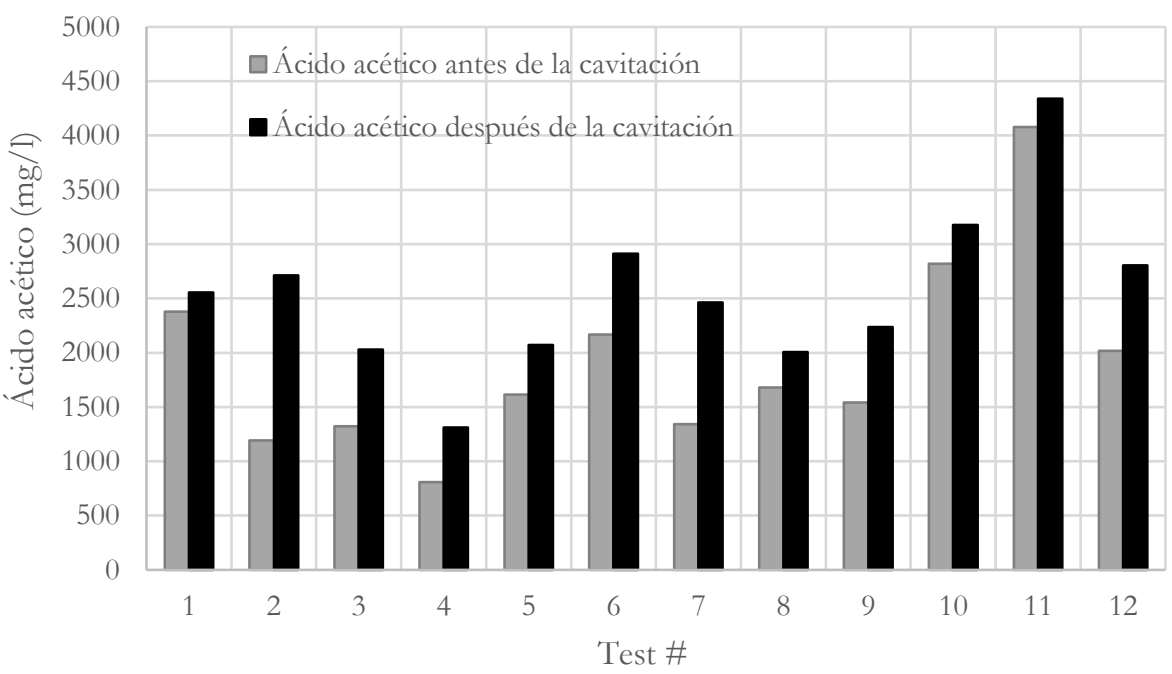

Figura 142: Evolución en la producción del ácido acético antes y después del proceso de cavitación.

Como se puede ver en la Figura 141, la cantidad total de AGVs en todas las pruebas ha aumentado después del proceso de cavitación. La única excepción se 
encontró en el ensayo 1, donde los AGV no se vieron afectados. El mejor resultado se obtuvo en el ensayo 2, donde los AGVs después de la cavitación se incrementaron a $2.816 \mathrm{mg} / \mathrm{l}$ y el promedio de todos los ensayos fue de $1.121 \mathrm{mg} / \mathrm{l}$. Liu y col. (2018) encontraron resultados similares al aumentar los AGVs de 7.87 a $22.7 \mathrm{mg} / \mathrm{l}$ cuando se usaba el pretratamiento con sonicación. Estos valores se obtuvieron después de 20-40 horas de sonicación y dieron como resultado una mejora de la tasa de producción de biogás.

\subsubsection{Efecto de escala}

Para considerar el efecto que produce realizar el escalado de proceso desde el laboratorio a la industria, se debe atender no solo al valor del DD obtenido, sino también a la cantidad de energía empleada para realizar el tratamiento. Así pues, para analizar el efecto del escalado, se han comparado los dos mejores ensayos realizados tanto a escala de laboratorio como a escala industrial y los resultados se muestran en la Tabla 15.

\begin{tabular}{|c|c|c|c|}
\hline & & Laboratorio & Industrial \\
\hline TS & $(\mathrm{mg} / \mathrm{l})$ & 7200 & 70000 \\
\hline $\mathrm{Kg}$ TS & $(\mathrm{kg})$ & 0,288 & 35 \\
\hline SCODi & $(\mathrm{mg} / \mathrm{l})$ & 63 & 3570 \\
\hline SCODf-SCODi & $(\mathrm{mg} / \mathrm{l})$ & 949 & 12290 \\
\hline DD & $(\%)$ & 26 & 17,4 \\
\hline degradación & (g) & 38 & 6145 \\
\hline Volumen & (l) & 40 & 500 \\
\hline Potencia & $(\mathrm{kW})$ & 5,7 & 6,9 \\
\hline Tiempo & (min) & 30 & 240 \\
\hline Energía & $\mathrm{kWh}$ & 2,9 & 27,7 \\
\hline Energía específica & $(\mathrm{kJ} / \mathrm{kg} \cdot \mathrm{TS})$ & 35750 & 2853 \\
\hline $\begin{array}{l}\text { Energía específica para la } \\
\text { solubilización del fango }\end{array}$ & $\begin{array}{c}(\mathrm{kJ} / \mathrm{g} \\
\mathrm{SCODi})\end{array}$ & 271 & 16 \\
\hline
\end{tabular}

Tabla 15: Comparación entre los mejores resultados obtenidos en los ensayos a escala de laboratorio y a escala industrial.

El ensayo a escala de laboratorio se corresponde al LT3, en el cual se consiguió obtener un grado de desintegración (DD) del $26 \%$. Por otra parte, en el ensayo a escala industrial que mejores resultados proporcionó se obtuvo un DD de $17.4 \%$. Atendiendo únicamente a este parámetro, parece evidente que al realizar el 
escalado a nivel industrial, se produce una disminución en la eficacia del proceso del $36.1 \%$ ya que el grado de desintegración es el que se encuentra directamente asociado con la cantidad de metano que se producirá posteriormente en la etapa de digestión.

Sin embargo, cabe recordar que debido a la dificultad de tratar los lodos en el laboratorio se utilizaron muestras con poca concentración. Por tanto, en estos ensayos la concentración no supera el $1 \%$, mientras que en los ensayos a escala industrial la mezcla de lodos presenta concentraciones en un rango del 4 al $7 \%$ de sólidos. Este aumento en los sólidos totales presentes en las muestras puede reducir la intensidad de la cavitación (Nouri et al., 2012) y, por ende, el valor de la DD obtenido, con lo que realizar una comparación directa de estos dos parámetros no sería lo más adecuado en este caso en particular.

Si en lugar del valor del DD se analiza la masa total de SCOD solubilizada en cada una de las escalas, puede verse que a nivel industrial se consigue degradar 6145 gramos frente a los 38 gramos obtenidos en el ensayo LT3. Una vez más, estos valores no son directamente comparables, ya que la cantidad de DQO inicial disponible para ser degradada en los ensayos a nivel industrial es muy superior a la disponible en los ensayos de laboratorio.

Sin embargo, existe un parámetro importante que sí puede ser comparado de forma directa en ambas escalas: la energía específica para solubilizar el fango. Este parámetro proporciona la cantidad de energía necesaria $(\mathrm{kJ})$ para solubilizar un gramo de DQO. Al comparar este parámetro se observa cómo la energía que se debe aportar en el caso de la escala industrial es de $16 \mathrm{~kJ} / \mathrm{g}$ SCOD, mientras que en el ensayo de laboratorio el valor se incrementa hasta los $271 \mathrm{~kJ} / \mathrm{g}$. Esta gran diferencia en la energía específica se debe a que la potencia empleada únicamente aumenta desde los 5.7 en la escala laboratorio a los $6.9 \mathrm{~kW}$ para la escala industrial, lo que, multiplicado por el tiempo de tratamiento en cada caso, da como resultado unas energías de 2.9 y $27.7 \mathrm{kWh}$ respectivamente, es decir, casi 10 veces más de energía en la escala industrial. No obstante, a escala industrial se degrada 160 veces más cantidad de SCOD (6145 gramos frente a 38 gramos a escala laboratorio) lo que hace que el proceso industrial, aun con valores de DD menores que en escala laboratorio, sea mucho más eficiente energéticamente.

\subsubsection{Análisis energético}

Durante los experimentos llevados a cabo, tanto en escala de laboratorio como en escala industrial, se ha podido registrar la tensión e intensidad eléctrica del motor que acciona el cavitador, así como de la bomba que impulsa el lodo a través del circuito. Con esta información, se han podido determinar las potencias consumidas durante la ejecución de los diferentes ensayos a escala de laboratorio e industrial. 
Dado que los ensayos a escala de laboratorio se llevaron a cabo bajo diferentes condiciones de temperatura y de caudal de recirculación, ha sido posible analizar cómo estas variables afectan a la energía consumida. En los gráficos de la Figura 143 y de la Figura 144, se ha representado la potencia absorbida por el motor eléctrico del cavitador y de la bomba respectivamente, en cada uno de los experimentos de laboratorio anteriormente descritos en la Tabla 9. En los gráficos pueden observarse los siguientes fenómenos:

- aumentar el caudal de recirculación aumenta significativamente la potencia absorbida por el motor eléctrico de la bomba;

- las potencias absorbidas por los motores eléctricos de la bomba y del cavitador son menores cuando no se utiliza sistema de refrigeración y la temperatura del lodo es elevada;

- La potencia empleada en el cavitador disminuye ligeramente cuando el caudal de recirculación de la bomba aumenta.

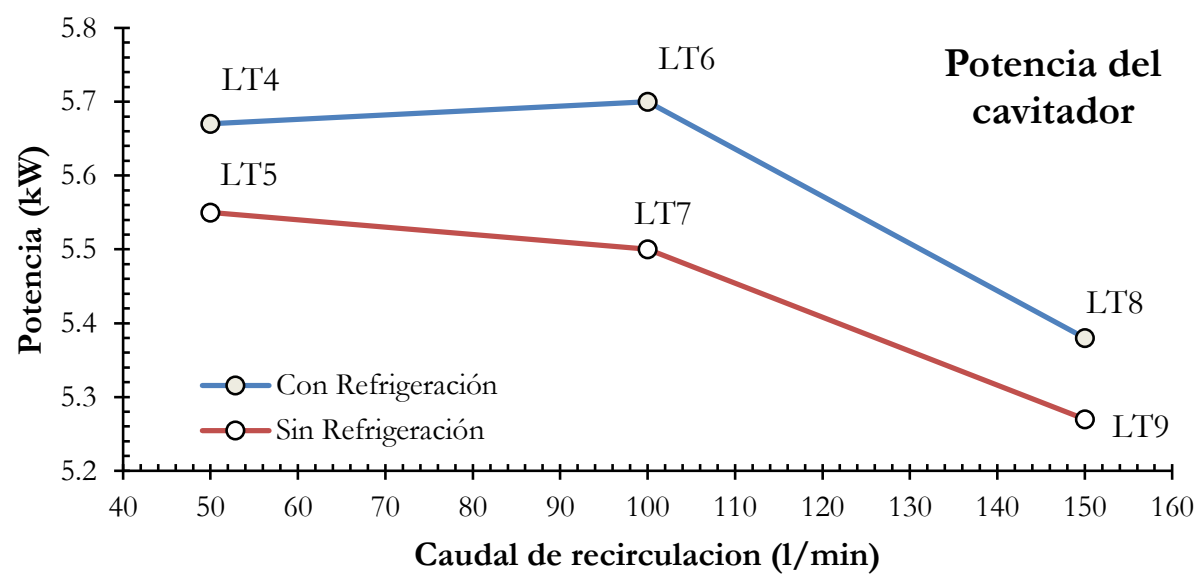

Figura 143: Potencias absorbidas por el cavitador en los diferentes ensayos a escala de laboratorio.

La explicación del aumento de la potencia con el aumento del caudal de recirculación es probablemente la más sencilla y evidente. Para cualquier bomba hidráulica, a mayor caudal de funcionamiento mayor es la potencia necesaria y menor la altura disponible en forma de presión. Por tanto, el aumento de potencia absorbida observado en la Figura 144 responde a este hecho. 


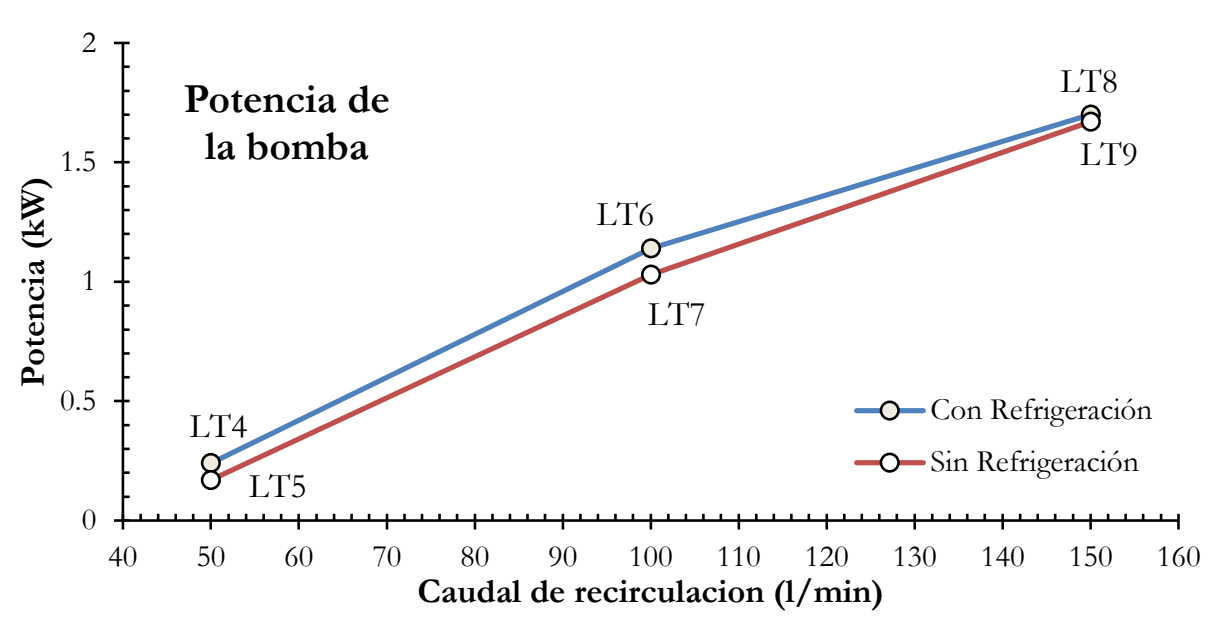

Figura 144: Potencias absorbidas por la bomba en los diferentes ensayos a escala de laboratorio.

Por otro lado, se ha podido observar cómo en ambos casos (cavitador y bomba) la potencia requerida por los respectivos motores es menor cuando se trabaja a temperaturas elevadas, es decir, sin utilizar dispositivo de refrigeración. La explicación a este efecto tiene su origen en la propia naturaleza del fluido ensayado. Los lodos, el licor mezcla y, en definitiva, cualquier mezcla de agua con cierto porcentaje de material sólido, se consideran como una sustancia o fluido no Newtoniano, ya que la tensión cortante no se encuentra relacionada de forma lineal con el gradiente de velocidades aplicado sobre el fluido (Dentel, 1997). Estudios reológicos llevados a cabo por diferentes autores (Tixier, Guibaud, \& Baudu, 2003) (Baroutian, Eshtiaghi, \& Gapes, 2013a), concluyen que el esfuerzo cortante disminuye con el incremento de la temperatura. Cuando los lodos se calientan, las fuerzas de cohesión entre las moléculas se reducen debido al movimiento térmico, lo que se traduce en una eventual disminución del esfuerzo cortante y, por ende, de la viscosidad del fluido. Tal y como se ha comentado anteriormente, las proteínas y los polisacáridos presentes en el lodo son los mayores responsables del comportamiento reológico del fluido (Forster, 1982). Por tanto, dado que la presencia de estos componentes es más elevada al aumentar el contenido en sólidos en el lodo, se produce un aumento del esfuerzo cortante y también de la viscosidad.

El tercer y último fenómeno observado durante el estudio energético tiene su raíz en el efecto de cavitación. En la Figura 143, se puede ver como la potencia eléctrica absorbida por el cavitador, disminuye ligeramente al aumentar el caudal de recirculación. Como se ha visto, al aumentar el caudal de recirculación de 50 a $150 \mathrm{l} / \mathrm{min}$, se produce un incremento en la potencia consumida por la bomba de entre 1.46 y $1.5 \mathrm{~kW}$ para los casos con refrigeración y sin refrigeración 
respectivamente. Sin embargo, para estos mismos casos se produce una disminución en la potencia consumida por el cavitador de entre 0.29 y $0.28 \mathrm{~kW}$. En este último caso, la disminución de la potencia representa un pequeño porcentaje del consumo total del cavitador (entre un 3-4\%). Es sabido, que cuando los dispositivos hidráulicos como las bombas entran en una zona de cavitación, se produce una caída en la altura proporcionada y, por tanto, en la potencia consumida (Binama, Muhirwa, \& Bisengimana, 2016). Sin embargo, la velocidad de rotación del cavitador es la misma en todos los ensayos (5600 rpm) y, en consecuencia, a priori no debería producirse una disminución en la potencia por una mayor presencia del fenómeno de la cavitación. Ahora bien, un aumento en el caudal que pasa a través del cavitador se traduce en una mayor caída de presión entre la entrada y salida del mismo. Esta mayor caída de presión favorece y facilita el efecto de la cavitación, lo que aumenta la cantidad de gas presente en la cámara del cavitador y produce una disminución en la potencia eléctrica absorbida.

Con el fin de determinar la eficiencia energética del tratamiento, no solo entre la escala de laboratorio y la industrial, sino también entre sistemas diferentes utilizando el mismo sistema de cavitación, en la Tabla 16, se muestra una comparativa con los valores de la energía específica $(\mathrm{kJ} / \mathrm{kg} \cdot \mathrm{TS})$ obtenida en múltiples tratamientos en los que se han empleado diversas técnicas. En las condiciones de funcionamiento óptimas establecidas en los ensayos a escala de laboratorio, se ha estipulado que la mejor degradación del lodo se obtiene utilizando un caudal de recirculación de $100 \mathrm{l} / \mathrm{min}$ sin utilizar ningún tipo de sistema de refrigeración para permitir el aumento de la temperatura del lodo. En estas condiciones, la potencia media absorbida por la bomba se estima en $1.03 \mathrm{~kW}$ y para el motor eléctrico que impulsa el cavitador en $5.5 \mathrm{~kW}$, lo cual supone un total de $6.63 \mathrm{~kW}$ para todo el sistema. Sin embargo, el mejor resultado obtenido durante toda la investigación (grado de desintegración del $26 \%$ ) se obtuvo previamente, cuando se estaba utilizando una bomba de menor caudal en la que se recirculaban únicamente $30 \mathrm{l} / \mathrm{min}$ y, por tanto, la potencia empleada en el bombeo fue mucho menor, disminuyendo la potencia total empleada por el sistema a $5.73 \mathrm{~kW}$. Han sido, por tanto, esta última potencia y el grado de desintegración los empleados para realizar la comparativa en la Tabla 16.

En cuanto a la energía absorbida por el sistema de cavitación y la bomba durante los 12 ensayos a escala industrial, se ha podido observar un aumento en la potencia total absorbida por el sistema, estimándose en $6.93 \mathrm{~kW}$. Este valor es superior al obtenido en los ensayos de laboratorio (LT7) bajo las mismas condiciones de temperatura y caudal de recirculación. Sin embargo, en este último caso la potencia obtenida (suma de la empleada en el cavitador más la de la bomba) es ligeramente inferior y con un valor de $6.52 \mathrm{~kW}$. Este aumento en la potencia se debe a que en los ensayos a escala industrial se utilizó un lodo con una mayor cantidad de sólidos y por tanto, la viscosidad del fluido se vio aumentada 
(Baroutian, Eshtiaghi, \& Gapes, 2013b), incrementando a su vez la potencia necesaria para realizar el tratamiento.

Atendiendo a los resultados de la Tabla 16, dónde se comparan los valores de energía específica $(\mathrm{kJ} / \mathrm{kg} \cdot \mathrm{TS})$ obtenidos por diferentes ensayos en esta y otras investigaciones realizadas, puede concluirse que el proceso se vuelve más eficiente cuando se realiza a una escala industrial o semi-industrial. Para el caso de esta investigación en concreto, la energía específica pasa de $35750 \mathrm{~kJ} / \mathrm{kg} \cdot \mathrm{TS}$ en el mejor de los ensayos realizados en laboratorio a $2853 \mathrm{~kJ} / \mathrm{kg} \cdot \mathrm{TS}$ para el mejor de los ensayos realizados a escala de laboratorio, lo que significa un aumento en este parámetro del $92 \%$. Analizando todos los casos de la Tabla 16, puede observarse como la mejora en la energía aplicada por cada kilo de sólidos totales es mayor en aquellos casos en los que, o bien se tratan volúmenes de lodo elevados (Martin Petkovšek et al., 2015) o bien las concentraciones de fango son elevadas (Kavitha et al., 2015) (Kuglarz et al., 2013b); y empeora drásticamente para pequeños volúmenes y bajas concentraciones de sólidos (I. Lee \& Han, 2013) (Şahinkaya \& Sevimli, 2013). Sin embargo, debido a las grandes diferencias existentes entre los estudios de los diferentes autores (en cuanto a sólidos totales y volúmenes de tratamiento utilizados), es complicado obtener una idea de la eficiencia obtenida utilizando únicamente el valor de la energía específica en términos de $\mathrm{kJ} / \mathrm{kg} \cdot \mathrm{TS}$. Se vuelve así necesario emplear energía específica para la solubilización del fango (EE $E_{D Q O S}$, que proporcione la cantidad de energía empleada en obtener cada gramo de SCOD (kJ/g SCOD liberada). Dado que la cantidad de SCOD liberada durante los ensayos está directamente relacionada con la cantidad de biogás generado en los procesos posteriores, este parámetro es más adecuado a la hora de relacionar la energía empleada en el tratamiento con la eficiencia conseguida en el proceso de desintegración del lodo.

Así pues, en la Tabla 17, se muestra la energía específica para la solubilización del fango (EE $E_{D Q O S}$ ) en kJ/g SCOD, para los mismos autores y ensayos presentados en la Tabla 16. Se puede observar como para ensayos a escala de laboratorio, los procesos más eficientes resultan ser las microondas de 700 y $900 \mathrm{w}$ de potencia utilizadas por Kuglarz et al. (Kuglarz et al., 2013), las cuales presentan valores de 39 y $35 \mathrm{~kJ} / \mathrm{g}$ SCOD respectivamente. Puede observarse cómo independientemente del tipo de técnica utilizada para producir la degradación, cuando se utilizan volúmenes pequeños (0.05 litros) la EE DQOs aumenta significativamente, lo cual indica que el proceso necesita más energía para transformar la DQO a soluble. Sin embargo, aquellos casos que utilizan volúmenes grandes (40, 196 o 500 litros) obtienen valores de EE presentados en las tablas, corresponde a uno de los ensayos a escala industrial llevados a cabo en la presente tesis, en el cual se registró un valor de $16 \mathrm{~kJ} / \mathrm{g}$ SCOD, menor incluso que el obtenido por M. Petkovšek (Martin Petkovšek et al., 2015) en los ensayos realizados con 196 litros. 


\begin{tabular}{|c|c|c|c|c|c|c|}
\hline Estudio & Técnica & $\begin{array}{c}T S \\
(m g / l)\end{array}$ & $\begin{array}{c}\text { Volumen } \\
\text { tratado (litros) }\end{array}$ & $\begin{array}{c}\text { Potencia de } \\
\text { entrada } \\
(k W)\end{array}$ & Tiempo (min) & $\begin{array}{c}\text { Energía } \\
\text { específica } \\
(\mathrm{kJ} / \mathrm{kg} \cdot \mathrm{TS})\end{array}$ \\
\hline \multirow{3}{*}{ Presente } & $\begin{array}{l}\text { Escala lab. } \\
\text { (mejor caso) }\end{array}$ & 7200 & 40 & 5.73 & 30 & 35750 \\
\hline & $\begin{array}{l}\text { Escala ind. } \\
\text { (promedio) }\end{array}$ & 55000 & 500 & 6.93 & 240 & 3631 \\
\hline & $\begin{array}{l}\text { Escala ind. } \\
\text { (mejor caso) }\end{array}$ & 70000 & 500 & 6.93 & 240 & 2853 \\
\hline $\begin{array}{c}\text { (Martin } \\
\text { Petkovšek et al., } \\
\text { 2015) }\end{array}$ & $\begin{array}{l}\text { Discos } \\
\text { rotativos }\end{array}$ & 10000 & 196 & 5.8 & 55 & 9765 \\
\hline \multirow{3}{*}{$\begin{array}{c}\text { (I. Lee \& Han, } \\
\text { 2013) }\end{array}$} & $\begin{array}{l}\text { Plato con } \\
\text { orificios }\end{array}$ & 9850 & 1,5 & 1.5 & 20 & 121827 \\
\hline & $\mathrm{UC}(20 \mathrm{kHz})$ & 9850 & 0.05 & 0.75 & 20 & 1827411 \\
\hline & Térmico & 9850 & 0.05 & 3 & 20 & 7309645 \\
\hline $\begin{array}{c}\text { S. Kavitha } \\
\text { (Kavitha et al., } \\
\text { 2015) }\end{array}$ & $\begin{array}{l}\text { Rotor } \\
\text { Estator }\end{array}$ & 15000 & 0.5 & $*$ & $*$ & 7377 \\
\hline (Feng et al., 2009) & $\mathrm{UC}(20 \mathrm{kHz})$ & 14337 & 0.5 & 0,75 & 3 & 18000 \\
\hline $\begin{array}{l}\text { (Park, Ahn, Kim, } \\
\text { \& Hwang, 2004) }\end{array}$ & Microondas & 30070 & 0.5 & 0.7 & 15 & 24600 \\
\hline \multirow{3}{*}{$\begin{array}{c}\text { (Kuglarz et al., } \\
2013 \mathrm{~b})\end{array}$} & $\begin{array}{c}\text { Térmico } \\
\left(900 \mathrm{w}, 90^{\circ} \mathrm{C}\right)\end{array}$ & 52700 & 1 & 0.9 & 135.5 & 8129 \\
\hline & $\begin{array}{c}\text { Microondas } \\
(700 \mathrm{w})\end{array}$ & 52700 & 1 & 0.7 & 91.4 & 5486 \\
\hline & $\begin{array}{l}\text { Microondas. } \\
(900 \mathrm{w})\end{array}$ & 52700 & 1 & 0.9 & 80.6 & 4833 \\
\hline $\begin{array}{r}\text { (Şahinkaya \& } \\
\text { Sevimli, 2013) } \\
\end{array}$ & $\mathrm{UC}(20 \mathrm{kHz})$ & 3935 & 0.1 & 0.15 & 10 & 228717 \\
\hline
\end{tabular}

Tabla 16: Comparación de la energía específica $(\mathrm{kJ} / \mathrm{kg} \cdot \mathrm{TS})$ utilizando diferentes técnicas de cavitación. 


\begin{tabular}{|c|c|c|c|c|c|c|}
\hline Estudio & Técnica & $\begin{array}{c}\text { SCOD } \\
\text { obtenido (mg) }\end{array}$ & $\begin{array}{l}D D \\
(\%)\end{array}$ & $\begin{array}{c}\text { Potencia de } \\
\text { entrada } \\
(\mathrm{kW})\end{array}$ & Tiempo (min) & $\begin{array}{c}E E_{D Q O S} \\
(\mathrm{~kJ} / \mathrm{g} S C O D i)\end{array}$ \\
\hline \multirow{3}{*}{ Presente } & $\begin{array}{l}\text { Escala lab. } \\
\text { (mejor caso) }\end{array}$ & 37960 & 26 & 5.73 & 30 & 271 \\
\hline & $\begin{array}{l}\text { Escala ind. } \\
\text { (promedio) }\end{array}$ & 1750000 & 10,1 & 6.93 & 240 & 57 \\
\hline & $\begin{array}{l}\text { Escala ind. } \\
\text { (mejor caso) }\end{array}$ & 6145000 & 17,4 & 6.93 & 240 & 16 \\
\hline $\begin{array}{c}\text { (Martin } \\
\text { Petkovšek et al., } \\
\text { 2015) }\end{array}$ & $\begin{array}{l}\text { Discos } \\
\text { rotativos }\end{array}$ & 109172 & * & 5.8 & 55 & 175 \\
\hline \multirow{3}{*}{$\begin{array}{l}\text { (I. Lee \& Han, } \\
\text { 2013) }\end{array}$} & $\begin{array}{l}\text { Plato con } \\
\text { orificios }\end{array}$ & 3577,5 & 20,3 & 1.5 & 20 & 503 \\
\hline & $\mathrm{UC}(20 \mathrm{kHz})$ & 102,4 & 23,7 & 0.75 & 20 & 8789 \\
\hline & Térmico & 102,4 & 20 & 3 & 20 & 35156 \\
\hline $\begin{array}{c}\text { S. Kavitha } \\
\text { (Kavitha et al., } \\
\text { 2015) }\end{array}$ & $\begin{array}{l}\text { Rotor } \\
\text { Estator }\end{array}$ & 2470 & 38 & * & * & $*$ \\
\hline (Feng et al., 2009) & $\mathrm{UC}(20 \mathrm{kHz})$ & 590 & 22 & 0.75 & 3 & 229 \\
\hline $\begin{array}{c}\text { Park et al (Park et } \\
\text { al., 2004) }\end{array}$ & Microondas & $*$ & 22 & 0.7 & 15 & $*$ \\
\hline \multirow{3}{*}{$\begin{array}{c}\text { (Kuglarz et al., } \\
\text { 2013b) }\end{array}$} & $\begin{array}{c}\text { Térmico } \\
\left(900 \mathrm{w}, 90^{\circ} \mathrm{C}\right)\end{array}$ & 3453 & 15 & 0.9 & 135.5 & 124 \\
\hline & $\begin{array}{l}\text { Microondas } \\
\quad(700 \mathrm{w})\end{array}$ & 7453 & 32 & 0.7 & 91.4 & 39 \\
\hline & $\begin{array}{l}\text { Microondas } \\
(900 \mathrm{w})\end{array}$ & 7353 & 33 & 0.9 & 80.6 & 35 \\
\hline $\begin{array}{l}\text { (Şahinkaya \& } \\
\text { Sevimli, 2013) }\end{array}$ & $\mathrm{UC}(20 \mathrm{kHz})$ & 61,4 & 15,2 & 0.15 & 10 & 1466 \\
\hline
\end{tabular}

Tabla 17: Comparación de la energía específica (kJ/g SCOD) utilizando diferentes técnicas de cavitación. 


\subsubsection{Conclusiones}

Durante el desarrollo de estos capítulos, se ha analizado el comportamiento del dispositivo real mediante ensayos en laboratorio y en la planta piloto. El principal objetivo ha sido analizar el efecto del sistema de cavitación sobre el incremento de la cantidad de DQO soluble, ya que este parámetro es el que permite cuantificar de manera indirecta la cantidad de biogás que se producirá en el posterior proceso de digestión anaerobia. El estudio se ha centrado en obtener las condiciones de operación óptimas en los ensayos en laboratorio para, posteriormente, aplicarlas en la planta piloto manteniendo los resultados obtenidos en laboratorio. Las principales conclusiones obtenidas se describen a continuación:

- Las condiciones de operación óptimas para este sistema de cavitación se corresponden a una velocidad de rotación de $5600 \mathrm{rpm}$ y un flujo de recirculación de $100 \mathrm{l} / \mathrm{min}$. Utilizar un flujo de recirculación mayor o menor que este valor o velocidades de rotación menores a $5600 \mathrm{rpm}$ conlleva un decremento en la cantidad de DQO soluble obtenida tras el tratamiento.

- El mayor grado de desintegración ha sido obtenido operando a temperaturas de entre 60 y $70^{\circ} \mathrm{C}$. El fango alcanza dichas temperaturas transcurridos 240 minutos en el caso de la planta piloto y 30 minutos en los ensayos de laboratorio sin la necesidad de utilizar ningún sistema de enfriamiento adicional. Por otro lado, el fango a esta temperatura puede ser directamente inyectado en el proceso de digestión anaerobia, con lo que toda la energía térmica generada durante el proceso de cavitación puede ser aprovechada.

- Cuando el proceso de cavitación se escala desde nivel de laboratorio a nivel industrial (en la planta piloto) la eficiencia del proceso (en términos de $\mathrm{kJ} / \mathrm{kg}$ TS) se incrementa en un $92 \%$ mientras que los valores del grado de desintegración obtenidos disminuyen un $36 \%$. A pesar de esta disminución en la desintegración, el valor obtenido se continúa considerando aceptable y por tanto se puede concluir que este sistema de cavitación puede resultar adecuado para uso industrial.

- Las comparaciones entre otros dispositivos de cavitación y técnicas de pretratamiento de fango muestran que la eficiencia del proceso incrementa con el volumen y cantidad de sólidos totales. A pesar de que otras alternativas a la hidrocavitación como la cavitación ultrasónica o tratamientos con microondas proporcionan mejores valores de desintegración del fango, resultan inviables para ser utilizados a escala industrial. 
- Tras el proceso de cavitación se ha registrado un incremento en la producción de ácidos grasos volátiles, lo que, según la literatura registrada por diversos autores, puede significar un posterior incremento en la cantidad de biogás obtenido.

- Algunos aspectos, como la variabilidad en los valores del grado de desintegración o la mejora obtenida en términos de cantidad de biogás real producido, son todavía desconocidos y deberán abordarse más profundamente en futuros estudios. 
Capitulo 7. Conclusiones 


\section{Capítulo 7}

\section{Conclusiones}

En este capítulo se resumen las principales conclusiones alcanzadas en cada uno de los capítulos estudiados a lo largo de desarrollo de la presente tesis doctoral. Se pretende de esta forma resumir de forma concisa pero rigurosa, las reflexiones más importantes derivadas de la ejecución de la investigación llevada a cabo.

\subsection{En relación con el diseño}

Durante el desarrollo del capítulo 3, se ha llevado a cabo un extenso estudio del estado del arte a través del cual se han explorado múltiples dispositivos de hidrocavitación ya existentes, así como su posibilidad de escalado y de ser utilizados para el tratamiento de cosustratos y fangos con alto contenido en sólidos.

Tras analizar numerosos dispositivos de hidrocavitación cuyos rendimientos a escala de laboratorio han dado buenos resultados (como por ejemplo cavitación ultrasónica o microondas) se ha podido observar que, aunque su capacidad de degradación es muy buena, la potencia requerida por unidad de volumen tratado los convierte en tecnologías inviables actualmente para ser empleados a escala industrial.

Por otro lado, dada la alta concentración de los fangos a tratar, no todos los dispositivos pueden garantizar el correcto funcionamiento durante su tratamiento. En este sentido, se ha podido concluir que dispositivos como el Venturi, los platos con orificios o los tambores rotativos con orificios, no pueden ser utilizados para el tratamiento de fluidos con alto contenido de sólidos ya que las pequeñas cavidades quedan quedarían obstruidas inutilizando dichos dispositivos. 
En consecuencia, con todo lo comentado anteriormente, se ha podido concluir que en la actualidad no existe ningún dispositivo de hidrocavitación que permita obtener buenos resultados a gran escala. Por tanto, se ha cumplido el objetivo de realizar un diseño robusto que permita no solo el tratamiento de volúmenes considerables de fango, sino también la utilización de ratios de potencia/tiempo asumible, y se ha conseguido dar respuesta a una necesidad que actualmente no se encuentra suplida por ningún otro sistema.

Finalmente, es importante destacar que, conscientes de que este primer modelo de cavitador desarrollado es muy susceptible a ser mejorado, el diseño se ha elaborado de manera que su modificación y mejora puedan realizarse de manera rápida, simple, y a bajo costo gracias al sistema de discos intercambiables. De esta forma, este dispositivo podrá ser utilizado como base para futuras investigaciones encaminadas a maximizar la eficacia y eficiencia del proceso utilizando este sistema.

\subsection{En relación con el modelo computacional}

Hasta la fecha existen numerosos estudios donde se presenta y estudia el fenómeno de la cavitación. En la mayoría de ellos, se busca la forma de minimizar o erradicar por completo su aparición, como es el caso de las bombas o sistemas de propulsión (hélices de barco). Sin embargo, en esta investigación el análisis y comprensión del fenómeno tienen como finalidad conseguir maximizarlo y producirlo en la cantidad y calidad deseada.

Es importante mencionar que el objetivo de la tesis, en cuanto al desarrollo del modelo CFD, no ha sido el de desarrollar un modelo matemático de gran precisión, sino un modelo que permita predecir cuándo y dónde se produce la cavitación y que estas predicciones, siendo coherentes con las observaciones experimentales, puedan aplicarse como ayuda en el proceso de diseño del sistema.

En este sentido, tras estudiar múltiples modelos de cavitación disponibles se ha se ha establecido el modelo Schnerr-Sauer como el más adecuado para ser calibrado e implementado en las simulaciones llevadas a cabo para el proceso de diseño del cavitador propuesto. Las simulaciones CFD con dicho modelo de cavitación incorporado han permitido llevar a cabo con éxito las pertinentes labores de diseño y desarrollo del prototipo, pudiéndose estudiar y cuantificar el efecto producido por las diferentes variables del diseño (distancia rotor estator, velocidades de giro y forma del diente).

Como conclusión final cabe decir que se ha alcanzado el objetivo de obtener un modelo CFD que facilitase la comprensión del fenómeno de la cavitación que ocurre en el sistema desarrollado, y que pudiera ser utilizado en el proceso de diseño para obtener una versión lo más optimizada posible del cavitador propuesto. 


\subsection{En relación con los ensayos experimentales}

Los ensayos experimentales desarrollados a escala de laboratorio han servido para validar las observaciones y conclusiones alcanzadas tras el análisis CFD, así como determinar las condiciones de funcionamiento que maximizan la eficiencia del dispositivo diseñado. Por otro lado, los ensayos a escala semi-industrial han permitido confirmar que el sistema es lo suficientemente robusto como para funcionar en condiciones reales de operación con un fango con alto contenido en sólidos. Gracias a estos ensayos se han podido comprobar los efectos reales que el dispositivo de cavitación produce sobre el fango tratado, y también establecer las condiciones bajo las cuales el sistema proporciona un mejor rendimiento en términos de degradación de DQO soluble utilizando un fango con alto contenido en sólidos.

Además, los ensayos en planta piloto han permitido obtener la información necesaria para realizar comparaciones directas con otros dispositivos de cavitación que se encuentran funcionando actualmente. De esta manera, se ha podido concluir que el dispositivo de cavitación diseñado en la actual tesis presenta unas ratios energéticas que permiten su escalabilidad, cosa que no sucede con otros dispositivos diseñados hasta el momento para el mismo fin. Si bien es imperativo analizar de forma más exhaustiva la cantidad de biogás producido tras el tratamiento de la cavitación con este sistema, los resultados obtenidos analizando la cantidad de ácidos grasos volátiles producidos, resultan prometedores para un dispositivo operando con volúmenes de fango tan elevados.

\subsection{Desarrollos e investigaciones futuras}

Tal y como se ha comentado en los anteriores apartados de conclusiones, durante el desarrollo de la presente tesis se ha conseguido dar respuesta a los dos principales objetivos de la investigación: elaborar un sistema de hidrocavitación suficientemente robusto como para poder tratar grandes volúmenes de fangos con alto contenido en sólidos, y desarrollar un modelo computacional con el que poder realizar labores de diseño y optimización de dicho sistema.

Sin embargo, la presente tesis doctoral no ha sido sino la base de partida para futuras investigaciones en las que se deberían tener en cuenta aspectos más específicos y detallados que, por razones de complejidad y extensión, no han podido abordarse durante el desarrollo de la actual investigación. En relación con estos aspectos, existen 3 puntos principales que podrían dar cabida a nuevas líneas de investigación separadas:

1. Estudio de nuevos indicadores para conocer el rendimiento del dispositivo. En el estudio actual, la eficacia del dispositivo se ha determinado en base a 2 parámetros fundamentales: la degradación de DQO total a soluble 
(grado de desintegración) y la producción de ácidos grasos volátiles. Estos dos parámetros no son sino indicadores indirectos de la producción de metano generada, lo cual es el objetivo último del sistema de hidrocavitación. Es por ello que resulta necesario relacionar de forma más directa la producción de biogás con el tratamiento mediante hidrocavitación, ya que es la única manera de obtener ratios energéticass fiables para conocer de manera exacta la viabilidad del proceso.

2. Actuaciones sobre el rotor. Aunque en esta investigación se ha hecho hincapié en el diseño de los dientes del estator, dada su facilidad para ser modificado y reemplazado en el sistema de cavitación el rotor no resulta menos especial. En este sentido, podrían realizarse estudios más detallados sobre el efecto de determinados cambios geométricos en el rotor (como por ejemplo el redondeo de las aristas del fondo de sus cavidades) que podrían generar mejoras en el funcionamiento del cavitador de igual o mayor magnitud que los producidos al realizar cambios en el estator.

3. Desarrollo del modelo CFD de cavitación. Gracias al modelo de cavitación aplicado durante las simulaciones CFD se ha podido dar respuesta a preguntas tales como cuándo y dónde se va a cavitar y en qué cantidad. Aunque este modelo ha sido suficiente para poder llevar a cabo las labores de diseño, optimización, y conocimiento del funcionamiento global del sistema, es necesario desarrollar de forma paulatina este modelo de cavitación para introducir parámetros cada vez más complejos como temperatura, intensidad de cavitación, incluso introducción de reacciones químicas. De esta manera, sería posible realizar predicciones directas de los AGVs generados o la cantidad de DQO soluble producida.

Por tanto, se espera que la tesis desarrollada pueda servir como precedente para el desarrollo de futuras tesis o líneas de investigación paralelas, y que utilizándose como punto de partida facilite el desarrollo de este tipo de dispositivos de hidrocavitación que puedan ser utilizados no solo para el tratamiento de fangos, sino también otros fines como el farmacéutico, aguas potables o procesos producción que requieran de un tratamiento específico. 


\section{Bibliografía}

Agostino, L., \& Salvetti, M. V. (2007). Fluid Dynamics of Cavitation and Cavitating Turbopumps. Italy: SpringerWienNewYork.

Angaji, M. T., \& Ghiaee, R. (2014). Ultrasonics Sonochemistry Decontamination of unsymmetrical dimethylhydrazine waste water by hydrodynamic cavitation-induced advanced Fenton process. ULTRASONICS SONOCHEMISTRY. https://doi.org/10.1016/j.ultsonch.2014.09.007

Appels, L., Baeyens, J., Degrève, J., \& Dewil, R. (2008). Principles and potential of the anaerobic digestion of waste-activated sludge. Progress in Energy and Combustion Science, $34(6)$

755-781. https://doi.org/10.1016/j.pecs.2008.06.002

Arrojo, S., \& Benito, Y. (2008). A theoretical study of hydrodynamic cavitation. Ultrasonics Sonochemistry, 15(3), 203-211. https://doi.org/10.1016/j.ultsonch.2007.03.007

Arrojo, S., Benito, Y., \& Martínez Tarifa, A. (2008). A parametrical study of disinfection with hydrodynamic cavitation. Ultrasonics Sonochemistry, 15(5), 903-908. https://doi.org/10.1016/j.ultsonch.2007.11.001

Ashrafizadeh, S. M., \& Ghassemi, H. (2015). Experimental and numerical investigation on the performance of small-sized cavitating venturis. Flow Measurement and Instrumentation, 42, 6-15. https://doi.org/10.1016/j.flowmeasinst.2014.12.007

Atiemo-obeng, V. a, \& Calabrese, R. V. (2004). HANDBOOK OF INDUSTRIAL MIXING Science and practice. New Jersey: Wiley-Interscience. https://doi.org/10.1002/0471451452

Badve, M., Gogate, P., Pandit, A., \& Csoka, L. (2013). Hydrodynamic cavitation as a novel approach for wastewater treatment in wood finishing industry. Separation and Purification Technology, 106, 15-21. https://doi.org/10.1016/j.seppur.2012.12.029

Badve, M. P., Alpar, T., Pandit, A. B., Gogate, P. R., \& Csoka, L. (2015). Modeling the shear rate and pressure drop in a hydrodynamic cavitation reactor with 
experimental validation based on KI decomposition studies. Ultrasonics Sonochemistry, 22, 272-277. https://doi.org/10.1016/j.ultsonch.2014.05.017

Bagal, M. V., \& Gogate, P. R. (2014a). Degradation of diclofenac sodium using combined processes based on hydrodynamic cavitation and heterogeneous photocatalysis. Ultrasonics Sonochemistry, 21(3), 1035-1043. https://doi.org/10.1016/j.ultsonch.2013.10.020

Bagal, M. V., \& Gogate, P. R. (2014b). Degradation of diclofenac sodium using combined processes based on hydrodynamic cavitation and heterogeneous photocatalysis. Ultrasonics Sonochemistry, 21(3), 1035-1043. https://doi.org/10.1016/j.ultsonch.2013.10.020

Bakir, F., Rey, R., Gerber, A., Belamri, T., \& Hutchinson, B. (2004). Numerical and Experimental Investigations of the Cavitating Behavior of an Inducer. International Journal of Rotating Machinery, 10 (November 2002), 15-25. https://doi.org/10.1080/10236210490258034

Balasundaram, B., \& Pandit, A. B. (2001). Selective release of invertase by hydrodynamic cavitation. Biochemical Engineering Journal, 8(3), 251-256. https://doi.org/10.1016/S1369-703X(01)00114-0

Bandelin, J., Lippert, T., Drewes, J. E., \& Koch, K. (2018). Cavitation field analysis for an increased efficiency of ultrasonic sludge pre-treatment using a novel hydrophone system. Ultrasonics Sonochemistry, 42(December 2017), 672-678. https://doi.org/10.1016/j.ultsonch.2017.12.025

Baroutian, S., Eshtiaghi, N., \& Gapes, D. J. (2013a). Rheology of a primary and secondary sewage sludge mixture: Dependency on temperature and solid concentration. Bioresource Technology, 140, 227-233. https://doi.org/10.1016/j.biortech.2013.04.114

Baroutian, S., Eshtiaghi, N., \& Gapes, D. J. (2013b). Rheology of a primary and secondary sewage sludge mixture: Dependency on temperature and solid concentration. Bioresource Technology, 140, 227-233. https://doi.org/10.1016/j.biortech.2013.04.114

Bashir, T. A., Soni, A. G., Mahulkar, A. V., \& Pandit, A. B. (2011). The CFD driven optimisation of a modified Venturi for cavitational activity. Canadian Journal of Chemical Engineering, 89(6), 1366-1375. https://doi.org/10.1002/cjce.20500

Binama, M., Muhirwa, A., \& Bisengimana, E. (2016). Cavitation Effects in Centrifugal Pumps-A Review Cavitation Effects in Centrifugal Pumps- A Review, (March 2017).

Biswas, S., Nazmi, A., Pitesky, M., Gallardo, R., \& Pandey, P. (2018). Thermal 
Inactivation of Escherichia coli and Salmonella Typhimurium in Poultry Carcass and Litter at Thermophilic Temperatures. The Journal of Applied Poultry Research, 28(2), 307-317. https://doi.org/10.3382/japr/pfy072

Braeutigam, P., Franke, M., Schneider, R. J., Lehmann, A., Stolle, A., \& Ondruschka, B. (2012a). Degradation of carbamazepine in environmentally relevant concentrations in water by Hydrodynamic-Acoustic-Cavitation (HAC). Water Research, 46(7), 2469-2477. https://doi.org/10.1016/j.watres.2012.02.013

Braeutigam, P., Franke, M., Schneider, R. J., Lehmann, A., Stolle, A., \& Ondruschka, B. (2012b). Degradation of carbamazepine in environmentally relevant concentrations in water by Hydrodynamic-Acoustic-Cavitation (HAC). Water Research, 46(7), 2469-2477. https://doi.org/10.1016/j.watres.2012.02.013

Brennen, C. E. (1995). Cavitation and bubble dynamics. Annual Review of Fluid Mechanics. Oxford University Press. https://doi.org/10.1017/CBO9781107338760

Briggs, L. J. (1950). Limiting Negative Pressure of Water, 721, 23-25. https://doi.org/10.1063/1.1699741

Byrne, B., Dunne, G., \& Bolton, D. J. Ã. (2006). Thermal inactivation of Bacillus cereus and Clostridium perfringens vegetative cells and spores in pork luncheon roll, 23, 803-808. https://doi.org/10.1016/j.fm.2006.02.002

Campos, R., Bakir, F., Campos, A., Palacios-gallegos, M., \& Rey, R. (2015). Numerical analysis of unsteady cavitating $\mathrm{fl}$ ow in an axial inducer, 75, 13021310. https://doi.org/10.1016/j.applthermaleng.2014.07.063

Cerecedo, L. M., Dopazo, C., \& Gomez-Lus, R. (2018). Water disinfection by hydrodynamic cavitation in a rotor-stator device. Ultrasonics Sonochemistry, 48(May), 71-78. https://doi.org/10.1016/j.ultsonch.2018.05.015

Chakinala, A. G., Gogate, P. R., Burgess, A. E., \& Bremner, D. H. (2008). Treatment of industrial wastewater effluents using hydrodynamic cavitation and the advanced Fenton process. Ultrasonics Sonochemistry, 15(1), 49-54. https://doi.org/10.1016/j.ultsonch.2007.01.003

Chand, R., Bremner, D. H., Namkung, K. C., Collier, P. J., \& Gogate, P. R. (2007). Water disinfection using the novel approach of ozone and a liquid whistle reactor, 35, 357-364. https://doi.org/10.1016/j.bej.2007.01.032

Chang, A. C., \& Chen, F. C. (2002). The application of $20 \mathrm{kHz}$ ultrasonic waves to accelerate the aging of different wines. Food Chemistry, 79(4), 501-506. https://doi.org/10.1016/S0308-8146(02)00226-1

Charrière, B., Decaix, J., \& Goncalvès, E. (2015). A comparative study of 
cavitation models in a Venturi flow. European Journal of Mechanics, B/Fluids, 49(PA), 287-297. https:// doi.org/10.1016/j.euromechflu.2014.10.003

Crudo, D., Bosco, V., Cavaglià, G., Grillo, G., Mantegna, S., \& Cravotto, G. (2016). Biodiesel production process intensification using a rotor-stator type generator of hydrodynamic cavitation. Ultrasonics Sonochemistry, 33, 220-225. https://doi.org/10.1016/j.ultsonch.2016.05.001

Dastane, G. G., Thakkar, H., Shah, R., Perala, S., Raut, J., \& Pandit, A. B. (2019a). Chemical Engineering Research and Design Single and multiphase CFD simulations for designing cavitating Venturi. Chemical Engineering Research and Design, 149, 1-12. https://doi.org/10.1016/j.cherd.2019.06.036

Dastane, G. G., Thakkar, H., Shah, R., Perala, S., Raut, J., \& Pandit, A. B. (2019b). Chemical Engineering Research and Design Single and multiphase CFD simulations for designing cavitating Venturi. Chemical Engineering Research and Design, 149, 1-12. https:// doi.org/10.1016/j.cherd.2019.06.036

Dentel, S. K. (1997). Evaluation and role of rheological properties in sludge management. Water Science and Technology, 36(11), 1-8. https:/ / doi.org/10.1016/S0273-1223(97)00662-8

Dewil, R., Baeyens, J., \& Goutvrind, R. (2006). Use of ultrasonics in the treatment of waste activated sludge. Chinese Journal of Chemical Engineering, 14(1), 105113. https://doi.org/10.1016/S1004-9541(06)60045-1

Duizer, E., Bijkerk, P., Rockx, B., Groot, A. De, Twisk, F., \& Koopmans, M. (2004). Inactivation of Caliciviruses Inactivation of Caliciviruses, 70(8), 45384543. https://doi.org/10.1128/AEM.70.8.4538

Dular, M., \& Coutier-Delgosha, O. (2013). Thermodynamic effects during growth and collapse of a single cavitation bubble. Journal of Fluid Mechanics, 736, 44 66. https://doi.org/10.1017/jfm.2013.525

Dular, M., Griessler-Bulc, T., Gutierrez-Aguirre, I., Heath, E., Kosjek, T., Krivograd Klemenčič, A., ... Kompare, B. (2016). Use of hydrodynamic cavitation in (waste)water treatment. Ultrasonics Sonochemistry, 29, 577-588. https://doi.org/10.1016/j.ultsonch.2015.10.010

Feng, X., Lei, H., Deng, J., Yu, Q., \& Li, H. (2009). Physical and chemical characteristics of waste activated sludge treated ultrasonically. Chemical Engineering and Processing: Process Intensification, 48(1), 187-194. https://doi.org/10.1016/j.cep.2008.03.012

Forster, C. F. (1982). Sludge Surfaces and their Relation to the Rheology of Sewage Sludge Suspensions, 799-807. 
Franc, J. P. (2007). The Rayleigh-Plesset equation: a simple and powerful tool to understand various aspects of cavitation. In Fluid Dynamics of Cavitation and Cavitating Turbopumps (pp. 1-41). https://doi.org/10.1007/978-3-211-766699_1

Franc, J. P., \& Michel, J. M. (2004). Fundametals of Cavitation. Saint Martin d'Hères Cedex: Kluwer Academic Publishers.

Fujikawa, S., \& Akamatsu, T. (1980). Effects of the non-equilibrium condensation of vapour on the pressure wave produced. Journal Fluid Mechanics, 3, 481-512.

Gagol, M., Przyjazny, A., \& Boczkaj, G. (2018). Wastewater treatment by means of advanced oxidation processes based on cavitation - A review. Chemical Engineering Journal, 338(November 2017), 599-627. https://doi.org/10.1016/j.cej.2018.01.049

Gaikwad, S. G., \& Pandit, A. B. (2007). Ultrasound emulsification: Effect of ultrasonic and physicochemical properties on dispersed phase volume and droplet size. Ultrasonics Sonochemistry, 15, 554-563. https://doi.org/10.1016/j.ultsonch.2007.06.011

Gao, S., Lewis, G. D., Ashokkumar, M., \& Hemar, Y. (2014). Inactivation of microorganisms by low-frequency high-power ultrasound: 2. A simple model for the inactivation mechanism. Ultrasonics Sonochemistry, 21(1), 454-460. https://doi.org/10.1016/j.ultsonch.2013.06.007

García Martín, J. F., \& Sun, D. W. (2013). Ultrasound and electric fields as novel techniques for assisting the wine ageing process: The state-of-the-art research. Trends in Food Science and Technology, 33(1), 40-53. https://doi.org/10.1016/j.tifs.2013.06.005

Gavala, H. N., Yenal, U., Skiadas, I. V, Westermann, P., \& Ahring, B. K. (2003). Mesophilic and thermophilic anaerobic digestion of primary and secondary sludge . Effect of pre-treatment at elevated temperature, 37, 4561-4572. https://doi.org/10.1016/S0043-1354(03)00401-9

Geciova, J., Bury, D., \& Jelen, P. (2002). Methods for disruption of microbial cells for potential use in the dairy industry - A review. International Dairy Journal, 12(6), 541-553. https:/ / doi.org/10.1016/S0958-6946(02)00038-9

Gewa, A. B. (2009). Ultrasonic waste activated sludge disintegration for improving anaerobic stabilization, 35(8), 2003-2009.

Gogate, P. R. (2007). Cavitational reactors for process intensification of chemical processing applications: A critical review. Chemical Engineering and Processing: Process Intensification, 47, 515-527. https://doi.org/10.1016/j.cep.2007.09.014 
Gogate, P. R., \& Kabadi, A. M. (2009). A review of applications of cavitation in biochemical engineering/biotechnology. Biochemical Engineering Journal, 44(1), 60-72. https://doi.org/10.1016/j.bej.2008.10.006

Gogate, P. R., Marie, A., \& Pandit, A. B. (2003). Some aspects of the design of sonochemical reactors q, 10, 325-330. https://doi.org/10.1016/S13504177(03)00103-2

Gogate, P. R., \& Patil, P. N. (2015). Ultrasonics Sonochemistry Combined treatment technology based on synergism between hydrodynamic cavitation and advanced oxidation processes. Ultrasonics - Sonochemistry, 25, 60-69. https://doi.org/10.1016/j.ultsonch.2014.08.016

Gogate, P. R., Shirgaonkar, I. Z., Sivakumar, M., Senthilkumar, P., Vichare, N. P., \& Pandit, A. B. (2001). Cavitation reactors: Efficiency assessment using a model reaction. AICHE Journal, 47(11), 2526-2538. https://doi.org/10.1002/aic.690471115

Gogate, P. R., Sivakumar, M., \& Pandit, A. B. (2004). Destruction of Rhodamine B using novel sonochemical reactor with capacity of 7.51 . Separation and Purification Technology, 34(1-3), 13-24. https://doi.org/10.1016/S13835866(03)00170-9

Gogate, P. R., Tatake, P. A., Kanthale, P. M., \& Pandit, A. B. (2002). Mapping of Sonochemical Reactors: Review, Analysis, and Experimental Verification, $48(7)$.

Harvey, E., Barnes, D. ., Mcelroy, W. D., Whiteley, A. H., Pease, D. C., \& Cooper, K. W. (1944). Bubble formation in animals, (1), 1-22.

Hauke, G., Fuster, D., \& Dopazo, C. (2007). Dynamics of a single cavitating and reacting bubble, (June), 1-14. https://doi.org/10.1103/PhysRevE.75.066310

Hickling, R., \& Plesset, M. S. (1964a). Collapse and Rebound of a Spherical Bubble in Water. Physics of Fluids, 7(1), 7. https://doi.org/10.1063/1.1711058

Hickling, R., \& Plesset, M. S. (1964b). Collapse and Rebound of a Spherical Bubble in Water. Physics of Fluids, 7(1), 7. https://doi.org/10.1063/1.1711058

Iben, U. (2002). Systems Analysis Modelling Simulation Modeling of Cavitation, 42, 1283-1307. https://doi.org/10.1080/716067218

Ivany, R. D., \& Hammitt, F. G. (1965). Cavitation Bubble Collapse in Viscous, Compressible Liquids-Numerical Analysis. Journal of Basic Engineering, 87(4), 977. https://doi.org/10.1115/1.3650853

Jangir, N., Diwedi, P., \& Ghosh, S. (2017). Design of a hydrodynamic cavitating reactor. Chemical Engineering and Processing: Process Intensification, 122(October), 
128-142. https://doi.org/10.1016/j.cep.2017.10.008

Ji, J., Wang, J., Li, Y., Yu, Y., \& Xu, Z. (2006). Preparation of biodiesel with the help of ultrasonic and hydrodynamic cavitation. Ultrasonics, 44, 411-414. https://doi.org/10.1016/j.ultras.2006.05.020

Joshi, R. K., \& Gogate, P. R. (2012a). Ultrasonics Sonochemistry Degradation of dichlorvos using hydrodynamic cavitation based treatment strategies. Ultrasonics - Sonochemistry, 19(3), 532-539. https://doi.org/10.1016/j.ultsonch.2011.11.005

Joshi, R. K., \& Gogate, P. R. (2012b). Ultrasonics Sonochemistry Degradation of dichlorvos using hydrodynamic cavitation based treatment strategies. Ultrasonics - Sonochemistry, 19(3), 532-539. https://doi.org/10.1016/j.ultsonch.2011.11.005

Jyoti, K. K., \& Pandit, A. B. (2001). Water disinfection by acoustic and hydrodynamic cavitation, 7(November 2000), 201-212.

Jyoti, K. K., \& Pandit, A. B. (2003a). Hybrid cavitation methods for water disinfection, 14, 9-17.

Jyoti, K. K., \& Pandit, A. B. (2003b). Hybrid cavitation methods for water disinfection: simultaneous use of chemicals with cavitation, 10, 255-264. https://doi.org/10.1016/S1350-4177(03)00095-6

Katopodes, N. D. (2019). Vorticity Dynamics. Free-Surface Flow (Vol. 59). https://doi.org/10.1016/b978-0-12-815489-2.00007-1

Katz, J., Bermejo, D., Escaler, X., Dular, M., \& Ruíz, R. (2019). Experimental Investigation of the Cavitation Effects on the Heat Generation in a Closed Loop Pumping System. Proceedings of the 10th International Symposium on Cavitation (CAV2018). https://doi.org/10.1115/1.861851_ch76

Kavitha, S., Yeom, I.-T., Rajesh banu, J., Saji Pray, S., Adish Kumar, S., \& Yogalakshmi, K. N. (2015). Effect of chemo-mechanical disintegration on sludge anaerobic digestion for enhanced biogas production. Environmental Science and Pollution Research, 23(3), 2402-2414. https://doi.org/10.1007/s11356-015-5461-z

Keller, J. B., \& Kolodner, I. I. (1956). Damping of underwater explosion bubble oscillations. Journal of Applied Physics, 27(10), 1152-1161. https://doi.org/10.1063/1.1722221

Kim, I., Lee, I., Jeon, S. H., Hwang, T., \& Han, J. I. (2015). Hydrodynamic cavitation as a novel pretreatment approach for bioethanol production from reed.

Bioresource

Technology,

192,

335-339. 
https://doi.org/10.1016/j.biortech.2015.05.038

Kosel, J., Šinkovec, A., \& Dular, M. (2019). A novel rotation generator of hydrodynamic cavitation for the fibrillation of long conifer fibers in paper production. Ultrasonics Sonochemistry, 59(March). https://doi.org/10.1016/j.ultsonch.2019.104721

Kovač, K., Diez-Valcarce, M., Raspor, P., Hernández, M., \& Rodríguez-Lázaro, D. (2012). Effect of high hydrostatic pressure processing on norovirus infectivity and genome stability in strawberry puree and mineral water. International Journal of Food Microbiology, 152(1-2), 35-39. https://doi.org/10.1016/j.ijfoodmicro.2011.10.005

Kubota, A., Kato, H., \& Yamaguchi, H. (1992). A new modelling of cavitating flows: A numerical study of unsteady cavitation on a hydrofoil section. Journal of Fluid Mechanics, 240(3), 59-96. https://doi.org/10.1017/S002211209200003X

Kuglarz, M., Karakashev, D., \& Angelidaki, I. (2013a). Microwave and thermal pretreatment as methods for increasing the biogas potential of secondary sludge from municipal wastewater treatment plants. Bioresource Technology, 134, 290-297. https://doi.org/10.1016/j.biortech.2013.02.001

Kuglarz, M., Karakashev, D., \& Angelidaki, I. (2013b). Microwave and thermal pretreatment as methods for increasing the biogas potential of secondary sludge from municipal wastewater treatment plants. Bioresource Technology, 134, 290-297. https://doi.org/10.1016/j.biortech.2013.02.001

Kumar, P. S., \& Pandit, A. B. (1999). Modeling Hydrodynamic Cavitation. Chemical Engineering \& Technology, 22(12), 1017-1027. https://doi.org/10.1002/(SICI)1521-4125(199912)22:12<1017::AIDCEAT1017>3.0.CO;2-L

Kuwahara, K., Gladstone, H. B., Gupta, V., Kireev, V., Neel, V., \& Moy, R. L. (2003). Rupture of Fat Cells Using Laser-Generated Ultra Short Stress Waves. Lasers in Surgery and Medicine, 285(December 2002), 279-285. https://doi.org/10.1002/1sm.10154

Lawrence, N., \& Coleman, W. P. (1997). The Biologic Basis of Ultrasonic Liposuction. American Society for Dermatologic Surgery, 23, 1197-1200.

Lee, A. K., Lewis, D. M., \& Ashman, P. J. (2014). Microalgal cell disruption by hydrodynamic cavitation for the production of biofuels. Journal of Applied Phycology, 27(5), 1881-1889. https://doi.org/10.1007/s10811-014-0483-3

Lee, G., Lee, I., \& Han, J.-I. (2019). A combined method of hydrodynamic cavitation and alkaline treatment for waste-activated sludge solubilization; 
$\mathrm{N} / \mathrm{P}$ recovery from anaerobic granular sludge. Journal of Environmental Chemical Engineering, 7(5), 103329. https://doi.org/10.1016/j.jece.2019.103329

Lee, I., \& Han, J. I. (2013). The effects of waste-activated sludge pretreatment using hydrodynamic cavitation for methane production. Ultrasonics Sonochemistry, 20(6), 1450-1455. https://doi.org/10.1016/j.ultsonch.2013.03.006

Lehne, G., Müller, A., \& Schwedes, J. (2001). Mechanical disintegration of sewage sludge. Water Science and Technology, 43(1), 19-26.

Li, G., Guo, W., Wang, J., Guo, P., \& Wang, X. (2007). Chemical effect of swirling jet-induced cavitation: Degradation of rhodamine B in aqueous solution. Ultrasonics Sonochemistry, 15(4), 357-363. https://doi.org/10.1016/j.ultsonch.2007.09.008

Li, H., Kelecy, F. J., Egelja-maruszewski, A., \& Vasquez, S. A. (2008). Paper No . IMECE2008-67450 ADVANCED COMPUTATIONAL MODELING OF STEADY AND UNSTEADY, 1-11.

Liu, H. L., Liu, D. X., Wang, Y., Wu, X. F., \& Wang, J. (2013). Application of modified $\mathrm{k}-\omega$ model to predicting cavitating flow in centrifugal pump. Water Science and Engineering, 6(3), 331-339. https://doi.org/10.3882/j.issn.16742370.2013.03.009

Liu, N., Jiang, J., Yan, F., Gao, Y., Meng, Y., Aihemaiti, A., \& Ju, T. (2018). Enhancement of volatile fatty acid production and biogas yield from food waste following sonication pretreatment. Journal of Environmental Management, 217, 797-804. https://doi.org/10.1016/j.jenvman.2018.03.135

Liu, Y., Yang, H., \& Sakanishi, A. (2006). Ultrasound: Mechanical gene transfer into plant cells by sonoporation. Biotechnology Advances, 24(1), 1-16. https://doi.org/10.1016/j.biotechadv.2005.04.002

Luque de Castro, M. D., \& Priego-Capote, F. (2007). Ultrasound-assisted crystallization ( sonocrystallization ), 14, 717-724. https://doi.org/10.1016/j.ultsonch.2006.12.004

Machnicka, A., Grubel, K., \& Suschka, J. (2009). The use of hydrodynamic disintegration as a means to improve anaerobic digestion of activated sludge. Water $S A, 35(1), 129-132$.

Maklno, K., Mossoba, M. M., \& Rlesr, P. (1983). Chemical Effects of Ultrasound on Aqueous Solutions. Formation of Hydroxyl Radicals and Hydrogen Atoms, (21), 1369-1377.

Mancuso, G., Langone, M., \& Andreottola, G. (2017). A swirling jet-induced cavitation to increase activated sludge solubilisation and aerobic sludge 
biodegradability.

Ultrasonics

Sonochemistry,

35.

https://doi.org/10.1016/j.ultsonch.2016.11.006

Mancuso, G., Langone, M., Laezza, M., \& Andreottola, G. (2016). Ultrasonics Sonochemistry Decolourization of Rhodamine B: A swirling jet-induced cavitation combined with $\mathrm{NaOCl}$. ULTRASONICS SONOCHEMISTRY, 32, 18-30. https://doi.org/10.1016/j.ultsonch.2016.01.040

Mata-Alvarez, J., Macé, S., \& Llabrés, P. (2000). Anaerobic digestion of organic solid wastes. An overview of research achievements and perspectives. Bioresource Technology, 74(1), 3-16. https://doi.org/10.1016/S09608524(00)00023-7

Merkle, C. L., Feng, J., \& Buelow, P. E. O. (1998). Computational modeling of the dynamics of sheet cavitation. Proc. 3rd Int. Symp. Cavitation, 3.

Merouani, S., Hamdaoui, O., Saoudi, F., \& Chiha, M. (2010a). Sonochemical degradation of Rhodamine B in aqueous phase: Effects of additives. Chemical Engineering Journal, 158(3),

$550-557$. https://doi.org/10.1016/j.cej.2010.01.048

Merouani, S., Hamdaoui, O., Saoudi, F., \& Chiha, M. (2010b). Sonochemical degradation of Rhodamine B in aqueous phase: Effects of additives. Chemical Engineering Journal, 158(3), 550-557. https://doi.org/10.1016/j.cej.2010.01.048

Miah, S., Tada, C., \& Sawayama, S. (2004). Enhancemet of Biogas Production from Sewage Sludge with the Addition of Geobacillus sp. Strain AT1 Culture. Japanese Journal of Water Treatment Biology, 40, 97-104.

Mishra, K. P., \& Gogate, P. R. (2010a). Intensification of degradation of Rhodamine B using hydrodynamic cavitation in the presence of additives. Separation and Purification Technology, 75(3), 385-391. https://doi.org/10.1016/j.seppur.2010.09.008

Mishra, K. P., \& Gogate, P. R. (2010b). Intensification of degradation of Rhodamine B using hydrodynamic cavitation in the presence of additives. Separation and Purification Technology, 75(3), 385-391. https://doi.org/10.1016/j.seppur.2010.09.008

MØRCH, K. A. (2009). Cavitation Nuclei: Experiments and Theory. Journal of Hydrodynamics, 21(2), 176-189. https://doi.org/10.1016/S10016058(08)60135-3

Moretti, E., Londoño, L., Caballero, Y. E., Galetto, M., \& Godoy, A. (2016). Efecto del ultrasonido quirúrgico de alta potencia en el tejido dérmico y adiposo . Estudio experimental para aplicación en marcación abdominal. 
Cirugia Plastica Ibero-Latinoamericana, 42, 227-232.

Muller, J. (2000). Disintegration as a key-step in sewage sludge treatment. Water Science and Technology, 41(8), 123-130.

Niedzwiedzka, A., Schnerr, G. H., \& Sobieski, W. (2016). Review of numerical models of cavitating flows with the use of the homogeneous approach. Archives of Thermodynamics, 37(2), 71-88. https://doi.org/10.1515/aoter-20160013

Nikolsky, V., Oliynyk, O., Lipeev, O., \& Ved, V. (2017). Examining a cavitation heat generator and the control method over the efficiency of its operation. Eastern-European Journal of Enterprise Technologies, 4(8-88), 22-28. https://doi.org/10.15587/1729-4061.2017.108580

Nouri, J. M., Mackenzie, S., Gaskell, C., \& Dhunput, A. (2012). Effect of viscosity, temperature and nozzle length-to-diameter ratio on internal flow and cavitation in a multi-hole injector. Fuel Systems for IC Engines, (June 2018), 265-278. https://doi.org/10.1533/9780857096043

Okamura, T., \& Kubota, J. (2006). Observation of impact phenomena of counterrotating cavitating vortex flows. Symposium A Quarterly Journal In Modern Foreign Literatures, (September), 1-7.

Park, B., Ahn, J. H., Kim, J., \& Hwang, S. (2004). Use of microwave pretreatment for enhanced anaerobiosis of secondary slugde. Water Science and Technology, 50(9), 17-23.

Patil, P. N., \& Gogate, P. R. (2012a). Degradation of methyl parathion using hydrodynamic cavitation: Effect of operating parameters and intensification using additives. Separation and Purification Technology, 95, 172-179. https://doi.org/10.1016/j.seppur.2012.04.019

Patil, P. N., \& Gogate, P. R. (2012b). Degradation of methyl parathion using hydrodynamic cavitation: Effect of operating parameters and intensification using additives. Separation and Purification Technology, 95, 172-179. https://doi.org/10.1016/j.seppur.2012.04.019

Patil, P. N., Gogate, P. R., Csoka, L., Dregelyi-Kiss, A., \& Horvath, M. (2016). Intensification of biogas production using pretreatment based on hydrodynamic cavitation. Ultrasonics Sonochemistry, 30, 79-86. https://doi.org/10.1016/j.ultsonch.2015.11.009

Petkovšek, M., \& Dular, M. (2013). IR measurements of the thermodynamic effects in cavitating flow. International Journal of Heat and Fluid Flow, 44, 756763. https://doi.org/10.1016/j.ijheatfluidflow.2013.10.005

Petkovšek, M., \& Dular, M. (2015). Experimental study of the thermodynamic 
effect in a cavitating flow on a simple Venturi geometry. Journal of Physics: Conference Series, 656(1). https://doi.org/10.1088/1742-6596/656/1/012179

Petkovšek, M., Mlakar, M., Levstek, M., Stražar, M., Širok, B., \& Dular, M. (2015). A novel rotation generator of hydrodynamic cavitation for waste-activated sludge disintegration. Ultrasonics Sonochemistry, 26, 408-414. https://doi.org/10.1016/j.ultsonch.2015.01.006

Petkovšek, M., Zupanc, M., Dular, M., Kosjek, T., Heath, E., Kompare, B., \& Širok, B. (2013). Rotation generator of hydrodynamic cavitation for water treatment. Separation and Purification Technology, 118, 415-423. https://doi.org/10.1016/j.seppur.2013.07.029

Qin, Z., \& Alehossein, H. (2016). Heat transfer during cavitation bubble collapse. Applied Thermal Engineering, 105, 1067-1075. https://doi.org/10.1016/j.applthermaleng.2016.01.049

Quarmby, J., Scott, J. R., Mason, A. K., Davies, G., \& Parsons, S. A. (1999). The Application of Ultrasound as a Pre- Treatment for Anaerobic Digestion. Environmental Technology, 1155-1166.

Rajoriya, S., Carpenter, J., Saharan, V. K., \& Pandit, A. B. (2016). Hydrodynamic cavitation: An advanced oxidation process for the degradation of biorefractory pollutants. Reviews in Chemical Engineering, 32(4), 379-411. https://doi.org/10.1515/revce-2015-0075

Riesz, P., \& Kondo, T. (1992). Free radical formation induced by ultrasound and its biological implications. Free Radical Biology and Medicine, 13(3), 247-270. https://doi.org/10.1016/0891-5849(92)90021-8

Rudolf, P., Hudec, M., Gríger, M., \& Štefan, D. (2014). Characterization of the cavitating flow in converging-diverging nozzle based on experimental investigations. EPJ Web of Conferences, 2101. https://doi.org/10.1051/epjconf/20146702101

Şahinkaya, S., \& Sevimli, M. F. (2013). Sono-thermal pre-treatment of waste activated sludge before anaerobic digestion. Ultrasonics Sonochemistry, 20(1), 587-594. https://doi.org/10.1016/j.ultsonch.2012.07.006

Šarc, A., Stepišnik-Perdih, T., Petkovšek, M., \& Dular, M. (2017). The issue of cavitation number value in studies of water treatment by hydrodynamic cavitation. Ultrasonics Sonochemistry, 34, 51-59. https://doi.org/10.1016/j.ultsonch.2016.05.020

Save, S. S., Pandit, A. B., \& Joshi, J. B. (1994). Microbial cell disruption: role of cavitation. The Chemical Engineering Journal and The Biochemical Engineering Journal, 55(3), 67-72. https://doi.org/10.1016/0923-0467(94)06062-2 
Schnerr, G. H., \& Sauer, J. (2001). Physical and Numerical Modeling of Unsteady Cavitation Dynamics. ICMF-2001, 4th International Conference on Multiphase Flow, 1-12. https://doi.org/10.1016/j.cap.2015.12.016

Sette, D., \& Wanderlingh, F. (1962). Nucleation by Cosmic Rays in Ultrasonic Cavitation, 125(1952).

Shi, H., Li, M., Nikrityuk, P., \& Liu, Q. (2019a). Experimental and numerical study of cavitation flows in Venturi tubes: From CFD to an empirical model. Chemical Engineering Science, 207, 672-687. https://doi.org/10.1016/j.ces.2019.07.004

Shi, H., Li, M., Nikrityuk, P., \& Liu, Q. (2019b). Experimental and numerical study of cavitation flows in Venturi tubes: From CFD to an empirical model. Chemical Engineering Science, 207, 672-687. https://doi.org/10.1016/j.ces.2019.07.004

Silva, F. V. M. (2015). International Journal of Food Microbiology Use of power ultrasound to enhance the thermal inactivation of Clostridium perfringens spores in beef slurry. International Journal of Food Microbiology, 206, 17-23. https://doi.org/10.1016/j.ijfoodmicro.2015.04.013

Simpson, A., \& Ranade, V. V. (2018a). Modeling hydrodynamic cavitation in Venturi: influence of Venturi configuration on inception and extent of cavitation. AIChE Journal, 65(1), 421-433. https://doi.org/10.1002/aic.16411

Simpson, A., \& Ranade, V. V. (2018b). Research and Design Modelling of hydrodynamic cavitation with orifice : Influence of different orifice designs. Chemical Engineering Research and Design, 136, 698-711. https://doi.org/10.1016/j.cherd.2018.06.014

Singhal, A. K., Athavale, M. M., Li, H., \& Jiang, Y. (2002). Mathematical Basis and Validation of the Full Cavitation Model. Journal of Fluids Engineering, 124(3), 617. https://doi.org/10.1115/1.1486223

Širok, B., Petkovšek, M., Heath, E., Blažeka, Ž., Zupanc, M., Dular, M., ... Kompare, B. (2012). Removal of pharmaceuticals from wastewater by biological processes, hydrodynamic cavitation and UV treatment. Ultrasonics Sonochemistry, 20(4), https://doi.org/10.1016/j.ultsonch.2012.12.003

1104-1112.

Sivakumar, M., \& Pandit, A. B. (2002). Wastewater treatment: A novel energy efficient hydrodynamic cavitational technique. Ultrasonics Sonochemistry, 9(3), 123-131. https://doi.org/10.1016/S1350-4177(01)00122-5

Suslick, K. S., Hammerton, D. A., \& Cline, R. E. (1986). Sonochemical Hot Spot. 
Journal of the American Chemical Society, 108(7), 5641-5642.

Tahmid, S. M., Gill, B. S., Park, K. M., Ryu, Y., \& Lee, S. H. (2013). Optimization and testing of a first generation cavitation heat pump. ASEE Annual Conference and Exposition, Conference Proceedings.

Tang, S. Y., \& Sivakumar, M. (2012). A Novel and Facile Liquid Whistle Hydrodynamic Cavitation Reactor to Produce Submicron Multiple Emulsions, $O(0)$. https://doi.org/10.1002/aic

Tao, Y., Cai, J., Huai, X., Liu, B., \& Guo, Z. (2016). Application of Hydrodynamic Cavitation to Wastewater Treatment. Chemical Engineering and Technology, 39(8), 1363-1376. https://doi.org/10.1002/ceat.201500362

Tixier, N., Guibaud, G., \& Baudu, M. (2003). Determination of some rheological parameters for the characterization of activated sludge. Bioresource Technology, 90(2), 215-220. https://doi.org/10.1016/S0960-8524(03)00109-3

Tomov, P., Khelladi, S., Ravelet, F., Sarraf, C., Bakir, F., \& Vertenoeuil, P. (2016a). Experimental study of aerated cavitation in a horizontal Venturi nozzle. Experimental Thermal and Fluid Science. https://doi.org/10.1016/j.expthermflusci.2015.08.018

Tomov, P., Khelladi, S., Ravelet, F., Sarraf, C., Bakir, F., \& Vertenoeuil, P. (2016b). Experimental study of aerated cavitation in a horizontal Venturi nozzle. Experimental Thermal and Fluid Science, 70, 85-95. https://doi.org/10.1016/j.expthermflusci.2015.08.018

Tsujimoto, Y. (2007). Tip Leakage and Backflow Vortex Cavitation. Fluid Dynamics of Cavitation and Cavitating Turbopumps SE - 6, 231-251. https://doi.org/10.1007/978-3-211-76669-9_6

Turner, C. (2002). The thermal inactivation of $\mathrm{E}$. coli in straw and pig manure, 84, $57-61$.

Wang, X., Wang, J., Guo, P., Guo, W., \& Wang, C. (2009). Degradation of rhodamine $\mathrm{B}$ in aqueous solution by using swirling jet-induced cavitation $\begin{array}{lllllll}\text { combined with } \mathrm{H} & 2 & \mathrm{O} & 2, & 169 & \text { 486-491. }\end{array}$ https://doi.org/10.1016/j.jhazmat.2009.03.122

Wang, X., \& Zhang, Y. (2009). Degradation of alachlor in aqueous solution by using hydrodynamic cavitation. Journal of Hazardous Materials, 161(1), 202-207. https://doi.org/10.1016/j.jhazmat.2008.03.073

Weemaes Marjoleine, P. J., \& Verstraete, W. H. (1998). Evaluation of Current Wet Sludge Disintegration Techniques.

Weissler, A. (1959). Formation of Hydrogen Peroxide by Ultrasonic Waves : Free 
Radicals. Journal of the American Chemical Society, 81, 1077-1081.

Wu, J. M., Huang, H. S., \& Livengood, C. D. (1992). Ultrasonic Destruction of Chlorinated Compounds in Aqueous Solution, 11(3), 195-201.

Wu, Z., Shen, H., Ondruschka, B., Zhang, Y., Wang, W., \& Bremner, D. H. (2012). Removal of blue-green algae using the hybrid method of hydrodynamic cavitation and ozonation. Journal of Hazardous Materials, 235-236, 152-158. https://doi.org/10.1016/j.jhazmat.2012.07.034

Zhang, Q.-A., Shen, Y., Fan, X.-H., \& García Martín, J. F. (2016). Preliminary study of the effect of ultrasound on physicochemical properties of red wine. CyTA - Journal of Food, 14(1), 55-64. https://doi.org/10.1080/19476337.2015.1045036

Zhang, X., Wang, D., Liao, R., Zhao, H., \& Shi, B. (2019). Study of mechanical choked Venturi nozzles used for liquid flow controlling. Flow Measurement and Instrumentation, 65(December 2018), 158-165. https://doi.org/10.1016/j.flowmeasinst.2018.12.001

Zieliński, M., Dębowski, M., Kisielewska, M., Nowicka, A., Rokicka, M., \& Szwarc, K. (2019). Cavitation-based pretreatment strategies to enhance biogas production in a small-scale agricultural biogas plant. Energy for Sustainable Development, 49, 21-26. https://doi.org/10.1016/j.esd.2018.12.007

Zupanc, M., Kosjek, T., Petkovšek, M., Dular, M., Kompare, B., Širok, B., ... Heath, E. (2014). Shear-induced hydrodynamic cavitation as a tool for pharmaceutical micropollutants removal from urban wastewater. Ultrasonics Sonochemistry, $21(3)$, 1213-1221. https://doi.org/10.1016/j.ultsonch.2013.10.025

Zwart, P. J., Gerber, A. G., \& Belamri, T. (2004). A Two-Phase Flow Model for Predicting Cavitation Dynamics. International Conference on Multiphase Flow, (152), $152 . \quad$ Retrieved from http://scholar.google.com/scholar?hl=en\&btnG=Search\&q=intitle:A+Two -Phase+Flow +Model+for+Predicting+Cavitation+Dynamics \#0 